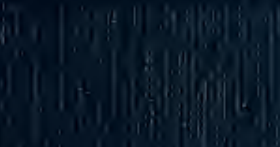
(3)

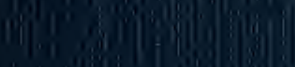

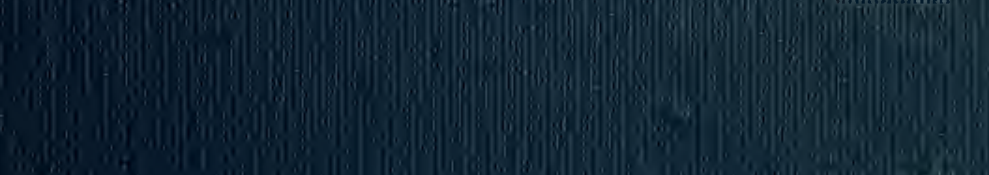





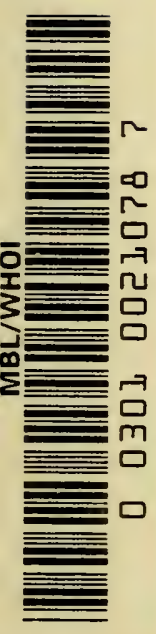





\section{SOCIETY OF AMERICAN BACTERIOLOGISTS}

MONOGRAPHS ON SYSTEMATIC BACTERIOLOGY

Volume I General Systematic Bacteriology R. E. Buchanan, Iowa State College 597 pages. $\$ 6.00$, net postpaid 


\section{GENERAL}

\section{SYSTEMATIC BACTERIOLOGY}





\section{GENERAL \\ SYSTEMATIC BACTERIOLOGY}

History, Nomenclature, Groups of Bacteria

BY

R. E. BUChanan, Ph.D.

Professor of Bacteriology, Bacteriologist of the Iowa Agricultural Experiment Station and Dean of the Graduate College, Iowa State College,

\section{BALTIMORE}

WILLIAMS \& WILKINS COMPANY 


\section{Copyright 1925 \\ WILLIAMS \& WILKINS COMPANY}

Made in L'nited States of America

Published January, 1925

ALL RIGHTS RESERVED

COMPOSED $\triangle N D$ PRINTED AT TRE WAVERLY PRESS

By the Willams \& Wirkins Company

BatTimore, Md., U.S. A. 


\section{CONTENTS}

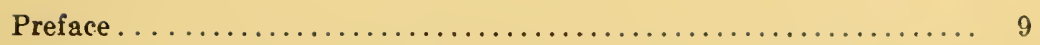

I. Classification of the Genera and Higher Groups of Bacteria. Historical,

II. Codes of Nomenclature and Their Application in Bacteriology......... 109

The Rules of Bacterial Nomenclature According to Lehmann and Neumann.......................................... 110

The International Code of Botanical Nomenclature.............. 113

The International Code of Zoological Nomenclature.............. 137

The Type Basis Code Suggested by the Committee on Botanical Nomenclature of the Botanical Society of America.................. 146

Suggestions and Recommendations of the Society of American Bacteriologists . . . . . . . . . . . . . . . . . . . . . . . . . . . 149

III. Nomenclatural Status of Names Which Have Been Applied to Groups of Bacteria of Higher Rank than Species. Alphabetically Arranged.. 152

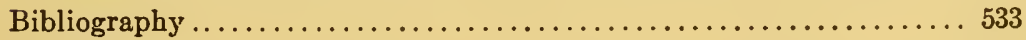

Subject Index .................................. 561

Author Index........................................ 589 


\section{PREFACE}

The present volume is the first of a series of monographs in the general field of systematic bacteriology. The data presented have been collected, compiled and annotated largely in connection with courses of lectures in systematic bacteriology given to graduate students dents in bacteriology at the Iowa State College during the past fifteen years. It is an attempt to bring together material which may prove of value to those who are desirous of knowing the probable nomenclatural status of the various names which have been used in bacterial terminology.

If science is to be defined as a system of classified knowledge, the subject of bacteriology is laboring under a serious handicap in lacking, probably more than any other branch of science, the advantages conferred by a satisfactory system of terminology or of nomenclature. It would seem that systematic bacteriology is deserving of even more recognition at the hands of teachers and investigators than has been accorded to it in the past.

Systematic bacteriology has two principal aims or functions which are of importance to the teacher and to the investigator. The first of these aims has to do with the presentation in graphic form of our present conception of the phylogeny and of the relationships of various groups of bacteria. The second is to give a greater degree of stability to the names used for particular groups of organisms and to prevent unnecessary nomenclatural confusion in literature. These aims are thoroughly scientific, their accomplishment will prove useful, we must therefore accord them careful consideration if our nomenclature is to be stabilized.

It is somewhat difficult to tabulate satisfactorily all of the factors instrumental in bringing about the present state of confusion and uncertainty in bacterial terminology. That there is such confusion is, of course, a self-evident fact. It has been rare in texts or articles (until comparatively recently) to find a consistent use made of generic names, and systems of classification taught in elementary courses in bacteriology have rarely been made use of later. In some quarters there are at the present time certain ill-advised attempts being made 
to standardize nomenclature. Certain American publishers for example have sought to fix upon the correct generic names for the designation of certain microörganisms, but apparently with no clear conception of the rules which should govern such standardization.

A study of the catalogs of various colleges and universities in the United States in which bacteriology is being taught at the present time reveals the fact that in very few cases are courses offered in which there is any emphasis placed upon systematic bacteriology and phylogeny. An examination of the courses offered in other biological sciences would show very different conditions. Another factor which has undoubtedly tended to confuse nomenclature in this science is the fact that until recent years most bacteriologists received their training in medical schools. During their medical course they were familiarized with several systems of nomenclature used in other sciences. In anatomy, for example, agreement is rapidly being reached that for each organ and anatomical unit a single international Latin name shall be adopted, and the student becomes familiar with the general rules for the formation of such names. In pathology and medicine diseases are designated in much the same fashion, a descriptive Latin phrase, frequently consisting of several words, is used. It is exceptional for the teacher in bacteriology to emphasize the fact that systems of names used in anatomy and pathology are utterly different and based upon other rules than those used in naming living plants and animals. Many of the polynomials which cumber our bacteriological literature have been applied by workers who do not have such distinctions in mind.

By far the most important factor which has determined the attitude of teachers and investigators toward this problem has been the lack of a really adequate system of group differentiation, of classification. It has taken bacteriological systematists a long time to realize that such group differentiation (the separation of species and genera), upon other than morphological differences, may be wholly valid. The botanical bacteriologist has ignored physiology which is so important. The physiological bacteriologist has, in many cases, not possessed the background of the systematist. The latter worker may point out the characters which should be used, but finds difficulty in their practical application to the specific problems of taxonomy.

The most hopeful sign of importance in this respect probably, has been the work of the committee on taxonomy of bacteria of the Society of American Bacteriologists under the chairmanship of Dr. Winslow, 
and of the more recent work of a committee on classification of bacteria under the chairmanship of Dr. Bergey. The work of Mrs. Enlows in the names of bacterial genera is also to be commended. It is to be expected that, as a result of their work, eventually a practical system of nomenclature which will be satisfactory and applicable to all fields of bacteriology will be evolved.

But, it may be asked, is a scientific classification of bacteria really important and desirable? Are we not making progress in our science quite as rapidly as we would without the increased emphasis upon taxonomy? The following statement by $H$. Marshall Ward, published two decades ago is apropos:

"The only really valid objection to a purely scientific classification is the old objection of the purely utilitarian practical man; and even there the objection is relative. This leads me to bring out the point that the bacteriologists in the widest sense of the word are really looking at the question of classification from at least two very different points of view: On the one hand, we have the botanists, who direct their attention to the organism, the Schizomycete itself, as a biological phenomenon to be examined and reported upon as thoroughly as possible, for them no classification is complete which does not record, or (which amounts to the same thing) imply in its records, all of the life phenomena of the organism, including its pedigree.

"On the other hand, we have the pathologists, hygienists, brewers, chemists, etc., who regard the organism simply as an object to be named for convenience in reference, because it brings about certain changes in tissues, waters, and other media which they are more especially concerned with. They do not care, and naturally so, what vagaries the organism exhibits, so long as they can recognize it when they meet with it. As a matter of experience, however, it is just these vagaries that bring about the sources of error which beset them on all hands, and hence they are equally interested with the botanist in having them cleared up and explained. When we come to the conclusion that, whatever may be believed to the contrary, the real interests of bacteriologists of all kinds are identical."

The first chapter of the present volume is devoted to a brief history of the various classifications of bacteria that have been proposed up to the present time. An effort has also been made to give dichotomous keys to the genera and higher groups recognized by the various writers whenever there seemed to be sufficient data for their formulation. Contrary to commonly accepted opinion, it will be found that a large 
number of observers have made contributions in this field, but the writings are so widely scattered and, in many cases, the journals and other publications so difficult of access that for the most part they are quite unknown to our modern writers or, at least, unheeded by them. It is believed that a synopsis of these various schemes of classification that have been proposed and a comparison of the various bases upon which these rest must surely be of service in developing a stable bacteriological nomenclature.

The second chapter has to do with codes of nomenclature and their relationships to the problems of bacterial terminology. The subject of nomenclature is, in part, distinct from that of classification. The latter deals with methods and criteria of use in the differentiation of groups from each other. The former has for its function the determination of the kind of a name that shall be applied to a group and the validity and suitability of names which have already been applied. This frequent confusion of nomenclature in classification has made us hesitate to give a name to that which we cannot accurately define. It is true, however, that species have not been accurately deliminated in the older biological sciences, but this fact has not interfered with at least tentative arrangements of the genera and higher groups nor of application of correct names. It seems to be self-evident that until the bacteriologists can agree upon a code and follow it consistently, there is little hope or remedy for our present chaos. It is believed that the discussion of the International Botanical Code given in this second section will show that it may constitute an adequate basis, which, with some modification, may prove satisfactory as a guide.

The third chapter is an alphabetical list of all of the names which have been used by various authors to designate bacterial subgenera, genera or higher groups so far as a rather comprehensive study of the literature has revealed them. Wherever practicable the original description has been quoted, the descriptions used by various subsequent writers discussed, and sufficient data included to make possible in most cases, at least, the formation of an opinion as to the probable nomenclatural status of each name. It is believed that this list will prove helpful in the determination of the exact meaning of the various names, in the formulation of adequate diagnoses for the determination of synonymy, and in preventing the introduction of new names where there are valid older names. 
The section on bibliography has been compiled with particular care, as have also the various indices.

I wish gratefully to acknowledge the assistance of many members of the staff in bacteriology at the Iowa State College, especially Miss Clarissa Clark, Mrs. C. H. Werkman, Miss Ruth Confare, Mr. J. C. Weldin and Dr. Max Levine. For interest and assistance in bibliographic details acknowledgment is due Miss Margaret Brown and Prof. C. H. Brown of the library of Iowa State College. 



\section{CHAPTER I}

\section{Classification OF THE GENERA AND HigheR GROUPS OF BACTERIA}

Apparently the first definite named description of any organism included now among the bacteria is probably that of Mueller in his Vermium terrestrium et fluviatilum (1773). The following key, abridged from his introduction, gives the main groupings and the genera of the group in which the bacteria fall.

\section{Mueller's Classification of Vermes (1773)}

a. Tentaculi destituti.

b. Vagantes ...................... Infusoria

c. Organis externis nullis

\section{d. Teretes.}

1. Corpus punctiforme.....Monas

2. Corpus sphaericina..... Volvox

3. Corpus cylindraceum ....Enchelis

4. Corpus elongatum ....... Vibrio

5. Corpus cavum...........Bursaria

dd. Complanati. (With four genera.)

cc. Organis externis. (With four genera.)

bb. Serpentes.........................minthica

aa. Tentaculis instructi.

(With eight genera.)

.Teslacea

(With twelve genera.)

Later in the introduction to the above volume the two genera Monas and Vibrio (which contain his bacterial species) are noted as found among the Aquatici, also among the Hyalini, also under Tentaculis nullis, inconspicui, teretes, and still later under Vacillantes, pellucidi. Finally he places these genera with Volvox and Enchelis in a classification under the headings Organis externis nullis, crassiuscula.

Three species of Monas are described. The generic description is "Vermis inconspicuus, simplicissimus pellucidus, punctiformus." The genus Vibrio is described as "Vermis inconspicuus, simplicissimus, teres, elongatus." Fifteen species are described. Several of them were doubtless bacterial forms.

In the year 1786 there appeared a posthumous volume by Mueller, entitled "Animalcula Infusoria fluviatilia et marina." The infusoria 
were divided into two groups "Organis externis nullis" and "Organis externis." The forms now included among the bacteria were all to be found in the ten genera of the first group. These were separated as follows (p. XXVI):

Mueller's Classification of Protozoa, etc. (1786)

Crassiuscula
1. Monas: Punctiforme
2. Proteus: Mutabile
3. Volvox: Sphaericum
4. Enchelis: Cylindraceum
5. Vibrio: Elongatum
Membranacea
6. Cyclidium: Ovale
7. Paramoecium: Oblongum
8. Kolpoda: Simatum
9. Gonium: Angulatum
10. Bursaria: Cavum

Two of these genera contained organisms now included among the bacteria. In the genus Monas were ten species and in Vibrio thirtyone species. Of these very probably Monas termo, M. punctum and $M$. lens, Vibrio lineola, V. rugula, V. bacillus, $V$. undula, V. serpens and $V$. spirillum were bacteria. The monads were spherical or ovoid in shape, the vibriones longer, and in most species spiral.

Within the next two decades, no advance was made in the classification of the forms now known as bacteria. However, three generic names were created by as many writers for organisms supposed to be fungi, but which many decades later were shown to be bacteria. The first of these was named by Link (1795), who described Polyangium vitellinum, an organism in its fruiting stages bearing a close resemblance to a mold, but which was later shown by Thaxter (1892) to belong to the Myxobacteriaceae. The second name was applied to the species Serratia marcescens by Bizio (1823). This investigator had undertaken to study the cause of an outbreak of "bloody" polenta which was causing much superstitious fear among the peoples of northern Italy. He attributed the difficulty to a fungus which developed a red pigment on farinaceous foods. This was probably the organism now more commonly termed Bacillus prodigiosus. Somewhat later Sette (1824, p. 51) named what is apparently the same organism Zaogalactina imetropha, also regarding it as one of the fungi. 
Persoon (1822, p. 96) used the designation Mycoderma mesentericum for the membrane which appears upon the surface of fermenting alcoholic solutions, consisting largely of acetic acid bacteria and yeasts. The organism was classed with the fungi; its relationship to the Infusoria of Mueller was not at the time apprehended.

Bory de St. Vincent (1824) created the genus Melanella to include all non-flexible organisms of the group of Vibrionides whether straight or spiral. To this genus he transferred four of Mueller's species of Vibrio. (V. lineola, V. rugula, V. bacillus and V. spirillum).

Bory de St. Vincent (1826) prepared a "Tableau des Ordes, des Familles et des Genres de Microscopiques." This was a dichotomous key to genera. A translation of the key carried out to include only the forms now listed with the bacteria is as follows:

Bory de St. Vincent's Classification (1826)

a. Without Testa.

b. Perfectly smooth, without cilia or other vibratile organs

c. Without appendages.

Order Gymnode

d. Never linear or wormlike. (5 families.)

dd. Linear or wormlike

Family Vibrionides

e. Body opaque.

f. Coiled in a discoid spiral.

$$
\text { Spirilina }
$$

ff. Not coiled in a discoid spiral.

Melanella

ee. Body transparent (diaphanous).

f. Attenuate at both tips.

Vibrio

ff. Obtuse.

g. With one end enlarged.

Lacrimatoria

gg. Not enlarged at one end.

Pupella

Von Baer (1827, p. 748) proposed to establish a genus Lineola to include all of the extremely minute Infusoria.

The first considerable contributions to our knowledge of bacteria and their classifications, following Mueller, were those of Ehrenberg (from 1828-1838). Certain of his genera of the Infusoria were made up almost entirely of organisms now included with bacteria. The following key will indicate the principal groups of the Infusoria and the position of the "bacterial" genera in the system. 


\section{Ehrenberg's Classification of the Infusoria (1838)}

a. Forms which ingest solid particles, as carmine

aa. Forms which never ingest particles.

Polygastrica

b. Family Monadina. Genus Monas, of which Monas crepusculum was probably a bacterium.

bb. Family Vibrionia. Forms which tend to form filaments as a result of incomplete fission.

c. Cells not flattened.

d. Cells not flexuous.

e. Forming straight rods ... Bacterium

ee. Forming spiral rods..... Spirillum

dd. Cells Hexunus.

e. Straight rods.......... Vibrio

ee. Spiral rods.............Spirochaeta

cc. Cells in form of a flattened spiral...Spirodiscus

He also described as a member of the diatom genus Gaillonella, a $G$. ferruginea now generally included among the bacteria. Later he changed the spelling to Gallionella. In spite of the fact that it is that of a recognized diatom genus, this name is still frequently incorrectly used as a bacterial generic name in the designation of this iron organism. In the form finally assumed by the Ehrenberg classification (1838) the bacterial species recognized were as follows: Bacterium triloculare, Vibrio lineola, $V$. tremulans, $V$. subtilis, $V$. rugula, $V$. prolifer and V. bacillus, Spirillum undula, S. tenue, Spirochaeta plicatilis and Spirodiscus fulvus. Later (1840, p. 202) he described Vibrio syncyaneus and $V$. synxanthus.

Kützing (1833, p. 385) described as a fresh water alga a form which he termed Sphaerotilus natans. This is now generally included among the filamentous water or iron bacteria.

Dujardin (1841, p. 209) used the family designation Vibrionia to include "Animaux sans organes locomoteurs visibles, se mouvent par l'effect de leur contractibilite generale." The genera recognized may be differentiated as follows:

\section{Dujardin's Classification of Vibrionia (1841)}

A. Cells straight, non-flexuous, more or less definitely jointed, with slow wave-like motility.........................

B. Cells straight or bent, more or less definitely jointed, flexuous

Vibrio

C. Filamentous forms spiral or screw shaped, never straight, and revolving rapidly on the axis. 
Trevisan (1842, p. 56) described an organism which he placed among the algae as closely related to Oscillatoria. To it he gave the name Beggiatoa punctata. This genus is now generally recognized as belonging among the sulphur bacteria. In the same year Goodsir (1842, p. 432) described an organism which he named Sarcina ventriculi. It occurred as masses of spherical cells forming regular packets in the vomit of a patient. The relationship of this organism to the types included by previous writers among the Infusoria was not recognized.

Kuetzing (1843, p. 198) described one of the iron bacteria, Leptothrix ochracea, which may be regarded as the type species of this genus. Later Robin (1853, p. 345) named one of the mouth bacteria Leptothrix buccalis. We know now that the two species named are not at all closely related, but the double use of this designation has led to much confusion in literature in recent years. Sanitary bacteriologists in general use the genus Leptothrix for iron bacteria, while many medical bacteriologists use the name for certain parasitic mouth forms.

Leidy (1849-1852) described several genera of "Entophyta" from the intestines of arthropods. Several of these, probably Arthromitus, Cladophytum, Corynocladus, Cryptodesma, Eccrina, and Enterobryus, may tentatively be included with the bacteria. It is noteworthy that in 1849 this author called attention to the probable relationships of the Vibrio and Bacterium to plants, that is to the Entophyta.

Perty (1852) in his "Zur Kenntniss kleinster Lebensformen" divided the Infusoria into Ciliata and Phytozoidia, the latter in turn he divided into three sections, the third of which he termed Lampozoidea. The family Vibrionida is included under this. The subfamilies and genera of the Vibrionida may be differentiated as follows:

\section{Perty's Classification of the Vibrionida (1852)}

a. Chains or filaments spirally wound.

Subfamily 1. Spirillina

1. Cells not flexuous................. Spirillum

2. Cells flexuous.................... Spirochaeta

aa. Filaments flexuous or straight. Subfamily 2. Bacterina

1. Cells flexuous................... Vibrio

2. Cells not flexuous, cells isolated........ Bacterium

3. Cells not flexuous, in filaments........ Metallacter

4. Cells not flexuous, filaments........ Sporonema

Three species of Spirillum, one of Spirochaeta, three of Vibrio, one of Bacterium, one of Metallacter and one of Sporonema were described. 
Griffith (1853, p. 438) recognized the fact that the Gallionella ferruginea of Ehrenberg was not a diatom, and created for it a new genus Didymohelix.

Ferdinand Cohn $(1854$, p. 123) described as a genus the slimy bacterial growth which develops in certain solutions, giving it the name Zoogloea. Later (1872) he abandoned this term recognizing this to be simply a growth stage in the developmental cycle. Cohn's most important conclusion at this time was to the effect that the bacteria (Vibrionien) belong in the plant kingdom rather than with the true Infusoria.

Henfrey (1856, p. 53) described as an alga a form which he termed Clathrocystis roseo-persinica. This was later placed among the sulphur bacteria by Winogradsky (1888).

Naegeli $(1857$, p. 760$)$ first created a definite group in the plant kingdom for the bacteria. He united the genera Bacterium, Vibrio, Spirillum, Sarcina, Umbina and Nosema under the group Schizomycetes, the name by which the bacteria have in general since been known.

Berkeley (1857, p. 313) in his Introduction to Cryptogamic Botany included two new genera among the molds, Chondromyces and Stigmatella. The work of Thaxter has shown these forms to be the fruiting bodies of myxobacteria.

In 1865 (p. 156) Trecul studied carefully certain vegetable cells which found developing in putrefying plant tissues. To the various shapes he gave the names Urocephalum, Amylobacter and Clostridium. These terms have been sometimes used by subsequent writers as generic names and ascribed to Trecul, but this ascription is not, strictly speaking, correct, for this author named no species, his names can be regarded only as pseudogeneric.

Rabenhorst (1865) in Sectio II, Algas Phycochromaceas Complectens of his Flora Europaea Algarum included a number of bacterial genera with the blue green algae. All are included in his order Nematogenae Family Oscillariaceae. The following key to the three subfamilies and to the genera of the subfamily Spirillineae will serve to show this author's conception of relationships.

\section{Rabenhorst's Classification of Bacteria (1865)}

A. Filaments more or less destitute of color, flexuous or spirally bent, not sheathed, often embedded in mucus.

Subfamily 1. Spirillineae 
I. Filaments short, cylindric or filiform..1. Vibrio

II. Filaments filiform, articulated, spirally twisted.

2. Spirillum

III. Filament spiral, much elongated......3. Spirochaeta

B. Filaments colored (often only pale blue) sheathed, usually not moving, rarely slowly oscillating............ Subfamily II. Leptothricheae.

One genus of the two included, Leptothrix, is often classed with the bacteria. C. Filaments more or less colored, sheathed, often showing active oscillation.

Subfamily III. Oscillarieae

One genus, Beggiatoa is now generally classed with the bacteria.

As a footnote under the heading "Fungorum genera Leptothricheis et Oscillariis quasi affinia:" the following genera are included: Cryptococcus, Ulvina, Sphaerotilus and Hygrocrocis.

In the genus Vibrio the following species are listed, $V$. lineola, $V$. tremulans, $V$. subtilis, $V$. rugula, $V$. prolifer, $V$. serpens, and $V$. bacillus. In the genus Spirillum are included $S p$. undula, Sp. tenue, $S p$. volutans and $S p$. rufum. The single species of Spirochaeta is $S p$. plicatilis.

Hallier (1866) introduced the theory of pleomorphism as applied to microörganisms. As a result of his work no additional knowledge of bacterial classification was developed, indeed it was probably somewhat instrumental in retarding advance. No generic names are to be ascribed to him, although he introduced certain names to designate what he believed to be growth forms, and which were later used by various authors as genera.

Davaine (1868) concluded as a result of his study of the anthrax organism that this microbe was closely related to the other bacteria, but unlike those previously described, non-motile. To this type he gave the generic name Bacteridium. A key to the genera of bacteria which he recognized is as follows:

\section{Davaine's Classification of Bacteria (1868)}

a. Filaments straight or bent, never spiral.

b. Motile.

c. Cells rigid ..................Bacterium

cc. Cells flexuous, sinuous............Vibrio

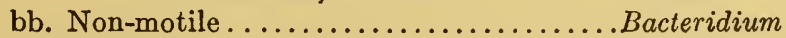

aa. Filaments spiral ................... Spirillum

Cohn (1870, p.108) described one of the filamentous iron bacteria as Crenothrix polyspora. Klebs (1871) in conformity with his ideas on bacterial pleomorphism gave the name Microsporon septicum to the pleomorphic organism which he associated with pus infections. 
Cohn (1872, p. 229) named a spherical organism which he found in smallpox lymph the Microsphaera vacciniae. Later the fact that this generic name had been previously used for a genus of Ascomycetes led him to change to the generic name Micrococcus.

The first measurably adequate classification of bacteria following the recognition of the fact that they were plants, not animals, was that of Cohn (1872, p. 127). He defined the bacteria as having cells free from chlorophyll, spherical, oblong or cylindric, straight or bent, multiplying exclusively by fission and either isolated or vegetating in cell families. Four tribes with a total of six genera were recognized. They may be differentiated by reference to the following key:

Cohn's Classification of Bacteria (1782)

A. Cells spherical ............... Tribe I. Sphaerobacteria

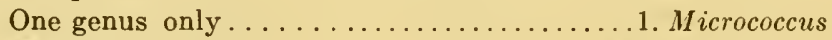

B. Cells isolated short rods......... Tribe II. Microbacteria

One genus only .................... Bacterium

C. Cells elongate or in filaments.... Tribe III. Desmobacteria

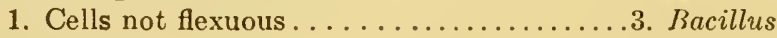

2. Cells flexuous................. Vibrio

D. Cells spiral ............... Tribe IV. SPIRobacteria

1. Cells not flexuous ................5. Spirillum

2. Cells flexuous...................6. Spirochaete

It will be noted that one new genus, Bacillus, was created with $B$. subtilis as the type. Two other species, Bacillus ulna and B. anthracis were included.

Billroth (1874) in a volume entitled "Untersuchungen über die Vegetationsformen von Coccobacteria septica," revived in a modified form the Hallier theory of pleomorphism. As the result of extended studies he came to the conclusion that various bacteria which he observed were different growth forms of the organism which he termed Coccobacteria septica. To the various growth forms he gave names, such as Micrococcos, Mesococcos, Megacoccos, Microbacteria, Mesobacteria, Megabacteria, Monococcos, Monobacteria, Petalococcos, etc. With a modified spelling some of these names have been used by subsequent writers as generic names for bacteria, and by some have been credited to Billroth. This is incorrect as the names were not used by this author in a generic sense, and had no species named.

Cohn (1875, p. 141) later greatly extended and improved his classification of bacteria. He concluded that they belonged with the blue green algae, differing principally in the absence of chlorophyll. His complete classification is as follows. 


\section{Cohn's Classification of the Schizophyta (1875)}

a. Cells free or united into slimy families by an intercellular substance.

Tribe I. Gloeogenae

b. Cells free or in twos or fours.

c. Cells spherical............... Chroococcus Naeg.

cc. Cells cylindrical ............... Synechococcus Naeg.

bb. Cells in resting stage united into amorphous slimy families.

c. Cell membranes continuous with intercellular substance.

d. Cells without phycochrome, very small.

e. Cells spherical.........Micrococcus Hall. emended ee. Cells cylindrical . . . . . . Bacterium Duj.

dd. Cells with phycochrome, larger.

e. Cells spherical.........Aphanocapsa Naeg.

ee. Cells cylindrical........A phanothece Naeg.

cc. Intercellular substance formed of layers of cell membranes.

d. Cells spherical ..............Gloeocapsa Kig. Naeg.

dd. Cells cylindrical ............Gloeothece Naeg.

bbb. Cells united into definite slimy families.

c. Cell families of a flat single layer of cells.

d. Cells in fours in one plane....Merismopedia Meyen.

dd. Cells irregularly grouped on surface of sphere.

e. Cells spherical, families broken into nets.

Clathrocystis Henfr.

ee. Cells cylindric......... Coelosphaerium Naeg.

cc. Cell families, many layered, united into spherical cell bodies.

d. Number of cells definite.

e. Cells spherical, in tetrads, colorless.

Sarcina Goods

ee. Cells cylindric, not regularly arranged, with phycochrome..............Gomphosphaeria Kg.

dd. Number of cells indefinite, very large.

e. Cells colorless, very small.

Ascococcus Billr. emended

ee. Cells with phycochrorne, larger.

\section{Polycystis Kg. \\ Coccochloris Spr. \\ Polycoccus Kg.}

aa. Cells united into filaments..... Tribe II. Nematogenae Rab.

b. Cell filaments always unbranched.

c. Filaments free or felted together.

d. Filaments cylindric, colorless, indefinitely jointed.

e. Filaments very slender, short.

Bacillus Cohn

ee. Filaments very slender, long.

Leptothrix Kg. em.

eee. Filaments thicker, long...Beggiatoa Trev. 
dd. Filaments cylindric, with phycochrome, definitely jointed. Reproductive cells unknown.

$$
\begin{aligned}
& \text { Hypheothrix Kg. } \\
& \text { Oscillaria Bosc. u. a. }
\end{aligned}
$$

3d. Filaments cylindric, jointed, forming gonidia.

e. Colorless............. Crenothrix Cohn

ee. With phycochrome......Chamaesiphon u. a.

4d. Filaments spiral.

e. Without phycochrome.

f. Filaments short, slightly wavy.

Vibrio Ehr. em.

ff. Filaments short, spiral, stiff.

Spirillum Ehr.

fff. Filaments long, spiral, flexuous.

Spirochaete Ehr.

ee. With phycochrome...... Spirulina Link

5d. Filaments rosary like.

e. Colorless.............. Streptococcus Billr.

ee. With phycochrome.......Anabaena Bory.

6d. Filaments tapered to tip..... Spermosira Kg. u. a. cc. Filaments united together into slimy families.

d. Filaments cylindric, colorless.Myconostoc Cohn

dd. Filaments cylindric, with phycochrome.

Chthonoblastus-Limnochlide

3d. Filaments rosary like.........Nostoc, Hormosiphon u. a.

4d. Filaments tapering to tip..... Rivularia Roth

bb. All filaments with false branches.

c. Filaments cylindric, colorless ...... Cladothrix Cohn

Streptothrix Cohn

ce. Filaments cylindric, with phycochrome.

Calothrix Ag.

3c. Filaments rosary like............Merizomyria Kg.

4c. Filaments tapering............... Schizosiphon $\mathrm{Kg}$.

It will be noted that the following bacterial genera were new, Ascococcus (species A. Billrothii), Streptococcus (erroneously ascribed to Billroth, even here without a species designation and probably therefore invalid) Myconostoc (M. gregarium), Cladothrix (sp. C. dichotoma, name invalid because earlier used for another genus of plants), Streptothrix (Str. Foersteri, generic name invalid because of previous use of this generic name for a genus of fungi).

It has been suggested that if a date for a point of departure for the classification of bacteria is to be fixed it might well date from this 1875 classification of Cohn.

In 1877 the veterinarian Bollinger sent to the botanist Harz purulent material from a case of "lumpy jaw" in a cow. Harz found present. 
an organism which he named Actinomyces bovis, the type of a group of organisms now recognized as showing many intermediate characters between the true bacteria and the fungi. Rivolta (1878, p. 169) objected to this name, and proposed in its place Discomyces bovis.

McNab (1877, p. 340) outlined a classification of the "Vegetable Kingdom." His lowest group was the Subkingdom Thallophyta, with several classes. The first of these he termed Schizophyta or Protophyta. The orders and families were as follows:

McNab's Orders of the Schizophyta (1877)

Order I. Cyanophyceae or Phycochromaceae

Families. Chroococcaceae, Nostocaceae, Oscillatoriaceae, Rivulariaceae, Scytonemaceae

Order II. Chlorophyllophyceae

Families. Palmellaceae, Euglenaceae

Order III. Schizomycetes

Family. Bacteriaceae

Order IV. Saccharomycetes

Family. Saccharomyceae

Van Tieghem (1878, p. 198) introduced the generic name Leuconostoc to designate a streptococcus-like form occurring in large gelatinous masses in syrup, an organism previously described by Cienkowski (1878, p. 12) as Ascococcus mesenteroides.

Magnin (1878) in his text "Les Bacteries" reviewed at length the classification of bacteria, and adopted the scheme of Cohn.

Miquel (1879-1881) published a series of articles on the organisms which produce ammoniacal fermentation in urine. He introduced the generic names Urobacillus, Urococcus and Urosarcina for bacilli, cocci and sarcinae which could bring about this change.

Trevisan (1879, p. 13) created several new genera of bacteria, and evolved the following classification.

\section{Trevisan's Classification of Bacterial Genera (1879)}

a. Unicellular bacteria, globose or cylindric. Spores solitary within the cells. Multiplication by division of the cells in one, two, or all directions.

Tribe I. Bacterieae

b. Cells free or when quiescent associated in indeterminate mucous colonies................ Subtribe I. Eubacterieae

c. Cells globose or globose ovoid. Multiplication by vegetative division of the cells in all directions

Genus 1. Micrococcus 
cc. Cells short cylindric, ellipsoid or fusiform. Multiplication by division of the cells always in the same direction.

Genus 2. Bacterium

bb. Cells associated by an intercellular substance into regular mucous colonies............... Subtribe II. Sarcineae

c. Cells globose, or when dividing ovoid, associated in tetrads in tabular colonies, surrounded by a thick gelatinous tegument. No common capsule about entire colony.

Genus 3. Sarcina

cc. Cells globose, or ovoid when dividing, associated in many layers in dense colonies, surrounded by 1 to 4 gelatinous teguments. No common tegument about entire colony.

Genus 4. Chlamydatomus

ccc. Cells globose, associated in large numbers in globular colonies without separate capsules. Colonies surrounded by a common gelatino-cartilaginous tegument.

Genus 5. Ascococcus

aa. Pluricellular bacteria. Individuals composed of numerous cells frequently in a filiform body. Spores in series within the cells. Cell division always transverse.

\section{Tribe II. Vibrionieae}

b. Free, without branching.... Subtribe I. Euvibrionieae

c. Somatia fusiform or cylindric distinctly articulate, short, straight, isolated.....Genus 6. Mantegazzaea

2c. Somatia cylindric, more or less distinctly articulate, slender, short, straight, isolated.

Genus 7. Metallacter

3c. Somatia cylindric, more or less distinctly articulate, slender, elongate, filiform, straight, loosely fasciculate.

Genus 8. Leptotrichia

4c. Somatia cylindric, more or less distinctly articulate, elongate, filiform, straight, loosely aggregated.

Genus 9. Beggiatoa

"5c. Somatia cylindric, distinctly articulate, elongate, arcuate or twisted, in masses, microgonidia formed from cells by repeated transverse and longitudinal divisions, globulose, in dense masses in a terminal pseudo-sporangium, escaping from the tip.

Genus 10. Crenothrix

6c. Somatia cylindric, articulate, short, undulate flexuose.

Genus 11. Vibrio

7c. Somatia cylindric, articulate, short, rigid, spirally twisted.

Genus 12. Spirillum

8c. Somatia cylindric, distinctly articulate, elongate, flexile, spiral. Genus 13. Spirochaete

9c. Somatia compressed like a blade, short, spirally twisted.

Genus 14. Spiromonas 
bb. Somatia associated into colonies through intercellular mucus. Unbranched............ Subtribe II. Myconostoceae

c. Somatia cylindric, slender, implicate, twisted, invested in mucus, in globular colony....Genus 15. Myconostoc

bbb. Somatia free, pseudoramose.

Subtribe III. Cladothriceae

c. Somatia cylindric, leptothrichoid, lower portion scarcely articulate, slender, straight or slightly bent, pseudo-dichotomous. Microgonidia formed by a series of successive longitudinal and transverse divisions, globose, in a pseuda-sporangium, escaping laterally and developing new somatia.

Genus 16. Cladothrix

cc. Somatia cylindric, leptothrichoid, indistinctly articulate, slender, straight or slender spirals, sparsely branched.

Genus 17. Streptothrix

Luerssen (1879) in the first volume of his Botanik discusses the genera of bacteria. Those recognized by him may be differentiated as follows:

\section{Luerssen's Classification of Bacteria (1879)}

a. Cells not united in filaments, after division quickly falling apart or remaining in pairs, free or united into colonies by mucus.

b. Cells divide in one plane.

c. Cells spherical................ Micrococcus

cc. Cells ellipsoidal or short ellipsoidal

\section{Bacterium}

bb. Cells dividing regularly in three directions of space forming cubical

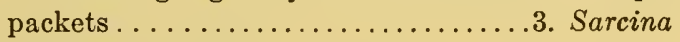

aa. Cells in cylindrical threads.

b. Filaments straight, indefinitely jointed.

c. Filaments very slender and short, rod shaped.

4. Bacillus

cc. Filaments very slender and long....5. Leptothrix

ccc. Filaments thick and long........6. Beggiatoa

bb. Filaments wavy or spiral.

c. Short and stiff.

1. Filaments slightly curved....7. Vibrio

2. Filaments spiral ........... Spirillum

cc. Long, flexuous............... Spirochaete

Duclaux (1879-80) in his extensive "Memoire sur le lait" described with the generic name Tyrothrix a considerable number of organisms isolated from milk and cheese. The species are not closely related, and the group decidedly heterogeneous, the name in consequence has been but little used. The same may be said of the generic name Actinobacter (species A. polymorphum which he isolated from milk).

Winter (1880) published in the volume "Die Pilze" of Rabenhorst's Kryptogamen-flora one of the most extensive classifications made up to this time. The key to the genera follows: 


\section{Winter's Classification of Bacteria (1880)}

a. Cells spherical or oval.

b. Cells isolated, in chains or embedded irregularly in mucus.

bb. Cells united into definite colonies.

1. Micrococcus Cohn

c. Colony hollow, with peripheral layer of cells.

cc. Colony solid, filled with cells.

2. Cohnia Winter

d. Cells united in small but definite numbers into regular families................ Sarcina Goodsir

dd. Cells in large and indefinite numbers united into irregular colonies.

4. Ascococcus Cohn

aa. Cells cylindric, short or long.

b. Cells short, cylindric, single or bound loosely together in pairs

5. Bacterium

bb. Cells longer, cylindric, united into filaments.

c. Filaments isolated or felted.

d. Unbranched.

e. Cells straight.

f. Short, definitely jointed

ff. Long, indefinitely jointed.

6. Bacillus Cohn

g. Very slender...7. Leptothrix Kützing

gg. Thicker.......8. Beggiatoa Trevisan

ee. Cells spiral or bent.

f. Cells short, with few turns, not flexuous.

9. Spirillum Ehr.

ff. Cells longer, with numerous turns, flexible.

10. Spirochaeta Ehr.

dd. With apparent branches.....11. Cladothrix Cohn

cc. Cells embedded in rounded gelatinous masses.

12. Myconostoc Cohn

aaa. Cells lancet-like; flat bands, spirally wound..13. Spiromonas Perty

In an "Anhang" he includes two other genera, Sphaerotilus Kützing and Crenothrix Cohn. The name Cohnia used as generic designation by Winter was preoccupied, and changed later by Schroeter to Lamprocystis.

Prazmowski (1880) in a study of certain anaërobic bacteria revived Trecul's casual name Clostridium, and created a genus with this designation to include those organisms which produce spores in more or less spindle-shaped cells.

De Lanessan (1880) gave an outline of a classification of the genera of bacteria as follows: 
de Lanessan's (1880) Classification of Bacteria

A. Cells not united in filaments, separating immediately after division, or in colonies (zoogloea) united by a gelatinous substance.

I. Cells dividing in one direction only.

a. Cells spherical . ................Micrococcus

b. Cells elliptical or short cylindrical.... Bacterium

II. Cells dividing regularly in three directions of space, forming cubical colonies. .Sarcina

B. Cells cylindrical in filaments.

I. Filaments straight, imperfectly segmented.

a. Filaments very slender and short, small rods.

Bacillus

b. Filaments slender and long........ Leptothrix

c. Filaments broader and long......... Beggiatoa

II. Filaments undulant or spiral.

a. Filaments short.

1. Filaments slightly undulant....Vibrio

2. Filaments spiral, stiff ......... Spirillum

b. Filaments long, flexible, with rapid undulations, spiral throughout length, slender, actively motile. . .Spirochaeta

Bergonzini (1881) named a violet organism which he studied Cromobacterium violaceum.

Kern (1882, p. 135) studied the organism producing a Caucasian fermented milk beverage. Because it apparently produced two spores to a cell he named it Dispora caucasica. Either Kern mistook other cell inclusions for spores or confused spore-bearing bacteria with the sour milk form. His organism cannot be satisfactorily identified from his description, and the genus name has not been used by other writers.

Zopf (1883) in the first edition of his "Die Spaltpilze" formulated a somewhat new characterization of bacterial genera. The families and genera recognized may be separated as follows:

\section{Zopf's Classification of Bacteria (1883)}

a. Cells spherical, sometimes in filaments made up of coccal elements. One

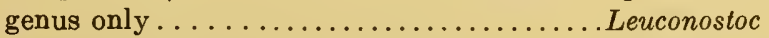

aa. Organisms showing coccus and rod shapes in growth stages.

b. Spiral forms lacking as a growth stage. Filamentous stage showing no differentiation of base and tip.

c. Not becoming spindle or club shaped when sporulating.

Bacterium

cc. Rods becoming spindle shaped or ellipsoidal or club shaped when sporulating ............Clostridium 
bb. Possessing spiral stage in the growth.

c. Not forming false branches.

Leptothrix, Beggiatoa, Crenothrix and Phragmidiothrix

cc. Forming false branches........... Cladothrix

Balcke (1884) according to Lindner named an organism from fermenting wort Pediococcus cerevisiae. This generic name has been commonly used since as a designation for organisms which occur in tetrads but do not form regular Sarcina packets.

De Bary (1884) introduced a new principle into the classification of bacteria by his separation of these organisms into two groups based upon the presence of endospores in the one and of arthrospores in the other. The following key will illustrate this method of differentiation:

De Bary's Classification of Bacteria (1884)

a. Producing endospores.

b. Rods straight or slightly bent (including all non-arthrosporous types of Clostridium, Bacteridium, Vibrio, etc.)

1. Bacillus

bb. Rods spiral ..................... Spirillum

aa. Producing arthrospores.

b. Rosaries of cocci, embedded in firm masses of gelatin.

3. Leuconostoc

bb. Simple rods....................... Arthrobacterium

bbb. Filamentous forms................5. Crenothrix

6. Beggiatoa

7. Cladothrix

8. Leptothrix

The classification used by Grove (1884) was an exact translation of that of Winter.

Van Tieghem (1884) agreed with Cohn in including the bacterial genera among the blue-green algae. The following key, carried to genera only for the bacteria, will illustrate the rather indefinite grouping used by this author.

\section{Van Tieghem's Classification of Bacteria (1884)}

A. Family I. Nostocaceae. Producing cysts. With many algal genera and the bacterial genera Beggiatoa and Leuconostoc.

B. Family II. Bacteriaceae. Producing spores.

I. Cell division in one direction of space.

a. Cells spherical. Micrococcus

(In gelatin, Ascococcus, Naked, Punctula.) 
b. Cells elongate.

1. Cells not spiral.

(a) Cells separating when formed.

\section{Bacterium}

(b) Cells forming a chain or filament. Bacillus

(c) Filaments relatively long.

(1) Sheathless........Leptothrix

(2) Sheathed........Crenothrix

(d) Filaments branched..... Cladothrix

(e) Enclosed in gelatin.....A scobacteria

(f) Naked cells ........... Polybacteria

2. Cells spiral.

(a) Cells separating quickly..Vibrio

(b) Spiral, like a spring..... Spirillum

(c) Cells longer and more slender.

(d) Cells embedded in gelatin.

Spirochaete

\section{Myconostoc}

II. Cell division in two directions of space, giving rise to tetrads.

Merista

III. Cell division in three directions of space forming cubical packets.

Sarcina

The genera Streptococcus for the chain cocci and Staphylococcus for the irregularly grouped cocci from pus were first adequately defined by Rosenbach (1884). Both of these names had previously been used by other writers, but Rosenbach was apparently the first to associate them definitely with species.

Zopf (1884) in the third edition of Die Spaltpilze materially modified and enlarged the bacterial classification used in the first and second editions. The four main groups were recognized as before, but the number of genera increased. Following is the classification used:

\section{Zopf's Classification of Bacteria (1885)}

a. Cells producing only a spherical stage.

b. Not embedded in firm masses of gelatin.

c. Cells regularly arranged.

d. Cells in chains.............. Streptococcus

dd. Cells not in chains.

e. Cell division in two planes, forming flat plates of cells................Merismopedia

ee. Cell division in three planes, forming regular cubes and packets..............Sarcina

cc. Cells irregularly arranged.........Micrococcus 
bb. Cells embedded in thick gelatinous masses.

\section{Ascococcus}

aa. Consisting of cocci, rods and filaments, or the latter two forms only; in filaments no differentiation of base and tip.

b. Spore formation unknown or not occurring.

c. Cells not spiral................Bacterium

cc. Cells spiral.................. Spirillum

bb. Spore formation known.

c. Filaments spiral .............. Vibrio

cc. Filaments not spiral.

d. Forming cocci and rods, spore formation in the former.

\section{Leuconostoc}

dd. Forming cocci and rods or latter only. Spores in rods or cocci..................Bacillus

ddd. As in dd, but spores in swollen cells.

\section{Clostridium}

3a. Consisting of coccus, rod and filament forms, the latter with a differentiation of base and tip.

b. Filaments containing sulphur, sheathless.

bb. Filaments without sulphur.

\section{Beggiatoa}

c. Filaments sheathed.............Crenothrix

cc. Filaments not sheathed, cell divisions ultimately both longitudinal and transverse............ Phragmidiothrix

ccc. Filaments with or without sheaths, no longitudinal cell division. Leptothrix

4a. Consisting of cocci, rods, filaments and spirals. False branching occurs. Spore formation is unknown............. Cladothrix

Trevisan (1885) described several new genera of bacteria, including Kurthia, Zopfiella, Bacteriopsis, Klebsiella and Gaffkya.

In the same year he also created the genus Pacinia to include organisms of the type of the Asiatic cholera organism.

Hauser (1885) described a new genus Proteus to include certain putrefactive bacteria which formed characteristic amoeboid colonies on gelatin and which exhibited a high degree of pleomorphism, varying from cocci to rods and spirals.

Lutz (1886) proposed the generic name Coccothrix to designate the acid fast bacteria of the types of the organisms of tuberculosis and of leprosy. He also made this genus the type of the family Coccothrichaceen. In the same year Weichselbaum used the designation Diplococcus pneumoniae for the causal organism of pneumonia.

Flügge (1886) outlined a classification of bacterial genera which has been extensively followed by medical bacteriologists. A key to his genera may be constructed as follows: 


\section{Flügge's Classification of Bacteria (1886)}

a. Cells spherical.

b. Cells isolated, or bound in chains united into amorphous slimy families.

1. Micrococcus

bb. Cells united into definite slimy families.

c. Colonies solid (filled with cells).

d. Cells united in large and indefinite numbers into irregular colonies.................2. Ascococcus

dd. Cells in small but definite numbers united into regular families . 3. Sarcina

cc. Colonies with peripheral layers of cells, no cells in the interior.

aa. Cells cylindric.

4. Clathrocystis

b. Cells short cylindric, single or loosely hanging together, or united into amorphous slimy masses..........5. Bacterium

bb. Cells longer cylindric, bound into filaments.

c. Filaments isolated, in filaments or in bundles.

d. Filaments unbranched.

e. Filaments straight.

f. Filaments short, definiteiy jointed.

6. Bacillus

ff. Filaments long, indefinitely jointed.

g. Filaments very slender.

gg. Filaments thicker.

7. Leptothrix

8. Beggiatoa

ee. Filaments undulating or spiral.

f. Short, stiff ........9. Spirillum

(Vibrio)

ff. Long, flexible.....10. Spirochaeta

dd. Filaments with false branches.

11. Streptothrix

12. Cladothrix

cc. Filaments enclosed in round gelatinous masses.

13. Myconostoc

Genera doubtfully belonging here: Crenothrix, Sphaerotilus, Spiromonas, Rhabdomonas, Monas.

Schroeter (1886) outlined the most complete and elaborate classification of bacterial genera and species that had been prepared up to that time. He introduced a number of new genera. His generic key is as follows:

\section{Schroeter's Classification of Bacteria (1886)}

I. Order: Coccobacteria. Cells in all stages of development, sphericalelliptical, never motile. Spores, if present, developing through transformation of an entire cell...Family Coccaccei Zopf. 
A. Cells or colonies free or embedded in slime, without definite gelatinous membranes.

1. Cells single or arranged irregularly.....Micrococcus Cohn

2. Cells united in chains............. Streptococcus Billroth.

3. Cells united in a stratum.

a. In tabular form .............Lampropedia n. g.

b. In hollow balls.............Lamprocystis $\mathrm{n}$. g.

B. Single cells or cell colonies with a definite firm gelatinous covering (cyst).

1. Cells single or irregularly grouped:

a. Each cell or small cell family included in a simple gelatinous cyst.................... Hyalococcus n. g.

b. Cells or few celled families included in a many layered slime capsule................. Leucocystis Schroeter

c. Cell families of many cells enclosed in an almost solid gelatinous mass . . . . . . . . . . A scococcus Billroth

2. Cell families regularly formed:

a. Cell families in packet-shaped bundles, each single cell with a capsule................ Sarcina Goodsir

b. Cells in chains, each family in a capsule.

II. Order: Eubacteria. Cells rod shaped, shorter or longer.

\section{Leuconostoc Van Tieghem}

\section{Family........Bacteriacei}

A. Cells or cell groups without definite gelatinous capsule.

1. Cells straight or slightly bent, not spiral.

a. Cells very small, elliptical, motile or non-motile, spores unknown ................ Bacterium Ehr.

b. Cells cylindrical, motile or non-motile:

(1) Cells relatively very broad. Red, with sulfur.

Chromatium Perty

(2) Cells in vegetative condition narrow rods. Endogenous spores.

(a) Spore bearing cells cylindric.

Bacillus Cohn

(b) Spore bearing cells spindle shaped.

Clostridium Praz.

2. Cells and cell chains spiral, usually actively motile.

a. Spirals stiff (not flexuous). Endogenous spores.

b. Spirals flexuous:

Spirillum Ehr.

(1) Cells known only in the form of a long flexuous spiral. Spores unknown...... Spirochaete Ehr.

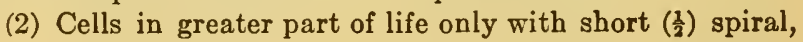
later growing to screw form. Spores spherical. Arthrospores..........Microspira n. g.

B. Cells enclosed in definite gelatinous masses.

1. Cells wound in small numbers in a transparent capsule. Myconostoc Cohn 
2. Cells rod shaped, in large numbers in a brown thick capsule.

Cystobacter $\mathrm{n}$. g.

III. Order: Desmobacteria. Long filaments, usually surrounded by a definite sheath:

A. Filaments unbranched....Family Leptotrichacei Zopf.

1. Filaments always non-motile.

a. Filaments with very thin sheaths. Multiplication by falling apart into two segments..... Leptothrix Kützing

b. With thick sheaths. Multiplication by spores and separation of single joints.......Crenothrix Cohn

2. Filaments motile................ Beggiatoa Trevisan

B. Filaments branched:

1. Filaments not club shaped or thickened at end:

a. Filaments free...............Cladothrix Cohn

b. Filaments bound in bundle by slimy capsule.

Sphaerotilus Kützing

2. Filaments club thickened at end....Actinomyces Harz.

The new genera described were Lampropedia, Lamprocystis, Hyalococcus, Leucocystis, Microspira and Cystobacter.

Trevisan (1887) outlined the following classification of bacterial genera.

\section{Trevisan's Classification of Bacteria (1887)}

1. Bacteriaceae trichogenae. Three stages of vegetative development.

1. Filaments (typical). 2. Rods. 3. Cocci.

A. Filaments fixed, with base distinct from tip.

(Leptotrichieae).

Genus 1. Cladothrix Cohn

Genus 2. Crenothrix Cohn

Genus 3. Sphaerotilus Kützing

Genus 4. Leptotrichia Trevis. (1879)

Genus 5. Beggiatoa Trevis. (1842)

Genus 6. Phragmidiothrix Engler (1881)

B. Filaments free, no distinction between base and tip.

1. Filaments spiral, not embedded in a mucous capsule. (Spirilleae).

Genus 7. Kurthia. Trevis. (1885)

Genus 8. Vibrio Cohn (1872)

Genus 9. Spirillum Ehrenb.

Genus 10. Spirochaete Ehrenb.

2. Filaments spiral, embedded in mucous capsule (Myconostoceae).

3. Filaments straight. (Zopfielleae).

Genus 11. Myconostoc Cohn

Genus 12. Zopfiella Trevisan (1885)

II. Bacteriaceae baculogenae. Three stages of vegetative development.

1. Rods (tvoical). 2. Filaments (abnormal or transitory stage). 3. Cocci. 
$\begin{aligned} \text { A. Not capsulated. (Bacilleae).... Genus 13. } & \text { Bacillus Cohn } \\ \text { Genus 14. } & \text { Pacinia Trevis. (1885) } \\ \text { Genus 15. } & \text { Clostridium Prazmowski } \\ \text { Genus 16. } & \text { Pasteurella Trevis. } \\ \text { Genus 17. } & \text { Bacterium Cohn (1872) } \\ \text { Genus 18. } & \text { Bacteriopsis Trevis. (1885) }\end{aligned}$

B. Normally capsulated. (Klebsielleae).

Genus 19. Klebsiella Trevis. (1885)

III. Bacteriaceae coccogenae. One stage only of development, coccus.

A. Cocci enclosed in common membranous mucous capsule (Ascococceae).

Genus 20. Leuconostoc Van Tieghem

Genus 21. Ascococcus Cohn

Genus 22. Gaffkya Trevis. (1885)

B. Cocci in packets, chains, or isolated. No capsules.

Genus 23. Sarcina. Goodsir

Genus 24. Staphylococcus Ogston

Genus 25. Streptococcus Zopf.

Genus 26. Micrococcus Cohn (emend)

Maggi (1887) in his "Acque potabili" outlined a bacterial classification as follows:

\section{Maggi's Classification of Bacteria (1887)}

A. Order I. Spirobacteria Cohn

I. Genus 1. Spirochaeta Ehr.

II. Genus 2. Spirillum Ehr.

III. Genus 3. Tibrio Auct. emend.

B. Order II. Desmobacteria Cohn

I. Genus 1. Cladothrix Cohn

II. Genus 2. Crenothrix Cohn

III. Genus 3. Beggiatoa Trevisan

IV. Genus 4. Leptothrix Kützing

V. Genus 5. Bacillus Cohn

C. Order III. Microbacteria Cohn

I. Genus 1. Bacterium Dujardin emend.

II. Genus 2. Zygobacterium Maggi.

D. Order IV. Sphaerobacteria Cohn

I. Genus 1. Micrococcus.

The new genus Zygobacterium with its single species $Z$. nitrosum does not seem to be adequately described. The figures show slender rods lying parallel to each other in pairs.

Metschnikoff (1888) described as Pasteuria ramosa an organism which he concluded was a bacterium which divided longitudinally rather than transversely. Although this generic name has been used by subsequent writers as a bacterial genus, it is probable that it is best regarded as protozoan. 
Winogradsky (1888) reported the results of a study on the morphology and physiology of the sulphur bacteria. A number of new genera were created, and several old genera brought definitely into this group. To the present time the account given by this author is the only recorded observation of certain of these forms. His key for the separation of these sulphur genera may be translated as follows:

\section{Key to Winogradsky's Genera of Sulphur Bacteria (1888)}

A. Colorless sulphur bacteria.

I. Filaments uniform in thickness, always free, motile, forming no gonidia. . Beggiatoa

II. Filaments of variable thickness, attached forming motile rod gonidia. Thiothrix

B. Red sulphur bacteria.

I. Cells united into families.

a. Division of cells in three planes.

1. Families of cells small, solitary or many surrounded by a gelatinous cyst, swarming....Thiocystis

2. Families of cells spread out on a substrate, spherical cells embedded in a common gelatin, not swarming.

\section{Thiocapsa}

3. Families packet shaped......Thiosarcina

b. Division of cells first in three planes, then in two. Families first solid, then hollow..............Lamprocystis

c. Division of cells in two directions of space. Families tabular, tetrads, swarming.............Thiopedia

d. Division of cells in one plane.

1. Families amoeboid motile. Cells united by plasma threads. A moebobacter

2. Families with thick gelatinous cysts. Cells in common gelatin, very loosely embedded, swarming. Thiothece

3. Families of rods united into a net.

\section{Thiodictyon}

4. Families solid, non-motile, of small cells closely appressed. Thiopolycoccus

II. Cells free, always swarming.

a. Cells cylindric-elliptic...........Chromatium

b. Cells rod and spindle shaped......Rhabdochromatium

c. Cells spiral ................. Thiospirillum

Hansgirg (1888, p. 229) called attention anew to the parallelism existing in morphology in the bacteria and the algae. He gives as an illustrative table the following: 
Hansgirg's Comparison of Bacteria and Blue-green Algae (1888)

$\quad$ Bacteria
Micrococcus-Hyalococcus
Bacterium-Streptococcus
Leucocystis-Mycothece
Ascococcus-Leuconostoc
Lamprocystis (Cohnia)-Sarcina.
(Lampropedia)
Bacillus-Leptothrix exp.
Beggiatoa-Spirochaete (Spirillum)
Myconostoc
Crenothrix
Cladothrix (Streptothrix)

Blue Green Algae
Aphanocapsa-Chrococcus
A phanothece-Synechococcus
Gloeocapsa-Gloenthece
Polycoccus-Anacystis (Polycystis)
Clathrocystis-Merismopedium
Lyngbya exp. (Leptothrix exp. Hypheo-
thrix)
Oscillaria-Spirulina
Nostoc
Chamaesiphon
Plectonema (Glaucothrix)

He also prepared an outline of the groups of bacteria with particular reference to the forms to be found in damp cellars and other subterranean habitats. While adequate descriptions are not given by Hansgirg, the following key is believed to represent the principal distinctions among the various groups.

\section{Hansgirg's Classification of Bacteria (Schizomycetes) (1888)}

A. Filamentous.............. Order I. Desmobacteria

I. With false branching.... Family Cladothricaceae

One genus only............. Genus Cladothrix Cohn

II. No false branching.

a. Gonidia formed..... Family Crenothricaceae Hansg.

One genus only........ Genus Crenothrix Cohn

b. No gonidia ......... Family Leptothricaceae

1. Filaments immobile.

Subfamily Leptothriceae

One genus only.... Genus Leptothrix Ktz. ex. p.

2. Filaments oscillating.

Subfamily Beggiatoeae Hansg.

One genus only..... Genus Beggiatoa Trevisan

(a) Filaments not colored.

Sec. 1. Eubeggiatoa Hansg.

(b) Filaments colored purple.

B. Cells elongate, but not filamentous.

Sec. 2. Chromobeggiatoa Hansg.

I. Cells not encysted......Family Bacteriaceae

a. Cells spirally bent... Subfamily Spirobacteria. Cohn

1. Cells flexuous...... Genus Spirochaete. Ehrb.

2. Cells not flexuous... Genus Spirillum Ehrb.

(a) Colorless, without sulphur.

Section 1. Vibrio (Cohn) Hansg.

(b) Rose colored, with sulphur. 
b. Cells not spirally bent.

Section 2. Ophidomonas (Ehr.) Hansg.

Subfamily Microbacteria Cohn

1. Cells elongate......Genus Bacillus Cohn

(a) Without sulphur inclusions.

Section 1. Eubacillus Hansg.

(b) With sulphur inclusions.

Section 2. Chromobacillus Hansg.

2. Cells short........ Genus Bacterium Ehrb.

II. Cells encysted...........Family Myconostocaceae Hansg.

One genus only............. Genus Myconostoc Cohn

C. Cells spherical............... Order III. Sphaerobacteria

One family only..............Family $M$ ycococcaceae

a. Cells encysted............ Subfamily Cystococcaceae Hansg.

1. Cells irregularly grouped.

a. Each cell or each group of a small number of cells in common cyst............. Genus Hyalococcus Schröter

b. As (a), but with many-layered cysts.

Genus Leucocystis. Schröter

c. Cell families of very numerous individuals in a common cyst.

Genus Ascococcus Billroth

2. Cells regularly grouped.

a. Cells in chains, encapsulated.

Genus Leuconostoc Van Tieghem

b. Cells in twos and fours, in many layered capsules. Cells elongate.......... Genus Mycothece. Hansg.

Metschnikoff (1888) suggested the generic name Sclerothrix for the acid fast bacteria of the type of the bacillus of tuberculosis. Evidently he was not aware of the previous use of this name by Kuetzing (1849) for a genus of algae.

Bollinger (1888) suggested the name Botryomyces as a designation for the genus of cocci found in the socalled botryomycomata of the horse. In this year Gamaleïa used the name Coccobacillus avicidus for the organism of chicken cholera.

Beijerinck (1889) proposed the generic designation Photobacterium to include all of the photogenic forms. This is perhaps the first genus of bacteria proposed based upon a physiologic character. Frank (1889) used Rhizobium as the generic name for the bacteria found in the root nodules of leguminous plants. Spirobacillus was named by Metschnikoff in the same year.

Probably the most elaborate classification of bacteria based entirely upon morphologic characters is that of De Toni and Trevisan (1889) published in Saccardo's. Sylloge Fungorum. Many new genera were 
recognized, and specific descriptions given of over 650 species. Many of the species and even some of the genera cannot at present be identified with certainty, but this classification has nevertheless been entirely too much ignored by bacteriologists.

\section{De Toni and Trevisan's Classification of Bacteria (1889)}

Key to Subfamilies of Schizomycetaceae Naeg.

1. Three stages of development, filaments, rods, and cocci. Filaments (in the primary stage) sheathed or sheathless, usually with base and apex differentiated, attached or radiating from a central point, rarely free. Rods and cocci included in the filaments................ Trichogenae Trev.

2. Three stages of development, individual rods, filaments and cocci. Rods (in the primary stage) forming filaments and cocci; filaments ( $2^{\prime \prime}$ stage) never sheathed, nor with distinct base, nor fixed, nor radiating from a central point, formed by single bacilli remaining attached, due to imperfect division. II. Baculogenae Trev.

3. One stage only, cells spherical..............III. Coccogenae Trev.

\section{Key to Tribes and Genera of the Trichogenae Trev.}

a. Spores (arthrospores) produced in special parts of the filaments (pseudosporangia)................ Tribe I. Crenotriceae Trev.

Filaments sheathed unbranched........... Crenothrix Cohn

aa. Spores (arthrospores) produced in normal filaments:

b. Filaments pseudoramose...Tribe II. Cladotriceae Trev.

c. Filaments sheathed:

d. Filaments subequal from base to apex. Arthrospores numerous, dividing in three directions of space.

Sphaerotilus Kuetz

dd. Filaments from base to apex more and more thickened. Arthrospores formed, dividing only transversely.

Cladothrix Cohn

cc. Filaments not sheathed. Arthrospores coccus-shaped, division transverse only................. Nocardia Trev.

bb. Filaments unbranched.... Tribe III. Kurthieae Trev.

c. Arthrospores rod shaped......... Detoniella Trev.

cc. Arthrospores cocci:

d. Filaments fixed at base in zoogloeal masses.

Rasmussenia Trev.

dd. Filaments free............ Kurthia Trev.

aa. Spores absent, at least never detected. Filaments unbranched.

Tribe IV. Leptotricheae Trev.

b. Filaments sheathed. Base and tip unequal. Rod-shaped gonidia. Leptotrichia Trev.

bb. Filaments, not sheathed, equal, no rod gonidia. 
c. Filaments fixed. Cell division transverse and longitudinal.

cc. Filaments free, division transverse only.

Phragmidiothrix Engler.

Beggiatoa Trev.

Key to Tribes and Genera of the Subfamily Baculogenae Trev.

a. Bacilli and cocci naked, never with a tegument.

Tribe I. Bacilleae Trev.

b. Producing endospores:

c. Division longitudinal .. Subtribe I. Pasteurieae Trev.

One genus only............... Pasteuria Metch.

cc. Divisions transverse:

d. Rods united in a reticulate coenobium:

Subtribe II. Thiodictyeae

One genus only............Thiodictyon Winogradsky

dd. Rods not united in reticulate coenobium.

e. Rods straight or slightly bent, never spiral.

Subtribe III. Eubacilleae Trev.

f. Spores not greater in diameter than normal vegetative rods.

g. Spores forming in unchanged rods:

h. Plasma uniformly diffused in rods:

i. Rods fusiform.

Mantagozzaea Trev.

ii. Rods cylindrical or cylindraceous.

Bacillus Cohn

hh. Plasma bipolar in distribution.

Pasteurella Trev.

gg. Spores with special integuments, cells becoming ellipsoid-fusiform:

Clostridium Praz.

ff. Spores greater in diameter than the normal vegetative rods.

g. Spores median in unchanged rods. Cornilia Trev.

gg. Spores apical in clavate rods.

Vibrio Zopf.

ee. Rods spirally bent.

Subtribe IV. Spirilleae Trev.

f. Rods circular in cross section.

Spirillum Ehr.

ff. Rods compressed in cross section.

Spiromonas Perty

bb. Producing arthrospores:

c. Cylindrical, straight or slightly curved. Filaments undulateflexuous or irregularly pseudospiral.

Pacinia Trev. 
cc. Rods ellipsoidal, straight, filaments never pseudospiral. Bacterium Ehr.

8. Bacilli and cocci surrounded by a special membranous-gelatinous capsule.

Tribe Klebsielleae Trev.

b. Bacilli straight or curved, never true spirals.

Subtribe Euklebsielleae Trer.

c. Capsule repeatedly ramose.......Winogradskya Trev.

cc. Capsule simple, never ramose.

d. Plasma uniformly diffused.... Klebsiella Trev.

dd. Plasma condensed at poles.... Dicoccia Trer.

bb. Rods spirally twisted....... Subtribe. Myconostoceae Trev. One genus only .................... yconostoc Cohn Anhang Cystobacter.

Key to Tribes and Genera of Subfamily Coccogenae

a. Cocci associated in families in bladder-like gelatinous masses or cysts:

Tribe Ascococceae Trer.

b. Cocci separated in mucus of the matrix.

c. Cocci destitute of special cysts, in families in common cysts.

Subtribe Euxscocccae

d. Cocci numerous, associated in large families:

e. Cysts homogeneous, not lamellose.

f. Families at first solid, then irregularly clathrate. Division at first in three directions, then in two directions......... Lamprocystis Schroet.

ff. Families in solid mass, cocci diriding in one direction............... Ascococcus Cohn

ee. Cysts lamellose. Solid colonies. Cocci divide in three planes...............Bollingera Trev.

dd. Cocci not numerous, associated in small families:

e. Cysts many layered. Division in three directions. Leucocystis Schroet.

ee. Cyrsts homogeneous, not lamellose:

f. Cocci all in periphery. Cocci divide at first in three directions in two.

Cenomesia Trev.

ff. Cocci few and scattered. Divide in one direction. Thiothece Winogr.

fff. Cocci in solid families, cocci divide in three directions............. Thiocystis Winogr.

cc. Cocci borne in special crsts. Common cysts absent.

Subtribe Gafikyeae Trev.

d. Cysts broad, persistent, numerous in conglobate heap, interior solid, densely aggregated.

Chlamydatomus Trev.

dd. Cysts tenuous, at length breaking apart, solitary, never associated in heaps....... Gafjkya Trer. 
bb. Cocci in mucoid matrix loosely joined in a plasmic filamentous series. Cysts very tenuous, at length breaking apart. Special cysts none. Subtribe Amoebobacteriae Trev.

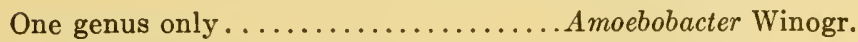

aa. Cocci in families of single or many layers, joined by mucus more or less conspicuous. No cysts, endospores small, appearing in cocci.

Tribe. Sarcineae Trev.

b. Cocci heaped up closely in firm mucous matrix.

c. Cocci in solid irregular heaped families without order, densely associated. Cocci divide in one direction.

Thiopolycoccus Winogr.

cc. Cocci closely associated in regular cubical families, dividing in three directions..............Sarcina Goodsir

bb. Cocci grouped loosely in mucous matrix.

c. Cocci in fours in one layered families, in firm mucus, forming parallelograms, loosely associated. Division in two planes.

Lampropedia Schroet

cc. Cocci few in irregular families in firm mucoid membranes, periphery amorphous, associated without regular order. Divide in three directions.............Thiocapsa Winogr.

ccc. Cocci in fours in small regular colonies, one layered, tenuous, amorphous, scarcely breaking apart, loosely associated. Divide in two planes.

Pediococcus Lindner.

aaa. Cocci in moniliform chains. Arthrospores large in the filaments or on apex.

Tribe III. Streptococceae Trev.

b. Filaments produced in a membranous, gelatinous capsule:

c. Capsules large, broad, lamellose....Leuconostoc Van Tiegh.

cc. Capsules close, tenuous, not lamellose.

Schuetzia Trev.

bb. Filaments in a cylindrical sheath.......Perroncitoa Trev.

bbb. Filaments naked:

c. Pseudodichotomous. Arthrospores at tip of filaments.

Babesia Trev.

cc. Simple. Arthrospores included in filaments.

Streptococcus Billroth

emended Zopf.

4a. Cocci not in cysts, capsules or sheaths, nor in chains, with endospores.

Tribe IV. Micrococceae Trev.

b. Cocci in pairs. ......................

bb. Cocci associated in botryoid masses.... Staphylococcus Ogston

bbb. Cocci solitary or associated in amorphous zoogloeal masses.

Micrococcus (Hallier) Cohn

Hansgirg (1890) described two new bacterial genera which have been uniformly ignor ed by subsequent writers. They are Mycacanthococcus and Mycotetraedron, both from wine cellars.

Baumgarten (1890) ignored the recognized rules of nomenclature in the following classification: 


\section{Baumgarten's Classification of Bacteria (1890)}

A. Species relatively monomorphic.

I. Cells spherical .............Genus Kokkus

a. Cells in pairs.......... Subgenus Diplokolkus

b. Cells in chains........... Subgenus Streptokokkus

c. Cells in tabular masses...Subgenus Merista or Merismopedia

d. Cells in regular packets...Subgenus Sarcina

e. Cells in irregular masses. Subgenus Mikrokokkus

II. Cells rod shaped. Many species with spores.

Genus Bacillus

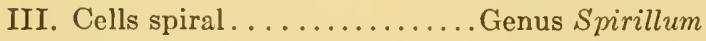

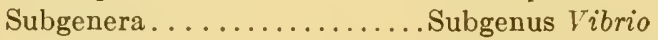

Subgenus Spirillum

Subgenus Spirochaete

B. Species relatively pleomorphic.

I. Rods and spirals. Proteus types.

II. Long filaments.

Genus Spirulina

a. Unbranched.......... Genus Leptothrix

Subgenera............ Subgenus Leptothrix

Beggiatoa

Crenothrix

Phragmidiothrix

b. Branched...............enus Cladothrix

The Cornil-Babes (1890) classification is another example of the carelessness in the definition of genera frequently to be found among the writers on medical bacteriology. The following outline will give the principal groups recognized, although generic names not here mentioned are used in the body of the text.

\section{Cornil-Babes' Classification of Bacteria (1890)}

Group I. Micrococcus. Cells spherical.

1. Cells in rosary ............... Streptococcus

2. Cells in irregular groups......... Staphylococcus

3. Cells in firm gelatinous masses... Ascococcus

4. Cells in regular packets........ Sarcina

Group II. Bacteriaceae. Short rods usually, may develop to filaments.

1. Without capsules.

a. Not polymorphic..........Bacterium

b. Polymorphic..............Proteus

2. Encapsulated.................Ascobacterium

Group III. Bacilli. Longer rods, producing spores. Genera Bacillus and Vibrio.

Group IV. Spirobacteria. Cells spiral.

Genera Spirillum, Spirochaete, Leptothrix, Beggiatoa, Streptothrix. 
In the same year also appeared the first of the classifications of bacteria used by Migula (1890). He gave no summarized statement, but the following outline shows his conception of generic relationships.

Migula's First Classification of Bacteria (1890)

A. Cells spherical.

I. Cells falling apart upon division.......Mikrococcus

II. Cells remaining united in groups.

a. Forming irregular masses........ Staphylococcus

b. Forming regular groups.

1. Cells in chains............ Streptococcus

2. Cells in regular packets....... Sarcina

3. Cells in flat plates, tetrads....Merismopedia

4. Cells in gelatinous masses..... Leuconostoc

B. Cells rod shaped.

I. No spores produced................Bacterium

II. Spores produced.

a. Cell when sporulating not spindle shaped.

b. Cell when sporulating spindle shaped.

Bacillus

C. Cells spiral.

Clostridium

I. Cells relatively short.

a. Stiff, not flexuous.............. Spirillum

b. Flexuous................... Tibrio

II. Cells relatively long and flexuous....... Spirochaete

D. Cells filamentous.

Genera. Beggiatoa, Crenothrix, Cladothrix and Sphaerotilus.

Guignard (1890) named an organism responsible for the formation of large slimy masses on rocks on the seashore, Streblothrichia Bornetii.

During the year 1891 at least three generic names were applied to bacteria as new. These were Micromyces by Gruber for a form of Actinomyces, Eubacillus by Dangeard for certain green bacteria (containing chlorophyll) and Rhodococcus by Zopf for the red cocci.

Ludwig (1892) outlined the following classification of bacterial genera. The number of genera recognized is smaller than those of some previous authors, but in some respects it represents a real adrance.

\section{Ludwig's Classification of the Bacteria (1892)}

I. Cocci, with spherical non-motile cells, without endospores, or with a single endospore in the cell:

A. Not embedded in slime:

1. Simply or irregularly grouped........ Micrococcus

2. Cells in pairs .................. Diplococcus

3. Cells in chains................. Streptococcus 
B. Embedded in slime:

1. Single cells..................Hyalococcus

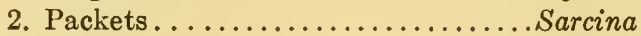

3. Chains .......................Leuconostoc

II. Forming rods, not long filaments:

A. Not embedded in slime:

1. Small elliptical cells............ Bacterium

2. Small rods with endogenous spores..Bacillus

3. Spiral:

a. Stiff or rigid........... Spirillum

b. Long and flexuous........Spirochaete

B. Embedded in slime:

1. Cells bent or spiral.............Myconostoc

2. Straight rods................. Cystobacter

III. Forming long filaments, usually with a sheath:

A. Unbranched:

1. Non-motile and without inner spore formation.

Leptothrix

2. Non-motile with sheath and inner spore formation.

Crenothrix

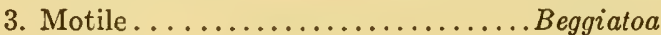

B. Branched:

1. Branches not swollen at tips:

a. Free..................... Cladothrix

b. In slimy sheath............. Sphaerotilus

2. Branches swollen at tips..........Actinomyces

Sternberg (1892) used a comparatively simple classification, merging genera in several cases. His conception of generic names however is in some cases inconsistent. The following key probably fairly indicates the principal points of difference as recognized by this author:

Sternberg's Classification of Bacteria (1892)

A. Cells spherical.

1. Cells not embedded in gelatinous masses.

a. Cell division in one direction.

1. Cells irregularly grouped....... Micrococcus

2. Cells in pairs.............. Diplococcus

3. Cells in chains............. Streptococcus

b. Cell division in two directions, forming tetrads.

Merismopedia

c. Cell division in three planes, forming regular packets.

Sarcina

II. Cells embedded in gelatin.

a. Cells separate in globular or lobulate zoogloeal masses.

Ascococcus

b. Cells solitary or in chains, with a thick gelatinous envelop.

Leuconostoc 
B. Rod shaped or filamentous, not spiral, no differentiation between the extremities of the rods.

I. With or without spores, if the former not fusiform when sporulating.

\section{Bacillus}

II. With spores, fusiform . ............. Clostridium

C. Curved rods or spiral filaments.

I. Not pleomorphic.

a. Cells not sinuous.

1. Cells rigid, not flexuous....... Spirillum

2. Cells flexible ............... Vibrio

b. Cells with sinuous motion........ Spirochaete

D. Cells filamentous, with differentiated base and apex.

I. Without pseudo-branches.

Genera. Leptothrix, Beggiatoa, Crenothrix and Phragmidiothrix.

II. With pseudo-branches..............Cladothrix

Attention should be called to the merging of all rod-genera (except Clostridium) into the genus Bacillus. This came in time to be the most commonly accepted of the medical definitions of the term.

Thaxter (1892) called attention to the existence of a new family of bacteria which he named the Myxobacteriaceae. The organisms belonging to this family show a more complex life history than the forms more commonly studied. The rod shaped cells are associated in a pseudo-plasmodium which in possession of motility resembles the plasmodium of a slime mold. The genera Myxobacter and Myxococcus were described.

During the same year the work of Winogradsky (1892) called to attention the important group of soil bacteria which oxidize ammonia to nitrites and nitrites to nitrates. To his work we owe the generic names Nitrobacter, Nitrosococcus and Nitrosomonas. The genus Nevskia was also described in the same year by Famintzin (1892) to include certain rod shaped bacteria which developed peculiar branched or lobed capsules due to the asymmetric deposition of the gummy material.

During the year 1893 the only generic name proposed was Achromatium by Schewiakoff for an organism of relatively monstrous proportions, which in its content of oxalates (?) simulated in appearance some of the sulphur bacteria.

Freudenreich (1894) recognized three genera of Coccaceae, Micrococcus, Sarcina and Streptococcus with their usual definitions, and in the Bacteriaceae the genera Bacterium and Bacillus, the latter with endospores, the former without. 
Bernhard Fischer (1894) gave the generic name Halibacterium to nonphosphorescent bacteria from salt water.

The most important contribution of 1894 was the appearance of the second Migula classification. In practically identical outline but with some elaboration of subgenera this classification appeared the next year (1895) under the heading of Schizomycetes in Engler and Prantl's Pflanzenfamilien. A key to the families and genera of bacteria as recognized by Migula is as follows:

Key to the Families of Bacteria. Migula (1894)

I. Cells in free state spherical, not lengthening before division. Cell division in one, two, or three directions of space.

Family I. Coccaceae

II. Cells short or long cylindric, divide only transversely, and before division extending to double length:

a. Cells straight, rod shaped, without sheath, non-motile or motile by means of flagella........ Family II. Bacteriaceae

b. Cells bent, without sheath.

c. Cells surrounded by a sheath.

Family III. Spirillaceae

Family IV. Chlamydobacteriaceae

d. Cells united into a filament, without sheath, motile by means of an undulating membrane..Family V. Beggiatoaceae

\section{Key to Genera of the Coccaceae}

I. Cells without organs of motion:

a. Division in one direction of space....... Streptococcus Billr.

b. Division in two directions of space.......Micrococcus (Hall) Cohn

c. Division in three directions of space.... Sarcina Goodsir

II. Cells with organs of motion:

a. Division in two directions of space......Planococcus Migula

b. Division in three directions of space.....Planosarcina Migula

\section{Key to the Genera of Bacteriaceae}

I. Cells without organs of motion............Bacterium Ehr. emend.

II. Cells with flagella:

a. Flagella over entire cell body...........Bacillus Cohn emend.

b. Flagella polar.......................Pseudomonas Migula

Key to the Genera of the Spirillaceae

I. Cells stiff, not bending like a snake:

a. Cells non-motile.................. Spirosoma Migula 
b. Cells with fiagella:

1. Cells with 1 , rarely 2 or 3 polar flagella.

2. Cells with tuft of polar flagella.... Spirillum Ehr.

II. Cells flexuous.................... Spirochaeta Ehr.

Key to the Genera of Chlamydobacteriaceae

I. Cells contents without sulfur granules:

a. Cell filaments unbranched:

1. Cell division continually in one direction of space.

Streptothrix Cohn emend.

2. Cell division before conidia formation in 3 directions of space.

$\mathrm{x}$. Cells surrounded by a very delicate, scarcely visible sheath (marine) ................Phragmidiothrix Engler

$\mathrm{xx}$. Sheaths definitely recognizable (fresh water).

Crenothrix Cohn

b. Cell filaments branched................Cladothrix Cohn

II. Cell contents with sulfur granules.......... Thiothrix Winogr.

Key to the Genera of the Beggiatoaceae

One genus only.

Beggiatoa Trev.

It will be noted that in Migula's classification emphasis is put largely upon the shape of the cell, motility and the distribution of flagella on the bacterial cells. Spores are not regarded as useful in the differentiation of genera. Neither the sulfur bacteria nor the Myxobacteria are recognized as distinct groups.

In 1895 appeared the first classification of Alfred Fischer. The principal differential characteristic will be noted in the family Bacteriaceae which is divided into sixteen genera based upon cell form, spore production, and location of the flagella. No species were known for several of the genera which he included. The classification of this family follows:

Fischer's Classification of Bacteria (1895)

Key to Genera of Bacteriaceae

I. Family Baciller. Non-flagellate.

a. Producing endospores.

1. Spore bearing rod cylindric........Bacillus

2. Spore bearing rod spindle shaped. . . Paracloster

3. Spore bearing rod clavate.........Paraplectrum

b. Producing arthrospores..............Arthrobacter

II. Family Bactrinieĩ. One polar flagellum.

a. Producing endospores.

1. Spore bearing rod cylindric........Bactrinium 
2. Spore bearing rod spindle shaped...Clostrinium

3. Spore bearing rod clavate..........Plectrinium

b. Producing arthrospores.............Arthrobactrinum

III. Family Bactrilleï. With polar tuft of flagella.

a. Producing endospores.

1. Spore bearing rod cylindric........ Bactrillum

2. Spore bearing rod spindle shaped...Clostrillum

3. Spore bearing rod clavate..........Plectrillum

b. Producing arthrospores...............Arthrobactrillum

IV. Family Bactridiez. With diffuse flagella.

a. Producing endospores.

1. Spore bearing rod cylindric........ Bactridium

2. Spore bearing rod spindle shaped...Clostridium

3. Spore bearing rod clavate:

(a) Single spored..........Plectridium

(b) With two spores........ Diplectridium

b. Producing arthrospores.............Arthrobactridium

The year 1896 was notable in the history of bacterial classification for the appearance of the scheme of Lehmann and Neumann. The outlines of classification of Migula, Fischer, and Lehmann and Neumann constitute the bases upon which practically all of the systematic work of the bacteriologists was built during the next two decades. Lehmann and Neumann separated from the true bacteria the bacteria-like Hyphomycetes and the filamentous water or algal bacteria. A key to the families and genera of the true bacteria is as follows:

\section{Classification of Lehmann and Neumann (1896)}

\section{Bacteria or Schizomycetes}

Small cells (almost) always free of chlorophyll, unbranched. Diameter usually not more than $2 \mu$, rarely $3-5 \mu$. Spherical, elongate or spiral, without organs other than flagella. Vegetative division usually transverse, very rarely longitudinal.

I. Cells spherical when free.......Family I. Coccaceae Zopf. emend. Migula.

a. Cells divide only in one direction of space, forming chains if cells remain united........................ Streptococcus Billroth

b. Cells divide on suitable media in three directions of space, forming

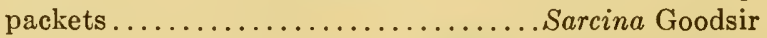

c. Cells divide irregularly, forming isolated cells or irregular masses.

Micrococcus Cohn

II. Cells at least $1 \frac{1}{2}$, usually $2-6$ times as long as broad, straight or slightly bent, never spiral............. Family II.

Bacteriaceae Zopf. emend. Migula.

a. Without endogenous spores, perhaps often with arthrospores. Rods usually under $0.8-1 \mu$ diameter........ Bacterium Cohn emend.

Hueppe. 
b. With endogenous spores. Rods often more than $1 \mu$ in diameter.

Bacillus Cohn emend.

Hueppe.

III. Cells bent or spiral.......... Family Spirillaceae Migula

a. Cells short, slightly bent, stiff, comma-like, sometimes in spiral cell groupings, usually with one, rarely two terminal flagella.

Vibrio O. F. Mueller emend. Löffler

b. Cells long, spirally bent, corkscrew like, stiff usually with a cluster of polar flagella................ Spirillum Ehrenb. emend. Löffler

c. Cells flexuous, long, producing spirally wound filaments. Flagella unknown. Motile by means of an undulating membrane.

Spirochaete Ehrenb.

As "Anhang I" three genera of the bacteria-like Hyphomycetes are included. They may be differentiated as follows:

\section{Lehmann and Neumann's Classification of Hyphomycetes (1896)}

A. Cultures showing ordinary bacterial character, flat or medium. Microscopically rods with swollen ends............ Corynebacterium L. \& N.

B. Cultures on solid media more or less folded, often "cartilaginous".

I. Usually only short slender rods, seldom short branched filaments without air mycelium and without aerial conidia, acid fast.

Iycobacterium L. \& N.

II. Mycelium filaments long, of ten bent, without sheath, with true branching. Many species produce conidia on aerial hyphae. Not acid fast.

Oospora Wallroth

The genera of the fission algae are differentiated as follows:

A. Filaments without sheaths.

1. Without sulphur granules............. Leptothrix

2. With sulphur granules, motile..........Beggiatoa

B. Filaments with sheaths.

1. Without sulphur granules.

a. Without pseudodichotomous branching.

Crenothrix

b. With pseudodichotomous branching. .Cladothrix

2. With sulphur granules................Thiothrix

In many ways this classification of Lehmann and Neumann is one of the most satisfactory that has been proposed.

During the year 1896 Beijerinck introduced the generic name Granulobacter for anaerobic spore-bearing bacteria of the butyric acid group; and Forti named an organism from wine Oenobacillus Abbae.

Alfred Fischer (1897) somewhat modified his earlier classification in his "Vorlesungen über Bakterien." The key to the higher groups and genera is as follows: 


\section{Fischer's Classification of Bacteria (1897)}

Order I. Haplobacterinae

Vegetative phase unicellular, spherical, cylindrical, or spirally twisted; isolated or united in chains or clusters.

\section{Family I. Coccaceae}

Vegetative cells spherical

\section{Sub-Family I. Allococcaceae}

Planes of fission without definite sequence; no pronounced colonies or growth forms, cells isolated or in short chains or irregular clusters.

Genus Micrococcus, Cohn. Non-motile. Includes most cocci, the pathological "staphylococci" etc.

Genus Planococcus, Migula. Motile.

Sub-family IT. Homococcaceae

Planes of fission in definite sequence.

Genus Sarcina, Goodsir. Three planes of division at right angles to each other. Cubical colonies, non-motile.

Genus Planosarcina, Migula. Similar to Sarcina, but monotrichous, and motile.

Genus Pediococcus, Lindner. Two planes of fission, alternate and at right angles.

Genus Streptococcus, Billroth. Planes of fission parallel, giving rise to chains; the pathological Streptococci and Leuconostoc.

\section{Family 2. Bacillaceae}

Vegetative cell straight, cylindrical, ellipsoidal or egg-shaped; very short forms difficult to distinguish from cocci. Fission always transverse.

Sub-family I. Bacilleae

Spore-forming ro ds cylindrical, unchanged.

Genus Bacillus, Cohn. Non-motile.

Genus Bactrinium, A. Fischer. Motile, monotrichous, with terminal cilium: includes provisionally all monotrichous rods whose spores are as yet unknown, e.g., Bac. pyocyaneum.

Genus Bactrillum, A. Fischer. Motile, with lophotrichous ciliation. Includes provisionally Bac. cyanogenum, and many other sporeless forms.

Genus Bactridium, A. Fischer. Motile, peritrichous, in some spores as yet unknown.

\section{Sub-family II. Clostridieae}

Rods spindle-shaped during sporulation.

Genus Clostridium, Prazmowski. Motile, peritrichous; includes some of the butyric bacteria. Genera with monotrichous and lophotrichous ciliation are unknown as yet.

\section{Sub-family III. Plectridieae}

Genus Plectridium, A. Fischer. Motile, peritrichous; some butyric bacteria, the parasite of tetanus and a methane ferment.

Family 3. Spirillaceae

Vegetative cell cylindrical but spirally twisted. Fission always transverse.

Genus Vibrio Müller and Löffler. Very slightly curved rods, "comma" shaped; motile, monotrichous. Vibrio cholerae asiaticae and numerous other vibrios of fresh and salt water. 
Genus Spirillum, Ehrenberg. Cylindrical cells twisted in an open spiral; motile, lophotrichous. Spirillum undula, Sp. rubrum.

Genus Spirochaete, Ehrenberg. Cells long and attenuated, spirally twisted with numerous turns; cilia unknown; the cell membrane is perhaps yielding. Spirochaete Obermeieri (remittent fever).

\section{Order II. Trichobacterinae}

Vegetative phase an unbranched or branched filament or chain of cells, the individual members of which break off as swarm-spores (gonidia).

Family 1. Trichobacteriaceae

(a) Filaments non-motile, rigid, enclosed in a sheath.

Genus Crenothrix, Cohn. Filaments unbranched and devoid of sulphur granules.

Genus Thiothrix, Winogradsky. The same, but containing sulphur granules.

Genus Cladothrix, Cohn. Filaments, branched, false dichotomy (includes Sphaerotilus).

(b) Filaments motile, with oscillating and gliding movements, and devoid of a sheath.

Genus Beggiatoa, Trevisan. Containing sulphur.

Chester (1897) adopted Migula's (1894) classification of Coccaceae, Bacteriaceae and Spirillaceae, but separated the forms included by Lehmann and Neumann in their Hyphomycetes, under the family name Mycobacteriaceae. His characterization of this family and the genera is as follows:

\section{Chester's Classification of the Mycobacteriaceae (1897)}

Cells short or long, cylindrical or clavate-cuneate in form without a sheath surrounding the chains of individuals. Without endospores, with possibly the formation of gonidia like bodies. With true dichotomous branching (this forms an important group standing between the true Bacteriaceae, and the true fungi on the one hand and Chlamydobacteriaceae on the other).

Order Mycobacteriaceae Chester

A. In cultures possessing the characters of true bacteria. Growth on solid media smooth, flat spreading. Rods with swollen ends or cuneate or clavate forms. Corynebacterium Lehm-Neum.

B. Cultures on solid media raised, folded or warty. Generally short slender rods, rarely short branched. Take the tubercle stain.

Mycobacterium Lehm-Neum.

The following key to the families Chlamydobacteriaceae and Beggiatoaceae shows that in the main Chester followed Migula.

\section{Chester's Classification of the families Chlamydobacteriaceae and Beggiotaceae} (1897)

I. Thread-like, composed of individual cells, surrounded by a sheath. Simple or with true branching. Ordinary vegetative growth by division in only one direction of space, i.e., at right angles to the longer axis. 
A. Cell content without sulfur granules.

1. Filaments unbranched:

Order Chlamydobacteriaceae

a. Cell division only in one direction of space.

\section{Streptothrix Cohn}

b. Cell division in gonidia formation in three directions of space.

$\mathrm{x}$. Cells surrounded by a very delicate, hardly discernible sheath (marine).......Phragmidiothrix Engler

xx. Sheath easily discernible (fresh water).

\section{Crenothrix Cohn}

2. Filaments branched............Cladothrix Cohn

B. Cell contents with sulfur granules....... Thiothrix Winogradsky

II. Thread-like, without a capsule, but with undulating membrane and as in

Oscillaria, motile cell contents show sulfur granules. Formation of conidia not certainly known.

\section{Order Beggiatoaceae}

A. Threads apparently not septate, septa only faintly visible with iodine staining. Colorless or faintly rose colored.

Beggiatoa Trev.

During this year (1897) Miyoshi reported three new genera of sulphur bacteria from hot sulphur springs, Thioderma, Thiosphaera and Thiosphaerion. Ellis named a new iron bacterium Spirophyllum and Meyer one of the bacteria of the B. subtilis group Astasia asterospora.

In this year also Migula published the first volume of his "System der Bakterien" containing a general discussion of bacterial morphology and physiology and an outline of the classification of genera essentially that of 1895 .

Hewlett (1898) in his Manual of Bacteriology recognized a small group only of genera. Of these the following were used in the sense of Zopf (1885) Micrococcus, Streptococcus, Sarcina, Clostridium, Cladothrix, Leptothrix. The genus Bacillus was defined to include all rod forms, Spirillum all spiral forms and Streptothrix all thread forms.

Chester in 1899 revised his classification of the family Mycobacteriaceae to read as follows:

\section{Mycobacteriaceae Chester (1899)}

A. Cells in their ordinary form as short cylindrical rods, often bent and irregularly swollen, clavate or cuneate. At times $Y$ shaped forms or longer filaments with true branchings. May produce short coccoid elements, perhaps gonidia..........Mycobacterium Lehm-Neum (including, Corynebacterium L. and N.

B. Cells in their ordinary form as long branched filaments. Produce gonidia-like bodies. Cultures generally have a mouldy appearance due to the development of aerial hyphae. 
In this year a peculiar genus of bacteria was described by Jennings (1899). He used the name Astrobacter to designate an organism which multiplied by longitudinal fission, forming radial clusters. The organisms were found only in certain stained preparations; it is not entirely certain that he was not observing an artifact or at least some organism not bacterial in nature.

Migula (1900) in the second volume of his "System der Bakterien" considerably increased the scope of his classification by dividing the Schizomvcetes into two classes which he termed the Eubacteria and the Thiobacteria, the true bacteria and the sulphur bacteria.

\section{Migula's Classification of Bacteria (1900)}

I. Order Eubacteria: Cells without any "Centralkörper" and free from sulfur and bacteriopurpurin:

A. Cells spherical. Family Coccaceae Zopf emend. Migula

1. Cells non-motile:

a. Division in one direction of space.

Streptococcus Billr.

b. Division in two directions of space.

c. Division in three directions of space.

Micrococcus (Hallier) Cohn

2. Cells motile:

Sarcina Goodsir

a. Division in two directions of space.

Planococcus Migula

b. Division in three directions of space.

Planosarcina Migula

B. Cells straight rods, at least never spiral.

Family Bacteriaceae

1. Non-motile....................Bacterium

2. Motile:

a. Flagella monotrichous....Pseudomonas Cohn emend. Smith

b. Flagella peritrichous..........Bacillus Cohn em. Migula

C. Cells spirally wound or representing a portion of a spiral:

1. Non-motile.................. Spirosoma Mig.

a. Not enclosed in gelatin.

Subgenus Euspirosoma Mig.

b. Enclosed in gelatin. . Subgenus Myconostoc

2. Motile:

a. One, two or three polar flagella.

Microspira Schroeter

b. Tuft of polar flagella........ Spirillum Ehr.

c. Slender and flexuous......... Spirochaete Ehr.

D. Cells cylindric, united into a sheathed thread.

Family Chlamydobacteriaceae 
1. Filaments unbranched.

a. No distinction between base and apex.

b. Filaments enlarged toward tips:

Chlamydothrix Migula

(1) Sheath relatively thick...Crenothrix Cohn

(2) Sheath relatively thin.... Phragmidiothrix Engler

2. Filaments branched dichotomously . Sphaerotilus Kützing

II. Order Thiobacteria; Cells without a "Centralkörpor" but with sulfur inclusions. Colorless, or rose, red or violet, with bacteriopurpurin.

A. Filamentous, destitute of bacteriopurpurin.

Family Beggiatoaceae

1. Threads attached, non-motile..... Thiothrix Winogr.

2. Threads free, motile.............Beggiatoa Trev.

B. Containing bacteriopurpurin.

\section{Family Rhodobacteriaceae}

1. Cells united in families. Division of cells in three directions of space............ Subfamily Thiocapsaceae

a. Families small compact, enclosed singly or several together in a cyst. Capable of swarming.

Thiocystis Winogr.

b. Non-swarming, globose cells spread out upon the substratum in flat families, loosely enveloped in a common gelatin.

Thiocapsa Winogr.

c. Non-swarming cells arranged in packets like Sarcina.

Thiosarcina Winogr.

2. Cells united into families. Division of cells first in three, then in two, directions of space.

Subfamily Lamprocystaceae

Families first solid, then globose hollow, perforated net.

Lamprocystis Schroeter

C. Cells united into families. Divisions in two directions of space. Subfamily Thiopediaceae

Families tubular formed of cells arranged in fours.

Thiopedia Winogr.

D. Cells united in families. Division in one direction of space.

Subfamily Amoebobacteriaceae

1. Cells connected by plasma threads. Families amoeboid motile.

2. Not as " 1 ": Amoebobacter Winogr.

a. Cells arranged in network, united by their ends.

b. Cells not arranged in network:

Thiodictyon Winogr.

(1) Capable of swarming. Cells loosely aggregated in gelatin.............Thiothece Winogradsky

(2) Non-motile, cells closely appressed in colony.

E. Cells free, capable of swarming at any time.

Thiopolycoccus Winogr. 
1. Cells cylindric-elliptic or elliptic. Moderately thick. Polar flagella....................Chromatium Perty

2. Cells rod shaped or spindle form, flagella at poles.

3. Cells spirally twisted.............Thiospirillum

Rhabdochromatium Winogr.

Beijerinck (1900) suggested the generic name Aërobacter to include the gram negative lactic acid and gas producing rods of the $B$. lactis aerogenes and coli types. Hartleb (1900) designated an organism from a root nodule as Pseudorhizobium, and Lagerheim named a bacterium found parasitic upon certain sea weeds, Sarcinastrum.

Chester (1901) in his Manual of Determinative Bacteriology used the following family and generic keys:

\section{Chester's Key to the families of Bacteria (1901)}

I. Cells unbranched, or show only a false branching in Cladothrix:

A. Cells in their free condition globular, becoming slightly elongated before division. Cell division in one, two, or three directions of space.........................Coccaceae

B. Cells short or long, cylindrical, straight, curved, or spiral. Without a sheath surrounding the chain of individuals; motile or non-motile; endospores present or absent..........Bacteriaceae

C. Cells surrounded by a sheath, and arranged in elongated filaments.

Chlamydobacteriaceae

D. Cells not surrounded by a sheath, arranged in elongated filaments, and motile by means of undulating membrane.

Beggiatoaceae

II. Cells short or long, cylindrical or filaments, often clavate; cuneate or irregular in form. Without endospores, but with the formation of gonidia-like bodies due to the segmentation of the cells. Without flagella. Division at right angles to the axis of a rod or filament. Filaments not surrounded by a sheath as in Chlamydobacteriaceae. With true dichotomous branching. Mycobacteriaceae

\section{Key to Genera of the Coccaceae}

A. Cells without flagella:

1. Division in one direction of space only.

Streptococcus Billroth

2. Division in two directions of space. Hicrococcus Hallier

3. Division in three directions of space.

B. Cells with flagella:

Sarcina Goodsir

1. Division in two directions of space. Planococcus Migula

2. Division in three directions of space.

Planosarcina Migula 


\section{Key to the Genera of the Bacteriaceae}

A. Flagella absent, endospores present or absent

B. Flagella present:

Bacterium Ehr.

1. Flagella arising from any part of the body, peritrichic

2. Flagella attached to one or both poles.

Bacillus Cohn

Pseudomonas Migula

\section{Key to the Genera of the Spirillaceae}

I. Cells stiff, not flexile:

A. Without flagella.................. Spirosoma Migula

B. With flagella.

1. With 1 , rarely with 2 or 3 polar flagella.

Microspira Schroeter

2. With a bundle of polar flagella.... Spirillum Ehr.

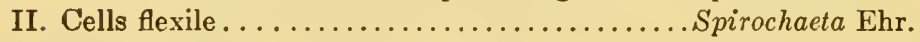

\section{Key to the Genera of Mycobacteriaceae}

Cells either short or long, cylindrical-clavate-cuneate in form, which at times may show true branching, or as long-branched mycelial-like filaments. Filaments not surrounded by a sheath as in Chlamydobacteriaceae. Without endospores, but with the formation of gonidia-like bodies due to a segmentation of the cells. Division at right angles to the axis of a rod or filament.

A. Cells in their ordinary form short cylindrical rods, often bent and irregularly swollen, clavate or cuneate. At times $\mathrm{Y}$-shaped forms or longer filaments with true branchings. May produce short coccoid elements, perhaps gonidia Mycobacterium (Lehmann-Neumann), including Corynebacterium (Lehmann-Neumann).

B. Cells in their ordinary form as long-branched filaments. Produce gonidia-like bodies. Cultures generally have a mouldy appearance due to the development of aerial hyphae. Streptothrix (Cohn); Oöspora (Lehmann-Neumann).

\section{Key to the Genera of Chlamydobacteriaceae.}

Filamentous bacteria composed of rod-shaped cells, and surrounded by a distinct sheath. Division of the cells at right angles to the axis of the filaments. In Phragmidiothrix and Crenothrix, however, in the formation of gonidia, a division of the cells in three directions of space takes place. Reproduction by means of gonidia, which are either motile or non-motile:

I. Cell contents without sulfur granules:

A. Filaments unbranched:

1. Cell division takes place in one direction of space.

Leptothrix 
2. Cell division, before the formation of gonidia, takes place in three directions of space:

a. Filaments surrounded by a delicate, scarcely discernible sheath ..................Phragmidiothrix

b. Filaments surrounded by a plainly discernible sheath.

Crenothrix

B. Filaments show false branchings......... Cladothrix

II. Cell contents contain sulfur granules....... Thiothrix

Lehmann and Neumann (1901) in the second edition of the Grundriss replace the designation of the Anhang I Hyphomycetes with the name Actinomycetes and the generic name Oospora with Actinomyces. Otherwise the classification remained the same. During this year the generic name Azotobacter was suggested by Beijerinck for certain non-symbiotic nitrogen fixing bacteria of the soil. He also used the name Urococcus as a generic designation of certain urea-hydrolyzing cocci. Bongert used Corynethrix to designate an organism associated with mouse pseudotuberculosis.

Kendall (1902) proposed a revision of the Migula classification by the addition of certain genera to the family Bacteriaceae. The new genera were based entirely upon flagella distribution. A key to the genera recognized by this author follows:

\section{Kendall's Classification of the Bacteria (1902)}

A. Coccaceae: Cells spherical in a free state, not elongate in any direction before division:

1. Non-motile:

a. Cells in chains, planes of fission parallel.

Streptococcus Billr.

b. Planes of fission without definite sequence.

Micrococcus Cohn

c. Planes of fission three, at right angles.

2. Motile:

Sarcina Goodsir

a. As in Micrococcus............Planococcus Migula

b. As in Sarcina............. Planosarcina Migula

B. Bacteriaceae: Cells elongated, cylindrical, cells elongated before division:

1. Non-motile:

a. Not branching............... Bacterium Ehr.

2. Motile:

b. Branching................Mycobacterium Leh.-Neum.

a. Flagella peritrichic..........Bacillus Cohn

b. Monotrichic................Bactrillius Kendall 
c. Lophotrichic...............Bactrinius Kendall

d. Unknown . . . . . . . . . . . . Bacterius Kendall

C. Spirillaceae: Cells cylindrical, spirally twisted:

1. Cells rigid, non-motile........... Spirosoma Migula

2. Cells motile:

a. Cell rigid:

(a) with one or two polar flagella.

Microspira Schroeter

(b) Lophotrichic.......... Spirillum Ehr.

b. Cells flexuous.............. Spirochaete. Ehr.

D. Chlamydobacteriaceae: Cells enclosed in a sheath:

1. Cell division always in one plane... Streptothrix Cohn

2. Cell division in three planes, very delicate sheath.

Phragmidiothrix Engler

3. As "2", but sheath clearly visible..Crcnothrix Cohn

4. Cells more or less branched........ Cladothrix Cohn

E. Beggiatoaceae: Cells without a sheath, motility by means of an undulating membrane. Cells contain sulfur granules

Beggiatoa Trev.

Allan J. Smith (1902) follows the Chester (1901) classification consistently.

Matzuschita (1902) in his Bakteriologische Diagnostik adopts the following simple scheme.

\section{Matzuschita's Classification of Bacteria (1902)}

Coccaceae: Cells spherical.

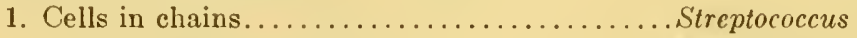

2. Cells irregularly grouped ..................

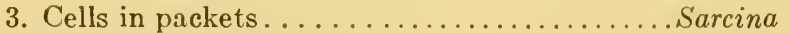

Bacillaceae: Rod shaped............................

Spirillaceae: Spiral or bent rods:

Short . . . . . ........................ Vibrio

Longer, relatively thick................ Spirillum

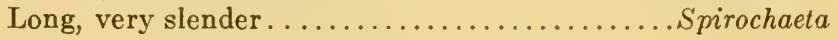

Klöcker (translation 1903) in general employed the generic name applied by the one who first named the organism. He recognizes the genera Micrococcus, Pediococcus, Sarcina, Bacterium, Bacillus, Termobacterium, Saccharobacillus, Clostridium and Granulobacter.

The classification used by Alfred Fischer (1903) in the second edition of his Vorlesungen is given below.

\section{Fischer's Classification of Bacteria (1903)}

A. Order I. Haplobacterinae. Vegetative body, one-celled, spherical, cylindrical or spiral; single or united to unbranched chains and other growth forms: 
I. Family I. Coccaceae: Vegetative cells spherical

a. Subfamily, Allococcaceae: Division in three directions of space, no sharply marked growth form, short chains, masses, in twos or singly:

1. Non-motile................... Ticrococcus Cohn

2. Motile..................Planococ sus Migula

b. Subfamily Homococcaceae: with definite division sequence for each genus:

1. Division in three directions of space, forming packets of cells.

(a) Non-motile............Sarcina Goodsir

(b) Motile ............... Planosarcina Migula

2. Division in two directions of space, forming fours or platelets....................Pediococcus Lindner

3. Division walls always parallel, grow in chains, pairs and singly, no plates or packets. Streptococcus Billroth

II. Family II. Bacillaceae: Vegetative cells cylindric, ellipsoid, oval, straight, during rapid multiplication, difficult to differentiate from cocci.

a. Subfamily Bacilleae: Spore forming rods unchanged, cylindric. Includes all forms not producing spores:

1. Non-motile................Bacillus Cohn

2. Motile.

(a) Monotrichous..........Bactrinium A. Fischer

(b) Lophotrichous.........Bactrillum A. Fischer

(c) Peritrichous...........Bactridium A. Fischer

b. Subfamily Clostridieae: Spore forming rods, spindle shaped:

1. Non-motile................Paracloster A. Fischer

2. Motile, peritrichous........... Clostridium Prazmowski

c. Subfamily Plectridieae: Spore bearing rods, drumstick shaped:

1. Non-motile.............. Paraplectrum A. Fischer

2. Motile, peritrichous ..........Plectridium A. Fischer

III. Family III. Spirillaceae: Vegetative cells cylindric, but spiral.

a. Slightly curved rods, motile, monotrichous

Vibrio (Müller-Loeffler)

b. Decidedly spiral in broad turns, motile, lophotrichous.

Spirillum Ehr.

c. Very slender, many turns, flagella unknown, perhaps cell wall flexile................... Spirochaete Ehr.

B. Order II. Trichobacterinae: Branched or unbranched cell filaments, whose segments are separated off as swarm cells (gonidia) or homogones. One family: Trichobacteriaceae.

I. Non-motile, rigid, enclosed in a sheath.

a. Unbranched:

1. Without sulfur inclusions:

(a) Not attached, cylindric gonidia, swarming.

Chlamyảothrix Migula

(b) Attached, spherical gonidia not observed to be motile. Crenothrix Cohn

2. With sulfur granules, attached.

Thiothrix Winog. 
b. Dichotomously pseudobranched; lophotrichous cylindric gonidia. Cladothrix Cohn

II. Filaments slowly moving, without sheath. Containing sulphur.

Beggiaoa Trev.

During this year the name Thiophysa was given by Hinze (1903) to a new genus of the sulphur bacteria; and Troili-Petersson named the lactic acid rods Brachybacterium.

Migula in 1904 again outlined his classification promulgated in 1900 and vigorously defended it from the criticisms that had been made against it. New genera described during the year were Hypnococcus (Bettencourt, Kopke, Renzende and Mendes) for an organism found associated with sleeping sickness, Clonothrix (Schorler) for one of the iron bacteria, and Thiobacillus (Beijerinck) for organisms which could reduce nitrates, oxidize sulphur and utilize $\mathrm{CO}_{2}$ in the manufacture of plant food.

Winslow and Rogers (1905) as the result of a careful study of many types and races of the cocci made some rather radical rearrangements of the groups, and created the new subfamilies Paracoccaceae and Metacoccaceae. New genera were Aurococcus, Albococcus and Rhodococcus. This classification was later further elaborated and published in 1910. A key to the families and genera recognized will be found under that year.

One of the most comprehensive analyses of the classification of bacteria which has been published in English is that of Erwin F. Smith (1905) in the first volume of his Bacteria in Relation to Plant Diseases. For his family and generic names he follows Migula (1900) consistently, except for several genera for which he substitutes older names. The genus Pseudomonas he concludes is a synonym of Bacterium Cohn. For Bacterium of the Migula system he proposes Aplanobacter. The genus Microspira Schroeter he concludes is a synonym of the older Vibrio. Furthermore he recognizes as a third order coördinate with Eubacteria and Thiobacteria the order Myxobacteria. His key to the genera of the Myxobacteria follows:

\section{Smith's Classification of the Myxobacteria (1905)}

III. Order Myxobacteria: Motile rod-like organisms, multiplying by fission, secreting a gelatinous base, and forming pseudoplasmodium-like aggregations before passing into a more or less highly developed cyst-producing resting stage, in which the rods become encysted in groups without modifcation, or may be converted into spore masses. 
1. Rods forming free cysts, in which they remain unmodified. Cysts various, sessile or borne on a more or less highly developed cystophore.

Chondromyces B. and C.

2. Rods forming large rounded cysts, one or more free without gelatinous matrix raised above the substratum.... Polyangium $\mathbf{K}$.

3. Rods slender, swarming together after a vegetative period to form definite more or less encysted, sessile or stalked masses of coccus-like

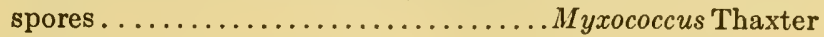

Particular attention was called to the group of spirochetes by the discovery by Schaudinn (1905) of the causal organism of syphilis. It was first named Spirochaeta, later Vuillemin (1905) proposed Spironema. This name was invalid under the rules of priority, so Schaudinn (1905) proposed Treponema and Stiles and Pfender (1905) a little later the name Microspironema. Two other new generic names were proposed during this year, Erythrobacillus by Fortineau for a red pyogenic rod, and Semiclostridium by Maassen for a spore-producing, gelatin-forming bacterium from sugar vats.

Blanchard (1906) discussed the relationships of the spiral organisms, and concluded that they should be placed in two groups, the plant forms in the Spirobacteria and the forms more closely related to the protozoa under Trypanosomidae. The following key gives the principal points of differences recognized.

\section{Blanchard's Classification of Spiral Organisms (1906)}

I. Spirobacteria, Cohn 1875, Bacteria more or less curved, sometimes the curve forming only an arc of a circle, at other times forming spirals of several or many turns. Organisms little or not at all flexible, multiplying by transverse division. Endospores formed in a number of species.
A. Non-motile.................... Spirosoma Migula 1900
B. Motile:

1. Cells rigid, forming a segment of a circle or united into spirals; 1,2 or 3 polar flagella........... Vibrio Ehrenberg 1838

2. Cells definitely spiral:

a. With endogenous spores. Flagella not polar.

Spirobacillus Metchnikoff 1889

b. With or without endogenous spores. Flagella polar.

Spirillum Ehrenberg 1838

II. Trypanosomidae Doflein 1901. Flagellum continuous in the form of a spiral with turns more or less numerous. Organisms flexible, form more or less fixed, multiplying by longitudinal division. No endogenous spores Gram -, not cultivable by ordinary means in laboratory:

A. Form constant, greatly elongate:

1. Undulating membrane present, cells flattened.

Spirochaeta 1838 Ehrenberg 
2. Undulating membrane absent. Cells round in cross section. Treponema Schaud.

B. Form changeable, not greatly elongate.

T'rypanosoma and Trypanoplasma

New genera named during this year were Rhodocapsa and Rhodothece, red sulphur bacteria, by Molisch (1906), Actinobacterium by Haass (1906) and Lipobacter by de Kruyff (1906) for certain lipolytic and fat oxidizing bacteria.

Lotsy (1907) apparently alone among writers on classification or bacteria has followed Fischer in his classification of bacteria.

Molisch (1907) in his "Purpurbakterien" created the order Rhodobacteria to include all of the forms which contain bacteriopurpurin. Many new genera of these forms which do not contain sulphur granules are included. A key to the families and to the subfamilies of the Thiorrhodaceae and to the genera of the Athiorhodaceae which he gives may be translated as follows:

\section{Molisch's Key to the Sulphur Bacteria (1907)}

\section{Order Rhodobacteria}

Bacteria whose cell contents are colored rose, red, violet or carmine by the presence of bacteriopurpurin, and as far as studied, by bacteriochlorin.

A. Cells have the ability to deposit granules of free sulphur in the cell contents.

I. Cells united in families.

\section{Family I. Thiorhodaceae}

a. Division of cells in three directions of space.

Subfamily 1. Thiocapsaceae

b. Division of cells first in three, then in two directions of space.

Subfamily 2. Lamprocystaceae

c. Division of cells in two directions of space.

Subfamily 3. Thiopediaceae

d. Division of cells in one direction of space.

Subfamily 4. Amoebobacteriaceae

II. Cells always swarming.

a. Not capsulated. Subfamily 5. Chromatiaceae

b. Capsulated Subfamily 6. Rhodocapsaceae

B. Cells are unable to deposit free granules of sulphur in the cell contents.

I. Cells united into families.

Family II. Athiorhodaceae

a. Cells rodshaped, embedded many together in a common capsule. Genus Rhodocystis

b. Cells spherical or short rods, in chains, each chain enclosed in a capsule............. Genus Rhodonostoc

II. Cells free.

a. Cells spherical, non-motile.

Genus Rhodococcus 
b. Cells straight rods, non-motile.

Genus Rhodobacterium

c. Cells motile rods........ Genus Rhodobacillus

d. Cells short, bean or comma shaped, monotrichous, actively motile. Genus Rhodovibrio

e. Cells spiral, actively motile by means of a cluster of polar flagella Genus Rhodospirillum

This work of Molisch is practically the only work of importance on these bacteria since the first formulation of description and the grouping together of these organisms by Winogradsky.

Other genera of bacteria described in 1907 include Pedioplana, a motile organism occurring in tetrads: named by Wolff; Thioploca a filamentous sulphur organism related to Beggiatoa, named by Lauterborn; Myxobacillus, Myxokokkus and Plennobacterium,organisms producing gums and slimes in sugar vats, named by Gonnermann; and Borrelia for the spirochetes of relapsing fever named by Swellengrebel. The last named classifies the spiral organisms as follows:

\section{Swellengrebel's Classification of the Spirillaceae (1907)}

Cells with rounded tips, constituting any part of a spiral.

I. Subfamily. Spirillaceae. (nov. fam.) Cells are not flexible. Genera, Spirillum and Tibrio with diagnoses of Migula.

II. Subfamily. Spirochaetaceae (nov. fam.) Cells are flexible.

a. Cells without cilia, with periplastic appendage well developed and often with an alveolar structure. Sometimes there is a band of myonemes in the appendage. .............. Spirochaeta Ehrenberg

Type Spirochaeta plicatilis Ehrenb. S. balbianii placed here provisionally.

b. Cells with one cilium at one end, sometimes at both extremities, which is a prolongation of the "calotte:" the appendage has been demonstrated sometimes.................Treponema Schaudinn

Types (S. buccalis, Tr. pallidum).

c. Cells with peritrichous cilia..........Borrelia n. gen.

Type, $S p$. gallinarum.

Ellis in 1907 as a result of studies on the iron bacteria came to the conclusion that they should be separated into two principal groups in accordance with the following scheme:

\section{Ellis' Grouping of the Iron Bacteria (1907)}

I. Reproduction by external abstriction of conidia:

Leptothrix ochracea

Gallionella ferruginea

Spirophyllum ferrugineum 
II. Reproduction by separation of internally produced cells:

Crenothrix polyspora

Cladothrix dichotoma

Clonothrix fusca

The Winslows (1908) presented the final results of their studies on the Coccaceae. A key to the subfamilies and genera recognized follows:

\section{Winslows' Classification of the Coccaceae (1908)}

\section{Cells spherical. Family Coccaceae}

I. Parasites. Growth not abundant (or one species, zooglea-forming saprophytes growth abundant in saccharose media). Generally gram + . Acid formers................. Subfamily Paracoccaceae

A. Cells in capsulated pairs. Parasites. Growth very meagre. Inulin fermented. No pigment.

Diplococcus (Weichselbaum) Winslow and Rogers

B. Cells in chains occuring in masses of zoogloea in sugar refineries. Aberrant saprophytic forms. Growth abundant in saccharose media. No pigment........Ascococcus (Cohn) Winslow and Rogers

C. Cells in chains. Parasites. Growth meagre. Inulin not fermented.

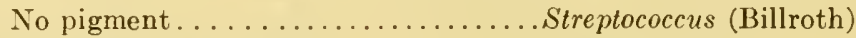

D. Cells in irregular groups............. Staphylococcus

1. Parasites. Growth fair. Orange pigment.

A urococcus Winslow and Rogers

2. Parasites. Growth good. White pigment.

Albococcus Winslow and Rogers

II. Saprophytes. Growth abundant. No zoogloea. Gram-generally. Not acid formers............... Subfamily Metacoccaceae

A. Cells in irregular groups. Pigment generally yellow.

Micrococcus (Hallier, Cohn), Winslow \& Rogers

B. Cells in packets. Pigment yellow.

Sarcina (Goodsir) Winslow and Rogers

C. Cells in irregular groups or packets, pigment red.

Rhodococcus Winslow and Rogers

Flügge (1908) in the classification of the pathogenic bacteria given in his Grundriss der Hygiene (sixth edition) made a distinct contribution to systematic bacteriology in the groupings which he created. From a strict nomenclatural point of view his terminology was in many cases technically incorrect, but the groups are very useful. His classification is as follows: 


\section{Flügge's Classification of the Pathogenic Bacteria}

(Lehrbuch der Hygiene, 6th ed., 1907, Quoted in Iíolle and Hetch, 3rd ed.

I. Coccaceae: Cells spherical. 1911, p. 18)

A. Family Streptococcus. Grow only in one direction, are Gram +, non-motile and grow only sparingly on artificial media.

1. Diplococcus type, forms in many media only round or lancet shaped diplococci, in others (bouillon) short chains. Pathogen: Diplococcus lanceolatus capsulatus.

2. Streptococcus type. In bouillon. generally forms long chains. Saprophytes, Streptococcus mesenteroides.

B. Family, Sarcina. Numerous species, in part motile and flagellated, dividing in three directions of space, forming packets, Gram - on solid media, growing usually in the form of dry layers, often colored, often in dust.

Pathogens: None.

C. Family, Micrococcus. Numerous species, of which many are saprophytic, found in dust. Cells divide irregularly in different directions of space and are often united in bunches of 2, 4, 8 or irregularly:

1. Diplococcus type. Elongated cocci with the long side appressed. Gram negative.

Pathogens: Micrococcus gonorrhoeae, Micrococcus intracellularis meningitidis, Micrococcus catarrhalis.

2. Tetragenus type. Forms cocci that remain in twos or more, frequently remain in fours.

Pathogen: Micrococcus tetragenus.

3. Staphylococcus type, Spherical. Grows on solid and fluid nutrient media in regular masses, with white, yellow or orange pigment. Pathogen: Staphylococcus pyogenes aureus.

II. Bacillaceae. Rod shaped. Not spiral.

A. Family, Bacillus. All rods which produce endogenous spores:

1. Aërobic forms:

a. Hay bacillus group. Relatively large bacilli, widely distributed, grow well on solid and liquid media, on the latter with membrane formation. Usually motile. Nonpathogens.

b. Anthrax group, As "a" but non-motile and pathogenic.

2. Anaërobic forms. Includes all the spore bearing types of butyric acid bacteria.

Pathogens: B. botulinus, Bacillus of blackleg, of edema, of tetanus.

B. Family Bacterium. All rods that produce no spores:

1. Fluorescent, phosphorescent, and pigment producing forms. Gram negative, may or may not liquefy gelatin.

2. Colon bacillus group, possesses flagella, more or less motile. Gram negative.

Pathogens: Bact. typhi, and Bact. paratyphi. 
3. Bact. aerogenes group, very near B. coli (but non-motile?). Pathogen: Bact. dysenteriae.

4. Plague and septicemia group. Non-motile, polar staining. Gram negative, do not liquefy gelatin.

Pathogen: Bact. pestis.

5. Influenza group. Very small. Gram-, growing only on media containing hemoglobin.

Pathogen: Bact. influenzae

6. Swine erysipelas group. Very small rods, do not liquefy gelatin. Gram positive.

Pathogen: Bact. Rhusiopathiae, Rabbit septicemia.

7. Glanders group. Very slender rod. Gram negative.

Pathogen: Bact. mallei.

8. Diphtheria group. Gram positive. Tendency to the production of club shaped involution forms and to granular disintegration. Pathogen, Bact. diphtheriae, Bact. xeroseos.

9. Acid fast group. Producing slimy wrinkled layers on the surface of solid and liquid media. Gram positive and acid fast.

Pathogen: Bact. tuberculosis.

III. Spirillaceae: Cells spiral.

A. Family Fibrio. All comma-shaped, bent, fission fungi with polar flagella. Often united to spirals. Gram negative.

Pathogen: Vibrio cholerae asiaticae.

B. Family Spirillum. Several corkscrew turns. Polar flagella. Many saprophytes.

Pathogens: None known.

The classification of the Trichomycetes or thread bacteria suggested by Jordan (1908) is worthy of note. He diagnosed the genera as follows:

\section{Jordan's Classification of the Trichomycetes (1908)}

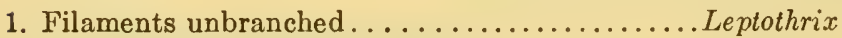

2. Filaments with pseudobranches.............. Cladothrix

3. Filaments with true branches.

a. Reproductive elements, spores observed...Nocardia

b. No spores observed....................tinomyces

Conn (1909) suggested the following classification:

\section{Conn's Classification of Bacteria (1909)}

\section{Spherical Bacteria:}

Dividing in one plane, so as to form chains, Streptococcus.

Dividing in two planes, and not forming chains, Micrococcus.

Dividing in three planes, and forming cubical masses, Sarcina.

Rod Shaped Bacteria:

With flagella, and consequently motile, Bacillus. 
Without flagella and consequently non-motile, Bacterium.

With a single flagellum, Pseudomonas.

Spiral Bacteria: Spirillum.

Higher Bacteria: (Cladothrix, Leptothrix, Streptothrix, Actinomyces)

The genus Bacillus is further divided as follows:

Bacilli with one flagellum are named Monotrichic Bacilli or Pseudomonas.

Bacilli with one flagellum at each end, Microsporon.

Bacilli with a tuft of flagella at one end are called Lophotrichic Bacilli.

Bacilli with flagella over the whole body are called Peritrichic Bacilli.

Orla-Jensen in 1909 proposed a totally new classification of bacteria. He divided the bacteria into two orders based upon primitive or advanced characteristics, distribution of flagella, etc. In many cases his published descriptions of genera are not very clear, and the construction of a key for the differentiation of the forms is correspondingly difficult. The following key will indicate differences between most of the genera described.

\section{Orla-Jensen's Classification of Bacteria (1909)}

\section{Key to Orders and Families}

I. Cells spherical, rod-shaped or spiral. Endospores formed only in a few sulfur-free spirilla. When motile, mono-or lophotrichous. Typically water bacteria. Secure energy almost exclusively by oxidative processes. Many develop poorly on laboratory media because organic substances are present in too concentrated a form.

Order I. Cephalotrichinae

A. Bacteria not in thread like filaments, no tendency to branch or produce mycelial growth:

1. Bacteria not containing sulfur or bacteriopurpurin:

a. Obligate aërobes, oxidizing carbon, hydrogen, or nitrogen compounds without production of noteworthy amounts of unoxidized split products.

Family 1. Oxydobacteriaceae

b. Luminous and fluorescent bacteria.

Family 6. Luminibacteriaceae

c. Active reducing organisms, facultative, all spiral forms reducing sulfates.

Family 7 . Reducibacteriaceae

2. Bacteria containing sulfur or bacteriopurpurin:

a. Containing no bacteriopurpurin.

Family 3. Thiobacteriaceae

b. Containing bacteriopurpurin.

Family 4. Rhodobacteriaceae

B. Bacteria tending to branch, to form filaments or to develop a mycelium. 
1. Not typically water forms. Cells tending to branch and to form branching hyphae. Not forming filaments usually.

Family 2. Actinomycetes

2. Typically water forms. Cells not tending to form mycelium. Typically filament ous.

Family 5. Trichobacteriaceae

II. Cells spherical or rod shaped, never spiral. Either peritrichous or nonmotile. Not typically the water bacteria. Do not secure growth energy solely by oxidative processes.

\section{Order II. Peritrichinae}

A. Typically not obligate anaërobic or microaërophilic.

1. Usually bringing about transformation in carbohydrates with the development of acids.

\section{Family 1. Acidobacteriaceae}

2. Usually bringing about an alkaline reaction by the development of ammonia....... Family 2. Alkalibacteriaceae

B. Typically obligate anaërobic or microaërophilic.

1. Acting largely upon carbohydrates, developing acids, particularly butyric acid....... Family 3. Butyribacteriaceae

2. Acting largely upon proteins, bringing about putrefactive clianges.

Family 4. Putribacteriaceae

\section{Order I. Cephalotrichinae}

Key to the Genera of Family I. Oxydobacteriaccae

I. Not oxidizing nitrogen compounds nor fixing free nitrogen:

A. Oxidizing methane to $\mathrm{CO}_{2}$ and $\mathrm{H}_{2} \mathrm{O} \ldots$ Methanomonas

B. Oxidizing $\mathrm{CO}$ to $\mathrm{CO}_{2} \ldots \ldots \ldots \ldots \ldots$ Carboxydomonas

C. Oxidizing $\mathrm{H}_{2}$ to $\mathrm{H}_{2} \mathrm{O} \ldots \ldots \ldots \ldots \ldots$ IIydrogenomonas

D. Oxidizing alcohol to acetic acid.........Acetimonas

II. Oxidizing ammonia or nitrites:

A. Oxidizing ammonia.............. Nitrosomonas

B. Oxidizing nitrites................ Nitromonas

III. Fixing atmospheric nitrogen............ Azotobacter

Key to the Genera of Family II. Actinomycetes

I. Not producing a much branched mycelium, individual cells only branching:

A. Symbiotic in the nodules of legumes..... Rhizomonas

B. Not symbiotic. Parasites in mammals :

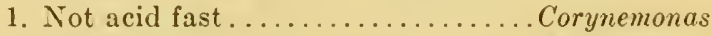

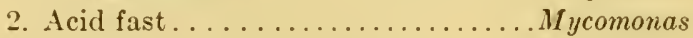

II. Producing a much branched mycelium........Actinomyces

Key to the genera of Family III. Thiobacteriaceae

I. Cells not spiral:

A. Cells rod-shaped, or not spherical:

1. Autotrophic, rod-shaped......... Sulphomonas

2. Not autotrophic, oval (?)........ Thiomonas 
B. Cells spherical ................. Thiococcus

II. Cells spherical .................... Thiospirillum

Key to the Genera of Family II. Rhodobacteriaceae

Uses the following genera with the same meanings as Winogradsky or Molisch.

Rhodomonas (Chromatium).

Rhabdomonas (Rhabdochromatium).

Rhododictyon (Thiodictyon).

Amoebomonas (Amocbolacter).

Rhodothece (Thiothece).

Rhodopolycoccus (Thiopolycoccus).

Rhodococcus (Thiopedia).

Lamprocystis.

Rhodocystis (Thiocystis).

Rhodocapsa (Thiocapsa).

Rhodosarcina (Thiosarcina).

Rhodospirillum (Thiospirillum).

Key to the Genera of Family V. Trichobacteriaccac

I. Not containing sulfur granules:

A. Branched (with pseudobranches)........Cladothrix

B. Not Branched

1. Not spiral:

a. Not attached.............. Leptothri:

b. Attached................... Crenothrix

2. Spiral:

a. Slender and flexuous......... Spirochaeta

b. Flattened................ Spirophyllum

II. Containing sulfur granules:

A. Not attached. Motile................ Beggiatoa

B. Attached ........................ Thiothrix

Key to the Genera of Family II. Luminobacteriaccae

I. Cells not spiral:

A. Cells rod-shaped:

1. Active denitrifiers ............. Denitromonas

2. Active liquefiers.............. Liquidomonas

B. Cells spherical:

1. Liquefying gelatin.............. Liquidococcus

2. Not liquefying gelatin............Solidococcus

II. Cells bent or spiral .................. Liquidovibrio

Key to the Genera of Family VII. Reducibacteriaceae

I. Short spiral. Not liquefying gelatin....... Solidovibrio

II. Longer spirals..................... Spirillum 


\section{Order II. Peritrichinae}

Key to Genera of Family I. Acidobacteriaceae

I. Active denitrifying forms ............. Denitrobacterium

II. Not as in I:

A. Rod shaped:

1. Organisms of the B. coli group..... Bacterium

2. Gram + lactic acid forms......... Caseobacterium

3. Producing propionic acid..........Propionibacterium B. Spherical:

1. In chains................... Streptococcus

2. Irregularly grouped............Micrococcus

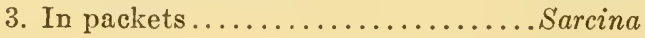

Key to the Genera of Family II. Alkalibacteriaceac

I. Organisms of the Proteus type............ Liquidobacterium

II. Organisms of the $B$. subtilis type........... Bacillus

III. Producing ammonia from urea........... Urobacillus

Key to the Genera of Family III. Butyribacteriaceae

I. Acting primarily upon sugars, forming butyric acid.

Butyribacillus

II. Acting primarily upon pectin............ Pectobacillus

III. Acting primarily upon cellulose........... Cellulobacillus

Key to the Genera of Family IV. Putribacteriaceae

I. Not producing an ectotoxin............... Putribacillus

II. Producing an ectotoxin.................. Botulobacillus

It will be noted that Orla-Jensen has created a considerable number of generic names, many times substituting new names for older and apparently perfectly valid terms.

Among the new genera described in 1909 by other authors were Hillhousia a giant sulphur organism named by West and Griffiths, Siderocapsa, a capsulated epiphytic coccus growing in water containing iron and with iron oxid deposition in the capsule, named by Molisch, and Erysipelothrix an organism of the general type of the bacterium of swine erysipelas named by Rosenbach.

Molisch (1910) in his book "Die Eisenbakterien" recognizes the genera and species separated by the following key.

\section{Molisch (1910) Classification of the Iron Bacteria}

\section{A. Filamentous bacteria.}

I. Filaments always unbranched.
a. With brown attaching disks .

b. Not as "a." 
1. With definite sheath, of ten broader toward end. Not spirally

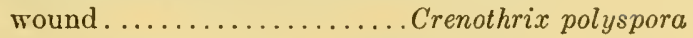

2. Without definite sheath. Spirally wound.

Gallionella ferruginea

II. Filaments unbranched or pseudodichotomously branched.

a. Swarm cells developed.

1. Regularly pseudodichotomously branched, usually colorless. Cladothrix dichotoma

2. Usually unbranched, usually encrusted with iron Chlamydothrix ochracea

B. Capsule bacteria.

b. Only non-motile gonidia...........Clonothrix fusca

I. Capsule with only a few (1-8) cells...... Siderocapsa Treubii

II. Capsule with $1-100$ cells. ............ Siderocapsa major

Among the new generic names of bacteria proposed in 1910 were the following: Fusiformis for the fusiform bacteria of the throat named by Hoelling, Asterococcus for the very minute organism responsible for the disease pleuropneumonia in cattle, named by Borrel et al, Actinobacillus by Brumpt for the causal organism of actinobacillosis of cattle, Nodofolium for one of the thread iron bacteria named by Ellis and Cristispira given by Gross as designation of the spiral "crested" organism from the crystalline styles of certain classes of mussels.

Dobell (1911) included the spirochetes in the group Spirochaetoidia, using the following generic differences for the three genera recognized. He emphasizes that this group of Protista should be included neither with the bacteria or protozoa.

\section{Spirochaetoidia}

1. Free living forms, fresh water or marine........ Spirochaeta Ehr.

2. Parasitic in animals (Vertebrates and Invertebrates).

Treponema Schaudinn

3. Parasitic in Lamellibranchia................ Cristispira Gross

In Doflein's Lehrbuch der Protozoenkunde (1911) the same problem is handled by considering Spirochaeta as a generic name which includes all forms, and regarding Spirochaeta, Cristispira and Treponema as the component subgenera. Gross in this year added the genus Saprospira to this group. He included it in the free living marine types.

Frost in Marshall's Microbiology (1911) used Migula's (1900) scheme of classification in its entirety. Heim in the 4th edition of his Lehrbuch der Backteriologie gives a very simple classification suitable particularly for the pathogenic bacteria. 
Heim's Classification of Bacteria (1911)

I. Coccaceae. Cells spherical:

A. Division in one direction of space...... Streptococcus

B. Division in different directions, no chains or packets.

Micrococcus

C. Dividing in three planes, forming packets.

Sarcina

II. Bacteriaceae, Rod-shaped:

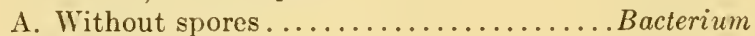

B. With spores...........................

III. Spirillaceae. Cells spiral:

A. Rigid spirals or sections of spirals...... Spirillum and Vibrio

B. Flexuous, Spirals................ Spirochacte

Kolle and Hetsch (1911) differentiate the bacteria into the fission fungi consisting of cocci, bacilli and spirilla and the fission algae including the sulphur bacteria, the iron bacteria and the Streptothricaceae.

Bosanquet (1911) in his book on Spirochactes places all in the genus Spirochaeta. During this year two other bacterial generic names were proposed: Paraspirillum for a flexile spindle formed spiral organism in water (Dobell) and Cohnistreptothrix for organisms of the type of Streptothrix Foersteri of Cohn (Pinoy and Morax).

Schneider (1912) follows the classification used by Chester (1901). Benecke (1912) gives one of the most complete of the recent systems of bacterial classification. The orders and families recognized are shown in the following scheme:

\section{Benecke's Classification of Bacteria (1912)}

A. Comparatively simple organisms, not growing as sheathed filaments, usually as single cells or colonies. . Order I. Haplobacterinae

I. Cells not forming a pseudoplasmodium.

a. Cells not tending to branch or form a mycelium.

1. Without bacteriopurpurin.

(a) Cells spherical.

(b) Cells elongate.

Family I. Coccaceae

(1) Cells straight.

Family II. Bacillaceae

(2) Cells spiral.

Family III. Spirillaceae

2. With bacteriopurpurin.

Family IV. Rhodobacteriaceae

b. Cells tending to branch or form a mycelium.

Family V. Mycobacteriaceae 
II. Cells in vegetative stage forming a pseudoplasmodium.

Family IV. Myxobacteriaceae

B. Cells in filaments, frequently sheathed.

Order II. Desmobacterineae

One family only..............Family VII. Desmobacteriaceae

While no new genera are described, a larger number of genera are included in several of the families than by most other writers.

Engler (1912) in the seventh edition of his syllabus gives the following outline of bacterial classification:

\section{Engler's Classification of Bacteria (1912)}

Schizomycetes

I. Order Eubacteria. Cells without sulfur and bacteriopurpurin:

A. Family, Bacteriaceae: Cells very small, cylindric, straight or slightly bent:

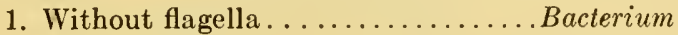

2. With flagella:

a. Peritrichous................Bacillus

b. Polar....................Pscudomonas

B. Family, Spirillaceae: Spiral cells:

1. Cells stiff, not serpentine:

a. Non-motile...............Spirosoma

b. Motile:

(1) With 1, 2, or 3 polar flagella.

(2) With bunch of polar flagella.

Microspira

Spirillum

2. Cells serpentine.............. Spirochaete

C. Family, Phycobacteriaceae: (Chlamydobacteriaceae) Filamentous, surrounded by a more or less definite sheath and dividing seldom in three directions. Multiplication by conidia.

Genera: Phragmidiothrix, Chlamydothrix, Gallionella, Crenothrix, Clonothrix, Sphaerotilus (Cladothrix).

D. Family, Actinomycetaceae: Filamentous colonies with true branching, radiating, non-motile. Filaments dividing up into oidia.

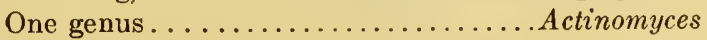

E. Family, Coccaceae: Cells spherical:

Genera, Streptococcus, Micrococcus, Leuconostoc, Sarcina, Azotobacter, Planococcus.

F. Family, Myxobacteriaceae: Cells more or less rod shaped, non-flagellate, with slimy membrane, moving slowly forward (Pseudoplasmodia) which become a cyst, sessile or stalked.

Genera: Polyangium, Chondromyces, Myxococcus.

II. Order, Thiobacteria: Cells with sulfur inclusions, colorless or red or violet with bacteriopurpurin. 
A. Family, Beggiatoaceae: Motile by an undulating membrane, filamentous colonies of colorless, sheathless cells, with sulfur granules. Genera: Beggiatoa, Thiothrix.

B. Family Rhodobacteriaceae: Cell content rose, red, or violet with sulfur granules.

Genera; Lamprocystis, Thiosarcina, Rhodobacillus, Thiospirillum, Chromatium.

Meyer (1912, p. 2) recognized as an order the Eubacteria the genera and generic sections of which may be separated by the following key:

Key to the genera and sections of the Eubacteria according to Meyer (1912)

a. Cells straight rods.

b. Not with polar flagella. Flagella when present-peritrichous.

c. Cells containing bacteriopurpurin. Genus Bacillus

Section Rhodobacillus

2c. Cells not containing bacteriopurpurin.

d. Flagella unknown.

Section Bacterium

2d. All other species.

\section{Section Eubacillus}

2b. With polar flagella.......... Genus Pseudomonas

2a. Cells not straight rods.

b. Cells curved rods.

c. Peritrichous flagella, with spores.

Genus Spirobazillus

2c. Polar flagella, spores unknown.

d. With 5-20 polar fiagella.

Genus Spirillum

e. Without bacteriopurpurin.

f. Flagella unknown.

Section Spirosoma

2f. Flagella known.

Section Euspirillum

2e. With bacteriopurpurin.

Section Rhodospirillum

f. Sulphur free.

Subsection $\alpha$

2f. With sulphur.

Subsection $\beta$

2d. With 1 rarely $2-3$ polar flagella.

Genus Microspira

e. With bacteriopurpurin.

Section Rhodospira

2e. Without bacteriopurpurin.

Section Eumicrospira 
2b. Cells spherical.

c. Cells in chains Genus Streptococcus

d. Without bacteriopurpin.

e. With flagella.

2e. Without flagella.

Section Planostreptococcus

Section Fixostreptococcus

d. With bacteriopurpurin.

Section Rhodococcus

e. Without sulphur.

Subsection $\alpha$

2e. With sulphur.

Subsection $\beta$

2c. Cells not in chains.... Genus Micrococcus

d. Division in two planes.

e. Without bacteriopurpurin.

f. Flagella unknown.

Section Fixococcus

2f. Flagella known.

Section Planococcus

2e. With bacteriopurpurin.

Section Rhodococcus

f. With sulphur.

Subsection $\alpha$

2d. Division in three planes.

Genus Sarcina

e. Without bacteriopurpurin.

f. With flagella.

Section Planosarcina

2f. Without flagella.

Section Fixosarcina

2e. With bacteriopurpurin.

Section Rhodosarcina

f. Without sulphur.

Subsection $\alpha$

2f. With sulphur.

Subsection $\beta$

Löhnis (1913) in his "Vorlesungen über landwirtschaftliche Bakteriologie" gives the following abbreviated classification of genera.

Löhnis' Classification of Bacteria (1913)

I. Cells as a rule sph erical, seldom assuming an elongated form:

a. Single, in pairs, fours, or irregular masses, never in chains.

Micrococcus

b. In shorter or longer chains.............Streptococcus

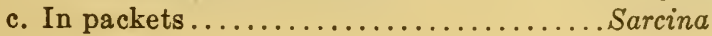


II. Cells as a rule rod shaped, seldom spherical, or bent:

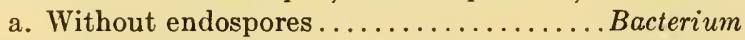

b. With endospores..........................

III. Cells as a rule slightly to decidedly spirally bent:

a. Comma shaped...................... Vibrio

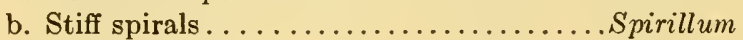

c. Flexose spirals................. Spirochaete

Chatton and Perard (1913) introduced the generic names Metabacterium and Oscillospira.

Vuillemin (1913) has given a comprehensive review of bacterial classification with particular reference to the fact that at the Botanical Congress that was to have met in 1915 the date of departure and special rules for bacterial nomenclature were to be considered. He suggested that the date of departure be fixed as 1915 and that the genera and higher groups that follow should be adopted as genera conservanda, or "natural history" genera.

\section{Vuillemin's Classification of Bacteria (1913)}

I. Plastids rounded (spherical).

A. Dissociated or grouped without regular order.

1. Polar flagella................Planococcus

B. Associated in elementary colonies of determined form.

1. Divisions parallel.

a. Grouped in rosaries.......... Streptococcus

b. Pairs encapsulated, isolated or united into a rosary. Elements sometimes elongated or pointed.

Klebsiella

2. Division in two planes at right angles.

a. Fission centripetal.

(1) Non-motile............Merista

(2) Flagellated.............Planomerista

b. Fission excentric.............. Neisseria

3. Division in three planes at right angles.
a. Non-motile.
Sarcina
b. Flagellated.
Planosarcina

II. Plastids rod-shaped.

A. Sporiferous elements specialized

1. Oval. Flagella unknown............Metabacterium

2. Claviform. Flagella diffuse.........Clostridium

B. None of the sporiferous elements distinct from the vegetative rods.

1. Flagella diffuse................. Serratia

2. Flagella polar.......................

III. Plastids sinuous.

A. Flagella polar.................. Spirillum 
Vuillemin also proposed that the following names be kept as "Formogenera conservanda," but without nomenclatural status, Micrococcus, Mantegazzaea, Bacillus and Spirosoma.

Gonder (1914) in Prowazek's Handbuch der pathogenen Protozoen gives the following classification of the spirochetes.

\section{Gonder's Classification of the Spirochetes (1914)}

Spirochaeta Ehrb. 1838.

Type species Sp. plicatilis Ehr.

Cristispira Gross 1910.

Type species, Cristispira balbiani.

Spironema Vuillemin 1905.

Type species Spironema recurrentis.

Treponema Schaudinn 1905.

Type species Treponema pallidum.

Buchanan (1915) reviewed the terminology for the Coccaceae proposed by Winslow and Rogers and suggested certain changes that should be made in names of genera and higher groups the better to recognize priority.

Buchanan (1917-1918) published a series of articles under the general heading of "Studies in the Nomenclature and Classification of the Bacteria," in which were listed the various names of genera and higher groups which had been recognized in the literature, and a classification of bacteria into orders, families and genera, with designation of type species for the genera. The dichotomous keys to the groups recognized follow:

\section{Key to the Orders of the Class Schizomycetes (Buchanan) (1917)}

A. Plant-like in the principal characters, not protozoan like, cells never slender, flexuous spirals; cell divisions never longitudinal.

I. Not producing a pseudoplasmodium during the vegetative stage; without a highly developed, cyst-producing, resting stage.

a. Containing neither granules of free sulphur, nor bacteriopurpurin, nor requiring the presence of hydrogen sulphid for the best development.

1. Not typically producing filaments as a regular growth form, though chains of cells may be developed. Conidia not developed, spores when formed are endospores.

Order I. Eubacteriales

2. Typically producing true filaments as a regular growth form. Conidia may be developed, but never endospores. (a) Alga-like, typically water forms. Filaments never showing true branching; false branching may be 
present. A sheath usually evident, and usually impregnated with iron.

Order II. Chlamydobacteriales

(b) Mold like, not typically water forms, not with the sheath impregnated with iron. True branching often evident.

Order III. Actinomycetales

b. Cells typically containing either granules of free sulphur or bacteriopurpurin or both, usually growing best in the presence of hydrogen sulphid.

\section{Order IV. Thiobacteriales}

II. Cells united during the vegetative stage into a pseudoplasmodium which passes over into a highly developed, cyst-producing, resting stage.............. Order V. Myxobacteriales

B. Protozoan-like in many characters. Cells usually relatively slender flexuous spirals; multiplication of cells apparently by longitudinal division in some types, by transverse division in others, or both.

Order VI. Spirochaetales

\section{Key to the families of the Eubacteriales}

A. Organisms usually growing more or less readily upon organic media, not securing growth energy primarily by the oxidation of ammonia or nitrites.

I. Cells typically spherical. . Family I. Coccaceae

II. Cells not spherical, elongate.

a. Cells not spiral..... Family II. Bacteriaceae

b. Cells spiral, or at least curved.

Family III. Spirillaceae

B. Not growing readily or at all on media containing considerable amounts of organic material; nitrifying bacteria, securing growth energy primarily by the oxidation of ammonia or nitrites.

Cells may be either spherical or rod-shaped.

Family IV. Nitrobacteriaceae

\section{Key to tribes of the Coccaceae}

I. Not epiphytes, not causing the deposition of iron upon capsules.

A. Commonly parasitic, in some forms saprophytic, usually thriving well under anaërobic conditions, not commonly producing luxuriant growths on artificial media, many forms failing to grow except upon special media. Cells in pairs, chains or irregular masses, never regular packets. Gram-positive, with exception of a few strict parasites. Acid usually formed in dextrose and lactose broth. Pigment white, orange or absent.

Tribe I. Streptococceae

B. Saprophytes, or facultative parasites. Usually grow best under aërobic conditions, producing abundant to luxuriant growth on artificial media. Planes of fission often at right angles: Cells aggregated in groups, packets or zoogloeal masses. Usually Gram-negative. Pigment as a rule yellow, red or orange.

Tribe II. Micrococceae 
II. Epiphytes, usually on leaves and stems of water plants. Iron oxid deposited upon the capsule........... Tribe III. Siderocapseae

Key to the genera of the Streptococceae

A. Cells occurring normally in chains.

I. Usually parasitic. Not forming zoogloeal masses in sugar solutions

Genus 1. Streptococcus

II. Saprophytic, occurring in cane sugar solutions in zoogloeal masses.

Genus 2. Leuconostoc

B. Cells not occurring usually or characteristically in chains.

I. Parasitic. Cells in pairs, growth as a rule meagre. No pigment formed.

a. Gram-positive......... Genus 3. Diplococcus

b. Gram-negative.......... Genus 4. Neisseria

II. Cells in irregular groups, usually parasites, growth as a rule good, pigment usually orange or white.

Genus 5. Staphylococcus

Key to the genera of Micrococceae

A. Cells not in regular packets.

1. Pigment generally yellow...... Genus 1. Micrococcus

2. Pigment red............... Genus 2. Rhodococcus

B. Cells in regular packets. Pigment yellow or orange.

Genus 3. Sarcina

Key to the genera of Siderocapseae

One genus only, Siderocapsa.

Key to the tribes of the Bacteriaceae

A. Cells not acid-fast.

I. Typically producing endospores under favorable conditions.

Tribe I. Bacilleae

II. Not producing endospores.. Tribe II. Bacterieae

B. Cells acid-fast, frequently showing some tendency to branching.

Tribe III. Mycobacterieae

Key to the genera of Bacilleae

A. Usually a single endospore formed within each cell.

I. Aërobic usually Gram-positive, as a rule liquefying gelatin, spores usually not distorting rods when formed.

Genus 1. Bacillus

II. Anaërobic or microaërophilic usually.

a. Spores produced at extreme tip of cells, forming typical drumsticks............... Genus 2. Plectridium

b. Spores not produced at extreme tip of cells, at least not forming drumsticks. Cells usually somewhat swollen when spores are formed .............Genus 3. Clostridium 
B. Usually a number of spores develop within a swollen cell.

Genus 4. Metabacterium

Key to the subgenera of Bacillus

A. Spore not barrel-shaped in longitudinal section and not star-shaped in cross section.

I. Motile by means of peritrichous flagella.

Subgenus 1. Eu-Bacillus

II. Non-motile................ Subgenus 2. Bacteridium

B. Spore barrel-shaped in longitudinal section, longitudinal striations evident.

Subgenus 3. Astasia

Key to the subtribes of the Bacterieae

A. Cells usually fusiform............ Subtribe I. Fusiforminae

B. Cells not fusiform.

I. Requiring serum or hemoglobin for development. Obligate parasites. Gram-negative. Non-motile.

Subtribe II. Hemophilinae

II. Not requiring serum, or at least hemoglobin, for development. Gramnegative or positive. Motile or non-motile.

a. Obligate aërobes, securing growth energy by oxidation, etc.

Subtribe III. Rhizobiinae

b. Not obligate aërobes, not securing growth energy by oxidation of carbonaceous compounds.

Subtribe IV. Bacteriinae

Key to the Crenera of Fusiforminae

One genus only Fusiformis.

Key to the Genera of Hemophilinae

A. Requiring serum for growth. Cells almost ultra-microscopic. Stain best by Giemsa. Involution forms characteristic.

Genus 1. Asterococcus

B. Requiring hemoglobin for growth. Stain readily with ordinary aniline dyes. Involution forms infrequent...... Genus 2. Hemophilus

\section{Key to the genera of Rhizobiinae}

A. Not fixing atmospheric nitrogen; securing growth energy usually by the oxidation of ethyl alcohol to acetic acid.. Genus 1. Mycoderma

B. Capable of fixing appreciable amounts of atmospheric nitrogen. Grow well on nitrogen-free media.

a. Small motile rods, with abundant involution forms, frequently living in root nodules of the higher plants (legumes).

Genus 2. Rhizobium

b. Not symbiotic. Cells larger, plump, almost spherical in some cases.

Genus 3. Azotobacter 
Key to the genera of Bacteriinae

A. Producing usually a yellowish or greenish or fluorescent pigment, usually Gram-negative, motile by means of polar flagella, or non-motile.

Genus 1. Pseudomonas

B. When pigmented not greenish or fluorescent, when motile with peritrichous flagella.

1. Cells typically pigmented, chromoparous.
a. Producing red or pink pigment.
b. Producing a violet pigment.
Genus 2. Serratia

Genus 3. Chromobacterium

2. Celis not typically definitely pigmented, or at least not red or violet.

a. Cells typically Gram-negative.

(1) Non-motile, showing bipolar staining commonly. Never produce gas from carbohydrates. Power of acid production low.

Genus 4. Pasteurella

(2) Not showing bipolar staining.

(a) Not producing honey-like growth on potato, branching forms uncommon.

$\mathrm{x}$. Gelatin not liquefied or liquefied very slowly. Motile or non-motile.

Genus 5. Bacterium

xx. Gelatin liquefied quickly. Motile.

Genus 6. Proteus

(b) Producing a honey-like growth on potato. Branched cells not uncommon. Genus 7. Pfeifferella

b. Cells typically Gram-positive. All non-motile.

(1) Usually microaërophilic. Not typically growing well on the surface of laboratory media. Without metachromatic granules.

(a) Non-pathogenic lactic acid bacilli.

Genus 8. Lactobacillus

(b) Pathogenic, slender, small rods, not lactic acid formers. Genus 9. Erysipelothrix

(2) Aërobic rods, frequently showing metachromatic granules or irregular staining. . Genus 10. Corynebacterium

\section{Key to the subgenera of Bacterium}

A. Organisms which show a maximum of fermentative power, including fermentation of lactose, rarely pathogenic, some forms slowly liquefy gelatin.

Subgenus 1. Aërobacter (or Eu-Bacterium)

B. Organisms not showing maximum fermentative power, never producing gas in lactose, frequently pathogenic, never liquefying gelatin.

1. Producing acid and gas from glucose, sometimes other sugars, but none from lactose.............. Subgenus 2. Salmonella

2. Producing gas from none of the carbohydrates, acid sometimes formed.

Subgenus 3. Eberthella 


\section{Key to the Genera of Mycobacterieae}

One genus only, Mycobacterium.

\section{Key to Genera of Spirillaceae}

A. Cells not larger at center, not tapering.

1. Cells usually short, only a segment of a spiral. One or rarely two or three polar flagella...............Genus 1. Vibrio

2. Cells longer, usually with a tuft of polar flagella.

B. Cells enlarged at center and tapering.

Genus 2. Spirillum

Genus 3. Paraspirillum

Key to the Genera of Nitrobacteriaceae

A. Cells rod shaped.

1. Oxidizing ammonia to nitrous acid. Motile.

Genus 1. Nitrosomonas

2. Oxidizing nitrous acid to nitric acid.

Genus 2. Nitrobacter

B. Cells spherical ................ Genus 3. Nitrosococcus

Key to the Genera of Chlamydobacteriaceae

1. Filaments not usually permanently attached.

a. Filaments straight, or at least not twisted.

Genus 1. Leptothrix

b. Filaments twisted......... Genus 2. Didymohelix

2. Filaments attached.

a. Filaments unbranched..... Genus 3. Crenothrix

b. Filaments show pseudodichotomous or false branching.

(1) Swarm cells developed (motile conidia). Usually without a deposit of iron oxid in the sheath.

Genus 4. Sphaerotilus

(2) Spherical, non-motile conidia. Usually with iron oxide.

Genus 5. Clonothrix

\section{Key to the Genera of Actinomycetaceae}

A. No evident aerial threads or conidia formed. Usually parasitic. Often anaërobic or microaërophilic.

1. Threads usually not branched.

a. Threads disjointing very readily; long mycelial threads uncommon.

Genus 1. Actinobacillus

b. Threads Ionger, not disjointing into short rods.

Genus 2. Leptotrichia

2. Threads more or less branched, frequently clubbed in tissues.

Genus 3. Actinomyces

B. Aërial threads and conidia evident on culture media.

Genus 4. Nocardia 
Key to the Families of Thiobacteriales

A. Cells containing sulphur granules (or in one species possibly oxalate crystals), but no bacteriopurpurin.

1. Unicellular, motile forms. Not filamentous.

Family I. Achromatiaceae

2. Filamentous forms.........Family II. Beggiatoaceae

B. Cells containing bacteriopurpurin with or without sulphur granules.

Family III. Rhodobacteriaceae

\section{Key to the Genera of Achromatiaceae}

A. Cells spherical or ellipsoidal.

1. Cells ellipsoidal (spherical when newly divided). Cells containing granules of calcium oxalate (perhaps sulfur).

Genus 1. Achromatium

2. Cells spherical, with sulphur granules in a central vacuole.

Genus 2. Thiophysa

B. Cells longer, very large (42 to $86 \mu$ ) with peritrichous flagella.

Genus 3. Hillhousia

Key to the Genera of Beggiatoaceae

A. Filament non-motile, with a contrast to base and tip, attached.

Genus 1. Thiothrix

B. Filaments motile (oscillating) not attached, no differentiation into tip and base.

1. Filaments not in bundles nor surrounded by a gelatinous sheath.

Genus 2. Beggiatoa

2. Filaments in bundles, surrounded by a gelatinous sheath.

Genus 3. Thioploca

Key to the Subfamilies of Rhodobacteriaceae

A. Cells containing sulphur granules.

Subfamily I. Chromatioideae

B. Cells without sulphur granules... Subfamily II. Rhodobacterioideae

Key to the Tribes of Chromatioideae

A. Cells united, at least during a part of the life history, into families.

I. Cell division such that masses of cells, not merely plates, are formed.

a. Cell division in three directions of space.

Tribe I. Thiocapseae

b. Cell division first in three, then in two directions of space.

Tribe II. Lamprocysteae

II. Cell division in two planes, forming plates of cells.

Tribe III. Thiopedieae

III. Cell division in one plane..Tribe IV. Amoebobacterieae

B. Cells free, capable of swarming at any time

Tribe V. Chromatieae 
Key to the Genera of the Thiocapseae

A. Cells capable of swarming.

I. Families small, compact, enclosed singly or several together in a cyst.

Genus I. Thiocystis

II. Cells large, 7 to $8 \mu$, loosely bound by gelatin into loose families.

Genus II. Thiosphaera

III. Cells small, united into solid, spherical families.

B. Cells not capable of swarming.

Genus III. Thiosphaerion

I. Spherical cells spread out upon the substratum in flat families, loosely enveloped in a common gelatin.

Genus IV. Thiocapsa

II. Arranged in regular packets like Sarcina.

Genus V. Thiosarcina

Key to the Genera of Lamprocysteae

One genus only: Lamprocystis.

Key to the Genera of Thiopcdieae

A. Cells occurring regularly in fours.... Genus I. Lampropedia

B. Cells occurring in a film or membrane, not regularly disposed in tetrads.

Genus II. Thioderma

Key to the Genera of Amoebobacterieae

I. Cells connected by plasma threads, families amoeboid motile.

Genus I. Amocbobacter

II. Cells not as I.

A. Cells arranged in a net, united by their ends.

Genus II. Thiodictyon

B. Cells not arranged in a net.

1. Capable of swarming. Cells loosely aggregated in gelatin.

Genus III. Thiothece

2. Non-motile. Cells closely appressed into a colony.

Genus IV. Thiopolycoccus

\section{Key to the Genera of Chromatieae}

A. Cells motile by means of polar flagella. Elongated.

I. Cells not spiral.

a. Cell cylindric......... Genus I. Chromatium

b. Cells with tendency to spindle shape.

Genus II. Rhabodomonas

II. Cells spiral ............... Genus III. Thiospirillum

B. Cells spherical, or little elongate, non-motile.

I. Cells not encapsulated....... Genus IV. Rhodocapsa

II. Cells encapsulated in pairs... Genus V. Rhodothece

Key to the Genera of Rhodobacterioideae

A. Cells rod shaped, many embedded in the same slimy capsule.

Genus I. Rhodocystis 
B. Cells spherical or short rods.

1. In chains, each chain surrounded by a capsule.

Genus II. Rhodonostoc

2. Cells free.............. Genus I1I. Rhodosphaera

C. Cells free and elongate.

1. Cells not bent.

a. Non-motile........ Genus IV. Rhodobacterium

b. Motile............Genus V. Rhodobacillus

2. Cells bent or curved.

a. Cells short, comma shaped, with single polar flagellum.

Genus VI. Rhodovibrio

b. Cells spiral, with polar flagella

Genus VII. Rhodospirillum

Key to the Genera of Myxobacteriaceae

I. Cells not transformed into coccus-like spores when encysted.

A. Rods forming free cysts in which they remain unmodified. Cysts various, sessile or borne on a more or less highly developed cystophore.

Genus I. Chondromyces

B. Rods forming large rounded cysts, one or more, free within a gelatinous matrix raised above the substratum.

Genus II. Polyangium

II. Rods transformed to form definite, more or less encysted, sessile or stalked masses of coccus-like spores..... Genus III. Myxococeus

\section{Key to the Genera of Spirochaetaceae}

I. Usually saprophytic, free living in water.

A. Protoplasm spirally wound around an elastic axis filament.

Genus I. Spirochaeta

B. Not as in (A), cross section circular.

Genus II. Saprospira

II. Usually parasitic.

A. Possessing a "crest" or ridge. Parasitic in mussels.

Genus III. Cristispira

B. Without a crest. Parasitic in warm blooded animals.

Genus IV. Treponema

In September, 1917, appeared the Preliminary Report of the Committee of the Society of American Bacteriologists on Characterization and Classification of Bacterial Types (Winslow, Broadhurst, Buchanan, Krumwiede and Smith). An historical review of systems of classification is given, likewise a review of the points found in the International Botanical Code of principal interests to bacteriologists. Four orders of bacteria were recognized. The subdivisions of the Eubacteriales alone were recommended. The classification in outline follows: 
Suggested Committee Classification of the Class Schizomycetes (1917)
A. Order. Myxobacteriales.
B. Order. Thiobacteriales.
C. Order. Chlamydobacteriales.
D. Order. Eubacteriales.

I. Family. Nitrobacteriaceae.

1. Genus. Hydrogenomonas.

2. Genus. Methanomonas.

3. Genus. Carboxydomonas.

4. Genus. Mycoderma.

5. Genus. Nitrosomonas.

6. Genus. Nitrobacter.

7. Genus. Azotobacter.

8. Genus. Rhizobium.

II. Family. Mycobacteriaceae.

1. Genus. Actinomyces.

2. Genus. Nocardia.

3. Genus. Mycobacterium.

4. Genus. Corynebacterium.

5. Genus. Fusiformis.

6. Genus. Leptotrichia.

III. Family. Pseudomonadaceae.

1. Genus. Pseudomonas.

IV. Family. Spirillaceae.

1. Genus. Tibrio.

2. Genus. Spirillum.

V. Family. Coccaceae.

a. Tribe. Streptococceae.

1. Genus. Neisseria.

2. Genus. Streptococcus.

3. Genus. Staphylococcus.

4. Genus. Albococcus.

b. Tribe. Micrococceae.

1. Genus. Micrococcus.

2. Genus. Sarcina.

3. Genus. Rhodococcus.

VI. Family. Bacteriaceae.

1. Genus. Bacterium.

2. Genus. Erwinia.

3. Genus. Pasteurella.

4. Genus. Hemophilus.

VII. Family. Lactobacillaceae.

1. Genus. Lactobacillus.

VIII. Family. Bacillaceae.

1. Genus. Bacillus.

2. Genus. Clostridium. 
E. Organisms intermediate between bacteria and protozoa.

1. Genus. Spirochaeta.

2. Genus. Cristispira.

3. Genus. Saprospira.

4. Genus. Treponema.

An artificial key to the orders and genera was also published as follows:

\section{Artificial Key to the Orders of the Schizomycetes}

a. Cells united during the vegetative stage into a pseudoplasmodium.

A. Myxobacteriales

2a. Cells not forming a pseudoplasmodium.

b. Cells free or united in elongated filaments, often with a well-defined sheath. Conidia frequently formed. Free sulphur, iron or bacteriopurpurin often present.

c. Cells typically containing granules of sulphur or bacteriopurpurin or both................ Thiobacteriales

2c. Sulphur and bacteriopurpurin absent; iron often present.

C. Chlamydobacteriales

2b. Cells never in sheathed filaments. Conidia only in the mycelial Mycobacteriaceae. Flagella often present. Free iron, sulphur, or bacteriopurpurin never present......D. Eubacteriales

\section{Artificial Key to the Families of the Eubacteriales}

a. Cells spiral with polar flagella............IV. Spirillaceae

2a. Not as above.

b. Cells spherical; rarely, if ever, motile; spores never produced; never securing growth energy from nitrogen or ammonia.

\section{Coccaceae}

2b. Not as above.

c. Cells short rod-shaped with a single (rarely two) polar flagellum; usually forming green or yellow pigment.

III. Pseudomonadaceae

2c. Not wholly as above.

d. Spores formed............VIII. Bacillaceae

2d. Spores never formed.

e. Metabolism simple, securing growth energy from carbon, hydrogen, or their simple compounds; flagella, if present, polar........ I. Nitrobacteriaceae

2e. Metabolism complex, dependent upon more complex carbohydrate and protein substances; flagella, if present, peritrichic.

f. Cells clubbed, fusiform, filamentous, branching or mycelial; those not distinctly so are either acidfast or show barred irregular staining.

II. Mycobacteriaceae 
2f. Not as above.

g. Gram-positive; non-motile

VII. Lactobacillaceae

2g. Gram-negative; often motile.

VI. Bacteriaceae

\section{Artificial Key to the Genera of the Eubacteriales}

a. Nitrobacteriaceae.

b. Fixing nitrogen or oxidizing its compounds.

c. Fixing nitrogen.

d. Cells large; in soil..........7. Azotobacter

$2 d$. Rods minute; in roots of leguminous plants.

8. Rhizobium

2c. Oxidizing nitrogen compounds.

d. Oxidizing ammonia........5. Nitrosomonas

2d. Oxidizing nitrites..........6. Nitrobacter

2b. Not as above.

c. Oxidizing hydrogen............. Hydrogenomonas

2c. Oxidizing carbon compounds.

d. Oxidizing alcohol; branching forms common.

4. Mycoderma

2d. Not as above, using simpler carbon compounds.

e. Oxidizing CO........... Carboxydomonas

2e. Oxidizing $\mathrm{CH}_{4} \ldots \ldots \ldots$....... Methanomonas

2a. Mycobacteriaceae.

b. Slender rods, staining with difficulty and acid-fast.

\section{Mycobacterium}

2b. Not as above.

c. Mycelium and conidia formed.

d. With aerial hyphae and conidia; usually saphrophytic soil organisms.

2. Nocardia

2d. Hyphae and conidia not aerial; usually parasitic in animals.

\section{Actinomyces}

2c. Not as above; cells rod-like, usually somewhat curved, clubbed, fusiform, or even branched, but never mycelial.

d. Thick, long threads, fragmenting into short, thick rods.

2d. Not as above.

6. Leptotrichia

e. Cells usually elongate and fusiform; filaments, if formed, not branching; staining somewhat irregularly.

\section{Fusiformis}

2e. Cells slightly curved, clubbed, or in old cultures even branching; not filamentous; showing definitely barred staining ........... Corynebacterium

3a. Pseudomonadaceae.

Generic characters mainly those of family...1. Pseudomonas

4a. Spirillaceae.

b. Flagellum single (rarely 2 or 3 )........ Vibrio 
2b. Flag ella tufted $(5-20) \ldots \ldots \ldots \ldots \ldots \ldots 2$. Spirillum

5a. Coccaceae.

b. Abundant red-pigmented growth on agar.

7. Rhodococcus

2b. Not as above.

c. Gram-negative.

d. Normally in pairs of flattened cells; growth on plain agar scanty, never bright yellow. 1. Neisseria

2d. Normally in plates, packets, or irregular masses; growth on plain agar abundant, pigment definitely yellow.

e. Cells in regular packets..6. Sarcina

2e. Cells not in regular packets.

\section{Micrococcus}

2c. Gram-positive (exceptions rare and not easily confused with above genera).

d. Cells normally in chains, sometimes in pairs (especially in acid environment) never in large irregular masses. Gelatine rarely liquefied. Growth on plain agar usually translucent, never heavy, never yellow or orange.

\section{Streptococcus}

2d. Cells normally in groups or masses (occasionally in plates in Albococcus?); chains short and irregular, if present. Gelatine often liquefied. Agar growth abundant, white to orange.

e. Pigment orange (rarely lacking); gelatine often liquefied actively........... Staphylococcus

2e. Whitish to porcelain white; liquefaction less vigorous.

4. Albococcus

6a. Bacteriaceae.

b. Plant pathogens................. Erwinia

2b. Not as above; saprophytes or in animal habitats (intestines, tissues, etc.)

c. Usually motile and exhibiting active fermentative powers; typically parasitic in intestines of man and higher animals; growing well on ordinary media...1. Bacterium

2c. Not wholly as above.

d. Growing only in presence of hemoglobin, ascitic fluid or serum............... Hemophilus

2d. Growth on media scanty, but less sensitive than the above; short rods with tendency to bipolar stain.

3. Pasteurella

7a. Lactobacillaceae.

Generic characters mainly those of family..1. Lactobacillus

8a. Bacillaceae.

b. Aerobic, usually saprophytic; cells not greatly enlarged (if at all) at sporulation..................... Bacillus

2b. Anaerobic, often saprophytic; cells frequently enlarged at sporulation.

2. Clostridium 
Brief diagnoses were given of all groups recognized, and type species indicated for the genera.

Castellani and Chalmers (Manual of Tropical Medicine, 3rd edition, 1919), published an unusually detailed classification of the bacteria, carrying the classification out only to include the most important pathogenic organisms which have been described. They use as a general name for the group as a whole, Schizomycetacea. The keys to the various groups which they recognize are as follows:

Key to the orders of Schizomycetacea. Castellani and Chalmers (1919)

A. Cells without sulphur or bacteriopurpurin.

Order I. Eubacteriales

B. Cells containing sulphur....... Order II. Thiobacteriales

C. Motile rods in pseudoplasmodial masses embedded in a gelatinous matrix and forming highly developed cysts.

Order III. Myxobacteriales

Key to the Families of Eubacteriales

A. Cells, in free condition, usually globular, in division somewhat elliptical.

Family 1. Coccaceae Zopf, 1885, emendavit Migula, 1900

B. Cells, long or short, cylindrical, straight; division one direction.

Family 2. Bacillaceae Fischer, 1894

C. Cells, spirally curved or representing part of a spiral; division in one direction.

Family 3. Spirillaceae Migula, 1900

D. Cells, surrounded by a sheath and arranged in elongated filaments.

Family 4. Chlamydobacteriaceae. Migula, 1900

E. Cells, short or long, cylindrical or filamentous, often clavate, cuneate, or irregular, with enclosed granules. Filaments without a sheath.

Family 5. Mycobacteriaceae. Chester, 1901

\section{Key to the Tribes of Coccaceae}

A. Parasitic on plants and animals, often growing best anaerobically but frequently with difficulty and in small amount, or even not at all, on artificial media; in pairs or chains, generally but not always staining by Gram, and often producing acidity in glucose and lactose media, and when pigmented generally white or orange.

Tribe I. Streptococceae. Trevisan, 1889, cmendavit Winslow and Rogers, 1905 B. Facultative parasites or saprophytes growing best under aerobic conditions and well on artificial media; in cell groups, packets or zoogloea masses and often Gram-negative, and when pigmented usually yellow or red.

Tribe II. Micrococceae. Trevisan, 1889, emendavit Winslow and Rogers, 1905

Key to the Genera of Streptococceae

A. Gram stain negative $\ldots \ldots \ldots \ldots \ldots \ldots \ldots \ldots$ Neisseria

B. Gram stain positive:

I. Pigment absent.

a. Cells in zoogloea masses,.........A scococcus 
b. Not in zoogloea masses:

1. Pairs or chains encapsulated, soluble in bile and salt solutions................... Diplococcus

2. Chains, not encapsulated, not soluble in bile or salt solutions.

II. Pigment present:

Streptococcus

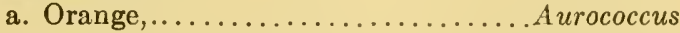

b. White,.....................Albococcus

Key to the Genera of the Tribe Micrococceae

A. Pigment red ................... Rhodococcus

B. Pigment yellow:

I. Cells in irregular groups............. Micrococcus

II. Cells in packets..................Sarcina

C. Pigment black ........................... igrococcus

Key to the Tribe of the Family Bacillaceae

Growth in ordinary laboratory media:

A. Entirely or almost entirely absent.

Tribe 1. Nitrobactereae

B. Poor, Gram-negative, grow best on blood media.

Tribe 2. Haemophileae

C. Extremely slow and scanty growth on ordinary and blood media.

D. Growth good:

Tribe 3. Graciloideae

I. Endospores present........Tribe 4. Bacilleae

II. Endospores absent:

(a) Fluorescent or chromogenic.

Tribe 5. Bacteridieae

(b) Neither fluorescent nor chromogenic:

1. Obligatory anaerobes.........Tribe 6. Bacteroideae

2. Aerobes often facultative anaerobes:

(1) Gelatine liquefiers.

Tribe 7. Proteae

(2) Gelatine non-liquefiers:

(i) Without capsules:

(A) With polar staining.

Tribe 8. Pasteurelleae

(B) Without polar staining.

Tribe 9. Ebertheae

(ii) With capsules.

Tribe 10. Encapsulateae

Key to the Tribe Encapsulateae

This tribe contains one genus only...........Encapsulateae

Key to the Genera of the Tribe Ebertheae

A. Glucose and lactose either not at all or only partially fermented with the production of acid, but no gas: 
I. Milk not clotted:

(a) Glucose and lactose not fermented.

Genus 1. Alcaligenes Castellani and Chalmers, 1918

(b) Glucose partially fermented with the production of acid and no gas; lactose not fermented:

1. Motile.... Genus 2. Eberthus Castellani and Chalmers, 1918

2. Non-motile.

Genus 3. Shigella Castellani and Chalmers, 1918

(c) Lactose and glucose partially fermented with the production of acid, but no gas.

Genus 4. Dysenteroides Castellani and Chalmers, 1918

II. Milk clotted:

Glucose partially fermented with the production of acid, but no gas; lactose not fermented (no gas in any sugar).

Genus 5. Lankoides Castellani and Chalmers, 1918

B. Glucose completely fermented with the production of acid and gas; lactose not fermented:

I. Milk not clotted.

Genus 6. Salmonella Lignières, emendavit Castellani and Chalıners, 1918

II. Milk clotted..... Genus 7. Balkanella Castellani and Chalmers, 1918

C. Glucose completely fermented with the production of acid and gas; lactose partially fermented with the production of acid and no gas:

I. Milk not clotted. Genus 8. Wesenbergus Castellani and Chalmers, 1918

D. Glucose and lactose completely fermented with the production of acid and gas:

I. Milk not clotted. Genus 9. Enteroides Castellani and Chalmers, 1918

II. Milk clotted..Genus 10. Escherichia Castellani and Chalmers, 1918

Key to the Subgenera of the Genus Shigella

A. Mannitol fermented.......Subgenus Flexnerella (Flexner group sensî lato)

I. Maltose fermented.................... Flexner group

II. Maltose not fermented...............Pseudodysentery group.

B. Mannitol not fermented............Subgenus Shigella

Key to the Tribe Pasteurelleae

One genus only: Pasteurella.

Key to the Genera of the Tribe Proteae

A. Rapid gelatine liquefiers; do not ferment lactose; mostly Gram-positive

Proteus

B. Slow gelatine liquefiers; ferment lactose; Gram-negative.

Cloaca

Key to the Tribe Bacteridieae

One genus only: Bacteridium.

Key to the Tribe Graciloideae

One genus only: Graciloides. 
Key to the Tribe Bacteroideae

One genus only: Bacteroides.

Key to the Tribe Bacilleae

One genus only: Bacillus.

Key to the Genera of the Family Spirillaceae

A. Non-motile, comma-shaped, or spirally curved filaments, rigid, without flagella............................ Spirosoma Migula, 1900

B. Motile, short, slightly curved, rigid, comma-like, sometimes in chains, with one, rarely more, flagella at one end, seldom at both ends.

Genus 2. Vibrio O. F. Müller, 1773, emendavit Loeffler

C. Motile, long, spirally curved, usually with a bunch of polar flagella composed of long and short forms.

Genus 3. Spirillum Ehrenberg. 1838 emendavit Loeffler

Key to the Family Mycobacteriaceae

One genus only: Mycobacterium.

Many of the Hyphomycetes are included under the class Fungi-Imperfecti and under the sub-class Hyphales.

Key to the Orders of Hyphomycetes

A. Mycelium composed of fine bacilliform hyphae in which the nuclei are usually indistinct.............. Order 1. Microsiphonales. Vuillemin, 1912

B. Mycelium not so composed:

1. Reproduction by thallospores.

Order 2. Thallosporales. Vuillemin, 1910

2. Reproduction by hemispores.

Order 3. Hemisporales. Vuillemin, 1910

3. Reproduction by conidia. Order 4. Conidiosporales. Vuillemin, 1910

Key to the Families of the Order Microsiphonales

A. Nocardiaceae Castellani and Chalmers, 1918. Synonyms.-Actinomycetes Lachner-Sandoval, 1898; Trichomycetes Petrusky, 1903.

Definition.-Microsiphonales with a mycelium.

Type Genus.-Nocardia Toni and Trevisan, 1889.

B. Mycobacteriaceae Miehe, 1909. Definition.-Microsiphonales without a mycelium.

Genus 1.-Mycobacterium Lehmann and Neumann, with the diphtheria bacillus as a type.

Genus 2.-Corynebacterium Lehmann and Neumann, with the tubercle bacillus as a type.

\section{Key to the Family Nocardiaceae}

A. Grows aerobically, easy of cultivation, and producing arthrospores (Fig. 549).

Genus 1. Nocardia Toni and Trevisan, 1889 
B. Grows best anaerobically, but can often grow aerobically; difficult of culture, and not producing arthrospores.... Genus 2. Cohnistreptothrix Pinoy, 1911

Mrs. Enlows (1920) prepared a most helpful bulletin in which was listed the various names which have been proposed by various writers for bacterial genera. She has in most cases indicated the type species.

Castellani and Chalmers (1920) proposed a classification of the family Bacillaceae Fischer 1894 into some 10 tribes differentiated by the following key:

\section{Key to Tribes of Bacillaceae}

A. No development in ordinary media........... Nitrobactereae

B. Growth poor in ordinary media, better on media containing blood. Gramnegative..........................Hemophileae

C. Very poor and slow growth on ordinary media, also on blood media.

D. Good development on ordinary media.

\section{Graciloideae}

I. Endospores present................Bacilleae

II. Endospores absent.

a. Fluorescent or chromogenic........ Bacteroideae

b. Neither fluorescent nor chromogenic.

1. Obligate anaerobes..........Bacteroideae

2. Aerobic, often facultative anaerobic.

(a) Liquefying gelatin.......Proteae

(b) Not liquefying gelatin.

(1) Without capsules.

$\mathrm{x}$. Bipolar staining.

$2 x$. No bipolar staining.

Pasteur elleae

Ebertheae

(2) With capsule.....Encapsulateae

It will be noted that there is an evident misprint, as both tribes 5 and 6 are termed Bacteroideae.

Three of the tribes are discussed in detail. The generic keys are given below.

\section{Tribe Encapsulateae}

The type and only genus is Encapsulatus Castellani and Chalmers.

\section{Tribe Ebertheae}

A. Either do not ferment glucose and lactose at all, or only partially, with production of acid without gas.

I. Milk not coagulated.

a. Ferments neither glucose nor lactose.

Alcaligenes. Castellani and Chalmers, 1918 
b. Ferments glucose partially, with production of acid but no gas, does not ferment lactose.

1. Motile........Eberthus. Castellani and Chalmers, 1918

2. Non-motile......Shigella. Castellani and Chalmers, 1918

c. Ferment glucose and lactose partially with production of acid,

but without gas.. Dysenteroides. Castellani and Chalmers, 1918

II. Milk coagulated. Partial fermentation of glucose with production of acid but no gas: does not ferment lactose (no gas from any sugar)

Lankoides. Castellani and Chalmers, 1918

B. Ferment glucose completely with production of acid and gas, but do not ferment lactose.

I. Do not coagulate milk.

Salmonella. Lignières emendav. Castellani and Chalmers II. Coagulates milk.............Balkanella. Castellani and Chalmers C. Ferment glucose completely with production of acid and gas; lactose partially fermented with acid and no gas, does not coagulate milk.

Wesenbergus. Castellani and Chalmers, 1918

In May 1920 the final report of the Committee (Winslow et al., was published. The principal changes from the suggested grouping of 1917 were as follows:

The group recognized in 1917 as the family Mycobacteriaceae has now been elevated to the rank of an order Actinomycetales, and divided into two families, Actinomycetaceae and Mycobacteriaceae. To the former family we have added the genera Actinobacillus and Erysipelothrix, and we have omitted Nocardia, which Breed (1919) has recently shown should be combined for the present with Actinomyces. To the second family we have added the genus Pfeifferella.

The Nitrobacteriaceae have been divided into two tribes, the Nitrobactereae and Azotobactereae, and the definition of the family has been modified to permit the inclusion of Rhizobium which recent investigations have shown to possess peritrichous flagella, but whose general characteristics ally it clearly with Azotobacter. The name Acetobacter has been substituted for Mycoderma to characterize the vinegar organisms.

Among the Coccaceae a new tribe was created for the genus Neisseria. The genus Albococcus is united with Staphylococcus and the new genera Diplococcus and Leuconostoc are added.

The Bacteriaceae are divided into seven tribes: Chromobactereae, Erwineae, Bactereae, Lactobacilleae, Pasteurelleae, Hemophileae, and Zopfeae, and the new genera Erythrobacillus, Chromobacterium, Zopfius, and Proteus are added. The Lactobacillaceae, originally recognized as a distinct family, are thus classed as a tribe of the Bacteriaceae.

\section{Artificial Key to the Families and Genera of the Actinomycetales and Eubacteriales. Winslow et al. (1920)}

A. Typically filamentous forms. Actinomycetaceae.

B. Mycelium and conidia formed ..........Actinomyces 
BB. No true mycelium.

C. Cells show branching.

D. Gram-negative..............Actinobacillus

DD. Gram-positive.............Erysipelothrix

CC. Cells never branch. Gram-positive threads later fragmenting into rods................... Leptotrichia

AA. Typically unicellular forms (although chains of cells may occur).

B. Spherical cells. Coccaceae.

C. Parasitic forms. Cells in pairs, chains or irregular groups, never in packets. Generally active fermenters.

D. Cells in flattened coffee-bean-like pairs. Gram-negative.

Neisseria.

DD. Cells not as above. Gram-positive.

E. Cells in lanceolate pairs or chains.

Growth on media not abundant.

F. Cells in lanceolate pairs. Inulin generally fermented...........Diplococcus

FF. Cells in chains. Inulin generally not fermented.

Streptococcus

EE. Cells in irregular groups. Growth on media fairly vigorous.

White or orange pigment.Staphylococcus

CC. Saprophytic forms. Chains occurring in zoogleal masses in sugar solutions...................euconostoc

CCC. Saprophytic forms. Cells in irregular groups or packets, not in chains. Fermentative powers low.

D. Packets formed.............Sarcina

DD. No packets.

E. Yellow pigment...........Micrococcus

EE. Red pigment...........Rhodococcus

BB. Rods.

C. Curved rods. Spirillaceae.

D. Short comma-like rods. One to three short flagella.

Vibrio

DD. Long spirals, five to twenty flagella.

CC. Straight rods.

Spirillum

D. No endospores.

E. Rods of irregular shape or showing branched or filamentous involution forms.

F. Animal parasites. Cells of irregular shape. Staining unevenly.

G. Acid fast.......Mycobacterium

GG. Not acid fast.

H. Cells elongate, fusiform.

$$
\text { Fusiformis }
$$

HH. Cells not fusiform, sometimes branching. 
I. Gram-positive. Slender, sometimes clubbed rods.

Corynebacterium

II. Gram-negative. Rods sometimes form threads. Characteristic honey like growth on potato.

Pfeifferella

FF. Not animal parasites. Cells staining unevenly and with branched or filamentous forms at certain stages. Never acid fast.

G. Metabolism simple, growth processes involving oxidation of alcohol or fixation of atmospheric nitrogen (latter in symbiosis with green plants).

H. Cells minute, symbiotes in roots of leguminous plants.

\section{Rhizobium}

HH. Oxidizing alcohol, branching forms common......Acetobacter

GG. Not as above. Proteus-like colonies.

H. Not attacking carbohydrates. Gram + Zopfius

HH. Fermenting glucose and sucrose. GramProteus

EE. Regularly formed rods.

F. Metabolism simple, growth processes involving oxidation of carbon, hydrogen or their simple compounds or the fixation of atmospheric nitrogen. Nitrobacteriaceae.

G. Fixing nitrogen or oxidizing its compounds.

H. Fixing nitrogen.

Cells large; in soil. Azotobacter

$\mathrm{HH}$. Oxidizing nitrogen compounds.

I. Oxidizing ammonia. Nitrosomonas

II. Oxidizing nitrites Nitrobacter

GG. Not as above.

H. Oxidizing hydrogen.

Hydrogenomonas

HH. Not as above, using simpler carbon compounds.

I. Oxidizing $\mathrm{CO}$.

Carboxydomonas

II. Oxidizing $\mathrm{CH}_{4}$.

Methanomonas 
FF. Not as above.

G. Flagella usually present, polar. Pseudomonadaceae. ..Pseudomonas

GG. Flagella when present perithrichic. Bacteriaceae.

H. Parasitic forms showing bipolar staining Pasteurella

HH. Not as above.

I. Strict parasites growing only in presence of hemoglobin or ascitic fluid.Hemophilus

II. Not as above.

J. Water forms producing red or violet pigment.

K. Pigment red. Erythrobacillus KK. Pigment violet. Chromobacterium

JJ. Not as above.

K. Plant pathogens.

Erwinia

KK. Not as above.

L. Gram positive, forming large amount of acid from carbohydrates and sometimes $\mathrm{CO}_{2}$ but no $\mathrm{H}_{2}$

Lactobacillus

LL. Gram negative, forming $\mathrm{H}_{2}$ as well as $\mathrm{CO}_{2}$ if gas is produced.

DD. Endospores present, Bacillaceae

\section{Bacterium}

E. Aerobes................Bacillus

EE. Anaerobes ............ Clostridium

Orla-Jensen (1921) suggested certain revisions in his classification, introducing the new generic names Fluormonas, Photomonas, Propionococcus, Microbacterium, Colibacterium, Aerogenesbacterium, Butyriclostridium and Putriclostridium.

Hilda Hempl Heller (1921, p. 549) suggested that Bacteria be recognized as a phylum, and the principal groups be differentiated as follows: 


\section{Key to the Orders of the Bacteria. Heller (1921)}

Simple, one-celled plants that multiply typically by binary fission and occasionally by budding. They show no form of sexual multiplication. They rarely contain cellulose and do not contain chlorophyll or phycocyanin.

A. Bacteria which do not form a complex fruiting body.

\section{Phylum 1. Bacteria}

\section{Class I. Eubacterieae}

Eubacterieae whose cells are never in sheathed filaments. Conidia not observed. Free iron sulphur or bacteriopurpurin never present. Multiplication always occurs by transverse fission.......... Order I. Eubacteriales

Sulphur bacteria............. Order II. Thiobacteriales

Iron and manganese bacteria... Order III. Chlamydobacteriales

B. Bacteria which join to form a complex fruiting body.

Class II. Myxobacterieae

She also added to the "Committee's" list of families of the Eubacteriales, the Clostridiaceae: with two subfamilies, the Clostridioideae and Putrificoideae. A key to the genera of the Clostridioideae was later (1922, p. 5) published as follows:

Key to the Genera of the Subfamily Clostridioideae. Heller (1922)

A. Do not produce $\mathrm{H}_{2} \mathrm{~S}$ demonstrable by lead-acetate-paper test were grown in blood-broth

B. Do not liquefy gelatin.

C. Very large rods that form oval spores and store up starch in carbohydrate media......Genus $1 . \quad$ Clostridium Prazmowski emend. Heller. Type species butyricum as described by Winogradsky (1895).

CC. Rods with spherical spores.

D. Do not grow on media containing much protein.

Genus. 2. Omelianskillus. nov. gen. Type species hydrogenicus as described by Omeliansky (1895 and 1904b).

DD. Grow on ordinary anaerobe media.

E. Sides of the bacilli parallel, spores strictly terminal.

Genus 3. Macintoshillus nov. gen. Type species tetanomorphus (pseudotetanus bacillus, McIntosh (p. 32), Bacillus tetanomorphus Committee (p. 41 ), as described by the Committee.

EE. Spores not always strictly terminal, sides of bacilli may not be parallel.

Genus 4. Douglasillus nov. gen. Type species sphenoides (Bacillus sphenoides Douglas, Fleming and Colebrook), as described by the Committee (p. 43). 
CCC. Slender rods with oval endospores, usually Gram-negative.

D. Clot milk and attack various sugars, produce much acid.

Genus 5. Henrillus nov. gen. Type species tertius (Bacillus tertius Henry) as described by Henry.

DD. Do not clot milk, attack few or no sugars, produce little acid.

Genus 6. Flemingillus nov. gen. Type species cochlearius (Bacillus cochlearius Douglas, Fleming and Colebrook) as described by the Committee (p. 40).

CCCC. Gram-positive rods which are not markedly slender and which produce oval spores.

D. Clot milk, saccharolytic.

E. Sporulate meagerly, attack a few sugars; occasionally moderately pathogenic tissue invaders.

Genus 7. Tallorillus, nov. gen. Type species fallax (Bacillus fallax Weinberg and Séguin) as described by the Committee (p. 27).

EE. Sporulate readily, attack several sugars; not known to be pathogenic.

Genus 8. Multifermentans nov. gen. Type species tenatbus (Bacillus multifermentans tenalbus Stoddard) as described by Stoddard (1919b).

DD. Do not clot milk. Large Gram-positive rods with long ellipsoid spores... Genus 9. Hiblerillus nov. gen. Type species sextus (bacillus VI of von Hibler) as described by von Hibler (1908). (Résumé by Weinberg and Séguin (p. 202).

BB. Liquefy gelatin.

C. Produce stormy fermentation of milk and sporulate on alkaline media only.......... Genus 10. Welchillus nov. gen. Type species aerogenes (Bacillus aerogenes capsulatus Welch and Nuttall), type 1 as defined by Simonds (1915 a and b).

CC. Do not produce stormy fermentation of milk.

D. Do not sporulate... Genus 11. Stoddardillus nov. gen. Type species egens (Bacillus egens Stoddard) as described by Stoddard

DD. Sporulate readily. (1919a).

E. Gram-positive, form woolly colonies in deep agar. Typically highly pathogenic tissue invaders of many species of animals.

Genus 12. Rivoltillus nov. gen. Type species vibrion (the vibrion septique of Pasteur) as defined in a future paper. 
EE. Gram-negative, may contain Gram-positive granules. Form smooth lenticular or modified lenticular colonies in deep agar. Typically pathogenic for cattle, sheep, and guinea-pigs.

Genus 13. Arloingillus nov. gen. Type species Chauvoei (Bacterium Chauvoei Arloing, Cornevin and Thomas) as described in a future paper.

AA. Produce $\mathrm{H}_{2} \mathrm{~S}$ demonstrable by a lead-a cetate-paper test when grown in blood broth.

B. Produce a large amount of gas from carbohydrates. Heavy Grampositive rods with little or no tendency to sporulation.

Genus 14. Meyerillus nov. gen. Type species sadowa nov. sp. to be described in a future paper.

BB. Produce less gas from carbohydrates. Heavy Gram-positive or Gramnegative rods that form oval spores that are usually subterminal

Genus 15. Novillus nov. gen. Type species maligni (Bacillus oedematis maligni 1I. Novy) as described by Novy.

A committee of the Society of American Bacteriologists (Bergey, Breed, Hammer, Harrison and Huntoon) have recently (1923) prepared a Manual of Determinative Bacteriology. In general, the classification suggested by Winslow et al. has been followed. In some groups genera have been added, and several new families created. In the treatment of the Bacteriaceae they have followed Castellani and Chalmers and in orders other than Eubacteriales they have followed Buchanan. The keys for differentiation of orders, families and genera follow.

The Classification of Bacteria according to Bergey et al. (1923)

Key to the Orders of the Class Schizomycetes

1. Simple and undifferentiated forms, the true bacteria.

\section{Eubacteriales}

2. Specialized or differentiated forms.

a. Plant like.

b. Mold like....................Actinomycetales

bb. Not mold like.

c. Sheathed ....................... Chlamydobacteriales

cc. Not sheathed.

d. Sulphur bacteria.........Thiobacteriales

dd. Slime-mold like............Myxomycetales *

aa. Protozoan like.................... Spirochaetales

* A misprint for Myxobacteriales. 


\section{Key to Families of the Order Eubacteriales}

1. Organisms obligate aerobes, using oxygen for direct oxidation of carbon, hydrogen, or nitrogen or compounds of these. Cells usually rod-shaped, occasionally spherical.................. Nitrobacteriaceae

2. Not securing growth energy as under I.

a. Cells spherical................... Coccaceae

aa. Cells not spherical.

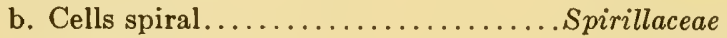

bb. Cells straight rods.

c. Not producing endospores. Cells motile or non-motile. Bacteriaceae

cc. Producing endospores.........Bacillaceae

Key to the Tribes and Genera of the Family Nitrobacteriaceae

1. Organisms oxidize simple compounds of carbon and nitrogen.

Nitrobactereae

a. Cells capable of securing growth energy by the oxidation of hydrogen to form water..................... Hydrogenomonas

b. Cells oxidize methane to form $\mathrm{CO}_{2}$ and water.

c. Cells oxidize $\mathrm{CO}$ to form $\mathrm{CO}_{2} \ldots \ldots \ldots$. Marboxydomononas

d. Cells oxidize ammonia to form nitrites..... Nitrosomonas

e. Cells oxidize nitrites to nitrates........... Nitrobacter

f. Cells oxidize alcohol to form acetic acid....Acetobacter

g. Cells oxidize compounds of sulphur....... Thiobacillus

2. Organisms capable of fixing free nitrogen of the air.

Azotobactereae

a. Cells capable of fixing free atmospheric nitrogen when growing in solutions of carbohydrates................Azotobacter

b. Cells capable of fixing free nitrogen when growing symbiotically on the roots of Leguminosae...............Rhizobium

Key to the Tribes of the Family Coccaceae

I. Strict parasites, failing to grow or growing very poorly on usual artificial media. Cells normally in pairs, occasionally in tetrads.

Neissereae

II. Parasites (except Leuconostoc) growing best in media containing serum. Occur in pairs or chains................. Streptococceae

III. Facultative parasites or saprophytes. Cell aggrcgates of groups, packets or zoogleal masses. Growth abundant......Micrococceae

Key to the Genera of the Tribe Neissereae

One genus only: Neisseria. 


\section{Key to the Genera of Tribe Streptococceae}

1. Parasites growing poorly, or not at all, on artificial media. Cells usually in pairs................... Diplococcus

2. Saprophytes, usually growing in cane sugar solutions. Cells in pairs or chains. Leuconostoc

3. Chiefly parasites. Normally forming short or long chains, sometimes pairs, but never packets...................... Streptococcus

4. Parasites. Cells in groups or short chains, rarely in packets.

Staphylococcus

\section{Key to Genera of Tribe Micrococceae}

1. Facultative parasites or saprophytes. Cells in plates or irregular masses (never in long chains or in packets)...........Micrococcus

2. Cell division occurs in three planes forming packets.

\section{Sarcina}

3. Saprophytes. Cells in groups or packets. Form red pigment on agar.

\section{Rhodococcus}

\section{Key to the Genera of Family Spirillaceae}

1. Cells short, bent rods, rigid, single or united into spirals.

\section{Vibrio}

2. Cells rigid, of various thickness and length and pitch of the spiral, forming either long curves or portions of a turn........Spirillum

\section{Key to the Tribes of Family Bacteriaceae}

1. Produce pigment on solid media. The pigment may be red, yellow, violet, green or blue.........................'hromobactereae

2. Without pigment formation on agar or gelatin. Achromobactereae

3. Cellulose digesting organisms occurring in soil. Cellulomonadeae

4. Plant pathogens, growth usually whitish.......Erwineae

5. Gram-positive rods, growing freely on artificial media. Do not attack carbohydrates...................... Zopfeae

6. Gram-negative rods growing freely on artificial media. Generally act on carbohydrates with formation of acid and gas.

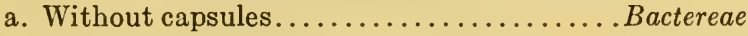

7. b. Encapsulated..................... Encapsulateae

8. Rods often long and slender. Gram-positive. Non-motile. Usually produce lactic acid from carbohydrates......... Lactobacilleae

9. Anaerobic, non-spore-forming rods..........Bacteroideae

10. Gram-negative rods, showing bipolar staining. Parasitic forms.

Pasteurelleae

11. Minute parasitic forms growing only (or best) in the presence of hemoglobin, ascitic fluid or other body fluids............. Hemophileae

\section{Key to the Genera of Tribe Chromobactereae}

1. Small, aerobic rods, producing a red or pink pigment on agar or gelatin. 
2. Small, aerobic rods, producing a yellow pigment on gelatin or agar.

Flavobacterium

3. Small, aerobic rods, producing a violet pigment on solid media.

Chromobacterium

4. Small, aerobic rods, producing a green or blue-green pigment.

Pseudomonas

Key to the Genera of the Tribe Achromobactereae

One genus only: Achromobacter.

Key to the Genera of the Tribe Cellulomonadeae

One genus only: Cellulomonas.

Key to Genera of Tribe Erwiniae

1. Motile rods.

a. Flagella peritrichous..................Erwinia

2. Rods motile or non-motile. Motile forms possess polar flagella.

Phytomonas

Key to the Genera of the Tribe Zopfeae

One genus only: Zopfius.

\section{Key to the Genera of Tribe Bactereae}

A. Ferment dextrose with production of acid or acid and gas.

1. Gas formed from dextrose.

a. Gas formed from lactose.

b. Acetyl-methyl-carbinol not formed from dextrose. Escherichia

bb. Acetyl-methyl-carbinol formed. .Aerobacter

aa. Gas not formed from lactose.

b. Gas formed from sucrose........Proteus

bb. Gas not formed from sucrose... Salmonella

2. Gas not formed from dextrose.

a. Acid formed from dextrose......... Eberthella

AA. Do not form acid or gas from any of the carbohydrates.

Alcaligenes

Key to the Genera of the Tribe Encapsulateae

One genus only: Encapsulatus.

Key to the Genera of the Tribe Lactobacilleae

One genus only: Lactobacillus.

Key to the Genera of the Tribe Bacteroideae

One genus only: Bacteroides.

Key to the Genera of the Tribe Pasteurelleae

One genus only: Pasteurella. 
Key to Genera of Tribe Hemophileae

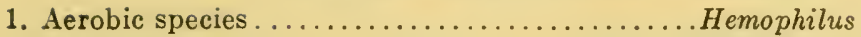

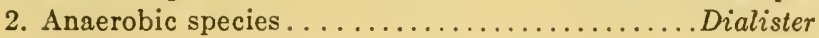

Key to the Genera of Family Bacillaceae

A. Aerobic forms, mostly saprophites.......... Bacillus

B. Anaerobic forms. Often parasitic...........Clostridium

Key to the Families of the Order Actinomycetales

A. Filamentous forms, often branched, sometimes forming mycelia. Conidia sometimes present. Some species parasitic..Actinomycetaceae

B. Parasitic forms. Rod-shaped, rarely filamentous, and with only slight and. occasional branching. No conidia..........Mycobacteriaceae

Key to the Genera of Family Actinomycetaceae

A. Parasitic forms.

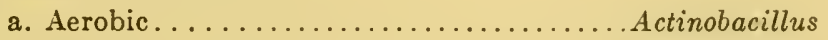

b. Anaerobic or facultative............... Leptotrichia

B. A few parasitic forms; mostly soil forms.

a. Filamentous, often branched, sometimes forming mycelia.

Actinomyces

b. Rods forming long filaments which rarely show branching.

Erysipelothrix

Key to the Genera of Family Mycobacteriaceae

A. Slender rods; acid fast.................. Iycobacterium

B. Slender, often slightly curved rods; not acid-fast.

C. Obligate parasites. Cells frequently fusiform.

Corynebacterium

Fusiformis

D. Slender, Gram-negative rods............... Pfeifferella

Key to the Families of the Order Chlamydobacteriales

One family only: Chlamydobacteriaceae.

Key to the Genera of the Family Chlamydobacteriaceae

1. Filaments usually not permanently attached.

a. Filaments straight or at least not twisted.. Leptothrix

b. Filaments twisted................ Didymohelix

2. Filaments attached.

a. Filaments unbranched................. Crenothrix

b. Filaments show pseudodichotomous branching.

1. Swarm cells developed (motile conidia). Usually without a deposit of iron in the sheath.............Sphaerotilus

2. Spherical, non-motile conidia. Usually with iron oxide.

Clonothrix 


\section{Key to the Families of the Thiobacteriales}

The keys to the subgroups and genera of this order are the same in general as those of Buchanan (1917-18) q.v.

Key to the Families of the Order Myxobacteriales

One family only: Myxobacteriaceae.

Key to the Genera of Family Myxobacteriaceae

I. Rods transformed into coccus-like spores when encysted, sessile or stalked masses of coccus-like spores............... Myxococcus

II. Cells not transformed into coccus-like spores when encysted.

A. Rods forming large, rounded cysts, one or more within a gelatinous matrix raised above the substratum.... Polyangium

B. Rods forming cysts in which they remain unmodified. Cysts various, sessile or borne on a more or less highly developed cystophore.

Chondromyces

Key to the Families of the Order Spirochaetales

One family only: Spirochaetaceae.

Key to the Genera of Family Spirochaetaceae

A. Usually saprophytic, free-living in water.

1. Protoplasm spirally wound around an elastic axis filament.

Spirochaeta

2. Cross section circular................ Saprospira

B. Usually parasitic.

1. Possessing a "crest" or ridge. Parasitic in mussels.

Cristispira

2. Without crest. Parasitic in warm blooded animals and in man.

Spironema

Treponema

3. Short, sharply twisted spirals. Parasitic in rodents and in man.

Leptospira 


\section{CHAPTER II}

\section{CODES OF NOMENClatURE AND THEIR APPLICATION IN BACTERIOLOGY}

If it be taken as a guiding principle that for each kind of organism there should be one valid name, and that there should be some criterion as to the correctness or validity of any name, it is evident that there must be developed and recognized some code of rules or laws. Such so-called "Codes of Nomenclature" have been developed both in Botany and in Zoölogy by International Congresses called among other things for this purpose. Inasmuch as the bacteria are plants, or at least most closely allied to the plant kingdom, it would be most natural to follow the botanical code. However, an element of confusion in practice is introduced because bacteriologists have shown a tendency in recent years to term themselves microbiologists and their subject microbiology to make it evident that their studies are not confined to the bacteria, or even to the plant kingdom. This has been fostered by the discovery of many diseases of man and animals caused by protozoa. In many cases these can be best studied by the methods which have been developed in the bacteriological laboratory. It has proved somewhat confusing to use the botanical code for the plant forms and the zoölogical code for the protozoa.

A careful study of the botanical and zoölogical codes will show them to be very similar in most essential characteristics. The botanical code is less rigid, and probably has something more of ambiguity in some of its statements than does the zoölogical. Logically it would seem that we should follow the botanical code with the bacteria and the zoölogical code with the protozoa.

The questions at once arise:

Are these codes really applicable to the nomenclature of microorganisms? Have they not been planned with higher groups of plants and animals in mind?

A careful study of the provisions of either code will show that there is no inherent difficulty in application to the lower forms of life. In the botanical code there are, perhaps, one or two rules which the bacteriologists might be reluctant to accept, particularly the rule that all 
new species of plants (in our case, bacteria) to be recognized as valid, must be published with a Latin diagnosis. From the standpoint at least of the bacteriologist it would be greatly improved by the introduction of the type concept. Furthermore, in both botanical and zoölogical codes there is a rule that no two genera (or other groups) can exist with the same name, and that duplicate genera in plant and animal kingdoms should be avoided as far as possible, but that such duplicates are not invalid. In other words, two plants can not have the same name, nor can two animals, but a plant and an animal may be named alike. It would appear that for the sake of the microbiologist there might be appended to each code the rule that in those groups whose position in plant or animal kingdom is in doubt there should exist no duplicate names. There is no reasonable question that the zoollogical code is the clearer.

In a final determination or formulation of the practice which will best serve the bacteriologist, and particularly in the formulation of a statement to govern practice in the present series, it will be necessary to discuss:

$a$. The principles suggested by bacteriologists before the latest revision of the botanical code, particularly the Rules of Nomenclature suggested by Lehmann and Neumann.

$b$. The Botanical Code of Vienna as modified at Brussels.

c. The Zoölogical Code.

$d$. The suggestions and recommendations of the Society of American Bacteriologists.

$e$. Suggested revision of the botanical code formulated by a committee of the Botanical Society of America.

\section{A. THE RULES OF BACTERIAL NOMENCLATURE ACCORDING TO LEHMANN AND NEUMANN}

Apparently the first bacteriologists to give very serious consideration to rules of nomenclature governing the naming of bacteria and to the formulation of such rules were Lehmann and Neumann. In general it may be said that these rules conformed measurably well to the principles of the botanical code. They undoubtedly constituted a very real advance over any previous statement. They are of sufficient importance to warrant their inclusion. The translation of the rules is given in smaller type. The comments are those of the author.

1. Every plant and, therefore, every Schizomycete belongs to a species, every species to a genus, and every genus to a family. 
2. Following the precedent of Linnaeus, every plant or animal, therefore, every microörganism must have two Latin names: the first designating the genus to which the organism in question belongs, this name being a substantive; the second indicating the species, which name is an adjective (not two) or the genitive of a substantive, or rarely a substantive in the nominative case.

Comment. The first two rules are basic, and generally accepted in all codes.

3. Genera must only be founded upon important morphologic characteristics; so called "biologic genera," such as Photobacterium for all light-emitting bacteria, Pyobacterium for rods causing suppuration, etc., are only calculated to produce confusion.

Comment. Modern tendency in bacteriology is to disregard this rule in part. Many valid genera are recognized at present in which physiologic as well as morphologic characters are used for purposes of diagnosis and differentiation.

4. As a designation for species many authors have used, instead of one adjective or substantive, a plurality of adjectives, evidently with the object of furnishing a description through the name: Bacillus rosettaceus metalloides, Staphylococcus pyogenes aureus, Bacillus pyogenes foetidus, Bacillus mesentericus panis viscosi I and II. This effort can be understood, but it has been abandoned as entirely impracticable by all descriptive naturalists since Linnaeus. The name of the species should indicate this unequivocally; the characterization belongs to the description. It does no harm if two or more organisms possess names which mean the same, if they do not sound alike. In addition to a Micrococcus albus, a Micro. niveus, Micro. albissimus, Micro. candicans, and a Micro. purus, may all be quite valid; we must look to the description to determine the exact differences which exist among these white cocci.

5. Names which have been formed improperly, i.e., contrary to the binomial rule, may be replaced. We have done this with the greatest consideration for the existing name whenever possible. We have not changed names like Bacillus acidi lactici, because acidum lacticum represents a single idea, and names like Sempervivum Reginae Amaliae, Pedicularis Friderici A ugusti, Trigonella Foenum Graecum, Pedicularis Sceptrum carolinum have remained, although certainly not convenient, still uncontested.

6. If names are properly formed in the binomial manner and correctly published, then they must not be changed by the author himself, much less by others, even if subsequently another appears better. Furthermore, the fact that a name is philologically incorrect or not beautiful, is no adequate reason for change. Even, for example, if it were literally more correct to call the genus we have named "Mycobacterium" by the new name "Tuberculomyces," such a proposition is absolutely unallowable. Renaming is required only when the name given was employed earlier with another signification. Thus, Cohn founded upon a certain organism the new genus Streptothrix, without knowing that Corda, about thirty years previously had conferred this name upon a fungus totally different 
from the one which he described. His new species, therefore, must receive a new genus name which he who first observed Cohn's oversight is justified in establishing.

7. It may happen that an author differs from his predecessor as to the boundaries of certain genera, and he, therefore, transfers a species from one genus into another, either one which previously existed or which is newly formed by himself. This is permissible; nevertheless the designation of the species must not be changed. So we had the right when we broke up the very large genus Bacillus, following the suggestion of Hüppe, into the two genera Bacillus and Bacterium, to rename a number of species (for example, Bacillus pyocyaneus renamed Bacterium pyocaneum), but we did not have the right, however much we disliked the species name pyocyaneum, to rename the organism Bacterium coeruleo-viride or Bacterium gessardi or anything else.

8. The author who names the genus places his name after the name given. We speak of Bacillus Cohn, and mean the genus Bacillus as Cohn established it; of Vibrio Ehrenberg emend. Loeffler, and mean the genus Vibrio as established by Ehrenberg and afterward more accurately described by Loeffler.

9. Whoever discovers a new species or names one not previously named gives it a genus and a species name, and places his own name after the latter. Flügge, who first named a large number of bacteria, gave, for example, the name Bacillus pyocyaneus Flügge, to the long known cause of bluish green suppuration.

10. When one places a species in a new genus he puts his own name after the new name, thus, Bacterium pyocyaneum Lehmann and Neumann, but it is always to be recommended that he add in parentheses, the name of the author who first named the species. Therefore we always write, where it does not become too cumbersome (in titles, etc.), Bacterium pyocyaneum (Flügge) Lehmann and Neumann.

While we believe that all names which express the systematic position of the organisms shall conform to the general rules of nomenclature, still we believe that names currently used in bacteriologic literature, as gonococcus, pneumococcus, staphylococcus, tubercle bacillus, diphtheria bacillus, can still be used, but as so-called ordinary names. Thus the technical botanist, if not speaking in a strictly systematic sense, of ten speaks of oak instead of Quercus, and strawberry instead of Fragaria. We must, however, strictly avoid smuggling into the literature as names of genera, such names as gonococcus, etc.

Comment. Migula in his monumental treatise on bacteria published in 1900, and Chester in his Manual of Determinative Bacteriology published in 1901 have both followed with a measurable degree of success, the rules which have been so clearly summarized in the above statement by Lehmann and Neumann. These rules are, of course, as the authors have indicated, only a condensed summary of international rules with a few interpolations of the authors themselves. In an extensive discussion or consideration of nomenclature, questions are constantly arising which can not be answered by this summary. It is necessary for sufficient and adequate information as to their solution, to turn to the international rules which govern botanical nomenclature. 


\section{B. INTERNATIONAL RULES OF BOTANICAL NOMENCLATURE}

On the following pages the botanical code (or international rules) as revised by the Brussels International Botanical Congress of 1910, is given in detail. In some cases the discussions given in the original rules under the heading of Examples, has been abbreviated, as many of the examples deal with problems not faced by the bacteriologist. In certain cases rules and recommendations have been omitted for the same reason. A paragraph headed "Comments" is added in many cases to point out certain applications in the field of bacteriology. In some cases comparisons with similar or antagonistic provisions in the zoölogical code are made. It will be evident as one studies these rules that the botanical code was drafted with the vascular plants in mind and most of the illustrations in consequence have been drawn from this field. However, it has been emphasized previously that a study of the various provisions will show that with but few exceptions they are equally applicable to the conditions which confront the bacteriologist.

\section{Chapter I. General considerations and leading principles}

Article 1. Natural history can make no progress without a regular system of nomenclature, which is recognized and used by the great majority of naturalists in all countries.

Comment. Apparently about 900 names have been proposed by various authors for genera and higher groups of bacteria up to 1924. Several thousand species have been named. However, it is probable that not one species in ten has been adequately described or named. It is evident that unless an effort is made to follow some system that the same name will be applied to many different kinds of bacteria, and many names to a single kind.

Article 2. The prescriptions which govern the exact system of botanical nomenclature are divided into principles, rules and recommendations. The principles (art. 1-9, 10-14 and 15-18) are the foundation of the rules and recommendations. The rules (art. 10-58), destined to put in order the nomenclature which has bequeathed to us, and to form the basis for the future, are always retroactive: names or forms of nomenclature which are contrary to a rule cannot be maintained. Recommendations bear on secondary points, their object being to ensure for the future a greater uniformity and clearness in nomenclature; names or forms of nomenclature contrary to a recommendation are not a model to copy, but cannot be rejected.

Article 3. The rules of nomenclature should neither be arbitrary nor imposed by authority. They must be simple and founded on considerations clear and forcible enough for everyone to comprehend and be disposed to accept. 
Comment. It may be emphasized that the International Botanical Congresses which have formulated and revised the International Code have no power to enforce these rules. Stiles (1905, p. 9) states the matter succinctly in his discussion of the zoölogist's code. He says:

Every person is still in a position to follow any code he desires, or to prepare one of his own, but, considering the responsibilities involved, there is undoubtedly a growing tendency to adopt the International Code. Further, it is considered ethical to ignore names used contrary to this and to other standard codes. While not attempting to dictate to men of science what they shall or shall not do, the commission submits the rules to the serious consideration of all workers in the spirit advanced by Strickland (1842), namely, "we offer them to the candid consideration of zoölogists in the hope that they may lead to sufficient uniformity of method in future to rescue science from becoming a mere chaos of words."

Article 4. The essential points in nomenclature are: (1) to aim at fixity of names; (2) to avoid or to reject the use of forms and names which may cause error or ambiguity or throw science into confusion.

Next in importance is the avoidance of all useless creation of names.

Other considerations, such as absolute grammatical correctness, regularity or euphony of names, more or less prevailing custom, respect for persons, etc., notwithstanding their undeniable importance are relatively accessory.

Article 5. No custom contrary to rule can be upheld if it leads to confusion or error. When a custom offers no serious inconvenience of this kind, it may be a ground for exceptions which we must, however, abstain from extending or copying. Finally in the absence of rule, or where the consequences of rules are doubtful, established custom becomes law.

Comment. This general principle is a useful guide in certain puzzling situations, and is a distinct help toward stability. For example, Article 21 of the code specifies that families are to be designated by the name of one of their genera or ancient generic name, with the ending -aceae. The family name Coccaceae has been quite generally used in bacteriology during the past two decades. There is, however, no valid, or strictly speaking, any ancient, bacterial genus Coccus in bacteriology. Nevertheless it is probably advisable to make this family name the basis of an exception, as such exception would quite certainly cause less confusion than the adoption of an entirely new designation.

Article 6. The principles and forms of nomenclature should be as similar as possible in botany and in zoölogy; but botanical nomenclature is entirely independent of zoölogical nomenclature.

Comment. The zoölogical code is somewhat more specific than is the botanical code in dealing with this problem. The corresponding article in the zoölogical rules reads as follows: 
Zoölogical nomenclature is independent of botanical nomenclature in the sense that the name of an animal is not to be rejected simply because it is identical to a name of a plant. If, however, an organism is transferred from the vegetable to the animal kingdom its botanical names are to be accepted in zoölogical nomenclature with the original botanical status; and, if an organism is transferred from the animal to the vegetable kingdom its names retain their zoölogical status.

The following recommendation is also added: "It is well to avoicl introducing into zoölogy as generic names, such names as are in use in botany." These points are of interest to the bacteriologist because until the suggestion was made in 1857 by Naegeli that bacteria are plants and not animals, most of the forms up to that time described which we now classify with the bacteria, had been included with the protozoa. This means that such names as Bacterium, Spirillum, Spirodiscus, Spirochaeta, and Vibrio were included. In the classification of Cohn (1872) these forms were definitely transferred to the plant kingdom. They have been used in both zoölogical and botanical terminology, and, therefore, they prevent subsequent use of these names for other forms among either plants or animals. However, the fact that Coccus is the name of a genus of insects would not interfere with its use as a genus in bacteriology. Neither does the fact that Spirillum was used in 1815 as the name of a worm prevent its acceptance as a valid genus of bacteria. Numerous examples might be cited of generic names which are identical in zoölogy and botany. It is well, however, to avoid the introduction of names used as genera of animals into botany when possible. This is particularly true in bacteriology, for many of the types have an uncertain position. The group of spirochetes, for example, is treated both by bacteriologists and protozoölogists. To introduce a generic name into this group under the impression that it belongs with plants when such a name has previously been used in zoölogy, is to cause unnecessary confusion and may very possibly invalidate the name. In a few instances organisms have been named as plants and later found to be animals. Stiles (1905, p. 10) states:

In these cases zoölogists accept the botanical names, thus Plasmodium malariae was originally (1881) classified in a plant genus as Oscillaria malariae. Now that this organism is classified as an animal the original specific name malariae (1881) is accepted in zoölogy with its original botanical date. The generic name Oscillaria is not taken over with the specific name because it was not proposed for this organism. Oscillaria remains as it was prior to 1881, a plant genus.

Article 7. Scientific names are in Latin for all groups. When taken from another language, a Latin termination is given them, except in cases sanctioned by custom. If translated into a modern language, it is desirable that they should preserve as great a resemblance as possible to the original Latin names. 
Comments. This rule has been too frequently disregarded by bacteriologists. In many cases this has come about through failure of the one who first described an organism to give to it a specific name, or one in the correct form. For example, Duclaux (1882) described an organism which he found associated with the production of slimy or ropy milk. This he placed in his genus Actinobacter but without giving it a specific name. In consequence this organism is commonly noted in literature as Actinobacter du lait visqueux Duclaux, an impossible combination. German writers furthermore have frequently changed the spelling of Latin words from their Latin form, as Bacterium to Bakterium, Bacillus to Bazillus, Streptococcus to Streptokokkus, in order to use them as vernacular designations. In many cases after having accepted this changed spelling, the fact is ignored that they have lost their status as generic names and the words are used as though they were in correct Latin form, as in the name Staphylokokkus pyogenes. German, French and Italian authors have also shown a tendency to change the names of families and of whole groups, from their correct Latin form, and yet continue to use them in a scicntific and not merely a vernacular sense, as Arthrobakteriaceen for Arthrobacteriaceae, Kokkaceen and Coccacées for Coccaceae.

Article 8. Nomenclature comprises two categories of names: (1) Names, or rather terms, which express the nature of the groups comprehended one within the other. (2) Names peculiar to each of the groups of plants that observation has made known.

Comments. The nature of the names noted under 1 and 2 will be evident after a perusal of Chapters II and III respectively in which these are discussed.

Article 9. The rules and recommendations of botanical nomenclature apply to all classes of the plant kingdom, reserving special arrangements for fossil plants and non-vascular plants.

Comments. A footnote to the code of 1905 states that the special arrangements noted were to be taken up at the next International Botanical Congress in 1910. These arrangements included "(1) Rules bearing on special points in relation to the nature of fossils or lower plants. (2) Lists of nomina conservanda for all divisions of plants other than Phanerogams." At this meeting several rules relating primarily to paleobotany and to the algae, fungi, hepatics, lichens and mosses were adopted, but the question of the date of departure and other questions relating to the bacteria and certain other groups were reserved for the International Congress which was to have met in London in 1915. 
It is evident that this principle makes possible the recommendation and adoption of special rules to govern groups such as the bacteria. Some such special rules have been suggested to the Society of American Bacteriologists through its committee on bacterial classification.

\section{Chapter II. On the manner of designating the nature and the sub- ordination of the groups which constitute the plant kingdom}

Article 10. Every individual plant belongs to a species (species), every species to a genus (genus), every genus to a family (familia), every family to an order (ordo), every order to a class (classis), every class to a division (divisio).

Article 11. In many species we distinguish varieties (varietas) and forms (forma); and in some cultivated species, modifications still more numerous; in many genera sections (sectio), in many families tribes (tribus).

Article 12. Finally if circumstances require us to distinguish a greater number of intermediate groups, it is easy, by putting the syllable $s u b$ before the name of a group, to form subdivisions of that group. In this way subfamily (subfamilia) designates a group between a family and a tribe, subtribe (subtribus) a group between a tribe and a genus, etc. The arrangement of subordinate groups may thus be carried, for wild plants only, to twenty-one degrees, in the following order: Regnum vegetabile, Divisio, Subdivisio, Classis, Subclassis, Ordo, Subordo, Familia, Subfamilia, Tribus, Subtribus, Genus, Subgenus, Sectio, Subsectio, Species, Subspecies, Varietas, Subvarietas, Forma, Individuum.

If this list of groups is insufficient it can be augmented by the intercalation of supplementary groups, so long as these do not introduce confusion or error.

Example: Series and Subseries are groups which can be intercalated between subsection and species.

Recommendation. I. In parasites, particularly in parasitic fungi, authors who do not recognize as species forms which are characterized from a biologic point of view, but little or not at all from the standpoint of morphology may differentiate within species special forms (forma specialis, $f . s p$.) characterized by their adaptation to their different hosts.

Article 13. The definition of each of these names of groups varies, up to a certain point, according to individual opinion and the state of the science, but their relative order, sanctioned by custom must not be altered. No classification is admissible which contains such alterations.

Examples of inadmissible alterations are-a form divided into varieties, a species containing genera, a genus containing families or tribes.

Article 14. The fertilization of one species by another gives rise to a hybrid (hybrida), that of a modification or subdivision of a species by another modification to the same species gives rise to a half-breed (mistus, mule of floristis).

\section{Chapter III. On the manner of designating each group or associa- tion of plants}

\section{Section 1. General principles; priority}

Article 15. Each natural group of plants can bear in science only one valid designation, namely, the oldest, provided that it is in conformity with the rules of Nomenclature and the conditions laid down in articles 19 and 20 of section 2. 
Comment. This is the essence of the whole matter. No matter what. our individual preferences may be, or how much better another more familiar name may sound. we should choose the oldest name if it is valid. In no other way can nomenclature be stabilized. Many cases in bacteriological literature may be eited in which authors have created new names needlessly, in some eases beemes the names seemed inappropriate for some reason.

Article 16. The designation of a group by one or several names is not for the purpose of describing the characters or the history of the group, but that we may be understood when we wish to speak of it.

Comment. Misunderstanding of this principle has led to many mistakes in literature. There is no good reason why the specific name of an organism must be descriptive of the organism in any way. Some authors have contended that the naming of organisms should in some manner conform to the principles which have been followed in the naming of compounds in the science of chemistry. Others have insisted upon the use of descriptive Latin phrases, such as those which have been approved in anatomy and pathology. As has often been pointed out in taxonomic discussions, there is no more reason why a specifie name should be descriptive of the organisms than that the given or Christian name of an individual should indicate his characteristics.

Article 17. To one should change a name or a combination of names without serious motives, based on a more profound knowledge of facts, or on the necessity of giving up a nomenclature that is contrary to rules.

Comment. Unfortunately there have been a few botanists, perhaps even some bacteriologists who have coined new names needlessly, evidently with the thought that such could in some way be of personal advantage. It is erident from the statement of this rule that when new names are coined or old names changed, an adequate reason for such new names or such new terms should be given.

Article 18. The form, number and arrangement of names depend on the nature of each group, according to the following rules.

Section 2. Point of departure for nomenclature; limitation of principle of priority

Article 19. Botanical nomenclature begins for the various groups of plants (both living and fossil) with the following dates:

a. Phanerogamae and Pteridophyta, 1753 (Linné., Species plantarum, ed. 1)

b. Muscineae, 1 S01 (Hedrig, Species Muscorum) 


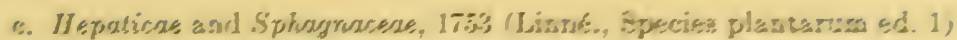

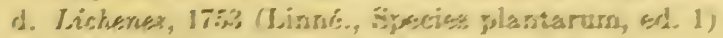

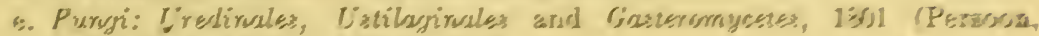
Eymopsia Methodica Fungornast

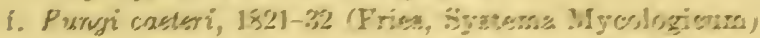

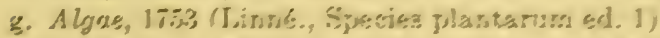

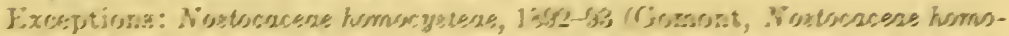

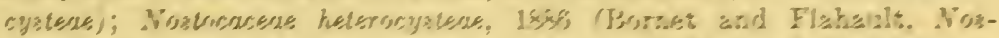

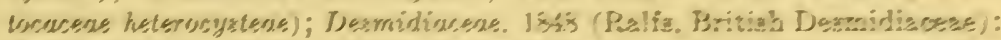

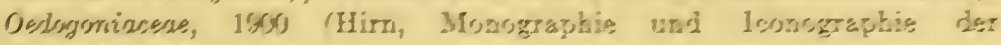
Oedogeraiacresis

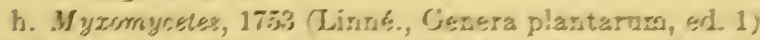

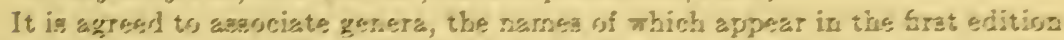

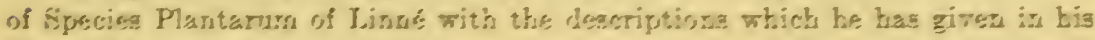
Geruera Plantasurs, ed. ¿j (175\%).

Cormuruent. A forstrotes to this articles in the Proreserlings of the Brissels: Crongress in 1910 states, "The proints of departires for the uornenclature, of the followirg grosups: Schizrmycetes (Bacteria); Schizopheycerse (excl. Nostocracere); Flagellaitae (incl. Dinoflagellatae) and Bacillariacene (Diatomacese) are reserved for the Congress of London in 1915." This Congress was postprored beceause rof the irterruption by the Eurrpsan War. There is therefore no authoritative starting prirat for bacterial nomernclature at the pressit time. At this Congress in Brusss.ss Vuillemin proprsed that 175.? be ardopted as the print of departure. Klebahn suggesterd that the work of $F$. Cohn (1870-ifj, Lntersuchungen über Bakterien) constituterd a more suitable proint of departure. This was approved by Engler. Magnus conterded that much work of systernatic value had been accomplished before 1870 and propresed that the publications of Ehrenberg (certainly a misprint) in 1789 should be the starting proint. Vuillemin contended that if a date subsequent to $17 \%$. be taken, it rnight well be 1910. The whole matter was firally ceferred to the rext Congress as noted above.

In preparation for this Congreas Tuillernin (1313) published a paper in which he discussed bacterial classification and nornenclature. He concluded that the best thing to do is to deternine which generic names are valid, prepare such a list, publish the names as genera conservarula and date all bacterial classification from 1915 when the list was to have been adopted by the Congress. A study of Vuillemin's paper despite his criticism of bacteriologists as taxonomists shows that he himself does not formulate tenable bases for differentiation of genera and his reason for choosing certain generic names and abardoning others will acarcely withstand critical analysis. 
The committee on classification of the Society of American Bacteriologists has suggested that the publication of the third edition of Zopf's "Die Spaltpilze" in 1885 be made the point of departure. Unexpected difficulties in the utilization of 1885 as the point of departure have arisen. It seems probable that the least confusion will eventually develop if 1753 be regarded as the date of departure.

Article 20. However, to avoid disadvantageous changes in the nomenclature of genera by the strict application of the rules of nomenclature, and especially of the principle of priority in starting from the dates given in Article 19, the rules provide for lists of names which must be retained in all cases. These names are by preference those which have come into general use in the fifty years following their publication, or which have been used in monographs and important floristic works up to the year 1890. For the use of paleobotanists two lists are provided (1) A list of generic names validly published and generally accepted, although they come into conflict with paleobotanic names which are older. (2) A list of generic names of fossil plants, validly published and generally accepted when they come into conflict with older homonyms of living plants which have been discarded into synonymy. In order to avoid using these names anew, these lists are given in an appendix to the rules of nomenclature.

Comments. Two lists of generic names have been proposed for eventual submission to an International Botanical Congress for use in bacteriology. The first of these was published by Vuillemin (1913) and is as follows: Planococcus, Streptococcus, Klebsiella, Merista, Planomerista, Neisseria, Sarcina, Planosarcina, Metabacterium, Clostridium, Serratia, Bacterium and Spirillum.

In 1916 the following list of genera was proposed to the Society of American Bacteriologists by its committee on classification. These names were to be considered for two years before a vote should be taken upon them. The list is as follows: Methanomonas, Carboxydomonas, Hydrogenomonas, Mycoderma, Nitrosomonas, Nitrobacter, Azotobacter Rhizobium, Nocardia, Actinomyces, Mycobacterium, Corynebacterium, Fusiformis, Leptotrichia, Pseudomonas, Vibrio, Spirillum, Neisseria, Streptococcus, Staphyloccccus, Albococcus, Micrococcus, Sarcina, Rhodococcus, Bacterium, Erwinia, Pasteurella, Hemophilus, Lactobacillus, Bacillus, Clostridium. More recent study shows that probably this list should be revised.

\section{Section 3. Nomenclature of the different kinds of groups}

\section{Subsection 1. Names of groups above the family}

Recommendations. The following suggestions as to the nomenclature of groups of higher rank than the family will tend to clearness and uniformity. 
II. Names of divisions and subdivisions, of classes and subclasses are taken from one of their chief characters. They are expressed by words of Greek or Latin origin, some similarity of form and termination being given to those that designate groups of the same nature.

III. Orders are designated preferably by the name of one of their principal families, with the ending -ales. Suborders are designated in a similar manner, with the ending -ineae. But other terminations may be retained for these names, provided that they do not lead to confusion or error.

Comment. The generally accepted name for the entire group of bacteria is Schizomycetes. This may be regarded as a class. The preferable designation for the orders of bacteria would have the ending -ales. The committee on classification of the Society of American Bacteriologists has suggested the following four orders: Myxobacteriales, Thiobacteriales, Chlamydobacteriales and Eubacteriales.

Subsection 2. Names of families and subfamilies, tribes and subtribes

Article 21. Families (familiae) are designated by the name of one of their genera or ancient generic names with the ending -aceae.

Examples: Rosaceae (from Rosa), Salicaceae (from Salix), Caryophyllaceae (from Dianthus Caryophyllus), etc.

Comment. Among the family names of bacteria which have been proposed and which are in correct form are: Spirillaceae from Spirillum, Bacteriaceae from Bacterium, Bacillaceae from Bacillus.

Examples of invalid families in. bacteriology are the following: Thiobacteriaceae, because there is no genus Thiobacterium, Thiorhodaceae because there is no genus Thiorhodum, Trichobacteria, both because it lacks the ending-aceae and because it contains no genus Trichobacterium.

Article 22. The following names, owing to long usage, are an exception to the rule: Palmae, Gramineae, Cruciferae, Leguminosae, Guttiferae, Umbelliferae, Labiatae, Compositae.

Article 23. Names of subfamilies (subfamiliae) are taken from the name of one of the genera in the group, with the ending -oideae. The same holds for the tribes (tribus) with the ending -eae, and for the subtribes (subtribus) with the ending -inae.

Comment. The following subfamilies of bacteria are in proper form: Chromatioideae from the genus Chromatium, Rhodobacterioideae from the genus Rhodobacterium. The following are examples of names of subfamilies incorrectly formed: Paracoccaceae and Metacoccaceae because there are no bacterial genera Paracoccus and Metacoccus, and also because of an incorrect ending. An example of a tribal name would be Streptococceae containing the genus Streptococcus; of a subtribe, Bacillinae containing the genus Bacillus. 


\section{Subsection 3. Names of genera and divisions of genera}

Article 24. Genera receive names, substantives (or adjectives used as substantives) in the singular number and written with a capital letter, which may be compared with our own family names. These names may be taken from any source whatever and may even be composed in an absolutely arbitrary manner.

Examples: Rosa, Convolvulus, Hedysarum, Bartramia, Liquidambar, Gloriosa, Impatiens, Manihot.

Comments. Examples of bacterial genera are Bacillus, Actinomyces and Vibrio.

Not infrequently, particularly in medical writers, one finds a decided tendency to ignore the rule that a genus name must, when used as such, always be written with a capital letter. Many of our medical journals and even some which publish scientific articles on medical bacteriology write bacillus typhosus or bacillus tuberculosis. It is true that sometimes a word with the same spelling as a generic name may be used as a morphologic designation. It cannot be considered incorrect to speak of tubercle bacillus, for this is a common name or vernacular designation. As Stiles (1905, p. 16) says: (this same rule holds in zoölogical nomenclature)

This custom of capitalizing the generic name has come down to us from former centuries, and while it now has its practical basis, its historic basis is probably due to the custom earlier authors had of capitalizing all Latin substantives when used in nomenclature. At present the custom is so thoroughly established that botanists and zoölogists experience much the same sensation in seeing "bacillus tuberculosis" or "plasmodium malariae," instead of Bacillus tuberculosis and Plasmodium malariae, that they would if they found a reference to "american" authors or to "doctor s. weir mitchell."

It is also considered good form to write names of genera, particularly when associated with a specific name, in italics. Some of our medical journals have recently abandoned this practice under the plea that it is an unnecessary expense and that italics should be used only for the sake of emphasis. This is unfortunate as it has in the past served as a satisfactory method to indicate clearly in a text just when names were being used in a strict scientific sense.

Some purists have taken exception to the statement that these names may be taken from any source whatever and may even be composed in an absolutely arbitrary manner. Clements (1902) in his paper on Greek and Latin in biological nomenclature states that vernacular names should be invalid, and that a name or term should be regarded as invalid unless constructed according to the principles of word formation in 
classic Greek or Latin; and all terms improperly constructed should be corrected. He further states that anagrams and geographic names should be regarded as invalid for genera.

Below under the heading of "Recommendations" there are many suggestions of the best form to follow in the creation of generic names, but failure to follow such recommendations does not render a term invalid.

Article 25. Subgenera and sections also receive names, usually substantives and resembling the names of genera. Names of subsections and other lower subdivisions of genera are preferably adjectives in the plural number and written with a capital letter, or their place may be taken by an ordinal number or a letter.

Examples: Substantives: Fraxinaster, Trifoliastrum, Adenoscilla, Euhermannia, Archieracium, Micromelilotus, Pseudinga, Heterodraba, Gymnocimum, Neoplantago, Stachyotypus. Adjectives: Pleiostylae, Fimbriati, Bibracteolata, Pachycladae.

Comments. Among names that have been applied to subgenera of bacteria are Eusarcina and Euspirillum.

Recommendations. IV. When the name of a genus, subgenus or section is taken from the name of a person, it is formed in the following manner:

a. When the name ends in a vowel, the letter $a$ is added (for example Glazioua Giaziou; Bureaua after Bureau), except when the name already ends in $a$, in which case $e a$ is added (e.g., Collaea after Colla).

b. When the name ends in a consonant, the letters $i a$ are added (thus Magnusia after Magnus; Ramondia after Ramond), except when the name ends in er, in which case $a$ is added (e.g., Kernera after Kerner).

c. The spelling of the syllables unaffected by these finals is retained, even with the consonants $k$ and $w$ or with groupings of vowels which were not used in classic Latin. Letters which are unknown to botanical Latin must be transcribed, diacritic signs are suppressed. The German ä, ö, ü, become ae, oe, ue, the French, é, è and ê become generally e.

d. Names may be accompanied by a prefix, or a suffix, or modified by anagram or abbreviation. In these cases they count as different words from the original name. E.g., Durvillea and Urvillea, Lapeyrousea and Peyrousea, Englera, Englerastrum and Englerella, Bouchea and Ubochea, Gerardia and Graderia, Martia and Martiusia.

Comments. Among the generic names of bacteria which have been derived from patronymics are Pasteurella, Salmonella, Klebsiella, Detoniélla, Zopfiella, Mantegazzaea, Erwinia, Pacinia, Cornelia, Newskra, Pollendera, Macintoshillus, Metchnikovillus, Zopfius. It will be noted that authors have frequently given generic names among the bacteria by adding -ella in accordance with above. The custom is so well established that there would seem to be little good reason at the present time 
for opposing it. There have been objections, however, raised by those who contend for the use of classic Latin names for all plants and animals. Clements (1902, p. 82) says: "A single generic name may be founded upon the name of a botanist. Such names are only to be formed by adding $-i a$ to cognomina ending in a consonant and $-a$ to cognomina in a vowel or in $-r$ except in the case of names already latinized in which case the termination is first dropped." Apparently Clements possessed a high estimate of the ability of classic Latin and Greek to furnish the tens of thousands of generic names that will still be demanded before all plants and animals have been named and classified. The formation of names by anagram is also objectionable to such purists, as witness the following statement from Clements (1902, p. 78):

Anagrams if they be considered words at all are vernacular since they are neither Greek or Latin. They are the ultimate product of puerility or illiteracy in nomenclature. Such a series as Filago, Gifola, Ifloga, Logfia and Oglifa throws a clear light upon the good sense and linguistic tests of the authors concerned. One might better make names after the fashion of Carroll or take names from the "dog latin" of childhood.

Views in contradiction to this are generally held, however, by most practical workers in the fields of zoölogy and botany. These workers have a firm conviction that botanical Latin does not need to be classic Latin. This is well stated in the following quotation from Stiles (1905, p. 12):

Nothing is stated in the rule as to what particular Latin should be used, but latitude is granted to use Latin or Latinized names, or to use names as if they were Latin. This latitude has its practical basis. The Latin poets and authors did not foresee the practical scientific use to which their language would be applied, and they failed to leave enough Latin words as names for the millions of animals and plants which come into consideration. Hence as a carpenter, a sailor or a manufacturer coins words which are accepted in English as English words of good standing, when applied to carpentry, nautical affairs, and trade, the zoölogists and botanists coin words upon Latin precedents, which we adopt as botanical and zoölogical Latin. Not in all cases do our efforts attain the highest standards of classical Latin (Taenia solium, and Gadus tomcod, for instance), but because of practical considerations such names are retained, although not recommended, as examples to be followed in coining new words.

V. Botanists who are publishing generic names show judgment and taste by attending to the following recommendations:

a. Not to make names very long or difficult to pronounce.

Comments. Clements believes that a generic name should be invalid if it contains more than six syllables. Apparently few generic names 
have been applied to bacteria which do not conform to this standard, though there are many with six syllables such as Botulobacillus, Actinobacillus, Actinocladothrix, Aphaneroglia and Arthrobactrinium. Some offenders are the following: Actinobacterium, Caseobacterium, Chromobeggiatoa, Corynebacterium, Liquidobacterium and Nitrosobacterium. These long names are, of course, valid.

b. Not to use again a name which has already been used and has lapsed into synonymy (homonym).

Comments. The zoölogical code goes farther than this and forbids the subsequent use for another group of any name which has previously been used. The rule reads "A generic name is to be rejected as a homonym when it has previously been used for some other genus of animals."

c. Not to dedicate genera to persons who are in all respects strangers to botany, or at least to natural science, nor to persons quite unknown.

d. Not to take names from barbarous tongues, unless those names are frequently quoted in books of travel, and have an agreeable form that is readily adapted to the Latin tongue and to the tongues of civilized countries.

e. To recall, if possible, by the formation or ending of the name, the affinities or the analogies of the genus.

f. To avoid adjectives used as nouns.

g. Not to give a genus a name whose form is rather that of a subgenus or section (e.g., Eusideroxylon, a name given to a genus of Lauraceae, which, however, being valid. cannot be changed).

Comment. The Eubacillus of Dangeard is a similar example from bacteriology.

h. Not to make names by the combination of two languages (nomina hybrida).

Comments. This is a common fault among names which have been applied in bacteriology. Among such may be noted Acetobacter, Caseobacterium, Coccobacillus.

VI. Botanists constructing names for subgenera or sections, will do well to attend to the preceding recommendations and also to the following:

a. Give, where possible, to the principal division of a genus, a name which, by some modification or addition, calls the genus to mind (for instance, $E u$ placed at the beginning of the name, when it is of Greek origin;-astrum, -ella at the end of the name, when Latin, or any other modification consistent with the grammar and usages of the Latin language).

b. Avoid calling a subgenus or a section by the name of the genus to which it belongs, with the final -oides or -opsis; on the contrary reserve this ending for a 
section which resembles another genus, by adding in that case -oides or -opsis to the name of that other genus, if it is of Greek origin, to form the name of the section.

c. Avoid taking as the name of a subgenus or section a name which is already in use as such in another genus, or which is the name of an admitted genus.

Comment. It may be noted that in zoölogy identical rules are used for the formation of genera and subgenera, because the subgenus of today may be the genus of tomorrow and, from the standpoint of nomenclature, both generic and subgeneric names have the same status. Unfortunately, perhaps, botanists have not seen fit to take this step.

Recommendation. VII. When it is required to express a subgeneric or sectional name together with the name of the genus and the name of the species, the name of the section is put between the others in a parenthesis. E.g., Astragalus (Cycloglottis) contortuplicatus.

\section{Subsection 4. Names of species and of subdivisions of species}

Article 26. All species, even those that singly constitute a genus, are designated by the name of the genus to which they belong followed by a name (or epithet) termed specific, usually of the nature of an adjective (forming a combination of two names, a binomial, or binary name).

Recommendations. VIII. The specific name should, in general, give some indication of the appearance, the characters, the origin, the history or the properties of the species. If taken from the name of a person, it usually recalls the name of the one who discovered or described it, or was in some way concerned with it.

Comment. Apparently this recommendation is sometimes taken to indicate that the specific name should constitute an adequate diagnosis of the organism in question.

IX. Names of men and women and also names of countries and localities used as specific names, may be substantives in the genitive (Clusii, saharae) or adjectives (Clusianus, dahuricus). It will be well, in the future, to avoid the use of the genitive and the adjectival form of the same name to designate two different species of the same genus, for example Lysimachia Hemsleyana Maxim (1891), and L. Hemsleyi Franch (1895).

X. Specific names begin with a small letter except those which are taken from names of persons (substantives or adjectives) or those which are taken from generic names (substantives or adjectives).

$\mathrm{XI}$. When a specific name is taken from the name of a man, it is formed in the following way:

a. When the name ends in a vowel, the letter $i$ is added (thus Glazioui from Glaziou; Bureaui from Bureau), except when the name ends in $a$, when $e$ is added (thus Balansae from Balansa). 
b. When the name ends in a consonant, the letters $i i$ are added (thus Magnusii from Magnus: Ramondii from Ramond), except when the word ends in er when $i$ is added (ex. Kerneri, from Kerner).

c. Syllables which are not modified by these endings retain their original spelling, even in the case of the consonants $\mathrm{k}$ and $\mathrm{w}$ or groupings of vowels which are not used in classic Latin. Letters foreign to the Latin of botanists should be transcribed, and diacritic signs suppressed. The German ä, ö, ü, become ae, oe, ue, the French é, è and ê become, in general, e.

d. When specific names taken from the name of a person have an adjectival form a similar plan is adopted (Geranium Robertianum, Carex Hallerana, Ranunculus Bureauanus, etc.).

XII. The same applies to the names of women. These are written in the feminine when they have a substantival form.

Example: Cypripedium Hookerae, Rosa Beatricis, Scabiosa Olgae, Omphalodes Luciliae.

XIII. In the formation of specific names composed of two or several roots and taken from Latin or Greek, the vowel placed between the two roots becomes a connecting vowel, in Latin $i$, in Greek $o$; thus we write menthifolia, salviifolia, not menthaefolia, salviaefolia. When the second root begins with a vowel and euphony demands, the connecting vowel is eliminated (e.g., calliantha, lepidan. tha). The connecting ae is legitimate only when etymology demands (e.g., caricaeformis from Carica, may be retained along with cariciformis from Carex).

XIV. In forming specific names, botanists will do well to note the following recommendations:

a. Avoid very long names and those which are difficult to pronounce.

Comments. A few specific names which have been applied to bacteria seem to transcend good usage, but this of course does not invalidate them. Among such long specific names which have been applied may be noted the following: saccharobutyricus, heminecrobiophilus, diphtheriae-columborum, viridi-pallescens, endoparagocicum, melanoglassophorus.

b. Avoid names which express a character common to all or nearly ail the species of a genus.

Comment. Among such names are the following: Streptococcus sphericus and Albococcus albus. These names are, of course, valid.

c. Avoid names taken from little known or very restricted localities, unless the species be very local.

Comment. Azotobacter vinelandii named after a locality in New Jersey is scarcely in conformity with this recommendation, but is, of course, not invalidated by this fact.

d. Avoid, in the same genus, names which are very much alike, especially those which differ only in their last letters. 
e. Adopt unpublished names found in travellers' notes and herbaria, attributing them to the authors concerned, only when those concerned have approved the publication.

f. Avoid names which have been used before in the genus, or in any closely allied genus, and which have lapsed into synonymy (homonyms).

Comment. The Zoölogical Code reads: "A specific name is to be rejected as a homonym when it has previously been used for some other species of the same genus." This recommendation should as far as practicable be given the force of a rule.

g. Do not name a species after a person who has neither discovered, nor described, nor figured, nor in any way studied it.

h. Avoid specific names formed of two words.

Comment. Bacillus acidi lactici is probably valid inasmuch as the specific name refers to a single concept, but it is not a form to pattern after. This, of course, does not validate such a name as Bacillus coli communis, which is a trinomial.

Article 27. Two species of the same genus cannot bear the same specific name, but the same specific name may be given in several genera.

Example: Arabis spathulata DC. and Lepidium spathulatum Phil. are valid as two names of Crucifers; but Arabis spathulata Nutt. in Torr. and Gray cannot be maintained, on account of the existence of Arabis spathulata DC., a name previously given to another valid species of Arabis.

Article 28. Names of subspecies and varieties are formed like specific names and follow them in order, beginning with those of the highest rank. The same holds for subvarieties, forms, and slight or transient modifications of wild plants which receive a name or numbers or letters to facilitate their arrangement. Use of a binary nomenclature for subdivisions of species is not admissible.

Examples: Andropogon ternatus subsp. macrothrix (not Andropogon macrothrix or Andropogon ternatus subsp. A. macrothrix); Herniaria hirsuta var. diandra (not Herniaria diandra or Herniaria hirsuta var. H. diandra); forma nanus, forma maculatum.

Recommendation. XV. Recommendations made for specific names apply equally to names of subdivisions of species. These agree with the generic name when they have an adjectival form (Thymus Serpyllum var. angustifolius, Ranunculus acris subsp. Friesianus).

Special forms are named by preference by means of the names of the host species. In making such names one may employ double names. Examples: Puccinia Hieracii f. sp. villosi, Pucciniastrum Epilobii f. sp. Abieti-Chamaenerii.

Article 29. Two subspecies of the same species cannot have the same name. A given name can only be used once for a variety of a given species, even when dealing with varieties which are classed under different subspecies. The same holds for subvarieties and forms.

On the other hand the same name may be employed for subdivisions of different species, and the subdivisions of any one species may bear the same name as other species. 
Examples: The following are admissible: Rosa Jundzillii var. leioclada and Rosa glutinosa var. leioclada; Viola tricolor var. hirta, in spite of the existence already of a different species named Viola hirta. The following are incorrect: Erysimum hieraciifolium subsp. strictum var. longisiliquum and $E$. hieraciifolium subsp. pannonicum var. longisiliquum-a form of nomenclature which allows two varieties bearing the same name in the same species.

Recommendation. XVI. Botanists are recommended to use as little as possible the privilege granted in the second part of article 29 , in order to avoid confusion and mistakes and also to reduce to a minimum the necessary changes of name when the subdivisions of species are raised to specific rank or vice versa.

Article 30. Forms and half-breeds among cultivated plants should receive fancy names, in common language, as different as possible from the Latin names of the species or varieties. When they can be traced back to a species, a subspecies or a botanical variety this is indicated by a succession of names.

Example: Pelargonium zonale Mrs. Pollock.

Subsection 5. Names of hybrids and half-breeds (mules)

This subsection contains four Articles and one Recommendation. It is not included here as it deals with problems which are not met in bacterial nomenclature.

Section 4. The publication of names and of the date of each name or combination of names

Article 35. Publication is effected by the sale or public distribution of printed matter or indelible autographs.

Communication of new names at a public meeting, or the placing of names in collections or gardens open to the public, do not constitute publication.

Examples: Effective publication without printed matter: Salvia oxyodon Webb and Heldr. was published in July, 1850, in an autograph catalogue and put on sale (Webb and Heldreich, Catalogus plantarum hispanicarum, etc., ab. A. Blanco lectarum, Parisiis, Jul., 1850, in folio).-Non-effective publication at a public meeting: Cusson announced his establishment of the genus Physospermum in a memoir read at the Société des Sciences des Montpellier in 1773, and later in 1782 or 1783 at the Société de Médecine de Paris, but its effective publication dates from 1787, in the Mémoires de la Soc. Roy. de Médecine de Paris, vol. V, 1 re partie.

Comment. The statement that the communication of new names at a public meeting does not constitute valid publication, is of particular interest to bacteriologists. Priority is always determined from date of publication and not from date of presentation. A committee appointed by the Society of American Bacteriologists on the classification of bacteria at a meetlng of the society recommended the use of the generic name Erwinia to include certain bacteria producing diseases of plants. This did not constitute valid publication. 
Article 36. On and after January 1, 1908, the publication of names of new groups of living plants will be valid only when they are accompanied by a Latin diagnosis. On and after January 1, 1912, the names of new groups of fossil plants will not be considered valid unless accompanied by a Latin diagnosis and by illustrations or figures showing the essential characteristics.

Comment. Bacteriologists in general have never subscribed to this rule. It is unusual to find modern bacteriologists giving Latin description to new species, in fact the rule may be said to be quite commonly ignored by botanists. The committee on classification of the Society of American Bacteriologists has recommended that bacteriologists follow the International Botanical Code in the nomenclature of bacteria with the exception of article 36 .

Article 37. A species or a subdivision of a species, announced in a work, with a complete specific or varietal name, but without diagnosis or reference to a former description under another name, is not valid. Citation in synonymy or incidental mention of a name is not effective publication, and the same applies to the mention of name on a ticket issued with a dried plant without printed or autographed diagnosis.

Plates accompanied with analyses are equivalent to a description; but this applies only to plates published before January 1, 1908.

Article 38. A genus or any other group of higher rank than a species, named or announced without being characterized conformably to article 37 cannot be regarded as effectively published (nomen nudum). The mere indication of species as belonging to a new genus or of genera as belonging to a higher group, does not allow us to accept the genus or group in question as characterized and effectively published. An exception is made in the case of the generic names mentioned by Linnaeus in the Species Plantarum ed. 1., 1753, names which we associate with the descriptions in the Genera Plantarum ed. 5., 1754 (see article 19).

Article 39. The date of a name or of a combination of names is that of their effective publication. In the absence of proof to the contrary, the date placed on the work containing the name or combination of names is regarded as correct. On and after January 1, 1908, the date of publication of the Latin diagnosis only can be taken into account in questions of priority.

Recommendations. Botanists will do well, in publishing, to conform to the following recommendations:

XVIII. Not to publish a name without clearly indicating whether it is the name of a family or a tribe, a genus or a section, a species or a variety; briefly, without expressing an opinion on the nature of the group to which they give the name.

When names of new groups are published the author should designate the subdivision which he considers as the type for the nomenclature of the group; he should indicate the generic type in a family, the species type in a genus, the subspecies or variety type in a species. This precaution will prevent difficulties in nomenclature if it should become necessary later to dissociate such groups. 
Comment. The Zoollogical Code not only recommends that specific types for genera and subgenera should be designated, but requires that the names of families and orders should be derived from the names of the type genera and type families respectively. This rule would be of assistance in botany and in bacteriology.

Recommendation. XIX. To avoid publishing or mentioning in their publications unpublished names which they do not accept, especially if the person responsible for these names have not formally authorized their publication (see Rec. $\mathrm{XIV}, e)$.

Recommendation. $\mathrm{XX}$. When publishing new names in works written in a modern language (floras, catalogues, etc.) to publish simultaneously the Latin diagnoses aud in paleobotany the figures which will make the names valid from the point of view of scientific nomenclature.

In view of the particular difficulties indicated in the identification of fossil plants, in addition to the Latin diagnosis, there should be included a detailed description in French, German or Italian.

When new groups of the lower Cryptogames especially the fungi or other microscopic plants are described, the description should be accompanied with a figure or figures of these plants with the microscopic details which will aid in their identification.

The description of a parasitic plant should always be followed by a designation of the host, particularly in the parasitic fungi. The hosts should be designated by their scientific Latin names and not by vernacular names in a modern language for these frequently have more than one meaning.

Recommendation. XXI. To give the etymology of new generic names and also of specific names when the meaning of the latter is not obvious.

XXII. To indicate precisely the date of publication of their works and that of the placing on sale or the distribution of named and numbered plants when these are accompanied by printed diagnoses. In the case of a work appearing in parts, the last published sheet of a volume should indicate the precise dates at which the different fascicles or parts of the volume were published, as well as the number of pages in each.

XXIII. When works are published in periodicals to require the editor to indicate on the separate copies the date (year and month) of publication and also the title of the periodical from which the work is extracted.

XXIV. Separate copies should always bear the pagination of the periodical of which they form a part, if desired they may also bear a separate pagination.

\section{Section 5. On the precision to be given to names by the citation of the author who first published them}

Article 40. For the indication of the name or names of a group to be accurate and complete, and in order that the date may be readily verified, it is necessary to quote the author who first published the name or combination of names in question.

Examples: Simarubaceae Lindley, Simaruba Aublet, Simaruba laevis Grisebach, Simaruba amara Aublet var. opaca Engler. 
Comment. It is evident from the reading of this rule that the author of the name is frequently not the individual who first described the organism. The name of the author is not quoted following the species in order to designate the discoverer of the organism, or even one necessarily who has studied it in detail, but merely to show who first used the particular combination of letters or words constituting the name under consideration. Any other procedure would be making the discoverer of an organism responsible for a name with which he has never had anything to do. As stated by Stiles (1905, p. 21) "This point of view lays stress upon holding an author responsible for the names he publishes, rather than upon 'giving him credit' for these names. The chief idea we have in citing the author of a name is to aid in tracing it." For example, one of the cocci associated with pus production was first adequately studied by Rosenbach and named by him Staphylococcus albus. Later it was renamed Albococcus albus by Winslow and Rogers. Certainly Rosenbach is no way responsible for the latter generic name. Welch discovered an organism which produced edema in man. He did not give it a name. Later the organism was termed Bacillus Welchii. We certainly could not write Bacillus Welchii Welch without giving the impression that Welch had named an organism after himself.

Article 41. An alteration of the constituent characters or of the circumseription of a group does not warrant the quotation of another author than the one who first published the name or combination of names.

When the changes have been considerable, the words: mutatis charact., or pro parte, or excl. gen., excl. sp., excl.var., or some other abridged indication, are added after the citation of the original author, according to the nature of the changes that have been made, and of the group in question.

Examples: Phyllanthus L. em. (emendavit) Müll. Arg.; Myosotis L. pro parte, R. Br.; Globularia cordifolia L. excl. var., etc.

Comment. The generic name Bacterium was first used by Ehrenberg in 1828. His definition was somewhat modified by Dujardin in 1841. It was again modified by Cohn in 1872 and by Migula in $\mathbf{1 8 9 4 .}$ The name should always be written therefore, Bacterium Ehrenberg. This does not indicate that we accept Ehrenberg's diagnosis of the genus but merely that he first used this particular designation.

Article 42. When a manuscript name has been published and referred to its author, the name of the person who published it should be appended to the citation. The same rule should be followed for names of garden origin when they are cited as "Hort."

Article 43. When, in a genus, a name is applied to a group which is moved into another group where it retains the same rank, or to a group which becomes of 
higher or lower rank than before, the change is equivalent to the creation of a new group and the author who has affected the change is the one to be quoted. The original author can be cited only in parenthesis.

Examples: Cheiranthus tristis L. when moved into the genus Matthiola becomes Matthiola tristis R. Br., or Matthiola tristis (L.) R. Br.-Medicago polymorpha L. var, orbicularis $\mathrm{L}$. when raised to the rank of a species becomes Medicago orbicularis All. or Medicago orbicularis (L.) All.

Comment. The corresponding zoölogical rule requires that the original author shall be cited in parenthesis instead of leaving it optional as in the above article.

Recommendation. XXV. Author's names put after names of plants are abbreviated, unless they are very short.

Section 6. On names that are to be retained when a group is divided, remodelled, transferred, or moved from one rank to another, or when two groups of the same rank are united, or when they concern groups possessing a pleomorphic cycle

Article 44. A change of characters, or a revision which involves the exclusion of certain elements of a group or the addition of new elements, does not warrant a change in the name or names of a group, except in cases provided for in article 51.

Examples: The genus $M$ yosotis as revised by R. Brown differs from the original genus of Linnaeus, but the name has not been changed, nor is any change allowable. Various authors have united with Centaurea Jacea L. one or two species which Linnaeus had kept distinct; the group thus constituted must be called Centaurea Jacea L. (sensu ampl.) or Ceniaurea Jacea L. (em. Visiani, em. Godron, etc.); the creation of a new name such as Centaurea vulgaris Godr. is superfluous.

Article 45. When a genus is divided into two or more genera, the name must be kept and given to one of the principal divisions. If the genus contains a section or some other division which, judging by its name or its species, is the type or the origin of the group, the name is reserved for that part of it. If there is no such section or subdivision, but one of the parts detached contains a great many more species than the others, the name is reserved for that part of it.

Examples: The genus Helianthemum contained, according to Dunal (in DC. Prodr. I. 266-284), 412 well-known species distributed in nine sections; several of these sections have since been raised to generic rank (Fumana Spach, Tuberaria Spach) but the name Helianthemum has been kept for the divisions grouped round the section Euhelianthemum. The genus Convolvulus L. em. Jacq. was divided into two by Robert Brown in 1810 (Prodr. fl. Nov. Holl., p. 482-484), who gave the name Calystegia to one of the genera which at the time contained only four species, and reserved the name Convolvulus for the other genus which contained a much larger number of species. In the same way Salisbury (in Trans. Linn. Soc. VI, 317, 1802) in separating Erica vulgaris L. from the genus Erica, under the name Calluna, kept the name Erica for the large number of species left. 
Comment. Winslow and Rogers in 1905 divided the genus Staphylococcus of Rosenbach into two genera Aurococcus and Albococcus, the name Staphylococcus should have been retained for one of these groups.

Article 46. When two or more groups of the same nature are united, the name of the oldest is retained. If the names are of the same date, the author chooses and his choice cannot be modified by subsequent authors.

Examples: Hooker f. and Thomson (Fl. Ind. p. 67, 1855) united the genera Wormia Rottb. and Capellia $\mathrm{Bl}$.; they gave the name Wormia to the genus thus formed because the last name dates from 1783 while Capellia dates from 1825In case of union of the two genera Cardamine and Dentaria, which were founded at the same time by Linnaeus (Sp. Pl. ed. 1, p. 653 and 654,$1753 ; G e n$. Pl. ed. $5, \mathrm{n} .726,727)$ the collective genus must be called Cardamine because that name was chosen by Crantz (Class. Crucif., p. 126, 1769), who was the first to suggest the union.

Recommendations. XXVI. Authors who have to choose between two generic names should note the following recommendations:

1. Of two names of the same date to prefer the one which was first accompanied by the description of a species.

2. Of two names of the same date, both accompanied by descriptions of species, to prefer the one, which, when the author made his choice, included the larger number of species.

3. In cases of equality from these various points of view to prefer the more correct and appropriate name.

XXVII. When several genera are united as subgenera or sections under one generic name, that subdivision which was first distinguished or described may retain its name (ex. Saxifraga aspera subsp. aspera) or bear a prefix (Alchemilla alpina subsp. eualpina) or be designated by some customary title (normalis, genuinus, typicus, originarius, verus, veridicus etc.). These prefixes or terms lapse when the subdivisions are raised to specific rank.

Article 47. When a species or subdivision of a species is divided into two or more groups of the same nature, if one of the two forms was distinguished or described earlier than the other, the name is retained for that form.

Article 48. When a subgenus or section or species is moved into another genus, when a variety or other division of a species is moved into another species, retaining there the same rank, the original name of the subgenus or section, the first specific epithet, or the original name of the division of the species must be retained or must be reestablished, unless, in the new position there exists one of the obstacles indicated in the articles of section 7 .

Article 49. When a tribe becomes a family, a subgenus or a section becomes a genus, a subdivision of a species becomes a species, or the reverse of these changes takes place, and speaking generally when a group changes its rank, the earliest name (or combination of names) received by the group in its new position must be regarded as valid, if it is in conformity with the rules, unless there exist any of the obstacles indicated in the articles of section 7.

Article 49a. Fungi having a pleomorphic evolutionary cycle in different successive states of the same species carry only a single generic and specific name (binôme); the oldest which has been given beginning with Persoon (Synopsis) 
or Fries (Systema), to the state containing the form which is generally regarded as being perfect, on condition that in other respects it conforms to the rules.

The ascus stage is considered the perfect state in the Ascomycetes, the basidia as the stage in the Basidiomycetes, the teleutospore or its equivalent in the Uredinales, and the spore in the Ustilaginales.

Generic and specific names given to other stages possess only a temporary value. They are not to be used to replace a generio, name already existing and applied to one or more species, any one of which contains the form termed perfect.

The nomenclature of fungi with an evolutionary cycle, but not pleomorphic follows the ordinary rules of nomenclature.

Recommendations. XXIX. $1^{\circ}$. When a sub-tribe becomes a tribe, when a tribe becomes a subfamily, when a subfamily becomes a family, etc., or when the inverse changes occur, do not alter the root of a name but only the termination (-inae, -eae, -oideae, -ineae, -ales, etc.), unless in the new position, one of the obstacles indicated in the articles of section 7 , supervenes, or the new designation becomes a source of error, or there is some other serious reason against it.

$2^{\circ}$. When a section or a subgenus becomes a genus, or the inverse changes take place, retain the old names, unless this results in two genera of plants having the same name, or the existence of two subdivisions of the same name in the same genus, or one of the obstacles indicated in the articles of section 7 supervenes.

$3^{\circ}$. When a subdivision of a species becomes a species or the inverse change occurs, retain the original epithets, unless this results in two species bearing the same name in the same genus, or two subdivisions bearing the same name in the same species, or unless any of the obstacles indicated in section 7 supervenes.

\section{Section \%. On names that are to be rejected, changed or modified}

Article 50. No one is authorized to reject, change or modify a name (or combination of names) because it is badly chosen, or disagreeable, or another is preferable or better known, or because of the existence of an earlier homonym which is universally regarded as non-valid, or for any other motive either contestable or of little import. (See also art. 57.)

Recommendations. See on the subject of homonyms recommendations $\mathrm{Vb}$ and XIV which suggest that cases of this kind should be avoided for the future.

Comment. A large proportion of the names which have been suggested for genera and species of bacteria must be rejected because of violation of this article. Orla-Jensen (1909) for example, created a large number of new genera, in order to make them conform to his ideas of fitness. Where such names are applied to groups which have had no previous generic designation they are, of course, valid, but he was not justified in substituting names which he preferred for old and valid designations.

The expression "because of the existence of an earlier homonym which is universally regarded as non-valid" is one which permits of a variety of interpretations. The zoölogists insist upon the rejection of any name which is a homonym of an earlier term. In this respect the two codes are at variance. 
Article 51. Every one should refuse to admit a name in the following cases:

1. When the name is applied in the plant kingdom to a group which has an earlier valid name.

2. When it duplicates the name of a class, order, family or genus, or a subdivision or species of the same genus, or a subdivisjon of the same species.

3. When it is based on a monstrosity.

4. When the group which it designates embraces elements altogether incoherent, or when it becomes a permanent source of confusion or error.

5. When it is contrary to the rules of sections 4 and 6 .

Comments. 1. The generic name Pneumococcus of Schmidlechner (1905) is an invalid synonym because of the older name Diplococcus given to the same group by Weichselbaum (1886).

2. The generic name Myxococcus of Gonnermann (1907) duplicates the name of an entirely different group termed Myxococcus by Thaxter (1892).

4. Much difficulty is found in bacteriology in determining the proper designation for some of the older species of bacteria because of the fact that some of the older authors were dealing with mixed or impure cultures.

Article 53. When a subgenus, a section or a subsection, passes as such into another genus, the name must be changed if there is already in that genus a valid group of the same rank, under the same name.

When a species is moved from one genus into another, its specific epithet must be changed if it is already borne by a valid species of the genus. Similarly when a subspecies, a variety, or some other subdivision of a species is placed under another species, its name must be changed if borne already by a valid form of like rank in that species.

Article 54. Names of genera must be rejected in the following special cases:

1. When they coincide with technical term currently employed in morphology unless they are accompanied by specific names.

2. When they express uninomial nomenclature.

4. When they are formed of two words, unless these two words were from the first united or joined by a hyphen.

Examples: $1^{\circ}$. Generic names such as Lignum, Radix, Spina, etc., would not now be admissible, on the other hand a generic name like Tuber should not be rejected when it has been published with specific names (Tuber cibarium, etc.).$2^{\circ}$ Ehrhart (Phytophylacium (1780)) and Beitrage (IV, 145-150) made use of a uninomial nomenclature for species known at that time under binary names (Phaeocephalum, Leptostachys, etc.). These names, which resemble generic names, must not be confused with such and are to be rejected, unless a subsequent author has given them the value of a generic name: for example Baeothryon, a uninomial expression of Ehrhart's has been applied to a genus characterized by A. Dietrich Spec. Pl. II, 89 (1833).-Names like Quisqualis (a single word from the first), Sebastiano-Schaueria and Neves-Armondia will stand. 
Article 55. Specific names must also be rejected in the following special cases:

$1^{\circ}$. When they are ordinals serving for purpose of enumeration.

$2^{\circ}$. When they merely repcat the generic name.

Examples: $1^{\circ}$. Boletus vicesimus sextus, Agaricus octogesimus nonus. $2^{\circ}$. Linaria Linaria, Raphanistrum Raphanistrum, etc.

Comments. 1. Many bacterial species have been named by the use of numbers or letters. Where these can be clearly differentiated, new specific names must be given.

2. This rule in the botanical code is contrary to that in the Zoölogical Code. Names such as A pis apis may be used in zoölogical literature, but not in botany, hence not in bacteriology. A varietal name may be the same as its species but the species name must be different from its genus. In zoölogy on the other hand, variety, genus and species may all have the same name.

Article 56. In the cases foreseen in articles 51 to 56 , the name to be rejected or changed is replaced by the oldest valid name in the group in question, and in default of such a one a new name (a new binomial) must be made.

By a valid name is meant a name or more particularly a combination of names created in conformity with the whole of the rules of nomenclature. The author of a new combination ought to borrow the specific epithet of an old non-valid binomial, or employ a new name.

Article 57. The original spelling of a name must be retained, except in case of a typographic or orthographic error. When the difference between two names, especially two generic names, lies in the termination, these names are to be regarded as distinct even though differing by one letter only.

Examples: Rubia and Rubus, Monochaete and Monochaetum, Peponia and Peponium, Iria and Iris.

Recommendations. XXX. The liberty of making orthographic corrections must be used with reserve, especially if the change effects the first syllable, and above all the first letter of a name.

XXXI. Many names differ by a single letter without risk of confusion (ex. Durvillea and Urvillea). In cases where a close approach to identity is a source of error (ex. Astrostemma and Asterostemma in one and the same family, Asclepiadaceae, Pleuripetalum and Pleuropetalum in Orchidaceae) only one, the older, of the names should be kept, in accordance with article $51,4^{\circ}$.

\section{Chapter IV. Modification of the rules of botanical nomenclature}

Article 58. The rules of botanical nomenclature can only be modified by competent persons at an International Congress convened for the express purpose.

\section{THE INTERNATIONAL RULES OF ZOÖLOGICAL NOMENCLATURE}

Although the bacteria are plants, and the bacteriologist is for the most part dealing with bacteria, it must be recognized that the bacteria 
intergrade with the protozoa. The bacteriologist must frequently deal also with problems in the nomenclature of protozoa, or even of higher animals. He is therefore vitally interested in the rules used by the zoölogist in his systematic nomenclature.

In many respects the zoölogical rules are more explicit than those of the botanist. They constitute primarily a type basis code. To many bacteriologists this appears to be highly desirable in the field of bacteriology. While the Zoölogical Code therefore cannot govern bacterial nomenclature, nevertheless an understanding of its rules and recommendations would be of great value in determining good usage on points not covered in the Botanical Code.

The code given below is that adopted by the Ninth International Zoölogical Congress at Monaco, 1913.

Article 1. Zoölogical nomenclature is independent of botanical nomenclature in the sense that the name of an animal is not to be rejected simply because it is identical with the name of a plant. If, however, an organism is transferred from the vegetable to the animal kingdom its botanical names are to be accepted in zoölogical nomenclature with their original botanical status; and if an organism is transferred from the animal to the vegetable kingdom its names retain their zoölogical status.

Recommendation. It is well to avoid introducing into zoölogy as generic names such names as are in use in botany.

Article 2. The scientific designation of animals is uninominal for subgenera and all higher groups, binominal for species, and trinominal for subspecies.

Article 3. The scientific names of animals must be words which are either Latin or Latinized, or considered and treated as such in case they are not of classic origin.

\section{Family and subfamily names}

Article 4. The name of a family is formed by adding the ending idae, the name of a subfamily by adding inae to the stem of the name of its type genus.

Article 5. The name of a family or subfamily is to be changed when its type genus is changed.

\section{Generic and subgeneric names}

Article 6. Generic and subgeneric names are subject to the same rules and recommendations, and from a nomenclatural standpoint they are coördinate, that is, they are of the same value.

Article 7. A generic name becomes a subgeneric name, when the genus so named becomes a subgenus, and vice versa.

Article 8. A generic name must consist of a single word, simple or compound, written with an initial capital letter, and employed as a substantive in the nominative singular. Examples: Cenis, Porca, Ceratodus, Hymenolepis. 
Recommendation. Certain biological groups which have been proposed distinctly as collective groups, not as systematic units, may be treated for convenience as if they were genera, but they require no type species. Examples: Agamodistomum, Amphistomulum, Agamofilaria, Agamomermis, Sparganum.

Recommendations. The following words may be taken as generic names.

a. Greek substantives, for which the rules of Latin transcription (transliteration (see Appendix F)) should be followed. Examples: Ancylus, Amphibola, Aplysia, Pompholyx, Physa, Cylichna.

b. Compound Greek words, in which the attributive should precede the principal word. Examples: Stenogyra, Pleurobrachus, Tylodina, Cyclostomum, Sarcocystis, Pelodytes, Hydrophilus, Rhizobius.

This does not, however, exclude words formed on the model of II ippopotamus, namely, words in which the attributive follows the principal word. Examples: Philydrus, Biorhiza.

c. Latin substantives. Examples: Ancilla, Auricula, Dolium, Harpa, Oliva. Adjectives (Prasina), past participles (Productus) are not recommended.

d. Compound Latin words. Examples: Stiliger, Dolabrifer, Semifusus.

e. Greek or Latin derivatives expressing diminution, comparison, resemblance, or possession. Examples: Dolium, Doliolum; Strongylus, Eustrongylus; Limax, Limacella, Limacia, Limacina, Limacites, Limacula, Lingula, Lingullella, Lingulepis, Lingulina, Lingulops, Lingulopsis; Neomenia, Proneomenia; Buteo, Archibuteo; Gordius, Paragordius, Polygordius.

f. Mythological or heroic names. Examples: Osiris, Venus, Brisinga, Velleda, Crimora. If not Latin, these should be given a Latin termination (Aegirus, Göndulia).

g. Proper names used by the ancients. Examples: Cleopatra, Belisarius, Melania.

h. Modern patronymics, to which is added an ending to denote dedication.

$\alpha$. Names terminating with a consonant taking the ending ius, ia, or ium. Examples: Stelysius, Lamarckia, Köllikeria, Mulleria, Stalia, Kryeria, Ibanezia.

$\beta$. Names terminating with the vowels $e, i, o, u$, or $y$ take the ending $u s, a$ or um. Examples: Blainvillea, Wyvillea, Cavolina, Fatioa, Bernaya, Quoya, Schulzea.

$\gamma$. Names terminating with $a$ take the ending $i a$. Example: Danaia.

$\delta$. In generic names formed from patronymics, the particles are omitted if not coalesced with the name, but the articles are retained. Examples: Blainvillea, Benedenia, Chiajea, Lacepedea, Dumerilia.

$\epsilon$. With patronymics consisting of two words, only one of these is used in the formation of a generic name. Examples: Selysius, Targionia, Edwardsia, Duthiersia.

$\zeta$. The use of proper names in the formation of compound generic names is objectionable. Examples: Eugrimmia, Buchiceras, Heromorpha, Möbiusispongia.

i. Names of ships which should be treated the same as mythological names $(V e g a)$ or as modern patronymics. Examples: Blakea, Hirondellea, Challengeria.

j. Barbarous names, that is, words of nonclassic origin. Examples: Vanikoro, Chilosa. Such words may receive a Latin termination. Examples: Yetus, Fossarus. 
k. Words formed by an arbitrary combination of letters. Examples: Neda, Clanculus, Salifa, Torix.

1. Names formed by anagram. Examples: Dacelo, Verlusia ? Linospa.

Article 9. If a genus is divided into subgenera, the name of the typical subgenus must be the same as the name of the genus (see Art. 25).

Article 10. When it is desired to cite the name of a subgenus, this name is to be placed in parentheses between the generic and the specific names. Examples: Vanessa (Pyrameis) cardui.

\section{Specific and subspecific names}

Article 11. Specific and subspecific names are subject to the same rules and recommendations, and from a nomenclatural standpoint they are coordinate, that is, they are of the same value.

Article 12. A specific name becomes a subspecific name when the species so named becomes a subspecies, and vice versa.

Article 13. While specific substantive names derived from names of persons may be written with a capital initial letter, all other specific names are to be written with a small initial letter. Examples: Rhizostoma Cuvieri or Rh. cuvieri, Francolinus Lucani, or F. luicani, Hypoderma Diana or H. diana, Laophonte Mohammed or L. mohammed, Oestrus ovis, Corvus corax.

Article 14. Specific names are:

a. Adjectives, which must agree grammatically with the generic name. Example: Felis marmorata.

b. Substantives in the nominative in apposition with the generic name. Example: Felis leo.

c. Substantives in the genitive. Examples: Rosae, sturionis, antillarum, galliae, sancti-pauli, sanctae-helenae.

If the name is given as a dedication to one or several persons, the genitive is formed in accordance with the rules of Latin declination in case the name was employed and declined in Latin. Examples: Plinii, Aristotelis, Victoris, Antonii, Elisabethae, Petri (given name).

If the name is a modern patronymic, the genitive is always formed by adding, to the exact and complete name, an $i$ if the person is a man, or an ae if the person is a woman, even if the name has a Latin form; it is placed in the plural if the dedication involves several persons of the same name. Examples: Cuviei, Möbiusi, Nunezi, Merianae, Sarasinorum, Bovi (not Bovis), Salmoni (not Salmoris).

Recommendation. The best specific name is a Latin adjective, short, euphonic, and of easy pronunciation. Latinized Greek words or barbarous words may, however, be used. Examples: gymnocephalus, echinococcus, ziczac, aguti, hoactli, urubitinga.

It is well to avoid the introduction of the names typicus and typus as new names for species or subspecies, since these names are always liable to result in later confusion.

Article 15. The use of compound proper names indicating dedication, or of compound words indicating a comparison with a simple object does not form an exception to Article 2. In these cases the two words composing the specific name 
are written as one word with or without the hyphen. Examples: SanctaeCatharinae or sanctacatherinae, jan-mayeni, or janmayeni, cornu-pastoris or cornupastoris, cor-anguinum or coranguinum, cedo-nulli or cedonulli.

Expressions like rudis planusque are not admissible as specific names.

Article 16. Geographic names are to be given as substantives in the genitive, or are to be placed in an adjectival form. Examples: sancti-pauli, sanctaehelenae, edwardiensis, diemenensis, magellanicus, burdigalensis, vindobonensis.

Recommendation. Geographic names used by the Romans or by Latin writers of the middle ages are to be adopted in preference to more recent forms. Words like bordeausiacus and viennensis are poor, but are not to be rejected on this account.

Article 17. If it is desired to cite the subspecific name, such name is written immediately following the specific name, without the interposition of any mark of punctuation. Example: Rana esculenta marmorata Hallowell, but not Rana esculenta (marmorata) or Rana marmorata Hallowell.

Article 18. The notation of hybrids may be given in several ways; in all cases the name of the male parent precedes that of the female parent, with or without the sexual signs:

a. The names of the two parents are united by the sign of multiplication $(X)$.

b. Hybrids may also be cited in the form of a fraction, the male parent forming the numerator and the female parent the denominator. Example: $\frac{\text { Capra hircus. }}{\text { Oris aries }}$ This second method is in so far preferable that it permits the citation of the person who first published the hybrid form as such. Example:

$$
\frac{\text { Bernicla canadensis }}{\text { Anser cygnoides }} \text { Rabé. }
$$

c. The fractional form is also preferable in case one of the parents is itself a hybrid. Example: $\frac{\text { Tetrao tetrix } \times \text { Tetrao urogallus }}{\text { Gallus gallus }}$. In the latter case, however, the parentheses may be used. Example: (Tetrao tetrix $\times$ Tetrao urogallus) $\times$ Gallus gallus.

d. When the parents of the hybrid are not known as such (parents), the hybrid takes provisionally a specific name, the same as if it were a true species, namely, as if it were not a hybrid; but the generic name is preceded by the sign of multiplication. Example: $\times$ Coregonus dolosus Fatio.

\section{Formation, derivation, and orthography of zoölogical names}

Article 19. The original orthography of a name is to be preserved unless an error of transcription, a lapsus calami, or a typographical error is evident.

Recommendation. For scientific names it is advisable to use some other type than that used for the text. Example: Rana esculenta (italics) Linné, 1758 , lives in Europe.

Article 20. In forming names derived from languages in which the Latin alphabet is used, the exact original spelling, including diacritic marks, is to be retained. Examples: Selysius, Lamarckia, Köllikeria, Mülleria, Stalia, Krфyeria, Ibanezia, Mobiusi, Medici, Czjzeki, spitzbergensis, islandicus, paraguayensis, patagonicus, barbadensis, faröensis. 
Recommendations. The prefixes sub and pseudo should be used only with adjectives and substantives, sub with Latin words, pseudo with Greek words, and they should not be used in combination with proper names. Examples: subviridis, subchelatus, Pseudacanthus, Pseudophis, Pseudomys. Words like subwilsoni and pseudo-grateloupana are not recommended.

The terminations oides and ides should be used in combination only with Greek or Latin substantives; they should not be used in combination with proper names.

Geographic and patronymic names from countries which have no recognized orthography or which do not use the Latin alphabet, should be transcribed into Latin according to the rules adopted by the Geographic Society of Paris. (See Appendix G.)

In proposing new names based upon personal names, which are written sometimes with ä, ö or $\ddot{u}$, at other times with ae, oe, and ue, it is recommended that authors adopt ae, oe and ue. Example muelleri in preference to mülleri.

\section{Author's name.}

Article 21. The author of a scientific name is that person who first publishes the name in connection with an indication, a definition, or a description, unless it is clear from the contents of the publication that some other person is responsible for said name and its indication, definition, or description.

Article 22. If it is desired to cite the author's name, this should follow the scientific name without interposition of any mark of punctuation; if other citations are desirable (date, sp. n., emend., sensu stricto, etc.) these follow after the author's name, but are separated from it by a comma or by parenthesis. Examples: Primates Linné, 1758, or Primates Linné (1758).

Recommendation. When the name of the author of a scientific name is abbreviated, the writer will do well to conform to the list of abbreviations published by the Zoölogical Museum of Berlin.

Article 23. When a species is transferred to another than the original genus or the specific name is combined with any other generic name than that with which it was originally published, the name of the author of the specific name is retained in the notation but placed in parentheses. Examples: Taenia lata Linné, 1758, and Dibothriocephalus latus (Linné, 1758); Fasciola hepatica Linné, 1758, and Distoma hepaticum (Linné, 1758).

If it is desired to cite the author of the new combination his name follows the parentheses. Example: Limnatis nilotica (Savigny, 1820) Moquin-Tandon, 1826.

Article 24. When a species is divided, the restricted species to which the original specific name of the primitive species is attributed may receive a notation indicating both the name of the original author and the name of the reviser. Example: Taenia solium Linné, partim, Goeze.

\section{The law of priority}

Article 25. The valid name of a genus or species can be only that name under which it was first designated on the condition:

a. That this name was published and accompanied by an indication, or a definition, or a description; and

b. That the author has applied the principles of binary nomenclature. 


\section{Application of the law of priority}

Article 26. The Law of Priority obtains and consequently the oldest available name is retained:

a. When any part of an animal is named before the animal itself.

b. When any stage in the life history is named before the adult.

c. When the two sexes of an animal have been considered as distinct species or even as belonging to distinct genera.

d. When an animal represents a regular succession of dissimilar generations which have been considered as belonging to different species or even to different genera.

Article 28. A genus formed by the union of two or more genera or subgenera takes the oldest valid generic or subgeneric name of its components. If the names are of the same date, that selected by the first reviser shall stand.

The same rule obtains when two or nore species or subspecies are united to form a single species or subspecies.

Recommendation. In absence of any previous revision, the establishment of precedence by the following method is recommended:

a. A generic name accompanied by specification of a type has precedence over a name without such specifications. If all or none of the genera have types specified, that generic name takes precedence the diagnosis of which is most pertinent.

b. A specific name accompanied by both description and figure stands in preference to one accompanied only by a diagnosis or only by a figure.

c. Other things being equal, that name is to be preferred which stands first in the publication (page precedence).

Article 29. If a genus is divided into two or more restricted genera, its valid name must be retained for one of the restricted genera. If a type was originally established for said genus, the generic name is retained for the restricted genus containing said type.

Recommendation. To facilitate reference, it is recommended that when an older species is taken as type of a new genus, its name should be actually combined with the new generic name in addition to citing it with the old generic name. Example: Gilbertella Eigenmann, 1903, Smithsonian Misc. Coll. v. 45, p. 147, type Gilbertella alata (Steindachner) = Anacyrtus alatus Steindachner.

Article 30. The designation of type species of genera shall be governed by the following rules $(\mathrm{a}-\mathrm{g})$, applied in the following order of precedence:

I. Cases in which the generic type is accepted solely upon the basis of the original publications:

a. When in the original publication of a genus, one of the species is definitely designated as type, this species shall be accepted as type, regardless of any other considerations. (Type by.original designation.)

b. If in the original publication of a genus, typicus or typus is used as a new specific name for one of the species, such use shall be construed as "type by original designation."

c. A genus proposed with a single original species takes that species as its type. (Monotypical genera.)

d. If a genus, without originally designated (see a) or indicated (see b) type, contains among its original species one possessing the generic name as its specific 
or sulsppecific name, either as valid name or synonym, that species or subspecies becomes ipso facto type of the gemus. (Type by absolute tautouymy.)

II. Cases in which the generie type is acepted not solely upon basis of the original pullication:

e. The following species are exchded from eonsiderstion in determining the tryes of geners.

a. Species which were not inchuled under the generie name at the time of its original publication.

$\beta$. Species which were species inquirendae from the standpoint of the anthor of the generic name at the time of its publieation.

$\gamma$. Apecies which the author of the genus doubtfully referred to it.

f. In ense a generic name without originally designated type is proposed as a substitute for another generie name, with or without type, the type of either. when estublished, becomes ipses facte type of ot her.

g. If au suthor, in publishing a genus with more than one valid species, fails to designate (see a) or to indicate (see b, d) its type, any subsequent author may select the type, and such designation is not subject to change. (Type by subsequent (designation.)

The me:ming of the expression "select the tyge" is to be rigidly construed. Mention of a speries as an illustration or example of a gemus does not constitute nselection of a type.

III. Recommendations. In selecting types by subsequent designation, authors will do well to govern themselves by the following recommendations:

h. In ('ase of limnsean genera, seleet as type the most eommon or the medicinal species. (limasan rule, 17al.)

1. If a genus, without designated type, contains anong its original species one possessing as a specitic or subspecitic name, either as valid name or symonym, a name which is virtually the same as the generie name, or of the same origin or same meaning, preference should be shown to that species in designating the type, unless such preference is strongly eontraindieated by other factors. (Type by virtual tautonyuy.) Examples: Bos taurus, Equus cuballus, Ovis aries, ścomber scombras, sphorestoma globiporum; contraindicated in Dipetulonema (eompare species Filaria dipetala, of which only one sex was described, based upon one specimen and not studied in detail).

j. If the genus eontains both exotic and nonexotic species from the standpoint of the original suthor, the type should be selected from the nonexotio species.

$k$. If some of the original species have later been classified in other geners, preference should be shown to the species still remaining in the original genus. (Type by cimination.)

i. Species based upon sexuslly mature specimens should take precedence over suecies based upon larral or immature forms.

m. Show preference to species bearing the name comimunis, mulgaris, medicinalis, or officindis.

n. Show preference to the best deseribed, best figured, best known, or most easily obtainable species, or to one of which a type specimen can be obtained.

o. Show preferenee to a species which helongs to a group containing as large a number of the species as possible. (De Cundolle's rule.)

p. In parasitic genera, select, if possible, a species which oceurs in the man or some food animal or in some very common and widespread host species. 
q. All other things being equal, show preference to a species which the author of the genus actually studied at or hefore the time he proposed the genus.

r. In case of writers who habitually placed a certain leading or typical species first as "elief de file," the others being deseribed by comparative referenee to this, this fact should be considered in the choice of the type species.

s. In case of those authors who have adopted the "first species rule" in fixing generie types, the first species named by them should be taken as types of their genera.

t. All other things being equal, page precedence should obtain in selecting a type.

Article 32. A generic or a specifie name, onee published, can not be rejeeted, even by its author, because of inappropriateness. Examples: Names like Polyodon, A pus, albus, etc., when onee published, are not to be rejected because of a claim that they indieate characters eontradictory to those possessed by the animals in question.

Article 33. A name is not to be rejected because of tautonymy, that is, because the specifie or the specific and subspecific names are identical with the generic name. Examples: T'rutta trulla, A pus apus apus.

Article 34. A generic name is to be rejected as a homonym when it has previously been used for some other genus of animals. Example: Trichina Owen, 183i), nematode, is rejeeted as homonym (1) of T'richina Meigen, 1830, inseet.

Article 35. A specifie nane is to be rejeeted as a homonym (1) when it has previously been used for some other species of the same genus. Examples: Taenia ovilla Rivolta, 1878 (n. sp.) is rejected as homonym of T. ovilla Gmelin, 1790.

When in consequence of the union of two genera, two different animals having the same specifie or subspecifie name are brought into one genus, the more recent specific or subspecific name is to be rejected as a homonym.

Specific names of the same origin and meaning shall be considered homonyms if they are distinguished from each other only by the following differences:

a. The use of ae, os, and $e$, as cacruleus, coeruleus, ceruleus; ei, $i$, and $y$, as chiropus, cheiropus; $c$ and $k$ as microdon, milkodon.

b. The aspiration or non-aspiration of a consonant, as oxyryncus, ocyrhynchus.

c. The presenee or absenee of a $c$ before $t$, as autumnalis, auctumnalis.

d. By a single or double consonant; litoralis, littoralis.

e. By the endings ensis and iensis to a geographical name, as timorensis, timoricnsis.

Article 36. Rejected homonyms (1) can never be again used. Rejected synonyms can again be used in case of the restoration of erroneously suppressed groups. Example: Taenia Giardi Monicz, 1870, was suppressed as a synonym of T'aenia ovilla Rivolta, 1878; later it was discovered that Taenia ovilla was preoccupied (Taeria ovilla Gmelin, 1790). Taenia ovilla, 1878, is suppressed as a homonym, and can never again be used; it was stillborn and cannot be brought to life, even when the species is placed in another genus (Thysanosoma). Taenia Giardi, 1879, which was suppressed as a synonym, becomes valid upon the suppression of the homonyin T'acnia ovilla Rivolta.

Recommendations. It is well to avoid the introduction of new generic names which differ from generic names already in use only in termination or in a slight 
variation in spelling which might lead to confusion. But when once introduced, such names are not to be rejected on this account. Examples: Picus, Pica; Polyodus, Polyodon, Polyodonta, Polyodontas, Polyodontus.

The same recommendation applies to new specific names in any given genus. Examples: necator, necatrix; furcigera, furcifera; rhopalocephala, rhopaliocephala.

If from the radical of a geographic name two or more adjectives are derived, it is not advisable to use more than one of them as specific name in the same genus, but if once introduced they are not to be rejected on this account. Examples: hispanus, hispanicus; moluccanus molluccensis; sinensis, sinicus, chinensis; ceylonicus, zeylanicus.

The same recommendation applies also to other words derived from the same radical and differing from each other only in termination or by a simple change in spelling.

\section{TYPE BASIS CODE SUGGESTED BY A COMMITTEE ON BOTANICAL NOMENCLATURE OF THE BOTANICAL SOCIETY OF AMERICA}

For a number of years the botanists of America have been divided into two groups, those who use the Vienna Code and those who use the socalled "American Code." In 1918 a Committee on Botanical Nomenclature was appointed by the Botanical Society of America to consider this subject and report. In 1920 the committee gave a majority report signed by seven of its members and a minority report signed by two. The majority report outlined a Type Basis Code of Botanical Nomenclature. The report is of so much importance that it is given below in full.

The Committee on Nomenclature of the Botanical Society of America was appointed at the Baltimore meeting of the Society in 1918. A preliminary survey of the situation showed that the taxonomists of the Society were about equally divided in their support of the Vienna Code and the American Code. An attempt to commit the Society to one or the other of these codes would inevitably result in conflict detrimental to progress in nomenclatural matters. The policy was adopted of working on nomenclature along parallel lines. Two subcommittees were appointed, one on the Vienna Code, with J. M. Greenman as chairman, and one on the American Code, with A. S. Hitchcock as chairman.

The subcommittee on the American Code has prepared a plan which is now submitted to the Society. It is not asked that the Society commit itself to this plan by adopting the report but it is hoped that the Society will receive the report without prejudice. The committee will then continue to study the plan and modify it if necessary to meet the wishes of its supporters. A part of the plan is the establishment of a Nomenclature Commission to pass upon exceptions to the Code. The Committee asks authority to organize this Commission.

We wish especially to call attention of the Society to the fact that the new code which we call the Type-basis Code is not antagonistic to the Vienna Code but is based upon the same principles with certain additions. Both codes are based upon the principle of priority. Both admit exceptions to the application of the 
rules. The Type-basis Code provides for a Commission to pass upon exceptions. The fundamental difference is the acceptance by the Type-basis Code of the principle of Nomenclatural Types. This principle is not included in the Vienna Code but is not antagonistic to it. The Committee offers the Type-basis Code of Botanical Nomenclature as a new code international in its scope with the hope that its merits will be so evident that it will receive support both in this country and abroad and that it may be combined with the Vienna Code at the nextinternational Congress. The chief differences between the two codes are (1) the concept of types, and (2) the idea of a commission to validate exceptions.

\section{A type-basis code of botanical nomenclature. Principles.}

1. The primary object of formal nomenclature in systematic biology is to secure stability, uniformity, and convenience in the designation of plants and animals.

2. Botanical nomenclature is treated as beginning with the general applications of binomial names to plants (Linnaeus' Species Plantarum, 1753).

3. Priority of publication is a fundamental principle of botanical nomenclature. Two groups of the same category cannot bear the same name.

Note a. This principle applies primarily to genera and species.

Note b. Previous use of a name in zoölogy does not preclude its use in botany; but the proposal of such a name should be avoided.

4. The application of names is determined by means of nomenclatural types.

Note. A generic name is always so applied as to include its type species; a specific name is always so applied as to include its type specimen.

\section{Rules and recommendations}

\section{Section 1. Publication of names}

Article 1. A specific name is published when it has been printed and distributed with a description, or with a reference to a previously published description.

Note. A recognizable figure may be the equivalent of a description in the literature of paleobotany and diatoms.

a. In the transfer of a species from one genus to another, the original specific name is retained, unless the resulting binomial has been previously published.

Recommendations. Botanists will do well, in publishing:

1. In describing parasitic fungi to indicate the host and to designate the name of the host by its scientific Latin name.

2. To give the etymology of all new generic names.

Article 2. A generic name is published when it has been printed and distributed. 
a. With a generic or specific description (or a recognizable figure, see Article 1, note) and a binomial specific name.

b. With a generic and specific name and the citation of a previously published description.

c. With a definite reference to at least one previously published binomial.

Note a. A name is not published by its citation in synonymy, nor by incidental mention. Such a name may be taken up but not to replace one already properly published.

Note b. Of names published in the same work and at the same time, those having precedence of position are to be regarded as having priority.

Recommendation. Botanists will do well, in publishing, to give the etymology of specific names when their meaning is not obvious.

\section{Section 2. Application of names}

Article 3. The nomenclatural type of a species is the specimen or the most important of the specimens upon which its original published description was based.

a. If only one specimen is cited, that is the type.

b. If one specimen is designated as the type, that specimen shall be so accepted, unless an error can be demonstrated.

c. A species transferred without change of name from one genus to another retains the original type even though the description under the new genus was drawn from a different species.

d. The publication of a new specific name as an avowed substitute for an earlier one does not change the type of the species.

e. When more than one specimen was originally cited and no type was designated the type should be selected in the following manner:

1. The type specimen interprets the description and fixes the application of the name, hence, primarily the description controls the selection of the type.

2. The type may be indicated by the specific name, this being sometimes derived from the collector, locality, or host.

3. If one specimen is figured in connection with the original description this may usually be regarded as the type.

4. Specimens that are mentioned by the author as being exceptional or unusual, or those which definitely disagree with the description (provided others agree) may usually be excluded from consideration in selecting the type.

5. An examination of the actual sheets of specimens studied by the author may aid in determining or selecting the type. He may have written the name or left notes or drawings upon one of the sheets.

Note. Specimens known to have been received by the author subsequent to the study resulting in the original publication should be excluded from consideration.

6. If an author, in publishing a new species, gives a description of his own, this takes precedence over synonymy or cited descriptions, in determining the type specimen.

Article 4. The nomenclatural type species of a genus is the species or one of the species included when the genus was originally published. 
a. If a genus includes but one species when originally published this species is the type.

b. When more than one species is included in the original publication of the genus, the type is determined by the following rules (these rules are Articles 3 to 6 of the Report of the Committee on Generic Types published in (1) Science N. S. 49: 334-336. 1919, (2) Bot. Soc. Amer. Publ. 73, 70-71. 1919).

Recommendations. In the future it is recommended that authors of generic names definitely designate type species; and that in the selection of types of genera previously published, but of which the type would not be indicated by the preceding rules, the following points be taken into consideration. (This includes Article 7, a to $\mathrm{g}$, of the Report on Generic Types published in Science and in Bot. Soc. Amer. Publ. 73, loc. cit.)

\section{Section 3. Rejection of Names}

Article 5. A name is rejected

a. When preoccupied (homonym).

1. A specific name is a homonym when it has been published for another species under the same generic name.

2. A generic name is a homonym when previously published for another genus.

3. Similar names are to be treated as homonyms only when they are mere variations in the spelling of the same word; or in the case of specific names, when they differ only in adjective or genitive termination.

b. When there is an older valid name based on another member of the same group (metonym).

c. When there is an older valid name based on the same type (typonym).

d. When it has not been effectively published according to the provisions of Section 1 of these rules (hyponym).

Article 6. There may be exceptions to the application of the principles and rules of this Code in cases where a rigid application would lead to great confusion. Such exceptions become valid when approved by the Nomenclature Commission.

\section{E. SUGGESTIONS AND RECOMMENDATIONS OF THE SOCIETY OF AMERICAN BACTERIOLOGISTS}

The preliminary report of the Committee of the Society of American Bacteriologists on Characterization and Classification of Bacterial Types (Winslow, Broadhurst, Buchanan, Krumwiede, Rogers and Smith 1917) suggested the following to the Society:

We recommend to the Society of American Bacteriologists:

a. That the International Rules for Botanical Nomenclature be accepted by the Society as governing bacterial terminology, with the exception that French, English or German may be substituted for Latin in the diagnosis.

b. That the date of publication of the third edition of Zopf's Spaltpilze be considered as the date for the beginning of bacteriological nomenclature for the purpose of determining priority, with the exception of a list of genera conservanda to be adopted by the Society at its 1918 meeting. 
c. That the Society take steps to present these recommendations to the next International Botanical Congress, and if possible to secure favorable action thereon by that body.

In the final report (1920) the following statement is made.

The following names are recommended for adoption as approved genera:

Acetobacter Fuhrmann
Actinomyces Harz
Bacillus Cohn
Bacterium Ehrenberg
Chromobacterium Bergonzini
Clostridium Prazmowski
Erythrobacillus Fortineau
Leptotrichia Trevisan

Its work so far as possible being completed, we recommend that the Committee on Characterization and Classification of Bacterial Types be discharged and that a new Committee on Bacterial Taxonomy be appointed (1) to study and report to the Society from time to time in regard to problems of nomenclature, including such revisions of the nomenclature in the present report as may seem necessary; and (2) to take the proper steps to secure action at the next International Botanical Congress leading to the general ends contemplated in the 1916 recommendations of the Society:

a. That French, English or German may be substituted for Latin in the diagnosis of bacterial species.

b. That the date of publication of the third edition of Zopf's Spaltpilze (1883) be considered the beginning of bacterial nomenclature for the purpose of determining priority, with the exception of a definite list of genera conservanda.

c. That such of the approved generic names specified above as may be found to require such action be recognized as genera conservanda in bacterial taxonomy.

\section{STATEMENT AS TO NOMENCLATURAL PRACTICE IN PRESENT VOLUME}

It would seem evident from the preceding discussion that the fundamental basis for nomenclature in bacteriology must be the International Botanical or Vienna-Brussels Code. However, it is quite apparent that there are certain rules which have not been and cannot well be recognized by bacteriologists, particularly the rule requiring that the specific diagnoses be published in Latin in order to be valid. It is also evident that stability in bacteriological nomenclature must come through the application of a type basis. Apparently the best that has been formulated for botanists is that contained in the majority report of the Committee on Botanical Nomenclature given above. We shall therefore utilize the latter as a basis for naming the bacteria described. It should be remembered that acceptance of the code of this report does not mean abandonment of the International Code. 
Occasional reference will be made to the Zoölogical Code where organisms have a doubtful status in the plant kingdom. It will also be used to determine good usage where the Botanical Code is silent or ambiguous. 


\section{CHAPTER III}

\section{Nomenclatural Status of Names Which Have Been Applied TO GROUPS OF BACTERIA OF HIGHER RANK THAN SPECIES}

On the following pages is given alphabetically arranged a list of the names which have been proposed for subgenera, genera, subtribes, tribes, subfamilies, families, orders, and classes of bacteria, including casual or vernacular terms which have had more or less extensive recognition and have been confused with scientific names. In general an attempt has been to give the original diagnosis of the term, to discuss its usage by bacteriologists, and to point out whether its use apparently contravenes good usage or the rules of the code. In many cases an opinion is given as to probable validity.

Acetimonas. A generic name for the vinegar bacteria proposed by S. Orla-Jensen $(1909$, p. 312). This genus is listed as the fourth of the family Oxydobacteriaceae, order Cephalotrichinae. The genus is first described as follows:

Die Essigsaure bakterien sind, soweit bekannt, ebensowie die vorhergehenden Bakterien monotriche oder unbewegliche Stäbchen, die sich auf der Oberfläche der Nährflüssigkeiten zu einer Haut ausbreiten. Ich habe ihnen daher den Gattungsnamen Acetimonas gegeben. Von den Schnellessigbakterien bis zu den Essigbildern des Weines und des Bieres steigen die Ausspruche auf organische Nahrung. Bekanntlich gedeihen die Schnellessigbakterien (z. B. B. Schützenbachii) mit Aethylalkohol als einzige Kohlenstoffquelle. Es ist jedoch kaum wahrscheinlich, dass Alkohol die erste Kohlenstoff- und Energiequelle war, die den Essigsäurebakterien hier auf der Erde zur Verfügung stand; dies sind eher Kohlenhydrate gewesen, welche sie ja auch in höherem oder geringerem Grade zu oxydieren im Stande sind. Nach meinem Untersuchungen können die meisten Essigsäurebakterien sich mit Saltpeter als Stickstoffquelle begnügen. Einzelne Arten (am stärksten $B$. aceti) reduzieren nach längerer Zeit kleinere Mengen Saltpeter bis zum Ammoniak, eine Eigenschaft die auch andere obligat aërobe Bakterien (z. B. Azotobacter und gewisse Heubacillen) besitzen, und die zeigt, dass solche Bakterien ausser dem freien Sauerstoff auch gebundenen verwenden können.

Later the same author (1909, p. 477) gave the following description: "Bedürfen in der Regel nicht organischen N-Quellen. Sauerstoffbedürfniss positiv. Oxydiert Alkohol zu Essigsäure." 
It will be noted that no type species is designated. Of the two species mentioned " $B$. Schützenbachii" is given first, and may be regarded as the type.

Other names which have been applied in a more or less strict generic sense to the group of acetic bacteria are Mycoderma (Persoon 1822, p. 96), Ulvina (Kützing 1837 ?), Umbina (Nägeli 1857, p. 760), Acetobacter (Beijerinck 1898 ?), Acetobacterium (Hoyer 1898, p. 870).

The organisms belonging to this group have commonly been placed in the genera Bacillus and Bacterium by various authors.

The name Acetimonas was regarded as a synonym of Mycoderma Persoon by Buchanan (1918, p. 45) and Winslow et al. (1917, p. 551), and finally of Acetobacter Fuhrmann by Winslow et al. (1920, p. 201).

It is here included as a synonym of Acetobacter Beijerinck, q.v.

Acetobacter. A generic name proposed by Beijerinck (?) for the group of acetic acid bacteria.

The exact time and method of publication is difficult to determine.

According to Enlows (1920, p. 11), the name is first found in Kral's Sammlung v. Mikroorg. (Prague 1898, pp. 7 and 8) where Acetobacter pastorianus (Hansen ?), Beijerinck and $A$. aceti are listed as synonyms of Bacterium Pasteurianum and Bact. aceti respectively. In the 1900 and 1904 editions these are likewise listed as synonyms of Bacterium Pasteurianum and Bact. aceti respectively.

Beijerinck (1901, p. 219), in an article in which he describes several genera of lactic bacteria at length, mentions Acetobacter as producing catalase, in contrast to Lactobacillus which produces none.

It is of interest to note that in a translation (published in 1898) of a Dutch paper (published in 1897) on the acetic bacteria, Beijerinck uses the name Bacterium consistently for the species of this group.

Ludwig (1898, p. 870) in a review of Hoyer's (1898) dissertation on the acetic bacteria uses the name Acetobacterium xylinum. Examination of the original is necessary to show whether this is a misprint.

The first adequate description of an organism placed definitely in this genus thus far found is Acetobacter plicatum Furhmann (1905, p. 8). It was this that led the Committee of the Society of American Bacteriologists to ascribe the genus to Furhmann. If this is done, however, his species $A$. plicatum would constitute the type.

Acetobacter melanoginum was described later by Beijerinck (1911, p. 171).

The generic name Acetobacter was accepted by Winslow et al. (1920, p. 201), for the acetic bacteria, displacing Mycoderma. They give the following description : 
Cells rod shaped, frequently in chains, non-motile. Cells grow usually on the surface of alcoholic solutions as obligate aerobes, securing growth energy by the oxidation of alcohol to acetic acid. Also capable of utilizing certain other carbonaceous compounds, as sugar and acetic acid. Elongated, filamentous, club shaped, swollen and even branched cells may occur as involution forms.

The type species designated by Winslow et al. was Acetobacter aceti (Thompson 1852) Committee.

It is probable that the correct designation of the type species would be Acetobacter aceti Beijerinck.

Other generic names which have applied more or less strictly to this group are Mycoderma (Persoon 1822, p. 96), Ulvina (Kützing 1837 ?), Umbina (Nägeli 1857), Acetobacterium (Ludwig? 1898) and Acetimonas (Orla-Jensen 1909) q. $\%$.

Buchanan (1918, p. 45) listed Acetobacter as a synonym of Mycoderma. Bergey et al. include this genus as the sixth of the tribe Nitrobactereae.

In this treatise Acetobacter is recognized as a valid generic name with Acetobacter aceti Beijerinck as the type.

Acetobacterium. A generic name apparently first used by Hoyer (1898) as a designation for acetic bacteria. The original thesis is not available, but the name Acetobacter xylinum is used by Ludwig (1898, p. 870) in an extended review of Hoyer's paper. He also in the same year apparently ascribed the name to Beijerinck in the following statement:

Nach den Beobachtungen Beyerinck's würde der Leuconostoc Lagerheimii mit dem Bacterium xylinum Brown zusammen in ein und dieselbe Gruppe der Acetobacterien gehören. Beyerinck bezeichnet ihn in lit. als Acetobacterium xylinum var. Lagerheimii.

The only reference to such a conception thus far found in the writings of Beijerinck is a footnote $(1898$, p. 211) to a brief description of Bacterium xylinum in which he says, "Hauptmasse des Schleims beim Schleimflusse lebender Eichen bildet." There is no use of the name Acetobacterium.

It is probable that Acetobacterium should be regarded as a synonym of Acetobacter.

Achromatiaceae. A family of the order Thiobacteriales proposed by Buchanan (1918, p. 462) to include the three genera Achromatium, Thiophysa and Hillhousia.

The diagnosis given is "Unicellular, large, motile (by means of flagella ?) cells containing granules of sulphur (or in one form possibly 
oxalate), but no bacteriopurpurin." The family is recognized by Bergey et al. (1923, p. 410) in this sense.

The generic type is Achromatium oxaliferum Schewiakoff (1893, p. 1).

Achromatium. A genus of schizophytes proposed by Schewiakoff $(1893$, p. 1) and tentatively placed by him with the bacteria.

The species described, Achromatium oxaliferum, was found in river slime, by R. Lauterborn, in considerable numbers. In form the organism varies from nearly spherical in newly divided cells to ellipsoidal. In size the organism is larger than any other form previously described among bacteria; cells about to divide are 15 to $43 \mu$ in length, diameter 9 to $22 \mu$. Occasionally longer cells are found. The cells are closely packed with large granules which were at first interpreted as composed of sulfur. The use of various solvents and microchemical tests indicated them to be, however, of calcium oxalate. When the granules are dissolved the cell is found to contain protoplasm of a coarse alveolar structure. The cells are motile, but flagella were not demonstrated. Cell division is described as the result of constriction, as among flagellates, rather than by the fission characteristic of most bacteria.

Migula (1900, p. 1038) tentatively added Achromatium Mülleri (Warming) Migula to this genus. The organism was originally described by Warming (1876) as Monas Mülleri. The descriptions make it probable that this organism is misplaced in Achromatium, and belongs with the sulfur forms. Migula gives the following description of the genus.

Zellen gross, eiförmig cylindrisch mit groblörnigem Inhalt, der jedoch nicht aus Schwefel, sondern aus Oxalsäure und einem Calciumsalz besteht. Bewegung vorhanden, doch ist eine Geissel als Bewegungsorgan nicht nachgewiesen. Teilung von der Bakterien abweichend, durch Einschnürung, wie bei den Flagelleten.

Achromatium oxaliferum Schewiakoff was subsequently described independently by Frenzel (1897, p. 801) as Modderula hartwigi (from the name "Modder" given by North German fishermen to the slimy river bottoms). Lauterborn (1898, p. 95) called attention to the previous description of Achromatium, and agreed with Schewiakoff in placing the organism with the bacteria. Frenzel found this form to vary from 12 to $50 \mu$ in length. He was able to find no adequate explanation of the motility. The cell membrane he describes as firm, almost doubly contoured, clear, colorless and structureless. He interpreted the granules contained within the cell as sulfur. The organism was not cultivated in artificial media, although it continued to 
multiply for a time in the laboratory. He concluded that the organism is most closely related to the bacteria, but that it constitutes a very distinct type.

It would appear that the genus Achromatium Schewiakoff is valid, with the type species $A$. oxaliferum Schewiakoff. It is listed by Smith (1905, p. 174) as a doubtful bacterial genus and in another list as a rejected name. Migula (1904, p. 128) states that he appends the genus Achromatium to the bacteria, although (because of the cell dimensions) he considers the relationship distant. A careful rechecking of the work of Schewiakoff on the question of the composition of the granules would be helpful in determining the affinities of this organism.

Buchanan (1918, p. 462) included this genus as the type of the family Achromatiaceae with the following description:

Cells large, nearly spherical in newly divided cells to ellipsoidal, 15 to 43 by 9 to $22 \mu$. Cells closely packed with large granules, at first interpreted as sulphur, but later interpreted as calcium oxalate. When granules are dissolved, cells show coarse alveolar structure. Cells are motile, flagella not demonstrated. Cell division resembles the constriction of flagellates rather than the fission characteristic of bacteria.

This generic diagnosis was also used by Bergey et al. (1923, p. 410). In this treatise Achromatium is accepted as a valid bacterial genus.

Achromobacter. A generic name proposed by Bergey et al. (Committce Soc. Am. Bact., 1923, p. 132) for the single genus of the tribe Achromobactereae. The generic description is:

Non-pigment forming (at most no pigment formed on agar or gelatin) rods, occurring in water and soil. Motile or non-motile. Gram-negative.

The type species is Achromobacter liquefaciens (Frankland).

In all some 51 species are included in the genus.

Achromobactereae. A name used by Bergey et al. (1923, p. 132) for the second tribe of the family Bacteriaceae. The tribal description is:

Rods, small to medium in size, occurring principally in water and soil. Form no pigment on agar or gelatin but may produce a brownish growth on potato. Cultural characters variable. Motile or non-motile. Gram-negative.

One genus only is included, Achromobacter.

Acidobacteriaceae. The first family of the order Peritrichinae of Orla-Jensen (1909, p. 343). It includes seven genera: Denitrobacterium, Bacterium, Propionibacterium, Caseobacterium, Streptococcus, Micrococcus and Sarcina. It includes organisms which usually cause acid 
formation from carbohydrates, which when motile, have peritrichous flagella, which are not obligate anaërobes and which do not typically form alkalies by splitting of proteins. The genus Denitrobacterium, characterized by large denitrifying powers, does not strictly belong in this family, but is intermediate between the other genera and the family Luminibacteriaceae of the preceding order Cephalotrichinae.

The genera of the family Acidobacteriaceae as recognized by OrlaJensen may be differentiated by the following key:

A. Primarily denitrifying rods. Genus 1. Denitrobacterium.

B. Not primarily denitrifiers.

I. Cells rod shaped.

a. Producing succinic acid. Colon group.

Genus 2. Bacterium.

b. Producing lactic acid. Genus 4. Caseobacterium.

II. Cells spherical.

a. Producing propionic acid.

Genus 3. Propionibacterium.

b. Not producing propionic acid.

1. Cells in chains. Genus 5. Streptococcus.

2. Cells irregularly arranged.

Genus 6. Micrococcus.

3. Cells in packets. Genus 7. Sarcina.

Orla-Jensen (p. 340) suggests that the additional genera Sporosarcina for sarcina forms that develop spores and Peptonococcus for the lactic acid bacteria that form peptones from proteins should be added.

The name apparently has not been used by subsequent writers.

It may be noted that the family name Acidobacteriaceae is not derived from any of the component genera, and is therefore incorrect in form, and may be regarded as invalid.

Actinobacille. A casual name given by Lignières and Spitz (1904, p. 454) to a group of bacteria related to Actinomyces. The French designation actinobacille was used apparently as a translation of the original Spanish term actinobacilo (q.v.) by Lignières and Spitz (1902, p. 169). This is the form later clesignated by the generic name Actinobacillus (q.v.) by Brumpt (1910, p. 849).

The description given by Lignières and Spitz is as follows:

L'agent spécifique de l'actinophytose à actinobacille se prèsente, dans les cultures sous l'aspect d'un microbe parfois à peine plus gros que celui du cholèra des poules. Dans les premières cultures, il est nettement bacillaire; plus tard, surtout sus gèlose, il affecte la forme du cocco-bacille ou de diplocoque; dans les cultures en bouillon sèrum, on observe l'aspect streptobacillaire. Enfin, 
dans les vieilles cultures, principalement en bouillon additioné de sèrum agglutinant, on trouve souvent des formes d'involution les plus bizarres.

Jamais on ne trouve de filaments dichotomisès comme les autres actinophytoses dèja signalès ici.

Enlows (1920, p. 11) gives the following characterization:

Pleomorphic. Sometimes rodlike, sometimes coccuslike, in pairs; also streptobacillary forms occur: $0.15 \mu$ to $1.25 \mu$ in length by $0.4 \mu$; non-motile: no spores; gram-negative; bipolar staining. The final stage of growth gives rise to little masses, in which the organisms are pressed closely together, giving the ray like aspect. These masses consist of a central germinative zone and an outer or vegetative zone. Cause of actinobacillosis in cattle.

This is to be regarded as a casual name for the genus Actinobacillus.

Actinobacillus. A generic name given by Brumpt (1910, p. 849) to the organism causing "Actinobacilosis" and termed "Actinobacilo" by Lignières and Spitz (1902, p. 169). The organism was accorded no specific name by Lignières; it was named by Brumpt in his honor, Actinobacillus Lignieresi. This species therefore constitutes the generic type.

The organism is the cause of an infection in cattle and sheep termed actinobacillosis. The lesions resemble closely those of actinomycosis. In culture of the organism on solid media small, transparent colonies appear in twenty-four hours. They consist of small diplococcus-like bacilli or of streptobacilli, resembling the fowl cholera organism when grown in broth in their occurrence in long chains. Dextrose and lactose are not fermented. Indol reaction is weak. The pus in the lesions contains granules the size of a millet seed. Microscopically these show at their peripheries swollen, finger shaped, branched forms whose central ends are pointed. The filaments are Gram-negative. The central portion does not contain a branched mycelium. Isolated threads are not found in the pus.

Enlows (1920) states "Type species (monotypy). A. lignieresi. Streptobacillary, bacillary or coccoidal in form. Gram-negative. Never filamentous."

Merrill and Wade $(1919$, p. 64) state that this name was given to a supposed subtype of Discomyces; but that the distinction has not been recognized, and by most authors the name is considered a synonym.

Buchanan (1918, p. 404), Winslow et al. (1920, p. 198) and Bergey et al. (1923, p. 338) recognize the genus with the following diagnosis:

Filament formation, resembling streptobacilli. In lesions no mycelium is formed, but at peripheries finger shaped branched cells are visible. Gram negative. Not acid fast. 
It is included in the family Actinomycetaceae.

Beijerinck (1914, p. 96) renamed his Bacillus oligocarbophilus as Actinobacillus oligocarbophilus and his Actinomyces (Streptothrix) paulotrophus as $A$. paulotrophus. No indication is given of the previous use of this generic name by Brumpt. The organisms described are probably sufficiently unlike those causing actinobacillosis in cattle to prevent their inclusion in the same genus. Probably Beijerinck's Actinobacillus is to be regarded as an invalid homonym. His description of the genus and the two species follows:

Drittens, die Gattung Actinobacillus, wclche zu der Familie der Actinomyceten gehört und desshalb typisch unbeweglich ist. Unterscheidet sich von der Neumann und Lehmann aufgestellten Gattung Mycobacterium durch das volständige Fehlen der Verzweigung, sodass man nur Stäbchen oder Fäden findet. Erzeugt die characteristische treibende "Kahmhaut" auf der Oberfläche der nitrifizirenden Flüssigkeiten. Darin finden sich zwei Arten nämlich:

a. Actinobacillus oligocarbophilus welche sich ernähren kann von den Kohlenstoff verbindungen der atmosferischen Luft und dann das "Kahmpilzmerkmal" zeigt; anderseits auf den verschiedensten organischen Nährböden wachst ohne das "Kahmpilzmerkmal." Letzterer Zustand auf Kieselplatten zurückgeimpft zeigt das "Kahmpilzmerkmal." Doch kann das Merkmal verloren gehen durch lange fortgesetzte saprophytische Lebensweise. Verflüssigt Nährgelatine nicht.

b. Actinobacillus paulotrophus. Erzeugt auf den nitratierenden Platten schimmelartige Kolonien mit "Lufthyphen;" besteht jedoch mikroskopisch anscheinend aus gleichärtigen Stäbchen und Fäden. Wächst durchaus nicht bei Gegenwart organischer Substanz.

Viertens, die Gattung Actinomyces wovon verschiedene Arten, in geringer Anzahl in den "Kahmhäuten" von Actinobacillus vorkommen können, daraus jedoch bei den Ueberimpfungen bisweilen gänzlich verschwinden.

If generic rank is to be accorded organisms of this type, the name Actinobacillus Brumpt would appear to be valid, otherwise it should be suppressed as a synonym. Organisms of this type have probably been included by various writers under the generic names Actinomyces, Bacterium and Bacillus.

It is possible that Actinobacterium Haass should be regarded as an invalid synonym.

In the present volume the generic name Actinobacillus is accepted in the sense of Brumpt.

Actinobacilo. A Spanish casual name first used by Lignières and Spitz (1902, p. 169) for the organisms later named Actinobacillus (q.v.).

Actinobacter. A generic name for certain milk bacteria proposed by Duclaux (1882, p. 110). 
The first species described (the type species) is Actinobacter polymorphum Duclaux. In milk the organism occurs as rods 2 to $3 \mu$ in length, each surrounded by a hyaline capsule 5 to $6 \mu$ in length. At first the milk retains its normal appearance, and gradually becomes gelatinous and at last viscous. The opacity is in part lost, the transparency increases, the coagulum settles out and disappears. Finally the transparent liquid shows little more viscosity than the normal milk. In the later stages the organisms are 2 to $3 \mu$ long by $1 \mu$ in diameter and without capsule. In Liebig's bouillon there are no capsules, the cells may attain a length of 8 to $10 \mu$. In a glycerine medium the capsules are present. The capsule does not disappear as in milk, "sans doute parce que le liquide reste acide." In sucrose medium the growth and appearance is much as in glycerine. Gas (carbon dioxide and hydrogen) were formed from sugar, but not from glycerine.

Maggi (1886, p. 174) includes Actinobacter as a valid genus. It appears evident from the characterization of this organism that it is a member of the colon group of bacteria, probably closely related to organisms of the type of Bacterium lactis aërogenes. The description is too indefinite however to allow of accurate diagnosis at the present time. It is included by Löhnis (1911) with the Bacterium pneumoniae group. It is rejected as invalid by E. F. Smith (1905, p. 174).

Enlows (1920, p. 12) characterizes the genus as follows:

Type species (monotypy). A polymorphus. Polymorphic. Non-motile, very thin small rods 2 to $3 \mu$ long, surrounded by a hyalin, oval or round, gelatinous envelope 5 or $6 \mu$ long. The organism gradually passes over into very short cylinders not more than $1 \mu$ long, which are not capsulated. No capsule ever forms in Liebig's bouillon, where the organism may reach $10 \mu$ in length. Aërobic. Multiplication by transverse division. Transforms the casein of milk into a water-soluble albuminoid, and milk-sugar into alcohol and acetic acid. Found in milk.

If the group of colon bacilli or colon-typhoid bacilli are to be accorded generic rank the name Actinobacter must be considered as one which might be used in its designation. It is questionable however whether the type species can ever be identified from the description, and probably it is unwise to use as a genus name one in which the type species is so uncertain. Other bacteria have apparently not been placed in the genus by other authors. It is evident thercfore that without emendation this name can scarcely be regarded as valid. It may be listed as a synonym of Bacterium (q.v.). 
Actinobacterium. A generic name proposed by Haass (1906, p. 180) to apply to two strains of organisms termed by him Actinomyces Klinik I and II which were found to differ from all of eleven other types studied. These were isolated from pus from cases of human actinomycosis. They were similar to the forms described by Wolff and Israel, by Silberschmidt and by Wright as anaerobes. The organisms had short cells, somewhat branched, and were Gram-positive. Haass notes that Lignières and Spitz previously used the generic name Actinobacillus for a similar type. He believes the genus to be intermediate between Actinomyces and Corynebacterium. Sampietro (1908, p. 331) described an Actinobacterium israeli var. spitzi.

No species of the genus was named by Haass, if valid therefore it should be credited to Sampietro. It may perhaps be regarded as a synonym of Actinomyces.

Reitz (1906, p. 731) apparently confused this name with Actinobacter (q.v.) and refers to Actinobacterium lactis viscosum.

Actinocladothrix. A generic name ascribed to Affanassieff by Levy (1899, p. 2), by Schlegel (1913, p. 303), and by others. It seems probable that they are in error in giving the name generic rank. Affanassieff $(1888$, p. 79) himself gave the name Bacterium actinocladothrix to an Actinomyces. De Toni and Trevisan (1889, p. 928) also give the synonym Bacterium actinocladothrix Afanassjew 1888 to Nocardia Actinomyces Trevisan (Actinomyces bovis Harz.) Brumpt (1910, p. 844) gives the name the same specific form. The use of the name Actinocladothrix as a generic designation is therefore based upon false premises. The correct generic designation would seem to be Actinomyces.

Actinococcus. A name proposed by Kützing for a genus of algae, included by Pfeiffer (1870, p. 11) in the tribe Chaetophorae.

Beijerinck (1914, p. 196) suggested the generic name Actinococcus to apply to a bacterial species $A$. cyaneus. Beijerinck isolated this organism from garden soil on a medium particularly adapted to the culture of Actinomyces, containing glucose, calcium malate, ammonium sulphite, dipotassium phosphate and agar. Gelatin was liquefied slowly, and agar made alkaline by the formation of ammonium carbonate. In a medium with peptone the color is rose, with glucose and nitrate of potassium or ammonium it remains violet. Ammonium acetate is very favorable for the production of the violet color. The pigment is blue with alkalies and red with acids. The organism he believes belongs with the genera Corynebacterium, Mycobacterium and Actinomyces. This relationship is indicated by the dry colonies, the disposition of the cell 
in radiating rays, and the branched appearance of the rays. Later (1914, p. 99) he mentions the creation of the generic name.

It would seem that the prior use of Actinococcus for a genus of algae would invalidate its use for a genus of bacteria.

Actinomyce. A generic name proposed by Meyen (1827, p. 442) for a fungus species Actinomyce Horkelii. The genus was placed in the new group Hydrotremellinae. The generic description follows:

Sporodochia, cellulis hyalinis simplicibus, enormiter et multipliciter ramificantibus sporis impletis, substantiae uniformi gelatinosa hyalina induta.

This generic name is of importance in bacteriology only because it was given prior to the use of Actinomyces by Harz for an entirely distinct organism. In many references the spelling is made identical, but it will be noted that there is a difference. For example Streinz $(1862$, p. 3) in his "Nomenclator fungorum" writes "Actinomyce Meyen (Strahlenpilz) eine neue Pilzgattung."

Perroncito (1879, p. 35), Musgrave, Clegg and Polk (1908, p. 458), Merrill and Wade (1919, p. 65), Chalmers and Christopherson (1916, p. 227) and others have urged that this use precludes the validity of Actinomyces Harz, q.v.

It is probable that Actinomyce Meyen should not render invalid Actinomyces for the following reasons:

1. The spellings are different. The botanical code expressly provides that names differing only by a single letter may both be valid if both do not come within the same family, and are not likely to give rise to confusion.

2. No other author apparently has used Actinomyce Meyen, and it may be said to be "universally regarded as invalid."

Actinomyces. The generic name Actinomyce was used by Meyen (1827, p. 442) for a genus of fungi belonging to the Hydrotremellinae Meyen, with one species A. Horkelii Meyen. For reasons why this should not be regarded as invalidating the subsequent use of Actinomyces, see Actinomyce.

In 1877 the name Actinomyces was applied to a genus of thread bacteria by Harz (1877, p. 125). The material containing the organism was sent to Harz by Bollinger. It consisted of granules secured from pus from cattle affected by "lumpy jaw." The granules were found to consist of slender filaments, irregularly branched, radiating from the center, and with the ends of the filaments in the form of refractive swellings. The name Actinomyces bovis was given it. 
In the following year, Rivolta (1878, p. 201) used the generic designation Discomyces (q.v.). The name Actinomyces bovis Harz, however, was recognized by Rivolta in 1884. At this time he differentiated between $A$. bovis and two other species which he termed Discomyces equi and $D$. pleuriticus.

Actinomyces was used as a generic name by several authors during the next decade. Perroncito $(1879, \mathrm{p} .35)$ noted that the name Actinomyces should be changed because of the previous use by Meyen of Actinomyce for one of the Coniomycetes. Hertwig (1886, p. 365) described an Actinomyces musculorum, which was further studied by Duncker (1887, p. 224). Schroeter (1886, p. 174) recognized the genus Actinomyces Harz, regarding Discomyces Rivolta as a synonym. He gives the following generic description:

Fäden sehr dünn, etwa bis $0.5 \mathrm{~mm}$. lang, um einen festen Kern, welcher in den Fäden durchzogen wird, strahlig ausgebreitet, mit unregelmässig abgehenden Aesten, an den Enden in keulenförmige, stark lichtbrechende Auschwellungen übergehend, welche Gliederung zeigen.

Trevisan (1889, p. 927) recognized the fact that an organism named by Cohn (1875, p. 186) Streptothrix Foersteri was closely related to the Actinomyces bovis Harz. He concluded that neither Actinomyces Harz, nor Streptothrix Cohn were tenable, the former because of prior use by Meyen (1. c.) and the latter by Corda (1839, p. 23). He accordingly named the genus Nocardia, with Nocardia Actinomyces Trevisan as one of the five species. Sauvageau and Radais (1892, p. 242) suggested as a result of comparing the genus Streptothrix of Cohn with other known Hyphomycetes, that this genus should be merged with the Ospora of Wallroth $(1837$, p. 182). Several authors have used this generic name. Lindau (1910, p. 720) as recently as 1910 reaches the conclusion that this form is most closely related to Oospora.

The name Actinomyces has been used as a generic designation by many authors. Ludwig (1892, p. 3) defined the genus as having branched filaments, the branches swollen at the tips. Terni (1894, p. 79) noted the previous use by Corda of Streptothrix and accepted Actinomyces. Gasperini (1895, p. 82) concluded that it is valid and should replace Streptothrix Cohn, Discomyces and Pleurimices Rivolta, Bacillus Nocard, Micromyces Grüber and Oospora Sauvageau and Radais. Lachner-Sandoval (1898) made a careful study of the nomenclature of the genus and concluded the right generic designation to be Actinomyces. Levy $(1899$, p. 1) confirmed his conclusions. Berestnew $(1899, \mathrm{p} .390)$ concluded that on botanical grounds the name is tenable, 
and that it is a most appropriate designation both because it indicates a most important characteristic of the colonies on artificial media and because it shows relationship to the fungi. Lehmann and Neumann (1896) in the first edition of their Grundriss use the name Oospora, but in later editions they have followed Lachner-Sandoval in the use of Actinomyces.

Gedoelst (1902) concludes Actinomyces to be invalid, and substitutes for it Rivolta's term, Discomyces. This point of view is also taken by Moore and Wade (1919, p. 55.)

Wright (1904, p. 349) concludes that the name Actinomyces should be strictly limited to the parasitic forms which produce rays in tissues, and do not form chains of conidia or spores on artificial media. For the forms which do not show the clubbing in tissues and which develop chains of conidia he used the name Nocardia Trevisan as emended by Blanchard (1896, p. 853). Jordan (1910, p. 411) used the same basis of differentiation. The genus Actinomyces has also been recognized by Orla-Jensen (1909, p. 334) and by Schlegel (1913, p. 302). The latter author emphasized the formation of a true branched mycelium, reproduction by conidial chains, and by the presence of the rayed form in the body tissues. Petruschky (1913, p. 270) gives a very confused discussion of this nomenclature. He concludes that Actinomyces should be strictly limited to the clubbed or ray forms in tissues, and that others should be termed Streptothrix. Pinoy (1911) introduced the new generic name Cohnistreptothrix for organisms of the type of Cohn's Streptothrix foersteri. In a later article (1913, p. 929) he reviews the use of the various generic names proposed, and concludes that Streptothrix must be reserved for the hyphomycete of Corda, and that Actinomyces is equally untenable. Discomyces he states was not proposed originally as a strict generic designation, but as a common name and furthermore that it resembles in form too closely the group name Discomycetes of the Pezizales. He quotes the action of the botanical section of the first International Congress of Comparative Pathology, which decided to adopt the generic name Nocardia of Trevisan. $\mathrm{He}$ divides the old genus Actinomyces into two, Nocardia with $N$. bovis as the type, and Cohnistreptothrix with $C$. foersteri and $C$. israeli as the best known species. Nocardia includes those forms which are aërobic, grow readily on artificial media and produce arthrospores. Cohnistreptothrix on the other hand, includes those forms which are anaerobic or at least microaërophilic, are relatively more difficult of cultivation and do not produce arthrospores. This author comes to the conclusion 
that the presence or absence of "clubs" when growing in tissues is not diagnostic. These are the result of certain interreactions between parasite and host, and may be produced in either genus under the right conditions.

Buchanan (1918, p. 405) characterized the genus as follows:

Branched filaments, resembling mycelium, breaking up into segments which may function as conidia. Usually parasitic. Clubbed ends conspicuous in lesions. Not producing aërial hyphae or conidia.

The type species is Actinomyces bovis Harz, the cause of bovine actinomycosis.

Castellani and Chalmers (1919, p. 1041) reject Actinomyces in favor of Nocardia. Waksman (1919) in his monographic treatment of the group accepts the generic name Actinomyces as does also Lieske (1921, p. 5).

The description used by the "Committee" of the American Society of Bacteriologists (1920, p. 198) and by Bergey et al. (1923, p. 339) follows:

Organism growing in form of a much-branched mycelium, which may break up into segments that function as conidia. Sometimes parasitic, with clubbed ends of radiating threads conspicuous in lesions in animal body. Some species are microaerophilic or anaerobic. Non-motile.

The type species is Actinomyces bovis Harz.

Merrill and Wade (1919, p. 63) insist upon the non-validity of Actinomyces and the validity of Discomyces.

The claim of legitimacy for Actinomyces as a generic name for the organism causing lumpy jaw and other similar affections is menaced by two facts: First, the name Actinomyce was used by Meyen in 1827 for an entirely distinct fungus; Second, the generic name Streptothrix Cohn has priority. Probably the best analysis of the situation is that which has been furnished by Breed and Conn (1919, p. 585; 1920, p. 489). They say (1919, p. 594)

Two attempts have already been made to establish the validity of a generic name for this group of organisms through legislative action both of which must be regarded as abortive. The first was taken by a Committee of the English Society of Pathologists who, as reported by Foulerton (1912, p. 304), approved the term Streptothrix Cohn in ignorance of the general and wide usage of Streptothrix Corda. The second was taken by the Botanical Section of the First International Congress of Comparative Pathology according to Pinoy (1913, p. 933) and confirmed by him in a letter dated September 9, 1918. The name ac- 
cepted was Nocardia. The official record of the Congress however contains no reference to this action which is stated to have been taken during the discussion of a paper by Potron (1912). As this action ignores the stronger claims of $A c$ tinomyces and Discomyces, and does not appear in the official record, it cannot be regarded as final.

And further:

Because of confusion between Streptothrix Corda 1839 and Streptothrix Cohn 1875 and the general use of the former term by mycologists, the latter term should be generally disregarded. According to the International Rules of Botanical Nomenclature, the limited use of the term Actinomyce by Meyen in $182 \mathrm{~S}$ and 1832 is not sufficient to invalidate the generally used Actinomyces Harz 1877 provided the latter is accepted as a genus conservandum by an International Botanical Congress. The continued use of the latter term is therefore recommended. The type species of the genus is $A$. bovis Harz.

Later they note that both botanical and zoölogical codes provide for the retention of generic names which differ only by a single letter (International Botanical Code, Chapter III, Article 57). They note further etymological differences between Actinomyce and Actinomyces, (1920, p. 490).

Although the stem words from which Actinomyce and Actinomyces are derived have identical meaning in the original Greek, "myce" is derivcd from the less commonly used feminine word, $\mu$ v̌ $\eta$, while "myces" comes from the masculine noun, $\mu$ vik $\eta$. Thus the two generic terms in question ought not to be regarded as homonyms as is done by Merrill and Wade. This view we find has already been expressed by Güssow (1914) in a paper which we had overlooked, and is confirmed by those authorities with whom we have consulted. This being the case legislative action by an International Congress is unnecessary. Actinomyces Harz is valid without such action and should be retained rather than Discomyces Rivolta.

The generic name Streptothrix Cohn which has been held by some writers to have priority over Actinomyces is clearly invalid. Corda's genus Streptothrix is well characterized both by description and figure, it has had additional species described, and is generally recognized in classifications of the Hyphomycetes. The genus Oospora Wallroth includes forms which are quite unrelated to Actinomyces; these forms should therefore not be ascribed to it.

A real difficulty also presents itself when an attempt is made to pick the type of the genus. It would seem certainly that to it the name Actinomyces bovis should be given. Harz did not publish cultural characters. It is impossible to determine with certainty just what his 
species was. Bostroem cultivated an aerobic type which produced spores. Wolf and Israel described an anaerobic asporogenous type. Wright and Pinoy have both shown the latter to be far more common. The probabilities are that it was this form that was observed by Harz. It would seem logical therefore to apply to it the name Actinomyces bovis. Pinoy (who accepts Nocardia instead of Actinomyces) insists that the organism described by Bostroem, i.e., the aerobic spore producing form be taken as the type. Wright states, "I think that the generic name Actinomyces should be restricted to microörganisms with the biological characters described in this paper (i.e., the Wolf-Israel type.)" Certainly to call the organism most frequently associated with lumpy jaw in cattle anything other than $A$. bovis would prore to be confusing.

The difficulty is even more apparent and its solution more important if the genus is to be split into two. IVright uses Actinomyces for the anaërobic sporeless forms, and for the aërobic conidia formers the name Nocardia, following the emendation of the genus by Blanchard (1896, p. 856). Pinoy, on the other hand, uses the designation Cohnistreptothrix for the forms termed Actinomyces by Wright, using the name Nocardia in Wright's sense.

It would appear, therefore, that the demands of priority would be satisfied by Wright's use of the terms. If all are to be included in a single genus, it should be Actinomyces, if two genera they should be Actinomyces and Nocardia. Cohnistreptothrix is to be regarded as a synonym of Actinomyces in the narrow sense. The generic names Streptothrix and Oospora should not be used for this group.

Actinomycetaceae. A family name suggested by Buchanan (1918, p. 403) as the single family of the order Actinomycetales. The Committee of the Society of American Bacteriologists (1920, p. 198) have suggested its use as the name of one of the two families of the Actinomycetales, the other being Mycobacteriaceae. The Committee description is "Filamentous forms often branched and sometimes formed mycelia. Conidia sometimes present. Some species parasitic." This description is also used by Bergey et al. (1923, p. 338).

In the present volume the recommendation of the Committee is followed.

Actinomycetales. A designation suggested by Buchanan (1917, p. 162) for the order of the mold bacteria. The original description follows:

Mold-like organisms, not typically water forms, saprophytic or parasitic. Sheath not impregnated with iron, true hyphae with branching often evident, 
conidia may be developed, but never endospores. Without granules of free sulphur and without bacteriopurpurin. Never producing a pseudoplasmodium. Always non-motile.

The description was emended by the Committee of the Society of American Bacteriologists to read as follows:

Cells usually elongated, frequently filamentous and with a decided tendency to the development of branches, in some genera giving rise to the formation of a definite branched mycelium. Cells frequently show swellings, clubbed or irregular shapes. No pseudoplasmodium. No deposits of free sulphur or iron. No bacteriopurpurin. Endospores not produced, but conidia developed in some genera. Usually Gram-positive. Non-motile. Some species are parasitic in animals or plants. Not water forms. Complex proteins frequently required. As a rule strongly aerobic, (except for some species of Actinomyces and the genera Fusiformis and Leptotrichia) and oxidative. Growth on culture media often slow; some genera show mold-like colonies.

This description is also used by Bergey et al. (1923, p. 337).

The committee recognized two families as belonging to this order, Actinomycetaceae and Mycobacteriaceae. The committee's suggestion is followed in the present volume.

Actinomycetes. This family designation of the thread fungi was probably first proposed by Balbiani (1886, p. 542). Later LachnerSandoval (1898) included in it the single genus Actinomyces Harz. Lehmann and Neumann (1901, p. 127) include within the family three genera, Corynebacterium L. and N., Mycobacterium L. and N., and Actinomyces Harz. They give the following description of the family.

Delicate thread organisms, without chlorophyll, with true branching, in some cases with an abundant branched mycelium and the formation of conidia. Young cultures often show only unbranched rods resembling bacteria which can in no way be differentiated from the ordinary fission fungi. According to many authors there is a tendency to the formation of clubs or knobs at the ends of the threads.

The three genera may be differentiated by the following key:

A. Cultures showing ordinary bacterial characters, flat or medium, microscopically rods with swollen ends. Corynebacterium L. \& M.

B. Cultures on solid media more or less folded.

I. Usually short slender rods only, seldom short branched filaments, without aerial mycelium and without aerial conidia. Acid fastMycobacterium L. \& N.

II. Mycelial filaments long, often bent, without sheath, with true branching. Many species produce conidia or aerial hyphae. Not acid fast-Actinomyces Harz. 
Orla-Jensen (1909) gives Actinomycetes as the name of the second family of the bacterial order Cephalotrichinae. He includes in it four genera, Rhizomonas Jensen, Corynemonas Jensen, Mycomonas Jensen, and Actinomyces Harz. The designation has been extensively used in the literature as a group name.

It would seem that the form Actinomycetaceae would better fit nomenclatural usage in accordance with Article 21 of the botanical code, and in this form would be a valid family name.

Aerobacter. A generic name proposed by Beijerinck (1900, p. 198) for certain gas producing bacteria of the so-called "colon" group. In sugar solutions all are facultative anaerobic, all ferment dextrose and levulose with the formation of levo-rotatory lactic acid and usually with production of gas as well. The gas is a mixture of carbon dioxide and hydrogen. Sulfates are never reduced, while nitrates are readily reduced with formation of nitrites, but never of ammonia. No spores are formed. The organisms are easily killed by heating to $65^{\circ} \mathrm{C}$. The cells are frequently motile, either peritrichous or monotrichous. The temperature optimum is about $28^{\circ} \mathrm{C}$. The following are the best known species which he lists.

Aërobacter aērogenes (Bacillus lactis aërogenes Escherich)

A. coli (with many varieties, best known, commune)

A. viscosum

A. liquefaciens (Digests gelatine, monotrichous)

Buchanan (1918, p. 53) used this as a subgeneric designation for the colon group of the genius Bacterium, with the following diagnosis: "Fermenting both glucose and lactose with formation of both acid and gas. Pathogenicity slight." The type species was designated as Bacterium (Aerobacter) coli. This is probably to be regarded as an error. A reading of the characterization of the genus by its author emphasizes that Bacterium (Aerobacter) aerogenes is, instead, the type for in the list and description of species the latter organism is first given.

Beijerinck (p. 197) emphasizes that this group is to be regarded as a true genus and not merely a physiological genus such as his Photobacter

Aerobacter is rejected by Smith (1905, p. 174).

An Aerobacter tartarivorum was named by Nijdam (1907).

Enlows (1920, p. 13) gives the following characterization of the genus. 
Facultative anaerobic organisms which give the "white lead test" with production of sulfides, and certain related ferment organisms. No spores. Very resistant to drying. Ferment dextrose and levulose with production of gas and usually lactic acid. Sulfates not reduced. Nitrates reduced to nitrites, but not to $\mathrm{NH}_{3}$.

Species. Bacillus coli communis Escherich. Includes here also B. liquefaciens Tataroff, and Bact lactis aerogenes Escherich, the latter becoming Aërobacter aerogenes.

Bergey (1923, p. 205) recognizes the genus with the following description:

Motile or non-motile rods, commonly occurring in the intestinal canal of normal animals. Produce acetyl-methyl-carbinol.

The type species is Aerobacter aerogenes (Escherich) Castellani and Chalmers.

If the colon typhoid group is to be subdivided, it would seem that Aerobacter should be regarded as a valid generic name with Aerobacter aerogenes (Escherich) Beijerinck as the type.

Aerogenesbacterium. A generic name suggested by Orla-Jensen (1921, p. 272). His statement follows:

The genus Bacterium will undoubtedly dissolve into several genera, of which I may especially mention the Colibacterium, and Aerogenesbacterium. The reason why I am now inclined, in contrast to my earlier opinion, to consider the coliand aerogenesbacteria as two different genera, is because they differ not only in morphological, but, as later researches have shown, also in biological respects. I have myself proved (1914), that the Aerogenesbacteria completely oxidize the carbohydrates when the nutrient matter offers a sufficient buffer effect, and they thus correspond with their name in forming more gas than do other bacteria, and Rogers, Clark and Davis (1914) have shown that in the gas developed by the Colibacteria there is proportionately more hydrogen than in that developed by the Aerogenesbacteria.

This generic designation is apparently a synonym of Aerobacter Beijerinck. It is also questionable whether the indirect reference is sufficient to establish a species. It is probable that Aerogenesbacterium aerogenes would be considered the type species, although this combination was not used by Orla-Jensen.

Aethyl-Bacillus. A name used by Fitz $(1878$, p. 48) as a pseudogeneric or casual designation for a rod shaped organism capable of producing ethyl alcohol from glycerin. It is rejected by Smith (1905, p. 174) and is invalid as a generic name.

Agonium. A generic name used by Oersted (1844, p. 44) to designate a marine organism, probably an alga (See De Toni. Sylloge 
Algarum 5, 684, 1907). It is placed questionably among the bacteria by De Toni and Trevisan $(1889$, p. 938) with the following description:

Filamenta cylindrica, articulata, simplicia, basi ab apice superiore distincta, e puncto centrali commune radiatim exorientia, caespites formantia. Sporae (endosporae) maximae, ovales, singulae in unoquoque articulo obvientes.

The only species (type) is Agonium centrale Oersted.

It is doubtful whether this genus should be included with the bacteria.

Aktinomyces. A German variant in the spelling of the generic name Actinomyces, q.v. Apparently the first record of its use is by Johne (1881, p. 143). It is probably invalid.

Albococcus. A genus of cocci proposed by Winslow and Rogers (1906, p. 541) with Micrococcus pyogenes (Ros.) Mig. as the type. The characteristics of the genus are given as follows:

Parasites. Cells in groups and short chains (never in packets). Generally stain by Gram. Growth on agar streak abundant and porcelain white in color. Sugars fermented with production of slight amount of acid. Gelatin liquefaction and nitrate reduction may or may not occur.

Four species are noted. Albococcus pyogenes (Ros.) W. and R., A. rhenanus (Mig.) W. and R., A. candicans (Flügge) W. and R. and A. canescens (Mig.) W. and R.

Later the Winslows (1908, p. 192) revised their list of species, giving Albococcus pyogenes (Rosenbach) Winslow, Alb. epidermidis (Goldon) Winslow, Alb. candidus (Cohn) Winslow, and Alb. tetragenus (Gaffky) Winslow.

Kligler (1913, p. 432) has added one species, Alb. ureae (Cohn, Flügge) Kligler.

The genus Albococcus is one of the genera included by the Winslows in the subfamily Paracoccaceae (g.v.)

To organisms of this group the generic name Micrococcus (q.v.) was given by Cohn. The forms occurring in irregular masses or grape like clusters, particularly those occurring in pus, were named Staphylococcus (q.v.) by Rosenbach (1884, p. 19). The species described were the golden and the white pus cocci, or Staphylococcus pyogenes aureus and Staphylococcus pyogenes albus. On a later page, in a main heading, the phrase "Staphylococcus aureus (mit oder ohne albus)" is used. The trinomial forms of the names first given would probably bar the use of the generic designation Staphylococcus unless a species 
Staphylococcus pyogenes with two varieties aureus and albus could be conceived. However, the use by Rosenbach himself of the binomial forms Staphylococcus aureus and Staphylococcus albus answers all nomenclatural requirements. Migula (1894, p. 237) concluded this genus should be merged with the older genus Micrococcus Cohn, the species becoming $M$. aureus (Ros) Migula and $M$. pyogenes (Ros.) Mig.

The Winslows concluded that these species should constitute the types of the genera Aurococcus and Albococcus respectively. They discarded the name Staphylococcus (q.v.) apparently without sufficient justification. The rules of botanical nomenclature state explicitly that when a genus is split into two genera the original generic name must be retained for one genus. (See Art. 45, International Rules for Botanical Nomenclature.) Inasmuch as Staphylococcus aureus was the first to be described, the generic name Staphylococcus might appropriately be retained for the genus of which this is the type. Accordingly the generic designation Albococcus for the white form would appear consistent. It should be noted that the original specific designation of albus should be retained, the type of the genus then being Albococcus albus (Rosenbach) and not Albococcus pyogenes (Rosenbach) Winslow.

In the Preliminary Report of the Committee of the Society of American Bacteriologists (Winslow et al., 1917, p. 559), the genus Albococcus is recognized with the following diagnosis:

Differs from Staphylococcus in forming more abundant surface growth of porcelain white color, and in fact that liquefaction of gelatin when present is less vigorous.

Buchanan (1917, p. 612) included Albococcus as a synonym of Staphylococcus.

In the Final Report (Winslow et al., 1920) the genus Albococcus is merged with Staphylococcus.

Enlows characterizes the genus as follows:

Parasites. Cells in groups and short chains (never in packets). Generally stain by Gram. Growth on agar streak abundant and porcelain white in color. Sugars fermented with production of a slight amount of acid. Gelatin liquefaction and nitrate reduction may or may not occur.

Type species (original designation). A. pyogenes (M. pyogenes (Rosenbach) Migula). Also include here A. rhenanus (Migula), A. candicans (Flügge), and A. canescens (Migula). 
This genus has been considered invalid by Winslow, Rothberg, and Parsons (J. Bact., v. 5, no. 2, 1920, p. 161). The type species A. pyogenes together with Staphylococcus epidermidis albus (Welch) Gordon, and Albococcus epidermidis the Winslows, becomes Staphylococcus epidermidis.

If the white pus cocci and related forms are to be grouped together as a genus, the generic name Albococcus Winslow with the type species Albococcus albus (Ros.) would appear to be valid. If they are not sufficiently distinct to warrant generic recognition, they should begrouped with the golden forms in the genus Staphylococcus Rosenbach.

Alcaligenes. A generic name proposed by Castellani and Chalmers. The first reference is 1919 , p. 936. It is here cited, however, as 1918. The diagnosis given is as follows:

Definition: Ebertheae which do not ferment glucose or lactose, and are characterized by their general lack of fermentative power and by actually increasing the alkalinity of the media. Milk is not clotted, and is rendered alkaline.

Type: Aicaligcnes faecalis (Petruschky, 1896), emendavit Castellani and Chalmers, 1918.

Here also comes Alcaligenes vivax (Archibald, 1918), which was obtained from the blood of a case of enteroidea in the Anglo-Egyptian Sudan, produced acidity in galactose and mannitol and was characterized by its marked motility.

The genus was also later discussed (1920, p. 604) with two species described.

Bergy et al. (1923, p. 233) included this as the sixth genus of the tribe Bactereae with the description "Motile or non-motile rods, generally occurring in the intestinal canal of normal animals. Do not form acetyl-methyl carbinol. Do not ferment any of the carbohydrates."

Alkalibacteriaceae. A family of bacteria named by OrlaJensen $(1909$, p. 313) belonging to the order Peritrichinae Orla-Jensen. It contains three genera, Liguidobacterium Orla-Jensen, Bacillus Cohn, Urobacillus Miguel. It includes those bacterial genera characterized by the production of a decided alkaline reaction in media as a result largely of the development of ammonia. The bacteria are neither obligate anaerobes or microaerophiles. The name of this family does not conform to Article 21 of the botanical code because it is not designated "by the name of one of its genera or ancient generic names with the ending aceae." It would appear therefore not to be tenable.

Alkaligenes. A variant spelling of Alcaligenes (q.v.). It was used by Castellani and Chalmers (1919, pp. 1405, 1408, 1409) in referring to their genus Alcaligenes described earlier in the same volume. It is also used by Evans (1923, p. 1945). 
Allococcaceae. A subfamily of bacteria belonging to the family Coccaceae described by Fischer (1897) (1903, p. 59). The subfamily is regarded as made up of two genera, Micrococcus Cohn and Planococcus Migula. It contains those cocci in which the planes of fission have no definite sequence, and there are no pronounced colonies or growth forms. The cells are isolated, in short chains or irregular clusters.

The ending of the name of this subfamily, if used, should be oideae rather than aceae in conformity with Article 23 of the International Code. The code specifically states: "Names of subfamilies (subfamilice) are taken from the name of one of the genera in the group with the ending oideae." As a subfamily name Allococcaceae would therefore appear not to be tenable for this reason and because not derived from the name of one of the constitutent genera.

Amoebobacter. A genus of the sulphur bacteria described by Winogradsky (1888, p. 71). He says,

. . . findet man eine Familie von so dicht zusammengepressten 7ellen, dass man die einzelnen Zellen fast gar nicht unterscheidet, und die ganze Gruppe fast homogen erscheint. Die Farbung ist zart rosenroth: hier und da finden sich wenige Schwefelkörnchen. Um die Zellenmassen sieht man eine Hülle, welche aus zwei Schichten besteht; eine immere schwach lichtbrechende und eine äussere stark lichtbrechende deutlich doppelt contourirte Schicht. Stellt man eine solch encystierte Familie ein, so sieht man etwa nach 4 Tagen dans die Cyste gesprengt wird und ihr nunmehr deutlich aus Coccen bestehender Inhalt äusserst langsam herauszukriechen beginnt. Der Austritt dauert manchmal 1-2 Tage. Es bliebt eine leere Cyst zürück, welche sich noch lange unverändert erhält. . . . . Der Gestaltwechsel der Amoebobacterfamilien hat seinen Grund darin, dass sowohl die einzelnen Zellen innerhalb der Familie, als die Familien als ganze beweglich sind.

Three species are described, Amoebobacter roseus, A. granula and A. bacillosus. In the first the cells are spherical 2.8 to $3.4 \mu$ in diameter, or elongate to $6 \mu$. In the second the cells are very minute, scarcely $0.5 \mu$, and in the last the cells are rod shaped, 2 to $4 \mu$ long and $1.7 \mu$ thick.

The genus was next recognized by De Toni and Trevisan (1889, p. 1043) as the only genus of the tribe Amoebobacterieae Trevisan. They give the following definition:

Cocci globos vel ovoideo-ellipsoidei, densissime in familias primitus adparenter fere homogenes, amoeboideomobiles cumulati cysti debus bistratosis circumcincti interiori stratu parum refringente, exteriori valde refrigente cito delabentibus. Cocci demum liberi mobiles. Coccorum divisio in unam directionem. 
Winogradsky's three species are recognized.

An adequate study of this group since the monograph of Winogradsky does not seem to have been made, although the genus Amoebobacter Winogradsky has been accepted by many subsequent authors. This genus was included by Migula (1900, p. 1045) in the subfamily Amoebobacteriaceae, together with the genera Thiodictyon, Thiothece and Thiopolycoccus. Migula (1904, p. 146) gave the following generic diagnosis: "Zellen zu Familien vereinigt, nach einen Richtung des Raumes sich teilend; Familien amoeboid beweglich, Zellen durch Plasmafäden verbunden."

Erwin F. Smith (1905, p. 163) likewise places the genus in the family A moebobacteriaceae, and with the following description:

Cells connected by plasma threads. Families amoeboid motile. The cell families slowly change form, the cells drawing together into a heap or spreading out widely, thus bringing about a change in the shape of the whole family. In a resting condition a common gelatin is extruded, the surface of which becomes a firm membrane.

In several descriptions, the connecting threads are designated as protoplasmic, apparently without sufficient justification. For example, Frost (1911, p. 61) in a tabulation of Migula's classification states:

The cells are united into colonies, and after division in one direction of space remain attached together by threads of protoplasm. The colonies possess amoeboid motility. The cells change form by contraction and the spreading out of the protoplasm.

Buchanan (1918, p. 469) designated the first species described by Winogradsky, A moebobacter roseus, as the type. His description follows:

Cells connected by plasma threads. Families amoeboid motile. The cell families slowly change form, the cells drawing together into a heap or spreading out widely, thus bringing about a change in the shape of the whole family. In a resting condition a common gelatin is extruded, the surface becomes a firm membrane.

Enlows (1920, p. 14) gives the following characterization:

Cells divide in one direction of space, usually round, and united into families by means of plasma threads. Families have amoeboid motion. In the resting state the extruded gelatin becomes stiffened, forming a firm 2-layered membrane. Sulfur granules here and there. Cell masses a delicate rose red.

Type species (subsequent designation by Buchanan (J. Bact., v. 3, no. 5, 1918, p. 469)). Amoebobacter roseus Winogradsky. Cells spherical, 2.8 to $3.4 \mu$ in diameter. Winogradsky also includes here A. bacillosus (rodlike cells 2 to 
$4 \mu$ long by $1.7 \mu$ ), and $A$. granula (cells spherical, exceedingly small-scarcely $0.5 \mu$ in diameter).

Bergey et al. (1923, p. 398) followed Buchanan.

Orla-Jensen (1909, p. 334) proposed that Amoebobacter be replaced by a new term Amoebomonas.

Apparently no author has studied the organisms of this genus since Winogradsky's original description.

Amoebobactereae. A variant spelling of Amoebobacterieae used by Bergey et al. (1923, p. 398) for the fourth tribe of the subfamily Chromatioideae with the description: "Sulphur bacteria in which the cells are united into families. Cell division occurring only in one direction of space."

One genus only, Amoebobacter is included.

Amoebobacteriaceae. A subfamily of the family Rhodobacteriaceae of the sulphur bacteria established by Migula (1900, p. 1045) to contain the genera Amoebobacter, Thiodictyon, Thiothece, and Thiopolycoccus.

This subfamily is characterized by having the cells united into families, cell division occurring in one direction of space. It has generally been recognized by subsequent authors dealing with this group, as Migula (1904, p. 146), Erwin F. Smith (1905, p. 163), Frost (1911, p. 61).

Article 23 of the International Rules for Botanical Nomenclature would require the change of the subfamily name to Amoebobacterioideae.

Amoebobacterieae. A subtribe of the tribe Ascococceae Trevisan (1889, p. 1043) established by Trevisan, to include the single genus Amoebobacter. The diagnosis given is "Cocci in muco matricali in series filamentosas laze conjuncti. Cystides universales tenuissimae, cito dilabentes. Cystides speciales nullae."

The International Rules of Botanical Nomenclature (Article 23) would require the change of this name if used for designation of a subtribe to Amoebobacterinae.

The same name was used by Buchanan (1918, p. 469) to designate a tribe with the following diagnosis "Sulphur bacteria in which the cells are united into families. Cell division occurring only in one direction of space." Four genera were included Amoebobacter, Thiodictyon, Thiothece and Thiopolycoccus. Bergey et al. (1923, p. 398) used the spelling Amoebobactereae g.v.

Amoebomonas. A name proposed by Orla-Jensen (1909, p. 334) to replace the generic name Amoebobacter, Winogradsky of the Rhodo- 
bacteriaceae. It is a synonym, and probably invalid as a generic designation. No species were designated.

Amphitricha. A designation suggested by Messea according to Kruse for those motile bacteria with a flagellum at each end of the cell. It is the first group of the Trichobacteria q.v.

Amylobacter. A casual name used by Trecul (1865, p. 435) for certain rods found between the cells of decaying plant tissues. He said

Malgré la varieté des formes de ces petits vegetaux, au plutôt à cause de cette varieté même puisqui l'on passe d'une forme à l'autre par toutes les gradations; en raison aussi de l'amidon qu'ils contiennent, et pour rappeler la resemblance des formes cylindroides avec les Bacteries, je crois utile de les reunir sous le nom d'Amylobacter. Si on voulait les diviser d'aprés les formes les plus disparates, on pourrait é tablir troir sous genres; 1, "l'Urocephalum qui comprendrait les formes en têtard; 2, l'Amylobacter vrai, auquel serarent attribuees les formes cylindraceés; 3 , le Clostridium, qui refermerait les formes en fuseau.',

This author gave no specific names. What was later regarded as the same organism was named Bacillus amylobacter by Van Tieghem (1879, p. 25).

Duclaux (1895, p. 813) revived the name, describing two species, Amylobacter butylicus, and Amylobacter ethylicus.

Ce sont partout des bacilles dont la largeur et la longueur varient avec le milieu de culture, cylindriques lorsqu'ils sont jeunes, se renflant plus ou moins quand ils vieillissent, en un point où apparaît la spore. Chez la plupart d'entre eux, de même du reste qu'avec des bacilles qui ne consomment ni amidon ni cellulose, la formation de les spore est précédée d'une période où une partié du protoplasme du bacille se colore par l'iode.

He notes that Beijerinck had previously suggested Granulobacter for this type of organism.

The genus should be ascribed to Duclaux. A. butylicus is the type. Amylobacter is listed as a synonym of Clostridium by Prazmowski (1880, p. 23) and by De Toni and Trevisan (1889, p. 1002). It is rejected by Erwin F. Smith (1905, p. 174).

The use by Trecul of the name Amylobacter does not entitle it to generic recognition because it was not coupled with the name of any particular species in the form of a binomial. It existed therefore, simply as a casual name until its use by Duclaux. In the meantime, however, the genus Clostridium (q.v.) had been created for such types of bacteria. As a generic designation it should probably be written 
Amylobacter Duclaux. It is a synonym of Clostridium, and Granulobacter at least in part.

Amylobakter. A German spelling of Amylobacter. A casual name. It has been used among others by Schattenfroh and Grassberger $(1899$, p. 700$)$. It is not a valid spelling of the generic name.

Aphaneroglia. A generic name proposed for the single genus of the first order Protobacteries by Maggi (1886, p. 81). One species, A. apuae potabilis is listed, but without description.

Aplanobacter. A generic name proposed for non-motile rods by Erwin F. Smith (1905, p. 171). The diagnosis given by Smith is as follows:

An unattached, non-motile, rod-shaped organism, destitute of chlorophyll and multiplying by fission, sometimes forming threads of considerable length. The type of the genus, in the family Bacteriaceae, is that organism causing anthrax and most commonly known in literature as Bacillus anthracis Cohn.

The generic names Bacillus Cohn and Bacteridium Davaine have both been applied to this type species. The type of the genus Bacillus Cohn is generally accepted as Bacillus subtilis Cohn. The essential morphological difference between $B$. subtilis and $B$. anthracis is the possession of peritrichous flagella by the former, and their absence in the latter. Smith contends that lack of motility is a characteristic which warrants the separation of the anthrax organism from Bacillus. Evidence is continually accumulating to show that generic separations among the bacteria solely on the basis of motility lead to a violent disarrangement of natural groupings. Granting, however, that another generic name should be found, Davaine's genus Bacteridium would appear to be tenable. It was founded upon the B. anthracis and created because of the lack of motility of this form. Smith argues that the name Bacteridium (q.v.) is preoccupied in botany. However, the names previously used (see discussion of Bacteridium) have been spelled Bactridium. Smith regards this as the same word, making Bacteridium untenable. As noted elsewhere, a strict interpretation of the rules of the International Code would indicate that the difference in spelling is sufficient to make the generic name Bacteridium valid. It should also be noted that the generic name Pollendera Trevisan (1885) has priority over A planobacter.

Migula has defined the genus Bacterium (q.v.) to include the nonmotile rods. As noted elsewhere, this use of the term Bacterium is scarcely justified, it probably should not be used in this group. 
It would seem that the generic name Aplanobacter Smith must be regarded as a synonym of Bacteridium Davaine, and hence invalid unless it can be shown that for some reason the latter name as well as Pollendera are not tenable.

Arloingillus. A genus of anaerobic spore bearing bacteria proposed by Heller (1922, p. 21). Her description follows:

Clostridioideae that attack sugars with considerable energy but have a somewhat restricted action on proteins. Liquefy gelatin but do not produce $\mathrm{H}_{2} \mathrm{~S}$ demonstrable by a lead-acetate-paper test in blood broth. In meat medium produce gas and a pink coloration that soon fades. Autoagglutinate readily. Clot milk if blood is present. Do not digest serum or egg. Vegetative forms are small Gram-negative rods with even staining; forms about to sporulate are uneven in staining reaction, often far larger than vegetative rods, citron or spindle shaped; orgonts (see Heller), show marked tendency to store up granulose. Spores oval, vary greatly in length. Bacilli do not form long chains in the liver of animals. Colonies in deep agar lenticular, sometimes showing concentric formation, or compound lenticular. Colonies vary considerably according to species. Typically toxic tissue invaders which produce marked haemolysis. Pathogenic for guinea-pigs, cattle and sheep.

Type species A. Chauvoei (Bacterium Chauvoei Arloing, Cornevin, and Thomas) as described in a future paper.

This genus contains several species which will be discussed. These organisms show some similarity to those of the genus Clostridium.

The B. enteritidis-sporogenes Klein, as described by von Hibler (1908) should probably be included in the genus. The only character which is markedly different from that of the genus is the energetic fermentation of milk shown by von Hibler's bacillus IV.

Arthrobacillus. A genus of bacteria proposed by Fischer (1895, p. 136) to include the non-motile rod-shaped organisms which produce arthrospores. No type was designated.

Arthrobacter. A generic name proposed by Fischer (1895, p. 141) to include all non-flagellate rod-shaped bacteria which produce arthrospores. No species are named, hence the genus is invalid. $\mathrm{He}$ says "Vorläufig kann keine Art mit Sicherheit hierhergestellt werden, vielleicht würde das Bacterium Ureae hierhergehören." He apparently ascribes the name to De Bary as he writes Arthrobacter (De Bary). Fischer (1903) himself later abandoned the designation. It is listed as invalid by Erwin F. Smith (1905, p. 174).

Arthrobacteriaceen. A "Gattung" proposed by Hueppe (1886, p. 145) to include the rod shaped bacteria which produce arthrospores or at least do not form endospores. The "Untergattungen" Arthrobakterium (Bakterium s. str.) and Spirulina (Proteus) are included. Evidently this should be regarded as a casual family name. 
Arthrobacterium. A name proposed by De Bary (1884) to include rod-shaped bacteria which produce arthrospores. No species were described. The genus was also mentioned by Hueppe (1886) and was included in his classification of bacteria. De Toni and Trevisan (1889, p. 1054) give Arthrobacterium De Bary (1887) as a synonym of Streptococcus. As stated by Vuillemin (1913, p. 520) this genus has not been preserved or used because it was founded upon the false assumption of arthrospore formation.

Enlows (1920, p. 15) states:

According to Comp. Morph. and Biol. Fungi, Mycetozoa and Bact., Auth. Eng. rev. trans. by Garnsey, Oxford, 1887, pp. 454 and 468. This genus is proposed for that group of the genus Bacterium in which no endogenous sporeformation occurs. "To denote the species which constitute the genus Bacterium of authors, I use partly the generic name Bacillus . . . . and partly the name Arthrobacterium. Single members may simply separate from their connections with others, and under suitable conditions become the initial members of new combinations; they have therefore claim to the name spore. In other respects there is no general characteristic distinction between them and the purely vegetative members.

Species. Bacterium zopfi Kurth, Bact merismopoedioides, Bact. aceti, and Bact. pastorianum Hansen.

Maggi (1886, p. 84) gives Arthrobacterium aceti De Bary as a synonym of Bacterium aceti Zopf.

It is doubtful whether the rather casual use by De Bary is sufficient to validate the genus. Apparently no type has been designated.

Arthrobactridium. A genus proposed by Fischer (1895, p. 140) to include those rod-shaped bacteria with diffuse flagella which produce arthrospores. The genus was later abandoned by Fischer (1903) as based upon a false interpretation of morphology. It is also rejected by Erwin F. Smith (1905, p. 174). The genus is not tenable because no species have been definitely assigned to it.

Arthrobactrillum. A generic name proposed by Fischer (1895, p. 139) to include those rod-shaped bacteria which are motile by means of a tuft of polar flagella, and which reproduce by means of arthrospores. The name is invalid. It rests upon a mistaken interpretation of morphology and has no described species. It was later abandoned by Fischer (1903) himself as untenable. It is also rejected by Erwin F. Smith (1905, p. 174).

Arthrobactrinium. A generic name proposed by Fischer (1895, p. 139) to include rod-shaped bacteria having one polar flagellum and producing arthrospores. This generic name has never come into 
general use. It is founded on a misconception of bacterial morphology, has no named species, and has been abandoned by its author (1903). It should be considered as invalid. It is rejected by Erwin F. Smith (1905, p. 174).

Arthrobakteriaceen. A variant of Arthrobacteriaceen. A name used by Hueppe, (1886, p. 145) for a "Gattung" including the rod-shaped bacteria which produce arthrospores or at least which do not produce endospores. The "Untergattungen" included are Arthrobakterium (Bakterium s. str.) and Spirulina (Proteus). The name is not Latin in form. It must be regarded as untenable.

Arthrobakterium. A spelling of Arthrobacterium De Bary (q.v.) used by Hueppe (1886, p. 145) to designate an "Untergattung" of the "Gattung" "Arthrobakteriaceen." It is also given as Bakterium sensu strictu. It includes those straight rod shaped organisms which produce arthrospores, or at least do not produce endospores.

Arthrokokkaceen. A name used by Hueppe (1886, p. 144) for a "Gattung" of bacteria with spherical cells which produce arthrospores or whose method of spore production is unknown. The following "Untergattungen" are included: Arthro-Streptokokkus, Leuconostoc, Merista, Sarcina, Mikrokokkus, Askokokkus. It may be regarded as invalid.

Arthromitus. A generic name proposed by Leidy (1849, p. 227) for two organisms found in the rectum of Julus. These he named Arthromitus cristatus and $A$. nitidus.

The following is the description given by Leidy to the genus and to the first species described:

Filaments always simple, cylindric, articulated, without ramuli, attached by means of a nuclear body, and with no evidence of interior structure.

Arthromitus cristatus. Filaments delicate, straight or inflected, growing in tufts usually of moderate density, from minute, attached, yellowish rounded or oval nuclear bodies. Articuli short, cylindric, uniform, measuring $\frac{1}{9} 0_{0} 0$ inch in length by $\frac{1}{150} \frac{1}{0} 0$ in breadth, with no traces of interior structure.

Length $\frac{1}{3} \frac{1}{7} 5$ to $\frac{1}{46}$ inch, breadth $\frac{1}{15 \frac{1}{000}}$ inch.

Habitat. Same as Cladophytum comatum, but rarely growing in such dense tufts.

Later $(1852$, p. 35) he described Arthromitus nitidus. This species is described as follows:

Filaments very long, hyaline, grows usually in twos or fours, pointed at the origin, rounded at the termination. Articuli very distinct, length equal to the breadth of the filament. Sporuli formed within the articuli solitary, usually oblique, oval, amorphous. 
Length 1 line by $\frac{1}{500}$ inch broad. Spores $\pi_{11}^{1} 1 \mathrm{~T}$ inch long, by $\frac{1}{2}, \frac{1}{5} \overline{0} 0$ inch broad.

Habitat. Grows in considerable quantity with a profusion of young of Enterobryus elegans from the mucous membrane of the posterior portion of the rectum of Julus marginatus.

Remarks. Since I established the genus Arthromitus I have observed the formation of its sporuli. These originate in the amorphous matter of the articuli, apparently by a very gradual aggregation and condensation of the contents. They are always single, and usually lie oblique, and frequently alternate with each other in this position in the different articuli. When they first appear they are larger than when fully formed, are frequently bent, or clavate in form, and very indistinct, but as they ripen they become more regular, oval, distinct, and quite refractile of light. Usually they are observed at the extremity of the filaments only, but frequently they are found existing in the whole length of the latter.

A species of Arthromitus, and also of Cladophytum is found in the intestine of Polydesmus virginiensis.

Robin (1853, p. 359) gives the following generic and specific description:

Filaments toujours simples, cylindriques, articulés, sans ramifications, fixés au moyen d'un corps nucléaire, sans structure bien définie.

Arthromitus cristatus, Leidy. Filaments fins, croissant en touffes médiocrement e'paisses, sur de petits corps arrondis, fixés et jaunatres; articles courts, cylindriques, uniformes, ayant $0^{\mathrm{mm}}, 002\left(\frac{1}{90} \overline{9} \overline{0}^{-}\right.$de pouce) de long et $0^{\mathrm{mm}}, 001\left(\frac{1}{1}, \frac{1}{0} \overline{0}\right)$ de pouce) de large, sans structure intérieure.

Ce végétal offre une longueur qui varie entre $0^{\mathrm{mm}}, 065$ et $0^{\mathrm{mm}}, 543\left(\frac{1}{375}\right.$ et $\frac{15}{45}$ de pouce), et une largeur de $0^{\mathrm{mm}}, 001\left(_{15} \frac{1}{0} \overline{0}\right.$ de pouce). Il se trouve dans les memes points que le Cladophytum comatum, mais rarement en truffes aussi épaisses.

Arthromitus nitidus, Leidy. Filaments très longs, hyaliıs. croissant au nombre de deux ou quatre, amincis à l'origine, arrondis vers leur terminaison: articles très distincts, à longueur égale à la largeur du filament, et renfermant des sporules généralement ovales, amorphes et isoiées.

Ce végétal a environ $2^{\mathrm{mm}}, 13$ (1 ligne anglaise de long), sur $0^{\mathrm{mm}}, 005{ }_{5} \frac{1}{000} \mathrm{de}$ pouce) de largeur. Spores, $0^{\mathrm{mm}}, 003\left(\frac{1}{711 \mathrm{~T}} \mathrm{dc}\right.$ pruce $)$ de long, ou $0 \mathrm{~mm}, 002 \frac{1}{12, \frac{1}{5}} \overline{0}$ de largeur.

Il croit en grande quantité avec l'Enterobryus elegans dans la muqueuse de l'extrémité du rectum du Iulus marginatus. Une espéce d'Arthromitus se trouve aussi dans l'intestin du Polydesmus virginiensis.

Les sporules des Arthromitus se forment par condensation de la substance amorphe qui remplit les articles. Ils sont toujours isolés, ordinairement placés obliquement. Quand ils commencent à se former, ils sont plus grands que lorsqu'ils ont acquis tout leur développement, un peu recourbés et très peu distincts; mais en murissant ils deviennent plus réguliers, ovales, très nets, et réfractant bien la muniére. Quelquefois on ne les trouve qu'à l'extrémité des filaments, mais souvent il en existe dans toute leur longueur. 
Collin (1913, p. 63) revived the generic name as a suitable designation for an organism from the alimentary tract of the frog. The species Arthromitus batrachorum is described as follows:

Son thalle filamenteux, non rameux, à croissance indéfinie, à contenu granuleux partagé en articles d'environ $3,5 u$ de large sur 2 a $3 \mu$ de hauteur, circulaires en coupe transverse, rappelle d'assez près le port de certaines Oscillariées mais il est incolore. De place en place, et sur certains thalles seulement, des cellules plus épaissies, à contenu très colorable font quelque peu saillie sur l'alignement des autres après la fixation; on voit souvent, de chaque coté, des cellules claires dégénérées. Je pense qu'il s'agit la peut-être d'éléments vieillis ou morts, tels que ceux qu'on observe chez beaucoup de Cyanophycées (les Scytonema par exemple), éléments qui pourraient se trouver libérés par la rupture du thalle. La sporulation a lieu par voir endogène, avec une spore pour chaque cellule et d'une manière toute sporadique pour les cellules d'un thalle donné; la spore est arrondie, circulaire en coupe transverse, mais très nettement ellipsoīde quand on l'apercoit de profil. Elle est située à l'intérieur de la cellule avec une forte obliquité. Les ébauches sporales, d'abord sphèriques et très petites, puis plus volumineuses, se colorent intensément par les méthodes à froid (hématoxyline ferrique par exemple), tandis au'à maturité complète, elles ne sont plus pénétrables qu'à chaud, comme chez les autres Bactéries. Rectum des tetards d'Alyte en compagnie de Bacillus camptospora et de Spirillum proeclarum; trouvé aussi (ou une forme très voisine) dans l'intestin postérieur des larves de Bufo calamita Laur. à Viarmes (Seine-et-Oise).

Chatton and Perard (1913, p. 1160) conclude that the Hygrocrocis intestinalis of Valentin and the Arthromitus cristatus of Leidy belong to the same genus, and on grounds of priority they select Hygrocrocis. They say:

Dans des préparations de contenu intestinal de termites nous avons retrouvé les Arthromitus de Leidy, et M. A. Borrel nous a montré chez des Blattes des schizophytes que nous identifions à l'Hygrocrocis intestinalis de Valentin. Il nous semble d'ailleurs que ces formes sont génériquement identiques.

Ce sont de longs filaments à compartiments subégaux, cubiques, à croissance indéfinie, immobiles, et qui au surplus sont, d'après Leidy, fixés à la paroi intestinale par bouquets sur une sorte de pied commun globuleux. Il y a dans les régions sporulées de ces filaments une endospore par cellule et ces cellules sporigènes ne sont point hypertrophiées. (See Hygrocrocis.)

Apparently Arthromitus is a valid generic designation.

Arthrospirobacterium. Enlows (1920, p. 16) states:

This genus has been ascribed to Hueppe. In his "Die Formen d. Bakt.," Wiesbaden, 1885, p. 146, where he classifies the bacteria, he gives as "Gattung" III, Arthro-Spirobakteriaceen. The vegetative cells are screw-like rods. No endogenous spores. Arthrospores. He places Spirochaeta as a subgenus of this. 
The ascription noted by Enlows has not been found.

Artho-Spirobacterium. Enlows (1920, p. 88) states:

Arthro-Spirobacterium: Klebs, 1887.

Die Allg. Path., Jena, 1887, p. 88. In a résumé of Hueppe's classification, Klebs gives this spelling, and cites the 1881 edition of Hueppe's Die Formen d. Bakt.

Arthrospirobakteriaceen. A name used by Hueppe (1896, p. 146) to designate a "Gattung" of bacteria in which the cells are spiral, and which produce arthrospores, or at least do not produce endospores. One "Untergattung" only, Spirochaeta, is included. The name is evidently invalid, or at most, a casual family designation.

Arthrostreptococcus. A variant (in proper form) of ArthroStreptokokkus q.v.

Arthro-Streptokokkus. A sub-generic name proposed by Hueppe (1886, p. 144) to include those bacteria with spherical cells, occurring in chains in indefinite zoogloea, and without endospores. It is based upon a misconception of morphology, it is not spelled as a Latin word, no species are definitely assigned to it, and it is essentially synonymous with Streptococcus.

Ascobacillus. Apparently first introduced as a casual name by Edington (1887, p. 1265) for an organism found in the blood of a patient with scarlet fever. De Toni and Trevisan (1889, p. 1034) under "species quod genus dubia" give Edington's "ascobacillus of Scarlet Fever" as a synonym of Klebsiella Edingtoni Trevisan. The following description is given.

Baculis cylindraceis, tenuibus, $0.8 \mu$ longis, $0.2 \mu$ latis. Sporae pluries centum in capsulis, quam baculis multo amplioribus, lucanicaeformibus contentae. Hab. in squamis et sanguine hominum scarlatina laborantium. In culturis gelatinamo lente liquefacit; coloniae flavae.

Enlows (1920, p. 16) says

Small rods, $0.8 \mu$ long by $0.2 \mu$ broad, often dumb-bell shaped, made up of long ovoid spheres. Spores are contained in large sausage-shaped capsules many hundred times larger than the bacilli themselves. Found in the blood of a patient dying of scarlet fever.

As a generic designation Ascobacillus was first used by Unna and Tommasoli (1889). The name first appeared (p. 15) as Ascobacillus citreus in a list of organisms isolated from the skin. Later (p. 60) the organism is more adequately described. 
The organism is a straight or somewhat bent rod, $1.3 \mu$ by $0.3 \mu$, single or in pairs or bundles, motile, spores unknown. On gelatin the growth is very slow, in two weeks the superficial colonies are opaque yellow points, the deep colonies scarcely yellow. Under low magnification the latter are gray yellow, opaque. The organism is aërobic, does not produce gas and forms a citron yellow pigment.

Migula (1900, p. 842) termed this organism Bacillus citreus.

Moreno (1901, p. 112) described an Ascobacillus aquatilis. Macé (1913, p. 586) regards Ascobacillus as a synonym of Ascobacterium q.v. making Ascobacillus citreus a synonym of Ascobacterium luteum Babes. Macé also includes as a synonym the Ascobacillus sacchari Greig-Smith (1903).

Enlows states (1920, p. 16: for the Unna type):

Straight or bent bacilli, 1 to $3 u$ by $0.3 \mu$, single or in twos, grouped or in bundles. Masses taken from agar present the appearance of Ascococcus billrothii Cohn. In the interior of these masses the bacilli are nonmotile, but at the periphery a whirling motion may be observed.

Type species (monotypy). A. citreus. Produces a citron yellow color on media. Liquefies gelatin.

If the organism described by Unna and Tommasoli is worthy of recognition as a generic type, the name Ascobacillus would probably be valid. It is possible that it might be used as a generic name for yellow pigment forming rods if these should be grouped together, as has been done in Flavobacterium q.v. Otherwise Ascobacillus may be regarded as a synonym and not tenable.

Ascobacteria. A name (form genus) suggested by Billroth (1874) but with no designation of species.

It was proposed as a generic name by Van Tieghem (1880, p. 151). Under the grouping of colonies provided with a membrane, he states that the types with cylindrical cells may be combined into the genus Ascobacteria, which he regarded as an encapsulated Polybacteria. One species was described, Ascobacteria ulvina Van Tieghem. It developed on the surface of water in which leguminous seeds (lupine) were rotting. It occurred in granular, polyhedral masses, each enveloped in a thick cartilaginous membrane, in a layer like the alga Ulva. Cells numerous small rods embedded in a common gelatin. After the mass reaches a certain size, it splits, while the gelatinous membrane is continued over the two daughter masses. 
Later Van Tieghem (1884, p. 1114) evidently regarded this as a form genus. It was also recognized by Billet $(1880$, p. 24$)$.

Apparently the genus was validly described, with type species Ascobacteria ulvina Van Tieghem. However, the species is so poorly characterized that its identification is questionable.

Ascobacterium. A generic name used by Babes $(1890$, p. 155) in his description of Ascobacterium luteum. This organism is mentioned as common in the air of the laboratory at Buda Pesth and in the water of the Dumbivotza. It forms very pronounced transparent, yellowish colonies on gelatin. The cells are rod-shaped, united in greater or less numbers by a large gelatinous or mucous capsule.

Macé (1897, p. 962) believes that there may be a relationship existing between this form and that described under the name Ascococcus.

Macé (1913, p. 586) states

Les éléments en bâtonnets, véntables Bacilles, sont réunis, en nombre plus ou moins consideráble, dans une grande capsule ovalaire, gélatineuse ou muquese. Le nom d'Ascobacillus doit être considéré comme synonyme et serait certainement à préférer, si l'on était tout à fait fix é sur l'individualité de ces types microbiens; on peut conserver le terme Ascobacterium comme provisoire. Il y a peut-être des rapports à établir entre ce type et ceux décrits sous le nom d'Ascococcus.

He describes Ascobacterium luteum Babes and Ascobacterium aquatile (Moreno) Macé (Ascobacillus aguatilis Moreno).

It would seem that this genus has been validly described, with type species Ascobacterium luteum Babes. It is possible that it should be regarded as a synonym of Ascobacillus, q.v.

Ascococceae. A name of a tribe of cocci of the subfamily Coccogenae Trevisan proposed by Trevisan (1889, p. 1037). It contains the sub-tribe Euascococceae Trev. with the genera Lamprocystis Schroeter, Ascococcus Cohn, Bollingera Trevisan, Cenomesia Trevisan, Thiocystis Winogradsky, Thiothece Winogradsky, Leucocystis Schroeter, the subtribe Gaffkyeae Trevisan with the genera Chlamydatomus Trevisan and Gaffkya Trevisan and the subtribe Amoebobacterieae Trevisan, with the single genus Amoebobacter Winogradsky.

It is characterized as follows: "Cocci in familias tegumentis vesicaeformibus gelatinosis (cystidibus) obductae consociati."

The name has apparently been used by no other author.

Ascococcos. A form genus proposed by Billroth (1874, p. 13). It was intended to include those growth forms of the polymorphic 
Coccobacteria septica (q.v.) in which the cells are spherical and embedded in relatively dense zoogloeal masses, the masses being well limited, usually oval and distinct. To one particular form the binomial Ascococcos parvus (p. 98) was given. This is insufficiently described and cannot now be recognized.

The generic designation Ascococcos Billroth should be regarded as invalid for the following reasons:

1. The name Ascococcos uses the Greek termination os instead of the Latin us. Article 7 of the Botanical Code specifically states:

Scientific names are in Latin for all groups. When taken from another language, a Jatin termination is given them, except in cases sanctioned by custom.

2. The name was never proposed by Billroth as a valid generic designation but as a growth form only.

3. The only species (A. parvus) assigned to the genus was inadequately described.

This name was changed to Ascococcus by Cohn $(1875$, p. 147) who writes "Billroth schreibt Ascococcos, wie Micrococcos, etc; der Gebrauch sanctionirt jedoch nur die lateinischen Endungen selbst bei Namen griechischen Stammes (Lois de la nomenclature botanique Article 66)." The generic name therefore, in spite of Cohn's statement "Ascococcus Billroth char. emend." should read Ascococcus Cohn" (q.v.).

Ascococcus. The form genus Ascococcos (q.v.) was created by Billroth (1874, p. 13) for a growth form of his Coccobacteria septica in which the spherical cells are embedded in gelatin or slime. This is not tenable as a generic designation. Cohn $(1875$, p. 154) published the genus name "Ascococcus Billroth char. emend." This should be written Ascococcus Cohn.

The generic description given by Cohn is:

Cellulae achromaticae globosae densissime consociatae in familias tuberculosas globosas vel ovales irregulariter lobatas, lobis in lobules minores sectis capsula globosa vel ovali gelatinoso-cartilaginea crassissima circumdatas, in membranam mollem facili secendentem floccosam aggregatas.

One species was described, Ascococcus Billrothii, from a zoogloea mass developing spontaneously in a culture medium of ammonium tartrate. The specific diagnosis is

Familiae tuberculosae $20-160 \mu$ capsula ad $15 \mu$ crassae. In solutione ammoni tartarici acidi aëro lavata vel butyrico praeditam formanten observavi Mart 
1874. Haud scio citrum eandem an affinem speciem ill. Billroth in aqua carnis foetida detexerit.

Cohn believed that the organism which he described was the same as that of Billroth, hence the choice of name. He also concluded that the Ascococcos parvus of Billroth was not a true Ascoccocus in the sense of Billroth's original description.

Cienkowski (1878, p. 12) described an organism responsible for a gummy or viscous fermentation of syrups in sugar factories. He regarded it as conforming to Cohn's conception of Ascococcus and named it $A$. mesenteroides. A study of the same organism was made by Van Tieghem (1878, p. 198). He concluded that this form was distinct from Ascococcus Cohn and made it the type of the genus Leuconostoc. He called attention to the points of difference between the two genera. In Ascococcus the cells are spherical, very small, and grouped in great numbers to form globular or avoid families which are lobed more or less irregularly. The cells are closely united, separated only by a small amount of gelatinous material; each family is surrounded by a cartilaginous envelope. In Leuconostoc the cells are arranged in bent chains separated from each other by a large amount of gelatinous material, the gelatin on the exterior not being thicker than that between the chains. The Ascococcus of Cohn grew in ammonium tartrate solution, the Leuconostoc in sugar and rendered the solution decidedly acid. He places the genus Leuconostoc among the Nematogenae in Cohn's classification, while Ascococcus is with the Glaeogenae.

Trevisan (1879, p. 137) reworded Cohn's description as follows: "Cellulae globosae, inordinate in colonias conglobotas pluristratas densissime consociatae, tegumentis propriis nullis. Coloniae tegumento communi gelatinoso-cartilagineo crassissimo obvolutae." He included it in the subtribe Sarcineae.

Ascococcus Billroth was recognized by Magnin (1880, p. 96) with the species $A$. billrothii Cohn. Winter $(1880$, p. 47) likewise recognized the genus as Ascococcus Cohn. He questions, however, the value of Cohn's genus and also whether the genera of Cohn and Billroth are based upon the same form. He believes it probable that Ascococcus Cohn is only a developmental stage of Micrococcus Cohn.

Van Tieghem (1880, p. 150) recognized the genus, and added to it the species Ascococcus vibrans from the surface of water in which Beggiatoa was putrefying.

Grove $(1884$, p. 15$)$ used practically the same words as Winter in his discussion of the genus. Van Tieghem regarded Ascococcus as a subdivision of Micrococcus including those forms with cells embedded in gelatin. 
Zopf $(1885$, p. 51$)$ in the third edition of his Spaltpilze, though not in the preceding, recognizes Ascococcus Billroth as a Micrococcus with intensive gelatin production. Hueppe (1885) states that in the genus Ascococcus the cells are spherical, not in chains, occurring in irregular masses in spherically segmented zoogloea. Schroeter (1886, p. 153) recognizes "Ascococcus Billroth 1874 (in der Umgrenzung von Cohn 1875)." According to Flügge (1886, p. 140) Ascococcus includes spherical bacteria united into definite slime families, colonies solid, filled throughout with cells, cells in large but indefinite numbers united into irregular colonies. The species Ascococcus Billrothii Cohn is discussed. Hansgirg (1888, p. 266) recognized Ascococcus as the second genus of his subfamily Cystococcaceae. The species A. Billrothii and a variety thermophilus are described by Hansgirg $(188$, p. 88). This variety was found in warm waters, cells $1 \mu$ thick, colorless, spherical or almost egg shaped, united into families, from 6 to $60 \mu$, colorless or yellowish. The same species and variety were included by De Toni and Trevisan (1889, p. 1038). They note that the divisions of the cocci occur in three directions, emphasizing thereby that the cells do not occur in chains. The genus was included by Billet (1890, p. 24) and by Cornil and Babes (1890, p. 148). Hansgirg (1890, p. 24) named an Ascococcus cellaris. He believes the Thiopolycoccus of Winogradsky should be regarded as a synonym. His description of $A$. cellaris follows:

Zellen kugelig oder fast kugelig, sehr viele zu kugeligen oder rundlichen, soliden, 6 bis $20 \mu$ breiten Familien, mehr weniger dicht gehäuft, seltener fest zusammengepresst, mit einer gemeinsamen, nicht geschichtlichen Gallert Hülle umgeben, 0.7 bis $1 \mu$ breit, farblos.

Sternberg (1892, p. 17) recognizes the genus Ascococcus, and describes Ascococcus Billrothii giving as its origin "Found by Billroth in putrefying flesh infusion." Miller (1892, p. 75) described a new species, Ascococcus buccalis from the mouth. He says:

Ein in etwas unregelmässigen Kokken resp. Diplokokken einzeln oder in Ketten vorkommendes Bacterium. Dasselbe bildet kleine erhabene glänzende, in alteren Culturen wie winzig kleine Glasperlen aussehende Colonieen welche sich besonders da durch auszeichnen dass sie eine knorpelartige consistenz besitzen und sich mit der Nadel nicht heben lassen, sondern vor derselben auf der Oberfläche der Gelatine herumgleiten.

Macé (1897, p. 335) designates the genus as Ascococcus Billroth. Migula (1897, p. 18) likewise concluded that Ascococcus is synonymous 
with Micrococcus, the species becoming Micrococcus Billrothii (Cohn) Migula. The species Ascococcus cantrabridgensis described by Hankin from the mouth of a student at Cambridge is noted by Lehmann and Neumann (1901, p. 179). Winslow and Rogers (1905, p. 669) revived Cienkowski's name, Ascococcus mesenteroides as the type of their emended genus Ascococcus (Cohn) Winslow and Rogers. This was characterized later at greater length (1908, p. 136). The Winslows discuss the name Ascococcus Billrothii of Cohn. They conclude that because of the cheesy odor and frequent confusion by Cohn of cocci and bacilli, that in all probability Cohn studied a rod-shaped organism. It would seem that they are in error in this matter, for the illustrations accompanying Cohn's description are very distinctive. They also note Cienkowski's use of the term Ascococcus and state

Van Tieghem (1878) a little later worked on the same form and substituted for Ascococcus the generic name Leuconostoc in order to emphasize the resemblance between the zoogloea-forming coccus and the blue-green alga, Nostoc.

This would seem to be scarcely a full statement of the case. Van Tieghem concluded that the organism of Cienkowski differed so markedly from Cohn's description of Ascococcus that a new generic designation was required. The Winslows emend the diagnosis of Ascococcus to conform to modern conceptions. It would seem that they are misled, perhaps, by the apparent appropriateness of the name Ascococcus. There seems to be little question but that Cohn's Ascococcus was a form entirely distinct from $A$. mesenteroides, and the generic designation should be reserved for Cohn's species. If Van Tieghem was in error in believing that Cienkowski's organism deserved generic separation from Ascococcus, then the name used by the latter may be revived. It should be noted that Winslow's designation Ascococcus (Cohn) Winslow and Rogers, is incorrect. Article 41 of the International Rules reads: "An alteration of the constituent characters or of the circumscription of a group does not warrant the quotation of another author than the one who first published the name or combination of names." The name Ascococcus was rejected by Erwin F. Smith $(1905$, p. 174). Vuillemin (1913, p. 520) lists Ascococcus Billroth 1874 as one of his "Formogenera conservanda."

Macé $(1913$, p. 433, 435, 646) is almost alone among recent writers in recognition of this generic name. He gives an extended description of $A$. Billrothii Cohn and A. equi Macé. 
Buchanan (1915, p. 5) discussed at length the use of the name by Winslow and Rogers. It is probable that Migula's conclusion that Cohn's Ascococcus is a growth form of a Micrococcus is correct. The species A. Billrothii Cohn has never been certainly recognized since described. The status of the genus is quite uncertain. Its type is A. Billrothii Cohn.

Ascokokkus. A variant of Ascococcus.

Askokokkus. A variant spelling of Ascococcus Cohn used by Hueppe $(1886$, p. 145). He includes this as an "Untergattung" of his "ArthroKokkaceen."

This spelling has been used not infrequently by German writers.

Astasia. This name was first applied to a protozoan genus by Ehrenberg. In this sense it is also given by Perty (1852, p. 167). Miore recently the same word has been used as a generic name by Meyer (1897, p. 185) for a new species of rod-shaped bacteria, Astasia asterospora. Two characteristics of the organism as described by Meyer differentiated it from other genera. The spore is barrel-shaped, ribbed longitudinally, and with a well differentiated extine and intine; the flagella are produced in bunches, laterally. The original description was later modified (1898, p. 49). Migula (1900, p. 528) regards Astasia as a synonym of Bacillus and writes Bacillus asterosporus (Meyer) Mig. The organism is described by Migula as a motile rod, usually single, seldom in short chains, 1 to $1.3 \mu$ thick, 3 to $6 \mu$ long, becoming motionless before spore formation. Spores ovoid, with longitudinal striae, star-shaped in cross section, with polar germination. Flagella distributed over the entire body. On sterilized beet slices it develops as a gray, glassy, gelatinous layer, which spreads so that after five days the slice is covered with a thin gelatinous layer, finally showing gas bubbles. The middle lamellae of the beet are dissolved so that the medium becomes soft. Spores are found after five days, in addition to resting and swarming rods. In dextrose gelatin rapid liquefaction occurs, with some gas bubbles. It grows in nutrient solution, causing a decided clouding. Migula groups this organism with Bacillus subtilis, B. ramosus, etc. The cultural characteristics with the exception of gas production seem to relate it quite definitely to these forms.

Buchanan (1918, p. 38) used this name as a subgeneric designation under the genus Bacillus, with the description "Motile rods, spores ovoid with longitudinal stripes, star shaped in cross section." The type is designated as Bacillus (Astasia) asterospora (Meyer) Migula.

Asterococcus. A generic name proposed by Borrel, DujardinBeaumetz, Jeantet and Jouan (1910, p. 179) for the organism causing 
bovine peripneumonia. The single species was named Asterococcus mycoides. The genus may be characterized as follows: Pleomorphic cells, appearing at different stages as cocci isolated and in chains, and as rods and filaments variously branched and swollen, apparently as involution forms resembling frequently the bacteroids of legumes, cells extremely minute, almost ultramicroscopic. Non-motile. No spores. Stain with difficulty, best with Giemsa. Growth in cultures only in presence of serum or hemoglobin. Apparently the organism has not again been seen or recorded.

The genus was recognized by Buchanan (1918, p. 44) and included in his subtribe Hemophilinae.

Astrobacter. A generic name given by Jennings (1896, p. 312) to an organism found in stagnant water near Rübingen by CoppenJones. Slides stained by Loeffler's method to demonstrate the flagella of Spirillum undula when examined were found to show the organism in question. The original material had been lost, so that the entire description is based upon observation of the mounted slides.

A simple rod-like bacterium. Initial cell division is marked by a bifurcation of the end of the rod, producing a Y-shaped form. The split deepens, and others occur, making tri-radiate types with the rays spreading at an angle of $120^{\circ}$. Four rayed forms with various angles occur, as do also forms with as many as eight rays. The rays do not appear to all lie in a single plane. In a few cases transverse constrictions of some of the rays were noted. Whether this genus has been based upon any form which actually occurs in nature has not been proved. It is entirely possible that the so-called organisms are artefacts of some type. Until there is a demonstration of the living organisms the generic name A strobacter Jennings may well be held in abeyance. It has apparently never been recognized or used by other investigators. It is definitely rejected by Erwin F. Smith (1905).

Athiorhodaceae. A family of the order Rhodobacteria proposed by Molisch (1907, p. 28) to include those forms that do not possess free sulfur granules in the cell contents. The following genera, described in the same work, make up this family: Rhodobacillus, Rhodobacterium, Rhodocapsa, Rhodothece, Rhodococcus, Rhodovibrio, Rhodocystis, Rhodonostoc, and Rhodospirillum. The organisms all develop in the presence of light. They possess two pigments called bacteriopurpurin and bacteriochlorin.

The family name does not conform to the botanical code in that it is not derived from the name of any one of the component genera. It is made a synonym of Rhodobacterioideae by Buchanan (1918, p. 128). 
Aurococcus. A generic name proposed by Winslow and Rogers (1906, p. 540) to include the orange cocci. The generic diagnosis given is:

Parasites. Cells in groups and short chains, very rarely in packets. Generally stain by Gram. On agar streak growth of orange color. Sugars fermented with formation of small amount of acid. Gelatin often liquefied very actively. May or may not reduce nitrates. Includes A. aureus (Rosenbach.)

The same genus was later discussed by the Winslows (1908, p. 255). They include three species, Aurococcus aureus (Rosenbach) Winslow, Aur. aurantiacus (Schröter, Cohn) Winslow, and Aur. mollis (Dyar) Winslow.

For the generic name Aurococcus Winslow and Rogers to be established as valid, it must be shown that the generic name Staphylococcus which is displaced is invalid. The latter name was proposed by Ogston (1883, p. 27), but first used as a generic name by Rosenbach (1884, p. 12) who described a Staphylococcus pyogenes aureus and a Staphylococcus pyogenes albus. The former is the type chosen for Aurococcus Winslow and Rogers. On a later page, Rosenbach uses the combination Staphylococcus aureus for the same organism. The genus Staphylococcus Rosenbach is split by Winslows into the two genera Aurococcus and Albococcus, and the original generic name discarded. Article 45 of the International Rules of Botanical Nomenclature states,

When a genus is divided into two or more genera, the name must be kept and given to one of the principal divisions. If the genus contains a section or some other division which, judging by its name or its species, is the type or the origin of the group, the name is reserved for that part of it.

It would seem that the Winslows have shown no adequate nomenclatural reason for abandoning the generic name Staphylococcus. It should, therefore, be retained for one of their genera. Inasmuch as Staphylococcus aureus was described first, and is in a sense the type of the group, the name Aurococcus should be reduced to a synonym of Staphylococcus. This genus can be emended, if desired, to exclude the white forms, thus making the genus Albococcus valid.

These facts were pointed out by Buchanan $(1915$, p. 8) and agreed to by the Committee of the Society of American Bacteriologists (1917, 1920) and by Winslow, Rothberg and Parsons (1920, p. 161).

Azotobacter. A genus of bacteria created by Beijerinck (1901, p. 561) to include certain non-symbiotic nitrogen fixing organisms of the soil. Beijerinck gives the following diagnosis of the genus: 
Dicke in jungem Zustande meist als grosse Diplokokken oder als Kurzstäbchen vorkommende Bakterien mit hyalinem, oft eine Vakuole führen dem Inhalte und schleimiger Wand von sehr verschiedenen Dicke. Jüngere Zustände mehr oder weniger beweglich vermittels einzelner polarer oder in polaren vier-bis zehnzahligen Bündeln angeordneten, kurzen Cilien, welche umgefähr so lang sind, wie die Bakterien selbst. Sporen fehlen, das heisst, wachstumfähig in Nährlösungen mit geeigneten Kohlenstoff quellen, welche sehr arm sind an Stickstoffverbindungen assimiliert den atmosphaerischen Stickstoff, und ist dadurch in Bezug auf die übrige Mikrobenwelt konkurrenzfähig Optimum temperature $28^{\circ}$.

The type species named was Azotobacter chroococcum.

Beijerinck and van Delden $(1902$, p. 3) again described the genus. The genus was rejected by Erwin F. Smith (1915). It was accepted by Stockhausen $(1907$, p. 88). The genus is quite generally recognized by writers on agricultural bacteriology. Orla-Jensen (1909, p. 328) changes the name of this genus to Azotomonas and places it in his family Oxydobacteriaceae.

Löhnis and Hanzawa $(1914$, p. 1) claim to have demonstrated that the organisms of this genus may at certain stages in their life history produce endospores. They conclude that Azotobacter is therefore an invalid synonym of Bacillus. The type species is renamed Bacillus azotobacter. It may be noted that even though the genus should be Bacillus, the species should be designated B.chroococcus in accordance with the botanical rules.

Winslow et al. (Committee 1917, p. 552) and Bergey et al. (1923, p. 38) accept the genus with the following diagnosis:

Relatively large rods, or even cocci, sometimes almost yeast-like in appearance, dependent primarily for growth energy upon the oxidation of carbohydrates. Motile or non-motile; when motile, with tuft of polar flagella. Obligate aerobes usually growing in a film upon the surface of the culture medium. Capable of fixing atmospheric nitrogen when grown in solutions containing carbohydrates and deficient in combined nitrogen. The best-known free-living nitrogen-fixing bacteria of the soil.

The same description is used by the Committee in 1920 (p. 203). Buchanan (1918, p.46) describes the genus as follows:

Relatively large rods, or even cocci, sometimes almost yeast-like in appearance, dependent primarily for growth energy upon the oxidation of carbohydrates; obligate aërobes, usually growing in a film upon the surface of the culture media. Capable of fixing atmospheric nitrogen in considerable amounts when grown in solutions deficient in combined nitrogen. Motile or non-motile, if the latter, with polar flagella. 
It is probable that $A$ zotobacter Beijerinck may be regarded as a valid genus.

Azotobactereae. A tribe of the Nitrobacteriaceae suggested by Winslow et al. (Committee Soc. Am. Bact., 1920, p. 203), to include the "nitrogen fixing bacteria." The genera Rhizobium and Azotobacter were included. Bergey et al. (1923, p. 38) include this as the second tribe of the family Nitrobacteriaceae. Probably the spelling should be emended to Azotobacterieae.

Azotomonas. This generic name was proposed by Orla-Jensen (1909, p. 484) to replace the older name Azotobacter Beijerinck (1901, p. 561) to conform to his rule that organisms with polar flagella should bear generic names terminating in -monas. It should be regarded as invalid because of the priority of Azotobacter.

Babesia. A genus of bacteria created by Trevisan (1889, p. 29) to include two species of cocci, one associated with yellow fever and described by Babes (1883,) and the other with erysipelas chronica. It was included as the fourth genus of his tribe Streptococcee. The diagnosis given by De Toni and Trevisan (1889, p. 1054) is as follows :

Cocci ellipsoidei, longitudinaliter binatim seriati (diplococci longitudinales) in filamenta moniliformia, pseudodichotoma nuda (i.e., nec capsulis nec vaginis obducta) concatenati. Arthrosporae macrosomae in apice filamentorum obvenientes.

The genus is differentiated from Streptococcus by the pseudodichotomous branching of the filaments and by the production of arthrospores at the ends of the filaments. The generic description corresponds with that of no organism at present known. The two species, B. xanthopyretica Trev. and $B$. erysipeloides Trev. were so inadequately described as not to be recognizable. The genus name has never come into use. It may be regarded as invalid or possibly as a synonym of Streptococcus (Erwin F. Smith 1905, p. 174).

Babesia xyanthopyretica Trev. (Streptococcus xanthopyreticus Trev.) may be regarded as the type.

Babesia is also used as a generic name in the pathogenic protozoa.

Bacillaceae. A family proposed by Fischer (1895, p. 139) with the spelling Bacillacei and with the following diagnosis:

Vegetationskörper einzellig, gerade mit ausgesprochener Längsachse, bald kurz ellipsoidisch, bald gestreckt stäbchenförmig: Theilung immer in derselben Richtung, senkrecht zur Längsachse mit oder ohne Kettenwuchs und Bewegung. Sporen theils endospor, theils arthrospor. 
In the translation of the Vorlesungen by Coppen Jones $(1897$, p. 32) this is spelled Bacillaceae. In the second edition (1903, p. 60) the diagnosis given is:

Vegetationskörper cylindrisch, ellipsoidisch, eiförmig, gerade; bei den kurzen, fast kugeligen Formen und die Trennung von Kokken schwer; Teilung immer senkrecht zur Längsachse, als Wuchsform nur unverzweighte Ketten.

In the original description four subfamilies are listed. Bacillei, Bacterineï, Bactrilleï and Bactrideï. Later (1903) the three subfamilies recognized were Bacilleae (with four genera) Clostridieae (two genera) and Plectridieae (two genera).

Schmidt and Weis $(1902$, p. 91) likewise used this family designation, including the three genera Bacterium, Bacillus and Pseudomonas with the following description:

Die Zellen sind cylindrisch, kürzer oder länger stäbchenförmig, gerade. Die Zellteilungen geschehen nur nach einer Richtung des Raumes. Vor der Teilung strecken sich die Zellen in einer senkrechten Richtung zu der später gebildeten Scheidewand. Endosporbildung bei mehreren Arten bekannt.

The name has also been used as a group designation by Flügge (1908).

This family name is also used by Benecke (1912, p. 188) to include the rod-shaped bacteria without sulphur or bacteriopurpurin, unbranched and not forming a pseudoplasmodium.

Winslow et al. (Committee Soc. Am. Bact., 1917, p. 561) used this as a designation for their seventh family of the Eubacteriales. The diagnosis is: "Rods producing endospores, usually Gram-positive. Flagella when present peritrichic. Actively decompose protein media through the agency of enzymes."

Winslow et al. (Committee Am. Soc. Bact., 1920, p. 212) in their final report used the same diagnosis.

Castellani and Chalmers (1920, p. 601) state:

Cette famille peut être définie: Eubacteriales avec cellules longeres ou courtes, flagellées ou non flagellees; sporogènes ou non sporogènes, mais toujours cylindriques et droites et se divisant seulement dans une direction.

Le genre type est Bacillus Cohn 1872, mais ce genre et l'autre genre ancien, Bacterium, renferment un si grand nombre d'espèces et de variétés que nous avons essayé de simplifier leur diagnose en définissant les tribus et les genres suivant.

They divide the family into 10 tribes.

Bergey et al. (1923, p. 272) included this as the fifth family of the order Eubacteriales with the description: "Rods producing endospores, usually 
Gram-positive. Flagella, when present, peritrichous. Often decompose protein media actively through the agency of enzymes."

Two genera, Bacillus and Clostridium are included.

Bacillaceî. A family name proposed by Fischer (1895, p. 139). For discussion, see Bacillaceae (the corrected form).

Bacilleae. A tribe established by De Toni and Trevisan (1889, p. 941) with the following diagnosis "Baculi cocci nunquam capsulis membranaceogelatinosis involuti." It is the first tribe of the subfamily Baculogenae Trev. It includes the sub-tribes Pasteurieae (one genus) Thiodictyeae (one genus), Eubacilleae (six genera) and Spirilleae (two genera).

With the spelling Bacilleï this name was also used by Fischer (1895, p. 140) as a subfamily of the family Bacillaceï to include all rod-shaped organisms "Unbeweglich, ohne Geisseln." Four genera were included, Bacillus, Bactrinium, Bactrillum and Bactridium.

The name was used by Buchanan (1918, p. 33) as a tribe of the family Bacteriaceae with the following description:

Cells rod shaped, never spiral or strictly filamentous, single or in chains, usually motile by means of peritrichous flagella, producing endospores under suitable conditions of growth, usually Gram-positive.

The four genera Bacillus, Plectridium, Clostridium and Metabacterium were included.

Castellani and Chalmers $(1919$, pp. 933,959$)$ propose this as a tribe of the family Bacillaceae. Apparently they are in error in ascribing the name to Castellani and Chalmers 1918. They state: "Bacillaceae growing well on ordinary laboratory media and producing endospores. One genus only is included, Bacillus, the type genus." They again describe it in 1920 (p. 601).

Bacillee. A name given by Trevisan (1889, p. 12) to the third tribe of the sub-order Baculogene. It is ascribed to Trevisan (1887). The description given is:

"Baculi, filamenti e cocchi non mai racchiusi in capsule membranaceo-gelatinose." Twelve genera are included, Pasteuria, Winogradskya, Thiodictyon, Mantegazzaea, Bacillus, Pasteurella, Cornilia, Clostridium, Vibrio, Pacinia, Spirillum and Spiromonas.

Bacillei. A subfamily name incorrectly spelled used by Fischer (1895, p. 140). For discussion, see Bacillaceae.

Bacillococcus. A casual name used by Frankland (1890, p. 122) for a nitrifying soil organism. 
Bacillopsis. A generic name suggested by Petschenko (1908, p. 359) for an organism questionably bacterial. Enlows (1920, p. 19) states:

Type species (monotypy). B. stylopygae. Found in the digestive tube of Blatta orientalis (Stylopyga orientalis). Length $10 \mu$, by $2.5 \mu$ wide. A slightly curved rod, with one end slightly pointed, the other obtuse. Nucleus is present. Also highly refractive "corpuscules" in the transparent protoplasm, which are probably nutritive substances. Reproduction by a sort of budding, in which the very small daughter cell remains attached to the mother cell by a delicate filament until it has attained the size of mother cell. After this stage of active growth there is a stage in which filiform prolongations appear, and the "corpuscules" unite into 1 or 2, rarely 3 large round bodies. Vacuoles observed. In doubt as to position of organism, but does not think it belongs with the bacteria. (Has been included by other authors among the bacteria.)

Bacillus. A generic name established by Cohn (1872, p. 174) to include three species of rod-shaped organisms, Bacillus subtilis, $B$. $u \ln a$ and B. anthracis. He included in this genus those rod-shaped organisms that grow in filaments. The type of the genus was $B$. subtilis. A discussion by Cohn of spore production in Bacillus subtilis embodied the first accurate description of endospores. His inclusion of the anthrax organism indicates that in his conception of the genus motility was an unimportant characteristic. In a later paper, Cohn (1875, p. 141) included the genus Bacillus under the tribe Nematogenes and characterized it as follows:

Cells disposed in filaments, filaments not branched, free or interlaced, cylindrical, colorless, articulations not very distinct, very slender and short.

It will be noted that in the preceding description emphasis is placed upon the occurrence of the rods in short chains or filaments. Sporulation and motility were not included in the generic diagnosis. Within the genus were listed both motile and non-motile forms. Sporulation was discussed in certain of these species, but not rated definitely as a generic character. These facts are emphasized because subsequent generic designations frequently stress other characteristics.

Winter $(1880$, p. 38) uses the genus practically in the sense of Cohn. He states:

Zellen verlängert cylindrische, fast stets in geraden, stielrunden (nicht oder wenig eingeschnürten) Reihen oder Fäden zusammenhängend, durch Quertheilung sich vermehrend. Sie bilden Zoogloeen, kommen aber oft auch in dichten Schwärmen (ohne Gallertausscheidung) vereinigt vor. Fortpflanzung durch Sporen. 
This is the first definite inclusion of the character of spore production in the generic diagnosis, but this should not be emphasized as a differential character, for in the description of Bacterium there is the statement "Sporenbildung ähnlich wie bei Bacillus."

Luerssen (1879, p. 22) accepted Cohn's classification practically without modification. Emphasis is placed upon the occurrence of the organism in jointed threads, and no mention is made of sporulation. Magnin (1880, p. 87) used the same description.

De Bary (1884) influenced largely by the idea of bacterial pleomorphism, abandoned the old genus Bacterium and put all endosporous rods into the genus Bacillus and all arthrosporous rods and those for which no spores are known into Arthrobacterium. De Bary states: (translation by Garnsey and Balfour 1887, p. 460)

The forms included under this term (endosporous bacteria) are chiefly known in the growth-form of single rods consisting of one or a few cells, or of rods joined together and forming long filaments; they may also be collected together into larger gelatinous masses or membranes. In some forms the rods are spirally twisted, and these I name here Spirillum of Van Tieghem. Others do not show these curvatures, but are either straight or very slightly bent, all these I include under the term Bacillus and place under that genus all the endosporous forms which have been hitherto known either as Bacillus or as Clostridium, Bacteridium, Vibrio, or by some other name. All non-endosporous forms bearing these names on account of their growth form are, of course, excluded from the group.

It will be noted that this is a direct abandonment of the generic conception of Cohn although the type species may well be said still to be B. subtilis.

Van Tieghem (1884, p. 1110) uses the term Bacillus as a form group to include those rods which are not associated but are united into filaments of greater or less length, practically in the sense of Cohn. Grove (1884, p. 26) follows Winter minutely. Trevisan (1885, p. 94) included in this genus those organisms showing three stages of development, as rods, filaments and cocci. In the rod or bacillus stage the cells are normally cylindric, or ellipsoid, straight or slightly curved, jointed or not, colorless or colored, cytoplasm equally distributed. Spores single in the rods. Filaments and cocci transitory stages. He included descriptions of thirty-one species, the first one described being Bacillus anthracis Cohn. The views of Van Tieghem were in part accepted by Zopf in the third edition of "Die Spaltpilze" (1885, p. 61). In previous editions the term Bacillus was regarded merely as the designation of a growth form of a Bacterium. His diagnosis in the third edition is: 
"Coccen und Stäbchenformen oder auch nur Stäbchen in gewöhnlichen oder gewundenen Faden. Sporenbildung vorhanden in Stäbchen oder in Coccen auftretend." Although the definition is greatly modified by the current ideas of bacterial pleomorphism the emphasis is placed upon the development of endospores by the members of the genus. Hueppe (1885) likewise included in the genus Bacillus those rods that developed endospores.

Flügge, (1886, p. 136) used "Bacillen" to include rods whose length was two to twenty times the diameter; returning in a sense to the conception of Cohn.

Maggi (1886, p. 173) included this genus, without description, in his fourth order, Desmobacteries. Eleven species are listed.

Schroeter (1886, p. 156) considers the genus Bacillus to include organisms with long cylindric vegetative cells, daughter cells often remaining united for a time in a chain, often actively motile, with endogenous spores produced singly in cells that do not become swollen when sporulating. In some species the cells grow into long filaments just preceding sporulation (Streptobacter). In a rather loose fashion a somewhat similar meaning is given by Cornil and Babes (1890, p. 165); these authors emphasize sporulation. Hansgirg (1888, p. 264) includes Bacillus as the first genus of the subfamily Microbacteria. He divides the genus into two sections or subgenera, Eubacillus and Chromobacillus. Trevisan (1889, p. 12) included Bacillus as the fourth genus of the tribe Bacillee. The generic description is "Baculi cilindrici, cilindracei o ellissoidi, con protoplasma uniformemente diffuso. Spore microsome (cioe che non mai raggingono un diametro maggiore del diametro transversale normale dei baculi entro cui si formano) provenienti in baculi normali immutati." The generic synonyms are given as "Metallacter e Chromatium Perty (1852); Bacteridium Davaine (1863); Bacillus e Bacterium F. Cohn (1873); Streptobacteria Billroth (1874); Pollendera Trevisan (1884); Coccobacillus Leube (1885); Proteus Hauser (1885); Bacteriopsis Trevisan (1885); Coccothrix Lutz (1886); Sclerothrix Metschnikoff (1888). In all 201 species were listed. De Toni and Trevisan (1889, p. 1889) elaborated the diagnosis of Bacillus somewhat to allow of the differentiation from it of numerous related genera. Their diagnosis is as follows:

Baculi cylindrici vel cylindracei, recti vel leviter curvi, apicibus conformibus rotundatis vel truncatis, plasmate uniformiter diffuso. Filamenta vulgarissima e baculis, coccis nullis interjectis conflata. Sporae (endosporae) microsomae, in baculis normalibus immutatis obvenientes. 
A large number (228) of species are described. Billet (1890, p. 23) described Bacillus as "Formes rectilignes, element 5 a 10 fois plus long que large."

Baumgarten (1890) was apparently the first to use the generic name Bacillus to include all rod-shaped, "monomorphic" bacteria, practically merging with it the genus Bacterium. This conception was adopted by Sternberg (1892, p. 18) who defined the genus as follows:

Rod-shaped and filamentous (not spiral) bacteria in which there is no differentiation between the extremities of the rods; reproduction by binary division in a direction transverse to the long axis of the rods, or by binary division and the formation of endogenous spores; rigid or flexible, motile or non-motile.

This use has led to the rapid "vulgarization" of the term Bacillus until it is frequently now noted as being used in two senses, a general sense with reference to shape, and as a genus name. This has contributed to much confusion in the literature.

Ludwig (1892) defines the genus as containing small rods which produce endogenous spores.

Clements $(1894$, p. 27) lists four species, with the following generic description:

Cells cylindrical, straight or curved, motile, filaments present at time of spore formation, falling into small cells as soon as the endogenous spore is formed.

Migula (1894, p. 237) emended the genus Bacillus Cohn, the diagnosis reading "Zellen mit über den ganzen Körper angehefteten Bewegungsorganen, oft mit Endosporenbildung. (Z. B. Bacillus subtilis Cohn.)" Migula (1895, p. 25) later elaborated this conception. He based his principal generic designations upon differences in flagellation. Accepting $B$. subtilis as the generic type, he characterized the genus as made up of straight rods with flagella scattered over the entire cell body. Sporulation and filament formation he considered secondary to flagellation.

The second emendation in 1895 of Bacillus was that of Fischer (1895, p. 140). This author rejects Migula's use and states:

Unbeweglich, ohne Geisseln, mit Endosporen in unveränderten, nicht spindeligen oder kopfigen Stäbchen; eine schwache allseitige Vergrösserung der Stabchen; bei der Sporenbildung kommt zuweilen vor. Sporen in der Mitte oder am Ende der Stäbchen, Bacillus anthracis Cohn Bacillus Carotarum A. Koch. 
Later $(1897$, p. 32) he says

The word Bacillus might then be used, in memory of Koch's first work for all those species which, like the anthrax parasite, are non-motile and retain their shape during sporulation.

This of course constitutes a direct abandonment of Bacillus subtilis as the generic type.

Lehmann and Neumann (1896, p. 279) returned to the differentiation of the genus upon the basis of endospore production. Their diagnosis reads: "Gerade Stäbchen haüfig zu Faden auswachsend. Dicke oft beträchtlich, selten unter 0.6 , meist über $0.8 \mu$. Endosporen bildend."

Migula later expanded his classification (1897, p. 47) and again emphasized the peritrichous flagellation of the cells as the principal diagnostic character. Macé (1897, p. 484) used as a diagnosis "Elements in the form of rods, short or long, straight or slightly bent." He concludes that the Bacteridium of Davaine, the Clostridium of Prazmowsky, the Tyrothrix of Duclaux, the Proteus of Hauser are synonyms. Hewlett (1898, p. 18) includes all rod-shaped bacteria under the genus Bacillus. Migula (1900, p. 515) again defined Bacillus as made up of peritrichous rods. He says:

Kürzere oder längere, stäbchenförmige bis ovoide gerade Zellen, oft zu ziemlich langen Fäden verbunden, beweglich, mit über den ganzen Körper zerstraut stehenden, wellig gebogenen Geisseln. Endosporenbildung ist häufig.

Lehmann and Neumann (1901, p. 124) consistently adhere to the diagnostic importance of endospores, and include all spore bearing rods in this genus. Chester (1901, p. 199) follows Migula in basing his diagnosis upon peritrichous fiagellation. The same description is used by Kendall (1902, p. 484). Schmidt and Weis (1902, p. 91) follow Migula. Matzuschita (1902, p. IV) included all rod-shaped organisms. Allan J. Smith (1902, p. 270) gives the generic description "Cells with flagella; peritrichous; endospores present or absent." Fischer in the second edition of his lectures (1903, p. 60) again defines Bacillus as comprising the non-motile rods. Migula (1904, p. 145) reaffirmed peritrichic flagellation as important. He is followed by Erwin F. Smith (1905, p. 160), Ellis (1909, p. 6), Frost (1911, p. 57), Schneider (1912, p. 23) and many other authors. Orla-Jensen (1909, p. 344) used the name Bacillus to designate organisms of the type of $B$. mycoides, placing the genus in his family Alkalibacteriaceae. These organisms are said to require organic nitrogen, free oxygen, produce spores and cause decay. Conn (1909, 
p. 12) apparently introduced still another conception of Bacillus when he included in the genus all "Rod-shaped bacteria with flagella and consequently motile"

Heim (1911, p. 250) and Löhnis (1913, p. 45) included in Bacillus the spore-forming rods. Vuillemin (1913, p. 526) comes to the conclusion that the name Bacillus has been so vulgarized by various usages among bacteriologists, that it should be regarded merely as a form genus without nomenclatural status. As a substitute for this generic designation he revives the name Serratia ( $q . v$.) and gives as the type Serratia subtilis Vuillemin.

Winslow et al. (Committee Soc. Am. Bact. Preliminary Report, 1917, p. 562) included the spore bearing rods in this genus with the following diagnosis: "Aerobic forms. Mostly saprophytes. Liquefy gelatin. Often occur in long threads and form rhizoid colonies. Form of rod usually not greatly changed at sporulation." Bacillus subtilis Cohn was designated as the type.

Buchanan (1918, p. 33) discussed in detail the generic designation, and defined the genus as follows:

Cells rod shaped, straight or at least never spiral, motile by diffuse flagella or non-motile. Endospores produced under favorable conditions, not usually distorting the cell, usually Gram-positive. Growth usually good on laboratory media; commonly liquefying gelatin. Aërobic or facultative.

Three subgenera were recognized, Eu-Bacillus, Bacteridium and Astasia.

Winslow et al. (Committee Soc. Am. Bact., 1920, p. 212) in their final report use the same diagnosis as in 1917. This is also used by Bergey et al. (1923, p. 272).

The usages of various authors may be summarized as follows:

1. Bacillus. Rod-shaped organisms occurring in filaments or chains. Spore production, flagella distribution, and motility not emphasized. Cohn (1872, and 1875), Magnin (1878), Winter (1879), Luerssen (1879)?, Van Tieghem (1884), Grove (1884), Flügge (1886), Schroeter (1886).

2. Bacillus. Rods producing endospores (some authors recognizing other spore-bearing genera in addition). De Bary (1884 and 1857), Zopf (1885), Hueppe (1885), Cornil and Babes (1885 and 1890), De Toni and Trevisan (1889), Ludwig (1892), Freudenreich (1894), Lehmann and Neumann (1896), Chester (1897), Flügge (1908), Orla-Jensen (1909), Heim (1911), Löhnis (1913), Winslow et al. (1917, 1920), Buchanan (1918), Bergey (1923). 
3. Bacillus. Rods motile by means of peritrichous flagellla. Migula (1895, 1897, 1904), Chester (1901), Kendall (1901), A. J. Smith (1902), E. F. Smith (1905), Ellis (1909), Frost (1911), Schneider (1912).

4. Bacillus. Non-motile rods, cylindrical, producing endospores. Fischer (1895, 1903), Lotsy (1907).

5. Bacillus. Any rod-shaped organism. Baumgarten (1890), Sternberg (1892), Macé (1897), Hewlett (1898), Matzuschita (1902).

6. Bacillus. Any motile rod. Conn (1909).

It would seem that the genus name Bacillus should be retained for the designation of a limited group of organisms, though probably no harm can come from the use of the term bacillus as a casual name to indicate rod-shaped organisms in general. It should be emphasized that when used as a generic designation it is a proper noun, and must be capitalized, whenever used. Many bacteriologists have ignored this rule which is followed so carefully by systematists and biologists in treating all other forms of life. Vuillemin's contention that the use of bacillus as a vulgar noun leads to confusion is not well premised. The genus Aster is universally recognized by botanists as valid. This does not interfere with the use and usefulness of the common name aster which includes many species not belonging to the genus Aster. By no means all of the plants commonly known as lilies are placed by the botanist in the genus Lilium. There is no reason why we cannot continue to speak of the tubercle bacillus even though it does not belong to the bacterial genus Bacillus.

In some form or with some definition the genus Bacillus should be retained. The type practically always accepted is $B$. subtilis. The definition of Fischer should therefore be abandoned as including only non-motile forms. He would exclude from the genus its first described species. The original description of Cohn is scarcely sufficient, for much stress was laid upon cell grouping and length of cell and not upon other characters. The use of Migula's diagnosis, including in the genus all rods with peritrichous flagella, is the cause of great confusion. It brings into the genus such discordant types as the hay bacillus and the typhoid bacillus. It excludes from the genus the anthrax bacillus so closely related to the hay bacillus. It does not result in bringing forms that are closely related together. Migula's definition should be abandoned as not based upon natural affinities. The definitions which would include all rods in the genus Bacillus have the merit of simplicity, but when organisms so diverse in characteristics as the tubercle bacillus, the typhoid bacillus, the tetanus bacillus, and the anthrax bacillus, are 
all included in one genus the simplicity is more apparent than real. The existence of such diverse forms has led most recent authors to arrange bacteria into well marked groups. It is the opinion of the author that the larger groups should be recognized as genera. The term Bacillus should therefore be restrieted. It would seem that it should be defined more nearly in the terms of De Bary, Zopf, Hueppe, ete., who emphasized the importance of spore production as a diagnostic character.

Objection may be raised that a definition of Bacillus as a genus made up of endosporous rods would exclude forms which have lost the power of spore formation but are in other respects closely related. It is evidently impracticable to base generie diagnoses upon a single character. Even though an organism be a variant in one or even more characters, the other resemblances would be sufficient to include the organism in question in the correct genus. Illustrations of this fact may be taken from higher plants. The Lombardy poplar is always classified in the genus Populus. It never produces fruit; it persists solely as the result of vegetative multiplication. Yet the genus Populus is based in part upon certain fruit characters. The other characters are so evidently poplar-like, however, that we do not question the correctness of the assignment of this species to the genus Populus.

Bactereae. A name given to the fourth tribe of the Bacteriaceae by Winslow et al. (Committee Soc. Am. Bact., 1910, p. 210). It is evidently a typographic error for Bacterieae q.v. This spelling is also used by Bergey et al. (1923, p. 194).

Bacteria. A group name frequently used by authors as synonymous with Schizomycetes. Hansgirg (1888, p. 299) gave the two as synonyms. Migula used this name with the following diagnosis:

Phycochromfreie Spaltpilzen mit Teilung nach ein, zwei oder drei Richtungen des Raumes. Viele Arten besetzen Endosporenbildung. Wo Beweglichkeit der Zellen vorhanden ist, wird dieselbe durch geisselartige Bewegungsorgane, seltener durch undulierende Membranen (Uebergang zu den Phycochromaceen) vermittelt.

The name in this general sense has been used by many writers. Heller (1912, p. 449) proposes this as the name of a phylum.

Bacteriaceae. Cohn (1872a, p. 237) under the description of Microsphaera uses the expression "Gruppe der Bacteriaceae." Cohn (1872b) says

Den gemeinschaftliche Charakter der von mir hier als Bacterien zusammengefassten Organismen scheint nur in Folgen dem zu liegen: Die Bacterien sind 
chlorophyllose Zellen von kugliger, oblonger oder cylindrischen, mituntcr gedrehter oder gekrïmmter Gestalt, welche ausschliesslich durch Quertheiling sich vermehren, und entweder isolirt oder in Zellfamilien vegetiren.

Apparently the name is used for the entire group of Schizomycetes.

The next reference to a use of this name in literature is apparently a statement of Lanzi $(1876$, p. 25) who mentions that Prof. Caruel in his lectures includes the family "Batteriacee" among the "Schizofiti." It was used in the next year by MacNab $(1877$, p. 340) and in much the same sense.

Trevisan $(1879$, p. 135) used the following description of this family:

Plantae fungales, unicellulares vel pluricellulares, liberae aut in muco matricali amorpho nidulantes, nunc motu proprio spontaneo, vel oscillante, vel rotatorio, vel flexuoso-repente, vel spirali praeditae, nunc immobiles, acidum carbonicum non assimilantes, in aquis plus minusque corruptis, dulcibus, thermalibus vel marinis, in liquidis fermentantibus, in substantiis putrescentibus, in corporibus animalium viventes. Vegetatio terminalis vel non terminalis. Ramificatio nulla aut rarissime spuria. Cytioderma flexibile, molle, tenuissimum. Cytioplasma chlorophyllo vel substantia chlorophyllo affini omino carens, achroum vel coloratum, nucleo destitutum. Multiplicatio divisione cellularum vegetativa aut in omnes directiones aut semper ad eandem directionem longitudinalem repetita. Propagatio tum sporis perdurantibus sine foecundatione e cytioplasmatis condensati metamorphosi genitis, tum microgoniis, in paucis detectis, e serie cellularum divisione longitudinali et transversa succendanae multipartitarum ortis. Per divisionem formae conservantur, multiplicantur et generationum series extensissimas evolvuntur; per sporas et microgonia morphae non raro parentibus plus minus dissimiles, colonias mucosas per cellularum generationes successivas ortas formantes, nascuntur.

This family name with the aberrant spelling Bacteriaceen was also used by Zopf (1883, p. 45). He included within it all organisms which might show four developmental stages, cocci, short rods (bacteria), long rods (bacilli) and filaments (Leptothrix forms). There is no differentiation of base and tip in the rods. Typical spiral forms are lacking. Two genera were recognized: Bacterium and Clostridium. In the third edition of Die Spaltpilze he (1885, p. 51) changes his conception of the family essentially. He now defines it to include organisms which show spherical, rod or filamentous growth forms, the latter either straight or bent. The coccus forms may be lacking. In the rod and filamentous forms there is no contrast between base and tip. Cell division, so far as is known, is in one direction of space. Spores present, lacking, or unknown. Six genera are recognized; Bacterium, Spirillum, Vibrio, Leuconostoc, Bacillus and Clostridium. Schröter (1886, p. 155) uses 
the family name Bacteriacei Zopf as the sole family of his order Eubacteria. He includes nine genera: Bacterium, Chromatium, Bacillus, Clostridium, Spirillum, Spirochaete, Microspira, Myconostoc and Cystobacter. Hansgirg (1888, p. 264) included Bacteriaceae as the first family of his order Eubacteria, but with no description. It is divided into the two subfamilies Spirobacteria and Microbacteria.

The classification of Hueppe (1891, p. 30) included two genera only; Bacterium and Bacillus. Migula (1894, p. 236) says:

Bacteriaceae Zopf emend Mig. Zellen länges oder kürzer cylindrisch, gerade, niemals schraubig, gekrümmt: Teilung nur nach einer Richtung des Raumes nach voraufgegangener Längstreckung des Stäbchens.

He (1895, p. 20) included three genera, excluding all spherical, spiral and filamentous forms. The genera recognized were Bacillus, Bacterium and Pseudomonas. Later (1897, p. 46) he gave the same definition.

Clements $(1894$, p. 25) redefined the family as follows:

Minute fungi without mycelium, typically unicellular, or at least the divisions not visible except at the time of the absection of new cells; cells of very diverse form (round, elliptical, bacillar, or filamentous), generally surrounded by a gelatinous envelope, one or both ends often provided with 1 to 3 flagella; growth peripheral, never apical; sexual reproduction undeveloped; asexual reproduction by simple division or by spores (endo-spores or arthrospores.)

Lehmann and Neumann (1896, p. 103) gave the following definition:

Zellen mindestens $1 \frac{1}{2}$ mal, meist aber 2-6 mal so lang als breit, gerade oder in nur einer Ebene etwas gekrümmt, nie schraubig, zuweilen lange echte oder Scheinfäden bildend. Teilung (fast) stets quer auf die Längsachse nach Streckung des Stäbchens. Mit oder ohne Geisseln. Mit oder ohne Endosporen. Die der Endosporen entbehrenden Arten sollen nach manchen Autoren zuweilen Arthrosporen bilden. Doch ist es nicht möglich, diese von vielen Forschern ganz geleugneten "Arthrosporen" diagnostisch zu verwerten.

Macé (1897, p. 438) recognized the family "Bactériacées." He says:

Ce groupe renferme des Bactéries dont les éléments allonges suivant une direction, ont une longueur qui l'emporte sur la largeur. La forme typique est le batonnet; il est tantôt court et trapu, apparait en coupe optique presque comme un carré ou comme un court rectangle; tantôt sa longeur dépasse un certain nombre de fois sa largeur. La première de ces dimensions peut devenir très grande par rapport à l'autre, c'est la forme de filament. Les batonnets ou les filaments sont droits ou courbés. La courbure peut être très simple et ne représenter qu'une faible portion de circonférence; elle peut être compliquée, l'élément décrit une spire à tours plus ou moins nombreux, plus ou moins serrés. Quelles que soient 
la forme ou la longueur de ces éléments, on ne leur distingue jamais d'extremité anterieure et d'extrémité posterieure, de base ni de pointe; les mouvements, lorsqu'ils existent, paraissent toujours se faire également dans les deux sens, et quand des individus se fixent ou plutôt s'accolent à un support, leur partie fixée ne différe en rien de celle qui reste libre.

The definition of Migula of Bacteriaceae has been followed among others by the following authors: Chester (1901, p. 117), Kendall (1902, p. 484), A. J. Smith (1902, p. 270), Klöcker (1903, p. 332), Migula (1904, p. 145), Erwin F. Smith (1905, p. 160), Ellis (1909, p. 3), Frost (1911, p. 57), Schneider (1912, p. 23).

Winslow et al. (Committee Soc. Am. Bact., 1917, p. 560) recognized this as the sixth family of the order Eubacteriales with the following diagnosis: "Rod-shaped cells without endospores. Gram-negative. Flagella when present peritrichic. Metabolism complex, amino-acids being utilized, and generally carbohydrates."

Buchanan (1918, p. 27) recognized this as the second family of the Eubacteriales, with the following description:

Cells rod-shaped, straight, or at least not spherical or spiral. Never containing sulphur granules, nor with bacterio-purpurin, many species pigmented. May or may not be motile by polar or diffuse flagella. Cells may be single or in chains. Endospores produced in some genera, not in others. A pseudoplasmodium never developed. Growth energy not secured by the oxidation of ammonia or nitrites.

In 1920 Winslow et al. (p. 208) describe Bacteriaceae as the fifth family of the Eubacteriales including seven tribes.

Bergey et al. (1923, p. 84) recognizes this as the fourth family of the order Eubacteriales with the description: "Rod-shaped cells without endospores. Motile or non-motile. Metabolism complex, aminoacids being utilized, and generally carbohydrates. Usually Gramnegative." Nine tribes are included.

It is evident that while the earlier writers used this name as a designation of the entire group of bacteria, the later writers have uniformly regarded it as a family within the group.

Bacteriaceen. An aberrant form of spelling of the family Bacteriaceae (q.v.) used by Zopf (1884, p. 45, and 1885, p. 51).

Bactériacées. An aberrant form of spelling of the family Bacteriaceae (q.v.) used, among others, by Cornil and Babes (1890, p. 151).

Bacteriacei. An aberrant form of spelling of the family Bacteriaceae (q.v.) used by Schröter (1885, p. 155). 
Bacteriales. An ordinal name suggested by Clements (1909, p. 8). His description is as follows: "Globose, rod-like or filamentous, single or in colonies, sometimes grouped into a loose mass (zoogloea), but never forming pseudoplasmodia or sporangium-like masses." He recognized five families, Beggiatoaceae, Chlamydobacteriaceae, Spirillaceae, Bacteriaceae and Coccaceae.

Bacteridia. The Anglicized equivalent of Davaines casual name bacteridie for the anthrax organism.

Bactéridie. A casual name given by Davaine (1863, p. 195) for the anthrax bacillus. Used for Bacteridium q.v.

Bacteridieae. The fifth tribe of the family Bacillaceae as described by Castellani and Chalmers (1919, p. 932). One genus only, Bacteridium Schroeter, is included. The tribal designation is,

Bacillaceae growing well on ordinary laboratory media, without endospores, and either fluorescent or chromogenic.

Type Genus. Bacteridium Schroeter, 1872.

Bacteridium. A genus proposed by Davaine (1868, p. 21) to include organisms with filiform bodies, more or less distinctly articulated in consequence of imperfect division, always non-motile. The name was created to provide for the anthrax bacillus. He states,

III Genre Bactéridic. Bacteridium (Davaine). Corps filiforme, droit ou infléchi, plus ou moins distinctement articulé, par suite d'une division spontanée *narfaite, toujours immobile.

Apparently in this article at least he did not give a species name. $\mathrm{He}$ writes "Bactéridie Charbonneuse (Davaine)" for the anthrax bacillus. The latin generic name is definite enough, as is also the species considered. The casual designation bactéridies was first proposed in 1863 (p. 195), in the following statement:

On voit, d'après les considérations qui précèdent, que le nom de bactérie, par lequel j'ai désigné primitivement ces corps, ne peut leur convenir. Lorsque l'étude des êtres microscopiques qui jouent un grand rôle dans la fermentation, dans la putréfaction, etc., est à peine commencée, il serait prématuré de vouloir classer d'une manière définitive les corpuscules du sang de rate, qui ont avec ces êtres une analogie évidente. Je me bornerai donc, pour désigner ces corpuscules, à modifier légèrement le nom que je leur ai primitivement donné, et je les appellerai désomais des bactéridies. $2 \mathrm{~m}$

It is apparent that we have the anomalous situation of a suitable generic name, Bacteridium, being published, together with an adequate 
description of a species which should be considered the type, but without a scientific name being given to the species. There may be some question under such circumstances of the validityof the generic name, though there would seem to be no statement in the International Rules of Botanical Nomenclature which would definitely make it invalid. It should be noted that while this author repeatedly in later writings used the term bacteridie, the generic name Bacteridium was not employed with a specific name to designate the anthrax bacillus (1864, p. 393), (1865, p. 334). It is of interest to note that Davaine earlier (1863, p. 222) used the designation bacterium du sang de rate.

Schroeter (1872, p. 110) used this designation to include certain nonmotile pigment-producing bacteria, among them Bacteridium prodigosum. This use of the genus name was discussed and disapproved by Cohn $(1872$, p. 182) because the pigment producers have no marked character in common with the anthrax bacillus other than lack of motility.

Cohn says,

Wegen des Mangels der spontanen Bewegung hat Schroeter in dem voranstehenden Aufsatz die Kugelbacterien, welche Pigmente erzeugen, mit demselben Namen belegt, welchen Davaine für die unbeweglichen Stäbchen des Milzbrandblutes eingeführt hat (Bacteridium). Die Milzbrandbacteridien unterscheiden sich jedoch durchaus von den Pigmentbacterien, da sie stäbchen- oder lang fadenförmig sind; sie können daher mit den Kugelbacterien nicht in einer Gattung suzammengestellt werden, da der Mangel der Bewegung der einzige beiden gemeinschaftliche Charakter ist.

The name was abandoned by Schroeter (1886). Macé (1897, p. 485) makes the following comments:

Davaine avait cru devoir distinguer autrefois un genre Bacteridium, caractérisé par l'immobilité des éléments à tour les stades de peur existence. Il l'avait établi pour la Bactéridie du charbon et quelques autres observées dans l'intestin et les infusions. Mais l'absence ou la présence de mouvements n'offre jamais de constance suffisante pour en faire un caractære spécifique. Un grand nombre d'espèces, très mobiles à une certaine phase de leur existence, deviennent complétement immobiles à la période suivante ou seulement quan les conditions de vie, tout en restant bonnes, viennent à changer; beaucoup deviennent inertes, par exemple au moment de la sporulation. Les Bactéries mobiles ne différent du reste des immobiles par aucun caractềre de valeur.

Erwin F. Smith (1905, p. 153) claims that this genus name is invalid because of the previous existence of the genus Bactridium Kunze 1817. Whether or not this use invalidates Bacteridium Davaine depends upon 
the interpretation of Article 57 and Recommendation XXXI of the botanical code. The former states that when the difference between two names, especially two generic names, lies in the termination, these names are to be regarded as distinct even though differing by one letter only. The latter reads:

Many names differ by a single letter without risk of confusion. In cases where a close approach to identity is a source of error (ex. Astrostemma and Asterosemma in one and the same family, Asclepiadaceae) only one, the older, of the names should be kept in accordance with Article $51,4^{\circ}$.

This last Article reads:

Every one should refuse to admit a name in the following cases:

4. When the group it designates embraces elements altogether incoherent, or when it becomes a permanent source of confusion or error.

Smith suggested the name A planobacter in its place.

Vuillemin (1913, p. 519) states that lack of motility does not justify generic recognition.

Buchanan (1918, p. 33) recognized Bacteridium as a subgenus of Bacillus to include the non-motile species, with Bacillus (Bacteridium) anthracis Cohn as the type.

Castellani and Chalmers (1919, p. 933) revive the Bacteridium of Schroeter with Bacteridium prodigiosum as the type. Their definition (p. 958) is "Bacteridieae which are chromogenic." It constitutes the type genus of the tribe Bacteridieae q.v. with the definition "Bacillaceae growing well on ordinary laboratory media, without endospores, and either fluorescent or chromogenic."

It would seem that the use of the genus Bacteridium in bacteriology and of Bactridium in mycology is valid if organisms of which the anthrax bacillus is the type are to be grouped into a separate genus. The previous use of Bactridium should no more invalidate Bacteridium than Micrococca Benth. a valid genus of the Euphorbiaceae created in 1849 should invalidate Micrococcus Cohn (1872).

Bacterieae. A tribe of bacteria created by Trevisan (1879, p. 136) with the following description:

Bacteriaceae unicellulares. Individua globulosa vel ellipsoidea vel cylindrica, e cellula unica conflata. Sporae intra cellulam matricalem solitariae. Multiplicatio divisione cellularum vegetativa in unam vel duos vel omnes directiones. 
Two subtribes were included, namely, Eubacterieae and Sarcineae.

Buchanan (1918, p. 39) recognized this tribe as the second of the family Bacteriaceae, with four subtribes Fusiforminae, Hemophilinae, Rhizobiinae and Bacteriinae. The description is: "Cells rod-shaped, never spiral nor strictly filamentous; single or in chains, motile or nonmotile, never producing endospores, either Gram-positive or -negative."

Bergey et al. (1923, p. 194) used this designation (with the spelling Bactereae) for the sixth tribe of the family Bacteriaceae with the following description: "Gram negative rods generally growing well on artificial media. Generally attack carbohydrates forming acid and often gas composed of $\mathrm{CO}_{2}$ and $\mathrm{H}_{2}$. When motile, the flagella are peritrichous." Six genera are included.

Bacterien. A casual name used by Cohn (1872, p. 132) and subsequent German writers for the bacteria.

Bactéries. A casual name used by Davaine (1863) and subsequent French authors for the group bacteria.

Bacteriinae. A subtribe of the tribe Bacterieae named by Buchanan (1918, p. 47) with the following diagnosis:

Cells not fusiform, rod shaped; not hemoglobinophilic; aërobic, facultative, or microaërophilic; not securing growth energy exclusively by the oxidation of carbonaceous compounds. Spores never formed. Motile or non-motile.

It included the following genera: Pseudomonas, Serratia, Chromobacterium, Pasteurella, Bacterium, Proteus, Pfeifferella, Lactobacillus, Erysipelothrix, and Corynebacterium.

Bacterina. A group created by Perty (1852, p. 179) to include the genera Bacterium, Vibrio and Metallacter. The name has never come into common use.

Bacteriopsis. A generic name proposed by Trevisan (1885, p. 103) for a group of bacteria. The organisms were considered as showing three stages of development: 1. Bacilli. 2. Filaments. 3. Cocci. The bacillus form was regarded as most typical. The cells were short cylindrical or ellipsoid, straight, not articulate, colorless or colored, showing both macrobacilli and microbacilli; cytoplasm equally diffused in cells. Spores none or unknown.

The species included in the genus are as follows:

Bacteriopsis Rasmusseni $=$ Leptothrix I Rasmussen.

Bacteriopsis aceti $=$ Mycoderma aceti Pasteur.

Bacteriopsis Pasteuriana $=$ Bact. Pasteurianum E. Chr. Hansen. Bacteriopsis merismopedioides $=$ Bact. merismopedioides Zopf. 
Bacteriopsis ureae $=$ Micrococcus ureae Zopf.

Bacteriopsis ianthina $=$ Bact. ianthinum Zopf.

Bacteriopsis synxantha $=$ Vibrio synxanthus Ehrenb.

Bacteriopsis ovata $=$ Panhistophyton ovatum Lebert.

The genus has not been used by subsequent authors, and is not even recognized by DeToni and Trevisan (1889).

It is rejected by Erwin F. Smith (1905, p. 174).

Probably the first named species, Bacteriopsis Rasmusseni, should be regarded as the type. It was later $(1889$, p. 930) placed by De Toni and Trevisan in the genus Rasmussenia (the fourth species, $R$. anceps). If no older generic name for the mouth leptothrix forms can be found, this would probably be a valid designation for them. It may be regarded as a synonym of Leptotrichia.

Bacterium. A generic name proposed by Ehrenberg (1828, p. 8). His diagnosis is as follows:

Bacterium, Novum Genus, Familia Vibrionorum. Character Generis: Corpus polygastricum? anenterum? nudum, oblongum, fusiforme aut filiforme, rectum, monomorphum (contractione nunquam dilatatum), parum flexile (nec aperte undatum), transverse in multas partes sponte dividuum.

The only species described was Bacterium triloculare The description was as follows:

B. triloculare nov. spec.; distincte triloculare s. triarticulatum, subfusiformum, hyalinum.

Animalculum 1/300 lineae longum, corpore tereti. Articuli s. septa interna divisionem instantem multiplicem transversam indicare videntur. Mobile sed pigrum animalculum.

In Oasi Jovis Hammonis Siwae observatum, praeterea nullibi.

Bacterii Generis physiologia huiusque obscurra. Cibo colorato Ventriculos replere hae formae respuunt ideoque ad Polygastrica non misi dubitanter et interim collocantur.

While it is not improbable that Ehrenberg actually described one of the organisms now included with the bacteria, it is evident that there is nothing in the description which would make probable a modern identification of the species.

Two years later Ehrenberg $(1830$, p. 38$)$ included some eleven species in his Bacterium. It is to be noted that some were not new species. Several of Mueller's species of infusoria described in 1783 were included, among them being Bacterium (Monas) termo (Mueller) Ehrenberg. In the previous (1828) paper, Ehrenberg had recognized Monas termo 
Mueller as distinct, not including it in the genus Bacterium. Inasmuch as Bacterium termo has been much discussed in the literature, the description given by Mueller (1786, p. 1) should be noted.

Monas termo. Animalculum omnium, quae microscopium simplex offert, minimum simplicissimum, punctulum, gelatinosae, substantiae pisum microscopium composirum eludere videtur, dum ne quidem sub hoc distinctius appareat.

Sphaericum, an orbiculare? haud video.

Guttula aquae, in qua maceratio facta est, his corpusculis adeo saepe repletur, et ne mimimum vacuum distingui liceat, ipsamque aque substantium in aliam minus hyalinam, globularem ex punctis consertissimis, omnem calculum superantibus mutatam crederes.

In hac massa motus, qualem radii solares in aqua micantes effingere solent, oculis exhibetur, dum animalcula, examinis.opum instar, vehementer cominoventur.

In infusione vegetabilium et animalium. Huius guttula jam intra vigenti quatuor horas conspicitur quasi massa globularis, aut nullus in ea motus nec odor percepitur, brevi vero motus seu fermentatio cum foetore interabili insequitur, at non in omni.

Fig. 1. Guttulam aquae fluvialis Monade Termone scetentam valde auctam exhibet.

Ehrenberg's description of Monas termo Mueller as given in 1828 is also pertinent.

$M$. Termo (Mueller): $1 / 1664$ ad 1/500 linea crassa, exacte blobosa, hyalina.

Specimena, seu potius Myriades, quas Siwae in Oasi libyca vidi et illae, quas infuso Pipere nigro in Arabia accepi, magnitudine 1/1664 lineae fere aequabant. Quae e sinaitica valle Wadi Esle depromsi mensuram 1/1660 lineae offerebant. Berolini et in Sibiria interdum maiora individua, ab eadem specie vix segreganda, vidi, maxima $1 / 500$ lineae crassa, quae, si divisione spontanea funduntur, in partes $1 / 1000$ lineae crassas, reliquis similes, abeunt.

Monadum speciales characteres, ob microscopiorum, quae vocamus, sufficienter eas augendi vim deficientem, praeter corporis formam et mensuram, non habent quo nitantur et firmitate physiologia saepe carent. Motus, coloris, mensurae et propagationis ratio cum forma nonnullas quidem species bene destinguere sunt, in aliis characterum gravitas desideratur, sed formarum magnam copiam in aquis vagari unusquisque, qui his animalculis studium impendit, facile sibi persuadet. Quin ex Monadibus, Vibrionibus, Bacteriis et Bodonibus iis, quae minutie excellunt et cibos colaratos respuunt, novae animalium classis vestigia posteris premenda enitescere saepe mihi visa sunt.

The generic description given for Bacterium by Ehrenberg (1830, p. 38) is: "Bacterium. Nov. Gen. Haec genera, Oscillatoriis valde affinia ore nutriri nundum vidi." Eleven species are listed.

Two years later (Ehrenberg 1832) differentiated six species of the genus Bacterium. Two of these, Bact. articulatum and Bact. triloculare 
are definitely included. Four other species Bact. Enchelys, Bact. punctum, Bact. tremulans and Bact. termo are questioned.

Six years later in his classic work on the Infusoria Ehrenberg (1836, p. 75) characterized the genus Bacterium as follows: "Animal e familia Vibrioniorum, divisione spontanea in catenam filiformen rigidulam abiens."

One species only, Bacterium triloculare is included. In his drawing of Bacterium triloculare a polar flagellum is shown.

A careful perusal of the description certainly reveals nothing that would enable one even with a moderate degree of certainty to identify Ehrenberg's species. Certainly most of them were based on impure or mixed cultures. From different localities and conditions the same organism was frequently described though differing sufficiently in size and appearance to justify the conclusion that the forms were quite distinct.

Inasmuch as some effort has been made to tie up the genus Bacterium to Bacterium termo as a type species, the following points are worthy of note.

1. Bacterium termo (Mueller) Ehrenberg was not included as a member of the Genus Bacterium in the paper in which the genus was first proposed, in fact, as Monas termo Mueller, it was placed in another genus.

2. Mueller (1786, p. 1) states that Monas termo is spherical and Ehrenberg (1828) likewise describes it as globular ("exacte globosa").

3. The organism was found in water and in infusions of animal and vegetable matter.

It should be noted that Ehrenberg includes the genus Bacterium as one of five genera in his family Vibrionia, the other genera being Vibrio, Spirochaeta, Spirillum and Spirodiscus. Bacterium is differentiated from Vibrio in that it is non-flexuous, while the latter is flexuous.

Dujarclin (1841, p. 212) practically adopted Ehrenberg's classification. He designated as Bacterium all those forms which are straight, more or less definitely jointed, non-flexile, and which were capable of only a slow wave-like motion. Vibrio, on the other hand, contained those organisms which are straight or bent, more or less definitely jointed, and which show sinuous motion like a snake. He placed three species in this genus, Bact. termo, Bact. catenula, and Bact. punctum. His description reads: "Corps filiforme, roide, devenant plus ou moins distinctement articulé par suite d'une division spontanée imparfaite. Mouvement vacillant non ondulatoire." Here again there is nothing which will enable the bacteriologist to identify any one of the species. 
It is of interest to note that many subsequent writers ascribe the species Bacterium termo to Dujardin.

Diesing (1850, p. 14) gives the following generic description of Bacterium.

Corpus nudum, lorica destitutum head mutabile, cylindricum subovatum aut subglobosum, partitione imperfecta uniseriali, multiplici, transversa in syntherium lineare, moniliforme, rigidulum, rectum, hyalinum accrescens. Flagellum in articulo primo terminale simplex. Ocellus nullus.

Perty (1852, p. 179) developed a classification of the infusoria, recognizing a family Vibrionida with two subfamilies Spirillina and Bacterina. Under the latter the genera Vibrio, Bacterium, Metallacter and Sporonema are included. Vibrio is defined as flexuous, Bacterium is non-flexuous. The only species of Bacterium described is Bact. termo ascribed to Dujardin. It is recorded as occurring "in den allerverschiedensten faulenden Aufgüssen und Sumpfwässern das ganze Jahr." He notes that it was recorded by Dujardin "im Eiter und andern pathologischen Flüssigkeiten" and even "nach Leeuwenhoek im Zahnschleim." The description is wholly unsatisfactory, and shows a tendency, which became more pronounced during the succeeding two decades, to call all organisms associated with putrefaction and decay Bacterium termo.

Cohn $(1854$, p. 123) for the first time definitely grouped the form now termed bacteria under the plant kingdom, removing them from the Infusoria. He studied at length the Bacterium termo Dujardin, which he regarded as a synonym of Vibrio lineola Ehrenberg. He concluded this form to represent merely the swarm cell state of an alga-like fungus. He was unable to see the "cilia." He gave it the generic name Zoogloea with the following characters:

Cellulae minimae, bacilliformes, hyalinae, gelatina hyalina in masses mucosas globosas, uvaeformes, mox membranaceas consociatae, dein singulae elapsae, per aquam vacillantes.

The species became Zoogloea termo. As synonyms he notes "Palmella infusionum Ehr., Micraloa teres V. Flotow, Bacterium termo Dujardin and Vibrio lineola Ehrenberg.

Several authors in the next two decades followed Cohn in the substitution of Zoogloea for Bacterium. For example, Rabenhorst (1865, p. 35) in his "Flora Europaea Algarum" includes this genus among the algae under the heading "Formae achroae, hyalinae (mea sententia ad 
fungos referendae"). The generic description given is identical with that of Cohn. The single species Zoogloea termo (Müller) Cohn is briefly described as: "Z. thallo gelatinoso globoso, cellulis liberis mobilibus, rectis, $1 / 2000-1 / 700^{\prime \prime}$ aequantibus. Hab. in aquis stagnantibus, imprimis corruptis ubique."

A Zoogloea ramigera was later described by Itzigsohn (1867, p. 414). The next author of note defining Bacterium was Davaine (1864, p. 629) who, like Cohn, separated the Vibriones from the protozoa, and described the genera Bacterium, Vibrio and Spirillum. His definition of Bacterium (given in 1868, p. 68) is identical with that of Dujardin. It should be noted that this author emphasized the importance of motility in the generic diagnosis.

An interesting sidelight on the utilization at this time of the term Bacterium termo to include the greatest variety of microörganisms is to be found in the writings of Lüders $(1866$, p. 36) who concluded that this wide spread organism was a growth stage of a fungus. Hallier (1886) introduced and developed his theory of pleomorphism which reached its culmination in the work of Billroth (1874). This led to general distrust at this time in the existence of true bacterial species and indirectly contributed to the lack of regard for the rules of nomenclature during the next several decades.

Davaine (1868, p. 21) used the name in the sense of Dujardin, differentiating the non-motile forms such as the anthrax bacillus in the new genus Bacteridium. His description of Bacterium is as follows:

Genre Bacterie. Bacterium (Ehrenberg, Dujardin). Corps filiforme, roide, devenant plus ou moins distinctement articule par suite d'une division spontané imparfaite; mouvement vacillant, non ondulatoire (Dujardin).

In summary, to the year 1872 , the generic name Bacterium was not applied to any species which can now be recognized satisfactorily. The original Bacterium triloculare Ehrenberg was no longer recognized in the literature. Bacterium termo the organism found commonly in putrefying solutions was the only species.

Cohn (1872, p. 167) rather radically emended the previous generic descriptions of Bacterium to include those rod-shaped organisms in which the cells are short, never filamentous. He made it the sole representative of his tribe Microbacteria. The cells are short cylindric or elliptical, never in chains or filaments, often forming firm zoöglocal inasses, alternating motile with non-motile stages. His description was largely based on his conception of Bacterium termo, which he regarded 
as the principal agency of decay. ("ohne Bacterium termo keine Fäulniss"). He described the reaction secured by inoculating the bacteria from putrefying beans into his ammonium tartrate solution and noted the development therein of a green fluorescence.

Should this description of Cohn be used as fixing the type for Bacterium as Bacterium termo? The following objections may be raised:

1. Unquestionably Cohn was dealing with impure or mixed cultures. The fact that when this mixture was inoculated into Cohn's nutrient solution a green fluorescence was produced by no means fixes this as a characteristic of Bacterium termo. Bacteria capable of bringing about this change are widely distributed in nature. In other words, in the heterogeneous mass of organisms present in infusions, known as Bacterium termo, there are included certain fluorescent bacteria capable of growing in Cohn's nutrient solution. The International Botanical Code is explicit on this point:

Article 51. Every one should refuse to admit a name in the following cases: 4 . When the group which it designates embraces elements altogether incoherent or when it becomes a permanent source of confusion or error.

2. The species Bacterium termo was first described as Monas termo Mueller, it was tentatively transferred to the genus Bacterium by Ehrenberg, but later rejected by him, and first definitely included in the genus by Dujardin. It was later made a type of the genus Zoogloea by Cohn. Inasmuch as this organism was not at first included in the genus Bacterium, in fact was definitely excluded by the author of the name, it does not seem advisable to accept it as the type.

Schroeter (1872, p. 120) put in the genus Bacterium three species of bacteria which had previously been described in other genera, the Vibrio synxanthus ${ }^{1}$ Ehrenberg (1840, p. 202) he renamed Bacterium synxanthum (the spore bearing rod responsible for yellow milk), the Vibrio syncyaneus Ehrenberg ${ }^{2}$ (1840, p. 202) he termed Bacterium syncyaneum (the polar flagellate organism of blue milk) and named the Bacterium aeruginosum, the polar flagellate organism of blue green pus. Both of these organisms were later $(1886$, p. 157) transferred by Schroeter to the genus Bacillus. The names used by Schroeter were accepted by Cohn (1872b, p. 173).

Should one of Schroeter's species be accepted as the generic type? It probably would be inadvisable to designate thus either of the species

1 The Vibrio xanthogenus, Fuchs (1841, p. 193).

2 The Vibrio cyanogenus, Fuchs (1841, p. 190). 
transferred to this genus from other genera, for it is quite conceivable, that inasmuch as Vibrio syncyaneus Ehrenberg was probably the first species of Vibrio sufficiently described so that it can be certainly recognized and identified today, it might be designated as the type of Vibrio. In other words, if it is to be accepted as a type, it should be for Vibrio and not for Bacterium. The form from yellow milk quite certainly should be placed in the genus Bacillus. Bacterium aeruginosum is so closely related to Bact. syncyaneum that they probably should be placed in the same genus. It would certainly be unwise to choose the former as the type, as there might well be question as to whether it did not belong likewise in the genus Vibrio. It would seem that stability of nomenclature would not be conserved by the choice of any one of these as a type species.

If Bacterium is to be retained as a bacterial genus, it seems necessary to pick the type species from those described subsequently to 1872 .

Lister (1873, p. 408) gave the name Bacterium lactis to an organism responsible for lactic acid fermentation. While his description may not be sufficiently accurate to enable us to determine with certainty whether he described the lactic streptococcus or one of the aerogenic lactic bacilli, (such as Bacterium aerogenes) now generally regarded as belonging to the colon-typhoid group, it is probable that the former should be the interpretation. Bacterium lactis became Streptococcus lactis and is not available as a type.

Lankester (1873, p. 13) described a "peach coloured Bacterium" from water under the name Bacterium rubescens. The description makes it evident that he was working with organisms belonging to the group of forms containing bacteriopurpurin, that is, to the group of sulfur bacteria. The description further makes it evident that he was not dealing with a pure culture. He dilates upon its variability, the appearance of rods and spirals, and motile and non-motile cells, etc. Certain of the forms were quite certainly previously described under other names. Cohn wrote Lankester (1874, p. 399) that his organism was the Monas Okeni Ehrenberg, the Clathrocystis roseopersicina of Cohn. While Lankester combated Cohn's statements, modern knowledge of the group would seem to justify them. Certainly the recognition of Bacterium rubescens as a type species would be unwise.

Warming (1875) described several species of Bacterium from the water on the coast of Denmark. These were Bacterium griseum, Bact. litoreum, and Bact. fusiforme. They were not grown in pure cultures and apparently are not identifiable with certainty. 
Dallinger (1878, p. 159) studied Bacterium termo microscopically, demonstrating motility to be due to a terminal flagellum. It is defined in the sense of Cohn.

In $1875 \mathrm{Cohn}$ included the genus in the tribe Glaeogenae. It was defined as having cylindrical cells, without phycochrome, very small, cells united in glairy families, amorphous when in repose, or entirely free, never disposed in filaments. In this revision he accredited the genus to Dujardin rather than to Ehrenberg. Magnin (1878, p. 80) follows Cohn exactly. The diagnosis reads:

Bacterium, Duj. emend. Cells cylindrical or elliptical, free or united in pairs during their division, rarely in fours, never in chains, sometimes in zoogloeae, having spontaneous movements, oscillatory and very active, especially in media rich in alimentary material and in presence of oxygen.

The species are divided into three groups:

1. The bacteria of putrefaction (Bact. termo Ehr. and Bact. lineola Cohn).

2. The bacteria of lactic and acetic fermentations, and

3. The chromogenic bacteria (including Bact. xanthinum Schröter, Bact. syncyaneum Schröter, Bact. aeruginosum Schröter, and Bact. brunneum Schröter).

Of the species, the chromogenic forms can for the most part still be readily recognized.

Lanzi $(1876$, p. 256) designated the organism responsible for acetic fermentation Bacterium aceti.

Trevisan (1879, p. 136) gives the following synonymy and description:

Bacterium Ehrenb. (1830 non 1825) emend Cohn (Beitr. I Heft 2, p. 177); (Chromatium Perty 1852; Zoogloea Cohn 1853; Rhabdomonas, Cohn 1875). Cellulae breviter cylindricae, vel ellipsoideae, vel fusiformes. Multiplicatio divisione cellularum vegetativa semper ad eandem directionem longitudialem.

The species recognized are Bact.aceti Lanzi 1876, Bact. termo Ehrenb., Bact. lineola Cohn, Bact. tremulans Trevisan, Bact. catenula Dujard., Bact. punctum Ehrenb., Bact. synxanthum Schroeter, Bact. syncyaneum Schroeter and Bact. aeruginosum Cohn.

The generic description of Bacterium by Luerrsen $(1879$, p. 20) does not assist in fixing a type species.

Van Tieghem (1879) described a Bacterium lucens from the surface of liquids.

Sternberg (1880, p. 80) in his translation of Magnin's (1878) text on the bacteria gives the following characterization of the genus Bacterium: 
Cells cylindrical or elliptical, free or united in pairs during their division, rarely in fours, never in chains (Leptothrix or Torula), sometimes in zoogloea (differing from the zoogloea of spherical bacteria by a more abundant and firmer intercellular substance), having spontaneous movements, oscillatory and very active, especially in media rich in alimentary material and in presence of oxygen.

He includes descriptions only of species which have already been noted. They are separated into three groups, the bacteria of putrefaction, those causing lactic and acetic fermentation, and the chromogenic forms.

Thin (1880) described a Bacterium foetidum from malodorous perspiration. The culture methods used did not insure pure cultures.

Winter (1880, p. 51) characterizes Bacterium (which he ascribes to Cohn) as follows:

Zellen kurz cylindrisch, lang elliptisch oder spindelförmig, durch Quertheilung sich vermehrend, spontan beweglich. Die Tochterzellen trennen sich entweder bald nach der Theilung von einander oder bleiben zu 2 bis mehr kettenartig vereinigt. Auch Zoogloea-Bildung ist häufig. Sporenbildung ähnlich wie bei Bacillus.

He lists and describes eight species, none new. It will be noted that he includes for the first time the possibility of spore formation as a character of the genus.

Van Tieghem (1881) described a green organism from rain water which had collected in the pileus of a Polyporus, giving it the name Bacterium viride.

Thin (1881) also described a Bacterium decalvans from alopecia areata.

Zopf (1883, p. 48) materially modified the definition of the genus following the conception of pleomorphism, to include those organisms showing four growth forms, cocci, short rods, long rods and filaments, the latter never with differentiation of base and tip. The following year $(1884$, p. 45$)$ he used the same definition. He included in the genus some seventeen species, most of which are still recognized. Organisms previously described by other authors as in the genus Bacillus are included, such as Bacterium tuberculosis, Bact. typhosum, Bact. subtile and Bact. anthracis. His Bact. ianthinum was the Bacteridium violaceum of Schroeter and the Chromobacterium violaceum of Bergonzini. The only organism apparently newly named and placed in this genus was Bacterium acidi-lactici. The description is scarcely adequate to identify this organism as the one now generally recognized under this name. The specific name acidi-lactici has been used in so many senses 
by subsequent authors as to make identification difficult. However, Bact. acidi-lactici may be regarded as a possible type species.

Engelmann (1882, p. 94) described an organism from water as $\mathrm{Bac}$ terium photometricum. It was insufficiently differentiated.

Kurth $(1883$, p. 97) isolated and described from the alimentary tract of the domestic fowl an organism which he named Bacterium Zopfi. This organism is adequately known at the present time.

Lanzi (1883, abs. 1884, p. 786) described an organism as Bacterium morbilli but not adequately.

Luerssen $(1879$, p. 20) used the generic diagnosis of Cohn as did also Grove (1884, p. 22). This latter author lists five colorless species (including Bact. termo) and four chromogenic species (including Bact. synxanthum Schröter, Bact. syncyaneum Schröter, Bact. aeruginosum Schröter and Bact. violaceum (Bergonzini) Grove). The chromogenic species may all be recognized.

Van Tieghem (1884, p. 1110) defined Bacterium as containing rodshaped cells, separating as soon as formed, never in filaments, never spiral. He regarded the name more as a form genus than a natural genus.

Escherich (1885) described two organisms, Bacterium coli commune and Bacterium lactis aerogenes, from infant stools. The description was greatly expanded the next year (1886, pp. 57 and 63). These organisms have been consistently known by these names to the present time.

In 1885 Trelease described several new species of pigmented bacteria under the names Bacterium candidum, Bact.luteum, Bact. aurantiacum, Bact. chlorinum and Bact. incarnatum. Zukal (1885) studied the morphology of a Bacterium tortuosum from water.

Zopf in 1885 (p. 61) completely revised his classification. Bacterium is defined as made up of those species which exist as cocci and rods, or the latter only, united into filaments, spore formation lacking or unknown. It will be noted that here the emphasis is changed to absence of spores. Hueppe (1885) used practically the same diagnosis. Maggi (1886, p. 84) listed five species of this genus.

Flügge (1886) outlined a classification of bacteria which has been extensively followed by medical bacteriologists. His genus Bacterium is defined to include cylindric forms, short, single or loosely united or in amorphous slimy masses.

Schröter $(1886$, p. 155) states that the genus Bacterium is not well characterized and possibly should be united with the genus Bacillus from which it is separated with difficulty. He accepts absence of spores 
as a generic character, and states that the vegetative cells are short rods, little longer than broad, in the rounded form either solitary or embedded in slime (Zoogloea), from which a motile form emerges. Three species only are listed: Bact. termo Ehr., Bact. septichaemiae and Bact. cholerae gallinarum. The chromogenic specics previously listed here by Cohn and Schröter are transferred to the genus Bacillus. Hansgirg (1888, p. 265) listed Bacterium as the second genus of the subfamily Microbacteria, but with no diagnosis. De Toni and Trevisan (1889, p. 1020) give the following generic diagnosis:

Bacterium Ehrenb. (1830) emend. Trev. Bacterii et Bacilli species Auctorum. Baculi vulgo brevis, interdum brevissimi, ut plurimum ellipsoidei, raro cylindracei, apicibus obtusis, recti. Sporae (arthrosporae) globosae, e coccorum metamorphosi ortae.

The genus is included in the subfamily Baculogenae and the tribe Bacilleae. In all, thirty-four species are described. Of these Bact. aceti (Kuetz) Lanzi, Bact. Pasteurianum (Hanson) Zopf, Bact. allantoides Trev. and Bact. Balbianii Billet are noted as particularly typical. The genus is divided into two primary groups, Bacteria achroa (22 species) and Bacteria chromogena (12 species). The first group is again sub-divided into Species Zymogena ( 8 species, mostly acetic acid bacteria), Species saprophyticae (13 species) and Species anthrophobiae (1 species). The second group is divided into Species granula sulphuris nulla secernentes (7 species) and Species granula sulphuris secernentes (5 species). Baumgarten (1890) abandoned the genus, including all rod forms in Bacillus. Billet (1890), p. 23) says "Formes rectilignes Bacterium, element 1 à 5 fois plus long que large." Sternberg (1892, p. 18) states: "This genus, established by Dujardin, is now generally abandoned, the species formerly included in it being transferred to the genus Bacillus." Ludwig (1892) included in Bacterium rod-shaped elliptical organisms, not in long filaments, not embedded in slime, and differentiated from Bacillus by lack of endogenous spores. Freudenreich (1894) defines a Bacterium as a rod without endospores or with arthrospores.

Migula (1894, p. 236) radically emended the genus to include only the non-motile rods, i.e., those forms with shorter or longer cylindric cells, sometimes forming filaments, without flagella, endospore formation observed in many species, in others apparently completely lacking. $\mathrm{He}$ states: "Bacterium Cohn.Zellen ohne Bewegungsorgane oft mit Endosporenbildung. (Z. B. Bacterium Anthracis)." He notes that about 200 species are known. 
Clements (1894, p. 27) defined the genus Bacterium as follows: "Cells very short, ellipsoid, rarely cylindrical, motile or non-motile, often imbedded in a gelatinous matrix and forming zoogloea."

Two species only are described, Bacterium termo and Bact. aceti.

The genus name Bacterium is not used by Fischer (1895) at all. Lehmann and Neumann (1896, p. 181) emphasized lack of endospores as the most important character. They say

Zellen mindestens $1 \frac{1}{2}$ mal. meist aber 2-6 mal als lang als breit, gerade oder in einer Ebene gekrummt, zuweilen lange echte oder Scheinfäden bildend, mit oder ohne Geisseln. Stets ohne Endospores, für einzelne Arten sind Arthrosporen beschrieben.

Macé (1897) retained the older conception of the genus. He states:

La longeur relative était le seul caractére qui le distingerait du genre Bacterium. Nous savons que ce caractére ne peut être considéré comme absolu, mais qui varie au contraire dans des limites tres larges, pour des conditions de vie qui peuvent être considereés comme normales.

Nigula in 1897 again discusses the importance of organs of motility in a system of classification, and once more defined the genus as consisting of non-motile rods. Chester in his Manual (1901, p. 117) adopts Migula's definition of Bacterium, as does also Allan J. Smith (1902, p. 270) and Kendall (1902, p. 484).

Klöcker (1903, p. 332) evades the issue by using the generic name given by the author of the specific name of the species under discussion. $\mathrm{He}$ states "For distinguishing purposes the spore formation and the flagella have been suggested, but these characteristics have proved to be insufficient."

Matzuschita (1902, p. IV) does not use the genus name Bacterium. Schmidt and Weis (1902, p. 294) define the genus as follows:

Die Zellen sind cylindrisch, stabförmig, frei oder zu Fäden verbunden. Geisseln fehlen stets, und diese Arten sind daher zu keiner Zeit ihres Lebens beweglich. Endosporenbildung bei vielen bekannt. Zur Gattung Bacterium gehört eine sehr grosse Anzahl (über 300) Arten, von denen viele pathogen sind.

Erwin F. Smith (1905, p. 160) discusses at considerable length the history of the generic name Bacterium. He comes to the conclusion that Bact. termo of Cohn can be identified with sufficient accuracy as a green fluorescent organism with polar flagella, developing in Cohn's nutrient solution when inoculated with beans. He, therefore, formulates the following diagnosis: 
Bacterium Cohn. Type: The one-flagellate, green fluorescent schizomycetes, capable of growing in Cohn's nutrient solution. To these should be added all the morphologically similar non-fluorescent and yellow species. Synonym: Pseudomonas Migula.

He creates the new genus A planobacter to replace the genus Bacterium of Migula.

Flügge (1908) includes in the genus all rods which develop no spores. He divides the genus into nine groups which are worthy of careful consideration as generic groups.

Ellis (1909, p. 6) follows Migula.

Orla-Jensen (1909, p. 344) places the genus Bacterium in his family Acidobacteriaceae, the type species being Bact. coli.

Conn (1909, p. 12) defines Bacterium as a non-motile rod, contrasting Bacillus which is defined as a motile rod. Heim (1911, p. 25) uses Bacterium as a subhead under Bacillus to include non-spore-bearing forms.

Frost (1911, p. 57) follows Migula exactly. Schneider (1912, p. 23) includes "the old genus Bacterium in the genus Bacillus." Meyer $(1912$, p. 2) uses Bacterium as a section of the genus Bacillus including those forms whose flagella are unknown.

Löhnis (1913, p.45) differentiates Bacillus and Bacterium on the basis of endospore production.

Vuillemin (1913, p. 524) advocates the designation of Bacterium as a Genus conservandum with a prototype Bacterium termo Ehr. and specific type Bacterium pyocyaneum. This, it will be remembered, is practically the recommendation of E. F. Smith. Vuillemin states that Ehrenberg differentiated Bacterium from other types of Schizomycetes by its oscillating movement. Today, he states, we know this type of motion to be due to two morphological characters, short rods and polar flagella. Bact. pyocyaneum is a short rod with polar flagella, hence the designation of this species as the type.

Winslow et al. (Committee Society of American Bacteriologists (1917, p. 561)) adopted the view of Orla-Jensen and gave the following generic definition:

Motile or non-motile rods, staining evenly. Easily cultivable. Animal pathogens or saprophytes. Often chromogenic. Many forms decompose carbohydrates.

The type species is Bacterium coli Escherich.

Buchanan (1918, p. 53) has likewise followed Orla-Jensen with the definition: 
Plump rods, without spores, Gram-negative, motile by means of peritrichous flagella, or non-motile, liquefying gelatin very slowly or not at all. Usually showing marked power to ferment carbohydrates, frequently with gas production.

The type species is Eacterium coli Escherich.

The genus is a large one, including many species. It is generally divided into subgroups based primarily upon the fermentative reactions. It may be convenient to recognize these as subgenera separated from each other by the characteristics noted in the following key:

\section{Key to the subgenera of Bacterium}

A. Organisms which show a maximum of fermentative power, including fermentation of lactose, rarely pathogenic, some forms slowly liquefy gelatin.

Subgenus 1. Aërobacter (or Eu-Bacterium).

B. Organisms not showing maximum fermentative power, never producing gas in lactose, frequently pathogenic, never liquefying gelatin.

1. Producing acid and gas from glucose, sometimes other sugars, but not

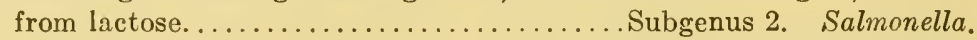

2. Producing gas from none of the carbohydrates, acid sometimes

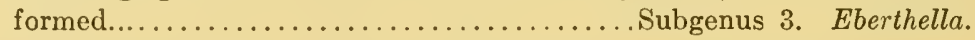

Breed, Conn and Baker (1918, p. 445) suggest that the name be dropped, or at most regarded as a general designation for insufficiently described organisms.

Winslow et al. $(1920$, p. 211) in the final report of the Committee use the following definition:

Gram-negative, evenly staining rods. Often motile, with peritrichic flagella. Easily cultivable, forming grape-vine leaf or convex whitish surface colonies. Liquefy gelatin rarely. All forms except $B$. alcaligenes and the $B$. abortus group attack the hexoses and most species ferment a large series of carbohydrates. Acid formed by all, gas $\left(\mathrm{CO}_{2}\right.$ and $\left.\mathrm{H}_{2}\right)$ only by one series. Typically intestinal parasites of man and the higher animals although several species may occur on plants and one ( $B$. aerogenes) is widely distributed in nature. Many species pathogenic.

Type species, B. coli Escherich 1885, p. 518.

Castellani and Chalmers (1919) have broken up the genus Bacterium into a large number of genera, apparently dropping this generic name entirely. In this they have been followed by Bergey et al. (1923).

It is evident from the preceding analysis of the important literature bearing on the subject that the various diagnoses of the genus Bacterium with their principal advocates may be grouped as follows:

1. Pre-Cohnian conceptions. Relatively rigid cells or chains of cells, not flexible, motile, oscillating. First species described Bacterium triloculare Ehr. No type species designated. No species described at pres- 
ent recognizable with certainty. Ehrenberg $(1828,1830,1836)$, Dujardin (1841), Perty (1852), Cohn (1854), Davaine (1864), Lüders (1866), Davaine (1868).

2. Cohnian conception. Short cylindric or elliptic cells, never in chains or filaments. Alternating motility and non-motility. Shape and grouping the primary characteristics. No definite designation of a type species, although in the earlier writings Bacterium termo is frequently mentioned. Cohn (1872, 1875), Lister (1873), Lankester (1873), Dallinger and Drysdale (1874), Magnin (1878), Winter (1879), Luerssen (1879), Trevisan (1879), Grove (1884), Van Tieghem (1884), Escherich (1885), Flügge (1886).

3. Zopfian conception. Rod shaped organisms which produce no endospores. Motility and grouping of cells regarded as secondary or non-essential characters. No type species designated. Zopf (1885), Hueppe (1895), Schroeter (1886), De Toni and Trevisan (1889), Ludwig (1892), Freudenreich (1894), Lehmann and Neumann (1896), Flügge (1908), Löhnis (1913).

4. Not recognized as a generic name. Forms usually included under Bacillus or other genera. Baumgarten (1890), Sternberg (1892), Fischer (1897), Matzuschita (1902), Schneider (1912), Breed, Conn and Baker (1918), Castellani and Chalmers (1919), Bergey et al. (1923).

5. Migula's conception. Non-motile, rod-shaped bacteria. No type designated definitely, unless it be Bacterium anthracis (Davaine) Migula. Migula (1895, 1897, 1904), Chester (1901), Smith (1902), Kendall (1902), Ellis (1909), Heim (1911).

6. Smith-Vuillemin conception. Rod-shaped organisms with polar flagella, type same one of the fluorescent bacteria, such as Bacterium aeruginosum (Schroeter) Cohn (Bacterium pyocyaneum (Gessard) Vuillemin). E. F. Smith (1905), Vuillemin (1913).

7. Conception of Orla-Jensen. The genus to be defined to include Bacterium coli Escherich as the type. Practically the colon-typhoid group. Jensen (1909), Buchanan (1918), Committee (1918-1920).

Of the species of Bacterium named before Cohn's description in 1872, there does not seem to be a single one that can be identified with certainty. Certain species of other genera can be recognized, but no organism designated Bacterium. The diagnosis of the genus given by Cohn was soon found to include forms that were diverse, and proved impracticable. However, certain of the species described and recognized by him can be identified. 
The generic diagnosis used by Zopf and by Hueppe, and more commonly used than any other includes in the genus the rod-shaped organisms which do not produce endospöres. This was a natural emendation of Cohn's definition, as the Bacilli described by him were endosporous.

The definition of Migula excludes from the genus all motile rods. Certainly most of the organisms previously termed Bacterium by Cohn and his predecessors were motile forms. Furthermore, motility is one of the most variable of bacterial characteristics. This definition associates in the same genus forms so distantly related as the tubercle and the anthrax bacilli, and places in separate genera closely related organisms of the intestinal group such as the colon bacillus and the organisms of gassy milk.

It might seem best to select some organism early named Bacterium as the type and so word the generic diagnosis as to include this form and the related species. But it should be described by the inclusion of more than a single character, such as motility. F. F. Smith has attempted to identify the Bacterium termo of Cohn, evidently intended by this author to constitute the type of the genus. Smith states:

Much discredit has been thrown on Bacterium termo in modern times, and it has been left out of many classifications. However, if one examines into the matter, there is no reasonable doubt as to what Cohn had in mind. His Bacterium termo was a small schizomycetous organism capable of growing freely in Cohn's nutrient solution, containing acid potassium phosphate and ammonium tartrate. It produced therein short rods (single, in pairs or fours, joined end to end) and roundish lobed white zoogloeae, together with a greenish fluorescence. This is Cohn's statement and De Bary's. It did not appear in boiled fluids, i.e. was destitute of endospores (Cohn), and the motile rods were killed by short exposure to $58^{\circ} \mathrm{C}$. (Schröter). In other words, it was a non-sporiferous greenfluorescent organism possessed of a single polar flagellum, or, in some cases perhaps, provided with paired or triple polar flagella. If we start with Cohn's classification in the year 1872 we may keep the name Bacterium for schizomycetous organisms of this type, and at the same time we shall not be doing any violence to the older use of the word of Ehrenberg, who figures and describes this kind of an organism. This the writer proposes to do, substituting Bacterium (Cohn emend.) for Pseudomonas Migula and for more recent names proposed by others.

Smith has attempted to follow Cohn's procedure in getting cultures of Bact. termo and succeeded by inoculating Cohn's solution with water into which beans had been thrown. A green fluorescent organism with a polar flagellum and incapable of gelatin liquefaction was secured.

It is interesting to note that by an entirely distinct line of reasoning Vuillemin came to a similar conclusion. He notes that Ehrenberg 
based the genus upon the type of movement of the cell. Today, he states, we know the characteristic type of motion to be due to the presence of polar flagella on short rods. He concludes that the Bact. termo is closely related to Bact. pyocyaneum and accepts this as the type of the genus. His result is a genus practically identical with that proposed by Smith.

A somewhat similar conclusion will be reached as the result of the examination of still another line of evidence, a study of the species of Bacterium other than Bact. termo recognized by Cohn and his associates. Three species previously known were placed in the genus Bacterium by Schröter. One of these was named Vibrio syncyaneus by Ehrenberg (1840, p. 202), Vibrio cyanogenus by Fuchs (1841, p. 190) and Bacterium syncyaneum by Schröter. It is the organism which has been repeatedly described as the cause of a blue coloration in milk. It has the morphology characteristics of the genus Pseudomonas of Migula. The species Bact. aeruginosum of Schröter is the earlier name of the blue pus organism variously called Bacillus pyocyaneus, Pseudomonas pyocyaneas and Pseudomonas aeruginosa, and chosen by Vuillemin under the name Bact. pyocyaneum to constitute the type of the genus. The Bact. brunneum resembles the two preceding in the formation of a water soluble pigment. The Bact. xanthinum, or as it now more commonly known, Bacillus synxanthus is an organism which is frequently recorded as the cause of orange or yellow milk. It does not appear to belong to the same group with the other forms. It would seem that at least two and probably three of the organisms recognized by Cohn and Schröter in addition to the Bact. termo forms which can be recognized today and studied readily, would conform to the generic diagnosis used by E. F. Smith and by Vuillemin.

A serious objection to this conception of Bacterium is the emphasis placed upon the flagella and motility. Smith would include, for instance, in his genus Bacterium, a green fluorescent monotrichiate rod but would exclude from the genus another organism which produced the same green fluorescence, had similar colonies and growth reactions in the various media, which in short, was culturally, physiologically, and morphologically identical except that it was non-motile. A genus ought not ordinarily to be constituted upon one character alone. It should group together closely related organisms. Disobedience to this principle would require the botanist to remove the Lombary poplar from the genus Populus because of its constant failure to produce the seeds and fruits characteristic of the genus. Conformity with all other 
characters of the genus, however, is of course regarded as overweighing the loss of a character which is generally emphasized as of great importance.

Strict application of the code would seem to necessitate the designation of Bacterium triloculare Ehrenberg as the type. Certainly, then, the designation of a more recently described species as the type would seem to require international sanction. Probably the best solution will be to adopt the suggestion of Breed, Conn and Baker, and not attempt to include the genus in our classifications until the original species can be recognized. This seems to have been followed by Castellani and Chalmers (1919) and Bergey et al. (1923) and may perhaps be recognized as a general tendency due to the advisability of splitting the unwieldy colon-typhoid series of bacteria into a number of genera.

Bacterius. A genus of bacteria proposed by Kendall (1902, p. 484) to include those rod-shaped bacteria which are motile, but on which the distribution of flagella is unknown. He states that this group would disappear as knowledge of the flagellation becomes more complete. The name has never come into use, and has not been applied to a species. It may be regarded as invalid.

Bacteroideae. A tribe (the sixth in the family Bacillaceae named by Castellani and Chalmers (1919, pp. 932, 959)) with the single (type) genus Bacteroides.

The tribal definition is:

Bacillaceae with good growth on ordinary laboratory media, without endospores, fluorescence, or pigment formation, and obligatory anaerobes.

Type Cenus. Bacteroides Castellani and Chalmers, 1918.

These authors again use this name in 1920 (p. 601).

Bergey et al. (1923, p. 255) recognizes this as the ninth tribe of the fanily Bacteriaceae with the following description: "Motile or nonmotile rods, without endospores. Show good growth on ordinary culture media; without pigment formation. Obligatory anaerobes."

One genus, Bacteroides is included.

Bacteroides. A generic name proposed by Castellani and Chalmers (1919, p. 959), for the sole genus of the tribe Bacteroideae, with the following description:

Definition: Bacteroideae with the tribal characters.

Type Species. Bacteroides fragilis Veillon and Zuber.

The type is found in abscesses from various parts of the body. Another species is the well-known Bacteroides fusiformis of Le Dantec and Vincent, found in 
hospital gangrene, and in Vincent's angina and many other conditions, as well as in the mouths of healthy persons and in the tartar on teeth.

It will be noted that the fusiform organism of Vincent's angina is included. Apparently the authors were unaware of the previous designation of $F$ usiformis (q.v.) as a generic name for this group. Eight other species are described as belonging to Bacteroides.

Whether Bacteroides is to be regarded as a valid genus depends on whether Bacteroides fragilis constitutes a generic type which should be placed in a genus other than Fusiformis.

Bactrella. A generic name proposed by Morren (1830) for an organism apparently to be placed among the bacteria. He states that the genus Vibrio of Bory-de-Saint-Vincent is divided into three subgenera "les lamellinaires, les gordioides et les oxyuroides." The first named of these is elevated to generic rank and named Bactrella. He (p. 354) gives the following descriptions:

Corpus simplex, elongatum, cylindricum, vel utroque extremo obtusum, vel antice tenuiter, postice e contra admodum attenuatum, undique clausum, vel omnio mobile.

The genus contained Bactrella undula (Vibrio undula Müll.), Bactrella bacillus (Vibrio bacillus Müll.), and Bactrella filum. The description of the last species is

B. corpore longissimo filiformi, cylindrico aequali vel simplici vel bifido (dum procreat) extremis obtuso, rotundato, vel purumper uncinato, praesertim in motibus; libero, recto, extenso rigido immobile vel parum erret languide natanti; affixo autem flexuoso, plicatulo, gyris sese contorquenti, apice mobiliore, perraroquieto, forma paulisper mutabile. Individua libera vel affixa, solitaria aut appropinquata, immenso numero corporibus immersis affixa et intermixta.

This generic name apparently has never been recognized by later writers. It may be regarded as invalid, although possibly the Bactrella bacillus was a Bacillus. Trevisan (1879, p. 137) states: "Resterebbe a vedere, non avendo il libro allo mano, se Bactrella di Morren sia identico con Metallacter, nel qual caso la demominazine proposta da Morren dovrebbe essere conservata." Because first described, Bactrella undula (Müller), Morren may be regarded as the type.

Bactridium. A generic name proposed by Kunze (1817) for a hyphomycetous fungus. It was later used by Wallroth $(1833, \mathrm{p} .315)$ for two species of fungi. The genus has been commonly accepted by subsequent writers on mycology. As a generic name for bacteria Bactridium was proposed by Fischer (1895, p. 139) to include those rod-shaped bacteria 
of the subfamily Bactrider which possess diffuse flagella and in which the cells containing endospores retain their cylindrical shape. Later (1897, p. 32) the diagnosis read: "Motile, peritrichous, in some spores as yet unknown. Very numerous representatives, e.g., B. subtilis, B. megatherium, B. vulgaris (old genus Proteus) B. typhi and B. coli." The second edition of the Vorlesungen (p. 60) does not materially change the diagnosis.

Chudiakov (1896) named an anaerobe Bactridium butyricum.

Erwin F. Smith (1905, p. 158) states that the generic name Bactridium has been used several times in botany as well as in zoölogy.

A Bactridium lipolyticum was named by Huss (1908, p. 474). It is evident that upon grounds of priority Fischers use of Bactridium is not tenable.

(For reason for not considering Bactridium as a homonym of Bacteridium see the latter.)

Bactrilleï. A name used by Fischer (1895, p. 139) for a subfamily of the Bacillaceae. It was defined to contain motile rod-shaped bacteria with lophotrichous flagella. The subfamily contains the genera Bactrillum, Plectrillum, Clostrillum and Arthrobactrillum.

The name is not in correct botanical form.

Bactrillius. A genus name proposed by Kendall (1902, p. 484) to include rod-shaped bacteria motile by means of a single polar flagellum. The name has never been used, and has not been applied to a speces. It is evidently invalid, (i.e., a hyponym).

Bactrillum. A genus name proposed by Fischer (1895, p. 139) to include those rod-shaped forms belonging to the subfamily Bactrillei which are motile by means of a tuft of polar flagella and which produce spores without causing any enlargement of the mother cell. This genus was redefined in 1897 (p. 32) as follows: "Motile rods with lophotrichous ciliation. Includes provisionally Bact. cyanogenus." In the second edition of his Vorlesungen, page 60 , it is noted that the spores of many species are not known. Of forms belonging to this genus, the organisms commonly known as Bact. syncyaneum and Bact. fluorescens are noted. This genus is practically synonomous with Pseudomonas Migula. It has never come into general use, and is commonly regarded as invalid. It is rejected by Erwin F. Smith (1905).

Probably Bactrillum pseudo-termo Fischer is to be regarded as the type.

Bactrinieï. A subfamily of the family Bacillaceae created by Fischer $(1895$, p. 141) to include all rod-shaped organisms motile by means of a 
single polar flagellum. Four genera are included, Bactrinium, Plectrinium, Clostrinium and Arthrobactrinium. This name is not in correct form.

Bactrinium. A genus of bacteria proposed by Fischer (1895, p. 41). This genus is one of four belonging to the subfamily Bactrinieï. The organisms belonging to this genus are rod-shaped and motile by means of a single polar flagellum. Spores are produced without any alteration in the shape of the mother cell.

Bactrinium nov. gen. Beweglich, mit polarer Einzelgeissel und Endosporen in nicht aufgeschwollenen Stäbchen. Eine eingeisselige Form mit Endosporen ist noch nicht ausführlich beschrieben dagegen kann mit grosser Wahrscheinlichkeit. der Bacillus pyocyaneus, der nach Löffler eine Geissel trägt, hierher gestellt werden; ebenso der von Löffler abgebildete grosse Bacillus aus einem Pflanzenaufguss. Ich selbst habe bis jetzt keine solche Forme gefunden. Auch die von Winogradsky beschriebenen Nitritbakterien von Zurich und Buitenzorg könnten hierher gehören.

Later the genus was defined (1897, p. 32) (1903, p. 60) as motile, monotrichous with a terminal cilium and including provisionally all monotrichous rods whose spores are as yet unknown, e.g., Bact. pyocyaneum.

This genus name has never come into common use. It is rejected by Erwin F. Smith (1905). It is generally regarded as invalid, and a synonym of Pseudomonas Migula. Possibly Bactrinium pyocyaneum (Löffler) Fischer may be regarded as the type.

Bactrinius. A genus of bacteria proposed by Kendall (1902, p. 484) to include those rod-shaped organisms motile by means of a tuft of polar flagella. This name has never come into common use and has probably not been used for any species of bacteria. It may be regarded as invalid, and a synonym of Pseudomonas.

Baculogenae. A subfamily of the family Schizomycetaceae proposed by Trevisan (1885).

The diagnosis of this subfamily as given by De Toni and Trevisan $(1889$, p. 939$)$ is as follows:

Adsunt tres status evolutionis h. e. baculi, filamenta, cocci. Baculi (status primarius, initialis seu archetypus) filamenta et coccos gignentes; filamenta (status secundarius transitorius) nunquam vaginata, nec basi distincta praedita, non affixa nec e puncto centrali radiantia, e prolongatione idefinita singuli baculi v. e. plurimorum baculorum conjunctione (ob divisionem imperfectam) efformati.

The subfamily is divided into the following tribes: Bacilleae (12 genera), Klebsielleae (4 genera). This designation of the subfamily 
has apparently not been used by other authors. It is not in correct form. It is not derived from a generic name.

Baculogene. A variant of Baculogenae used by Trevisan (1889, p. 11) for the second suborder of the bacteria. Two tribes, Bacillee and Klebsiellee are included.

Bakteriaceen. A name used by Hueppe (1886, p. 142) to designate a "Gattung," of rod-shaped bacteria "mit Bildung endogener Sporen" with the two subgenera Bacillus and Clostridium. It may be regarded as a variant spelling of Bacteriaceae (q.v.).

Bakterium. An aberrant form of the spelling of the genus Bacterium used by some German authors as Hueppe (1891, p. 30).

Balkanella. A generic name proposed by Castellani and Chalmers $(1919$, p. 934) for the seventh genus of the tribe Ebertheae. It is defined (p. 940):

Definition. Ebertheae which ferment glucose completely with the production of ac1d and gas; lactose not fermented. Milk clotted.

Type Species. Balkanella coagulans Castellani, 1916.

It is also defined later $(1920$, p. 609).

Batteriacee. A spelling of Bacteriaceae used by Italian writers, particularly Lanzi $(1876$, p. 259) and Trevisan (1889, p. 1).

Beggiatoa. A genus of bacteria created by Trevisan (1842, p. 56) to include certain filamentous water bacteria. The generic definition given is:

Thallus e filis muco obvolutis, liberis, oscillantibus, simplicibus, elasticis, rigides, arachnoideis, punctis asterisceformibus, primum in fascias dispositis deinde inordinatis, notatis conflatus.

Two species are described, the $B$. leptomitiformis and $B$. punctata. The genus is included under Sub. IV, Lyngbioideae, Tribus VII Lyngbeae. The genus is variously placed by different authors with the Algae and with the Fungi. Frequently it has been grouped with Oscillatoria among the blue-green algae. The type species may probably be designated as Beggiatoa alba (Vauch) Trev. (named Beggiatoa punctata by Trevisan in 1842). Kuetzing (1849, p. 237) included Beggiatoa as the first subgenus of Oscillaria, using the following subgeneric description: "Trichomata tenuissima laba, obsolete articulata vel continua, substantia interna gonimica granulosa opaca." Seven species are described. Rabenhorst (1865, p. 94) gives the following generic diagnosis: 
Trichomati simplicia, tenuissima, hyalina, muco involuta (non-vaginata), libera, solitaria vel aggregata, rigida, oscillantia cytioplasma pallidissime albidum (subachromaticum), punctis asterisciformibus, primum in fascias dispositis, deinde inordinates, notatum.

Seven species are listed.

Cohn $(1875$, p. 173) included this genus in the tribe Nematogenae with the description: "Zellen in Fäden geordnet, Zellfäden stets unverzweigt, frei oder verfilzt, fäden cylindrisch, farblos, undeutlich gegliedert, stärker, lang." Cohn also noted the presence of sulphur granules in the cells.

Luerssen $(1879$, p. 24) differentiates this genus from Bacillus by the relatively large, long, more or less definitely jointed filaments, more or less filled with dark granules, resembling in many ways $O$ scillaria among the $C$ yanophyceae, and showing a similar oscillating movement, forming slimy masses in sulphur springs, etc.

Trevisan $(1879$, p. 138) includes this in his subtribe Euvibrionieae, with the following description: "Somatia cylindrica, plus minus distincte articulata valida, elongata, filiformia, recta, laxe aggregate." Six species are described.

The genus is included among the bacteria by several writers before 1888, including Magnin (1879), Winter (1880, p. 57), Van Tieghem (1884, p. 1114), Grove (1884, p. 36), Zopf (1885, p. 95), and Flügge (1886, p. 396). Hansgirg (1888, p. 263) included this as the only genus of his subfamily Beggiatoeae. He divided the genus into two subgenera Eubeggiatoa and Chromobeggiatoa.

Winogradsky $(1888$, p. 17) as a result of his study of the sulphur bacteria made the generic diagnosis somewhat clearer. Previous descriptions were not all in harmony. He described the genus as made up of exclusively colorless, sheathless, always freely motile filaments never attached to a substratum. The filaments are quite variable in thickness, they show a uniform intercalary growth, and have no differentiation between base and tip. Under normal growing conditions they always contain sulphur granules in quantities varying with the conditions. These granules appear in the form of round oily drops, which consist of a semi-fluid or soft sulphur; crystals of sulphur are never observed in the living filament. The definite jointing of the filaments can be seen in cells full of sulphur only after the sulphur has been dissolved out. The differentiation of good species on the basis of size Winogradsky considers to be difficult. 
The diagnosis of Winogradsky has been quite generally accepted by subsequent writers on systematic bacteriology, among others by Schroeter (1886, p. 171), Trevisan (1889, p. 10), De Toni and Trevisan (1889, p. 935), Hueppe (1891, p. 30), Ludwig (1892), Clements (1894). Migula (1894, p. 238) stated:

Beggiatoa Trevisan, Zellen mit Schwefelkörnchen. Diese letzere Familie und Gattung schliess sich auch in ihrem anatomischen Bau so eng an die Oscillarien an, dass sie besser mit diessen vereinigt und die Schizophyceen zugeweissen wird.

The definition of Winogradsky is also used by Chester (1889, p. 64), Fischer (1897, p. 32), Migula (1900, p. 1040), Chester (1901, p. 379), Schmidt und Weis (1902), Kendall (1902, p. 484), Fischer (1903, p. 62), E. F. Smith (1905, p. 162), Orla-Jensen (1909, p. 334), Frost (1911, p. 60) and Heim (1911, p. 254).

The following diagnosis of E. F. Smith taken from Migula will give the modern conception of the genus:

Threads destitute of a sheath, formed of flat discoidal cells, free, i.e., not attached. Multiplication by folding and separation of the threads. Motile by means of an undulating membrane as in Oscillaria. The organism creeps along, but at the same time rotates around the long axis, mostly with a swinging of one or both free ends. Habitat, hot sulphur springs and other fluids in which hydrogen sulphide is developed. No reliable method is yet known for the separation of the species. The number and size of the included sulphur granules are not of specific value. They depend on the amount of hydrogen sulphide in the water.

Buchanan (1918, p. 464) designated the type species as Beggiatoa alba (Vaucher) Trevisan.

Bergey et al. (1923, p. 409) include this as the second genus of the family Beggiatoaceae with the following description:

Threads sheathless, formed of flat, discoidal cells, not attached. Multiplication by transverse splitting of the threads. Show undulatory creeping. Cells contain granules of sulphur.

The type species is Beggiatoa alba (Vaucher) Trevisan.

Beggiatoaceae. A family of bacteria created by Migula (1894, p. 238). It included the single genus Beggiatoa. The diagnosis given in (1895, p. 41) follows: "Fadenbacterien, fäden ohne Scheide durch undulierende Membran wie Oscillaria beweglich. Zellinhalt mit Schwefelkörnchen. Bildung von Conidien nicht sicher beobachtet."

In his "System der Bakterien" Migula (1900, p. 1039) includes in the family those genera of sulphur bacteria that have the cells in filaments, destitute of bacteriopurpurin. As thus defined it contains both the genera Beggiatoa and Thiothrix. 
This family name has been commonly used by recent bacteriologists who have discussed Beggiatoa (q.v.), among them Chester (1901, p. 379), Schmidt and Weis (1902, p. 92), Kendall (1902, p. 486), Migula (1904, p. 145), Corsini (1905), Erwin F. Smith (1905, p. 162), Clements (1909, p. 7), Frost (1911, p. 60), Schneider (1912, p. 23), and Bergey et al. (1923, p. 407).

Buchanan (1918, p. 463) included three genera, Thiothrix, Beggiatoa and Thioploca.

Beggiatoeae. A subfamily of the family Leptothrichaceae proposed by Hansgirg (1888, p. 263). The group is defined as follows: "Faden mit lebhaften, oscillarien-artiger Bewegung, im protoplasmatischen Zellinhalte Schwefelkörnchen and nicht selten auch einen rosenrothen oder violetton Farbtoff enthaltend." One genus only, Beggiatoa, is included.

Betabacterium. A generic name proposed by Orla-Jensen (1919, p. 175) for certain lactic rods. The genus is described in a somewhat informal fashion, but the following quotations will probably serve to identify the group.

The betabacteria (Table XXXI) are in most respects so closely allied to the betacocci that they may be regarded as the analogous rod forms, and they can, like the betacocci, be divided into those which ferment arabinose (Nos. 1-20) and those which do not (Nos. 21-33). The Bacterium casei [varieties] formerly described by me are typical representatives of these groups, and as they also differ in morphological respects - the arabinose-fermenting rods being generally shorter than the others-we consider ourselves justified in establishing the species Betabacterium breve and Betabacterium longum. Besides occurring in vegetable matter, they are also found in cheese, faeces and kefir grains. The rods forming the tissue of the kefir grains (Nos. 1 and 2) are, however, so different from the remaining betabacteria that they must undoubtedly be reckoned as a distinct species which we will call Betabacterium caucasicum, as the kefir rods are now for the most part known under the name of Bacterium caucasicum. This last name is also erroneously used for streptobacteria, which are likewise also found in kefir (though not as a rule in the grains themselves), and which are considerably easier to obtain in pure cultures.

Most of the betabacteria are not altogether killed by heating until $75^{\circ}$. They form inactive lactic acid, at times with a surplus of dextro-lactic acid. The great majority of strains develop gas (carbonic acid and more or less hydrogen). When the development of gas is strong, succinic acid is also formed. The power to form any considerable quantity of gas, and thus succinic acid, is, however, soon lost in artificial nutritive substrates, and in most of our strains, gas development could only be observed by sowing out closely in sugar agar tubes. From laevulose, some few strains can form a small amount of mannite, and as the manniteforming mash bacterium L actobacillus fermentatum, which has been closely studied by Jan Smit, has the greatest resemblance to the betabacterium (judging from 
its fermentation of sugar, with Bbm. longum) it should doubtless be reckoned under this head. Possibly the mannite bacteria so dreaded in the making of wine also belong here. Some of these form, like the betacocci, slime from cane sugar, which the betabacteria investigated by us never do.

The betabacteria grow poorly in milk, and do not as a rule attack casein at all. When cultivated at a freshly isolated state, were able to curdle milk, and even with a slight development of gas, but this power was soon lost. The frequent occurrence of these bacteria in cheese is due to the fact that they are better able to utilize lactate of lime as a source of carbon than are most other lactic acid bacteria.

A characteristic feature in the betabacteria is their lack of ability to ferment salicin and alcohols, and, with the exception of the $B b m$. longum forms, their preference for pentoses. The betabacteria have also always a slight fermentation of mannose. Some of the strains (as for instance Nos. 6 and 7) which in a freshly isolated state fermented mannose comparatively strongly, lost this power later on.

Betacoccus. A genus proposed by Orla-Jensen (1919, p. 146) for certain lactic acid cocci. He says,

. . . the betacocci are found in green vegetable matter and juicy roots. They are introduced with vegetable food into the intestinal canal of animals, and pass thence into the milk. In the retting process we always encounter arabinosefermenting betacocci, which might be connected with the fact that pectin substances always contain an arabinose group. . . . . As the betacocci are far more variable in all respects than the streptococci, it is very difficult to divide them up into clearly defined species, and I therefore prefer to treat the genus Betacoccus under one head and merely note in conclusion what features might seem to justify our uniting certain strains into independent species. . . . .

The betacocci can as a rule stand heating to $60^{\circ}$ but rarely to $65^{\circ}$. In a slimy state, however, they can stand higher temperatures, as the slime protects them, and it has been observed at sugar factories that thin syrup which had been heated to $80^{\circ}$ to $85^{\circ}$, and could not possibly have become infected afterwards, has grown slimy (No. 11 had formed zooglea masses under such conditions). The optimal temperature lies at about $30^{\circ}$ or under, a single strain (No. 14) was even found to grow best at indoor temperature, and this temperature is, as in the case of Sc. cremoris, the most favorable one for slime formation. The maximal temperature is $35^{\circ}$ to $37^{\circ}$ (rarely $40^{\circ}$ ) and the minimal $5^{\circ}$ to $7^{\circ}$. Some few strains (Nos. 1,45 , 46 , and 47) grow, however, at $45^{\circ}$, but on the other hand thrive but poorly below $15^{\circ}$.

The betacocci always form laevo-lactic acid, more rarely also equivalent quantities of dextro-lactic acid, so that we find inactive lactic acid (Nos. 43-47). . . . The betacocci also as a rule develop gas, (carbonic acid with more or less hydrogen). The gas development is strongest in laevulose solutions, and next in cane sugar solutions. . . . . In most strains, however, the gas development is so slight that it can only be observed by sowing out strongly in tall sugar agar tubes, and a few strains (Nos, 1, 2, 3, 38, 36, 37 and 43-47) do not seem to develop gas at all. Several of these last grow ehiefly in the upper part of the agar tube, though they are not otherwise obligatorily aerobic. . . . . On 
ordinary cane sugar agar, the slime develops but poorly, but appears in a very characteristic manner on cane sugar gelatin. Large colonies, clear as water, appear on the plates, resembling the colonies of certain aerogenes species (the slimy aerogenes forms produce, however, slime from all the sugars which they ferment) and in stabs, we get very characteristic pictures. . . . . Though these bacteria do not liquefy ordinary gelatin, and are not provided with other proteolytic qualities, several of them can, after some length of time, liquefy cane sugar gelatin, which figure is indicated in the tables by 1 (liquare).

As the genus Betacoccus contains all possible degrees of sliminess and liquefying power, we cannot attach too much importance to these characteristics and we may find cases where of two strains, otherwise entirely alike (as Nos. 38 and 39) which were, moreover, found in the same sample of material, one will liquefy and the other not.

When isolated from vegetable matter, the betacocci thrive as a rule but poorly in milk; when isolated from milk, on the other hand, or from dairy products, and sometimes from dung, they can form comparatively large quantities of acid in milk, and even dissolve some casein (Nos. 29 and 34). The power of souring milk, however, is comparatively soon lost, but can be regenerated by continued transference from milk to milk. The bacteria are often abundantly supplied with lactase, and it may happen that nearly all the lactose of the milk is hydrolyzed without any considerable quantity of it being fermented, which shows that the proteins of the milk are a poor source of nitrogen. When isolated from beets, they prefer beet juice to casein peptone (Nos. 11 and 12).

The betacocci exhibit a certain preference for pentoses. Strains isolated from vegetable matter for the most part ferment both xylose and arabinose whereas those isolated from dung, milk, or dairy products, will as a rule ferment only one of the two, or sometimes no pentoses at all. Of the hexoses, they often prefer laevulose, and of the disaccharides, often saccharose. They frequently ferment raffinose, but of true polysaccharides, only a little dextrin at the outside. With regard to salicin, the different strains vary considerably. When they do not ferment raffinose, then in most cases they will not ferment salicin either. The betacocci do not as a rule attack alcohols to any perceptible degree; only a few strains ferment a little mannite (No. 20 even a little sorbite).

No other bacteria have proved so variable with regard to the sugars as the betacocci. . . . .

Without cane sugar, the betacocci form small colonies, and are in all cultural respects indistinguishable from the streptococci. Morphologically also, they resemble the latter though the faculty of dividing in two directions is often more developed. . . . .

The above mentioned morphological differences between the $\mathrm{AO}$ and $\mathrm{A}+$ $\mathrm{X}$-forms on the one hand, and the $\mathrm{X}$ - and $\mathrm{O}$-forms of the other, render it likely that we have here to deal with two distinct species. As the former always (at any rate unless in a weakened state) ferment arabinose, we will term them Betacoccus arabinosaceus, and as the latter (especially the typical $\mathrm{X}$-forms) can be isolated from most cowdung after enrichment in acid sugar broth, we will call them Betacoccus bovis. As the betacocci are for the most part known under the name of Streptococcus mesenteroides, it would have been reasonable to use the name Betacoccus mesenteroides for one of the species, had it not been that both comprise 
strains which do not form slime, and consequently also no mesentery. It is possible that the betacocci should be divided into more than the two mentioned species. With all experiments in this direction, however, I have felt that I was working on treacherous ground, as these bacteria exhibit such great variability in almost all respects.

Winslow (1920, p. 102) regards this as synonymous with Leuconostoc Von Tieghem.

Billetia. A genus of bacteria founded by Trevisan (1889, p. 11) upon the species Bacterium Laminariae of Billet (1888, p. 293). The genus was reduced to synonomy with Kurthia by De Toni and Trevisan $(1889$, p. 931). The genus name has apparently never come into use. It should probably be considered a "genus incertae sedis" until the original species can again be identified and its right to generic rank decicled. The generic description reads "Kurthia sporifera con vagine distinte." It is included as the sixth genus of his tribe Leptotrichiee.

Bollingera. A genus proposed by Trevisan (1889, p. 26) but without description. One species, Bollingera equi is included. The diagnosis given by De Toni and Trevisan is as follows (1889, p. 1034):

Discomyces Rivolta (1884), Botryomyces Bollinger (1886) nomen tantum et ut Discomyces valde ineptum; Botryococcus Kitt (1886) nec Kuetz. (1849). Cocci globosi v. divisionis tempore globoso ovoideis, cystidibus specialibus destituti, numerosissimus, in muco matricali nidulantes, segregati, in familias globosas magnas, singulas cystidibus universalibus amplis crassis lamellosis summe firmis cartilagineis involutas, inordinate consociati. Glebae globosae ovoideae vel piriformes, omni aetate intus solidae, in acervos permagnos solidissimos. Ruborum fructus externam faciem quodianmodo simulantes, densissime cumulatae. Coccorum divisio in tres directiones.

Two species are given, Bollingera equi Trevisan (synonyms Zoogloea pulmonis equi Bollinger 1870, Discomyces equi Rivolta 1884, Micrococcus ascoformans Johne 1885, and Micrococcus botryogenes Rabe (1886)) and B. Vacchetae Trevisan (Discomyces pleuriticus canis familiaris, Rivolta 1884). The type is Bollingera equi Trev.

The genus has never come into common use, and may probably be suppressed as a synonym. It is rejected by Erwin F. Smith (1905).

Borrelia. A generic name proposed by Swellengrebel (1907, p. 582) to include those forms of the family Spirochaetaceae in which the cells are provided with peritrichous flagella. The type species is given as Borrelia (Spirochaeta) gallinarum. If this organism should stand as a generic type, the name would appear to be valid but possibly it should be reduced to a synonym of Spiroschaudinnia, 
Treponema or Spirochaeta. It is probably based upon a false morphological assumption (peritrichous flagella). Gleitsmann (1913, p. 31) says:

Da Saunbon erst in August 1907 init der Bezeichnung Spiroschaudinnia herauskam, Swellengrebel dagegen bereits in Juni desselben Jahres auf Grund der Borrelschen Ausführungen das Virus Borrelia taufte, so muss der Streit über den neuen Namen des Virus zugunsten der Borrelia entschieden werden.

Botryococcus. A generic name first proposed by Kuetzing (1849, p. 892) for an algal genus in the Chlorophyceae. It has been used by most subsequent writers on this group of algae, among them Rabenhorst (1864, p. 42), De Toni (1889, p. 674) and West (1904, p. 237). It must be regarded as a valid genus of algae containing several well known species.

The name Botryococcus was introduced independently by ritt (1888, p. 247) for the organism Micrococcus ascoformans. The name as thus used is invalid. It is not infrequently used as a casual designation of the organism causing botryomycosis. It is given as a synonym of Bollingera by De Toni and Trevisan (1889, p. 1039).

With the spelling botryocoques this organism is discussed by Nicolle and Cesari (1914, p. 229). These authors conclude that Botryococcus is a synonym of Staphylococcus. It is evident that it is not a valid bacterial generic name.

Botryomyces. A generic name proposed by Bollinger (1888, p. 177) for the organism variously termed Micrococcus botryogenes Rabe. M. ascoformans Johne and Discomyces equi Rivolta. The description is summarized by Enlows (1920, p. 24) as follows:

Similar macroscopically to Actinomyces. Under strong magnification the grapelike colonies consist of conglomerate, roundish, varying-sized broom-like groups or heaps of micrococci (4 to $4.5 \mu$ ). Each colony (150 to $250 \mu$ ) is surrounded by a homogeneous capsule-like membrane, and in this respect resembles the Ascococcus of Billroth. Ray-fungus-like, fibrous masses produced at times in host.

Type species (monotypy). B. ascoformans (Johne). (Bollinger's earlier name was Zoogloea pulmonis equi.) Syn. (Bollinger): Micrococcus botryogenes Rabe, 1886; M. ascoformans Johne, 1885; Discomyces equi Rivolta and Micellone, 1879.

The name is termed inept by De Toni and Trevisan (1889, p. 1039) and made a synonym of Bollingera.

The name is rejected by E. F. Smith (1905).

Botulobacillus. A genus of bacteria proposed by Orla-Jensen (1909, p. 343) as the second in the family Putribacteriaceae. It is defined 
as including anaërobic bacteria with peritrichous flagella, producing an exotoxin which exerts specific action upon the central nervous system. The species do not attack lactose. The organism causing botulism and tetanus belong here. Probably Botulobacillus botulinus Orla-Jensen may be regarded as the type.

The genus name must yield priority to Clostridium and Plectridium, and is probably to be regarded as invalid, unless the type species is to be separated.

Brachybacterium. A generic name used by Troili-Petersson (1903, p. 138) to include certain lactic acid bacteria. The organisms are separated into two genera, Bacterium and Brachybacterium. The diagnosis of the latter genus is: "Short, oval or ellipsoidal rods whose length is not more than double their width, round forms are present in addition to the rods." In Bacterium, on the other hand, the rods are in length more than double their width.

Nine species of Brachybacterium are described. Most of them are designated by number only. No. 22 is the Bacterium lactis acidi of Leichmann or Bact. lactis of Lister. One species, No. 26 is named Brachybacterium apiculatum.

It is possible that this genus should be reduced to a synonym of Lactobacillus (q.v.), or of Streptococcus (g.v.). Apparently no type species has been designated.

Brachybacterien. A term used by Troili-Petersson according to Löhnis (Handbuch, p. 198).

Brucella. A generic name proposed by Meyer and Shaw (1920, p. 176) for the causal organisms of Malta fever and infectious abortion. They state,

On morphologic grounds the organisms of undulant fever and of infectious abortion of domesticated animals must therefore be considered as identical and must be placed together in the genus Bacterium. For reasons to be given in detail in the second paper it is proposed in accordance with the suggestions made by Buchanan (1918, p. 8) of the Committee on Classifications of the Society of American Bacteriologists that a genus, for which we propose the name "Brucella" be created in the family Bacteriaceae to separate and to distinguish properly these important pathogenic microörganisms from the other members of the recognized genus Bacterium which is already overburdened with representatives, which have little in common with the B. melitensis and B. abortus.

Evans (1923, p. 1944) discussed in detail the generic designation of the group. She says: 
That the Malta fever and contagious abortion organisms are closely related was confirmed by Fleischner, Meyer and Shaw in 1919, and later by a number of other investigators. Meyer and Shaw (1920) proposed the generic name "Brucella," in the family Bacteriaceae to include the Malta fever and contagious abortion organisms. That name has met with general approval, and has been used by foreign investigators (Khaled, Archibald).

Meyer and Shaw did not, however, give a generic diagnosis for the genus Brucella, and they did not consider other species besides the melitensis-abortus group which would logically belong to the new genus. They were apparently unaware that Castellani and Chalmers had already described a newly created genus, "Alkaligenes," which, according to its definition, would include the melitensis-abortus group. The definition is as follows: "Bacillaceae growing well on ordinary laboratory media; not forming endospores; aerobes, and often facultative anaerobes; without fluorescence, pigment formation, or gelatin liquefaction; without polar staining; Gram-negative, without a capsule. . . . . Milk not clotted; glucose and lactose not fermented." The type species of the genus "Alkaligenes" as established by "original designation," is A. faecalis, a common intestinal saprophyte. Castellani and Chalmers left the "Micrococcus melitensis" unclassified generically- "Incertae sedes"-because they were doubtful as to whether it should be considered a coccus or a rod form.

Bacteriological nomenclature is passing through an experimental, transitional stage, and criteria which should serve for valid specific or generic distinctions have not been established in detail. The characteristics which are available at present for bacterial classification are few; they are more or less variable according to varying conditions; and they are not well correlated. Hence comes the difficulty in classifying bacteria into a system comparable with that of the higher organisms. It appears that, in many cases, distinction must be made by means of the sum total of differences, rather than by differences in particular stable characteristics, such as obtains in the classification of higher organisms.

If melitensis is considered cogeneric with faecalis, then the Law of Priority demands the acceptance of the generic name Alkaligenes. If, however, the differences between the two species are sufficient for generic distinction, the valid name of the genus is Brucella. The writer is of the opinion that a generic distinction should be made between the organisms under discussion, which are characteristically invaders of the tissues of animals, and the type species of Allaligenes, which is characteristically a saprophyte. Morphologically, also, melitensis is readily distinguished from faecalis by its smaller size and by its great numbers of coccoid cells.

There is given herewith a general description of melitensis, the type species of the genus Brucella:

Minute rods with many coccoid cells; (the cells of two-day cultures grown on the surface of plain agar and stained with carbol fuchsin appear about 0.5 of a micron wide and 0.5 to 2 microns long); not forming endospores; non-motile; aerobic, or preferring a slightly reduced, partial pressure of oxygen; without gelatin liquefaction; Gram-negative; parasitic, invading animal tissues; neither gas nor acid production from the carbohydrates.

Other species, which vary somewhat from the foregoing description, will logically be allocated to the genus Brucella. This genus should include a variety of 
small rod-forms commonly present in freshly drawn cow's milk. These forms were described in an earlier publication (Evans 1918) as bacteria related to "Bacterium abortus." Some of them vary from the typical Brucella in the production of a slight amount of acid from the carbohydrates. The genus Brucella should also include the species bronchisepticus, which varies from the typical Brucella in being motile. A number of other species should also probably be classified in the genus Brucella.

Meyer and his associates have continued the use of the abbreviation "B." for the generic designation of melitensis and abortus. Since that is the accepted abbreviation for the genus Bacillus, there should be some other for the Brucella. The abbreviation $\mathrm{Br}$. is proposed for that genus.

But the point may be made here that whenever a generic name is referred to in any paper it should be printed in full the first time it is cited in the article.

Every investigator since 1918 who has compared the Malta fever and the contagious abortion organisms has found a close relationship between them. The literature on this subject is reviewed in the following paper. The accumulating evidence of the close relationship between the strains of bovine and human origin has culminated in the conclusion by Burnet, that melitensis and abortus are not distinct bacteriological species, but merely distinct serological varieties or subspecies of one and the same species. All the literature on the subject leads to this conclusion. Observing priority of publication as determining the nomenclature, we must adopt as the specific name for the melitensis-abortus group the name melitensis.

Butyl-Bacillus. A casual name used by Fitz (1878, p. 48) to designate bacteria capable of producing butylic fermentation.

Butyribacillus. A generic name proposed by Orla-Jensen (1909, p. 342) to include the butyric acid bacteria. It is the first genus of the family Butyribacteriaceae. These forms are anaërobic peritrichous rods which as a rule split certain kinds of sugar with the development of gas and butyric acid, and do not ferment pectin or cellulose, and do not attack proteins actively.

Nach Pringsheim ${ }^{1}$ ist $C$. Pasteurianum nur ein einzelner Repräsentant einer weitverbreiteten Gattung von Erdbakterien, und laut einer vorläufigen Mitteilung von Bredemann ${ }^{2}$ können alle echten Buttersäurebakterien zur Stickstoffassimilation befähigt werden. Eine Gruppierung derselben in solche, die sich mit anorganischen Stickstoffquellen begnügen können, und in solche, die nur gedeihen, wenn sie organische Stickstoffquellen zur Verfügung haben, ist deshalb nicht statthaft, sondern wir müssen alle diese Organismen, wozu nach Grassberger und Schattenfroh auch Bacillus Chauvoei gehört, unter der Gattungsbezeichnung Butyribacillus sammeln. Wahrscheinlich sind die ältesten obligat anaëroben Bacillen auch die ältesten Sporenbildner, denn ohne die Fähigkeit zur Erzeugung von Endosporen würden diese Bakterien im allerhöchsten Grade der

${ }_{1}$ Centralbl. f. Bakt., Abt. II., Bd. XX, 1908, p. 248.

${ }^{2}$ Berichte der Deutschen botanischen Gesellsch., Bd. XXVIa, 1908, p. 362. 
Vernichtung durch den Luftsauerstoff ausgesetzt sein, sobald der Abbau des Substrats, in welchem sie sich entwickelt haben, vollbracht ist.

Apparently no type species has been designated, although Butyribacillus Pasteurianus Orla-Jensen is the first mentioned.

Butyribacteriaceae. A family name proposed by Orla-Jensen (1909, p. 343) to include the genera Butyribacillus, Pectobacillus and Cellulobacillus. These organisms are all anaërobic, peritrichous, rod-shaped bacteria which ferment carbohydrates with production of gas and butyric acid.

Butyriclostridium. A generic name suggested by Orla-Jensen (1921, p. 273). He says:

The use of the term Clostridium as a generic name presents the inconvenience that under the same we must group together not only the clostridia but also the plectridia. The division into true butyric acid bacteria (Butyriclostridium), the requirements of which in regard to nitrogenous nutriment are very moderate (they are able to assimilate even the nitrogen of the air) and anaerobic, putrefying bacteria (Putriclostridium) seems natural to me.

No species is mentioned.

Byolysis. A generic name suggested by Salisbury (1868).

Enlows states:

A minute "algoid vegetation developing in and on the human body in typhoid fever." Flourishes with great luxuriance in the "agminated and solitary glandules of Peyer." The spores multiply by duplicative segmentation, and develop rapidly on and in the cells of the epidermic and mucous surfaces. Spores frequently found in the colorless corpuscules, destroying their contents and dilating their walls, so that the cells are often from 2 to 4 times normal size.

Several of the figures on the plate illustrating this genus resemble streptococci. Salisbury refers to a filamentous stage in this genus only in the figure descriptions where he states that the more mature stage is filamentous. Marchand (Bot. Crypt., t. 1, 1883, p. 471) thinks this genus is synonymous with Crypta Salisbury.

Calymmatobacterium. According to Enlows (1920, p. 25) a generic name proposed by Beaurefaire-Arago and Vianna (1913, p. 222). She says:

Type species (monotypy). C. granulomatis. Encapsulated coccus 0.2 to $0.3 \mu$ in diameter, or rods with rounded ends of 0.5 to $2 \mu$ in length; also encapsulated. Prior to division the rod presents a median constriction, appearing as a diplococcus. Found in granulomata.

Carboxydomonas. A genus proposed by Orla-Jensen (1919, p. 311) to include autotrophic bacteria which are able to oxidize carbon monoxide. This is the second genus of his family Oxydobacteriaceae. 
Winslow et al. (Committee Soc. Am. Bact., 1917, p. 551; 1920, p. 201) use the following description: "Autotrophic rod-shaped cells capable of securing growth energy by the oxidation of carbon monoxide (forming carbon dioxide)." The type species, Carboxydomonas oligocarbophila (Beijerinck and van Delden) Jensen, is described as nonmotile.

Bergey et al. (1923, p. 33) use this description, including this as the third genus of the tribe Nitrobactereae.

Carphococcus. A generic name used by Hohl (1902, p. 338) to include a bacterial species which he termed Carphococcus pituitoparus. The organism was isolated from straw. It is a coccus varying from 0.7 to $1.5 \mu$ in diameter. It grows readily upon culture media. Milk develops a very marked slimy consistency and within fourteen hours the upper layers become decidedly viscous. Acid is not produced and the milk is not digested.

It does not seem that Hohl had sufficient justification to warrant the creation of a new genus. The name has not been accepted by other writers and may be regarded as a synonym of Micrococcus.

Carteria. Merrill and Wade (1919, p. 64) state:

The adoption of this new name (as "Carterii") was tentatively suggested by Musgrave and Clegg as possibly advantageous for the purpose of avoiding further controversy, although they did not definitely advocate this highly informal procedure.

It was proposed as a substitute for Actinomyces. See Carterii.

Carterii. Musgrave, Clegg and Polk (1908, p. 470) in a discussion of the validity of Actinomyces, Streptothrix, etc., conclude Streptothrix to be the correct name. They say: "In making this decision we are fully aware of the rights of those who favor Actinomyces or Nocardia, and under the circumstances are tempted to introduce a new name (Carterii) for the genus."

See also Carteria.

Caryobacterium. A generic name proposed by Mori (1913 p. 1) for a species $C$. equi found associated with Brustseuche in the horse. The organism is described as a coccobacillus, straight or slightly curved, isolated or in chains, $2.5 \times 0.5 \mu$, motile, staining readily. Gram positive and without capsule. Aerobic and facultative anaërobic, gelatin not liquefied, no indol, milk not coagulated, does not attack maltose, but ferments lactose with production of gas and acid. In cells stained with methylene blue, or better with Giemsa a definite nucleus is visible, 
whence the name Caryobacterium. The nucleus is not permanent and is visible only from cultures in peptone-carbohydrate (preferably maltose) and a polyvalent alcohol (mannitol).

Caseobacterium. A genus proposed by Orla-Jensen (1909, p. 311) to include those gram positive rod-shaped lactic acid bacteria which for the most part attack or degrade the casein, forming monoamino acids. These forms are facultative or anaërobic. All are non-motile. The only species definitely ascribed to this genus is Caseobacterium case $i$ which may be regarded as the type. It is placed in the family Acidobacteriaceae of the order Cephalotrichinae.

This generic name may be a synonym of Lactobacillus which has priority over it. The name has not come into general use.

Cellulobacillus. A genus proposed by Orla-Jensen (1909, p. 343) to include those anaërobic peritrichous bacteria which ferment cellulose, and are capable of producing butyric acid and gas from sugars. No species is definitely ascribed to this genus by the author. It is included as the third genus of the family Butyribacteriaceae.

The author states:

Von der Gattung Butyribacillus müssen wir ebenfalls die cellulosevergäronden Bakterien, die Gattung Cellulobacillus, ableiten. Wahrend diese interessanten Mikroorganismen sich einerseits mit Ammoniak als einziger Stickstoffquelle begnügen können, zeigen sie andererseits eine eigentümliche Spezialentwickelung dadurch, dasz sie imstande sind, ein so widerstandsfähiges Kohlenhydrat wie die Cellulose anzugreifen, und dasz sie von den anaëroben Bakterien die Kohlenhydrat am besten ausnutzen (siehe die Methangärung). Da Cellulobacillus somit einen Kulminationspunkt bezeichnet, können wir nicht ohne zwingende Gründe hiervon andere Gattungen ableiten sondern müssen diese Gattung als einen insolierten Seitenzweig betrachten.

Enlows (1920, p. 26) gives the type species (monotype) as Cellulobacillus methanigenes.

Cellulomonadeae. A name proposed for the third tribe of the family Bacteriaceae by Bergey et al. (1923, p. 154). The description follows:

Short rods, occurring in soil, having the property of digesting cellulose. Motile, or non-motile. Chromogenic or non-chromogenic. Growth on ordinary culture media often not vigorous. Gram-negative.

There is a single genus Cellulomonas.

Cellulomonas. A name proposed by Bergey et al. (1923, p. 154) for the single genus of the tribe Cellulomonadeae.

The description is as follows: 
Small rods, with rounded ends, non-spore-forming, motile or nonmotile, occurring in soil and having the property of digesting cellulose.

The type species is Cellulomonas biazoteus (Kellerman).

Cenomesia. A generic name proposed by De Toni and Trevisan (1889, p. 1039) with the following diagnosis:

Cocci globosi vel divisionis tempore globosovoidei, modice numerosi, in muco matricali nidulantes, segregati, in familias globosas parvas singulas cystidibus universalibus ampliusculis, crassiusculis homogeneis, non lamellosis, firmis, gelatinosis involutas, consociati. Familiae e coccis ad peripheriam cumulatis compositae, demum intus medio inanes. Cystides speciales nullae. Coccorum divisio, initio generationum serierum, in duas directiones.

Obs. Coelosphoerium Naegelii, Algarum Phycochromophycearum genus, exacte analogum.

The genus is included in the subfamily Coccogenae and the subtribe Eu-Ascococceae. Two species are described, both named by Trevisan, Cenomesia albida and $C$. lilacina. Both contain sulphur granules and the latter contains bacteriopurpurin.

This name does not seem to have come into common use. The writer has not been able to find any other author who has discussed these species. It is possible that the descriptions are not sufficient to make possible identification, and that the name Cenomesia is to be regarded as a nomen nudum. More probably it is to be regarded as a synonym of the genus Lamprocystis. It is rejected by Erwin F. Smith (1905, p. 174).

No type species has been designated, although Cenomesia albida. Trevisan from its position may be regarded as such.

Cephalotrichinae. The name given the first order of bacteria created by Orla-Jensen (1909, p. 325). He includes in this order microörganisms with spherical, rod-shaped or spiral cells. Endospores are found only in a few sulphur-free spirilla. The cells may be motile or non-motile; if the former either monotrichous or lophotrichous. They are typically water bacteria. They secure their growth energy almost exclusively by oxidative processes. Many of the members of this group develop poorly in laboratory media because the organic constituents are present in too concentrated a form.

The order is divided into seven families as follows: Oxydobacteriaceae (7 genera), Actinomycetes (4 genera), Thiobacteriaceae (4 genera), Rhodobacteriaceae (12 genera), Trichobacteriaceae (7 genera), Luminibacteriaceae (5 genera), Reducibacteriaceae (2 genera). 
Chatinella. A generic name proposed by Roze (1898, p. 69) for an organism observed microscopically in decaying plant tissue (straw in stable manure and horse dung). The cells measured 12 to $27 \mu$ in diameter, multiplying by fission. A membrane 1 to $3 \mu$ in thickness enveloped the cells. One species (type by monotypy) is Chatinella scissipara. In spite of the unusual size and characteristics, Roze assigns this organism to the fission fungi. Its position is doubtful.

Chionyphe. A generic name given to a fungus closely related to Mucor by Thienmann (1839). Its only interest to bacteriology is through the association by Carter of a Chionyphe Carteri Berkeley with madura foot as a probable etiologic factor. Castellani and Chalmers (1919, p. 2114) say:

He placed some black particles, taken from a food, on cotton soil moistened with animal juices and enclosed in a stoppered bottle, which he left unopened for two and three-quarter years, when he found a thin reddish film had appeared. Other black particles sown on rice paste for the same length of time remained unchanged, but on opening the bottle a red mould speedily made its appearance.

With reference to this mould, he says: "It had not, however, a clear connection with the fungus particles, but seemed to spring up independently of them upon the rice whenever this was exposed to the air."

This statement is of importance, as he grew a fungus from the white variety which was pink in colour and produced sporangia resembling those of a species of the genus Mucor Micheli, 1729, but differing therefrom in the absence of a columella, which should have brought it under the genus Mortierella Coemans, 1863; but Berkeley; who examined the growths from a botanical point of view, classified it under the genus Chionyphe Thienmann, 1839, calling it Chionyphe carteri Berkeley, 1862, and defining it as: "Hyphasmate ex albo flavorubroque, sporangiis demum coccineis, sporis breviter fusiformibus."

The genus Chionyphe, however, was never recognized by mycologists generally, as its species came under the genera Mortierella or Mucor, while Chionyphe carteri was most undoubtedly a contamination, as its connection with the black or white grains was never proved, as we have noted above with regard to the former.

Chlamydatomus. A genus of cocci in the subtribe Sarcineae created by Trevisan $(1879$, p. 137). The generic diagnosis is as follows:

Cellulae globosae, divisionis tempore ovoideae, inordinate in colonias conglobatas pluristratas densissime consociatae, 1-4 tegumentis propriis gelatinosis crassiusculis confluentibus obvolutae. Coloniae tegumento communi desitutae.

One species is listed, Chlamyd. Beigelii Trevisan. He later (1889, p. 27) included it as the fifth genus of the tribe Ascococcee.

De Toni and Trevisan (1889, p. 1042) give the following description: 
Cocci globosi, division is tempore ovoidei, in muco matricali nidulantes, singuli v. 2-4 cystidibus specialibus gelatinosis, crassiusculis, persistentibus involuti. Cystides in acervos numerosos conglobatos, intus solidos, dense et inordinate aggregati. Cystides universales nullae. Coccorum divisio in unam directionem. Sporae ignotae.

The genus is included in the subtribe, Gaffkyeae, of the tribe Ascococceae of the subfamily Coccogenae. Two species are described Chlamydatomus Beigelii (Küch. Rabenhorst) Trevisan (Synonyms, Pleurococcus Beigelii Küchenmeister and Rabenhorst 1867. Sclerotium Beigelianum, Hallier 1868, Zoogloea Beigeliana Eberth, 1873, Hyalococcus Beigelii Schroeter (1886)) and Chlamydatomus cellaris (Hansg.) Trevisan (Synonym, Hyalococcus cellaris, Hansgirg (1880)).

Chlamydatomus Beigelii is the type (monotypy). It is now not regarded as a bacterium at all, but as a fungus, a member of the genus Trichosporum. Castellani and Chalmers (1919, p. 1103) recognize Trichosporum beigetii Vuillemin 1901 as the cause of piedra, in nodosities on the hairs of the moustache.

It would seem that Vuillemin was in error in substituting the new generic name Trichosporum for the older generic name Chlamydatomus.

Chlamydobacteriaceae. A family name proposed by Migula (1894, p. 237) to include those genera of bacteria which are characterized by the possession of firm membrane or sheath surrounding the filaments. The description is as follows:

Familie Chlamydobacteriaceae nov. Fam. Formen von sehr verschiedener Entwickelungsstufe, aber alle ausgezeichnet durch eine feste Hïlle oder Scheide, welche die zu verzweigten oder unverzweigten Fäden vereinigten Zellen umgiebt.

The filaments may be branched or unbranched. The family as first described contained the following genera: Streptothrix Cohn emend., Phragmidiothrix Engler, Crenothrix Cohn, Cladothrix Cohn, and Thiothrix Winogr. This family name was used by Chester (1897, p. 64). In the second volume of his System, Migula (1900, p. 1030) gives the following diagnosis of the family:

Zellen cylindrisch zu Faden angeordnet, die von einer Scheide umgeben sind. Vermehrung erfolgt durch bewegliche oder unbewegliche Conidien, welche direkt aus den vegetativen Zellen hervorgehen und, ohne eine Ruheperiode durchzumachen, zu neuen Fäden auswachsen.

The family is used without material alteration in definition by Chester (1901, p. 369), Schmidt and Weis (1892, p. 92), A. J. Smith (1902, p. 272), Kendall (1902, p. 484), Migula (1904, p. 145), E. F. 
Smith (1905, p. 161), Ellis (1909, p. 7) Clements (1909, p. 7) and Frost (1911, p. 59).

Vuillemin (1913, p. 526) places this family among the Schizophyceae and not among the bacteria.

Buchanan (1918, p. 301) and Bergey et al. (1923, p. 390) included this as the only family of the order Chlamydobacteriales q.v. Five genera were listed, Leptothrix, Didynohelix, Crenothrix, Sphaerotilus and Clonothrix.

Castellani and Chalmers (1919, p. 924) list this as the fourth family of the order Eubacteriales.

It should be noted that this name does not conform to the nomenclatural rule that the name of a family should be fashioned from one of the constituent genera.

Chlamydobacteriales. A name proposed by Buchanan (1917, p. 162) for the second order of the class Schizomycetes. The description given follows (1918, p. 301):

Filamentous bacteria, alga-like, typically water forms, frequently sheathed, without true branching although false branching may be present. The sheath is frequently impregnated with iron. Conidia may be developed, but never endospores. Sulphur granules or bacteriopurpurin never present. Mature cells or filaments not motile, not protozoan-like.

The order contains a single family Chlamydobacteriaceae.

The name was accepted by Winslow et al. (Committee Society of American Bacteriologists (1917, p. 551)), and by Bergey et al. (1923, p. 390).

Chlamydobacterinae. A variant of Chlamydobacteriaceae used by Schmidt and Weis (1902, p. 375) as a family name.

Chlamydothrix. A genus name proposed by Migula (1900, p. 1030) to replace the name Streptothrix previously used by this author, and to include the two species commonly known as Leptothrix ochracca Kützing and Gallionella ferruginea Ehr.

Fischer (1903, p. 61) used the following description: "Nicht fest gewachsen, schwärmende Cylindergonidien, Beispiel: Chl. ochracea."

The genus is characterized by Smith (1905, p 162) as follows:

Cells cylindric, non-motile, arranged in unbranched threads, with a sheath of varying thickness. Frequently the septation of the threads is only demonstrable after the use of reagents. Reproduction by means of non-motile roundish or ovoid conidia, which arise directly from the vegetative cells. Synonyms: Streptothrix (Cohn) Mig., Leptothrix Kutz. ex. p. and Gallionella Ehrenberg. ex. p. 
Ellis (1909, p. 156) regards the genus as synonymous in part with Leptothrix (Chlamydothrix ochracea) and Gallionella (Ch. ferruginea). Molisch (1910, p. 21) recognizes the genus Gallionella as distinct, and includes Migula's species Chlam. ochracea, and a new species which he names Chlam. sideropous. His description of Chlam. orchracea is as follows:

Faden bestehend aus cylindrischen farblosen Zellen, mit anfangs farbloser dünner, später, dicker, gelb- und braunwerdener Scheide. Junge Fäden $0.9 \mu$. Durch Inkrustation mit Eisenoxydhydrat wird die Scheide allmählich dicker, gelb bis rostbraun und der Faden erreicht heirdurch die doppelte oder manchmal sogar die mehrfache Dicke der Zellen. Durch Behandlung mit 2-5 per cent Salzäure löst sich das Eisenoxyd, die Gallerthülle wird undeutlich und die Zellen, von einer Zarten Innenschicht der Hülle umgeben, treten scharf hervor. Die nach einiger Zeit zur Ruhe kommen, sich gewöhnlich festsetzen und wieder zu Fäden auskeimen mit deutlicher Spitze und Basis.

Die Schwärmer setzen sich häufig an schon vorhandene Fäden fest, keimen hier zu Fäden aus und täuschen hier Verzweigung kommt vor, aber seltem und nie so regelmässig wie bei Cladothrix.

Alte Scheiden entleeren ihre Zellen, bleiben als rostrote Röhrchen übrig und bilden dann oft kolossale Mengen ockeriger Massen in eisenhaltigen Wassern und mitunter auch in Rasenerzen.

Frost (1911, p. 59) gives the following generic description:

The cells are cylindrical, non-motile, and arranged in unbranched threads and surrounded by a sheath of varying thickness in different species, being the same diameter at apex and base. Reproduction takes place by means of gonidia, which are round and arise directly from the vegetative cell. This genus is called Leptothrix by Kützing and Streptothrix by Cohn.

It is probable that Chlamydothrix should be reduced to a synonym of Leptothrix, (q.v.) for the latter name is apparently valid as a generic name for this form of iron organism. Orla-Jensen (1909, p. 331) takes this view.

Enlows (1920, p. 21) designates the type in the following statement:

Cells cylindrical, non-motile, arranged in unbranched threads surrounded by a sheath of varying thickness. Septation of threads often demonstrable only after the use of reagents. Reproduction by means of round or ovoid, nonmotile conidia, which arise directly from the vegetative cells. Syn. (Migula) Streptothrix (Cohn) Migula, Leptothrix (Kützing) exp., Gallionella Ehrenberg exp.

Type species. $C$. ochracea (Kützing). He also places here $C$. ferruginea (Ehrenberg), C. hyalina Migula, C. epiphytica Migula, C. fluitans Migula.

Chlorobacterium. A genus named by Guillebeau (1890, p. 32) for the species Chlorobacterium lactis, isolated from an inflamed udder. 
The organism is actively motile, cells about $1 \mu$ by $3 \mu$. Gelatin is rapidly liquefied. Creen pigment is produced upon potato and nutrient agar.

The type species (monotypy) was designated by Enlows (1920, p. 27) as Chlorobacterium lactis.

Chlorobakteriaceae. A family proposed by Lauterborn (1913, p. 99) to include the chlorophyll-producing bacteria.

His reasons for its establishment he gives as follows:

Wenn man den sehr schwefelwasserstoffreichen Schlamm am Grunde von Characeenteichen durchmustert, fallen neben den blaugrünen Filzen der Cyanophy ceen sowie den rötlichen Wucherungen der Purpurbakterien vielfach auch kleinere oder grössere Flocken von gelbgrüner Farbe auf. Dieselben gestehen neben Fäden von Oscillatoria chlorina Kützing, O. putrida Schmidle und O. Lauterbornii Schmidle besonders aus Ansammlungen kleiner Zellen von gelbgrüner Farbe in gallertigen, bisweilen ziemlich lockeren Verbänden, die bisher, soweit beschrieben, der Gattung A phanothece zugezählt wurden. Hierher gehören Aphanothece luteola Schmidle sowie A. clathratiformis Szafer. Ein genaueres Studium dieser Formen hat in mir die Uberzeugung befestigt, dass dieselben nicht zu den eigentlichen blaugrünen Algen gehörer, sondern sich direkt den Schizomyceten anschliessen und hier eine den Purpurbakterien durchaus gleichwertige Gruppe bakterienartiger Organismen mit gelbgrünem Farbstoff (Bakteriochlorin) darstellen. Wir hätten es hier also mit einer neuen Familie der Schizomyceten zu tun, die man als Chlorobakteriaceae den Rhodobakteriaceae gegenüberstellen kann.

He included in this family the genera Chlorochromatium, Pelodictyon, Schmidlea, Pelogloea and Pelochromatium. The spelling should be Chlorobacteriaceae. It is probably invalid.

Chlorobium. A generic name proposed by Nadson (1906, p. 190) according to Enlows for

A green chlorophyll containing organism, which author thinks belongs with the bacteria or close to Stichococcus bacillaris.

Type species (monotypy). C. limicola. Cocci 0.4 to $0.5 \mu$ in diameter, round or elliptical, or short rods. Non-motile. Multiplication by cross division. Long chains common in both the round and rod forms. Involution and apochlorotic forms occur.

Chlorochromatium. A genus of bacteria proposed by Lauterborn (1906, p. 197) in the following description:

Chlorochromatium aggregatum nov. gen. nov. spec. Gestalt ungefähr elliptisch bis spindel- oder tonnenförmig, an den Enden etwas verschmälert und abgestutzt. Farbe grüngelb wie bei Oscillatoria chlorina. Bei schwacher Vergrösserung der Körperrand scheinbar etwas krenuliert und dunkler grün gefärbt als die Mitte. Bei sehr starker Vergrösserung erscheint der Organismus zusammengesetzt aus 
einer Anzahl kleiner gestreckt elliptischer, bakterienartiger Körper, welche eine stärker grün gefärbte Rindenschicht und eine hellere centrale Partie erkennen lassen. Indem diese Körper, in etwas unregelmässigen lockeren Längsreihen angeordnet, mantelförmig einen axialen farblosen (wohl gallertigen?) Hohlraum umschliessen, kommt das oben geschilderte Aussehen bei schwacher Vergrösserung zustande. Freibeweglich mit Hilfe von Geisseln. Länge des Organismus : 0,009-0,012 mm. Breite 0,005-0,007 mm.

Vermehrung durch Querteilung: der Organismus streckt sich in die Länge und schnürt sich in der Mitte durch eine Ringfurche quer durch. Auch mehrfach Zerfall in die einzelnen bakterienartigen grünen Körper beobachtet, welche sich selbst wieder quer teilen können. Auf diese Weise kommen unregelmässige, bisweilen netzartig durchbrochene und dann im Habitus an Lamprocystis roseapersicina erinnernde hellgrüne Kolonien zustande.

Later (1913, p. 99) he included this genus in his family Chlorobakteriaceae. Its position among the bacteria is questionable.

Chloronium. A generic name proposed by Buder (1914, p. 80) with the species Chloronium mirabile. The type species was designated by Enlows as follows:

Type species (monotypy). C. mirabile. Found in water in the Leipzig Botanic Garden. A cylindrical rod 0.7 to $1 \mu$ by 1 to $2 \mu$ with rounded ends, sometimes slightly curved, green, united into a zoogloeal mass, in the center of which is a colorless, spindle-shaped, 1-polar flagellate organism. The latter measures 2 to 2.5 by $5 \mu$. Multiplication by transverse division. The "peripheral component" is sometimes of coccus form also green of $0.75 \mu$ diameter. Usually about 10 to 30 arranged in rather definite order about the colorless central organism. Perfiliev (j. Mic. Biol., v. 1, 1914, p. 223) says that the peripheral forms described here are identical with Chlorochromatium aggregatum Lauterborn. Buder is in doubt as to the systematic position of Chloronium. Perfiliev describes the "central organism" of Buder's Chloronium as Cylindrogloea, q.v.

Chondromyces. A genus credited to Berkeley and Curtiss by Berkeley (1857, p. 313) in an illustration, figure 70, which has the explanation "Chondromyces crocatus Berkeley and Curtiss, with its spores. Both magnified. From specimens on a decayed gourd from South Carolina." In the text the genus is not described, but is classified under the Hyphomycetes, in the family Isariacei Corda-Stern. Under Isarei Fr. (p. 314) is the following statement:

Several genera which find their proper place in this highest group, and the last are, in fact, compound forms of organisms which appeared under other tribesChondromyces and Stigmatella are compound Mucedines.

The first description was published by Berkeley (1874, p. 64) as follows: "Stipes e floccis compactus ramosus induratus: sporae apicales." 
Saccardo (1886, p. 576) gives the following diagnosis: "Stipes ex hyphis compactus, ramosus, induratus, Conidia apicalia, capitulata, elongato-ovata, continua."

The true nature of this organism was first recognized by Thaxter (1892, p. 401). He designated it as one of the genera of the Myxobacteriaceae (g.v.). His diagnosis is as follows: "Rods forming free cysts in which they remain unmodified. Cysts various, sessile, or borne on a more or less highly developed cystophore." This genus is distinguished from the related genus Polyangium Lk. in that the latter forms its one or more cysts within a gelatinous matrix raised about the substratum, and from the genus Myxococcus in that no coccuslike spores are formed by the fruiting bodies.

Thaxter gives the following synonomy: "Stigmatella B. and C. in Berk, Introduct. Crept. Bot. p. 313. fig. 70, b. (no description). 1857, do. in Grevillea 3 97. 1874 (first description).

(?) Polycephalum Kalch and Cke. in Grevillea 9: 22. 1880.

(?) Cystobacter Schröter in Kryptogamen Flora v. Schlesiens. Die Pilze, p. 170."

The species described by Schröter was named Cystobacter erectus. What is evidently a species practically or quite identical with Chondromyces crocatus was described by Zukal (1896, p. 346) as Myxobotrys variabilis (q.v.). This author also regarded it as a fungus.

Buchanan (1918, p. 542) diagnosed the genus as follows:

Rods forming free cysts in which they remain unmodified. Cysts various, sessile or borne on a more or less highly developed cystophore.

The type species is Chondromyces crocatus Berkeley and Curtiss.

This description is also used by Bergey et al. (1923, p. 416).

Chorynebacterium. Apparently a misprint for Corynebacterium found in the index of Migula's System der Bakterien (1900, vol. 2, p. 1061).

Chromatiaceae. A subfamily of sulphur bacteria created by Migula (1900, p. 1047) to include three genera. Chromatium, Rhabdochromatium and Thiospirillum. He states: "Zellen frei, zeit lebens schwärmfähig." The subfamily is characterized as containing those sulphur bacteria in which the cells are free and capable of swarming at any time.

The subfamily has been generally recognized by those who have discussed classification of the sulphur bacteria such as Migula (1904, p. 146) E. F. Smith (1905, p. 164) and Frost, (1911, p. 61). 
It may be noted that the correct designation of the subfamily would be Chromatioideae (q.v.).

Chromatieae. The fifth tribe of the subfamily Chromatioideae named by Buchanan (1918, p. 470). The diagnosis follows, "Sulphur bacteria in which the cells are not united into families, but free, and capable of swarming at any time." The tribe is the equivalent of Migula's Chromatiaceae q.v. Five genera were included, Chromatium, Rhabdomonas, Thiospirillum, Rhodocapsa and Rhodothece.

This usage is followed by Bergey et al. (1923, p. 400).

Chromatioideae. The first subfamily of the family Rhodobacteriaceae named by Buchanan (1918, p. 464) with the description: "Cells not filamentous, containing both sulphur granules and bacteriopurpurin.

The subfamily is practically the equivalent of Thiorhodaceae q.v.

Five tribes are included, Thiocapseae, Lamprocysteae, Thiopedieae, Amoebobacterieae, and Chromatieae.

Bergey et al. (1923, p. 394) have followed in the use of this term.

Chromatium. A generic name created by Perty (1852, p. 179) with the following diagnosis:

Korper äusserst klein, cylindrisch, roth, braun, violett, grün gefärbt, im ausgebildeten Zustand mit innem Bläschen (Blastien). Ein Bewegungsfaden am Vorderende? Vermehren sich durch Quertheilung.

Two species were described, C. Weissii and C. violascens. He states the former to be related to the Monas Okenii of Weiss, but smaller. The genus was recognized and more fully described by Schroeter (1886, p. 156) as containing those organisms with cylindrical-elliptical or relatively thick cylindrical cells multiplying by fission, and with cell contents colored red, and containing black (sulphur) granules. $\mathrm{He}$ states that this genus is placed with the bacteria only provisionally, for it has many resemblances to the monads. Winogradsky (1888, p. 86) includes the genus among his sulphur bacteria. He accepts the Schroeter diagnosis of the genus and recognizes the best known species Chromatium Okenii. In this species the cells are very large, averaging $15.3 \mu$ in length and $6 \mu$ in maximum width. The cells are somewhat variable in shape, straight or more or less bent, short cells ovoid and longer forms more cylindrical. The cells are motile by means of polar flagella. Other species are Chr. weissii, Chr. minus, Chr. vinosum and Chr. minutissimum.

The genus is included in classifications of sulphur bacteria in the subfamily Chromatiaceae by Migula (1900, 1904), E. F. Smith (1905, 
p. 164) and Frost (1911, p. 61). Migula (1900, p. 1047) states, "Zellen cylindrisch-elliptisch oder elliptisch, verhaltnissmässig dick." It should be noted that E. F. Smith (1905, p. 205) also included Chromatium in his list of rejected bacterial names. Orla-Jensen (1909, p. 330) says: "Die sehr hellroter schwefelbakterien (wie Z. B. Chromatium vinosa) bilden den natürlichen Uebergang von Thiomonas zu Rhodomonas." He makes it a synonym (p. 334) of Rhodomonas.

Buchanan (1918, p. 470) and Bergey et al. (1923, p. 400) gave the following diagnosis:

Cells cylindric-elliptical or relatively thick cylindrical. Cell contents red, containing dark sulphur granules. Cells somewhat variable in shape, straight, more or less bent, short cells ovoid and longer forms more cylindrical. Motile by means of polar flagella.

The type species is Chromatium okenii Perty.

Chromatoideae. A variant spelling of Chromatioideae used by Bergey et al. (1923, p. 394).

Chromobacillus. The second section of the genus Bacillus recognized by Hansgirg (1888, p. 265) with the following description "Einzelne Zellen scheinbar fast farblos, in grosserer Menge (Zoogleen) rosen bis blut roth, blau etc. gefärbt." The Bacillus sanguineus Schroeter is given as the only species. It was found "In Sumpfen bei Chlumec und Magdalena nächst Wittengau und bei Neu-Bestritz nächst Neuhaus in Sudböhmen."

It apparently should rank as a subgenus with the type Bacillus (Chromobacillus) sanguineus Schroeter.

It is possible that the type organism belongs with the purple bacteria.

Chromobactereae. A tribe named by Winslow et al. (Committee Soc. of American Bacteriologists 1920, p. 208) with the diagnosis: "Water bacteria producing a red or violet pigment." The genera Erythrobacillus and Chromobacterium were included.

The spelling probably should be changed to Chromobacterieae.

Bergey et al. (1923, p. 85) recognize it as the first tribe of the family Bacteriaceae with the following description: "Water and soil bacteria producing a red, yellow, violet or blue-green pigment."

Four genera are included.

Chromobacterium. A revision of the spelling of Cromobacterium Bergonzini. (q.v.) used in a review (anonymous) of Bergonzini's work (Journ. Roy. Mic. Soc., 1881, p. 285) and by Grove (1884, p. 26) in the synonymy of Bacterium violaceum. This form is also quoted by De Toni and Trevisan (1889, p. 978). 
Buchanan (1918, p. 52) emended the description of the genus as follows:

Rod-shaped bacteria, without spores, aerobic, producing a violet chromoparous pigment soluble in alcohol but not in chloroform, motile or non-motile, Gram stain variable.

The type species is Chromobacterium violaceum Bergonzini.

The genus was recognized by Winslow et al. (Committee Soc. Am. Bact., 1920, p. 209) with the following description:

Aerobic bacteria, producing a violet chromoparous pigment, soluble in alcohol but not in chloroform. Motility and Gram reaction variable.

Type species, Chr. violaceum Bergonzini.

Bergey et al. (1923, p. 117) include this as the third genus of the tribe Chromobactereae.

If the violet bacteria should have generic recognition the name is apparently valid.

Chromobeggiatoa. The second section (subgenus) of the genus Beggiatoa recognized by Hansgirg (1888, p. 264) with the following descriptions: "Täden von rosen-bis-pfirsch rother Farbe, rosen-oder blutrothe, violette bis violettbräunliche Ueberzüge an im Wasser faulenden Substanzen bildend, oder das Wasser roth färbend." The only species listed is Beggiatoa roseo-persicina Zopf.

Chromococcus. A revision of the spelling of Cromococcus Bergonzini q.v. used in an anonymous review in Journ. Roy. Mic. Soc, (1881, p. 284).

This form is also used by De Toni and Trevisan (1889, p. 1067) in the synonymy of Streptococcus violaceus. The type species (monotypy) is Chromococcus violaceus Bergonzini.

Cladochytrium. A genus of fungi named by Nowakowski (1876).

The name Cladochytrium tuberculorum was proposed by Vuillemin (1888, p. 121) for the fungus which he believed was the primary cause of nodule formation on the roots of leguminous plants. The bacteroids were concluded to be simple differentiations of the plasma. The infection threads he believed to be fungal in nature. See Rhizobium.

Cladophytum. A generic name used by Leidy (1849, p. 227) for two species of entophytes from the intestine of Julus (thousand leg).

The original description of the genus, and the first species follows:

Filaments minute, attached by means of a roundish nucleus, simple or compounded near the base of attachment, with minute lateral ramuli, inarticulate, and with no evidence of interior structure. 
Cladophytum comatum. Filaments delicate, regular, colorless, simple, more frequently branched near the base at very acute angles, growing in more or less dense bunches from a yellowish rounded or oval, attached, nuclear body varying in size from $\frac{1}{500}$ to $\frac{1}{600}$ of an inch. Lateral ramuli very minute, measuring in

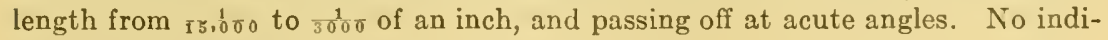
cation of articulation or interior structure.

Length from $\frac{1}{66}$ to $-\frac{1}{2} 0$ of an inch.

Habitat. Growing more or less profusely from the mucous membrane of the small intestine of Julus margina!us, occasionally from the same surface at the commencement of the large intestine, from any part of the exterior surface of entozoa infesting those cavities, and also from any part of the surface of Enterobrus elegans.

A second species, Cladophytum ramosissimum was later (1849, p. 250 ) described by Leidy, but still later (1851, p. 37) was made a synonym of $\mathrm{Cl}$. comatum. The generic description (1851, p. 37) is: "Thallus attached by means of one or more granules, filamentous, simple, with minute lateral ramuli, or branched, inarticulate, amorphous in structure.

This genus is described as follows by Robin (1853, p. 358):

Nouveau genre voisin des Mycodermata. On sait que le genre Mycoderma, de Persoon, n'etait pas formé par des espéces de Champignons comme il le croyait, mais bien par des Algues appartenant aux genres Leptomitus et Hygrocrocis.

Filaments petits fixés par un noyau arrondi, simples ou compliqués vers leur point d'insertion par de petits ramuscules latéraux inarticulés, sans structure intérieure définie.

Apparently the organism has not been studied by later writers. The exact position and relationships of this organism are uncertain. The type species is Cladophytum comatum Leidy.

Cladothriceae. A subtribe of the tribe Vibrionieae created by Trevisan (1879, p. 137). The description given is "Somatia libera Pseudo-ramosa." Two genera are included, Cladothrix and Streptothrix.

Cladothrichaceae. A name proposed by Zopf (1884, p. 45) with the aberrant spelling Cladothricheen as a family to include the single genus Cladothrix. He states: "Sie zeigen Coccen-, Stäbchen-, Fädenund Schraubenformen. Die Fadenform ist mit Pseudoverzweigungen versehen." In 1885, p. 51, he adds "Sporenbildung nicht nachgewiesen."

Schroeter (1886, p. 173) also used this name with the spelling Cladothrichacei and the description "Faden durch falsche Astbildung verzweigt. Die weiteren Charaktere die der VI Ordnung." 
Apparently Hansgirg (1888, p. 229) was the first to use the correct spelling Cladothrichaceae. He included it as the first family of the order Desmobacteria, with the single genus Cladothrix.

Hueppe (1891, p. 31) followed Zopf, as did Baumgarten (1900, p. 129).

This family name has apparently not been recognized by later writers.

Cladothrichacei. An aberrant form of spelling the family Cladothrichaceae (g.v.) used by Schroeter (1889, p. 173).

Cladothricheae. A tribal name used by Hueppe (1885) to include the genus Cladothrix. A variant of Cladothriceae q.v.

Cladothricheen. An aberrant method of spelling the family name Cladothricaceae (g.v.) first used by Zopf $(1884$, p. 45) to include the genus Cladothrix Cohn. This designation has also been used by Zopf (1885), Hueppe (1885), Baumgarten (1900), etc.

Cladothrix. This generic name was published in De Condollés Prodromus (1849) for a genus of the phanerogamic family Amarantaceae. It has since generally been recognized as valid in this sense by botanists.

Cohn $(1875$, p. 185) used this as a bacterial generic name to include the single species Cladothrix dichotoma, an organism found in foul water. It is colorless, partly floating on the water and partly attached to decaying algae. The filaments are very slender, apparently unsegmented, straight or somewhat bent, similar to a colorless Leptothrix. The filaments of the latter, are however, unbranched while in Cladothrix they are repeatedly branched and with considerable regularity. By use of high magnifications he noted that it was not a true dichotomy, but false branching, as in the blue green alga Scytonema. The genus was included in the tribe Nematogenae.

Trevisan $(1879$, p. 139) included this as the sixteenth genus of his family Bacteriaceae in the tribe Vibrionieae and subtribe Cladothriceae with the following description:

Somatia cylindrica, leptotrichoidea, infeme vix articulata, pupeme distincte articulata, tenerrima, stricta vel subundulata pseudo-dichotoma, microgonidia e serie cellularum divisione longitudinali et transversa succedanea multipartitarum orta, globulosa, diaphragmatibus ruptis in pseudo-sporangium densissime congesta, demum e vagina lateraliter erumpentia et in somatia evoluta, foventia.

Magnin (1880, p. 97) followed Cohn's description without modification. 
Winter (1880, p. 59) described the genus as Leptothrix-like, very slender, colorless, not jointed, straight, slightly wavy or even partially irregularly spiral, with false branching. He states, however, that he is unable to find sufficient grounds for differentiation between Cladothrix and Streptothrix and concludes that both are doubtful genera. He cites in justification for this conclusion the work of Cienkowski. Grove $(1884$, p. 40) followed Winter in emphasizing the resemblance of Cladothrix and Streptothrix. Zopf (1885, p. 51) made this the only genus of the family Cladothricheen, characterized by having growth forms as cocci, rods, filaments and spirals, with the filamentous stage showing false branching, spore formation unknown. Schroeter (1886, p. 174) revised the diagnosis of the genus, including in it filaments surrounded by delicate sheaths, non-motile, and dichotomously branched, at first apparently not jointed, later fragmenting, and the segments developing into new filaments. Hansgirg (1888, p. 229) described a new variety, Cladothrix dichotoma var leptochaetoformis.

De Toni and Trevisan (1889, p. 927) emphasize the development of arthrospores. Their generic diagnosis reads: "Filamenter basi ab apice superiore distincta, vagina crassa obducta, cylindrica, aetate provecta, pseudoramosa. Arthrosporae binae in singulis microbaculis ellipsoideis ortae."

Hueppe (1891) defines the genus as made up of filamentous organisms, sheathed, branched, and with the filaments differentiated into base and tip. Ludwig (1892) agrees with Hueppe in not stating that there is "false" branching. He says that the branches are not swollen at the tips, free, not embedded in slime. Sauvageau and Radais (1892, p. 246) state with emphasis that the genera Streptothrix and Cladothrix are very distinct. Migula (1894, p. 237) says:

Cladothrix Cohn Zellen zu pseudodichotom verzweigten Fäden verbunden. Teilung nur nach einer Richtung des Raumes. Vegetative Vermehumg durch polar begeisselte Schwärmzellen, die sich fest setzen und zu neuen Fäden auswachsen. Endosporenbildung bei Cladothrix dichotoma einmal beobachtet. Hierzu gehören auch die Gattungen Sphaerotilus Küutz, und Actinomyces.

Migula (1895, p. 40) defined the genus in somewhat greater detail as filaments with delicate sheaths, attached when young, non-motile, cells cylindric, breaking occasionally through the sheath by intercalary growth and forming false branches, a pseudo-dichotomy, multiplication through swarming gonidia, which have a cluster of flagella attached laterally near one pole. Fischer (1897), Migula (1897, 1900) 
Chester (1897, 1901), Hewlett (1898), A. J. Smith (1902), Fischer (1903), Jordan (1908), Orla-Jensen (1909), Ellis (1909) and Heim (1911) have all used the term in a somewhat similar sense. Migula later decided that the genus name Cladothrix Cohn is synonomous with Sphaerotilus Kützing. In this he has been followed by many recent writers. However, it would seem that the original descriptions of Sphaerotilus (q.v.) and Cladothrix may be sufficiently distinctive to warrant the separation of the genera. Sphaerotilus has its filaments disposed in considerable numbers in gelatinous branched threads, the filaments lying parallel to each other. This massing of filaments into threads does not seem to be characteristic of Cladothrix though doubtless the two genera are closely related.

That Cladothrix is worthy of generic recognition is argued by Molisch who states:

Migula stellt Cladothrix zu Sphnerotilus. Ich habe vorläufig davon Abstand genommen, weil Bau und Entwicklung der letzteren Gattung noch der Sphaerotilus natans und nach einem genaueren Studium dieser vielleicht doch herausstellen dürfte, dass die Aufstellung der Gattung Cladothrix neben Sphaerotilus erzeuge dicbotom verzweigte Fäden ohne Gegensatz von Spitze und Basis. Aber die Fäden der Cladothrix dichotoma, die er zu Sphaerotilus stellt, lassen doch deutlich Spitze und Basis unterscheiden.

\section{Molisch's description of $C$. dichotoma is as follows:}

Meist farblose Flöckchen, festsitzend, aus Fäden bestehend, die niemals echt, sondern in weiten Abständen wiederholt unecht dichotom verzweigt sind. Die Fäden setzen sich aus stabförmigen, ovalen oder länglichen Zellen zusammen, die von einer dünnen festen Mangehaft bekannt sind und weil sich nach Gewinnung von Reinkulturen Scheide umgeben sind. Fäden durchschnittlich $2 \mu$ dick, mit Gegensatz von Spitze und Basis. Indem die Stäbchen sich innerhalb der Scheide teilen, werden die vorderen nach der Spitze des Fadens gedrängt oder sie wachsen unter entsprechender Auftreibung der Scheide aneinander vorbei, wobei die beiden oder auch nur die eine der einseitig freiwerdenden Polzellen selbständig weiter wachsen und die nun entstehenden Äste gewöhnlich in losem Verband verbleiben. Auf diese Weise entsteht die falsche Dichotomie. Die Vermehrung geschieht durch unbewegliche und durch schwärmende Gonidien, die gestalteich den vegetativen Zellen gleichen und sich aus diesem dadurch entwickeln, dass sich seitlich unterhalb des einen Endes ein Büschel von Geisseln bildet. Sie schwärmen nach dem Verlassen der Scheide einige Zeit umher, setzen sich dann fest und kennen zu neuen Fäden aus. Ein namentlich in mit organischen Substanzen verunreinigten Wässern sehr häufiger und weit verbreiteter Organismus.

More or less confusion has arisen due to loose definitions of the genus such as that of Kendall (1902, p. 484) who records the genus as 
that group of the family Chlamydobacteriaceae in which the cells are more or less branched. Macé (1897, p. 1024) came to the conclusion that the Cladothrix dichotoma of Cohn did not exist as a well defined type, and that it had been interpreted in different ways by various investigators. He therefore proposed that Cladothrix be substituted for Streptothrix Cohn, because the latter generic name is a homonym of Streptothrix Corda. His definition reads:

Ces sont des Bactéries filamenteuses, a éléments droits ou sinueux dépourvus de gaine, produisant latéralement des ramifications disposess d'une facon irreguliere; dans certaines conditions, les filaments se segmentent ou très courts batonnets ou articles sphériques ou ovoides que l'ou doit probablement considérer comme arthrospores.

The conclusions of Macé have not been generally accepted, and his statements have but served to confuse nomenclature.

Krligler (1915, p. 327) described a Cladothrix placoides from the teeth. Some fifty-eight strains were studied. The characters are given as follows:

Morphology. The morphology of this organism is very variable. It often appears like a coccus, sometimes like a diphtheroid rod, or short club-end thread. Usually one finds all three in the same preparation. The coccus-like forms are probably spores, and the others are pleomorphisms of the thread. Microscopic pictures are often obtained which look identical with $L$. innominata of Miller.

Chromology. It stains readily with ordinary anilin dyes and is usually Grampositive. Often the spore retain the stain while the threads are decolorized when treated by Gram's method. Biological properties. They are aerobic, non-motile, non-branching threads. They grow best at $37^{\circ} \mathrm{C}$., only very slowly at $20^{\circ} \mathrm{C}$.

Cultural characters. On agar they form round, raised, lustrous, white colonies which can be picked up entire from the medium. On glucose-agar the colonies are usually larger and more grayish. Microscopically the surface colonies are convoluted and are often seen on the plates enclosing underneath them small colonies of other bacteria. In broth the growth is very sparse, and the wall of the tube is usually covered with a granular layer of discrete colonies $0.5 \mathrm{~mm}$. or less in diameter which are not readily removed by shaking the tube. In glucosebroth the growth is very abundant, giving both a heavy turbidity and a granular deposit on the wall. Gelatin was liquefied by some strains but not by others. They all fermented glucose, most of them fermented sucrose, while some also fermented lactose. Gas is not produced. They generally reduce nitrates and fail to produce indol or ammonia. When first isolated they should be kept on glucose-agar and transferred every two weeks.

Buchanan (1918, p. 302) rejected the name as invalid as a bacterial genus because of its use for a phanerogam. 
Castellani and Chalmers (1919, p. 1068) recognize and describe Cladothrix dichotoma Cohn.

It would seem that the genus Cladothrix Cohn with the description as emended by Migula is not valid, because of prior use by De Candolle. The name should not be used for organisms which show true branching, as Actinomyces, Nocardia, etc. It may probably be regarded as a synonym of Sphacrotilus.

Cladotriceae. A tribal name proposed by Trevisan (1879, p. 15) with the following diagnosis, "Sporae (arthrosporae) in filamentis normalibus obvenientes. Filamenta pseudoramosa, basi ab apice superiori distincta, vaginata vel evaginata." Later (1889, p. 926) De Toni and Trevisan included the following genera, Sphaerotilus Kütz, Cladothrix Cohn and Nocardia Trevisan.

This name (with the spelling Cladotricheae) was also used by Sternberg $(1892$, p. 19) to include the genus Cladothrix.

Cladotricee. A variant of Cladotriceae used by Trevisan (1889, p. 9) for the first tribe of the suborder Tricogene.

Cladotricheae. A name used by Sternberg, a variant of Cladotriceae, q.v.

Cladotricheen. A variant of Cladotriceae q.v. used by Zopf (1885, p. 51) to include the genus Cladothrix.

Clathrococcus. A generic name proposed by Schmidt and Weis (1902, p. 29) to replace Clathrocystis, q.v. as a name for a bacterial genus. The generic description is (p. 292),

Die einzelnen Zellen sind kugelig oder durch den Druck der sie umgebenden etwas eckig. Die Teilungen geschehen erst nach drei Raumrichtungen, später nur nach zwei, und aus den anfangs soliden Zellverbänden geht daher eine hohlkugelige Wuchsform hervor mit zuletzt netzförmig durchbrochener Wand. Die Zellen sind anfangs unbeweglich, allmählich aber lösen sie sich gruppenweise ab und schwärmen mittelst Geisseln davon.

Apparently these authors have overlooked the genus Lamprocystis created by Schroeter for this same purpose.

The type species (monotypy) is Clathrococcus roseo-persicinus (Cohn) Schmidt and Weis.

Clathrocystis. A genus of blue green algae proposed by Henfrey (1856, p. 52) for the species Cl. aeruginosa (Kützing) Henfrey. This genus was used by Cohn $(1875$, p. 156) to include an organism which is now generally placed among the bacteria. This was named Clathrocystis roseo-persicina. It was found upon twigs and other plant 
remains which were decaying on the bottom of standing water. It occurred in the form of cherry red flecks, which under the microscope showed a loose aggregate of small spherical or oval cells. According to Cohn, Kützing (p. 341) first described this organism as Protococcus. Rabenhorst (1856, p. 28) used the name Pleurococcus roseo-persicinus. Cohn described the genus Clathrocystis as having spherical cells, united into families with reticulate structure without regular arrangement, and places it in the tribe Gloeogenae. The genus was noted by Flügge (1886).

Winter $(1880$, p. 37$)$ separated this species from the algae, creating the generic name Cohnia q.v. Schroeter $(1886$, p. 151) called attention to the fact that this name was preoccupied, and proposed Lamprocystis $\mathrm{q} . \mathrm{v}$.

This name was accepted by Winogradsky $(1888$, p. 67) for a certain type of blue green algae, but it should not be used for a bacterial genus.

Clitridium. Apparently a casual name used by Billet (1890, p. 54). Enlows states,

Bacterium of average length in the form of a biscuit, "c'est-à-dire en train de se segmenter." (Possibly refers to a division stage-merely states the "Clitridium des auteurs," without any further reference.)

Cloaca. A generic name proposed by Castellani and Chalmers (1919, p. 943) for the second genus of their tribe Proteae. The generic description is: "Slow gelatine liquefiers; ferment lactose; Gram negative."

The type species is designated (p. 958) as Cloaca cloacae (Jordan) Castellani and Chalmers.

Clonothrix. A genus of iron bacteria described by Schorler (1904, p. 691) to include the species Clonothrix fusca. The generic diagnosis is: Filaments dichotomous or irregularly branched, fixed, with base and tip contrasted, tapering somewhat to the free end. Sheath constantly present, thin in the young filaments, later thicker, and becoming impregnated with iron or manganese oxide. Cells cylindric. Multiplication by means of small non-motile spherical gonidia which arise from the vegetative cells.

The species $\mathrm{Cl}$. fusca produces gray to dark brown and black masses similar to Crenothrix and is often in association with it. He concludes that all Cladothrix descriptions of iron bacteria belong here. The genus is recognized by Ellis (1909, p. 158) and by Molisch (1910). 
G. S. West (1904, p. 335) in his discussion of Phormidium says "Clonothrix gracillima W. \& G. S. West is one of the Schizomycetes of the genus Cladothrix."

Buchanan (1918, p. 305) gives the following description:

Filaments with false dichotomous or irregular branching, attached, with contrast of base and tip, tapering to the tip. Sheath always present, thin on young filaments, later becoming thicker and encrusted with iron or manganese. Multiplication by small non-motile gonidia of spherical form, formed from the disk shaped cells near tip by longitudinal division on rounding up.

The type species is Clonothrix fusca Schorler.

This is included as the fifth genus of the family Chlamydobacteriaceae by Bergey et al. (1923, p. 393).

Clostridiaceae. A family name proposed by Heller (1921, p. 550) as a sixth family of the Eubacteriales with the following description:

Eubacteriales that are rod-like, not spiral, that will not grow within $7 \mathrm{~mm}$. of the surface of a shaft of clear tissue-free agar medium contained in a tube $12 \mathrm{~mm}$. or more in diameter, incubated in air, in which they are able to grow in the depths. They may or may not possess peritrichial flagella, they may or may not form endospores. Most members of the group are characterized by their energetic catalytic action on proteins or on carbohydrates or on both of these types of substances.

Two subfamilies were included, Clostridioideae and Putrificoideae.

Clostridieae. A subfamily of bacteria proposed by Fischer (1897, p. 32) to include those forms of the family Bacillaceae in which the sporebearing rods are spindle-shaped. Two genera are included, Paracloster A. Fischer and Clostridium Prazmowski. The same designation is used in the second edition of the Vorlesungen (1903).

This subfamily designation does not seem to have been used by other authors. It may be noted that as a subfamily the designation should be Clostridioideae.

Clostridioideae. A subfamily named by Heller (1921, p. 449) as the first of the family Clostridiaceae. The first description follows: "Clostridiaceae which on meat medium produce after twenty days incubation under oil at $37^{\circ}$ a reaction of $\mathrm{pH} 7.0$ or a more acid reaction, the reaction being read after the culture has been boiled."

Later (p. 550) the type genus is designated as Rivoltillus Heller.

A list of fifteen genera were described and included, with designation of type species. The genera included are Clostridium, Omelianskillus, Macintoshillus, Douglasillus, Henrillus, Flemmingillus, Vallorillus, 
Multifermentans, Hiblerillus, Welchillus, Stoddardillus, Rivoltillus, Arloingillus, Meyerillus and Novillus.

Clostridium. A generic name proposed by Prazmowski (1880, p. 23). The origin of the name is given in the following words:

Um die Synonymik der Bacterien nicht mit einem neuen Worte zu bereichern, habe ich den von Trecul für eine Habitusform des Buttersäureferments zuerst angewendeten Namen Clostridium zur Bezeichnung meiner Gattung gewählt.

Trecul's name (as a form genus or casual name) was given in 186.5 (p. 435).

Two species, Clostridium butyricum and $C l$. polymyxa were described. The genus was differentiated from Bacillus by the production of spores in spindle shaped cells. In this article Prazmowski disposed of the prevalent idea that Bacillus subtilis causes butyric acid fermentation. Zopf (1885, p. 61) described the genus as containing organisms which resemble Bacillus, but producing the spores in characteristically broadened cells. The genus was also recognized by Schroeter (1886, p. 166) with the single species $C$. butyricum.

Trevisan (1889, p. 22) included Clostridium as the eighth genus of his tribe Bacillee, with eight species. Bacillus amylobacter Van Tieghem 1877 is given as a synonym of Clostridium butyricum Prazmowski.

De Toni and Trevisan (1889, p. 1002) described nine species. The generic description given is: "Baculi dimorphi, plasmate uniformiter diffuse. Sporae (endosporae) microsomae in baculis specialibus intumescentibus ortae, ovoideae vel ellipsoideo-cylindraceae. Among the species were C. polymyxa Prazm., C. butyricum Prazm., and C.feseri Trev. (the cause of blackleg in cattle).

Hueppe (1891) and Sternberg (1892) used Zopf's diagnosis. Macé (1897, p. 468) concludes that the enlargement of the cell at the time of sporulation (the spindle shape) is not sufficiently distinctive for generic differentiation. He cites the organism of symptomatic anthrax as one which shows great variation in the cell shape during sporulation.

By most writers of the last two decades the genus Clostridium has been submerged in Bacillus. Fischer (1895, p. 143) divided the spindle shaped bacteria into four genera, defining Clostridium as the type in which the cells are motile by means of diffuse flagella. Later $(1897,1903)$ he recognized two genera only of spindle shaped bacteria, Paracloster non-motile, and Clostridium with peritrichous flagella. 
Erwin F. Smith (1905, p. 174) rejects this generic name. Orla-Jensen (1909) abandons this generic name, using Butyribacillus. Vuillemin (1913, p. 525) suggests that this genus be made a "Genus conservandum" with Clostridium butyricum Prazmowski as the type.

Winslow et al. (Committee Soc. Am. Bact., 1917, p. 562) used this as a designation for all spore bearing anaerobes with the following description:

Anaerobes. Often parasitic. Rods frequently enlarged at sporulation, producing clostridium or plectridium forms.

The type species is Clostridium butyricum Prazmowski.

Buchanan (1918, p. 38) recognized both Clostridium and Plectridium for the spore bearing anaerobes. The following generic description of Clostridium was given.

Cells rod-shaped, straight or at least never spiral. Frequently showing granules. Endospores usually produced in cells showing some enlargement; usually the cells become spindle-shaped. Anaërobic or microaërophilic. Usually Gram-positive.

The type species is Clostridium butyricum Prazmowski.

Orla-Jensen (1921, p. 273) suggests that the genus Clostridium as described by the Committee (Winslow et al.) might well be split into two genera Butyriclostridium and Putriclostridium.

Heller (1922, p. 9) radically emended the generic definition, making it the first of the fifteen genera included in her family Clostridioideae q.v. The definition is:

Clostridium Prazmowski 1850, emend. Heller, Clostridioideae that do not liquefy gelatin. Most species eause stormy fermentation of milk. Highly saccharolytic, many even splitting pectins. Produce considerable amounts of butyric acid as a split-product of carbohydrate fermentation. May fix nitrogen. Readily derive their nitrogen from inorganic nitrogen salts. Large rods which are frequently polymorphic and form large orgonts and oval spores. Frequently store up starch. Form in deep agar large lenticular or modified lenticular colonies. Common destroyers of plant tissue (not cellulose) in soil. Used in the retting of flax to split pectins.

Type species, C. amylobacter van Tieghem as described by Winogradsky (1896). Probable synonyms: Amylobacter Trécul, Clostridium butyricum Prazmowski, Amylobalter Gruber, Granulobakter saccharo-butyricum Beijerink, B. saccharobutyricus von Kelcki, Granulobacillus saccharobutyricus mobilis nonliquefaciens Grassberger and Schattenfroh, B. amylobacter von Hibler, B. amylobacter Arthur Meyer and Bredemann. Most of these are today incapable of accurate definition and several of them represent groups and not entities. For this reason the type description chosen is that of Winogradsky instead of that of Prazmowski. 
Trécul (1865) gave the bacteria that contain starch the name of Amylobacter. He (1S67) declared the Amylobacter to be heterogenetic, formed of minute particles that organise themselves into bacilli in decaying plant tissue. Van Tieghem (1877) named Bacillus amylobacter bacilli which contained amorphous starch during their growth. He believed such organisms to be the agents of cellulose destruction. Prazmowski (1880) described and figured Clostridium butyricum, which though it was in impure culture, was evidently of the type described above. Winogradsky (with Fribes) (1896) first defined a type that can be considered a species; he assigned no name to the organism. He declares that it does not split cellulose, but pectin. It ferments glucose, sucrose, lactose and starch in peptone media.

Apparently the type species of the genus is Clostridium amylobacter (Van Tieghem) Winogradsky unless it can be shown that the specific name butyricum antedates amylobacter.

Bergey et al. (1923, p. 216) follows Winslow in including this genus as the second in the family Bacillaceae.

Clostrillum. A generic name proposed by Fischer (1895, p. 144) to include those rod-shaped bacteria which become spindle shaped when sporulating and which have a tuft of polar flagella. No species has been named, the generic designation is therefore a numen nudum and invalid. It was abandoned later by Fischer himself (1897 and 1903).

Clostrinium. A generic name proposed by Fischer (1895, p. 144) to include those rod-shaped organisms which become spindle shaped when sporulating and which are motile by means of a single polar flagellum. No species were described, and the name is a nomen nudum. The name apparently was later abandoned by Fischer himself (1897 and 1903).

Clostrydium. Apparently a typographic error, a misprint for Clostridium found in the index to the second volume of Migula's System der Bakterien (1900, p. 10o1). Enlows states (1920, p. 30) that this variant spelling has also been used by others in literature.

Coccaceae. A family of bacteria proposed under the name Coccaceen by Zopf (1884, p. 45) with the description "Sie besitzen nur die Coccen- und die durch Aneinanderreihung von Coccen enstehende Fadenform." The only genus recognized in this edition was Leuconostoc. The next year (1885, p. 50) however, he included four genera, Streptococcus, Micrococcus, Merismopedia and Sarcina. The family was defined to comprise only cocci and filamentous forms consisting of rows of cocci, in which spore formation had not been recognized with certainty, and in which cell division occurred in one or more directions 
of space. Schroeter (1886, p. 143) recognized the family (with the spelling Coccacei) making it the only family of his fourth order of bacteria (Coccobacteria). He states:

Vegetative Zellen kuglig oder kurz elliptisch zu keiner Zeit ihrer Entwickelung zu Stäbchen oder Fadenformen auswachsend, immer unbewegt. Die einzelnen Individuen im Substrat resp. der von ihnen gebildeten Schleimmasse zerstreut oder in typischer Art zu bestimmt geformten Familien vereinigt. Die einzelnen Individuen oder auch die Familion oft mit scharf begreizten Gallerthüllen umzogen-Sporen, soweit wie bekannt, aus einem vollständigen ZellIndividuum hervorgehend (Arthrosporen).

The genera recognized were increased to nine.

Hansgirg (1888, p. 266) listed this as a synonym of his Mycococcaceae. Migula (1894, p. 236) says,

Familie Coccaceae Zopf emend. Mig. Zellen im freien Zustande völlig kugel rund; Teilung nach ein, zwei oder drei Richtungen des Raumes, in dem sich jede Kugelzolle in Kugelhäften, Kugelquadraten oder Kugeloctanten teilt, die wieder zu Vollkugeln heranwachsen. Endosporenbildung selten.

The genera included were Streptococcus, Micrococcus, Sarcina, Planococcus and Planosarcina.

Most recent writers on the classification of bacteria have used the name. Among these may be cited Hueppe (1895, p. 37), Lehmann and Neumann (1896, p. 101), Fischer (1897, p. 32), Macé (1897), Migula (1897, p. 116, 1900, p. 1, 1904, p. 144), Chester (1897, p. 62, 1901, p. 55), A. J. Smith (1902, p. 268), Schmidt and Weis (1902), Kendall (1902), Klöcker (1903, p. 330), Fischer (1903, p. 59), E. F. Smith (1905, p. 159), Flügge (1908), Ellis (1909, p. 3), Frost (1911, p. 56), Schneider (1912, p. 22), Benecke (1912). The Winslows (1908, p. 249) have emended somerwhat the family diagnosis as follows:

Cells, in their free condition, spherical; during division somewhat elliptical. In the latter condition, division has already set in, although it may not be apparent. Division in one, two or three planes without previous elongation of the cells. If the cells remain in contact after division they are frequently flattened in the plane of division. Motility is present only in a few forms. Formation of endospores appears to be absent or very rare.

These authors subdivide the family into the subfamilies Paracoccaceae and Metacoccaceae (q.v.).

Winslow et al. (Committee Soc. Am. Bact., 1977, p. 557) use the following description: 
Cells in their free conditions, spherical; during division somewhat elliptical. Division in one, two or three planes. If the cells remain in contact after division they are frequently flattened in the plane of division. Motility rare. Endospores absent. Metabolism complex, usually involving the utilization of aminoacids or carbohydrates.

Buchanan (1917, p. 603) emended the description as follows:

Cells usually spherical, sometimes somewhat elongated just before division, or when occurring in pairs or groups cells may be somewhat flattened on sides in contact. Never containing granules of sulphur, nor with bacteriopurpurin. Many species develop a pigment. Some species are motile by means of flagella. Cells frequently remaining in groups after division, forming chains, regular packets or irregular masses. Spore production doubtful, having been reported for but one species. Pseudoplasmodium never produced. Growth energy not secured by the oxidation of ammonia or nitrites.

Three tribes were included, Streptococceae, Micrococceae and Siderocapseae.

Castellani and Chalmers (1919, p. 924) accept the Committee's (Winslow et al.) emendation. They recognize the tribes Streptococceae and Micrococceae. They designate Micrococcus Hallier 1866 emendavit Cohn 1872 and Winslow and Rogers 1905, as the type genus.

Winslow et al. (1920, p. 205) slightly modified their original (1917) definition by including "forming chains, packets or irregular masses."

Bergey et al. (1923, p. 41) recognize Coccaceae as the second family of the order Eubacteriales.

It may be noted that objection might be raised to the fact that the family Coccaceae does not include any genus Coccus. Its use, however, is well established, it leads to no confusion, and there would seem to be no good reason for abandoning it.

Coccaceen. An aberrant form of spelling of the family Coccaceae. This was first used by Zopf (1884, p. 45), and later by other German writers.

Coccaceés. An aberrant form of spelling of Coccaceae used by certain French writers, as Macé (1897, p. 334).

Coccacei. An aberrant form of spelling the family name Coccaceae. This was used by Schroeter (1886, p. 143).

Coccobacillus. De Toni and Trevisan (1889, p. 966) state that Leube (1885) used the designation Coccobacillus zymogenes. They refer also to Cornil and Babes (1885). A careful study of Leube (1885, pp. 540-570) fails to show any such term. He describes a 
Bacterium ureae and a Micrococcus ureae together with other unnamed organisms. Cornil and Babes (1890, p. 153) in the third edition of "Les Bactéries" figure a "Coccobacillus zymogene de Leube." The figure is of two distinct organisms, No. 1 and No. 3 of Leube. Apparently De Toni and Trevisan are in error in ascribing a Coccobacillus zymogenes to Leube or to Cornil and Babes. Bergey et al. (1923, p. 265) state that Coccobacillus avicidus was used by Perroncito (1879, p. 22). A careful examination of the original shows no such use.

This name was also introduced independently by Gamaleïa (1888, p. 167) in the name Coccobacillus avicidus used for the organisms which caused bird septicemia (including fowl cholera). The name in this sense, however, is a synonym of the earlier name, Pasteurella Trevisan, which has priority.

Tissier (1900, p. 70) described a Cocco-Bacillus anaerobius perfoetans from infant diarrhea.

Tissier (1905, p. 114) notes a Coccobacillus perfoetans from the intestines. This organism is of two varieties, one which ferments glucose and saccharose, the other glucose, saccharose and lactose. Inactive lactic acid is produced, and small quantities of butyric and valerianic acids. Does not form indol. This generic name is rejected by Erwin F. Smith (1905, p. 174).

The name has also been used as a casual designation of the conjunctival organisms commonly known as diplobacilli. This is the use made by Ruata (1909, p. 630) who designates the organism as Coccobacillus conjunctivae. A species, Coccobacillus fusiformis has also been named by Karwacki (1909, p. 679).

Coccobacillus acridiorum in a name applied by D'Herelle (1914, p. 408) to an organism causing a disease in locusts. This is Gramnegative motile bacillus, fermenting glucose, levulose, maltose and galactose. It apparently belongs with the colon typhoid series of bacteria.

Cocco-Bacillus. A variant of Coccobacillus q.v. used by Tissier $(1899$, p. 70$)$ for the species Cocco-Bacillus anaerobius perfoetans. As it was part of a trinomial, it may be regarded as invalid.

Coccobacteria. This generic name was introduced by Billroth (1874, p. 1) for the species Coccobacteria septica. This author conceived all bacteria to belong to one very pleomorphic species. $\mathrm{He}$ describes it as a kind of plant which consists partly of spherical and partly of rod-shaped cells which may show considerable variation in size. Each form may change into the other, although there is a certain 
amount of constancy in that a coccus will for a long time form cocci, and bacteria similarly produce bacteria. Both types of growth forms may produce a gelatinous capsule, forming cell plates (Petalococcos and Petalobacteria) or cell masses (Gliacoccos) or cocci may enlarge greatly and the contents divide forming a cell mass inside a capsule ( $A$ scococcos). The rod-shaped forms may multiply in the same manner. Chains of cells (Streptococcos and Streptobacteria) may be formed. At certain times any of these cell types may show motility when not surrounded by capsular material and when not too large.

Billroth's conceptions of bacterial classification and growth have been disproved by time. The name Coccobacteria as a generic designation has never come into use.

The name was also proposed by Schroeter (1886, p. 143) for his fourth order of bacteria and as a synonym for Sphaerobacteria Cohn. It contained one family only Coccacei. It included all bacteria in which the cells are spherical or short elliptical, always non-motile, frequently united in slimy masses or definite families, spores if any, arthrospores. The diagnosis given by Schroeter is as follows:

Vegetative Zellen kuglig oder kurz elliptisch, zu keiner Zeit ihrer Entwickelung zu Stäbchen- oder Fadenform auswachsend, immer unbewegt. Die einzelnen Individuen im Substrat resp. der von ihnen gebildeten Schleimmasse zerstreut oder in typischer Art zu bestimmt geformten Familien vereinigt. Die einzelnen Individuen oder auch die Familien oft mit scharf begrenzten Gallerthüllen umzogen. Sporen, soweit sie bekannt, aus einem vollständigen ZellIndividuum hervorgehend (Arthrosporen).

The name has not been used by other authors as a bacterial order.

Coccobacteriaceae. A name proposed by Orla-Jensen (1921, p. 264) in the statement:

As to the family names of the bacteria, it will be convenient to let all of them end in -Bacteriaceae, by which it will be seen directly what is in question. If there are to be formed families of the cocci and spirilla, they must consequently be termed Coccobacteriaceae and Spirillobacteriaceae (or by the older name of Zopf, Spirobacteriaceae).

Coccobacterium. According to Trevisan (1887, p. 105) this term as a generic designation was first used by Rivolta. The former author states:

Rivolta sembra che miri a risuscitare l'appellativo Coccobacterium per un genere di sui non fa conoscere ne caratteri, ne limiti, di cui cita solo una seconda specie, il Cocco-batterio della tuberculosi, che per ogni altro e un Bacillus; e naturalmenti non potra essere seguito de veruno. 
Rivolta (1888, p. 1) says:

"Nel N. 1 Maggio 1887 nel giornale l'Allevatore descrissi un microbo del gatto, coccobacterium felis il quale, moltiplicandosi prodigiosamente nel sangue delgatto, fu causa di una ma lattia letale," also "Coltivazione. Si semino il contagio nell'infuso di carne peptone gelatina; si moltiplico bene ed il liquido divenne torbido. Si semino pure il virus nel brodo di carne di pecora per conservarlo."

Descrizione del virus. Il virus venne studiato nel sangut de' conigli e nelle culture ed e rappresentato da cocco-bacterini mobili in alto, in basso e qualcuno sull' asse trasversale; sono formati da due cellule minime o da tre talor come fuse insieme; quelli che si presentano all' osservatore per una delle loro estremita appaiono come micrococchi; sono un po' splendenti, della lunghezza di $0^{\mathrm{mm}} 00142$, altri sono piu corti ed alcuni pare che arrivino a $0^{\mathrm{mm}} 00285$.

This organism was later named Bacillus felis (Riv.) Trev. by Trevi$\operatorname{san}(1889$, p. 14).

Klinger (1912, p. 188) described a Coccobacterium mucosum anaërobium from pus. The organism is an anaerobic gas producing rod or coccus, growing only at blood heat and in serum medium. The generic name is probably invalid.

Schmidt and Weis (1902, p. 10) again introduced the term for a generic name with the species Coccobacterium prodigiosium (Ehrenberg) S. \& W. This is a synonym of the older Serratia q.v.

Cocco-Bacterium. A generic name proposed by Rivolta (1888, p. 1) for the species Cocco-Bacterium felis. See Coccobacterium.

Coccogenae. A subfamily of the bacteria proposed by Trevisan $(1885$, p. 92$)$ to include all bacteria which have spherical cells, at least some stage in their life history. The diagnosis is "Status unicus evolutionis coccos sistens." It is the equivalent of the family Coccaceae (q.v.) as commonly used.

Later De Toni and Trevisan (1889, p. 1035) include the following tribes: Ascococceae, Sarcineae, Streptococceae, and Micrococceae.

Coccogene. A variant of Coccogenae used by Trevisan (1889, p. 26) for the third suborder of Batteriacee. Four tribes, Ascococcee, Sarcinee, Streptococcee, and Micrococcee were included.

Coccoglia. A synonym of Zoogloea, introduced by Billroth (1874, p. 7) to include those cocci which occur embedded in gelatinous slime. It apparently is synonymous with Gliacoccos. It was not proposed as a generic name, but as a growth form of his pleomorphic Coccobacteria septica. It has not been used by other authors.

Coccomonas. A generic name suggested by Orla-Jensen (1921, p. 268) in the following statement: 
For the Gram-negative, non-acid-forming or, at most, very slightly acid-forming cocci (among which must probably be reckoned the gonococci and the meningococci too, as well as Gram-negative streptococci, if such exist) we might simply use the generic name Coccus, or, if they should turn out to have terminal flagella, Coccomonas.

Coccos. A name proposed by Billroth $(1874$, p. 4) for a growth form of his pleomorphic Coccobacteria septica which is characterized by the production of spherical cells. In the form "coccus" it has been commonly accepted as a morphological term. It is not a generic designation in any strict sense. It is rejected by Erwin F. Smith (1905, p. 174).

Coccothrichaceen. An "Abteilung" created by Lutz (1886, p. 22) to include his genus Coccothrix. It has apparently not been used by other authors.

Coccothrix. A generic name proposed by $\operatorname{Lutz}(1886$, p. 22) for the organisms causing leprosy and tuberculosis. The diagnosis given by Lutz is as follows:

K̄leine, runde, kokken-ähnliche Zellen, die sich ohne Mitbeteiligung der Zellmembran nur in einer Richtung teilen und daher einzeln oder in Reihen getroffen werden. Dieselben sind von den gedehnten, allmählich gallertig verquellenden, Zellhäuten überzogen; zwischen den Durchmesser an Grösse übertreffen. Durch Farbung der innersten Schichten der membranös gallertigen Hülle enstehen Bilder, welche wie auf Faden angereihte Perlen oder wie Stäbchen aussehen. Es finden sich ausserdem grössere zum Teil ovale und doppelt konturierte Zellen, teils frei, teils am Ende der Zell reihen. In dieses Genus ist vorderhand mit Sicherheit der Lepra- und Tuberkelpilz einzurichen.

It is true that Iutz misinterpreted some of his observations. To be accurate, his genus requires emendation in order to include the organisms of tuberculosis and leprosy. However, if the acid fast bacteria of which these are types are to be given generic recognition, Coccothrix would appear to be valid, with the type species either Coccothrix tuberculosis Lutz or Coccothrix leprae Lutz.

The name is rejected by Erwin F. Smith (1905, p. 174).

Tuillemin (1913, p. 527) notes this name, but believes that it resembles Coccotrichum Wallroth (1833, p. 314) too closely. It would seem that these names are sufficiently unlike so that they would not be confused, and that both would be valid under a strict interpretation of the botanical code.

Synonyms of Coccothrix are Sclerothrix Metschinikoff and Mycobacterium Lehmann and Neumann. By many authors (as De Toni and Trevisan 1889, p. 943) it is regarded as a synonym of Bacillus. 
Coccus. This name with the spelling Coccos (q.v.) was first used by Billroth $(1874$, p. 6) to designate the growth form of his Coccobacteria septica in which the cells assumed a spherical form. It was not used in a generic sense, however.

As a genus name Coccus has been accepted by several writers, but in most cases examined, they have been used in a trinomial combination and without any adequate generic diagnosis. Among such trinomial names may be mentioned Coccus cumulus minor Black (1886) (probably a Sarcina according to Miller 1892, p. 78), Coccus salivarius septicus Biondi (1887, p. 217) and Coccus albus non-liquefaciens Fick (1887).

Apparently the first use of Coccus in a binomial was by Fick (1887) for a Coccus candicans from the conjunctival sack. De Toni and Trevisan (1889, p. 1078) rename this organism Micrococcus Fickii Trevisan.

It has also been used by Nissen (1889, p. 487) for a Coccus aquatilis. Billet (1890, p. 24) accepts Coccus as a generic name with the statement "Formes arrondies, Coccus, élément isolé." With the spelling Kokkus this term has also been used by Eisenberg (1886) and other German writers. It is given as a synonym of Micrococcus by De Toni and Trevisan (1889, p. 1076). Baumgarten (1890, p. 127) says "1 Gatt. Kokken, Bacterienarten umfassend, welche nur kugeliege Vegetations formen bilden." The name is rejected by Erwin F. Smith (1905).

Orla-Jensen (1921, p. 269) states:

For the Gram-negative, non-acid-forming or, at most, very slightly acid-forming cocci (among which must probably be reckoned the gonococci and the meningococci too, as well as Gram-negative streptococci, if such exist) we might simply use the generic name Coccus, or, if they should turn out to have terminal flagella, Coccomonas.

The status of Coccus as a generic name is uncertain. Possibly the type Coccus candicans Fick cannot be identified.

Cohnia. A valid name given by Kunth (1850) to a genus of the family Liliaceae. The same name was given by Reichenbach, (1852) to a genus in the family Orchidaceae, now a synonym of Cohniella Pfitz.

This name was later proposed by Winter $(1880$, p. 48) to include the bacteria which had been assigned to the algal genus Clathrocystis Henfry. In this genus the cells are spherical, embedded in gelatin in a simple peripheral layer, forming hollow, round or irregular bladders or vesicles, which finally become reticulate. The diagnosis given follows: 
Zellen rundlich, in einfacher peripherischer Schicht von gemeinsamer Gallerte umschlossen, hohle kuglige oder später unregelmässiger geformte Blasen oder Säcke bildend, die schliesslich netzförmig durchbrochen sind. Vermehrung der Zellen durch wiederholte Zweitheilung der Familien durch Furchung und Abgliederung von Tochterfamilien. Die Cohn'sche Gattung Clathrocystis umfasst nach meiner Auffassung Algen und Pilze. Da nun der Gattungsname zuerst für eine Alge ( $\mathrm{Cl}$. aeruginosa Henfry) angewendet wurde, so ist es rathsam, ihn dieser zu lassen, und die zu den Pilzen gehörige Art zur Repräsentantin eines neuen Genus zu machen, dem ich, zu Ehren des um die Erforschung der Schizomyceten so hoch verdienten Professor Dr. F. Cohn in Breslau den Namen Cohnia gegeben habe.

This genus is also recognized by Grove $(1884$, p. 17). The name is rejected by Erwin F. Smith (1905, p. 174) and as used for bacteria is generally regarded as a synonym of Lamprocystis.

The type species is Cohnia roseo-persicina (Cohn) Winter.

Cohnistreptothrix. A genus of thread bacteria proposed by Pinoy (1913, p. 929) to include those forms which differ from Nocardia by anaërobic or microaërophilic growth and by absence of conidia (gonidia).

The genus is accepted by Castellani and Chalmers (1919, p. 251 and p. 1063). They give the following statement (p. 1063):

Definition. Nocardiaceae growing best anaerobically, but can grow aerobically; usually difficult to cultivate and do not produce arthrospores.

Type Species. Cohnistreptothrix israeli (Kruse, 1896)

Historical. In 1891, Wolff and Israel published a beautifully illustrated account of a streptothrix, which they had isolated from two cases of actinomycosis in man-viz., from the lungs and from a retromaxillary growth. This organism was considered to differ from $N$. bovis, in that it grew best anaerobically, that branching was absent, and that its injections into animals were regularly positive in their result. These three characteristics induced Kruse, in 1896, to make a new species for it under the name Streptothrix israeli. In 1911, for reasons already set forth, Pinoy founded a new genus. Cohnistreptothrix, with Israel's organism as the type species, and therefore its name becomes Cohnistreptothrix israeli (Irruse, 1896).

These authors list a considerable number of species.

Coleothrix. Veley and Veley (1898, p. 154) according to an abstract (Kochs Jahresber., 9, 154, 1898) named a branched filamentous organism, sometimes appearing as cocci, Coleothrix methystes. It is one of the important causes of faulty rum in the West Indies.

Colibacterium. A generic name proposed by Orla-Jensen (1921, p. 272 ) in the following statement:

The genus Bacterium will undoubtedly dissolve into several genera, of which I may especially mention the Colibacterium, and Aerogenesbacterium. The 
reason why I am now inclined, in contrast to my earlier opinion, to consider the coli-and aerogenesbacteria as two different genera, is because they differ not only in morphologcal, but, as later researches have shown, also in biological respects. I have myself proved (1914) that the Aerogenesbacteria completely oxidize the carbohydrates when the nutrient matter offers a sufficient buffer effect, and they thus correspond with their name in forming more gas than do other bacteria, and Rogers, Clark and Davis (1914), have shown that in the gas developed by the Colibacteria there is proportionately more hydrogen than in that developed by the Aerogenesbacteria.

Conidiothrix. A natie suggested by Beneeke (1912, p. 489) as a generic designation. In a discussion of the work of Ellis on the iron bacteria, he says:

Es leuchtet ein, dass diese Form von der Leptothrix ochracea, wie sie oben beschrieben worden ist, ganz ausserordentlich abweicht. Ich möchte für den Fall, dass die Richtigkeit der Beschreiben sich auch später hin bestätigen sollte,was vorlaufig recht zweifelheft, erscheinen muss, den Namen Conidiothrix für sie vorgeschlagen.

The suggestion has apparently not been adopted by other authors. It may be regarded as a synonym of Leptothrix.

Coniothecium. According to Trevisan (1879, p. 144) the name Coniothecium syphiliticum was given by Hallier to an organism which he regarded as causing syphilis. Loeffler (1886, p. 143) quoted several paragraphs from an article by Fillier (1868, p. 327) in which he mentions this organism.

The organism evidently was so inadequately described that the name is probably invalid.

Cornilia. A genus deseribed by Trevisan (1889, p. 21) as the seventh of the tribe Bacillee. The description reads "Baculi con protoplasma uniformemente diffuso. Spore macrosome provenienti nelle parti mediane intumescenti, di regola non mai nelle estremita, di baculi normali immutati." Two subgenera are included, Eucornilia and Pleurospora. Fourteen species are listed, the first being Cornilia alvei (Bacillus alvei Flugge). De Toni and Trevisan (1859, p. 998) give the following diagnosis: "Baculi plasmati uniformiter diffuse foeti. Sporae (endosporae macrosomae) in partibus medianis tumefactis baculorum normalium immutatis exorientes numquam (in baculis) apicales."

Two subgenera are included, Eucornitia with sixteen species and Pleurospora with two.

What species should be regarded as the type is uncertain. It is possible that it should be Cornitia Pasteuri, the name given by Trevisan to 
the vibrion septique of Pasteur, or to the first species Cornilia alvei (Cheshire and Cheyne) Trevisan.

Altogether eighteen species are listed. The generic name is rejected by E. F. Smith (1905, p. 174) and by Vuillemin (1913, p. 521).

Corynebacterium. A genus of bacteria founded upon the diphtheria bacillus by Lehmann and Neumann (1896, p. 350) with the following description:

Kulturen, durchaus den Charakter echter Bakterienkulturen tragend, weich, den Nährböden flach und locker aufliegend. Der Organismus fürbt sich mit den gewöhlichen Bakterienfärbemitteln gut. Mikroskopisch; Stäbchen, die an den Enden häufig keulig angeschwollen sind, aus verschieden färbbaren Scheiben aufgebaut erscheinen und in manchen Kulturen durchweg eine unzweifelhafte echte dichotome Verzweigung zeigen.

The genus is accepted by Chester $(1897$, p. 63$)$. It was rejected by Erwin F. Smith (1905, p. 174). This is suggested as a Genus conservandum by Vuillemin (1913, p. 527) and placed among the Microsiphonés.

Winslow et al. (Committee Soc. Am. Bact., 1917, p. 555 and 1920, p. 199) include this as the second genus of the family Mycobacteriaceae with the description:

Slender, often slightly curved, rods with tendency to club formation, branching cells occasionally seen in old cultures. Barred irregular staining. Not acidfast. Gram-positive. Non-motile. Aerobic. No endospores. Some pathogenic species produce a powerful exotoxin. Characteristic snapping motion is exhibited when cells divide.

The type species is Corynebacterium diphtheriae (Loeffler) Lehmann and Neumann.

Buchanan (1918, p. 55) includes this as the tenth genus of the family Bacteriaceae. He gives the following description:

Rods which stain interruptedly (striped) with weak staining solutions. Not acid-fast. Clubbed, wedge-shaped and pointed rods frequent. Gram-positive. Non-motile. No spores. Aërobic.

The type of the genus is Corynebacterium diphtheriae Lehmann and Neumann.

Bergey et al. (1923, p. 380) recognize this as the second genus of the family Mycobacteriaceae, and use the diagnosis proposed by Winslow.

It probably may be regarded as a valid generic name if the diphtheria bacillus and related forms are to be accorded generic recognition. 
Corynemonas. A genus of bacteria proposed by Orla-Jensen (1909, p. 344) to replace Corynebacterium Lehmann and Neumann (q.v.). It has as its type species Corynemonas diphtheriae and is placed in the family Actinomycetes as its second genus. It is to be regarded as an invalid synonym of Corynebacterium.

Corynethrix. A generic name used by Bongert (1901, p. 449) in the title of a paper, but not used by him in the article. It is possible that the name has been used previously, but no earlier reference has been found.

The organism Corynethrix pseudotuberculosis murium is described as a non-motile rod in young cultures on agar $0.5,1$ to $2 \mu$. Older cultures show great numbers of involution forms. On potatoes the cells may become $15 \mu$ in length, and cultures three to four weeks old are almost Actinomyces-like. The older rods stain irregular, and showing pronounced metachromatic granules. In young cultures the cells are said to be gram negative, but when the granules appear they become gram positive. Neisser's stain shows the metachromatic granules distinctly. The organism is grouped quite definitely with the diphtheroid forms.

The generic name occurs in a trinomial, and should probably be regarded as invalid, or at most as a synonym of Corynebacterium.

Corynocladus. A genus of filamentous bacteria proposed by Leidy (1849, p. 250). The generic description and the description of the single species Corynocladus radiatus are as follows:

Filaments hyaline, inarticulate, very compound; branches thicker than the trunk, clavate, without ramuli, growing from rounded or oval granular masses.

Corynocladus radiatus. Comatose, growing in very dense bunches, occasionally straggling; branches spreading, terminal ones very long, simple, clavate, $\frac{t}{150}$ inch long.

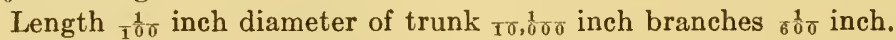

Habitat. Growing profusely in the ventriculus of Passalus cornutus, from the mucous membrane.

This organism was again described and figured by Leidy (1851, p. 38).

Apparently the genus has not been recognized since the original description. It may be included among the genera incertae sedis.

Crenothrichaceae. The second family of the order Desmobacteria recognized by Hansgirg (1888, p. 229). He says:

Diese bisher mit den Leptothricheen vereinigte Spaltpilzgruppe muss aus denselben Gründen wie die ihr unter den blaugrünen Algen (Schizophyceen) 
entsprechende Familie der Chamaesiphonaceae, welche früher (noch von Rabenhorst) zu den Oscillariaceen, den Parallelformen der Leptothricheen gezählt wurde, von diesen getrennt werden.

One genus only is included, Crenothrix Cohn.

Crenothrix. A genus of filamentous bacteria proposed by Cohn (1872, p. 130) for the species Crenothrix polyspora Cohn. Cohn gives the following description:

Trichomata plus minus stricta arcuata vel contorta in caespitulos libere natantes intricata libera vel alia aliis affixa, in modum Oscillariarum cylindrica elongate filiformia basi tenuissima sursum paullatim incrassata subulata vel subclavata divisione transversa succedanea articulata vaginata hyalina, cellularum plasmate homogeneo intus saepe cavo non granuloso, vagina tenerrima hyalina demum indurata nec non ferro interssuscepto flava.

Sporangia terminalia apice trichomatum vagina intumescente elongato-claviformia gonidiis subglobosis numerosissimis densissime repleta; gonidia duplicis generis, saepissime in filis diversis formata:

1. Microgonidia e serie cellularum divisione longitudinali et transversa succedanea multi-partitarum orta, rotundata et diaphragmatibus ruptis im sporangium terminale densissime congesta, demum ex apice vaginae erumpentia, in aqua motu lento circumvoluta secedentia vel in cumulos gelatinosos zoogloeis consimiles coacervata, cilii, destituta globosa ovalia elliptica transverse plusminus constricta vel divisa, demum in trichomata evoluta.

2. Macrogonidia, singula e cellulae contento toto indiviso, vel bivel quadri partito orta rotundata, ex apice vaginae vix inflatae erumpentia secedentia, motu forma microgonidiis similis sed majora et minus numerosa, demum germinantia. Sporaes? ex articulo trichomatis terminali elongata aucto formata plasmate denso repleta, quod e vagina erumpere et in trichoma Oscillariae forme evolvi videtur.

Genus unter Lyngbyam et Chamaesiphonem intermedium nec von ad Bangias accedens Oscillarieas cum Florideis connectit.

The genus was included by Trevisan $(1879$, p. 138) in his subtribe Euvibrionieae with the following description:

Somatia cylindrica distincte articulata, valida, elongata, arcuata vel contorta, in caespitulos intricata, microgonidia e serie cellularum divisione longitudinali et transversa succedanea multipartitarum orta, globulosa, diaphragmatibus ruptis in pseudosporangium terminale densissime congesta, demum ex apice vaginae erumpentia et in somatia evoluta, foventia.

The genus has been generally recognized by subsequent writers. Winter (1880) and Grove (1884, p. 54) used the following definition:

Threads cylindrical, somewhat clavately thickened upwards, articulated, provided with a sheath. Multiplication by means of the joints, which escape 
from the sheath and grow into threads. Reproduction by spores, which are formed in the sheath by further subdivision of the joint-cells. The spores either grow directly into threads, or form by continued subdivision gelatinous colonies of roundish cells, which afterwards produce threads.

Other writers who recognized the genus were Van Tieghem (1884), Zopf (1885), Flügge (1886), Schroeter (1886, p. 172), Hansgirg (1888, p. 230), Trevisan (1889, p. 10), De Toni and Trevisan (1889) and Hueppe (1885, 1891). Hansgirg (1891, p. 313) discussed the synonomy of the genus, and included within it the genus Phragmidiothrix Engler. $\mathrm{He}$ divided the genus into two sections, as follows:

Section 1. Phragmidiothrix (Engler) nob. Plantae marinae. 1. Crenothrixfoetida (Fior.-Mazz.) nob. (C. marina Hansg.) cum aliis synonymis. Section 2. Eucrenothrix nob. Plantae aquae dulcis. 2. Crenothrix Kuhniana (Rbh.) Ciard. (C. polyspora Cohn) cum synonymis.

Ludwig (1892), Hueppe (1895, p. 38), Migula (1895, p. 40, 1897, p. 47,1900 , p. 1033 , 1904, p. 145), Fischer (1897, p. 32,1903, p. 61$)$, Chester (1897, p. 64, 1901, p. 372), Schmidt and Weis (1902, p. 380) A. J. Smith (1902, p. 272), Kendall (1902), Erwin F. Smith (1905, p. 162), Ellis (1909, p. 9), Orla-Jensen (1909, p. 334), Molisch (1910), Frost (1911, p. 59) and Heim (1911, p. 254) have all described this genus

Migula (1894, p. 238) says:

Zellen zu unverzweigten Fäden vereinigt, mit anfang nur nach einer Richtung vor sich gehender Teilung. Später teilen sich die Zellen nach allen drei Richtungen des Raumes, die Teilungsprodukte runden sich ab und werden zu Fortpflanzungszellen.

The later diagnosis of the genus by Migula gives the modern conception of the genus:

Cells united into unbranched filaments, attached, and gradually enlarging toward the free end, i.e., with a distinction between base and apex. Sheath rather thick. In iron waters the old and empty sheaths are permeated with iron oxid hydrate. Cells cylindric or flat discoidal. Multiplication by non-motile (mostly roundish) conidia, which arise from the vegetative cells by division and rounding off. For this purpose the cell of the thicker threads divide in three directions of space, those of the thinner threads only perpendicularly to the long axis of the thread. The conidia are discharged and germinate immediately, often on the sheath of the mother thread.

Molisch (1910, p. 16) used practically the same description. $\mathrm{He}$ discusses Crenothrix polyspora Cohn at length. He states that there 
has been confusion as to the correct specific name. Migula (1900, p. 1033) notes that he examined the exsiccatti of Rabenhorst's Leptothrix Kuhniana (Algens Sachsens No. 284), but that it contained no organisms of the type of Cohn's Crenothrix polyspora, but a mixture of Leptothrix ochracea and Gallionella ferruginea. Zopf's use of the name Crenothrix Kuhniana he considers invalid.

Buchanan (1918, p. 305) included this genus as the third in the family Chlamydobacteriaceae with the following description:

Filaments unbranched, showing differentiation of base and tip, attached, usually thicker toward the tip. Sheaths plainly visible, usually colorless, brownish from iron oxid in old filaments. Cells cylindric to spherical. Multiplication by non-motile, spherical, conidia; cells dividing in 3 planes to form conidia.

The type (and only) species is Crenothrix polyspora Cohn.

This description is also followed by Bergey et al. (1923, p. 392).

Crenotrichaceae. A family named by Hansgirg (1890, p. 20) for a group of Mycophyceae, including the genus Crenothrix.

Crenothriceae. A tribe of the family Trichogenae proposed by De Toni and Trevisan (1889, p. 925) with the following diagnosis: "Sporae (arthrosporae) in specialibus filamentorum partibus (pseudosporangiis) obvenientes. Filamenta simplicia, basi ab apice superior distincta, vaginata."

Crenothrix was the only genus included.

Cristispira. A genus of spirochetes proposed by Gross (1910, p. 44) to include those forms found in the crystalline style of mussels. The body of the organism is circular in cross section, more or less spirally wound and possessing a longitudinal "comb" or "crest" which does not extend quite to the end. This crest has been compared to the undulating membrane of the trypanosomes, though Gross does not consider them to be homologous organella. Gross states that the organism is divided by cross walls into separate chambers or cells. His generic diagnosis (p. 89) reads: "Spironemacea mit spiralig gebogenem Körper und Crista. Theilung durch einfache Durchschnürung oder Ausbildung einer Scheidewand, meist mit vorhergehender Incurvation." Two species are described C. veneris and C. interragationis.

This name is used as a subgeneric designation by Doflein (1911, p. 356). It is recognized as a valid genus by Dobell (1911, p. 536) and by Gonder (1914, p. 678). The latter author summarizes the conclusions of various writers relative to the morphology of the organisms belonging to this genus. 
Winslow et al. (Committee Soc. Am. Bact., 1917, p. 563) give this as the second genus under the heading of forms intermediate between bacteria and protozoa. The description is:

Cristispira Gross. Giant forms with undulating body and peculiar flattened ridge erroneously called an "undulating membrane" which runs the length of the body. Parasitic in molluses.

The type species is Cristispira balbianii Certes, from the crystalline style of the oyster.

Buchanan (1918, p. 544) makes this the fourth of the family Spirochaetaceae.

Spiral organisms known only from the crystalline style of mussels. The body of the organism is circular in cross section, more or less spirally wound and possessing a longitudinal comb or crest which does not extend quite to the tips.

The type species is Cristispira veneris Gross.

Bergey (1923, p. 423) recognized this as the third genus of the family Spirochaetaceae with the following description: "Giant forms with undulating body and peculiar flattened ridge erroneously called an 'undulating membrane' which runs the length of the body. Parasitic in molluses."

It would appear that Cristispira Gross constitutes a valid genus name. It is questionable, however, whether these forms are to be considered among the bacteria or the protozoa. Most authors include them among the latter. C. veneris Gross is the type.

Cromobacterium. A generic name proposed by Bergonzini (1881, p. 153) for the species $C r$. violaceum. The organism was first observed in a solution of egg white, producing a dark violet scum. Microscopic examination showed it to be made up of motile rods two to three times as long as broad. The solubility of the pigment in alcohol, but not in water, was noted. The original diagnosis reads:

Elementi cellulari cilindrici per lo piu isolati, 2 a 3 volte cosi longhi come larghi dotati di movimento oscillante, colorati in violetto da una sostanza speciale insolubile nell 'acqua. Grossezza da 0.6 a $1 \mu$; lunghezza da 2 a $3 \mu$. Vegetano specialmente nelle soluz. d'albume d'ovo.

This organism has been variously named Bacillus violaceus and Bacterium violaceum. This genus with the spelling Cromobacterium does not appear to have been generally recognized by other writers, but with corrected spelling Chromobacterium q.v. it has been suggested as a generic name for the violet bacteria. 
Cromococcus. A generic name used by Bergonzini (1881, p. 149) for a violet organism Cromococcus violaceus which he found in egg albumen. The original description is as follows:

Osservai adunque che il liquido del bicchierino, che per evaporazione era ridotto a meno della metà, da bianco opalino era diventato giallo leggermente verdastro ed era coperto da una pellicola molta densa di un colore violetto scuro molto manifesto.

Dapprima dubitai che fosse caduto qualche cosa accidentalmente entro il liquido, probabilmente dell'annilina, ma poi pensando che da due mesi non era stata toccata annilina nel mio studio, e che la colorazione violetta era limitata all superficie del liquido, anzi ad una pellicola superficiale affiatto identica a quelle di color bianco sporco che si presentano sopra tutti i liquidi di putrefazione, pensai ad una vegetazione bacterica colorata, e probabilmente al Cromococcus violaceus l'unico bacterio che presenta questa colorazione quantunque esso non sia mai stato osservato sull'albumina d'ovo.

Ma dovetti ben presto ricredermi per due ragioni. Primo perché staccato un frammento di questa pellicola violetta e triturata nell' acqua essa non vi si scioglieva punto, mentre le zooglee del Cromoccocus violaceus sono solubili nell'acqua. In secondo luogo poi perché l' esame microscopico invece di lasciarmi vedere la pellicola formata d' una zooglea di micrococchi me la mostrócomposta di un numero straordinario di microbacteri violetti immobili riuniti a sciami (micoderma) i quali pigliavano un movimento distintissimo quando venivano disaggregati e potevano nuitare liberamente nel liquido.

This generic name has apparently not been adopted by other writers. The description is scarcely sufficient to enable one to recognize the original species.

The spelling was corrected to Chromococcus q.v.

Crypta. A generic name proposed by Salisbury (1868, p. 19) with the following description: "Minute, transparent, highly refractive algoid filaments, which develop in living organic matter from spores."

Enlows (1920, p. 34) discusses the species as follows:

C. syphilitica n. sp. A homogeneous filament, with extremities obtusely rounded. No transverse markings, except in early stage of development. Filaments either straight, coiled, or aranged in curves. They develop from spores which may be active or inactive in the connective tissue, and may be transplanted from one individual to another. Believed to be the cause of syphilis. C. gonorrhoeae. Spores very minute and well defined. Often in twos and sometimes in fours, undergoing the process of duplicative segmentation. They occur and develop rapidly in and among the parent cells of the mucous surfaces affected. In some instances the pus cells become filled with the spores of this "vegetation." The filamentous stage of this plant is frequently met with in and among the epithelial cells. In their embryonic stages a moniliform arrangement may be seen at times. In later and more advanced stages they are usually homogeneous 
throughout their entire length. Occur singly or in little knots. Limited in its invasion to the epithelial tissue. Bergonzini (Lo Spallanzani, An. 12, f. 10 Modena, 1884) places these species among the Schizomycetes.

Cryptococcus. A genus of "algae" described by Kützing (1833, p. 374), later used as a genus of fungi, to which occasionally bacteria have been referred, as Cryptococcus xanthogenicus Freiere. (See Koch's Jahresber, 1, 346, 1885.)

Cryptodesma. A genus of entophyte named by Leidy (1849, p. 250) with the following description: "Filaments ribbon-like, growing from attached granular masses. Consisting of a single cell, with a very delicate cell wall, and minute granular contents." One species C. tenuis was described from the ventriculus of Passalus cornutus. The specific description is as follows:

Filaments hyaline, compressed, attenuated at both extremities, growing in dense bunches from rounded granular masses. Cell wall very thin and delicate, granular contents of cell very fine and indistinct, measuring from $\frac{10,0}{100} 0$ to $\frac{1}{6000}$ inch with a few coarser granules, and occasionally a few globules, measuring ${ }_{18}^{\frac{1}{7}} 75$ inch. Length of filaments $\frac{1}{500}$ to $\frac{1}{75}$ inch greatest breadth $\frac{1}{1700}$ inch.

Leidy (1851, p. 39) later questioned the ascription of name to this organism, doubting the entophytic nature of the form. The name is probably to be regarded as of doubtful validity.

Cylindrogloea. A genus of bacteria described by Perfiliev (1914, p. 223). Enlows (1920, p. 35) states:

Type species (monotypy). C. bactifera. A bacterium living symbiotically with Chlorochromatium aggregatum Lauterborn. A cylindrical, colorless zoogloeal mass, consisting of an axial filament formed by colorless cells, rectangular and numbering 20 to 35 , measuring 0.7 to $0.8 \mu$ by 2 to $4 \mu$, separated by interstices and surrounded by a mucilaginous envelope. In this outer mucilaginous zone the green bacteria lie, which Perfiliev says react in the same manner as the green form described by Lauterborn. The axial filament is not easily visible, because of the overlying Chlorochromatium.

Cystobacter. A genus of bacteria proposed by Schroeter (1886, p. 170) to include two species, C. fuscus and C. erectus Schroeter. The generic description reads:

Zellen in Form kurzen, dünner Stäbchen, in eine verbreitete Schleimmasse eingebetten, später in längeren Fäden zusammenhängend. Die Schleimmasse theilt sich in unregelmässige rundliche Klumpen, welche sich später mit einer festenhornatigen structurlosen Hülle umgeben. 
The genus was accepted by De Toni and Trevisan (1889, p. 1035) and Ludwig (1892). Thaxter (1892, p. 394) concluded that this genus is a synonym of Chondromyces B. and C. (q.v.) and subsequent authors have accepted his findings. The generic name is therefore to be regarded as invalid.

Cystococcaceae. The first subfamily of the family Mycococcaceae proposed by Hansgirg (1888, p. 266). He gave the following diagnosis "Zellen oder Zellfamilien von bestimmt umgrenzten Gallerthüllen (Cysten) umgeben." The following genera were included, Leuconostoc, Ascococcus, Mycothece, Leucocystis, Hyalococcus.

Cytobacter. A casual name suggested by Duclaux (1895, p. 814) to designate certain bacteria which destroy the cellulose wall of the potato cell without attacking the starch, as distinguished from Amylobacter which destroys starch but not cellulose.

Deazotonitraazobacterium. A name proposed by Ambroz (1913, p. 10) for organisms which are capable of producing free nitrogen from nitrates. One species is noted, Deazotonitraazobacterium thermophilum Ambroz.

It would seem that a name of this length (12 syllables) would rather transcend good usage.

Deazotonitranitriazobacterium. A name suggested by Ambroz (1913, p. 10) to designate bacteria which set free atmospheric nitrogen from nitrates and nitrites. See preceding.

Deazotonitriazobacterium. A name suggested by Ambroz (1913, p. 10) to include bacteria which can free elementary nitrogen from nitrites. See preceding.

Denitrobacillus. One of several names applied by Ambroz (1913, p. 6) to Denitrobacterium thermophilum, Ambroz. Probably to be regarded as a casual designation.

Denitrobacterium. A genus of bacteria proposed by Orla-Jensen $(1909$, p. 314) to include those organisms which show active denitrifying powers, and have peritrichic flagella. He notes the type to be the Bacillus denitrificans II of Burri and Stutzer, which has the power of reducing nitrates to nitrites and of freeing elementary nitrogen. The genus is regarded as an intermediate type between the two orders Cephalotrichinae and Peritrichinae, and is placed tentatively as the first genus in the family Acidobacteriaceae of this latter order.

Ambroz (1913, p. 3) named a Denitrobacterium thermophilum.

Enlows (1920, p. 35) states: "Type species (monotypy). D. agile (Bacillus denitrificans agilis Ampola and Garino 1896)." 
If organisms of this type are to be accorded generic recognition, this genus name would appear to be valid.

Denitromonas. A genus of bacteria proposed by Orla-Jensen (1909, p. 314) for those organisms belonging to his family Luminibacteriaceae which show active denitrifying powers. The organisms of this genus are usually fluorescent and differ from Liquidomonas in their lack of ability to liquefy gelatin. The type species is Denitromonas fluorescens (Bacterium fluorescens nonliquefaciens). The name Denitromonas Orla-Jensen may be regarded as a synonym of Pseudomonas Migula and probably invalid.

Enlows (1920, p. 36) states Bacillus denitrificans Burri and Stutzer, to be the type.

Desmobacteria. A tribe of bacteria proposed by Cohn (1872, p. 173) to include the two genera Bacillus and Vibrio. It comprises all filamentous bacteria, which consist of elongated cylindrical joints, which multiply by transverse fission and which occur in longer or shorter chains or filaments. The cells are not constricted at the joints. The original description reads:

Alle Fadenbacterian bestehen aus verlängerten cylindrischen Gliedern, welche, wenn sie isolirt vorkommen, dem Bact. Lineola ähnlich sind, durch Quertheiling aber vermehrt, sich zu längeren oder kürzeren Ketten oder Fäden aneinanderreihen; diese Fäden sind jedoch nicht an den Gelenken eingeschnürt wie die Rosenkranzketten (Torulaform) der Oscillarien, an die sie sich zunächst anschliessen; sie werden in diesem Zustand als Leptothrixfäden bezeichnet. Die Fadenbacterien bilden oft Schwärmern, nie aber, wie ich schon in einer Abhandlung von 1853 (Nov. Act. 1. c. p. 124) hervorgehoben, ZoogloeaGallert; doch wechseln auch bei ihnen bewegliche und unbewegliche Zustände, je nach der Anwesenheit oder dem Mangel an Sauerstoff, der Reaction des Mediums und andern noch unerforschten Bedingungen; gewisse Arten scheinen nie bewegt zu sein (Bacteridium Dav).

This grouping was also used by Schroeter $(1886$, p. 170) as an order with the families Leptotrichacei and Cladothrichacei.

Hansgirg (1888, p. 229) also adopted this name for his first order of bacteria. No description is given. The three families Cladothrichaceae, Crenothrichaceae and Leptothrichaceae are included.

With the spelling Desmobacteriaceae, this was used as a family name by Benecke (1912, p. 188). This family he included in the order Desmobacterinae.

Desmobacteriaceae. A name proposed by Benecke (1912, p. 188) for the single family of the order Desmobacterinae. This includes all 
of the filamentous bacteria, usually grouped under Trichobacteriaceae and Chlamydobacteriaceae.

Desmobacteries. The fourth order of bacteria, according to Maggi (1886, p. 173), including the genera Bacillus, Actinobacter and Dispora. No description is given.

Desmobacterinae. An ordinal name used by Benecke (1912, p. 188) to include the single family Desmobacteriaceae.

Desmobacterium. Included as a synonym of Bacillus by Klein (1885, p. 37) in the statement "Bacillus (Desmobacterium Cohn.)"

Detoniella. A bacterial genus proposed by Detoni and Trevisan (1889, p. 929) with the following diagnosis:

Filamenta cylindrica articulata, simplicia, basi ab apice superiori distincta, propter pulvinulum mucosum primitus affixa immobilia, serius libere natantia, lente oscillantia et in strata varie implexa. Cocci constanter nulli. Multiplicatio baculogonidiis e vaginae apice egredientibus, primitus vivacissime mobilibus, cito immotis. Arthrosporae 4-5 in singulis articulis baculiformibus obvenientes. OBS. Genus a ceteris Kurthiensis arthrosporis in bucalis ortis coccorumque constanti defectu primo intuitu probe distinguendum.

It is included in the tribe Kurthieae Trevisan (q.v.)

The genus includes three species of which the first described $D e-$ toniella ochracea (Roth) Trevisan may be regarded as the type. The organisms included are those which are generally listed with Leptothrix and the genus may be regarded as a synonym of this term.

Dialister. A name proposed by Bergey et al. (1923, p. 271) for the second genus of the tribe Hemophileae with the description:

Minute rod-shaped cells, occurring singly, in pairs and short chains. Nonmotile. Strict parasites. Growth occurs only under anaerobic conditions in media containing fresh, sterile tissue or ascitic fluid.

The only species known is Dialister pneumosintes (Olitsky and Gates) comb. nov.

Diaschizae. A subdivision of the group Schizomycetes coördinate with Paraschizae proposed by Jennings $(1899$, p. 315) to include all bacteria which multiply vegetatively by transverse division.

Dicoccia. A genus of bacteria proposed by Trevisan (1889, p. 26). De Toni and Trevisan (1889, p. 1034) give the following diagnosis: "Baculi Klebsiellae, capsulis, inclusi, plasmate polari-diblastico foeti; sporae, ignotae. Obs. Ut Pasteurella a Bacilio, hoc genus a Klebsiella distat." This genus is included in the tribe Klebsielleae Trevisan (q.v.) and the subtribe Euklebsielleae. The cells resemble Klebsiella Trevisan (q.v.) except that the cells show bipolar characters similar 
to Pasteurella Trevisan (q.v.). One species only is given: Dicoccia glossophila Trevisan. This is the "Bakterien menschlicher Mundsecrete, zweite Art" of Flügge (1886, p. 258). It is probable that this organism should be included with the hemorrhagic septicemia forms although the specific determination is not practicable from Flügge's description. This would make Dicoccia a synonym of Pasteurella. The genus is rejected by Erwin F. Smith (1905, p. 174).

Didymohelix. A generic name proposed by Griffith (1853, p. 438) for the organism termed Gallionella ferruginea by Ehrenberg, Gloeotila by Kützing and Meloseira ochracea by Ralfs. He points out that each of these authors included this species with others of the genus among the diatoms. This organism, as it is not a diatom, cannot be included either in Gallionella or Gloeotila. He notes that the organism usually has the appearance of two intertwined filaments, and proposes the name Didymohelix. For discussion of the synonymy, see Gallionella.

Buchanan (1918, p. 304) recognized this as the second genus of the family Chlamydobacteriaceae with the following diagnosis.

Filament twisted, simple, or two filaments, twisted together. Young cell colorless, later yellow brown to rust red through deposition of iron. Simple filaments show no division into cells, even when iron is removed with acid and stain applied. Sheath not demonstrable.

The type species is Didymohelix ferruginea (Ehr.) Griffith.

Diffusionsbacillus. A casual name used by Beijerinck (1893, p. 830) Enlows states: "A species closely related to $B$. perlibratus. Probably did not intend to use it as a generic name."

Diplectridium. A genus of bacteria created by Fischer (1895, p. 2) to include those rod-shaped organisms having diffuse flagella which become clavate when spores are produced, one spore being formed in each end of the cell. No species apparently have been described within this genus and the name itself has been abandoned by Fischer in later publications (1903). This generic name is to be regarded as a nomen nudum and invalid. It is rejected by Erwin F. Smith (1905, p. 174).

Enlows (1920, p. 147) states the type to be "B. solmsii Klein."

Diplobacillus. Maggi (1886, p. 174) used this term in designating a growth form of a Bacillus. Apparently it was first used as a generic name by Weichselbaum (1887, p. 212) in the combination Diplobacillus brevis endocarditidis to designate a short rod which occurred in pairs and was apparently associated with a case of endocarditis. The cells 
characteristically show polar staining, only the youngest cells stain uniformly. The organisin grew well at room temperature on ordinary media. The name as used, in the form of a trimonial, is non-valid. De Toni and Trevisan (1889, p. 997) included this organism in the genus Pasteurella, naming it Pasteurella Weichselbaumii.

Morax (1896, p. 337) described a diplobacillus associated with conjunctivitis, the same organism being discussed in greater detail later by Axenfeld (1897, p. 1). This organism has been commonly known since as the Morax-Axenfeld bacillus, or in some cases as Diplobacilius Morax. The latter designation is binomial in form, and perhaps might validate the generic name Diplobacillus for this group of organisms. The species is termed Bacterium duplex by Lehmann and Neumann and Bacillus lacunatus by Muir and Ritchie.

Petit (1898) described a related organism from a case of hypopyonkeratitis, as a "Diplobacille liquefiante." McNab (1904, p. 64) discussed this organism under the name "Diplobacillus liquefaciens" Petit, and the earlier organism as Diplobacillus Morax-Axenfeld.

Diplobacteria. This name was applied by Billroth (1874, p. 16) to a growth form of his Coccobacteria septica in which the rod-shaped organisms occurred in pairs. The name has never been used as a generic designation. It is rejected by Erwin F. Smith (1905, p. 174).

Diplobacterium. A casual name used by Haase (1887, p. 347) in the phrase, "Diplobacterium der Brustseuche." The name was also used as a morphological term by Billet (1890). It has not been used as a generic designation.

Diplococcos. A growth form of Coccobacteria septica named by Billroth $(1874$, p. 5$)$ to indicate a grouping of cocci in which the organisms occurred normally in pairs.

The spelling has been changed to Diplococcus by later writers and used as a generic designation.

Diplococcus. The name Diplococcos was first used by Billroth $(1874$, p. 5) to designate a growth form of his Coccobacteria septica in which the sperical cells occurred in pairs. It was not used in a strict generic sense.

As a generic name Diplococcus came into use without any definite characterization. Bumm (1885, p. 16) used the term diplococcus, though not in a generic sense, to designate the characteristic grouping of the gonococcus and related forms. In no case was it used in a strict binomial designation. Fluegge (1886, p. 183) follows Bumm in the 
use of the name Diplococcus albicans tardissimus, but as this is a trinomial it is invalid. In the same year Weichselbaum (1886, p. 506) gave to the pneumococcus the name Diplococcus pneumoniae, a valid binomial. This seems to be the first correct designation of a species of the genus, and the pneumococcus should therefore be regarded as the type. Several other species were assigned to this genus in the next two years, but of these only four appear to have binomial form and therefore valid. These are Diplococcus roseus and $D$. subflavus described by Bumm (1887), D. luteus Adametz (1887, p. 9) and D. coryzae Hajek (1888).

As the designation of a genus, Diplococcus has rarely found its way into formal classifications, although diplococcus is in common use as a casual designation. For example, Sternberg (1892, p. 17) under the heading of Diplococcus makes the following statement:

Association in pairs is common to all of the micrococci, inasmuch as they multiply by binary division. When such association has rather a permanent character it is customary to speak of the microörganism as a diplococcus, but we doubt the propriety of recognizing this mode of association as a generic character.

Winslow and Rogers (1905, p. 669) have included Diplococcus as one of the valid genera in their studies of the classification of the Coccaceae. In further contributions on the same subject the genus was accurately defined as follows (1908, p. 250):

Strict parasites, not growing, or growing very poorly, on artificial media. Cells normally in pairs, surrounded by a capsule. Fermentative powers high, most strains forming acid in dextrose, lactose, saccharose and inulin. Hemolytic power generally lacking. Characteristic group serum reactions.

They assign to this genus the pneumococcus, the gonococcus, the meningococcus and the coccus of catarrh.

If the Gram-positive cocci of which the pneumococcus is a type are to be grouped together into a genus, it would appear that the generic name Diplococcus is valid; if, however, the gram negative cocci of which the gonococcus is the type are to be included in the same genus, Diplococcus becomes a synonym of an earlier genus, Neisseria Trevisan. This latter genus was founded upon the gonococcus by Trevisan in 1885 (p. 16). Article 46 of the botanical code states: "When two or more groups of the same nature are united, the name of the oldest is retained." Inasmuch as the genus Diplococcus as used by the Winslows contains also the type of the genus Neisseria Trevisan, and since the latter name has priority, Neisseria should replace Diplococcus. 
Buchanan (1817, p, 612) included this as the third genus of the tribe Streptococceae with the diagnosis:

Parasites growing poorly or not at all on artificial media. Cells usually in pairs, capsulated. Fermentative powers high, most strains forming acid in dextrose, lactose, saccharose and inulin. The cells are Gram-positive.

The type species is Diplococcus pneumoniae Weichselbaum.

Winslow et al. (Committee Soc. Am. Bact., 1920, p. 206) describe the genus as follows:

Parasites, growing poorly, or not at all, on artificial media. Cells usually in pairs of somewhat elongated cells, often capsulated, sometimes in chains. Gram positive. Fermentative powers high, most strains forming acid in glucose, lactose, sucrose and inulin.

Type species, D. pneumoniae Weichselbaum.

Castellani and Chalmers (1919, p. 927) diagnose the genus as follows:

Streptococceae usually in encapsulated pairs, forming acid in glucose, lactose, saccharose, and inulin. Haemolysis usually absent. Characteristic group serum reactions. Soluble in bile salts. Undergo autolysis in cultures and in emulsions of physiological saline.

Bergey et al. (1923, p. 44) include this as the second genus of the Streptococceae and follow the Committee's description.

It would appear that Diplococcus Weichselbaum is a valid generic name for the pneumococcus and the related forms, if they are worthy of generic recognition. If the gonococcus and its relatives are to be included in the same genus, the name Neisseria Trevisan should be used.

Diplokokken. Baumgarten (1890. p. 127) states: "1 Untergattung: Diplokokken; die Zellen bleiben nach der Theiling zu je zweien im Zusammenhang."

Diplokokkus. An aberrant form of spelling of Diplococcus used by certain German authors, as Baumgarten (1890, p. 127), Klebs (1887, p. 321).

Diplopneumococcus. A casual name used by Krokiewicz (1904).

Diplostreptococcus. A generic name used by Lingelsheim (1912, p. 494) in a discussion of "Brustseuche der Pferde." He states, "Als erreger hat man längere Zeit, den von Schütz (1887, p. 27) zuerst gefundenen Diplostreptococcus pleuropneumoniae der sich vielfach in den Krankheitherden findet angesehen." This reference to Schütz as an authority for this generic name is erroneous as a careful search of the 
text fails to show, by this author, any use of the name, Diplostreptococcus pleuropnermoniae.

It is possible that it has been used previously to the article by Lingelsheim. It does not appear that this organism is sufficiently distinct from other streptococci to warrant separate generic recognition.

This name has also been used as a casual designation for the lactic organism of the fermented milk. "Yoghurt," by Luerssen and Kühn (1908, p. 241). It was not used, however, as a generic name.

This designation has also been used by Bettencourt and others for streptococci showing diploid elements when taken from cerebrospinal fluid $(1904$, p. 55). Perrone $(1905$, p. 371) mentions a Diplostreptococcus intestinatis of Tavel.

Diplovibrio. A name given by Maggi (1886, p. 176) to a growth form of Vibrio.

It has also been used by Billet (1890, p. 23).

A casual name.

Discomices. Apparently a typographical error for Discomyces q.v. Migula (1900, p. 116).

Discomyces. A generic name proposed by Rivolta (1878, p. 208) to replace Actinomyces Harz, which he regarded as inept. Rivolta and Micellone (1879, p. 145) used the name Discomyces equi to designate the organism causing socalled "botryomycosis" of the horse. Later Rivolta (1884, p. 198) also described a species Discomyces pleuriticus from the dog. This genus was at first regarded by Rivolta as identical with Actinomyces Harz, but later both genera were recognized as is evident from the following statement by Rivolta (1884, p. 188):

Discomyces. Il micelio di questo fungo é fatto da grandicellule otricellari granulose.

Differisce dall actinomyces bovis Harz per la grandezza e disposizione degli elementi che lo constituiscono e per la struttura piú semplice.

Esaminando questa specie, il Prof. Harz si convincera come non possa venir confusa con l'actinomyces bovis perché ha nulla di raggiato. E fatto da grandi cellule e non da filamenti. Le si conviene adunque il nome di discomyces equi.

Si puo pertanto founare un gruppo di discomiceti patogeni compredente le seguenti specie.

I. L'actinomyces bovis Harz. Sin. Corpuscoli o cespugli discoidi Rivolta, colle due varieta: Actinomice granuloso e Actinomice degli ascessi.

II. Il. Discomyces pleuriticus canis familiaris.

III. Il. Discomyces equi. Rivolta e Micellone.

Discomyces Rivolta is listed as a synonym of the genus Nocardia Trevisan, by De Toni and Trevisan (1889, p. 927) although the two 
species of Rivolta are not included here, but under Bollingera Trevisan (p. 1039) as Bollingera equi Trev. and B. Vacchetae Trevisan.

This generic name has generally been disregarded because of confu-. sion with the Discomycetes among the sac bearing fungi, because of the priority of other generic names and because of the lack of a careful characterization of the organisms. The species described as Discomyces equi is generally regarded as a capsulated coccus and not a filamentous form related to Actinomyces at all.

Blanchard (1895) came to the conclusion that the older generic name Actinomyces was invalid because of its prior use to designate an unrelated fungus, and proposed the use of Discomyces to replace it. In this proposal he has been followed by Brumpt (1910, p. 842).

Discomyces is definitely rejected by Smith (1905, p. 174) and by Vuillemin (1913, p. 527).

Merrill and Wade (1919, p. 64) review the status of this name very completely, and conclude that it is the valid designation. They say:

Vuillemin, and more recently Chalmers and Christopherson, in advocating Nocardia as the valid generic name, hold that Rivolta's use of Discomyces was trivial and without botanical significance. We do not agree with this argument, which is clearly refuted by Rivolta's original paper. Here he distinctly proposes Discomyces bovis as the name for the organism called Actinomyces bovis by Harz in a manner that must be acknowledged as valid from the viewpoint of botany, even though it is not in conventional form and was advocated on irrelevant, inadequate grounds. Therefore, it is in no sense a "medical genus," as Vuillemin asserts. The fact that subsequently Rivolta erroneously referred other organisms to this genus has no bearing on the case. His original application of it was to the organism of Bollinger and Harz alone, which is, therefore, the type of the genus. Nor does the fact that to propitiate Harz, Rivolta later agreed to accept Actinomyces affect the question. As Blanchard pointed out, a name once introduced is no longer the property of its originator to withdraw or modify at will.

Finally, to argue, as do Chalmers and Christopherson, that Discomycetaceae, a group name, invalidates Discomyces, as a generic name in the connection in which Rivolta used it, on the ground that the type genus of Fries's Discomycetaceae, published in 1836, should bear the designation Discomyces, indicates an erroneous conception of the principles of nomenclature and priority in technical names; a family name such as Discomycetaceae cannot invalidate a similar specific name. This generic name was new with Rivolta, and there is no valid objection to its adoption in taxonomy.

For reasons for the invalidity of Discomyces see Actinomyces.

In the present work Discomyces is regarded as a synonym of Actinomyces. 
Dispora. A generic name proposed by $\operatorname{Kern}(1882$, p. 135) in a preliminary note for a rod-shaped organism found by him in kefir grains and regarded by him as the organism causing the development of the lactic acid. In a later contribution (1882, p. 141) he described the organism in greater detail.

The organism in the kefir grains occurs in the form of zoogloeal masses associated with a yeast. The vegetative cells when in active growth are described as 3.2 to $8 \mu$ in length by $0.8 \mu$ in diameter. Under the influence of acids, of high temperatures, etc., the cells become Leptothrix-like and filamentous. These filaments ordinarily contain spores. The vegetative cells may be motile, when they are supplied at one end with a slender flagellum. The spores are spherical, and are always found in pairs, each cell producing two spores, one in each end. The spores are not large enough to cause any distortion of the cell. Within the cells the spores are apparently $0.8 \mu$ in diameter, when free $1 \mu$. In the Leptothrix forms the spores appear to be in rows. Careful examination, however, shows them to occur always in pairs within separate cells. In germination an exo- and endosporium are recognizable.

Kern states that in the vegetative condition this organism resembles Bacillus subtitis Cohn, but that the presence of two spores in a cell is an adequate generic differential character.

The generic name Dispora is accepted and used by Maggi (1886, p. 176).

De Toni and Trevisan (1889, p. 1015) included this form in the genus Pacinia under the name $P$. caucasica (Kern) Trevisan. Cornil and Babes (1890, p. 183) recognized the genus by describing the species $D$. caucasica. The genus has in general not been recognized by recent writers. Either Kern worked with an organism which has not been since recognized, or he grossly misinterpreted what he saw. Certainly the organism now regarded as the most important in Kefir manufacture does not conform to the description given by Kern.

If the organism commonly called Bacillus bulgaricus, B. caucasicus or $B$. lebenis is to be made the type of a genus, it is important to determine the status of the generic name Dispora. If Kern misinterpreted what he saw, and in reality named the high-acid bacillus of Kefir Dispora, the name, in spite of its lack of appropriateness would appear to be valid. If, however, as seems probable, Kern was describing not the causal organism of Fiefir but some other, the name can be rejected for this purpose. Inasmuch as the organism described by Kern has 
not been later recognized, the name Dispora may be regarded as a nomen nudum, or possibly as a synonym of Bacillus Cohn. It is rejeeted by Erwin F. Smith (1905, p. 174) and by Vuillemin (1913, p. 520).

Douglasillus. The fourth genus of the subfamily Clostridioideae proposed by Heller (1922, p. 14) with the following description:

Clostridioideae that do not liquefy gelatin. They produce little gas in meat medium. They may not clot milk. Gram-negative bacilli which are frequently fusiform, and may show peculiar involution forms. Spherical spores are formed in the bacilli; the rods are usually widened by the spores so that their sides are not parallel. Young spores may not be truly spherical. Occasionally found in moulds. Probably incapable of invading tissue.

Type species sphenoides (Bacillus sphenoides Douglas, Fleming and Colebrook), as described by the Committee (p. 43): the type which ferments glucose, maltose, galactose, lactose, salicin, mannitol, sucrose, dextrin and starch.

Drepanospira. A generic name used by Boris de Petschenko (1911, p. 249) to designate a species of bacterium, Drepanospira Mülleri found to be parasitic within the bodies of paramoecia, and having a relatively complex life cyele. Enlows (1902, p. 39) is apparently in error in writing Drepanospora. She states:

Order Eubacteria, fam. Spirillaceae occupying an intermediate place between Spirosoma Migula and Microspira Schröter. Cells with 2 spirals, one end pointed, the other somewhat rounded. No cilia or flagella. Helicoidal motion. "Pas de division cellulaire." Endospores. Regular spherical colonies formed by the individuals in certain stages of development. Measure $7 \mu$ long by $0.75 \mu$ wide. Cell membrane visible on the living cell. In the vegetative state protoplasm composed of an anterior, smaller, strongly refractive part, and a larger posterior or dull part. The anterior portion he considers to be nuclear.

Dysenteroides. The fourth genus of the tribe Ebertheae proposed by Castellani and Chalmers (1919, p. 934). The description (p. 938) is as follows:

Definition. Ebertheae fermenting glucose and lactose partially, with the production of acid, but no gas. Milk not clotted.

Type Species. Dysenteroides metadysentericus (Castellani, 1917).

Ebertheae. The ninth tribe of the family Bacillaceae proposed by Castellani and Chalmers (1919, p. 932). The description given follows:

Bacillaceae growing well on ordinary laboratory media; not forming endospores, aerobes, and often facultative anaerobes; without fluorescence, pigment 
formation, or gelatine liquefaction; without polar staining; Gram-negative, without a capsule.

Type Genus. Eberthus Castellani and Chalmers, 1918.

Ten genera are included, Alcaligenes, Eberthus, Shigella, Dysenteroides, Lankoides, Salmonella, Balkanella, Wesenbergus, Enteroides and Escherichia.

Eberthella. A subgenus of Bacterium proposed by Buchanan (1918, p. 53) to include those forms "Not producing gas from any of the carbohydrates, acid may or may not be formed." The type species is designated as Bacterium (Eberthella) typhi. Flügge.

Bergey et al. (1923, p. 221) erected Eberthella into a genus, erroneously ascribing the name to Castellani and Chalmers. Possibly this is a misprint for the generic name Eberthus used by Castellani and Chalmers for the same group. It is included as the fifth genus of the tribe Bactereae with the following description:

Motile or non-motile rods, occurring in the intestinal canal of man, usually in different forms of enteric inflammation. Attack a number of carbohydrates with the formation of acid but no gas. Do not form acetyl-methyl-carbinol

The type species is Eberthella typhi (Eberth-Gaffky) Castellani and Chalmers.

Eberthus. The second genus of the tribe Ebertheae named by Castellani and Chalmers (1919, p. 934). The description (p. 936) follows:

Bacillaceae motile, partially fermenting glucose with the production of acid and no gas. Lactose not fermented. Milk not clotted.

Type Species. Eberthus typhosus (Zopf, 1885).

Later (1920, p. 604) four species are described.

Eccrina. A generic name proposed by Leidy (1851, p. 35) for an entophyte with "Characters same as Enterobryus, except that it divided into numerous cells at the free extremity." Two species were described, Eccrina longa from the mucous membrane of the intestine of Polydesmus virginiensis, and Eccrina moniliforma from Polydesmus granulatus.

Leidy (1851, p. 29) later described the genus as follows:

Thallus attached, consisting of a single very long tubular cell, filled with granules and globules, producing at its free extremity a succession of numerous globular or oblong cells, and growing at the other end from a relatively short, cylindroid, amorphous coriaceous pedicle, commencing with a discoidal surface of attachment. 
The description given for $E$. longa is as follows:

Thallus long, filiform, colorless, or brownish, transparent, cylindrical, usually not holding a constant relation of breadth to the length, forming a simple curve or single spiral turn, and then proceeding in a straight line or gently flexuose curve to the free extremity. Pedicle very short, columnar, expanded at the base. Principal cell very long, uniformly cylindrical. Secondary cells in various stages of development from ten to thirty in number, oblong, or short cylindrical, with obtusely rounded extremities when completed.

Whole length from 2 to 7 lines. Length of pedicle $\frac{x}{3000}$ to $\frac{1}{15^{2}} 00$ of an inch. Breadth of principal cell, from $\frac{1}{200}$ to the $5^{\frac{1}{1}}$ of an inch. Length of secondary cells, from the $\frac{1}{2} 5$ to the $\frac{1}{5} 50$ of an inch.

Habitation. Parasitic, growing in profusion from the mucous membrane of the posterior part of the intestinal canal of Polydesmus virginiensis.

The generic name is probably valid, but it is questionable whether the organism belongs with the bacteria.

Eiterbacterium. A casual designation used by Küttner (1895, p. 263) for his Pyobacterium fischeri.

Eitercoccus. A casual name used by German writers as a designation for pus coccus. (Rosenbach 1884, p. 23.)

Encapsulateae. The name proposed by Castellani and Chalmers (1919, p. 932) for the ninth tribe of the family Bacillaceae. The description $(1919$, p. 934$)$ is as follows:

Bacillaceae growing well on ordinary laboratory media, without endospores; neither fluorescent nor chromogenic aerobes, not liquefying gelatin, possessing capsules in animal tissues.

Type Genus. Encapsulatus Castellani and Chalmers, 1918.

One genus only, Encapsulatus, is included.

Bergey et al. (1923, p. 237) recognize Encapsulateae as the seventh tribe of the family Bacteriaceae with the following description:

Short rods, somewhat plump with rounded ends, mostly occurring singly. Encapsulated. Non-motile. Gram-negative. Ferment a number of carbohydrates with the formation of acid and gas. Encountered principally in the respiratory tract of man. Aerobic, growing well on ordinary culture media.

This probably should yield priority to Klebsielleae q.v.

Encapsulatus. The only genus of the tribe Encapsulateae proposed by Castellani and Chalmers (1919, p. 934) with the description:

Encapsulateae with the tribal characters.

Type Species. Encapsulatus pneumoniae (Friedlaender, 1883). 
Later (1920, p. 602) the following statement is made:

Ce genre est actuellement le seul de la tribu, et il embrasse l'ancien groupe des bacilles encapsulés qui ont été passés en revue par Fricke en 1896, Clairmone en 1902, Perkins en 1904, Abel et Kallwacks en 1912 et Fitzgerald en 1914.

Les espèces sont ordinairement des organismes courts, non mobiles, gramnégatifs, encapsulés, pléomorphiques, qui font fermenter le glucose et le lactose; mais en ce qui concerne ce dernier sucre, ils peuvent produire seulement de l'acidité quoique habituellement ils forment de l'acide et du gaz.

Bergey et al. recognize this as the single genus of the tribe Encapsulateae.

Apparently Encapulatus must yield priority to Klebsiella q.v. for both are based upon the same type species.

Endobacterium. Lehmann and Neumann $(1896$, p. 103) in a discussion of Bacillus state: "Den uns besonders geeignet erscheinenden Namen 'Endobacterium' unterdrücken wir, um nicht weitere neue Namen zu benützen."

Endostreptococcus. A name proposed by Hueppe (1885) for organisms having spherical cells in chains, producing endospores, zoogloea not formed. Apparently this has never been coupled with a species name, and is a "nomen nudum."

Endostreptokokkus. A German variant of Endostreptococcus q.v. used by Hueppe (1891, p. 33).

Enterobrus. A genus of organisms described by Leidy (1849, p. 225) to include certain parasitic organisms found in the intestines of milliped Julus and the beetle Passalus. Leidy regarded it as a genus of Confervaceae. The original description reads:

Simple, attached, isolated filaments consisting of a long cylindrical cell (containing protoplasm, granules, and large translucent globules enveloped in a primordial utricle) with a distinct coriaceous peduncle or stripe of attachment, and at length producing at the free extremity one or two, rarely three, shorter cylindrical cells, (filled with the same matter as the parent cell).

The first species described was Enterobrus elegans from the intestine of Julus marginatus. Later (1848, p. 249) he described Enterobrus spiralis from Julus pusillus and Enterobrus attenuatus from Passalus cornutus.

Later Leidy published revised descriptions with drawings of these various species (1851, p. 19-20). The revised description reads as follows:

Thallus attached, consisting of a single, very long, tubular cell, filled with granules and globules, producing at its free extremity one, usually two, rarely 
three, shorter tubular cells, and growing at the other end from a relatively short, cylindroid, amorphous, coriaceous pedicle, commencing with a discoidal surface of attachment.

There is doubt as to whether the organism described and figured so carefully by Leidy should be placed with the bacteria. In many of its characteristics it seems to approach certain forms of the fungi.

It should be noted that in the last mentioned publication of Leidy (1851, p. 19-20) the generic name is spelled Enterobryus.

E.nterobryus. A spelling of the generic name Enterobrus used by Leidy (1851, p. 19).

Enterococcus. A casual name given by various writers to cocci found in the intestinal tract. Apparently it was first used by Thiercelin (1898) in the form Enterocoque. Tissier (1900, p. 65) pointed out that his organism is apparently identical with the Micrococcus ovalis of Escherich (1886). Tissier at this time gave a fairly complete description of the organism. It was also studied by Höllig (1904, p. 11). According to Tissier (1905, p. 114) Enterococcus produces an acid fermentation in glucose, saccharose and lactose. Rougentzoff (1914, p. 648) discusses an Enterococcus saccharomyces from the intestines of the rabbit.

Enterocoque. A casual name used by Thiercelin (1899) and Tissier (1899, p. 65) for Enterococcus (q.v.) the Micrococcus ovalis of Escherich.

Enteroides. A name given to the ninth genus of the tribe Ebertheae by Castellani and Chalmers $(1919$, p. 935) with the description:

Ebertheae which ferment glucose and lactose completely with the production of acid and gas. Milk not clotted.

Type Species. Enteroides entericus (Castellani, 1907).

These authors name five species (1920, p. 618).

Erebonema. Cohn $(1883$, p. 198) gives the fcllowing account of this genus:

Römer (Deutschlands Algen, S. 70) hat in den tiefen Gruben bei Clausthal im Harz Schleimüberzüge gefunden, die von locker verwebten, gegliederten, farblosen Fäden durchzogen waren. Er beschrieb sie unter dem Namen Erebonema und unterschied nach der Dicke und Gruppirung der Fäden zwei Arten, E. hercynicum und E. divaricatum. F. T. Kützing, welcher Römer'sche Exemplar untersuchte, hat (Species Algarum 1849, S. 157) die Gattung dahin charakterisirt: deutlich gegliederte, sehr locker verwebte, farblose, verzweigte Fäden, $z w$ ischen einer schleimiggallertartigen, aus sehr kleinen schleimigen Kügelchen zusammengesetzter Grundmasse nistend; Glieder hohl, schlaff letzte Verzweigungen erweit- 
ert. Kützing hat also die Fäden in der Gallert für die Hauptsache, die Coccen, die er gleichwohl schon auffand und in seinen Tabulae phycologicae abbildete, für nebensächlich gehalten.

Professor Ferinand Cohn untersuchte im Jahre 1857 eine röthlichgelbe Gallert, welche in einer 60 Lachter tiefen Grube bei Volpersdorf gefunden worden war. Ihr Aussehen war ganz so, wie ich es bei dem Kellerschleim gefunden, sie hing auch hier von dem Gestein als Zapfen herab. Professor Cohn erklärte den Schleim für identisch mit Erebonema hercynicum Kig. und fand in ihm Fäden, ähnlich wie sie Kützing beschreibt, nur waren sie nicht, wie dieser angiebt, an den Enden angeschwollen, sie stimmten also mit den Fäden des Kellerschleims überein. Zwischen den Fäden, welche Cohn für eine Leptomitusartige Alge erklärte, lagerten in structurloser Gallert zahllose ovalstäbchenförmige, farblose Körperchen dicht nebeneinander, so dass sie den Bau einer Palmella darboten. Er stellte es bereits als zweifelhaft hin, ob die Fäden wirklich zum Begriff der Species gehörten oder nur zufällig in der Palmella als Parasiten existiren, und neigte sich der letzteren Ansicht zu.

\section{Schroeter (1883) termed the organism Leucocystis cellaris.}

This latter name is also accepted by De Toni and Trevisan (1889, p. 1041). The name Erebonema is rejected by Erwin F. Smith (1905, p. 174).

Ermengillus. A genus of anaerobic bacteria proposed by Heller (1922, p. 28). It is the twenty-fourth genus of the family Clostridiaceae, and is included in the subfamily Putrificoideae. The description is:

Putrificoideae that produce a yellowish coloration in meat medium, and later blacken and digest it. They are more highly proteolytic than the organisms of the foregoing genera. They ferment various sugars. Gram-positive rods which form sub-terminal oval spores. Their colonies in deep agar, are, when discrete, lenticular or kidney shaped, and may show tufted smooth or woolly polar projections and infrequently fine loose woolly radiations. Fairly common in soil, grow readily in vegetable material and on meat. Form a characteristic and powerful neuro-toxin.

Type species E. botulinus (Bacillus botulinus von Ermengen) as described by K. F. Meyer and co-workers in a future paper.

Erwineae. A tribe named by Winslow et al. (Committee, Soc. Am. Bact., 1920, p. 209) as the second in the family Bacteriaceae, with the following description: "Plant pathogens. Growth usually whitish, often slimy. Indol generally not produced. Acid usually formed in certain carbohydrate media, but as a rule no gas."

The single genus is Erwinia.

Bergey et al. (1923, p. 168) have used the variant spelling Erwiniae. Probably the spelling should be Erwinieae. 
Erwinia. A generic name proposed by Winslow et al. (Committee Soc. Am. Bact., 1917, p. 560) with the following description: "Plant pathogens. Growth usually whitish, often slimy. Indol generally not produced. Acid usually formed in certain carbohydrate media, but as a rule no gas."

Later $(1920$, p. 209) it was included as the single genus of the tribe Erwineae, and the type species designated as Erwinia amyiocora (Burrill) Committee.

Bergey et al. (1923, p. 168) follow the committee in placing the genus in the tribe "Erwiniae" with the following description: "Motile rods, possessing peritrichous flagella. The rods are white and few species form pigment."

Erwiniae. A variant spelling of Erwinieae or Erwineae q.v. used by Bergey et al. (1923, p. 168). It is included as the fourth tribe of the family Bacteriaceae with the following description:

Plant pathogens. Growth usually whitish, often slimy. Indol generally not produced. Acids usually formed in carbohydrate media, forming acid or acid and gas. Motile, or non-motile. Gram-negative.

Erysipelcoccus. A casual designation apparently first used by Bender (1888, p. 10) for Erysipelkokken of Fehleisen. Enlows states:

This name has been ascribed by numerous authors to Fehleisen. In Sitz. d. Phys.-Med. Gesellsch. z. Würz., 1881-1885, p. 126 (1881) and p. 9 (18S3), he described a micrococcus "der Mikrokokkus des Erysipels." In his second paper he uses in the title of the paper the word "Erysipelkokken," but in the text he uses "nuikrokokken."

Erysipelococcus. Enlows (1920, p. 41) states this is found in Lipp. Med. Dict. Phil., 1920, p. 322., syn. Streptococcus erysipelatis.

Erysipelothrix. A generic name proposed by Rosenbach (1909, p. 367 ) to include the causal organisms of swine erysipelas, human erysipeloid and mouse sepsis. As characters differentiating this genus from Bacillus are noted the formation of long filaments and the regular development of branches, the thickening of the filaments with the characteristic granules. The species named are Erysipelothrix porci, $E$. erysipeloides and $E$. murisepticus.

Buchanan (1918, p. 55) included this as the ninth genus of the family Bacteriaceae with the following description:

Rod-shaped organisms with a tendency to the formation of long filaments which may show branching. The filaments may also thicken and show charac- 
teristic granules. No spores. Non-motile. Gram-positive. Does not produce acid. Microaërophilic. Uusally parasitic.

The type species is Erysipelothrix rhusiopathiae (E. porci), the causal organism of swine erysipelas.

Winslow et al. (Committee Soc. Am. Bact., 1920, p. 198) emended the diagnosis as follows:

Rod-shaped organisms with a tendency to the formation of long filaments which may show branching. The filaments may also thicken and show characteristic granules. No spores. Non-motile. Gram-positive. Do not produce acid. Microaerophilic. Usually parasitic.

The type species is Erysipelothrix rhusiopathiae (Bacillus rhusiopathiae suis Kitt 1893; Mycobacterium rhusiopathiae Chester 1901; Erysipelothrix porci Rosenbach 1909), the causal organism of swine erysipelas.

Bergey et al. (1923, p. 371) follow the Committee and include the genus as the fourth in the family Actinomycetaceae.

Erythrobacillus. A generic name used by Fortineau (1905, p. 104) for an organism, Erythrobacillus pyosepticus. This species is described as a motile coccobacillus, but without flagella, without spores, staining readily and gram negative. In culture it grew well at $37^{\circ}$ but showed pigment development best at $19^{\circ}$ to $22^{\circ}$. In bouillon a distinct clouding developed, and a delicate rose colored film. On agar a vermillion mucus-like layer formed. Serum and gelatin were both liquefied. In Uschinsky solution there was growth but no pigment production. Ammonia, hydrogen sulphid and indol were formed, nitrates reduced and sugar fermented feebly. Pigment was produced only in presence of air. It was soluble in water, alcohol, slightly soluble in chloroform and insoluble in ether, carbon disulphid and benzine, and decolorized by alkalies.

Winslow et al. (Committee Soc. Am. Bact., 1920, p. 209) recognizes this genus with the following diagnosis:

Small aerobic bacteria, producing a red or pink pigment, usually a lipochrome. Gram stain variable. It is possible that related yellow and orange chromogens should be included here as well.

Type species, Erythrobacillus prodigiosus (Ehrenberg) Committee.

It is probable that the committee's designation of $E$. prodigiosus is not valid, as this species was not mentioned by Fortineau. The type is E. pyosepticus. Enlows (1920, p. 41) states:

Type species (monotypy). E. pyosepticus. A motile "coco-bacille," with no spores; flagella; Gram-negative; grows at $37^{\circ} \mathrm{C}$., red pigment forms best at $19^{\circ}$ 
to $22^{\circ} \mathrm{C}$. Pigments soluble in water, the alcohols, slightly so in chloroform, and insoluble in ether, carbon bisulphide, benzine. Pathogenic for the guinea pig, etc. Isolated from the chemise of a patient at the Hotel-Dieu, Nantes.

It is not probable that this name is to be regarded as a valid generic name, although it is possible that it might be used for the red bacilli if they are to be accorded generic recognition providing Serratia and Zaoglactina are invalid. It is rejected by Erwin F. Smith (1905, p. 174).

Erythroconis. A generic name proposed by Oersted (1840, p. 555) for an organism described by him from the Danish coast. The description given is "Character genericus. Massa pulveracea parum mucosa ex corpusculis quadratis rigidis fragilibus per quaterna aggregates constans. Genus e familia Diatomerarum analogon Palmellae et Tetrasporae."

His species, Erythroconis littoralis is described by Rabenhorst (1865, p. 57) as follows: "Thallo mucoso-grumoso indefinito olivascente familiis minimis e cellulis cubico-polygonisi 32 compositis; cytioplasmate aerugineo-viridi. Diam. cell. circ. $1 / 300^{\prime \prime \prime}=0.00029 . "$ This later author regards Erythroconis as a subgenus of Merismopedia Meyen among the blue green algae, with the characterization "Species in aqua natantes vel in limo nascentes," and including with it all those species not belonging to "Sarcina medicorum."

Winter (1884, p. 50) uses the name Sarcina littoralis with the following description:

Zellen kuglig order vor der Theilung oval, $1.2 \mu$, selten 2 oder mehr $\mu$ in Durchmesser, zu 4, 6, 8, etc., zu Familien verbunden, die ihresseits grössere Colonien (bis zu 64 Tetraden in einer Colonie) bilden. Plasma farblos, aber in jeder Zelle 1-4 rothe Schwefelkörner. In faulenden Meerwasser.

De Toni and Trevisan (1889, p. 1049) regarded this generic name as a synonym of Lampropedia Schroeter, though this latter author did not include Oersted's species.

Migula (1900, p. 1045) regards Erythroconis littoralis Oerstedt as a doubtful synonym of Thiopedia rosea Winogradsky.

The genus is rejected as invalid by Erwin F. Smith (1905, p. 174).

The type species is Eruthroconis littoralis Oersted. 
Escherichia. A name given to the tenth genus of the tribe Ebertheae by Castellani and Chalmers (1919, p. 935). The description (p. 941) follows:

Ebertheae which ferment glucose and lactose completely; milk clotted.

Type Species. Escherichia coli (Escherich, 1886).

Some 16 species (1920, p. 619) are listed.

Bergey et al. (1923, p. 194) includes Escherichia as the first genus of the tribe Bactereae with the following description:

Motile or non-motile rods, commonly occurring in the intestinal canal of normal animals. Attack numerous carbohydrates forming acid and frequently acid and gas. Do not produce acetyl-methyl-carbinol.

The type species is Escherichia coli (Escherich) Castellani and Chalmers.

Eu-Ascococceae. A name given by De Toni and Trevisan (1889, p. 1035) to a subtribe of the tribe Ascococceae, with the following diagnosis: "Subtribus I. Eu-Ascococceae: Cocci in muco matricali segregati, in familias cystidibus universalibus obductas cumulati. Cystides speciales nullae." It contains seven genera: Lamprocystis Schröter, Ascococcus Cohn, Bollingera Trevisan, Leucocystis Schröter, Cenomesia Trevisan, Thiothece Winogradsky, Thiocystis Winogradsky.

This name does not appear to have been used by other investigators.

Eubacilleae. The third subtribe of the tribe Bacilleae proposed by De Toni and Trevisan (1889, p. 939) with the following diagnosis: "Baculi (divisione semper in unam directionem transversalem) liberi, numquam spiraliter torti, Endosporae." Ten genera are noted: Mantegazzea Trevisan, Bacillus Cohn, Pasteurella Trevisan, Cornilia Trevisan, Clostridium Prazmowsky, Vibrio Zopf, Spirillum Ehrenberg, Spiromonas Perty, Pacinia Trevisan, Bacterium Ehrenberg.

Eubacillus. This name was first used by Hansgirg (1888, p. 264) for the first section of the genus Bacillus with the following diagnosis: "Zellen mit farblosen, feinkörnigen Plasma. ohne grössere Schwefelkörnchen, zu farblosen oder grau-bis gelblich-braunlichen Schleimmassen (Zoogloeen) vereinigt." B. subtilis was included in this section.

A genus of green bacteria proposed by Dangeard (1891, p. 151) was also given this name. This genus was created to include those organisms, rod-shaped in form, or variable length, with hyaline protoplasm, containing no granules and with a small amount of chlorophyll in the protoplasm, spore bearing filament may be simple or branched, the green color more pronounced in the swellings, spores 
formed by the contraction of the protoplasm of the swellings; spores refringent, grouped or isolated, separated from each other by septa. The genus is divided into two sections, the first containing the type species, Eubacillus multisporus Dangeard. This organism is made up of filaments which are simple, long, and slender and of a faint green color. The spore bearing filaments are likewise quite long, producing the numerous spores isolated or grouped in pairs, threes, fours, separated by septa. Spores are elliptical in shape and of a decided green color with one or two refringent granules. Length of spores: 5 to $8 \mu$, width: $3 \mu$. Habitat: Developing in cultures of algae from fresh water.

In the second section, the author includes five species of bacteria which have been described by Kline, all of which are green in color.

Lehmann and Neumann (1896, p. 11) question the ascription of this genus to the bacteria. Migula (1897, p. 94) concludes that the organisms described under this name by Dangeard do not belong to the bacteria, both because the spore bearing filaments of his Eubacillus multisporus were branched at times and because of the formation of spores in chains which is not characteristic of bacteria.

Meyer $(1912$, p. 2) uses the name Eubacillus for the third section of the genus Bacillus with the statement: "Enthält alle übrigen Spezies der Gattung, auch die, für welche Sporangienbildung nicht gesehen wurde."

Doubt as to the generic validity of Eubacillus Dangeard is raised by the previous use of the term by Hansgirg, in practically a subgeneric sense. There is also some reasonable doubt as to whether Dangeard's organism belongs with the bacteria.

Eu-Bacillus. A subgenus of Bacillus proposed by Buchanan (1918, p. 38). A variant of Eubacillus Hansgirg. The description follows:

Motile, usually by means of peritrichous flagella. Spores not barrel-shaped without longitudinal ridges. Other characters those of the genus.

The type species of the subgenus is Bacillus subtilis Cohn.

Eubacteria. The fifth order of bacteria recognized by Schröter (1886, p. 154) with the following diagnosis:

Vegetative Zellen kürzer oder länger stäbchenförmig, ruhend oder bewegt, frei oder in Schleim eingebettet. Häufig wachsen sie in lange Fäden aus, welch aus einzelnen Gliedern bestehen, die bei der Sporenbildung wieder durch schärfere Theilung deutlich werden; sie zeigen keine deutliche gemeinsame Scheiden. Sporen meist einzeln innerhalb der Zellen gebildet und deren Raum nicht ganz 
ausfüllend, seltener aus dem Inhalte eines Gliedes derart gebildet, dasz die Spore diesem an Grösse gleichkommt oder dasselbe übertrifft.

There are included in this order the single family Bacteriaceae Zopf, and nine genera, namely: Bacterium Ehrenberg, Chromatium Perty, Bacillus Cohn, Clostridium Prazmowsky, Spirillum Ehrenberg, Spirochaete Ehrenberg, Microspira Schröter, Myconostoc Cohn, Cystobacter Schröter.

Hansgirg (1888, p. 264) used this as the designation of his second order of Bacteria, containing the two families Bacleriaceae and Myconostocaceae. The name was adopted by Migula (1900, p. 1) for his first order of Bacteria with the following diagnosis: "Zellen ohne Centralkörper, Schwefel und Bacteriopurpurin, farblos oder schwach gefärbt, chlorophyllgrün." He divides the order into four families: Coccaceae, Bacteriaceae, Spirillaceae, Chlamydobacteriaceae.

This name has been used in a similar sense by Erwin F. Smith (1905, p. 159) Frost (1911, p. 56), and Meyer (1912, p. 1).

Eubacteriaceae. A spelling of the order Eubacteria used by A. J. Smith (1902, p. 270). This name is not in the correct form for the designation of an order.

Eubacteriales. An ordinal name apparently first proposed by Buchanan (1917, p. 347) for the first order of the Schizomycetes. Following is the description used:

This order includes the true bacteria, those forms which are least differentiated and least specialized. The cells are usually minute, spherical, rodshaped or spiral, not typically producing true filaments although the cells may occur in chains or other groups. The cells do not have a well-organized or differentiated nucleus. They may be motile by means of flagella, or non-motile, never notably flexuous. Multiplication by transverse fission, never by longitudinal. Some forms, particularly rod-shaped types, produce endospores, but never conidia. Branching of cells occurs in a few forms which intergrade with the Actinomycetales. Neither sulphur granules nor bacteriopurpurin are present, though the cells may be pigmented. Chlorophyll is absent (with the possible exception of one genus). The cells may be united into gelatinous masses, but never form motile pseudoplasmodia, nor develop a highly specialized cyst-producing fruiting stage.

Four families were included: Coccaceae, Bacteriaceae, Spirillaceae and Nitrobacteriaceae.

The description was emended by Winslow et al. $(1917$, p. 550) as follows:

The order Eubacteriales includes the forms usually termed the true bacteria, that is, those forms which are considered least differentiated and least specialized. 
The cell metabolism is not primarily bound up with hydrogen sulphide or other sulfur compounds, the cells in consequence containing neither sulfur granules nor bacterio-purpurin. The cells apparently do not possess a well-organized or welldifferentiated nucleus. The cells are usually minute and spherical, rod-shaped or spiral in shape, in most genera not producing true filaments; the filaments when formed not sheathed, and frequently branching, thus being differentiated from the iron bacteria. The cells may occur singly, in chains or other groupings. The cells may be motile by means of flagella, or non-motile; they are never notably flexuous. Cell multiplication occurs always by transverse, never by longitudinal fission. Some genera produce endospores, particularly the rod-shaped types. . . . Chlorophyll is absent, though the cells may be pigmented. The cells may be united into gelatinous masses, but never form motile pseudo-plasmodia nor develop a highly specialized cyst-producing fruiting stage, such as is characteristic of the Myxobacteriales.

Castellani and Chalmers (1919, p. 924) use the simple definition, "Schizomycetes which contain neither sulphur nor bacterio-purpurin." They include five families, Coccaceae, Bacillaceae, Spirillaceae, Chlamydobacteriaceae and Mycobacteriaceae.

In the final revision Winslow et al. $(1920$, p. 200) emended the description as follows:

The order Eubacteriales includes the forms usually termed the true bacteria, that is, those forms which are considered least differentiated and least specialized. The cell metabolism is not primarily bound up with hydrogen sulphide or other sulphur compounds, the cells in consequence containing neither sulphur granules nor bacterio-purpurin. The cells apparently do not possess a well-organized or well-differentiated nucleus. These organisms are usually minute and spherical, rod-shaped or spiral, in most genera not producing true filaments; and rarely branching. The cells may occur singly, in chains or other groupings. They may be motile by means of flagella, or non-motile; but are never notably flexuous. Cell multiplication occurs always by transverse, never by longitudinal fission. Some genera produce endospores, particularly the rod-shaped types. Conidia not observed. Chlorophyll is absent, though the cells may be pigmented. The cells may be united into gelatinous masses, but never form motile pseudoplasmodia nor develop a highly specialized cyst-producing fruiting stage, such as is characteristic of the Myxobacteriales.

Heller (1921, p. 449) makes this the first order of the class "Eubacterieae," with the definition: "Eubacterieae whose cells are never in sheathed filaments. Conidia not observed. Free iron, sulphur, or bacteriopurpurin never present. Multiplication always occurs by transverse fission. (Committee.)"

Eubacterieae. A subtribe of bacteria proposed by Trevisan (1879, p. 136) with the following diagnosis: "Cellulae liberae vel in statu quiescente in colonias mucosas indeterminatas consociatae." It is 
the first subtribe of the tribe Bacterieae, and contains the genera Micrococcus and Bacterium.

Heller (1921, p. 449) has proposed Eubacterieae as a class name coördinate with Myxobacterieae in the phylum Bacteria. This spelling is not in correct form for a class name.

Eubeggiatoa. The first section of the genus Beggiatoa recognized by Hansgirg (1888, p. 263). He gives the following description: "Fäden farblos, zu kreideweissen bis graugelblichen schleimigen Massen vereinigt." Two species are listed, Beggiatoa alba (Vauch) Trev. and $B$. arachnoideae (Ag.) Rbh. var. uncinata Hansg.

Eucoccaceae. The second subfamily of the family Mycococcaceae described by Hansgirg (1888, p. 267) with the following description: "Zellen oder Zellfamilien ohne bestimmt begrenzte, Gallerthüllen, nackt oder von einer gemeinsamen Gallerte umgeben." One genus only, Micrococcus, is included.

Eucoccus. A subgenus of the genus Micrococcus Cohn created by Migula (1895, p. 16) to include those forms in which the cell contents are colorless and free from sulphur granules. The second section is Thiopolycoccus Winogradsky.

Eu-Cornilia. A subgenus of the genus Cornilia Trevisan established by De Toni and Trevisan $(1889$, p. 998) to include those species which are saprogenic and anaërobic. A variant of Eucornilia.

Eucornilia. The name applied by Trevisan (1889, p. 21) to the first subgenus of Cornilia. The second subgenus is Pleurospora. Altogether twelve species are listed, of which the first is Cornilia alvei Trev.

Eucrenothrix. A section of the genus Crenothrix suggested by Hansgirg (1891, p. 314) to include the fresh water forms of the genus with $C$. Kuhniana as the type. The other section for marine forms he terms Phragmidiothrix.

Eu-Klebsielleae. A subtribe of the tribe Klebsielleae created by De Toni and Trevisan (1889, p. 1028) with the following diagnosis: "Baculi recti vel curvi, numquam spiraliter torti." It contains three genera: Winogradskya Trevisan, Klebsiella Trevisan, Dicoccia Trevisan.

Eumantegazzaea. A subgenus of the genus Mantegazzaea created by De Toni and Trevisan $(1889$, p. 942$)$ to include three species which are colorless and do not contain granules of sulfur.

Eumicrospira. The name applied by Meyer (1912, p. 4) to the second section of the genus Microspira. He included in the section Rhodospira "Bakteriopurpurin enthaltende Species" and in Eumicrospira "Alle anderen Species." 
Eümonas. Enlows (1920, p. 42) states:

Eümonas: Diesing, 1S50. Systema Helminthum v. 1, Vindobonae, 1850, p. 22. Subgenus of Monas Müller and Ehrenberg. Diesing says Monas is synonymous with Bodo and Bacterium Ehrenberg. Eümonas: Animalcula solitaria libera, corpus ecaudatum, subglobosum, ovatum, v. obconicum, hyalinum v. coloratum, haud mutabile, divisione spontanea simplici bipartitum, v. indivisum. Os terminale truncatum, limbo ciliatum v. nudum. Flagellum nudum oscellus nullus. Includes 20 species: Monas (Eümonas) crepusculum Ehrenberg, $M$. (Eümonas) bicolor Ehrenberg, M. (Eümonas) ochracea Ehrenberg, M. (Eümonas) hyalina Ehrenberg, etc.

Eu-Pacinia. A subgenus of the genus Pacinia Trevisan named by De Toni and Trevisan (1889, p. 1019) to include those species which conform to the following diagnosis: "Baculi recti vel raro levissime curvuli, interdum in filamenta recta vel subrecta consociati, Arthrosporae magnae, quadruplooctuplo et ultra diametri transversalis baculorum latiores." Eleven species are included. It is interesting to note that Pacinia cholerae-asiaticae, the organism upon which the genus Pacinia was founded is not included in this subgenus; in other words, the type species of the genus is apparently regarded by $\mathrm{De}$ Toni and Trevisan (1889, p. 1018) as not typical of the genus. A variant of Eupacinia.

Eupacinia. The first subgenus of Pacinia (Trevisan 1889, p. 23). The description is "Filamenti normali di Bacillus." Nine species are included, but Pacinia cholerae-asiaticae is placed in the second subgenus Pseudospira.

Euplanococcus. A subgenus of the Planococcus created by Migula (1895, p. 19) to include those forms in which the cell contents are colorless and free from sulphur granules. The second subgenus is Thiopedia Winogradsky.

Euplanosarcina. A subgenus of the genus Planosarcina Migula created by Migula (1895, p. 20) to include those forms in which the cell contents are colorless and without sulphur granules. The other subgenera are Thiocystis Winogradsky and Lamprocystis Winogradsky.

Eupseudomonas. A subgenus of the genus Pseudomonas Migula proposed by Migula (1895, p. 29) to include those forms in which the cell contents are colorless and without sulphur granules. The second subgenus is Chromatium Perty.

Eusarcina. A subgenus of the genus Sarcina Goodsir proposed by Migula (1895, p. 18) to include forms in which the cell contents are colorless and free from sulphur granules. The second subgenus is Thiosarcina Winogradsky. 
Euspirillum. A name first proposed by Trevisan (1889, p. 24) for the first subgenus of Spirillum. The description is "Spirilli tipici, constantemente con forme a guisa di cavaturaccioli." Twenty-five species are included. The second subgenus is Pseudospirillum. This name was also used by Migula (1895, p. 33) for the first section under his genus Spirillum to include those forms in which the cell contents are colorless differentiating it from the second section, Thiospirillum Winogradsky.

Meyer (1912, p. 3) included in this section of the genus Spirillum all those species which contain no bacteriopurpurin and are motile.

Eu-Spirillum. A subgenus of the genus Spirillum proposed by De Toni and Trevisan (1889, p. 1009) with the following diagnosis: "Spirilli regulariter spirales, rigidi, abbreviata, spiris uniformibus." Twenty species are included, among them Spirillum undula, S. tenue and S. serpens. This is a variant of Euspirillum.

Euspirosoma. A subgenus of the genus Spirosoma created by Migula (1900, p. 955) to include those forms in which the cells are free, that is not embedded in gelatin. The second subgenus was Myconostoc.

Euvibrionieae. A subtribe of bacteria proposed by Trevisan (1879, p. 137) with the following description: "Somatia libera eramosa." It was included in the tribe Vibrionieae, and contained the following genera: Mantegazzaea, Metallacter, Leptotrichia, Beggiatoa, Crenothrix, Vibrio, Spirillum, Spirochaete, and Spiromonas.

Fenobacter. This name has been used by Beijerinck (1900, p. 200) as a generic designation of organisms belonging to the hay bacillus group. Apparently it has not been used by other authors. It may possibly be regarded as a synonym of Bacillus although the author emphasizes its relationship to Aerobacter. It is rejected as invalid by Erwin F. Smith (1905, p. 174).

Ferribacterium. A generic name proposed by Brussoff (1916, p. 547) for a species Ferribacterium duplex (the type). The summary of the characters which he gives follows:

1. Ferribacterium duplex ist ein unbewegliches, dunkel oder hellgelb gefärbtes Bacterium.

2. Es hat meistens die Form eines Doppelstäbchens mit abgerundeten Enden, erscheint aber auch in der Form von Stäbchen und kurzen Ketten.

3. Die Längen der Stäbchen mit dem Gallerthof schwankt zwischen ca. $2 \frac{1}{3}$ und $5 \mu$, die Breite ist ca. $1 \frac{1}{4} \mu$ gleich und ungefähr dieselbe bei allen Individuen.

4. In jungen Torf-Wasser-Kulturen und in allen, selbst in alten Eisenammoncitrat- und Eisenpepton-bouillonkulturen besteht jedes Individuum meistens aus drei Elementen: dem inneren Stäbchen, dem es umgebenden Gallerthof und der 
Eisenausscheidung um ihn herum; die Eisenausscheidung kann auch fehlen. Diese Formen färben sich bei der Behandlung mit gelbem Blutlaugensalz und Salzsäure intensive blau.

5. In älteren Torf-Wasser-Kulturen kommen Individuen vor, bei denen die Eisenausscheidung um den Gallerthof herum immer fehlt, dagegen ist dieser von einer dunklen Hülle umgeben, welche für die Lösung des gelben Blutlaugensalzes undurchlïssig ist. Deswegen lassen sich diese Individuen mit der Eisenreaktion nicht blau färben.

6. Die dunkle Hülle hat meistens eine ovale Form, zeigt aber manchmal auch unregelmässig zerhackte Konturen. Es kommen auch Fälle vor, wo sie teilweise fehlt, und dann färben sich solche Bakterien leicht blau.

7. Die unter 4, 5, und 6 angeführten Formen kommen in älteren Torf-WasserIiulturen nebeneinander vor.

8. Die Kolonien bilden eine Haut an der Oberfläche des Wassers oder der künstlichen Nährlösungen.

9. Die Haut an der Oberfäche des Wassers ist schwach regenbogenfarbig oder metallisch glänzend und makroskopisch deutlich sichtbar, wogegen.

10. Die Haut auf Eisenammoneitrat- und Eisenpeptonbouillonlösungen immer makroskopisch unsichtbar bleibt und nur durch das Übertragen auf den Objekttrïger bemerkbar gemacht werden konnte.

11. Mikroskopisch erscheint die Haut immer mehr oder weniger deutlich gelb gefärbt.

Fixococcus. A name proposed by Meyer $(1912$, p. 5) for the first section of the genus Micrococcus. His description is "Die Formen, bei denen keine Geisseln nachgewiesen wurden." The other sections are Planococcus (motile) and Rhodococcus (with sulphur granules).

Fixosarcina. A name proposed by Meyer $(1912$, p. 5) for the second section of the genus Sarcina with the description, "Die Spezies bei denen Geisseln nicht nachgewiesen wurden."

Fixostreptococcus. A name applied to Meyer (1912, p. 4) to the second section of the genus Streptococcus. This includes "Alle Spezies für welche Geisseln nicht bekannt wurden."

Flavobacterium. A name used by Bergey et al. $(1923$, p. 97) for the second genus of the tribe Chromobactereae with the description:

Rods of medium size, occurring in water and soil, forming a yellow to orange pigment on culture media. Characterized by feeble powers of attacking carbohydrates, occasionally forming acid from hexoses but no gas. Motile or nonmotile. Generally Gram-negative.

The type species is Flavobacterium aquatilis (Frankland).

Flemingillus. A name given by Heller (1922, p. 15) to the sixth genus of the subfamily Clostridioideae. The definition follows:

Clostridioideae that do not liquefy gelatin. They produce little gas or acid in meat medium. They do not grow very abundantly in milk or change it. They 
do not show any marked tendency to split sugars. Slender Gram-negative rods with oval terminal spores. Colonies in deep agar lenticular, may show an areola of fine radiations. Frequently found in moulds, not pathogenic for guineapigs.

Type species $F$. cochlearius (Bacillus cochlearius Douglas, Fleming and Colebrook) as described by the Committee. The type is highly motile and it split none of the carbohydrates in which it was grown. It was described as bacillus III type $\mathrm{C}$ by MeIntosh.

Flexnerella. The first subgenus of the genus Shigella named by Castellani and Chalmers (1919, p. 937). It differs from the second subgenus (Shigella) in that mannitol is fermented. It is subdivided into two groups, the Flexner group and the Pseudodysentery group. Later (1920, p. 606) two species are listed. The type is Shigella flexneir Castellani and Chalmers.

Fluormonas. A generic name proposed by Orla-Jensen (1921, p. 271) to include his earlier described Denitromonas and Liguidomonas. He says:

As the property of liquefying gelatin also cannot be adopted as a generic character but only as a species character, I think it would be best to group together my earlier genera Denitromonas and Liquidomonas in a single genus, which can be conveniently termed Fluormonas, as the bacteria of this group are ordinarily fluorescent. I cannot agree to call this genus Pseudomonas merely out of regard for so-called priority, as each and all of the bacteria which belong to the order under consideration are really Pseudomonades as well.

No species is named.

Fusiforminae. A subtribe named by Buchanan (1918, p. 44) to include the single genus Fusiformis.

Fusiformis. A generic name proposed by Hoelling (1910, p. 240) to include the fusiform bacteria. He concludes that those organisms usually included in the name Bacillus fusiformis should not be placed in the genus Bacillus. He mentions as species Fusiformis dentium, F. muris, $F$.termitidis. He describes the morphology of the last named species in detail. He states that the protoplasm of the young organisms is relatively homogeneous, sometimes staining more intensely toward the pointed ends. The larger cells sometimes show an alveolar plasma structure. The nuclei are in general stained dark. The nuclei in some are oval and show a definite structure, others show, especially in mononucleate cells, as a broad band. Evidently the Bacillus fusiformis is Fusiformis termitidis. The name is accepted by Dobell (1911, p. 486). 
Vuillemin (1913) suggested the revival of Trevisan's name Mantegazzaea for this group as one of the "formogenera conservanda" with the fusiform bacillus of the medical writers as the type. The name as used by Trevisan, however, was used principally for certain of the sulfur bacteria and not for forms related to this type.

Winslow et al. (Committee Soc. Am. Bact., 1917, p. 555, 1920, p. 199) and Bergey et al. (1923, p. 388) recognize this genus with the following description:

Obligate parasites. Cells usually elongate and fusiform, staining somewhat irregularly. Filaments sometimes formed; non-branching. Non-motile. No spores. Growth in laboratory media feeble.

The Type species (?) is Fusiformis termitidis Hoelling.

Buchanan (1918, p. 43) used the following description:

Obligate parasites. Cells usually elongate and fusiform. Gram-negative? Anaërobic. Non-motile. No spores. In some respects approaching the spirochetes in morphology.

The type species is Fusiformis termitidis Hoelling (possibly F. dentium).

Castellani and Chalmers (1919, p. 959) have suggested the name Bacteroides q.v. for this group.

Apparently Fusiformis constitutes a valid generic designation, with Fusiformis termitidis? Hoelling as the type.

Gaffkya. A genus of bacteria proposed by Trevisan (1885, p. 105) based upon Micrococcus tetragenus Gaffky as a type. The description of the genus is: "Colonie di 4 cocchi globosi, avviluppati da una capsula mucosa, ialina, globulosa, da ultimo liberi. Specie unica." The diagnosis given by De Toni and Trevisan (1889, p. 1042) follows:

Cocciglobosi vel divisionis tempore ovoidei, in muco matricali nidulantes, quaterni, cystidibus specialibus parvulis, gelatinosis, tenuiculis, demum dilabentibus, solitariis, nunquam in acervos consociatis, obducti. Cystides universales nullae. Coccocorum divisio in duas directiones. Sporae ignotae.

Four species are included. The type species may be taken as Gaffkya tetragena (Gaffky) Trevisan. Should this organism prove to be entitled to generic recognition, the genus Gaffkya would be valid. The name does not appear to have been used by other authors. It is rejected by Erwin F. Smith (1905, p. 174).

Gaffkyeae. The second subtribe of the tribe Ascococceae proposed by Trevisan according to De Toni and Trevisan (1889, p. 1042) with the following diagnosis: "Cocci cystidibus specialibus obducti, Cystides 
universales nullae." Two genera are included: Chlamydatomus Trevisan and Gaffkya Trevisan.

Gaillonella. A genus of algae named by Bory de St. Vincent (1823, p. 393). Enlows states:

Gaillonella: Bory de St. Vincent, 1823. Dict. classique d'Hist. Nat., v. 4, 1823, p. 393 . See also idem, v. 7, 1825, p. 101. Simple cylindrical filaments, articulated, each section including two capsulary corpuscles, spheroidal, transparent, even when filled with ferruginous coloring matter, and divided into two equal parts by a "dissépiment" which appears as a line. "Nous n'hésitons pas à regarder les Gaillonelles comme de simples végétaux."

Type species (original designation).-Conferva moniliformis Müller. Places C. nummuloides here also.

No species were described in 1823 .

In 1824 Agardh created the genus Meloseira with 5 species. The following year (1825) Bory included two of these species in his genus Gaillonella. Ehrenberg (1833, p. 294) gives the following synonymy and description:

Gaillonella Bory de St. Vincent 1823, Meloseira Agardh 1824, Gallionelle. Familie der Stabthierchen, Bacillaria. Character generis: Polygastricum, anenterum, Gymnicum, Pseudopodium?, loricatum. Lorica subglobosa aut oblonga bivalvis divisione, spontanea intra vaginam deciduam peragenda catenformis, filiformis.

He described Gaillonella lineata Bory. In 1835 Ehrenberg included in the genus an organism which he termed "Gaillonella ferruginea," and which he believed might be the same as the Hygrocrocis ochracea of the botanists. In the following year (1836, p. 217) Ehrenberg discussed this organism at greater length including it with several of the species of diatoms of the same genus. He terms it the "Eisenockerthierchen," and notes finding its "shell" in many places as a fossil. His figure shows his conception of the organism to be a very minute diatom in chains.

In his later monumental publication on the infusoria (1838, p. 166) the name was changed to the form Gallionella, a form which has been commonly accepted. The generic diagnosis is given as follows:

Gallionella. Gaillonelle. Character Animal e familia Bacillariorum, liberum lorica simplici, bivalvi (silicea); cylindricium globosum aut disciforme, spontanea imperfecta divisione cateniforme.

Seven living and three fossil species are described. Three of these had been previously listed as species of the genus Meloseira by Agardh. 
Included is the species (p. 169) Gallionella ferruginea, "rostfarbende Dosenkette" with the following description: "G. corpusculis tenuissimus, utrinque convexis, ovatis, ferrugineis, filis articulatis saepe conglumatis, subramosis." with the following synonomy: Conferva ochracea Roth? Catal. bot., I, p. 165, Tab. 5, Fig. 2, 1797, Schumacher? Enumeratio plant. Zeelandiae, 1803, II, p. 105, Dillwynne? Synops. of brit. Conferv., 1809, pl. 62. Lyngbya ochracea Leiblein: Flora, bot. Zeit., 1827, p. 260, 280. Oscillatoria ? ochracea Lyngbye ? Tent. Hydrophyt. dan., T. 26, C-— ? Agardh ? Syst. Alg., 1824, p. 69, incerta species. Gaillonella ferruginea Ehr. Taf. x. dieses Werk., 1835.

Gaillonella ferruginea Bericht der Berl. Akad. d. Wissensch., 1836, 27, Jan., p. 52, 84.

Why Ehrenberg abandoned the earlier specific ochracea is not evident.

Ralfs in 1843 (p. 351) described the same organism in the diatom genus Melosira as follows: "Melosira ochracea. Frustules very slender, convex at each end, ovate, not striated, ferrugineous; filaments often connected together in a subramose manner." He gives as synonyms the following: Gallionella ferruginea Ehrenberg, Conferva ochracea Dill. t. 62 and Oscillatoria ochracea Grevil. He further states:

Filaments are so slender and joints so obscure that I have been unable to determine the form of the frustules, and therefore have taken the specific characters from Ehrenberg. Having received from Mr. Dillwyer a specimen of his Conferva ochracea, which I am able confidently to refer to this species, I have restored the original specific name.

Kützing (1849, p. 28) included this organism in his genus Gloeotila. The description given is as follows:

Gloeotila Kützing, Trichomata eramosa viridia mucosa, ex cellulis monogonimicis composita. (Paludosae, inundatae). Gl. ferruginea Kg. Phyc. Germ. p. 191. G. ochracea, trichomatibus brevissimis moniliformibus, articulis ovato-globosis Diam. 1-2000"'. Gallionella ferruginea Ehrenb. Infus., T. 10, f. 7. Melosira minutula Brebiss. Falais. p. 42 , pl. 5. In fontibus martialibus (v. v.). Cf. Kg. Bacillac, p. 56. Gallionella ferruginea.

Griffith (1853, p. 28) pointed out that this organism (Gallionella ferruginea Ehrenb.) is not a diatom, and that it cannot be retained in Kützing's genus Gloeotila. He states that the organism consists of two intertwined filaments, and proposed the name Didymohelix.

According to Molisch, Mettenheimer (1856, p. 139) inclined to the view that Gallionella and Leptothrix are identical. 
According to Löhnis (1913, p. 704) this organism was placed in the genus Gloeosphera by Rabenhorst, with the name G. ferruginea. De Toni and Trevisan (1889, p. 1007) give as authority Rabenhorst, Alg. Mitteleur, n. 387. Kützing (1865, p. 53) used Gallionella as the second subgenus of Melosira. Later (p. 56) he says "Ganz ausgeschlossen muss werden Gallionella ferruginea Ehr. welch gar keine Diatomee, sondern eine Conferva ist." Kirchner (1878, p. 250) placed this organism in the genus Spirulina with the name Sp. ferruginea. Hansgirg (1888, p. 264) uses the designation Spirochaete ferruginea (Ehr.) Hansg. De Toni and Trevisan (1889, p. 1007) included the species in the genus Spirillum because of its curved form. De Toni (1891, p. 1331) used Gallionella Bory as a valid generic name of a diatom genus. Hansgirg (1873, p. 184) used the designation Leptothrix ochracea to include this organism not recognizing any distinction between Leptothrix and Gallionella. Migula (1897, p. 321) discussed this organism.

In his "System" Migula named the organism Chlamydothrix ferruginea (1900, p. 1031). In this genus was included the Leptothrix ochracea also.

Ellis (1907, p. 516) returns to the designation "Gallionella ferruginea," He states,

The structure is like that of a hairpin, spirally wound round itself. The spiral winding produced a number of loops, the number of which may be few or many. The thickness of the threads varies usually from $\frac{1}{2}$ to $\frac{3}{4} u$. The winding may be loose or tight. The structure of the cell is perfectly homogeneous. Migula states that an extremely delicate membrane is present, but $\mathrm{I}$ have not been able to confirm this observation. Multiplication takes place freely by the cutting off of small portions, which then elongate to form a new individual. Conidia formation is also quite common, though not universal as in Leptothrix ochracea. The process of formation of conidia is identical with the same in this organism, as is also the size and shape of conidia. The deposit of iron is the same as in other iron bacteria. In no stage of its life history was any motility observable.

\section{Orla-Jensen (1909, p. 331) says}

Die Schraubenform des Leptothrix sind Gallionella und Spirophyllum. Jedoch kann den mehr oder weniger zufälligen Biegungen und Flechten der GallionellaFäden nicht dieselbe systematische Bedeutung wie den regelmäszigen Windungen der starren Spirillen zugeschrieben werden, und wir tun daher besser, Gallionella nur als eine Leptothrix-Art aufzufassen.

The name Gallionella ferruginea Ehrenberg was also accepted by Molisch $(1910$, p. 22) who studied the organism at length and has given us the best description. He states: 
Fäden geschlängelt, einfach, oder je zwei schraubenfòrmig dicht um einander gewunden und daher einen Zopf bildend. Hierdurch gewinnt der Faden oft ein kettenartiges Aussehen. Fäden inder Jugend farblos, später infolge von Eisenhydrateinlagerung gelbraünlich bis rostrot. Gewöhnlich sin die Doppelfäden eng verschlingen, stellenweise lösen sie sich aber deutlich in die Einzelfäden auf, ähnlich wie man dies bei Spirulina beobachten kann. Ist der schraubig gewundene Faden breiter der vereinigen sich zwei solchen Fäden zu einem Zopf, so enstreht ein kettenartiger Fäden, dessen einzelne Glieder früher fälslich für Sporen gehalten worden sind. Die Einzelfäden zeigen keine Gliederung in Zellen, selbst nicht nach Behandlung mit Farbstoffen und verdünnten Saüren und zeigen auch keine nachweisbare Scheide. Durch hochgradige Inkrustation mit Eisenoxyd können die Fäden und ihr Verlauf ganz verdeckt werden. Breite der Fäden bezw. Zöpfe $1-6 \mu$. Lange bis $270 u$ und darüber. In einsenhaltigen Wassern häufig und weit verbreitet. Lässt sich vorläufig nicht kultiveren.

He states further that Migula first figured the organism accurately, but that he cannot agree with this author in its inclusion in the genus Chlamydothrix for no sheath is present. Furthermore there is not the slightest trace of the jointing of the filaments into cells. He also concludes that the Spirophyllum ferrugineum of Ellis (1897, p. 21) is probably not specifically distinct, for he has found intermediate forms. $\mathrm{He}$ suggests therefore the name Gallionella ferruginea var. lata. He is also inclined to regard the Nodofolium ferrugineum of Ellis (1910, p. 32) as a broad form of Gallionella ferruginea. He concludes further, that Leptothrix (Chlamydothrix) and Gallionella are distinct. His pure cultures of Leptothrix never gave rise to Gallionella forms. Therefore Schwers $(1908$, p. 53) was in error in his statement "Tout nous port donc a croire avec Hansgirg, qu'il s'agit d'une seule et meme espèce."

Gaillonella (or Gallionella) since the time of Ehrenberg has been recognized as a valid genus of diatoms or a subgenus of Melosira by many writers on algology.

There does not seem to have been sufficient reason for Ehrenberg's change of spelling Gaillonella to Gallionella. The recognition of the fact that the Gallionella ferruginea of Ehrenberg was not a diatom, and the creation of the genus Didymohelix by Griffiths would appear to be valid. The original specific designation was ochracea, which was changed to ferruginea by Ehrenberg. It would seem that this organism should therefore be termed Didymohelix ochracea, and that Gallionella should not be used as a bacterial genus.

Galactobacterium. A casual name given by Guillebeau (1890, p. 43) to an organism associated with inflamed udder in a cow. No description is given 
Galactococcus. A generic name proposed by Guillebeau (1890, p. 32) for three species. They are described by Enlows (1920, p. 44) as follows:

G. versicolar $\mathrm{n}$. sp. Cocci of about $\mathrm{l}_{\mu}$ diameter. Nonmotile. Gram positive. Long chains in milk, which is rapidly acidified. Aerobe, Belongs to the "häufigeren Mastitispilzen." G. fulvus n. sp. Cocci of not more than $1 \mu$ diameter. Nonmotile. Gram positive. Ochre-yellow on potato. G. albus n.sp. Cocci about $1 \mu$ diameter. Nonmotile. Gram-positive. White colonies on milk gelatin, which is not at all or only slightly liquefied. Dirty white growth on potato. All of these species found in milk from an inflamed udder.

Apparently the organisms described belong to the genus Slaphylococcus, of which Galactococcus may be regarded as a synonym. The type species probably should be designated as Galactococcus versicolor, the first species described.

Gallionella. A spelling of Gaillonella introduced by Ehrenberg (1838, p. 166) and commonly used by subsequent writers. For discussion, see Gaillonella.

Glaeogenes. A tribe of Schizophytes named by Cohn (1875). The tribe included many forms now classed among the bacteria as well as forms now included with the blue green algae. The tribe is characterized by having its cells free or united into glairy families by an intercellular substance.

Gleobacter. A casual name used by Fischer (1895, p. 135) according to Enlows (1920, p. 44) to include capsulated rod-shaped bacteria. Klebsiella Trevisan is stated to be a synonym.

Gliabacteria. A name proposed by Billroth $(1874$, p. 5) to designate a growth form of his Coccobacteria septica in which the organisms appear as rods embedded in a mass of gelatin. It is not a generic name.

Gliacoccos. A name proposed by Billroth $(1874$, p. 5$)$ to designate a growth form of his Coccobacteria septica in which the cells appeared as cocci united by gelatin into irregular colonies. He proposed this name to replace an earlier designation Zoogloea Cohn. With the spelling Gliacoccus it was rejected by E. F. Smith (1905).

Gliacoccus. See discussion of Gliacoccos. Maggi (1886, p. 82) gives Gliacoccus aceti as a variety of his Micrococcus aceti.

Glia-Kokkus. A variant spelling of Gliacoccus used by Klebs (1887, p. 310).

Glischrobacterium. An aberrant spelling of Gliscrobacterium (g.v.).

Gliscrobacterium. A casual designation introduced by Malerba and Sanna-Salaris $(1888$, p. 196) for an organism found by them to 
produce a high degree of viscosity in urine. The same organism was studied by Rothmann (1904, p. 491) under the name Glischrobacterium. This term has not been used as a generic name. It is rejected by Erwin F. Smith (1895, p. 174).

Gloeosphaeria. Rabenhorst (alg. Mitteleur No. 387) distributed an organism as Gloeosphaeria ferruginea $(1854$, p. 43). The name has never been recognized by other writers. The organism is one of the iron bacteria, variously termed Chlamydothrix ferruginea, Gallionella ferruginea or Didymohelix ferruginea. The name may probably be regarded as nonvalid as a bacterial generic designation.

Gloeotila. A name used by Kützing (1843, p. 245) for a genus of algae with the following description:

Trichomata parenchymatica viridia, simplicia, monogonimica, libera. Cellulae gelineae delicatissimae, mucosae. Gonidia oblongo-angulata, vel rotundata, hinc flaccida, illinc, turgida (nunquam longitudinaliter divisa).

Six species are recognized. Later this author (1849, p. 363) included one species: Gloeotila ferruginea which is generally regarded as a synonym of Gallionella ferruginea or Didymohelix ferruginea, one of the bacteria. The description given is: "G. ochracea; trichomatibus brevissimis moniloformibus, articulis ovato-globosis. Diam. 1/1200Gallionella ferruginea Ehrenb." In addition nine other algal species are described. This name is also used by Perty $(1852$, p. 215). Gloeotila is a valid genus of algae and should not be used for bacteria.

Glucobacter. See Glycobacter.

Glycobacter. A generic name proposed by Wollmann (1912, p. 613) for a group of amylolytic intestinal bacteria. Two species were described of which the first, Glycobacter proteolyticus may be regarded as the type. This organism was isolated from the ileum of a monkey. It is a rod, usually straight, rarely slightly bent, about $1 \mu$ in diameter and 2 to 6 or even $10 \mu$ in length. Cells usually isolated, rarely in pairs, never in chains. The cells stain readily, but take the Gram stain poorly. They do not give the granulose reaction. Spores are readily produced, on agar within twenty-four hours. The spore is subterminal or medium, the cell somewhat inflated. The spores are resistant even to boiling temperatures. The bacilli are very motile.

On sloped agar the cultures are quite transparent and delicate, where colonies are isolated they reach $1 \mathrm{~mm}$. in diameter. In sugar gelatin shake cultures, small irregular colonies appear in twenty-four hours, and gas is formed. Gas is formed in glucose broth in the first twentyfour hours. Milk is feebly coagulated after forty-eight hours: whey 
is clear, the casein is slowly digested, the reaction remains acid. In gelatin the colonies are round, liquefied. Egg white is not attacked appreciably. On potatoes a granular layer in twenty-four hours. Starch is rapidly liquefied in the presence of a suitable source of nitrogen. It attacks albumins, but does not seem to break them down completely. Amylase may be readily demonstrated in filtrate from potato broth culture. With glucose, levulose, maltose, saccharose and lactose it gives an acidity corresponding to 1.2 to 1.47 grams of $\mathrm{H}_{2} \mathrm{SO}_{4}$ per liter; in lactose about 0.49 gram. Small amount of alcohol produced.

The second species Glycobacter peptolyticus resembles the first in digestion of starch, but does not cause proteolysis.

The genus Glycobacter evidently includes the amylolytic aerobic spore producing organisms usually assigned to the genus Bacillus.

Gonium. A genus of algae named by Müller (1773). Ehrenberg assigned to it the species; Gonium hyalinum, one of the bacteria. This organism was removed from this genus by Schröter (1886, p. 151) who gave to it the name Lampropedia hyalina. According to Robin (1847, p. 110), Busk (1843) regarded Sarcina ventriculi as a species of Gonium. The genus Gonium is a valid genus of algae, but not of bacteria.

Gonococcus. A name first used as a casual designation for the organism which is the specific cause of the disease gonorrhea. The name is usually ascribed to Neisser (1879, p. 497).

Apparently its use as a generic name has been without formal designation as such. Migula (1896, p. 16) gives Gonococcus gonorrhoeae Neisser as a synonym of his Micrococcus gonorrhoeae. However, examination of the work of Neisser fails to show this designation, it cannot be validated by quotation in synonymy. (See Botanical Code.)

Lindau (1898, p. 100) named the species Gonococcus neisseri.

This organism was earlier named Neisseria q.v. by Trevisan. Gonococcus as a generic designation is a synonym, and must be ascribed to Lindau (?).

Graciloideae. A name given by Castellani and Chalmers (1919, p. 932) to the third tribe of the family Bacillaceae. The description (p. 958) is:

Bacillaceae growing very slowly and scantily on ordinary and blood media, without endospores or capsules, neither fluorescent nor chromogenic.

Type Genus. Graciloides Castellani. 
Graciloides. The name given by Castellani and Chalmers (1919, p. 933) to the single genus of the tribe Graciloideae, with characters of the tribe, q.v., and the type species Graciloides albofaciens (Castellani) Castellani and Chalmers.

Granulobacillus. A genus named by Schattenfroh and Grassberger (1899, p. 202) for two species of anaerobic bacteria. Enlows (1920, p. 45) states that it differs from Granulobacter Beijerinck in that it includes both motile and non-motile organisms. The species named are Granulobacillus saccharobutyricus immobilis liquefaciens and $G$. saccharobutyricus mobilis nonliquefaciens. The names are polynominals, hence invalid. This invalidates the generic name as well.

Granulobacter. A genus of bacteria created by Beijerinck (1893, p. 7). He named at this time four species. His generic description follows:

Obligat- oder temporär anaërobe Gährungsbacterien (Für die Erklärung des Ausdruckes "temporär anaërobie" verweise ich auf Par. 12)-welche bei vollständinger Anaërobiose sich theilweise oder ganz mit granulose anfüllen und dann Clostridiumform annehmen. Bei Gegenwart von Sauerstoffspuren entstehen schnell bewegliche Stäbchen, quelche mit Jod gelb werden. Sporen entstehen in den Clostridien, und können einige Secunden oder Minuten auf $95^{\circ} \mathrm{C}$. bis $100^{\circ} \mathrm{C}$. in den Nährflüssigkeiten erhitzt werden, wodurch die Entfernung von verunreinigten Bacterien möglich ist. Unter den Gährungsproduction finden sich immer Kohlensäure und gewöhnlich auch Wasserstoff, während Methan vollständig fehlt.

The first species described (which may be considered the type) is Granulobacter butylicum. This is said possibly to be identical with Gruber's Bacillus amylobacter I. Other species described are G. saccharobutyricum, G. lactobutyricum and G. Polymyxa.

Later $(1896$, p. 1) the generic diagnosis is as follows:

Granulobacter. Bacterie de fermentation, anaerobies temporaires ou obligatories, qui si l'anaerobiose est complete se remplissert soit en partie soit en totalite de granulose et prennent alons la form de clostridiums. S'il y a des traces d'oxygene en presence il se forme des batonnets à motilité tres vive, quise colorent en jaune par l'iode. Des spores se forment dans les clostridiums et peuvent resister pend aut quelques secondes ou quelques minutes, dans les liquides de culture, a une temp. de $95-100^{\circ} \mathrm{C}$. On trouve toujours parmi les produi des fermentation de l'acide carbonique et d'ordinaire aussi de l'hydrogen tandisque le methan fait completement defaut.

The species first named is G. butylicum. The following description given by Stockhausen (1907, p. 42) characterizes the genus well. 
Zur Gattung Granulobakter stellt Beijerinck alle jene obligat oder temporär anaerobiotischen Gärungsbakterien zusammen, welche bei vollständige Anaerobiose sich teil weise oder ganz mit Granulose anfüllen, den Clostridium form annehmen. Bei Gegenwart von Sauerstoffspuren entstehen schnell bewegliche Stäbchen. Die in den Clostridien enthaltenen Sporen halten einige Minuten 95-100 ${ }^{\circ}$ aus. Unter den Gärungsproduktion finden sich immer Kohlensäure, meist auch Wasserstoff. Zu dieser Gattung gehören die Bakterien der Butylalkolgärung (Gran. butylicum) der Buttersauregärung und die Bakterien der Flachsrotte, Gran. pectinovorum und Gran. urocephalum.

This name has been used for the most part only by Beijerinck and his pupils. Lindner (1909, p. 515) defines the genus as follows: "Obligat oder temporär anaerobe Gärungsbakterien, welche bei vollstandiger Anaerobiose sich teilweise oder ganz mit Granulose anfüllen und dann Clostridium form annehmen."

Granulobacter may probably be regarded as a synonym of Clostridium. It is rejected by Erwin F. Smith (1905, p. 174).

Granulobakter. A variant of Granulobacter, used by certain German authors as Grassberger and Schattenfroh (1899, p. 702), Stockhausen (1907, p. 42).

Grippestreptokokkus. A casual designation proposed by Seligmann (1912, p. 81) for a streptococcus associated with an epidemic of "Grippe" among infants.

Gummibacillus. According to Migula (1900, p. 577) this is a casual designation used by Loeflier for the organism Bacillus liodermos Flügge. It is rejected by Erwin F. Smith (1905, p. 174).

Gymnobacteria. A group name for the "naked" bakteria as distinguished from the Trichobacteria used by Messea (1891) according to Kruse.

Gyrococcus. A generic name proposed by Glaser and Chapman (1912, p. 223) for the species (type) Gyrococcus flaccidifex. Enlows (1920, p. 46) summarizes the description:

Cells in free state spherical, becoming slightly oblong just before division. Division in 1 direction only. After division each half may be spherical or may come to an abrupt tip, assuming a more or less heart-shaped appearance. Frequently the two halves are unequal; one-half may be spherical while the other may be more or less heart-shaped, or slightly oblong. If cells remain connected after fission, chains of 3 or 4 are formed. Diameter of cells 0.51 to $0.85 \mu$. No endospores. Capsule distinct. Motile-progressing in a gyrating manner,but no flagella were stained. Gram negative. Very closely resembles the Pneumococcus, except that it is Cram negative, and motile. Cause of wilt disease or "flacherie" of the gypsy moth. 
Haematococcus. This generic designation of the "red snow" alga was first given by Agardh (1828, p. 45) to the species Haematococcus nivalis. Since that time this name has been frequently used for an algal genus. It is generally now regarded as a synonym of Sphaerella, according to Hazen (1896, p. 238) and West (1904, p. 189). Wille (1903) regards the generic name as valid and as replacing Sphaerella.

In a different sense the same generic name has been used a few times in bacteriology. V. Babes $(1889$, p. 81$)$ in describing the causal organism of bovine hemoglobinuria used the phrase (p. 103) "für die Krankheit Charakterischen Hämatokokken" and later (p. 106) "Neben dem Haematococcus finden sich," etc.

The same organism was earlier discussed by Babes (1888, p. 692) and according to several authors (Doflein, 1911, p. 815, Eisenberg, 1891, p. 271) the name Haematococcus was here first used. A careful examination of the article fails to show that the term is here used. Babes regarded the organism as a bacterial form.

The name Haematococcus is invalid in bacteriology because of the prior existence of the algal genus of the same name. Furthermore no species name seems to have been used, the term as employed by Babes was apparently only as a casual designation. The first use of the term is a strict generic sense seems to have been by Eisenberg (1891, p. 271) with the spelling Hämatokokkus, and the species $H$. bovis. This organism is now recognized as a protozoan. The generic name Haematococcus is not valid as a protozoan genus because of previous use.

Hämatokokkus. A variant of Haematococcus q.v. used by Eisenberg (1891, p. 271).

Haemophileae. The name given by Castellani and Chalmers (1919, p. 932) to the second tribe of the family Bacillaceae. Growth in laboratory media is poor, the organism is Gram-negative, grows best on blood media. The single genus is Haemophilus.

Haemophilus. A generic name (variant of Hemophilus q.v.) used by Castellani and Chalmers (1919, p. 933) as the single genus of their tribe Haemophileae. The type species is designated as Haemophilus influenzae (Pfeiffer) Castellani and Chalmers.

Halibacterium. A generic name proposed by B. Fischer (1894, p. 19) to include certain organisms living in salt water, including Halibacterium pellucidum (p. 19), H. roseum (p. 19), H. liquefaciens (p. 21), H. polymorphum (p. 25), H. aurantiacum (p. 26), H. rubrofuscum (p. 28), H. purpurium (p. 30). The description of $H$. pellucidium (p. 22) which may be regarded as the type follows: 
Kleine bis mittelgrosse Kurzstäbchen, fast wie Kokken, einzeln oder zu 2 oder in kürzeren Ketten zu 4, 6 selten mehr vereinigt. Manchmal die Kurzstäbchen in ähnlicher Weise angeordnet wie bei Sprossverbänden der Bierhefe, alsdann gewöhnlich in Zoogloeamasse eingebettet. Neben den Kurzstäbchen oft auch etwas längere, spindelförmige Stäbchen mit hier und da soeben angedeuteter kommaartiger Krümmung, zuweilen aber auch typische Komma-und S-Formen, ferner kurze, ungegliederte, gerade oder gebogene Fadenstücke, theils wie um die Längsachse gehreht und von ungleicher Dicke, theils deutlich schraubenförmig, theils unregelmässig gewunden. Oft erhebliche Unterschiede in der Grosse. Manchmal lebhafte Eigenbewegung. Leicht färbbar. Kolonien in Gelatineplattenrunde, graue, durchscheinende Tröpfchen, die tiefgelegenen mit gelblichem Stich, nicht verflüssigend. Bei schwacher Vergrösserung rund oder citronenförmig, schmutziggelb, gleichmässig oder feinkörnig, oft koncentrische, manchmal wie mit kleinen Luftbläschen besetzt, manchmal von gelappter oderhöckeriger bezw. rosettenartiger Form. In Stichkulturen ausgesprochenes Oberflächenwachsthum, anfangs durchscheinende, später mehr, trübe, trockene und bräunliche, oder auch grauweisse, runzlige, blattartige Auflagerung. Auf Strichkulturen feuchter, grauer, durchscheinender, weiterhin oft runzligfaltiger Belag. Für Mäuse nicht pathogen. Im Oceanwasser weit verbreitet Wegen der durchscheinenden Beschaffenheit der jüngeren Kulturen weiterhin als Halibacterium pellucidum bezeichnet.

This has generally been regarded as a physiological genus, and has not been recognized as valid by subsequent authors. It is rejected by Erwin F. Smith (1905).

Haplobacteriaceĩ. An ordinal name proposed by Fischer (1895, p. 138) coördinate with Trichobacteriaceï. It includes all those bacteria whose cells are not united into true filaments. He says

Das unterschiedende Merkmal liegt in dem Bau des Vegetationskörpers, der bei den Trichobakterien immer ein unverzweigter auf einzelnen aufgebauter Faden ist, während die Haplobakterien einen einzelligen Vegetationskörper besitzen, der kugelig, stabartig oder schraubig ist.

With the spelling Haplobacterinae (q.v.) this name is used in Coppen Jones (1897, p. 32) translation.

Haplobacterinae. An ordinal name first used with the spelling Haplobacteriaceï by Fischer (1895, p. 138). Coppen Jones (1897, p. 32 ) in the translation of Fischer's Vorlesungen used the form Haplobacterinae. It was later used by Benecke (1912, p. 1888) for a group coördinate with Desmobacterinae to include all non-filamentous bacteria. According to the last author it contains six families, Coccaceae, Bacillaceae, Spirillaceae, Rhodobacteriaceae, Mycobacteriaceae and Myxobacteriaceae. 
Haplobakterien. A casual name used by Fischer (1895, p. 138) for his group Haplobacteriaceï q.v.

Helicobacterium. A generic designation used by Miller (1886, p. 119) for a species Helicobacterium aerogenes. The organism is a slender motile rod, single or in chains, and may develop to long, wavy bent filaments, which may resemble "Spirulinen." It forms transparent white or only weakly yellow colored colonies which are exceedingly variable in form. In stab cultures the organism grows throughout the length of the stab with a light yellow color and covers the surface in twenty-four hours with a thin, scarcely visible, bluish, dry layer. On stroke culture there develops a thin broad growth, which in transmitted light shows a flocculent or crystalline appearance. Growth on agar is not characteristic, growth on potato is slow, with a dry surface and yellow brown color. Poor growth in the absence of oxygen. It is again described by Miller (1892, p. 370). An Helicobacterium klebsiï is also described.

Enlows (1920, p. 47) states, "H. aerogenes (Escherich) Miller."

The genus is made a synonym of Bacillus by De Toni and Trevisan (1889, p. 952). Apparently the name has not been given generic recognition by subsequent authors. The description is scarcely adequate for identification; probably the genus should be regarded as invalid.

Helicomonaden. A casual name used by Klebs (1879, p. 161) for the organism which he believed to be the etiologic factor in syphilis. Enlows summarizes his description (1920, p. 47) as follows:

A pleomorphic organism, consisting at times of short rods, arranged in more or less spiral form, and of granules; motile. The granules arise from the rods, which toward the end of a spiral series become shorter and shorter, finally appearing as small round bodies. As to their being micrococci he says "Die Möglichkeit dass dem so sei, lässt sich nicht ableugnen, doch wird es in diesem Falle nicht an der Auffindung weiterer Differenzen fehlen, welche uns gestatten werden, ein kürzestes Stäbchen, ein Brachbactron etwa, von einem Coccus zu unterscheiden." He thinks no spores are formed, and that longitudinal division occurs. The granules (körnchen) also form spiral-like masses. The rod form in culture forms "Bakterienballen.

Helicomonas. Enlows (1920, p. 47) states:

The name Helicomonas syphititicum for the organism Iilebs describes as above has been ascribed to Klebs, but in none of his publications have I found it. This name occurs in many German papers on this subject, and in Lipp. Med. Dict., Philadelphia, 1910, p. 411. 
Inasmuch as the description of the species is quite inadequate, the genus name has not come into use. Its validity is doubtful. It is rejected (1905) by Erwin F. Smith.

Helikobacterium. Probably to be regarded as a variant of Helicobacterium. It was used by Escherich $(1886$, p.2) in the combination Helikobacterium zopfii. Enlows (1902, p. 47) states:

Characterized by its spiral colonies on gelatin plates. As the gelatin liquefies zoogloeae of spindle-shape are formed, which anastomose, covering the entire surface of the gelatin, and consisting of "swarming" bacteria, spirilla, and watchspring-like threads. In older gelatin cultures round and elliptical forms in varied grouping are found (diplococci, tetrads, chains, etc). He figures what he describes as "spirochäten" occurring in a milk culture of his Helikobacterium.

Species. Thinks Bacterium zopfi Kurth belongs here and suggests the name $H$. zopfi for it. In one paragraph he writes his genus Helikobacterium(Klebs), probably referring to Helicomonaden Klebs.

Helikomonas. A variant of Helicomonas used by German writers as Escherich (1886, p. 2).

Helobacteria. A name applied by Billroth (1874, p. 27) to the growth form of his Coccobacteria septica in which sporulation occurred. The genus is discussed and rejected by Cohn $(1875$, p. 188) and is rejected by Erwin F. Smith (1905). The name has never been used in a strict generic sense.

Hemophilaeae. A name given by Winslow et al. (Committee Soc. Am. Bact., 1920, p. 212) to a tribe with the genus Hemophilus. The tribal description is: "Minute parasitic forms growing only in presence of hemoglobin, ascitic fluid or other body fluids."

The name should probably be spelled Hemophileae. The latter spelling is used by Bergey et al. (1923, p. 268).

Hemophileae. A corrected spelling of the tribal name Hemophilaeae, suggested by Bergey et al. (1923, p. 268). Two genera are included. The description follows:

Minute parasitic forms growing only in the presence of hemoglobin, ascitic fluid or other body fluids, or in the presence of certain growth accessory substances found in sterile, unheated plant tissue (potato). Mon-motile. Gramnegative.

Hemophilinae. A name given by Buchanan (1918, p. 44) to the second tribe of the Bacteriaceae with the description: "Strict parasites, requiring hemoglobin or at least serum for their growth in media. Gram-negative. Non-motile. Cells may be pleomorphic. Usually very small. No spores." 
Two genera are included, Asterococcus and Hemophilus.

Hemophilus. A name used by Winslow et al. (1917, p. 561) for the fourth genus of the family Bacteriaceae with the following discription:

Minute rod-shaped cells, non-motile, without spores, strict parasites, growing best (or only) in the presence of hemoglobin, and in general requiring blood serum. or ascitic fluid. Gram-negative.

The type species is Hemophilus influenzae (Pfeiffer).

Buchanan (1918, p. 44) used the same definition. The "Committee" (1920, p. 212) added to the diagnosis "sometimes thread forming and pleomorphic."

Castellani and Chalmers (1919, p. 933) use the spelling Haemophilus $q . v$.

Bergey et al. (1923, p. 268) includes the genus as the first in the tribe Hemophileae with the description:

Minute rod-shaped cells, sometimes thread forming and pleomorphic. Nonmotile. Strict parasites growing best (or only) in the presence of hemoglobin and in general requiring blood serum, ascitic fluid, or certain growth accessory substances. Gram-negative.

Henrillus. A name given by Heller (1922, p. 15) to the fifth genus of the Clostridioideae with the following description:

Clostridiodeae that do not liquefy gelatin. They produce acid and gas in meat medium. They clot milk readily and attack many sugars, producing much acid. Gram-negative or gram-positive slender rods with terminal oval spores. Their colonies in deep agar are large, lenticular and opaque. Very common in soil, often found in wounds, do not invade tissue.

Type species $H$. tertius (Eacillus tertius Henry) as described by Henry. Henry believes that the conception $B$. tertius applies to a group and not to a species. His nine strains which may be taken as a type split the mouoses, bioses, mannose, xylose, starch, dextrin, glycogen, salicin, amygdalin and mannitol.

This type was described by von Hibler with the number IX. Fleming (Bac. Y), Rodella (1902) (Bac. III), Robertson (1916 a), McIntosh, Adamson (1919) and the Committee and Weinberg and Séguin also describe it. Choukevitch (1913) identifies spherical sporulating organisms with Rodella III. The original Rodella III did not clot milk and should perhaps be associated with Flemingillus.

Hiblerillus. A name proposed by Heller (1922, p. 17) for the ninth genus of her tribe Clostridioideae. The description is:

Clostridioideae that do not liquefy gelatin. They do not clot milk. Large gram-positive rods which form more or less reluctantly long ellipsoid spores; they may form orgonts. Colonies in deep agar, small and lenticular or with fine radia- 
tions. May be pathogenic for the guinea-pig, producing oedema and gas, or paralysis.

Type species $H$. sextus (Bacillus VI of von Hibler), as described by von Hibler (résumé by Weinl)erg and Séguin, pl. 212).

Von Hibler describes another species which he terms VII. These organisms have much in common and we are probably justified in including them in one genus as Hiblerillus sextus and Hiblerillus septimus. The latter resembles an organism described by Tizzoni and Cattani, according to von Hibler. There are probably many organisms in soil which are pathogenic for rabbits and guineapigs when given certain conditions favorable to invasion, which rarely invade under natural conditions or which on account of shy growth habit are missed when they invade in the company of other organisms.

To this genus may be assigned two organisms isolated from the intestine of the horse and described by Choukevitch (1911); they possess similar fermentative ability: the production of acid and no gas in glucose agar. A non-pathogenic one, Streptobarillus anaerobicus-rectus may be termed $H$. rectus; another, $H$. meaalosporus, produced a fibrino-purulent peritonitis in a guinea-pig.

Hillhousia. A generic name proposed by West and Griffiths (1909, p. 398) for a giant sulphur organism. The following summary taken from their paper satisfactorily characterizes the genus.

Hillhousia mirabilis is a sulfur bacterium of giant proportions, and is much the largest solitary bacterium which has so far been discovered. Its average length is about $60 \mu$ and breadth about $36 \mu$.

The organism is a peritrichous bacterium with a large number of short cilia. It occurs among decaying organic matter in the mud of shallow fresh water pools.

Each individual contains a protoplasmic network in the wide meshes of which large globules of sulfur (probably not pure, but in loose combination with proteid material), are locatcd. The network included numerous small granules, a considerable proportion of which consist of some nucleo-proteid. None of them are chromatin granules.

The cell-wall is firm and has great powers of resistence to reagents. It is not homogeneous, and 5 per cent carbolic acid demonstrates its lamellose character.

The multiplication of the organism is relatively slow, one division occupying upwards of twenty-four hours.

The genus is recognized by Buchanan (1918, p. 463) as the third in the family Achromatiaceae with the following description:

Cells very large, 42 to 86 by 20 to $33 \mu$, motile by means of peritrichous flagella. Cells packed with large globules of oily amorphous sulphur.

The type species is Hillhousia mirabilis West and Griffiths.

It is included by Bergey et al. (1923, p. 412) as the fourth genus of Achromatiaceae. Borsa (1920, p. 231) concludes that this is a synonym of Achromatium Schewiakoff. 
Homococcaceae. A subfamily of the family Coccaceae created by Fischer (1897, p. 32) to include those cocci in which the planes of fission are in a definite sequence. The following genera were included, Sarcina, Planosarcina, Pediococcus and Streptococcus.

The same name was also used by Fischer in 1903, p. 59 .

It should be noted that the name is not derived from one of the constituent genera.

Hyalococcus. A generic name proposed by Schroeter (1886, p. 152) with the following generic description:

Zellen kugelig oder elliptisch, einzeln oder zu 2, seltener in Reihen zu 4 und 6 in einfache, weit abstehende, scharf umgrenzte Kapseln eingeschlossen. Two species were included, $H$. pneumoniae (the pneumococcus of Friedländer) and H. Beigelii.

Hansgirg (1888, p. 266) included this as the fifth genus of his subfamily Cystococcaceae. It was listed as a synonym of Chlamydatomus by De Toni and Trevisan (1889). It was recognized by Ludwig (1892).

The name was rejected by Erwin F. Smith (1905) and by Vuillemin (1913, p. 521).

The fact that Hyalococcus pneumoniae is given first would seem to fix it as the type. It is the pneumobacillus of Friedlander (not Fraenkel's pneumococcus). It would seem that this is a valid generic designation for this group of organisms, in spite of its inappropriateness, providing they are worthy of generic recognition. It would seem to have priority over Encapsulatus q.v. which has the same type species.

Hydrogenomonas. A generic name proposed by Orla-Jensen (1909, p. 311) in the following paragraph:

Die Oxydation des Wasserstoffes:

$$
\mathrm{H}_{2}+\mathrm{O}=\mathrm{H}_{2} \mathrm{O}+69 \mathrm{Kal} \text {. }
$$

Per Gramm $3.83 \mathrm{Kal}$.

Nach Kaserer wird dieser Prozesz von einigen monotrichen Kurzstäbchen ausgeführt, die von ausschlieszlich anorganischer Nahrung leben können, jedoch auch auf organischem Substrat gedeihen, weshalb er sie Bacillus pantotrophus genannt hat. Nach B. Niklewski wächst dieser Organismus nur im Verein mit anderen Bakterien autotroph. Nach meiner Nomenklatur kann man ihm passend den Gattungsnamen Hydrogenomonas geben.

It is included as the third genus of his family Oxydobacteriaceae.

Niklewski (1910, p. 113) accepted this generic designation and named two species, $H$. vitrea and $H$. flava. 
Winslow et al. (Committee Soc. Am. Bact. (1917, p. 551, 1920, p. 201)) give the following diagnosis:

Monotrichic short rods capable of growing in the absence of organic matter, and securing growth energy by the oxidation of hydrogen (forming water). Kaserer (1905) who first described the organism states that his species will also grow well on a variety of organic substances.

The type species is Hydrogenomonas pantotropha (Kaserer) Jensen. Nikleuski (1910) described two additional species, H. vitrea and $H$. flava.

The genus is included by Bergey et al. (1923, p. 31) as the first in the tribe Nitrobactereae.

Hygrocrocis. A genus of algae created by Agardh (1824). It has been recognized as such by several algologists. To it were referred certain bacteria by various writers. For example, one of the iron bacteria (Gallionella ferruginea) was placed here by Perty (1852, p. 215). It is invalid as a bacterial genus.

Valentin in 1836, p. 110 , described an organism from the intestinal tract of the common cockroach Blatta orientalis which he named Hygrocrocis intestinalis. He gives the following description: "Fila simplicia, tenuissima, prolonga, articulata, serpentina, apice recta, moniliformia, articulis globosis.

Leidy (1851, p. 41) states that while he was able to find many entophytes in the intestinal tract of the cockroach, he was unable to find the organism described by Valentin. Chatton and Perard (1913, p. 1160) noted the name Hygrocrocis intestinalis of Valentin. As a result of a comparison of material from Blatta and that from the Julus, these authors conclude that the Hygrocrocis intestinalis of Valentin and the Arthromitus cristatus of Leidy are of the same genus. They accept Hygrocrocis as having priority. They describe the form as follows:

Ce sont de longs filaments à compartiments subègaux, cubiques, à croissance indéfinie, immobiles, et qui au surplus sont, d' aprés Leidy, fixés à la parci intestinale par bouquets sur une sorte de pied commun globuleux. Il y a dans les régions sporulces de ces filaments une endospore par cellule et ces cellules porigénes ne sont point hypertrophiées.

Nous ne croyons pas pouvoir attribuer au genre Hygrocrocis (Arthromitus) le parasite des cohayes, qui s'en distingue par son cloisonnement trés étroit et irrégulier, sa croissance limitée, le nombre restreint des endospores, la différenciation des cellules qui les contienment, et enfin sa condition libre et mobile. Ces caracteres seront ceux du nouveau genre Oscillospira.

Hypheothrix. A genus of algae created by Kützing (1843). Some of the iron bacteria have been placed here by various writers. De Toni and Trevisan (1889) make it in part a synonym of Detoniella. 
Hyphomycetes. A general name frequently used by mycologists to include the molds. It has been used by Lehmann and Neumann (1896, p. 107) to include the mold-bacterial genera Mycobacterium, Corynebacterium and Oospora with the following diagnosis:

Chlorophyllfreie Fadenpilze teils immer, teils vorwiegend mit echt verzweigtem Mycel ohne Endosporen, z. T. mit Bildung conidienartiger Sporen. Von dieser sehr grossen, durchaus provisorischen Familie haben wir nur 3 Gattungen berücksichtigt, ausschliesslich solche, die durch ihr dünnes Mycel in Fragmenten als Spaltpilze imponieren konnten und $z$. T. allgemein imponiert hatten.

Later these authors substituted the name Actinomycetes (q. v.).

Hyphomicrobium. A generic name proposed by Stutzer and Hartleb (1901, p. 76) for a species $H$. vulgare. The description is summarized by Enlows (1920, p. 49) as follows:

A nitrifying (?) organism found in soil. Related to the bacteria and to the hyphomycetes. On nitrate agar, small homogenous rods, with usually pointed ends, 0.6 to $0.8 \mu$ by 1 to $1.5 \mu$ long. Stained with phenol fuchsin a darker central body surrounded by a clear zone may be observed. Egg-shaped forms in older cultures, which send out threads, some of which show true branching. MIttiplication also by transverse division. Found also in cement which they think was decomposing through the assistance of this organism.

Hypnococcus. A pseudo-generic name given by Bettencourt, Kopke, de Renzende and Mendes (1904, p.55) to a "diplo-streptococcus" which they isolated from the meningeal fluid of patients suffering from sleeping sickness and believed this to be the causal organism. The name is not a true generic designation.

Indiella. A genus of fungi created by Brumpt (1906 according to Castellani and Chalmers 1919). It is of bacteriological significance because Indiella somaliensis Brumpt was later made a synonym of Nocardia somaliensis by Chambers and Christopherson (1916).

Indiellopsis. The following summary is given by Enlows (1920, p. 49):

According to Chalmers and Christopherson: Ann. Trop. Med. and Parasitol., Liverpool, 1915, pp. 240-255. Brumpt classified the cause of certain mycetomas of the hand as Indiella somaliensis (1906). In 1913 he renamed this species Discomyces somaliensis, and in the same year created a new genus or subgenus for it: Indiellopsis somaliensis (Brumpt, 1906). Brumpt based his Indiellopsis on the fact that the species secreted around itself in the grain a hard sheath, insoluble in potash and eau de javelle, which no other Nocardia is known to do.

Indolococcus. A generic name tentatively proposed by Orla-Jensen (1909, p. 340$)$ in the following paragraph: 
Da die peptonisierenden Milchsäurekokken reichliche Mengen Pepton, aber sehr wenig weitere Eiweiszzersetzungsprodukte, bilden, während die von den Proteus-Bakterien abgeleiteten Kokken durch Indolproduktion charakterisiert sein mussen, so liesze sich vielleicht zwischen den Gattungen Peptonococcus und Indolococcus unterscheiden.

The genus is not included in his outlined classification.

Iodococcus. A corrected spelling of Jodococcus q.v. (Miller 1892, p. $63)$ used by Migula (1900, p. 218) and others.

Jodococcus. A generic name used by Miller (1888, p. 612) to designate certain cocci found in the mouth which stain blue to violet with iodine.

The first organism named by Miller was Jodococcus magnus. This is a large coccus or diplococcus of variable size (1892).

Das Reinzuchten gelang zuerst auf einem Nahrboden, der aus gleichen Theilen Agar-agar Gelatine und einer, bei Zimmertemperatur eben starr werdenden Lösung von Zahnbeinleim zusammengestezt war. Er enthielt ausserdem 1.5 Zucker und 1.5 Stärke.

Upon this medium an abundant growth quickly developed. The plate was then covered with a weakly acidified iodine potassium iodid solution. The medium was colored bluish, and most bacterial colonies yellowish. Some, however, show a violet color, and subcultures from these retain this power. The reaction shows up best on agar containing sugar.

A second species described is Jodococcus parvus. A third species, Jodococcus vaginatus (1892, p. 63) is described as follows:

Er erscheint in Ketten sind mit einer Scheide versehen, in welcher die Zellen als flache Scheiben oder in mehr abgerundeten, auch viereckigen Formen erscheinen, die zuweilen grosse Aehnlichkeit mit Tetraden besitzen. Die Verbände haben einen Durchmesser von 0.75. Mitunter findet man Ketten, in welchen ein oder mehrere Glieder fehlen oder ausgefallen sind, wieder andere, bei denen die Hulse zersprengt worden ist, die Glieder aber ihre Verbindung mit der Kette nicht völlig gelöst haben, die Reste der zersprengten Scheide sind mit unter leicht nachweisbar; dieselbe nimmt keine violette Färbung an, sondern bleibt farblos oder wird nach längerer Einwirkung des Reagens schwach gelblich. Der Zelleninhalt färbt sich mit Jod stets tiefblau bis violett.

Migula $(1900,218)$ has attempted to identify Miller's Jod. vaginatus, but without success.

The species of Miller do not seem to have been recognized by later authors. It is rejected by Erwin F. Smith (1905). 
The first species described, Jodococcus magnus may be regarded as the type. The organisms, however, have not been identified. The position of the genus and its nomenclatural status is certain.

Kalymmabacterium. A name used by Beaurefaire-Aragao and Vienna (1912). See Calymmatobacterium.

Karphococcus. A variant of the generic name Carphococcus (q.v.).

Karpholkokkus. A variant spelling of Carphococcus q.v.

Keratophyton. A casual name used by Rosenbach (1908, p. 514) to an organism believed to cause corneal ulcers. Enlows (1920, p. 50) gives the following characterization:

Doubtful as to its position-belongs either with the bacteria or with the "schimmelpilzen." Varied form and size. Some of the rods are so short as to appear like cocci, many are somewhat longer, others again (young cultures) form very long, wave-like, at times branched threads. Here and there are thick, spindle-shaped or irregular drawn-out forms, which sometimes are filled with vacuoles. Many of the rods are similar to the bacilli of chicken cholera.

Kladothrix. A German spelling of Cladothrix, q.v.

Klebsiella. A genus named by Trevisan (1885, p. 105) with the following description.

Due stadi di sviluppo vegetativo: 1. Bacilli. 2. Cocchi. Bacilli (stadio protoplastico tipico) cilindrici, diritti, inarticolati, incolori, biformi: macrobacilli e microbacilli; citioplasma equabilmente diffuso, Cocchi (stadio finale) derivati da microbacilli, seriati in monili, appaiatico solitari. Bacilli e cocchi costantemente in ogni stadio racchiusi in crasse vagine sacchiformi membranaceomucose. Spore nulle. Specie unica. Klebsiella crouposa. Bacterium Pneumoniaecrouposae Zopf (Spaltpilze, 3 ediz. pag. 66, fig. 20).

Later $(1887$, p. 94) he expanded the generic description as follows:

Tre stadidi sviluppo vegetativo: 1. Baculi; 2. Filamenti; 3 . Cocchi. Baculi (stadio primigeno tipico) cilindrici, inarticolati, incolori, biformi; macrobaculi e macrobaculi e macrobaculi. Filamenti (stadio anormale transitorio, osservato solamente in culture nella camera umida) resultanti da baculo o cocchi rimasti in congiunzione per incompleta temnogenesi. Cocci segregati (monococchi od ottoformi) o seriati in catenelle. Baculi e cocchi normalmente raccheusi in crasse capsule membranaceo-mucose. Spore (osservate nella sola Klebsiella rhinoscleromatis) provenienti nei baculi o ignote.

The following species are listed: 1. Klebsiella rhinoscleromatis (Bacillus of rhinoscleroma of Frisch). 2. K. salivaris (Microbe de la salive of Pasteur). 3. K. pneumoniae, and 4. K. aerobia (capsulated air bacillus of Babes). Trevisan later (1888, p. 787) discussed the genus Klebsiella in detail. Sixteen species were described. The 
species previously termed Klebsiella crouposa or $K$. pneumoniae was renamed $K$. Friedlanderi. According to De Toni and Trevisan (1889, p. 1028) the diagnosis is as follows:

Baculi recti, tum cylindracei apicibusque rotundatis, tum ellipsoideo-fusiformes apicibusque attenuatis, in articulati, hyalini, immobiles vel rarius mobiles; plasma aequaliter diffusum. Filamenta flexuosa vel recta, cylindracea vel moniliformia, articulata, a baculis temnogenesi transversali imperfecta adhue conjunctis constitua. Cocci globulosi, e baculorum seu filamentorum transformatione orti. Baculi, filamenta, cocci intra capsulas membranaceomucosas, raro firmas, inclusi. Sporae (endosporae) in baculis provenientes.

The generic description does not fit closely any of the species included by De Toni and Trevisan as they are now understood. The genus is divided into two species groups. "Species anthrophobiae," with fourteen species, and "Species zoobiae," with three. Two species Klebsiella rhinosclcromatis and $K$. salivarius are credited to "Trevisan 1887." Of the species named in 1889, K. Friedlanderi (Friedlanders pneumobacillus) and $K$. enteritidis are well known. This genus name is rejected by Erwin F. Smith (1905).

Vuillemin (1913, p. 525) has proposed that Trevisan's Klebsiella salivarius (Diplococcus pneumoniae of Weichselbaum) be constituted the type of a "Genus conservandum," with an emended diagnosis. However, the generic name Diplococcus pneumoniae Weichselbaum has priority, and Diplococcus (q.v.) should be used if the pneumococcus is to constitute the type of the genus.

As indicated by Enlows (1920, p. 50) the type species is Klebsiella crouposa Trevisan.

De Toni and Trevisan (1889, p. 1029) give the following synonymy for Trevisan's Klebsiella Friedlanderi:

Hyalococcus pneumoniae Schroeter (1886)

Pneumococcus Friedlander

Bacterium pneumoniae-crouposae Zopf.

Klebsiella crouposa Trevisan 1885

Klebsiella pneumoniae Trevisan 1887

It is evident that the correct name for the type species therefore is that of the Friedlander pneumobacillus. Its name is probably either Klebsiella crouposa or Klebsiella pneumoniae. From the standpoint of usage the latter is preferable. Klebsiella has priority over Hyalococcus and Encapsulatus, both based on the same type species.

Klebsielleae. A tribe of bacteria proposed by De Toni and Trevisan (1889, p. 1028) with the following diagnosis: "Baculi tegumentis speci- 
alibus membranaceogelatinosis (capsulis) involuti." The following subtribes are included: Euklebsielleae (genera Winogradskya, Klebsiella and Dicoccia) and Myconostoceae (genus Myconostoc).

Klebsiellee. A rariant of Klebsielleae used by Trevisan (1889, p. 25) with the description "Baculi, filamentie cocchi racchiusi in capsule membranaceo-gelatinose." It constituted the second tribe of Baculogene and contained the three genera Klebsiella, Dicoccia and Myconostoc.

Kokkaceen. An aberrant spelling of the family Coccaceae used by certain German writers (as Hueppe 1886, p. 140).

Kokken. Baumgarten (1890, p. 127) states: "1. Gatt. Kolken, Bacterien arten umfassen $d$. welche nur kugelige Vegetationsformen bilden."

Usually used as a casual designation in German.

Kokkobacillus. A generic name used by Biedert (1885, p. 439) for the species $K$. zymogenus. It is to be regarded as a variant of Coccobacillus (q.v.). Kokkobacillus avicidus is listed by Eisenberg (1891, p. 275) as a synonym of Bacillus cholerae gallinarum.

Kokkobacteria. A variant spelling of Coccobacteria used by Klebs (1887, p. 50).

Kokkobacterium. A variant spelling of Coccobacterium, q.v. The name Kokkobacterium Lyssae is used in a review of an article by Rivolta in Deutsche. med. Wochenschr. (1886, p. 313).

Kokkothrix. A German variant of Coccothrix (Unna 1887, p. 29).

Kokkus. A spelling of Coccus or coccus used by certain German authors. For discussion see Coccus.

Kurthia. A genus established by Trevisan (1885, p. 92) to include Kurthia zopfi, the Bacterium zopfii of Kurth. The original description follows:

Tre stadi di sviluppo vegetativo: 1. Filamenti. 2. Bacilli. 3. Cocchi. Filamenti (stadio protoplastico tipico) cilindrici, dapprima apparentemente inarticolati, dappoi articolati, diritii, uniformi, agglomerati in colonie irregolarmente arrotondate. Cocchi (stadio finale dapprima appaiati, indi liberi. Spore nulle od ignote. Specie unica. Kurthia Zopfii.

It is noted as the fifth genus of Leptotrichiee by Trevisan (1889, p. 11) with the description "Vagine nulle."

Later the organism named Bact. Laminariae of Billet was included. The generic diagnosis as given by De Toni and Trevisan (1889, p. 931) is as follows: 
Filamenta cylindrica, vagina delicatissima evanescente obducta, simplicia, utrinque apicibus conformia, primitus apparenter subcontinua, cito articulata, articulis aetate provecta, vagina evanida, in baculos et coccos soluta. Multiplicatio baculis primitus vivide mobilibus, propere immotis. Arthrosporae transformatione cocei singuli ortae. Obs. Arthrospore in parvulos acervos zoogloeicos conglobantur in quibus nova filamenta radiatur exoriuntur.

The genus is rejected by Erwin F. Smith (1905).

Bact. zopfii Kurth may be regarded as the type.

Apparently Wenner and Rettger were not aware of the use of Kurthia with the species $K$. zopfii as the type, as this has priority over Zopfius $q . v$. which has the same specific type.

Kurthieae. A tribe created by De Toni and Trevisan (1889, p. 929) with the following diagnosis: "Sporae (arthrosporae) in filamentis normalibus obvenientes. Filamenta simplicia, basi ab apice superiori ut plurimum distincta, vaginata vel evaginata."

The following genera are included, Detoniella, Rasmussenia, and Kurthia.

Lactobacillaceae. A family named by Winslow et al. (Committee Soc. Am. Bact., 1917, p. 561) with the following description:

Rods, often long and slender, Gram-positive, non-motile, without endospores. Usually produce acid from carbohydrates, as a rule lactic. When gas is formed, it is $\mathrm{CO}_{2}$ without $\mathrm{H}_{2}$. The organisms are usually somewhat thermophilic. As a rule microaerophilic; surface growth on media poor.

The genus Lactobacillus ivas included.

Lactobacillae. A variant spelling of Lactobacilleae used by Bergey et al. (1923, p. 241). It is included as the eighth tribe of the family Bacteriaceae. The description follows:

Rods, often long and slender. Gram-positive. Non-motile. Without endospores. Usually produce acid from carbohydrates, as a rule lactic. When gas is formed it is $\mathrm{CO}_{2}$ without $\mathrm{H}_{2}$. The organisms are usually somewhat thermophilic. As a rule, microaerophilic. Surface growth on media is poor.

Lactobacilleae. A tribe named by Winslow et al. (1920, p. 211).

Rods, often long and slender, Gram-positive, non-motile, without endospores. Usually produce acid from carbohydrates, as a rule lactic. When gas is formed, it is $\mathrm{CO}_{2}$ without $\mathrm{H}_{2}$. The organisms are usually somewhat thermophilic. As a rule microaerophilic; surface growth on media poor.

It includes the genus Lactobacillus.

Lactobacillus. A genus of bacteria proposed by Beijerinck (1901, p. 214) to include all rod shaped forms "qui produisent l'acide actif 
lévogyre." It differs from the genus Aerrobacter in that no hydrogen is produced. Included in this genus are those forms which produce lactic acid at temperatures above $30^{\circ} \mathrm{C}$. and which are responsible for the fermentations of Kefyr, of Koumys and of the Matzoon. The acidification begun by the Lactococcus is continued in milk by Lactobacillus. These organisms are likewise responsible for the souring of ensilage, and constitute the socalled acidophile flora of the intestines of infants. The species Lactobacillus fermentum, $L$. delbrückii and $L$. caucasicus are listed, the two former from fermentation industries, the latter from Kephir.

Beijerinck says (1901, p. 213) that Lactobacillus and Lactococcus "sont certainement des genres phylogenetiques et nur point des 'genres physiologiques' comme par exemple Photobacter, ou simplement morphologiques comme les 'genres' Bacillus, Pseudomonas, Micrococcus, etc." Later he diagnoses the genus as follows:

Au genre Lactobacillus doirent être rapportes les ferments lactiques actif de forme bacillaire qui produisant l'acide actif levogyre et qui se rapprochent du genre Aerobacter dont jai donné la diagnose en 1900. Pourtant Lactobacillus se distingue de se genre en ce que la production l'hydrogene, caractere important pour le diagnostic d'Aerobacter y manque absolument, ainsi que dans tous le autres ferments lactiques actifs.

Beijerinck (1908, p. 370) discussed the characters which differentiate Lactobacillus caucasicus and $L$. longus.

The type species is somewhat difficult to determine. Beijerinck (1901) states that the question of species is troublesome, then

Passant sous silence pour le moment les $L$. fermentum et $L$. Delbrücki, producteurs du levain lactique, nous rencontrous en premier lieu le Lactobacillus caucasicus, dont les zooglées sont bien connues sous le nom de grains de Kéfyr.

$\mathrm{He}$ then describes the last named species. It would seem that although $L$. fermentum is first mentioned, $L$. caucasicus may be regarded as the type.

Winslow et al. (Committee Soc. Am. Bact. 1917, p. 561) state the generic characters are those of the family Lactobacillaceae and the type species is $L$. caucasicus (Kern?) Beijerinck.

Buchanan (1918, p. 54) states:

Rod-shaped organisms, cells frequently quite elongate, non-motile, without spores, Gram-positive in young cultures. Produce acid, largely lactic, from carbohydrates. When gas is produced, it is $\mathrm{CO}_{2}$ without hydrogen. For the most part the organisms are thermophilic. Microaerophilic.

The type species is Lactobacillus caucasicus (Kern) Beijerinck. 
Bergey et al. (1923, p. 241) include this as the single genus of the tribe Lactobacillae.

Lactobacter. A name applied by Beijerinck (1900, p. 200) to include all lactic acid bacteria, both rods and cocci. It may be regarded as a physiological genus. It has been used only as a casual name. It is rejected by Erwin F. Smith (1905).

Lactobacteriaceae. A family name proposed by Orla-Jensen (1921, p. 271) in the following statement:

Although it is well-known that the rod as well as the colorless sulphur bacteria may appear in all the forms known in the world of bacteria, and that even a single species of bacteria (for instance, Crenothrix and Azotobacter) in the first state of development may only divide in one plane but later in more planes, yet the Committee cannot admit that in case of other bacteria there may be a near relationship between sphere-, rod-and screw-forms. Still I entertain a perhaps not unwarranted hope, that my recently published monograph of the lactic acid bacteria may be able to change the opinion of the Committee. Here we have to do with a large group of bacteria consisting of sphere- as well as rod-forms, nevertheless forming a natural family which we could call Lactobacteriaceae. This family I have founded, of course, not only on the specially developed power of forming lactic acid (since there exist many different organisms which are able to form, at any rate, small quantities of lactic acid); but I base it upon the fact that the bacteria which we call true lactic acid bacteria have so many other properties in common that there cannot be any doubt about their close relationship. Thus, they are Gram-positive, facultatively anaerobic (withoutsurface growth in stab culture), they make excessively great demands as to nitrogenous nutriment, and, most remarkably, in contradistinction to most other bacteria, they are unable to liberate oxygen from peroxide of hydrogen.

Lactococcus. A genus proposed by Beijerinck (1901, p. 213). He emphasizes that this genus and Lactobacillus are natural genera. $\mathrm{He}$ states:

Les ferments actifs (lactique) appartiennent a deux genera naturels, Lactobacillus et Lactococcus, qui se distinguent nettement aussi bien par la forme que par leurs qualities physiologiques et qui, d'apres ma conception sont certainement des genres phylogenetiques et non point des genres physiologiques, comme par example Photobacter, ou simplement morphologique comme les genres Bacillus, Pseudomonas, Micrococcus, etc., qui tous contiennent des formes bien e'loignées dans le systéme naturel.

The genus includes those cocci, both diplococci and streptococci which at temperatures below $30^{\circ} \mathrm{C}$. produce the lactic fermentation of milk, and which commonly produce dextrorotatory lactic acid. The most common species, the form which may be regarded as the type, is Lactococcus lactis, the Bacterium lactis acidi of Leichmann (1896, p. 
777). A second species is Lactococcus hollandiae Weigmann. The genus is discussed by Stockhausen (1907, p. 164). Beijerinck later (1908, p. 641) named a third species, Lactococcus agglutinans, a form previously described by Barendrecht as Leuconostoc agglutinans (1901, p. 623). The genus is also recognized by Kossowicz (1912, p. 94). It is probable that this genus is to be regarded as a synonym of Streptococcus.

The type species is Lactococcus lactis Beijerinck. If the milk cocci are to be separated from the pathogenic forms of the genus Streptococcus this would appear to be a valid genus.

Lactosarcina. A generic name used by Beijerinck (1908, p. 359) for sarcinae which produce lactic acid. He concluded that the Sarcina ventriculi produces sufficient lactic acid in milk to justify its inclusion in this genus.

This name has apparently not been used by other writers, and is probably to be regarded as a synonym of Sarcina Goodsir.

Lampozoidia. The subdivision of the protozoa created by Perty (1852, p. 179) to include the form now know as bacteria (among others). The definition of the group is as follows:

Farblos seltener blau, gelb, röthlich (nicht grün) gefürbt, ohne specifische Organe, kaum mit einer Spur von Differenzirung ihrer Substanz. Bewegung scheinbar willkührlich, in Wahrheit automatisch. Vermehrea sich durch Quertheilung und stellen so Ketten und Fäden dar.

Lamprocystaceae. A subfamily of the sulphur bacteria named by Migula (1900, p. 1043). The diagnosis is as follows: "Zellen zu Familien vereinigt. Teilung der Zellen zuerst nach 3, dann nach 2 Richtungen des Raumes." This subfamily contains the single genus Lamprocystis. The subfamily is again recognized by Migula (1904, p. 146) by Erwin F. Smith (1905, p. 163) and by Frost (1911, p. 61).

Lamprocysteae. A name proposed by Buchanan (1918, p. 467) for a tribe of sulphur bacteria containing the single genus Lamprocystis. The definition is: "Cells united into families in which division of the cells occur first in three planes, then in two."

This designation is used by Bergey et al. (1923, p. 297) in the same sense.

Lamprocystis. A generic name proposed by Schroeter (1886, p. 151) to replace the invalid Cohnia Winter (q.v.). He gives the following generic description: 
Zellen elliptisch, anfangs zu rundlichen Zellhaufen zusammengeballt, später hohle Säcke bildend, in welchen die Zellen einschichtig einer Schleimmasse eingebettet lagern; zuletzt zerreisst die Haut stellenweise und bildet ein Netz. Zellinhalt röthlich. Von der Spaltalgengattung Clathrocystis Henfrey nur durch den Mangel des Phycochroms verschieden.

One species is included, Lamprocystis roseo-persicina. Winogradsky $(1888$, p. 71$)$ described the genus in somewhat greater detail. $\mathrm{He}$ states :

Ihre Zellen sind nach der Theilung kugelig oder kaum merklich elliptisch, mit einem Durchmesser von $2.1 \mu$, vor der Theilung fast doppelt so lang. Die Farbung ist nur in der Masse ziemlich intensiv violett. Die sehr kleinen, punkt förmigen Schwefelkörnchen verleihen der Zoogloea einen braünlichen Ton. Die Intensität der S Einlagerung und Oxydation ist viel geringer als bei Thiocystis.

De Toni and Trevisan (1889, p. 1038) give the following diagnosis:

Cocci globosi vel subelliptici, numerosissimi, in muco matricali nidulantes, in familias globosas magnas inordinate cumulati. Glebae singulae cystidibus universalibus gelatinosis involutae, initio globoso-ovideae, nitus solidae, dein cavo-saccatae, aetate provecta figuratae, irregulariter clathratae, demum in parvos cumulos libere natantes solutae. Cystides speciales nullae. Coccorum divisio mitio glebarum in tres directiones, dein in duas. Sporae ignotae.

The generic description most frequently used is that of Migula (1900, p. 1043): "Familien anfangs solid, darvor hohlkugelig, netz formig durchbrochen, endlich in kleine, schwarmfähige Gruppen sich auflösend." He includes the genus in the Rhodobacteriaceae. This description has been used by Smith (1905, p. 163) and Frost (1911, p. 61). The generic name is also used by Orla-Jensen (1909, p. 334) for the eighth genus of the family Rhodobacteriaceae of the order Cephalotrichinae.

Buchanan (1918, p. 467) gave the following generic description:

Cells ellipsoidal, dividing at first in three planes to form spherical cell masses, later in two planes, forming hollow sacks in which the cells lie embedded in a layer in the walls, finally the membrane ruptures, and the whole mass becomes net like, much as in the algal genus Clathrocystis. Usually colored intensely violet. Small sulphur granules present. Capable of swarming.

The type species is Lamprocystis roseo-persicina (Cohn) Schroeter.

Bergey et al. (1923, p. 387) follow Buchanan, including this genus in the tribe Lamprocysteae.

Lampropedia. A genus of cocci proposed by Schroeter (1886, p. 151) with the following diagnosis: 
Zellen zu 4 oder mehr zu regelmässigen flachen Täfelchen vereinigt, farblos oder lebhaft (nicht grün) gefürbt. Von der durch Phycochrom gefärbten Spaltalgen Gattung Merismopedia Meyen nur durch den Mangel des spangrünen Pigments verschieden.

One species is included, L. hyalina (Kützing) Schröter.

The genus is included in Thiopedia (q.v.) by Winogradsky (1888, p. 65). De Toni and Trevisan (1889, p. 1049) give Erythroconis Oerst. (1842) as a synonym. Their description of the genus is as fol'ows: "Cocci quaternati in exiplanato, ambitu parallelogrammico, obvolutas laxe consociati. Coccorum divisio in duas directiones." They divide the genus into two sections, one containing sulphur granules, and one not containing them, with four species in the first and two in the second section. Vuillemin (1913, p. 520) regards this genus as a synonym of Merista Van Tieghem 1883.

Buchanan (1918, p. 468) included this as the first genus of the tribe Thiopedieae with the description:

Cells united into tetrads, forming flat tubular masses. Contain sulphur granules and bacteriopurpurin.

The type species is Lampropedia hyalina (Kuetzing) Sehroeter.

Most recent writers have followed Winogradsky and Migula in disregarding the genus. It is rejected by Erwin F. Smith (1905).

Lankoides. A name given by Castellani and Chalmers (1919, p. 934) to the ninth genus of the family Ebertheae. Their description is:

Ebertheae fermenting glucose partially with the production of acid, but no gas; lactose not fermented or only partially, without gas production. Milk clotted.

Type species.-Lankoides pyogenes (Passet, 1902).

Later (1920, p. 606) five species are included.

Leptomitus. A generic name used by Agardh (1824, p. 83) to include "algae" of various types which grew in certain solutions. The generic description given by Kuetzing (1843, p. 154) reads:

Trichoma articulatum, in apicem attenuatum, ramosum; articulovaginati. Spermatia lateralia, epispermio pellucido cincta. Ausser den angeführten Merkmalen weichen die meisten Arten dieser Gattung auch noch dadurch von Hygrocrocis ab, dass ihre Zellen hohl und ihre Zelleninhalt häufig vielkörnig (polygonimisch) ist; er wird von Jodintinctur, die auch hier bei der Untersuchung gute Dienste leistet, braun gefärbt. Die ersten Arten schliessen sich sehr an die letzten von Hygrocrocis an. 
Three species were described at this time. Later (1849, p. 154-157) thirty species were included, some of them doubtless being mold mycelia, others yeasts and probably some bacteria.

De Toni and Trevisan (1889, p. 933) regarded one species, $L$. divergens as a bacterial form and named it Leptotrichia rigidula.

This is not a valid bacterial genus.

Leptonema. A genus of algae named by Rabenhorst (1857). It is invalid because of prior use in botany for other forms (Jussieu, 1824, Hooker 1844) according to De Toni and Trevisan who (1889, p. 932) give Leptonema nivea Rabenhorst as a synonym of Leptotrichea nivea Trevisan.

Leptospira. A generic name proposed by Noguchi (1917, p. 755). Enlows (1920, p. 51) summarizes as follows:

Type species (monotypy). L. icterohaemorrhagiae (Inada and Ido, 1914). Cause of infectious jaundice. Closely wound, 10 to 12 coils within $5 \mu$, slender, cylindrical filaments with gradually tapering ends. Lengths 7 to $14 \mu$; rarely 30 to $40 \mu$; diam. 0.25 to $0.3 \mu$. Spiral amplitude, 0.45 to $0.5 \mu$. Spiral depth, $0.3 \mu$ regular. One or more gentle wavy curves throughout the entire length. In a free space one or both ends may be semicircularly hooked, while in semisolid media the organism appears serpentine, waved or bent. Flexible. No axial filament present; no chambered structure; no membrane; no crista; no flagellum; no terminal finely spiral filament; terminal or caudal (last 6 or 8 spirals) portion highly motile. Division transverse. Stains reddish violet by Giemsa's solution. Also places here Spirochaeta biflexa Wolbach and Binger. Noguchi considers this genus intermediate between the protozoa and bacteria. He later included the cause of yellow fever under this genus: L. icteroides Noguchi. See J. Exp. med. v. 29, 1919.

Bergey et al. (1923, p. 429) include this as the sixth genus of the family Spirochaetaceae with the following description:

Parasitic forms. Sharply twisted cylinders with flagelliform tapering ends, one extremity being sharply curved into a "hook."

The type species is Leptospira ictohemorrhagica (Inado and Ido) Noguchi.

Leptothrichaceae. See Leptotrichaceae. The third family of the order Desmobacteria proposed by Hansgirg (1888, p. 230). Two subfamilies are included, Leptothricheae and Beggiatoeae. No description is given.

Leptothricheae. A family name first used by Kuetzing (1843, p. 197) with the following diagnosis: "Trichomata tranquilla tenuissima, continua, (vel obsolete articulata). Cellulae propagatoriae propriae nullae." As a subfamily this name was also used by Rabenhorst (1865, p. 73) with the following diagnosis: 
Trichomata aut libera aut adhaerentia, simplicia, plerumque distincte articulata et vaginata, rarissime oscillantia, singula vel fasciculata, plerumque in stratum compactum saepe longe lateque diffusum, tenue (VIX lineam crassum) vel superimpositione ad pollicem usque incrassatum, spongiosum, interdum stratose zonatum et varie coloratum dense intracata. Propagatio adhuc ignota.

The following genera are included: Leptothrix Kuetzing, and Hypheothrix Kuetzing.

This name is the equivalent of Leptotricheae (q.v.). Robin (1853, p. 345) used this family name with the description given by Kuetzing, with the following addition: "Filaments tubuleux, déliés, continus, sans articulations, privés de mouvement, remplis d'un contenu (endochrome) confluent, indistinct. Cellules propagatrices speciales nulles ou inconnues." It was also used by Hansgirg (1888, p. 230) as the first subfamily of Leptothrichaceae including the single genus Leptothrix Kuetzing.

Leptothricheen. A family name used by Zopf (1884, p. 45) with the diagnosis: "Sei besitzen Coccen-, Stäbchen-, Fadenformen (welche einen Gegensatz von Basis und Spitze zeigen), und Schraubenformen." He included the genera Leptothrix, Beggiatoa, Crenothrix and Phragmidiothrix. Hueppe uses the same term (1891, p. 30) with the description: "Leptothricheen bilden im vegetativen Stadium Stäbchenwelche meist längere Faden bilden." Baumgarten (1890 p. 127) defines the term as a genus (Gattung), following Zopf in his definition, and terming Zopf's genera "Untergattungen." It may be regarded as the equivalent of Leptothrichaceae and Leptotrichaceae (q.v.).

Leptothrix. This genus was proposed by Kützing (1843, p. 198) for a group of algal species with the following description "Trichomata simplicia tenuissima, monogonomica, turgida, continua, vel obsolete articulata, in stratum vel caespitosum vel compactum, continuum, plerumque late expansum complicata." Four species are included, Leptothrix ochracea (Lyngbya ochracea Leibl.), L. aeruginea, L. lutescens (Hygrocrocis ochracea Ag., Calothrix lutescens Meneghini) and $L$. fontana (Hygrocrocis olivacea Kg. Bangia tenuis Kg.). The first species described ( $L$. ochracea) may be taken as the type. Its description is as follows:

L. fluctuans, natans, ochraceae; trichomatibus curvatis, intricatis, subtilissimis (diam. 1/1500-1/1200"'); articulis globosis vel oblongis. In Eisenquellen, besonders auf sumpfigen Wiesen und in seichten Gräben. 
The next reference to Leptothrix is for an entirely distinct type. Robin (1847, p. 345) according to Winter (1884, p. 56), De Toni and Trevisan (1889, p. 930) and Schroeter (1886, p. 171) described an organism from the teeth of a horse, which he termed Leptothrix buccalis. An examination of this reference shows the organism to be referred to (pp. 42-46) as "Algu filiforme de la bouche," but the name Leptothrix buccalis does not appear. Later Robin $(1853,345)$ gave the following generic description of Leptothrix and specific description of $L$. buccalis.

Genre Leptothrix, Iï̈tz, Trichomata tenuissima eramosa, nec concreta Filaments non rameux, ni engainés, ni cohérents. Trichomatibus rigidulis, linearibus rectis vel inflexis, non moniliformibus, achromaticus, extremitatibus obtusis, basi in stromate amorpho granuloso adhaerentibus. Long. $0^{\mathrm{mm}}, 020$ $0^{\mathrm{mmm}} 100$, lat. $0^{\mathrm{mm}}, 1005$. Hab. In superficie linguae, intervallis dentium, cavo dentium corruptorum, et in succis stomachi et intestini. Filaments assez roides, droits ou courbés, quelquefois coudés brusquement, à angle généralement obtus à bords nets, non moniliformes, extrémités non effilées, larges de $0^{\mathrm{mm}}, 0005$ et longs de $0^{\mathrm{mm}}, 020$ à $0^{\mathrm{mm}}, 100$, incolores, élastiques, réunis généralement, par la base, à une gengue amorphe granuleuse, et formant des faisceaux plus ou moins serrés, à moins qu'ils n'aient été détachés (pl. I, fig. 1 et 2). Hab., surface de la langue, matiéres accumulées dans les interstices des dents, ou la cavité des dents cariées, d'ou ils passent dans les liquides de l'estomac, ou de l'intestin dans les cas de diarrhée.

Robin also described a Leptothrix insectorum, from the rectums of various insects, particularly those living in water. The generic description given to fit this form by Trevisan $(1879$, p. 147) is "Somatia cylindrica, plus minus distincte articulata, tenuis, elongata, filiformia, recta, laxe fasciculata."

Kuetzing in 1847 (p. 220) published nine species of Leptothrix, all of them water and algal forms. Two years later (1849, p. 262) he listed and described a total of thirty-seven species. His generic description reads "Trichomata tenuissima eramosa nec vaginata, nec concreta." Eight species are grouped in the first division of the genus under the heading "Species basi adnatae." All of them are water algae, usually colored, but in some species colorless. Under the heading "Species trichomatibus liberis, vel intracatis et stratum formatibus" the other twenty-nine species are described. The first of these is $L$. ochracea. All species are water forms, and most are greenish in color. The $L$. buccalis is not recognized.

Rabenhorst (1865, p: 73) includes this genus among the Nematogenae with the description 
Trichomata tenuissima, abbreviata, adhaerentia, segregata vel laxe aggregata, nunquam intricata, saepius oscillantia, indistincte articulata et saepe distincta vaginata; cytioplasma homogeneum, aetate provecta granulosum nonnunquam fasciatim contractum.

Billroth $(1874$, p. 15) used the term to designate one of the growth forms of his pleomorphic Coccobacteria septica in which the organism occurred as a slender filament without visible articulations.

Cohn (1875) included this genus in his tribe Nematogenes to include those organisms which produce slender filaments, in which the articulations are indistinct, colorless, cylindrical, free and unbranched.

Trevisan (1879, p. 147) concluded that the genus Leptothrix is strictly algal, and created the new genus Leptotrichia (q.v.) with the single species $L$. buccalis.

Luerssen (1879, p. 24) accepts both the free living water forms and the parasitic types as members of this genus. He says:

Von der Gattung Bacillus nur durch die sehr langen dünnen undeutlich gegliederten Fäden verschieden. Im Wasser auf anderen Algen und Wasserpflanzen u. s. w. bei gewissen Krankheit prozessen auch am menschlichen Körper beobachtet. L. buccalis Rob. Auf dem Epithelium der menschlichen Mundhöhle, im Zahnen.

Magnin (1880, p. 90) emphasized that Leptothrix differs from Bacillus in that the filaments are long, adherent, very slender and indistinctly articulated.

Winter (1880, p. 56) includes two species only in his genus, Leptothrix buccalis and $L$. parasitica. His generic description is "Faden sehr lang und dünn, unverzweigten scheinbar ungegliedert, farblos, ohne Bewegung, ohne Körnchen, frei oder verfilzt." He states that the fungi which have been assigned to the genus Leptothrix are of very questionable specific value, and that the most of the true species of Leptothrix are typical algae containing phycochrome, implying that another designation should be formed for the organisms which are colorless and are grouped with the bacteria.

Grove's statement (1884, p. 34) is essentially a translation of that of Winter.

Zopf (1885, p. 95) states "Faden bescheidet oder unbescheidet. Theilungen sehr weit gehend. Zellen schwefellos."

From this time the term Leptothrix is frequently found used as a morphological designation for slender unbranched long rods. For example, Flügge states (1886) that "formerly" the bacilli were subdivided to include the true bacillus and leptothrix or very long rods. 
Schröter (1886, p. 170) used the following generic description: "Faden sehr zart, mit dünnen Scheiden, unbeweglich, Gliederung anfangs undeutlich. Vermehrung durch Zerfall des Fadens in Glieder." He includes three species only, L. ochracea, $L$. parasitica and $L$. buccalis. It may be noted that this definitely excludes from the genus the more strictly algal forms. He furthermore emphasizes a possible relationship of $L$. ochracea to Gallionella ferruginea.

Hansgirg (1888, p. 230) recognized this as the only genus of his subfamily Leptothricheae. He described one new species, Leptothrix cellaris and listed two others, $L$. ochracea and $L$. Thuretiana.

De Toni and Trevisan (1889, p. 930) removed $L$. buccalis to a new genus Rasmussenia to include five species, all of them forms from the mouth and related to $L$. buccalis. The genus Leptotrichia was reserved for some of them excluding $L$. ochracea. This species together with two others are included in still another genus, Detoniella.

Billet (1890, p. 23) says "Leptothrix, élément filamenteux dout la longueur depasse 10 fois la largeur."

Hueppe (1891, p. 30) states "Leptothrix unterscheidet sich von den arthrosporen Bakteriuaceen dadurch, dass die Faden einem Gegensatz von Basis und Spitze zeigen."

Leptothrix according to Ludwig (1892) includes bacteria which occur in long filaments, are unbranched, are without spores and are nonmotile.

The tendency of those interested primarily in medical bacteriology to limit the term Leptothrix to filamentous bacteria from the mouth is well shown in the following statement from Macé (1897, p. 1020).

Le genre Leptothrix n'est peut-etre pas à distinguer due genre Bacillus. Beaucoup de Bacilles, en effet, possédent la propriété, dans des conditions particuliéres de milieu, de croitre en trés longs filaments dont la composition en batonnets n'est visible que lorsqu 'on les traite par des reactifs coagulants ou coiorants. Or, c'est ce qui arrive pour le seul Leptothrix dont la morphologie est un peu connue, celui de la bouche. Plusieurs espéces de Bactéries en batonnets, habitant normalement la cavite buccale, peuvent peutêtre contribuer, ̀̀ cause des conditions de milieu, à donner ces touffes de longs filaments; on s'expliquerait alors facilement la divergence des caractères exposes par les divers auteurs, surtout la différence des dimensions.

\section{Chester (1901, p. 369) gives the following generic description.}

Filaments unbranched, non-motile, enclosed in very delicate or rather thick sheaths, either fixed or associated in slimy masses. The separation of the filaments and the presence of a sheath is demonstrated by special methods of stain- 
ing. The contents of the filaments become segmented, forming round or ovoid gonidia, which escape from the sheath and develop into filaments. Gonidia nonmotile.

In this he is followed by Allen J. Smith (1902, p. 272). Erwin F. Smith (1905) rejects the name as a generic designation.

Petruschky (1913, p. 270) includes this as one of the genera of the trichobacteria which never shows branching, is never wavy, with stiff filaments in which stages of division are to be recognized with difficulty.

Ellis (1907, p. 515) uses the $L$. ochracea as the type of the genus, defining the genus as consisting of organisms with sharply defined stiff membranes. Following are some of the principal characteristics of the organism. Usually associated with Gallionella ferruginea, over which it preponderates to the extent of about 20 to 1. Organism consists of a number of straight filaments free at both ends. Ends often unsymmetrical. Membrane very sharply contoured, internally as well as externally. Breadth varies from $1 \frac{1}{2}$ to $2 \mu$, but when covered with ferric hydroxide often reaches $3 \mu$ and more. Length reaches up to $200 \mu$ and possibly more. Formation of conidia takes place by means of a process of budding, constriction taking place as soon as the requisite length has been obtained. Sometimes the constriction is prolonged so that a number of quill-like structures are seen protruding from the organism. Eventually these also are abstricted and elongate to form new threads. The conidia are oral in shape and measure about $1 \mu$ in breadth and about $1 \frac{1}{4} \mu$ in length. Each has a single membrane. Multiplication also takes place by cell-division. At various unequal distances along both sides of the membranes, small nodules are formed. Each nodule divides into two, the split taking place between the two daughter-nodules. As the pairs of nodules are not exactly opposite the pairs on the other side of the membrane the daughter-cells are not symmetrical at the ends. The cell- and conidium-contents are perfectly homogeneous. In no stage of its life-history is any motility observable.

Jordan (1908) includes in the genus those trichobacteria with unbranched filaments.

Schwers (1908) used the name Leptothrix ochracea.

West (1904, p. 334) lists L. ochracea as a synonym of Lyngbya ochracea among the Myxophyceae.

Orla-Jensen (1909, p. 331) includes Leptothrix as the fifth genus of his Trichobacteriaceae in which the cells are unattached, not spiral, 
unbranched, without sulphur granules and in filaments. He concludes that Gallionella and Spirophyllum are growth forms of this genus.

Heim (1911, p. 254) again emphasizes the L. buccalis type. He says:

Diese in der Mundhöhle anzutreffenden Mikro-organismen sind steife, unverzweigte, fadenähnliche Gebilde, die sich mit Jodlösung gelb farben. Es gibt auch fadenartige Mikroorganismen, die sich mit Jod violett färben; sie sind bei Munderkrankungen wiederholt in körnerartigen Gebilden gefunden worden, die in ihrem Aussehen an Aktinomyzeskörner erinnerten. Genaueres liess sich über sie nicht ermitteln, weil ihre Züchtung bis jetzt nicht gelungen ist.

The legitimacy of $L$. ochracea as a species name is disputed by Molisch, who reduces this designation to a synonym of Chlamydothrix.

In a careful study of the organisms of the teeth Kligler (1915, p. 328) cultivated fifteen strains of Leptothrix buccalis, and used this designation. His characterization is as follows:

Morphology. A thick, long, straight, or curved thread with a club-head at one extremity and a tapering end at the other. It is generally $0.8-1 \mu$ thick and upwards of $10 \mu$ in length. Chromology. It stains readily with anilin dyes in young cultures. In older cultures it has the appearance of a faintly stained sheath enclosing a number of heavily stained granules. Young cultures are Gram-positive. In older cultures the sheath is decolorized while the granules retain the stain. It is not pleomorphic but the threads fragment very early into short, thick rods. Coccoidal forms are not seen. Biological properties. They are anaerobic, facultative-aerobic, non-motile, non-branching threads. They grow at $37^{\circ} \mathrm{C}$. and practically not at all at $20^{\circ} \mathrm{C}$. Cultural characters. No growth is obtained on agar. On glucose-agar-plates they give minute pin-point colonies after 3 to 4 days' incubation. Examined microscopically with a low power, they have a dark center with hairy outgrowth. They grow fairly well in serum-glucose-agar, best in the stab and only sparsely on the surface. The surface colony is raised, round, whitish, lustrous, rarely more than $0.5 \mathrm{~mm}$. in diameter. The addition of salivary mucinate to ordinary agar renders the latter a very favorable medium, a thin, grayish, white, spreading growth being obtained in 24 hours. Glucose, sucrose and maltose are fermented, but lactose is not attacked. Gelatin is not liquefied and neither indol nor ammonia is produced.

It is evident from the preceding discussion that the name Leptothrix has been used in four different ways:

1. Leptothrix. A genus of algae which may or may not include $L$. ochracea.

2. Leptothrix. A genus of iron bacteria with type L. ochracea.

3. Leptothrix. A genus of elongate bacteria, principally from the mouth, with $L$. buccalis as the type.

4. Leptothrix. Any elongate, rod-shaped organism. 
It would seem logical to make the first named species, $L$. ochracea, the type. This would limit the genus to the iron bacteria. The mouth forms may well be placed in the genus Leptotrichia in accordance with the proposal of Trevisan.

This was done by Buchanan (1918, p. 303) in the description:

Filaments of cylindric colorless cells, with a sheath at first thin and colorless, later thicker, yellow or brown, becoming encrusted with iron oxide. The iron may be dissolved by dilute acid, whereupon the inner cells show up well. Multiplication is through the division and abstriction of cells and motile cylindric swarm cells. Swarm cells sometimes germinate in the sheath giving appearance of branching. Pseudodichotomous branching may occur.

The type species is Leptothrix ochracea (Leiblein) Kuetzing.

Castellani and Chalmers (1919, p. 1068) give the following description of the genus and designation of type species.

Filamentous fungi with long, very thin mycelial threads, with no capsule or only a very delicate one; non-branching, non-septate, generally non-cultivable.

Type species. Leptothrix maxima Miller.

Some five species are listed, all parasitic.

Lieske (1921, p. 2) regards $L$. ochracea as the generic type.

Bergey et al. (1923, p. 390) follow Buchanan including the genus as the first in the family Chlamydobacteriaceae.

Leptotrichacei. A family name used by Schroeter (1886, p. 170) for Zopf's Leptotricheen (q.v.). The following genera are included: Leptothrix Kützing, Beggiatoa Trevisan and Crenothrix Cohn.

Leptotrichaceae. The corrected form of Leptotrichacei used by an abstracter (Journ. Roy. Mic. Soc., 1890, p. 758) of the work of Hansgirg (1890).

Leptotricheae. A family name given by Kuetzing (1843, p. 198) to a group of algae including the genus Leptothrix. Later it was used as a "generic" name by Sternberg (1892, p. 19) with the description:

The vegetative cells present rod-shaped and spiral forms, and grow out into straight, wavy or spiral filaments; these may show a difference between the two extremities of base and apex. Cocci-like reproductive bodies are formed by segmentation of the rod-shaped elements in these filaments. In some of the species the segments are enclosed in a common sheath. Subgenera; Leptothrix, Beggiatoa, Crenothrix, Phragmidiothrix.

Leptotricheen. A family name used by Zopf $(1885$, p. 51) with the following diagnosis: 
Sie besitzen Cocen-, Stabchen-, Fadenformen (welche einen Gegensatz von Basis und Spitze zeigen). Letztere gerade oder schraubig. Sporenbildung nicht nachgewiesen. Genera: Beggiatoa, Leptothrix, Crenothrix, Phragmidiothrix.

Later Baumgarten (1890, p. 12) used the same family name as a "genus" with the following description:

Leptoturicheen (Zopf), die vegetativen Zellen besitzen Stäbchen- und Schrauben Form; durch Verbildung der Einzelzellen entstehen grade, wellige und schraubige Fäden; die Fäden zeigen bisweilem dadurch, dass das eine Ende sich an einer Stelle des Nährbodens festsetzt, einen Gegensatz von Basis und Spitze. An den freien Enden der Fäden gliedern sich kugelige Bildungen ab, welche theilweise wohl unzweifelhaft die Bedeutung von Arthrosporen haben; ob diese kugeligen Glieder, wie Zopf annimmt, unter Unständen auch direct theilungsfähig sind, d. h. also sich wie echte Kokken verhalten, erscheint noch sehr fraglich. Bei einigen Arten dieser Gattung (Crenothrixarten) bilden sich um die Fäden Scheiden, in denen sich Eisensalze allagern können.

Untergattungen: Leptothrix, Beggiatoa, Crenothrix, Phragmidiothrix.

Hueppe (1891, p. 30) also used this form of spelling.

Leptotrichia. A genus of bacteria created by Trevisan (1879, p. 138) with the description: "Somatia cylindrica, plus minus distincte articulata, tenuia elongata, filiformia, recta, laxe fasciculata." The justification for this name for a group of organisms from the older genus Leptothrix is given as follows:

Da denominazione generica Leptothrix fu tanto istrattata che sarebbe forse miglior partito matterla fatto da parte; in ogni caso spetta alle Alghe, Percio, e per mutare il meno possibile, modificherei la desinenza.

One species, L. buccalis is given with Leptothrix buccalis Robin and Lebert as a synonym. Trevisan $(1889, \mathrm{p} .10)$ included this as the second genus of his tribe Leptotrichiee. Fourteen species are listed, the thirteenth in the list being Leptotrichia buccalis. The synonomy and generic diagnosis are given by De Toni and Trevisan (1889, p. 932) as follows:

Leptotrichia Trevisan (1879) Batter. ital., p. 14, Gen., p. 10, Leptothrix Kuetz. (1843). Phycologia generalis, p. 198, exparte, ein Winter. Die Pilze, p. 56, Schroet. Pilz. Schles., p. 170. Leptonema Rabenh. (1857) non Jussieu (1824) nec Hooker (1844), Ophryothrix Borzi (1878) N. Giorn. bat. ital., x., p. 274, Thiothrix Winogradsky (1888) Beitr. I, p. 29. Filamenti cylindrica, vagina tenuissima obducta, articulata, simplica, basi ab apice superiori distincta, inaequilata, ut plurimum propter pulvinulum mucosum affixa, raro libera, immobilia vel rarissime lente oscillantia. Multiplicatio filamentorum divisione ad unam directionem in articulos mobiles (baculogonidia) secedentium. 
Thirteen species of this genus are listed, included under four subgenera, Leucothrix Oersted, Ophryothrix Borzi, Thiothrix Winogradsky and Leptotrichiella Trevisan.

It is of interest to note that the original species named (Leptotrichia buccalis) is no longer included, but removed to the genus Rasmussenia.

Winslow et al. (Committee Soc. Am. Bact., 1917, p. 555) aecept this genus with the following description:

Thick, long, straight or curved threads, frequently clubbed at one end and tapering to the other. Gram-positive when young. Threads fragment into short, thick rods. Anaerobic or facultative. Non-motile. Filaments sometimes granular; non-branching. No aerial hyphae or conidia. Parasites or facultative parasites.

The type species is Leptotrichia buccalis (Robin) Trevisan.

Buchanan (1918, p. 405) states: "Rod shaped or filamentous cells, non-motile, unbranched, without aerial hyphae or conidia: parasites or facultative parasites."

Bergey et al. (1923, p. 338) follow the Committee, including this as the second genus of the family Actinomycetaceae.

In spite of Trevisan's disavowal, Leptotrichia buccalis (Robin) Trevisan is the type of the genus.

Leptotrichieae. A tribal designation used by De Toni and Trevisan $(1889$, p. 932) with the following deseription: "Sporae nullae aut saltem huiusque numquam detectae. Filamenta simplicia."

The following genera are included, Leptotrichia Trevisan, Phragmidiothrix Engler and Beggiatoa Trevisan.

Leptotrichiee. A name given by Trevisan (1889, p. 10) to the second tribe of his suborder Tricogene. The description is "Sempliee." Six genera were included, Cladothrix, Leptotrichia, Phragmidiothrix, Beggiatoa, Kurthia and Billetia.

Leptotrichiella. The fourth subgenus of the genus Leptotrichia according to De Toni and Trevisan (1889, p. 935). The sole description is: "Zoobia." The only species is Leptotrichia amphibola Trevisan, from the stomach of a dog, the Streptomesobacterio of Maggi.

Leucocystis. A generic name proposed by Schroeter (1883, p. 196) for the species Leucocystis cellaris. The organism was found in slimy masses on the walls of wine cellars. The original description follows:

Die Hauptmasse des Schleimes wird gebildet durch zahllose Schizomyceten, die verschiedenen Gattungen angehören. Die häufigste und zwar überall mit Regelmïssigkeit vorkommende Form ist ein eigenthümlicher Micrococcus, den ich als Leucocystis cellaris beschreiben will. Er bildet kugelige oder kurz ellip- 
tische Körper von 1,5-2 $\mu$ Länge und etwa 1-1,5 $\mu$ Breite, die farblos, stark lichtbrechend sind. Sie werden von einer weiten Gallerthülle umgeben, die den Durchmesser des Coccus um das Mehrfache übertrifft, und dadurch eine Weite von 5 bis $8 \mu$ erreichen kann. Die Coccen mit ihren Hüllen liegen dicht an einander, grosse Klumpen bildend, die Hüllen fliessen aber nicht zusammen, sondern zeigen sich bei Zerdrücken der Ballen immer gesondert. Man findet in den verschiedenen Ballen Coccen in den verschiedenen Entwickelungszuständen, aus denen man erkennt, dass sich die Coccen durch fortgesetzte Zweitheilung in allen drei Richtungen des Raumes vermehren. Bis zu einer gewissen Grenze bleiben sie dabei in der Mutterhülle eingeschlossen; man findet daher Hüllen, welche einen, andere, welche zwei, vier und selbst acht Coccen enthalten. Die Hüllen, die mit zahlreichen Coccen gefüllt sind, sind etwas weiter als die, welche nur wenige enthalten, aber im Verhältniss nicht so dick. Durch Anilin-Farbstoffe wurden die Coccen stark tingirt, aber auch die Hüllen färben sich durch dieselben kräftig. Wendet man starke Farbstofflösungen an, so sieht man dann nur die stark gefärbten Hüllen, die selbst das Bild riesiger Coccen vortäuschen. Bei vorsichtiger Färbung, indem man sich durch scharfes Aufpressen und Abziehen des Deckglases eine sehr dünne Schicht darstellt, diese über der Flamme mässig erwärmt, dann mit nicht zu stark concentrirter Farbstofflösung allmählich färbt, erhält man sehr schöne Bilder, in welchen sich die Coccen lebhät, die Hüllen schwach gefärbt zeigen. Bei Betrachtung unter Oelimmersion und mit Beleuchtungsapparat sieht man nun, dass häufig die einzelnen Coccen in der Mutterhülle besondere Hüllen umgeben, oft auch ist die Mutterhülle aus mehreren. bis zu 5, verschiedenen Schichten gebildet, so dass das Ganze im optischen Durchschnitt fast das Aussehen eines Kartoffelstärkekornes erhält. Wurden die Coccen mit alkalischen Farbstofflösungen gefärbt, so wurden sie durch Zusatz von Säuren wieder vollständig entfärbt.

Diese Coccen haben in ihren einfachsten Entwickelungszuständen eine gewisse Aehnlichkeit mit denen, welche von C. Friedländer bei den an croupöser Pneumonie leidenden Kranken in den Lungen mit Constanz gefunden worden sind. Bekanntlich sind auch diese Coccen mit einer starken Schleimhülle umgeben, und auch bei ihnen sind die ersten Theilungszustände meist noch in dieselbe Hülle eingeschlossen. Weiter reicht indess die Aehnlichkeit nicht. Die vielkernigen Cysten von Leucocystis sind bei dem Pneumonie-Coccus (Leucocystis Pneumeniae) nicht gefunden, auch ist bei ihm eine Schichtung der Hülle nicht nachgewiesen.

Ich habe den Coccenschleim wochenlang im feuchten Raume unverändert gehalten, eine wirkliche Züchtung der Coccen, eine Vermehrung derselben habe ich aber bis jetzt nicht erzielen können. In Alcohol lassen sie sich sehr gut conserviren, sie nehmen auf Zusatz von Ammoniak nach langer Convervirungen ihre ursprïngliche Gestalt wieder an, zeigen auch Hülle wieder unverändert.

Later (1884, p. 299) he concluded the organism to be the same as Erebonema. Later (1886, p. 152) he gave the following generic diagnosis: "Zellen kuglig oder elliptisch einzeln oder zu mehreren zusammenstehend, von weiten, mehrschichtigen fest abgegrenzten Gallerthüllen umgeben und in Schleimmassen zusammenfliessend." 
Hansgirg (1888, p. 266) noted the presence of this organism in wine cellars, and gave Erebonema hercynicum Ktz. as a synonym. The genus is also recognized by De Toni and Trevisan (1889, p. 1041) with the description:

Cocci globosi v. divisiones tempore globosoovoidei, pauci in muco matricali nidulantes, segregati, in familias parvulas, singulas cystidibus universalibus, amplis, crassis, plurilamellosis, gelatinosas, involutas, inordinate consociati. Cystides in membranulam mucosam confluentes. Cystides speciales nullae. Coccorum divisio in tres directiones. Obs. Generis Thiothece clade affines, a quo cystidibus e stratis pluribus latis efformatis in primis distinquitur.

The only species given is Leucocystis cellaris with the variety cavernarum Hansgirg.

Migula (1900, p. 195) reduced this generic name to a synonym of Micrococcus, the species becoming Micrococcus cellaris. The genus is rejected by Erwin F. Smith (1905). Apparently the name has not been recognized by other authors.

If the organisms described by Schroeter is worthy of generic rank, probably Leucocystis is valid as its name.

Leuconostoc. A generic name proposed by Van Tieghem (1878, p. 198) for the organism studied by Cienkowski and regarded as responsible for the formation of gum in sugar factories. Cienkowski (1878) named his organism Ascococcus mesenteroides. Van Tieghem showed that this organism was distinct from Cohn's Ascococcus (q.v.). The genus Leuconostoc was created with the following diagnosis:

Cellulae achromaticae minimae globosae, in catenas laxas flexuoso-curvatas implicata, vagina gelatinose cartilaginea lobata crassissima circumdatas, consociatae. Vaginae in thallum gelatinose-cartilagineum, subglobosum vel crassissimo membranaceum, irregulariter expansum, extus cerebroideum, intus pseudoparenchymaticum aggregatae. Sporae singulae, globosae, majores, terminales vel interstiales, pachydermaticae, intus homogeneae.

Van Tieghem places Leuconostoc among the Nematogenae of Cohn's classification, while Ascococcus was placed by Cohn in the Glaeogenae.

The genus with its species Leuconostoc mesenteroides (Cienkowski) Van Tieghem was recognized by Winter (1880) and by Grove (1884, p. 16).

It was included by Van Tieghem (1884) in the tribe Oscillariae of the family Nostocaceae. De Bary (1884) describes the genus as consisting of rosaries of cocci embedded in firm sheaths of mucilage, and with arthrospores. Zopf (1885, p. 61) states: "Bildet Coccen 
und Stäbchen. Sporenbildung in Coccen." Hueppe (1886, p. 144) included Leuconostoc in his "Gattung Arthro-Kokkaceen." Schroeter (1886, p. 154) likewise-emphasizes the production of spores. His diagnosis is as follows:

Vegetative Zellen kugelig, zu Ketten verbunden. Jede Kette in eine besondere Schleimkapsel eingeschlossen und in grösserer Menge zu zähen Schleimmassen verbunden. Sporen aus einer Zelle (einem Gliede der Kette) gebildet, welche auschwellt und sich mit einer festen Membran umgiebt. Aus jeder Spore geht bei geeigneter Ernahrung eine neuer Kette hervor.

Maggi (1886, p. 84) recognized the genus.

Ludwig (1886, p. XXV) named a Leuconostoc Lagerheimii from the oak slime.

Hansgirg (1888, p. 266) placed this genus in his subfamily Cystococcaceae, and described a variety, subterraneum of a L. Lagerheimii first noted by Ludwig (1886, p. XVII).

This genus is described by Trevisan (1889, p. 28), De Toni and Trevisan (1889, p. 1051) and by Sternberg (1892). Ludwig (1892, p. 29) noted that the genus contained organisms in which spherical cells occurred in chains and embedded in slime. Lehmann and Neumann (1896, p. 102) concluded that Leuconostoc is only a Streptococcus with enormously thickened capsules. Macé (1897) used much the same description as Schroeter. Migula (1900, p. 25) followed Lehmann and Neumann in concluding that Leuconostoc is not distinct from Streptococcus, and combined the two genera under the latter name. The interpretation of Migula has been accepted by most subsequent authors. Barendrecht (1901, p. 632) described a Leuconostoc agglutinans, a lactic acid organism from wort. It was later named Lactococcus agglutinins by Beijerinck (1908, p. 644). The generic name is rejected by Erwin F. Smith (1905, p. 174).

Winslow and Rogers (1905, p. 669) have revived Cohn's Ascococcus, accrediting it to Cienkowski and emending it to replace Leuconostoc. They state:

Van Tieghem (1878) a little later worked on the same form (Ascococcus mesenteroides Cienkowski) and substituted for Ascococcus the generic name Leuconostoc in order to emphasize the resemblance between zoogloea-forming Coccus and the blue green alga, Nostoc.

It would seem, however, that Cohn's name Ascococcus was applied to an entirely distinct type of organism, and that the Winslows' substitution of Ascococcus is unfortunate. Their characterization of the genus, however, gives the modern conception of this form: 
Saprophytic, growing vigorously in saccharine solutions. Cells in pairs or in true chains. In presence of certain carbohydrates large, lobed, gelatinous masses of zoogloeae are formed. Fermentation powers high, acid being produced in dextrose, lactose and saccharose.

Vuillemin (1913, p. 520) concludes that Leuconostoc should be treated as a section of the genus Streptococcus.

Buchanan (1917, p. 611) states:

Saprophytic, usually growing in cane sugar solutions. Cells in chains or pairs. Forming large zoogloeal masses when grown in sugar solutions. Produces acid actively from carbohydrates. Some types at least are Gram-negative.

The type species is Leuconostoc mesenteroides (Cienkowski) Van Tieghem.

Winslow et al. (Committee American Soc. of Bact. 1920, p. 206) give the following diagnosis:

Saprophytes, usually growing in cane sugar solutions. Cells in chains or pairs, united in large zoogloeal masses. Some types at least Gram-negative.

Type species, L. mesenteroides (Cienkowski) Van Tieghem.

Bergey et al. (1923, p. 45) follows the Committee, including the genus as the second in the tribe Streptococceae.

Leucothrix. A generic name adopted from Oersted (1844, p. 44) by De Toni and Trevisan (1889, p. 932) to serve as a subgenus of Leptotrichia Trevisan. The type species is Leptotrichia (Leucothrix) mucor (Oersted) Trevisan. The subgeneric description given is simply "Marinae, majores." Leucothrix was previously used by Trevisan $(1879$, p. 138) as a synonym in part of Beggiatoa.

Lineola. A name used by von Baer (1827, p. 748) in the following sentence:

Die Reihe für die Thiere des Typus mit vorherrschender Längendimension beginnt mit lebendigen Fäden; Lineola, (so mögen die einfachsten Vibrionen heissen), reprïsentirt sie unter den Protozoen.

Lipobacter. A generic name proposed by de Kruyff (1906. p. 1) for bacteria which hydrolyze and oxidize fat. These organisms are common in the soil, hydrolyzing fat to glycerine and fatty acids and later oxidizing each of these products.

If these organisms are deserving of generic recognition, this name possibly would be valid, although his species were numbered only and not named.

Liquidobacterium. A generic name proposed by Orla-Jensen (1909, p. 337) for organisms of the Proteus type. He says: 
Die Definition einer Proteus-Bakterie wird daher: Eine sporenfreie, peritriche Stäbchenbakterie, welche die Gelatine verflüssigen kann, und ihr Gattungsname musz in Analogie mit meiner übrigen Nomenklatur Liquidobacterium sein. Laut dieser Definition müssen wir unter anderem die farbstoffbildenden Bakterien $B$. prodigiosum und $B$. violaceum als Proteus-Bakterien betrachten. Dies stimmt auch gut: denn beide erzeugen Indol und andere stinkende Produkte. Ueberdies bildet Liquidobacterium prodigiosum ebenso wie Liquidobacterium vulgare aus Zucker vornehmlich Bersteinsäure und Ameisensäure. Es erinnert durch sein hohes Fettspaltungsvermögen an Liquidomonas fuorescens und durch seine Vorliebe für stärkehaltige Substanzen an die Kartoffelbacillen.

The genus is assigned to the order Peritrichinae family Alkalibacteriaceae, and is defined as requiring as a rule organic $\mathrm{N}$. sources, and as being an aërobic decay bacterium which does not produce spores, and which liquefies gelatin.

Since it is first mentioned, probably Liquidobacterium prodigiosum (Ehrenberg) Orla-Jensen is to be regarded as the type.

Liquidococcus. A gencric name proposed by Orla-Jensen (1909, p. 332). The genus is included in the family Luminibacteriaceae of the order Cephalotrichinae.

It is defined to contain those cocci which liquefy gelatin and which do not as a rule require organic nitrogen sources for development. No species is named or designated.

As a generic name Liquidococcus is probably best regarded as invalid or as a synonym of Staphylococcus or Micrococcus.

Liquidomonas. A genus of bacteria proposed by Orla-Jensen (1909, p. 332). It is included in the family Luminobacteriaceae of the order Cephalotrichinae. It includes straight rod-shaped organisms which are active liquifiers, which as a rule do not require organic nitrogen, aerobic and are as a rule fluorescent and sometimes denitrifying.

The first mentioned organism (type) is Liquidomonas fluorescens Orla-Jensen.

Later (1921, p. 271) he states:

As the property of liquefying gelatin also cannot be adopted as a generic character, I think it would be best to group together my earlier genera Denitromonas and Liquidomonas in a single genus, which can be conveniently termed Fluormonas, as the bacteria of this group are ordinarily fluorescent. I cannot agree to call this genus Pseudomonas merely out of regard for so-called priority, as each and all of the bacteria which belong to the order under consideration are really Pseudomonades as well.

And also: 
Perhaps the Committee is right in not regarding the Proteus-bacteria (my genus Liquidomonas) as a separate genus, as their whole metabolism indicates that they are to be looked upon as gelatin-liquefying Coli- and Aerogenesbacteria.

Probably this genus is to be regarded as a synonym of Pseudomonas.

Liquidovibrio. A gencric name proposed by Crla-Jensen (1909, p. 334). It is included in his family Luminibacteriaceae of the order Cephalotrichinae.

The generic characters are: Cells bent or spiral, usually not requiring an organic source of nitrogen, aerobic, often photogenic. The type species given is Liquidovibrio comma.

This name is probably to be regarded as invalid, and a synonym of Vibrio or of Microspira.

Lophotricha. A group name proposed by Messea (1891) to include bacteria with a cluster of flagella at one pole.

Luminibacteriaceae. A family name proposed by Orla-Jensen (1909, p. 333) to include the photogenic and fluorescent bacteria which do not contain sulphur or bacterio-purpurin, cells never in threadlike filaments and with no tendency to branching. The genera included are: Denitromonas, Liquidomonas, Liquidococcus, Solidococcus, and Liquidovibrio.

Macintoshillus. A name given by Heller $(1922$, p. 13) to the third genus of her tribe Clostridioideae with the following description:

Clostridioideae that do not liquefy gelatin. They produce acid and gas and no putrefaction in meat media. They do not readily attack milk and they ferment few or no sugars. Gram-negative rods with parallel sides and with terminal spherical spores. Colonics in deep agar are small and irregular but not woolly. Frequently found in wounds. Apparently incapable of invading tissue.

Type species tetanomorphus (pseudotetanus bacillus, McIntosh (p. 32), Bacillus tetanomorphus Committee (p. 41)), as described by the Committee. Glucose and maltose are fermented.

Macrococcus. A name occasionally used to contrast with micrococcus. It apparently has not been used as a generic name. It has the same meaning as megacoccus which is the preferable form. It has been used princinally with the spelling "Makrokokkus" (q.v.). It is listed among the rejected names by Erwin F. Smith (1905).

Makrokokkus. A name used by Miller (1892, p. 73) in his discussion of cocci. He states: "Dieselben zeigen sehr verschiedene Dimensionen, von sehr kleinen runden Kokken bis zu auffallend grossen Kokken "Makrokokken." It is an aberrant spelling of Macrococcus (q.v.). A better form is Megacoccus. It is not a generic name. 
Malleomyces. According to Trevisan (1879, p. 144) this name was applied by Hallier to the organism causing glanders, with the name Malleomyces equestris. It is possible that this should displace the much less appropriate Pfeifferella as a generic designation for the glanders group.

Mantegazzaea. A genus created by Trevisan (1879, p. 137). The description is as follows:

Somatia fusiformia vel cylindrica, distincte articulata, valida abbreviata, recta, segregata. Oss. VI appartegono due specie: Mantegazzaea Cienkowskii e $M$. articulata (Bacterium articulatum e B. triloculare Ehrenb., (1831). La prima ricorderebbe alquanto per la forma Bacterium roseum e Bacterium fusiforme di Warming, la seconda Bacterium Lineola. Da Bacterium pero differiscono perche evidentemente composte di piu cellule, ne ad alcun altro genere di Vibrioniee potrebbersi riferire. Il nome generico ricorda Paolo Mantegazza, che primo di tutti (1851) investigo e descrisse le spore perduranti delle Batteriacee in germinazione.

Later $(1889$, p. 12) he included it as the fourth genus of the tribe Bacillee. Five species are listed. The generic description is "Baculi fusiformi con protoplasma uniformemente diffuso. Spore ignotae."

The synonomy given by De Toni and Trevisan $(1889, \mathrm{p} .942)$ is as follows:

Rhabdomonas Cohn (1875) Beitr. 1, 3. p. 167. (nomen ineptum).

Rhabdochromatium Winogr. (1888) Beitr. 1. p. 100 et. in Bot. Centralbl. 1889, N. 6, 172.

The diagnosis is as follows: "Baculi fusiformes vel subcylindracei, recti, plasmate uniformiter diffuse, divisione transversali sese multiplicantes. Sporae ignotae.

Two subgenera are recognized, Rhabdochromatium with three species and Eumantegazzaea with three.

This generic name has not been generally recognized by writers on bacterial nomenclature. Vuillemin $(1913$, p. 521) has proposed that this name be retained as one of the "formogenera conservanda" with Mantegazzaea (Bacillus) hastilis (Seitz, 1889), the fusiform bacillus of the medical writers as the type species. This last suggestion would be invalid because of the earlier use of the name Fusiformis.

The type species (first species named and described) is Mantegazzaea Cienkouskii Trevisan. It is an organism occurring upon the surface of putrefying meat. Its identification is probably quite uncertain. It is quite improbable that it is related to the socalled "fusiform" mouth bacteria, and its use should not be revived. 
Martellillus. A name given by Heller (1922, p. 25) to one of the genera of her tribe Putrificoideae.

Hardy Putrificoideae that in meat medium multiply rapidly at an early stage of incubation, producing a greyish coloration and later a blackish deposit on the meat particles, and after three days' incubation cease to multiply actively. Sporulate early in the development of a culture, later cease to do so but vegetate very slowly. Produce very little gas in meat medium. Digest milk. Attack a few sugars. Heavy deeply gram-positive rods, may vary greatly in size. Spores usually cocoon-shaped, usually median or sub-terminal, do not greatly bulge the sides of the bacillus. Colonies in deep agar lenticular, irregular, or stellate. Common putrefactive organisms that readily invade tissue in company with other organisms, producing a greenish proteolytic gangrene. I have found them in the heart's blood and organs of a woman dying of pernicious vomiting and uraemic poisoning and apparently the only invader in a mouse dying from an otherwise unknown cause. The Committee find $B$. bifermentans in acute cases of gas gangrene. Weinberg and Séguin state that such an organism invades guinea-pigs in company with $B$. perfringens. It is possible that Martellillus bacilli produce metabolites poisonous to themselves and to animals and that cause early sporulation. They frequently cease active multiplication when the culture has a reaction near $\mathrm{pH} 7.0$.

Type species $M$. bifermentans (Bacillus bifermentans-sporogenes Tissier and Martelly) as defined by Tissier and Martelly.

Mastichomonas. A subgenus of Monas used by Diesing (1850, p. 22). Enlows (1920, p. 55) states:

Animalcula solitaria libera. Corpus ecaudatum, elongatum, subglobosum, ovatum, turgidum, v. planum, haud v. mollitie sua solum mutabile, divisione spontanea simplici perfecta bipartitum v. indivisum. Os terminale. Flagellum simplex. Ocellus nullus. Est Parenema (Euparenema) corpore haud mutabile. Includes under this subgenus 22 species: Monas (Mastichemonas) termo Müller (Ehrenberg), M. (Mastichemonas) punctum, M. (M.) lens, M. (M.) okenii, etc.

Megabacteria. Use ascribed to Billroth (1874, p. 16) for one of the growth forms of his Coccobacteria septia. See Megabacterien.

Megabacterien. A casual name used by Billroth (1874, p. 16) for one of the growth forms of his Coccobacteria septica.

Megabacterium. A name ascribed to Billroth (1874, p. 16) with the spelling Megabacterien to designate that growth form of his pleomorphic Coccobacteria septica in which the cells assumed the shape of large rods. The name has apparently never been used as a generic designation, although Smith (1905) has included this name in his list of invalid bacterial genera.

Megacoccos. A name used by Billroth (1874, p. 16) for a growth form of his pleomorphic Coccobacteria septica in which the cells assume 
the form of large cocci. The name has apparently never been accepted as a generic designation, although it is included by Smith (1905) (with the spelling Megacoccus) in his list of invalid genera.

Megacoccus. Maggi (1886, p. 83) termed one of his bacteria (the fermentum butyricum of Fitz.) Micrococcus (Megacoccus) butyricus. The name was listed as invalid by Erwin F. Smith (1905, p. 152).

The incidental use by Maggi is scarcely sufficient to validate the term.

Megalothrix. A generic name proposed by Schwers (1912, p. 273) to designate a genus of iron bacteria, with the single species Megalothrix discophora. The original description follows:

Besonders ist mir seit Jahren eine Fadenbaliterie aufgefallen, welche sich von den Leptithrix ochracea- Füden stets leicht unterscheiden liesz durch einen zarter abgegrenzten Kanal und durch eine sehr breite, homogene, oder sehr feinkörnige, graue, hellgelbe oder hellorange Scheide, deren Umfang nur langsam nach einem Ende des Fadens abnahm; seltener kam eine Dichotomie vor; selten auch war es mir möglich, durch die dicke Scheide ein deutliche Einteilung des Fadens in längliche Zellen zu sehen.

Diesen eigenartigen Faden beobachtete ich zuerst nur spärtlich bei zahlreichen anderen Bakterien, bis ich einen eisenhaltigen Niederschlag auffand, der aus lauter solchen Fäden bestand. Auffallend was in diesem Präparat schon bei geringer Vergröszerung, die Gruppierung der Fäden, deren Büschel perückenförniig an einer Seite scharf abgregrenzt waren. Bei genauer Beobachtung konnte man erkennen, dasz jeder Fader für sich an seinem dicken Ende mit einem dunklen Quertrich aufhörte, und dasz gewisse dieser Büschel von diesem Strich ab auf einer dünnen Pflanzenwurzel hafteten. Ferner liesz sich bei vereinzelten Fäden die er Strich wiederfinden; bei anderen zahlreichen Fäden war aber der Strich durch eine runde Scheibe erzetzt, in deren Mitte der Kanal des Fadens deutlich endete. Dazu boten die isolierten Fäden nie ein solches Bild an beiden Enden. Bei Bruchstüicken waren gewöhnlich die beiden Enden ohne Haftscheibe; nur selten war diese an einem der Enden vorhanden. Es handelte sich also hier um Fadenbakterien, die mit einer Haftscheibe enden; letzere entspricht dem breitesten Ende des Fadens und stimmt mit ihm in der Grösze überein. Je nach der Stellung des Fadens wird im Gelatineglyzerinpräparat die Scheibe Seitlich schräg oder von vorne gesehen, und ist stäbchenförmig, oval oder rund. In der Mitte dieser runden Scheibe ist ein runder, heller Hof welcher dem Ende des Kanals entspricht; an dieser Stelle scheint die Scheibe bis auf das äuszerste verdünnt zu sein. Bei Fïden von einer Länge von durchschnittlich $300 \mu-$ wenn nicht gebro-

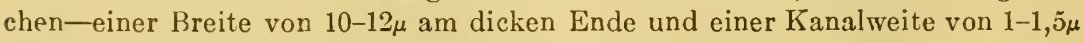
hatte die Haftscheihe entsprechend einer Diameter von $10-12 \mu$ wovon $1-1,5 \mu$ auf den $H_{o}$ entfielen, und eine Dicke von 0,3 bis $0,5 \mu$.

\section{Enlows (1920, p. 55) gives the following characterization:}

Type species (monotypy). M. discophora. Threads $300 \mu$ long, and 8 to $12 \mu$ wide, which contain longish cells. Distinguished from Leptothrix by the pos- 
session always of a delicate sharply defined canal, and a very wide, homogeneous or very finely granular, gray, bright yellow or bright orange sheath, whose circumference decreases gradually toward one end of the thread; dichotomy rare; seldom possible, because of thickness of sheath, to observe the division of the threads into the long cells.

Ellis (1913, p. 450) after a study of this organism concluded it to be simply a growth form of Crenothrix polyspora Cohn.

Melanella. A generic name created by Bory de St. Vincent (1824, p. 46). It is later described (1826, p. 533) as the second genus of the family Vibrionides. 'The organisms were described as linear or wormlike, opaque, not coiled in a discoid spiral.

Bory described at least three species of organisms, Melanella monadina, M. flexuosa and M. Spirillum. As a generic name this term seems to have been used by no other writers. Ehrenberg (1828, p. 17) gave Melanella atoma as a synonym of Vibrio lineola and $M$. erythraea as a synonym of $V$. rugula. Attempts have been made by various authors to identify his types, particularly Vuillemin (1913, p. 521). This author concludes that good generic characters and recognition of type species are impossible, and that the name should be rejected.

Trevisan $(1879$, p. 148) regarded Melanella as a synonoym of Vibrio, listing Melanella flexuosa Bory and M. erythraea Hempr. et Ehrenb. (1828) as synonyms of Vibrio Rugula. The name is rejected by Erwin F. Smith (1905).

Melococcus. A generic name used by Amiradzibi (1907, p. 309) for the species Melococcus ostrijanini, an organism isolated from the alimentary tract of the bee moth Galeria melonella. The organism in many ways resembled a Streptococcus culturally. Growth was always slow. Gelatin was not liquefied. The organism stains well with fuchsin and by Gram's method. No gas was formed from dextrose.

It would appear that the description of the organism is inadequate, and the nomenclatural status of the generic name uncertain.

Meloseira. (Melosira.) A genus of cliatoms created by Agardh (1824). The organisms usually known as Gallionella ferrugenea was incorrectly placed in this genus by Ralfs (1813, p. 351) as Melosira ochracea. This is one of the genera of diatoms commonly recognized today, and the name is invalid as a bacterial designation.

Meningococcus. A casual name frequently applied to the causal organism of epidemic cerebro-spinal meningitis in man.

According to Enlows (1920, p. 56) the designation was first used by Foà and Bordono-Uffreduzzi (1888, p. 67). The first use in a generic 
sense, that is, with a species name, apparently is that of Coats and Forbes (1911, p. 242) who used the combination Meninigococcus intracellularis. This would seem to validate the name, even though the authors were not aware that they were introducing a new generic name. However, it must be dated from its first use in binomial nomenclature, and must yield priority to Neisseria.

Meningokokkus. A variant of Meningococcus used by German writers as a casual name.

In binomial nomenclature apparently it was first used by Huebner $(1896$, p. 6) in the form Meningokokkus intracellularis. Neisseria has priority.

Merismopedia. A genus of blue green algae created by Meyen, (1839, p. 67). Kützing (1849, p. 471) described the genus as follows: "Phycoma parvulum non afficum, quadratum, planum; gonidiis quaterniis, solidis (A quaticae)." Rabenhorst (1865, p. 56) gives the following description: "Cellulae globosae, tempore divisionis oblongae, tegumentis subcrassis confluentibus, $4,8,16,32,64,128$ in familias tabulatas unistratas consuciatae, thallum quadratum planum libere natans formantes." One species included, M. littoralis, is a form that is probably to be reckoned among the bacteria.

Merismopedia is a valid algal genus, its use in bacterial nomenclature is therefore quite invalid. However, certain writers have placed in this genus bacteria which resemble Merismopedia in cell shape and grouping. The bacterial equivalent is Merista Van Tieghem.

Robin (1853, p. 331) placed Sarcina ventriculi Goodsir in this genus.

Zopf (1885, p. 51) recognized this as a bacterial genus with the diagnosis: "Tafelcocen. Theilungen nach zwei Richtungen des Raumes, zur Bildung von Zellflachen in Tafelform führend, deren Glieder Später ausser Verband treten." The only species assigned to the genus was the Merismopsdia Gonorrhoeae, the newly described gonococcus. As a bacterial genus, Merismopedia was also recognized by Billet (1890, p. 24) with the description: "Merismopedia, zooglee tabulaire, à éléments unis par 4." Sternberg (1892, p. 17) likewise included this genus in his classification of the cocci. Lehmann and Neumann (1896, p. 102) conclude that all forms included in Merismopedia should be placed in Micrococcus. The name is rejected by Erwin F. Smith (1905).

Caspary $(1874$, p. 104) named an organism Merismopedium Reitenbachii, which was included among the bacteria as Lampropedia Reitenbachii by De Toni and Trevisan (1889, p. 1048). He says: "Es ist 
daher gegen richtige Grammatik diesen Gattungsnamen zu schreiben; Merismopedia wie Meyen (Weigmanns Archi V 67)."

Merismopedium. A correction of the spelling of Merismopedia q.v. proposed by Caspary (187.t, p. 10t) and used in the new species Merismopedium reitenbachii.

Merista. Cunningham (1839, p. 47) listed Merista laevigata Banks and Soland Mss. 1769 as a synonym of Myrisine Urvillei one of the spermatophytes. It is regarded as a synonym of Rapanea Aubl. in Engler and Prantl's Planzenfamilien As a bacterial generic name this was used by Van Tieghem $(1884$, p. 1114) with the following description: "Deux directions de cloisonnement. Thalle membraneux; se dissociant en tétrades caneés à mesure qu'it s'accroit." Hueppe (18S6, p. 144) included this type in his "Gattung ArthroKokkaceen" as an "Untergattung."

Prazmowski (1888, p. 235) renamed the Micrococcus ureae of Cohn, Merista ureae. Apparently this is the first use of the term in a strict generic sense, that is, as a binomial for bacteria.

Billet (1890, p. 24) includes the genus in his "Formes zoogleiques" with the descriptions, "zooglee tabualire, à éléments unis 4 par 4." Lehmann and Neumann (1896, p. 102) concluded that the genus should be merged in Micrococcus. Vuillemin (1913, p. 525) concluded that this genus has the same reason for existence as has Sarcina or Streptococcus, and that the characteristic tetrad grouping is worthy of generic recognition. He had proposed therefore that this be constituted a "Genus conservandum" with Merista tetragena (Micrococcus tetragenus Gaffky, Gaffkya tetragena Trevisan) as the type. If Mic. tetragenus is to constitute the type of a genus, it would seem that Gaffkya Trevisan has priority.

The type species evidently is Merista ureae (Cohn) Prazmowski.

Whether the previous use of Merista for a genus of phanerogams invalidates its use for bacteria is somewhat problematical. Apparently Banks and Soland never published their name, it was never proposed. Quotation in synonymy does not validate a name. It would seem therefore that Merista Prazmowski is valid if its type requires separate generic recognition.

Merizomyria. A genus of algae ascribed to Kützing (1843). Rabenhorst (1865, p. 224) lists six species, giving the following diagnosis:

Trichomata flagelliformia simplicia rarius pseudoramosa, arctissime vaginata, basi cellula perdurante instructa, sursum moniliformia, in apicem capillarem cuspidata, in muco matricali nidulantea plerumque in stratum difforme coacervata. 
This name is of significance in bacteriology because according to De Toni and Trevisan (1889, p. 926) Sphaerotilus thermalis Kuetz. is a synonym of Merizomyria aponina var. fasciculata Kuetz.

Mesobacteria. According to Enlows $(1920$, p. 57) used by Billroth (1874, p. 6). See Mesobacterien.

Mesobacterien. A name used by Billroth $(1874$, p. 16) to designate a growth form of Coccobacteria septica in which the cells are rod shaped and of moderate size The name has apparently not been used as a generic name, although Smith (1905) has included this in his list of invalid genera, with the spelling Mesobacterium.

Mesobacterium. Listed by Erwin F. Smith (1905) as invalid. Probably refers to Mesobacterien q.v.

Mesococcos. A name used by Billroth $(1874$, p. 6) to designate a growth form of his Coccobacteria scptica in which the cells were spherical and of moderate size. The name has been spelled Mesococcus by later writers. This term has apparently never been used as a generic designation.

Mesococcus A variant spelling of Mesococcos (q.v.). It is listed by Smith (1905) as an invalid genus.

Metabacterium. A genus of bacteria proposed by Chatton and Perard (1913, p. 1232) for the species Metabacterium polyspora from the coecum of the cavy. The authors give the following description:

Elle se rattache aux bactéries disporées du type B. Bütschlii. Mais elle en différe nettement par ce caractére jusqu'ici unique, croyons-nous, chez les Bactéries, de pouvoir former un nombre de spores supérieur à deux, et variable de une à huit, par élément. Ces éléments sont toujours isolés. Ils sont enforme de fuseau tronqué aux deux extrémités et mesurent de 10 à $25 \mu$ de long sur $5 \mu$ de large en moyenne. Nous ne les avons jamais vus mobiles. Ils présentent une mince membrane d'enveloppe à l'intérieur de laquelle on distingue une masse cytoplasmique peu dense, le plus souvent réduite à des trabécules. La majeure partic du contenu est condensé en masses chromatiques, qui, lorsqu'elles sont au nombre de deux, sont situées chacune à l'un des poles de l'élément. Il est trés rare de n'en observer qu'une, qui d'ailleurs est également polaire. Il y a par contre trés souvent plus de deux masses chromatiques, trois, quatre, cinq-, jusqu'à huit, ces nombres étant d'autant plus fréquents qu' ils sont moins élevés. Dars ces cas, deux des masses sont toujours polaires, les autres étant situées en des points quelconques de l'élément. Les unes et les autres sont toujours au contact de la pellicule d'enveloppe. Chez quelques bacilles à deux masses polaires, nous avons observé, unissant ces deux masses, ce gros noyau chromatique circonvolutionné, que Schaudinn, Swellengrebel, Dobell ont décrit chez diverses bactéries disporées: B. Butschlii, B. maximus-buccalis, B. flexilis et $B$. spirogyra. Nous ne pouvons nous prononcer sur la signification précise de cette structure que nous n'avons pu retrouver chez des éléments ayant plus de deux 
masses chromatiques. Quant à ces masses memes, elles ne nous paraissent pas avoir la valeur de vrais noyaux, bien que, chez certains individus, leur structure habituellement dense fasse place à une structure vésiculaire. Nous n'avons d'ailleurs jamais vu ces masses se diviser (à moins que l'on doive interpréter comme une figure de division le noyau chromatique de la figure 3 ), et il scmble qu'elles procédent toutes de condensations isolées de substance chromatique. Chacune d'eiles est l'ébauche d'une future spore. Pour former les spores, ces masses s'accroissent et régularisent leur forme en celle d'un cylindre arrondi aux deux bouts, cylindre d'abord court, qui s'al longe progressivement sans s'épaissir notablement, jusqu'à mesurer de 10 à $15 \mu$ de long sur $2 \mu$ de large environ. Il se forme autant de spores qu'il $\mathrm{y}$ avait de masses chromatiques, mais on voit souvent une ou plusieurs spores avorter en cours de développement La spore mure ne se colore plus en totalité, sa paroi devenue impénétrable ne prend plus au fer qu'une teinte gris bleu. Au Ziehl, qui colore intensément en rouge les spores d'Oscillospira, celles de notre bacille ne prennent qu'une teinte rose pale. Il persiste toujours au pole libre de la spore une calotte chromatique. Le nombre de ces spores varie de une a huit par élément. Elles sont d'autant plus longues et plus larges qu'elles sont moins nombreuses, sans que les écarts dépassent $5 \mu$ en longueur et $1 \mu$ en largeur. Les spores étant longues chevauchent les unes sur les auires, lorsq'elles sont plusieurs, comme chex les formes disporées du B. Duboseq. de Joyeux. La sporulation absorbe la plus grande partie du contenu de l'élément, ne laissant qu'un insignifiant reliquat dans l'enveloppe qui se moule sur les spores. Nous n'avons jamais vu les formes végétatives en division. Nous n'avons pas constaté en particulier cette scissiparité compléte ou abortive que Schaudinn et Dobell décrivent chez leurs bacteries disporées avant la sporulation ét que Schandinn avait interprétée comme l'ébauche d'une zygose. Nous n'oserions pas affirmer cependant que notre espéce ne se divise jamais. Mais il est certain qu'elle présente par rapport aux autres bactéries une reproduction scissipare réduite, compensée par une reproduction sporogénétique qui atteint chez elle un degré de perfection beaucoup plus élevé que chez les autres représentants du groupe. L'absence ou la rareté de la reproduction scissipare n'en a pas moins cette conséquence que jamais notre bacille ne se présente en culture dense dans le caecum des cobayes. It parait d'ailleurs dépourvu de tout pouvoir pathogéne.

According to Vuillemin $(1913$, p. 520) this should be regarded as a genus conservandum.

Buchanan (1918, p. 39) give the following generic description:

Rod-shaped, known only in the sporulating state, from the caecum of a guineapig. Sporogenous cell becomes ellipsoidal with one to eight endospores within a single cell.

The type species is Metabacterium polyspora Chatton and Perard.

He includes it as the fourth genus of his family Bacillaceae. Enlows (1920, p. 57) gives the following description:

Type species (monotypy). M. polyspora n. sp. Found in the caecum of the guinea-pig. Characterized by its ability to form from 1 to 8 spores in a single 
cell. A truncated spindle-shaped organism, always single, 10 to $25 \mu$ long by $5 \mu$ wide. Nonmotile. Cytoplasm condensed into chromatic masses, from which the spores develop, which (when limited to 2) are usually bipolar. The vegetative forms have never been observed to divide. Nonpathogenic.

Metacoccaceae. A subfamily of the family Coccaceae proposed by Winslow and Rogers (1905, p. 669) to include the genera Micrococcus, Sarcina and Rhodococcus. The diagnosis given is:

Facultative parasites or saprophytes. Thrive best under aerobic conditions. Grow well on artificial media, producing abundant surface growths. Planes of fission often at right angles; cells aggregated in groups, packets or zoogloea masses.

In later descriptions (1906, p. 485, 1908, p. 258) the Winslows have added: "Generally decolorize by Gram. Pigment yellow or red."

It was pointed out by Buchanan (1915, p. 9) that the name Mctacoccaceae fails to conform to the rules of botanical nomenclature in that it does not carry the right ending and is not formed from the name of one of the constituent genera. Possibly this name should be replaced by the tribal designation Micrococceae used by Trevisan.

Metacoccus. A name stated by Conn (1909, p. 12) to have been recognized in "recent classification of the spherical forms." The writer has been unable to find the classification to which Conn refers. It may be regarded as a nomen nudum.

Metallacter. A generic name proposed by Perty (1852, p. 180) for a rod-shaped bacterium occurring in filaments or chains The type was $M$. Bacillus, the Vibrio Bacillus of Mïller and of Ehrenberg. The name was used as a synonym of $V$. Bacillus Müller by Rabenhorst (1865, p. 72).

Concerning Perty's organism, Cohn (1875, p. 188) has the following statement:

Perty hatte, wie ich erst nachträglich erfahren, unsere Bacillusarten schon im Jahre 1852 als eine selbständige Gattung von den eigentlichen Bacterien unter dem Namen Metallacter abgetrennt (von einem griechischen Worte, welches sich "verändernd" bedeutet), weil dieselben in steife oder wenig biegsame, unbewegliche, ungemein verlängerte Hygrocrocis (oder Leptothrix)-fäden unter gewissen Umständen sich umwandeln; und ebenso hatte er äusserst kleine, bewegliche cylindrische Fäden beobachtet, welche an einem, oder seltener an beiden Enden eine, manchmal auch zwei elliptische Körperchen (wohl Sporen) einschliessen; obwohl er dieselben öfters mit Bacillus (Metallacter Bacillus Perty) zusammen fand, denen sie sehr gleichen, hielt er sie doch für eine selbstständige Gattung und Art (Sporonema gracile Perty). 
Cohn created the genus Bacillus which replaced Metallacter. Trevisan $(1879$, p. 137) recognized the genus Metallacter in the following description and statement:

Metallacter Perty, 1852; Bacteridium Davaine (Compt. rend. de l' Acad. des sc. de Paris, Tom. LVII) 1863; Bacillus Cohn (Beitr. I, Heft 2, p. 174) 1872; Streptobacteria Billroth, 1874. Somatia cylindrica, plus minus distincte.

Oss. Perty fondo il suo genere Metallacter sulla stessa specie (Vibrio Bacillus O. F. Müller) pella quale, vent' anni pui tardi, Cohn propose il suo Bacillus. Il nome generico Metallacter, non contrario aj caratteri, ne ad alcuna legge di nomenclatura, anzi accennate la proprieta di mutarsi, in date condizioni, in somazj filiformi, straordinariamente allungati, leptotrichieformi, rigidi, immobili (1), quindi nome sotto ogni aspetto ineccezionabile, deve avere la preferenza. Resterebbe a vedere, non avendo il libro alla mano, se Bactrella di Morren (in Bullet. des scienc. natur., n XXVII, 1830) sia identico con Metallacter, nel qual caso la denominazione proposta da Morren dovrebbe essere conservata.

As species he lists Metallacter ulna, M. bacillus (B. subtilis), M. amylobacter, $M$. tremulus, and $M$. anthracis.

Later Trevisan (1882, p. 151) again emphasized the genus Metallacter as follows:

Per essa Klebs mise innanzi l'appellativoBacillus typhosus; pero, sia pel diritto di priorita che il nome generico Metallacter (Perty 1852) ha sull'altro Bacillus (Cohn 1872), sia pel diritto di priorit che la piu appropriata denominazione specifica Ileotyphi ha sull 'altra typhosus, avrebbesi piu correttamente a chimare Metallacter Ileotyphi.

The next year he again used this name (1883, p. 149). Two years later, however, he abandoned Metallacter for Bacillus (1885, p. 94)

De Toni and Trevisan (1889, p. 945) give Metallacter as a synonym of Bacillus.

Migula $(1879$, p. 7 ) has the following to say of Perty's genus.

Sein Metallacter ist ein Bacterium, welches sich durch die Eigenschaft, lange geteilte Fäden bilden zu können, zuszeichnet: "Bakterienähnliche Einzelmesen verlängern sich durch fortgesetzte Teilung zu steifen oder wenig biegsamen Fäden, welche unter gewissen Umständen nach einiger Zeit die Bewegung verliersen, ungemein wachsen und einer Hygrocrocis ähnlich werden, indem sie aus längeren verfilzten, flockige farblose oder grauliche Massen darstellenden Fäden bestehen." Als Art rechnet er hierzu MI. Bacillus (= Vibrio Bacillus), ferner als Formen dieser Art $V$. subtilis und Bacterium Catenula Duj.

The name is rejected by Erwin F. Smith (1905).

Vuillemin (1913, p. 519) states that Metallacter is a synonym of Serratia and so disappears. 
With the exception of Trevisan, it does not appear that as a generic name Metallacter has been used since Perty's description. It is generally regarded as invalid. If it were possible to fix exactly the species Metallacter bacillus it probably would be necessary to recognize the genus. Unless it can be shown that it is the same as Cohn's Bacillus subtilis it will scarcely replace Bacillus. Trevisan's use of Bacillus subtitis as a synonym is scarcely adequate.

Metchnikovillus. A name proposed by Heller (1922, p. 29) for a genus of the tribe Putrificoideae. The description is:

Highly protelytic Putrificoideae that readily blacken meat. They do not produce in it abundant amino-acid crystals, but digest meat, serum, egg and casein rapidly, forming more alkali or less fatty acid than do the organisms of the succeeding group. They split few sugars. Gram-positive or weakly Gram-positive rods, vegetative forms uniform and considerably smaller than sporangia. Sporulate readily in ordinary media, forming oval spores which are usually subterminal, though in some strains median spores predominate. Multiplication is exceedingly active, forty-ejght hour colonies in deep agar are large and woolly. Frequently a few colonies are larger than the others but they do not give rise in a following generation to a preponderating number of large colonies. Ubiquitous. Common intestinal organisms, abundant in soil; very common in infected wounds. Not capable of invading in pure culture in moderate doses, may invade in company with other organisms or alone when given in large doses.

Type species $M$. sporogenes (Bacillus spurogenes type $A$. of Metchnikoff) as described by the Committee (p. 36). Klein described as B. enteritides-sporogenes a mixed culture which contained a non-proteolytic organism, a pure culture of which was described by von Hibler as $B$. enteritidis-sporogenes Klein (von Hibler IV). This tissue invading pathogen, thought by some to have been $B$. welchii, is most referable to the genus Arloingillus. The strain was derived from patients with enteritis and it was apparently contaminated with a proteolytic organism of the genus Metchnikovillus. Metchnikoff described two types, A and B, of intestinal anaerobes which he thought were similar to the organism of Klein, and which he termed $B$. sporognes. His descriptions permit of no identifications. Choukevitch, working in Metchnikoff's laboratory described B.-sporogenes A and B more carefully. Type B should be referred to genus Martellillus. Weinberg made the identification of type A more exact, and the Committee discuss it at some length. They allow two species, B. sporogenes type A of Metchnikoff, and $B$. parasporogenes McIntosh, which are different in colony formation and serologically. Donaldson describes the "reading" bacillus, to be assigned to this genus. Superficial acquaintance with many strains of preteolytic anaerobes leads me to suggest that Metchnikovillus may be defined as a genus of many species; Dr. K. F. Meyer is also of this opinion. Henry (p. 361) believes it likely that the conception "sporogenes" refers to a group of organisms.

Methanomonas. A generic name proposed by Orla-Jensen (1909, p. 311). This is the first genus of the family Oxydobacteriaceae of the 
order Cephalotrichinae. The organisms of this genus are described as autotrophic, monotrichic, aerobic short rods capable of oxidizing methane.

Winslow et al. (Committee Soc. Am. Bact. 1917, p. 551, 1920, p. 201) and Bergey et al. (1923, p. 32) describe the genus as follows:

Monotrichic short rods capable of growing in the absence of organic matter and securing growth energy by the oxidation of methane (forming carbon dioxide and hydrogen). The type species is Methanomonas methanica (Söhngen) Jensen.

Meyerillus. A generic name proposed by Heller (1922, p. 22) for the fourteenth genus of her tribe Clostridioideae. Her diagnosis is:

Clostridioideae that produce $\mathrm{H}_{2} \mathrm{~S}$ on blood broth and liquefy gelatin. In meat medium they produce gas, but little or no pink coloration; they show no marked proteolytic action. Do not readily attack milk. Large Gram-positive rods with little or no inclination to form spores. Attack a few sugars. Colonies in deep agar large, opaque and lenticular. Typically attack connective tissue more than the muscle.

Type species $M$. sadowa nov. sp. To be described in a future paper. This organism was at first taken for $B$. Welchii. It does not sporulate. It is one of the four guinea-pig invaders isolated from a case of human gas gangrene. I am inclined to place the sporulating bacillus L of Adamson (1919) in this genus but have not handled that organism. Perhaps it is premature to decide whether sporulation may be used as a generic character. Adamson finds bacillus L very slightly proteolytic on milk and not so on other media. $M$. sadowa does not grow on milk.

Microbacillus. According to Schamberg (1902, p. 293), Sabouraud named an organism Microbacillus seborrhoeae. The original references have not been available.

Microbacteria. According to Enlows (1902, p. 58) used by Billroth. See Microbacterien.

It was used by Cohn $(1872$, p. 167) to designate his second tribe of bacteria.

Die zweite Tribus der Bacterien bezeichne ich als Microbacteria oder Stäbchenbalterien; sie stimmen mit den Kugelbacterien in der Kleinheit ihrer \% llen und deren zeitweiser Vereinigung zu Gallert-oder Schleimmassen überein, unterscheiden sich jedoch, abgesehen von ihrer physiologischen Thätigkeit, durch dis kurzcylindrische Gestalt und die spontane Bewegung der Zellen.

This name was also used by Hansgirg (1888, p. 264) to designate the second family of his order Eubacteria Two genera were recognized, Bacillus and Chromobacillus. 
Microbacterien. A name used by Billroth (1874, p. 16) to designate a growth form of his Coccobacteria septica in which the cells are rodshaped and small.

Microbacteries. Maggi (1886, p. 84) used this designation for his third order of bacteria, with the single genus Bacterium. No description was given.

Microbacterium. A form of the name Microbacterien (q.v.). It is listed by Smith (1905) with the invalid bacterial genera, although the writer has not been able to find an instance of its use as a generic name previous to this time. Klein (1885, p. 37) uses "Bacterium (Microbacterium Cohn)" as a heading. Apparently Klein has confused this generic name with Cohn's Microbacteria q.v.

In a strict generic sense the name was first used by Orla-Jensen $(1919$, p. 179) in the following statement.

Of the other Gram-positive, rod-shaped lactic acid bacteria (Table XXXII) which we have encountered in our investigations, the majority (Nos. 3 to 10) are considerable smaller than the rod forms hitherto described, and have so many peculiar qualities in common that it will be only natural to collect them in a genus, which may suitably be named Microbacterium.

The microbacteria do not, for the most part, curdle milk, and are on the whole weak acid formers and produce dextro-lactic acid, with the single exception of No. 10, which forms inactive lactic acid. When sown out in high agar tubes, they grow only in the upper part, and in stab cultures, they exhibit more or less pronounced surface growth. No. 7 even forms a highly curled surface layer. Nos. $3-6$ on the other hand, give only surface growth with favourable sources of nitrogen, and even then not always to any perceptible degree. The best nitrogen source for these bacteria is casein peptone; yeast extract, on the other hand, is as a rule very unfavorable. With the exception of No. 1, they split up hydrogen peroxide and reduce nitrate to nitrite. In biological respects, the micro-bacteria thus greatly resemble the tetracocci, and there is also a gradual transition to forms which are no longer acid formers, but which liquefy gelatin to a slight degree, and can break down amino-acids. The true microbacteria never ferment pentoses, and of alcohols, at the outside a little mannite.

The microbacteria fall again into several well distinguished species. Nos. $3,4,5$, and 6 , for instance, are closely allied forms, and as they very often occur in milk, we will call them Microbacterium lacticum. No. 7 we will call Microbacterium mesentericum, from its very characteristic surface growth, and Nos. 8 and 9 , which have constantly exhibited a powerful yellow surface growth, Microbacterium flavum. No. 10 probably also constitutes a distinct species.

Later (1921, p. 272) he states:

Microbacterium is to be understood as merely a provisional collective name for Gram-positive rods of size a little smaller than the ordinary bacteria. In biologi- 
cal respects some of these rods (Bacillus acidophilus) are closely related to the true lactic acid bacteria, whereas others approach the Tetracocci or the aerobic bacilli.

The first mentioned species Microbacterium lacticum Orla-Jensen is apparently to be regarded as the type.

Micrococceae. A tribal name used by De Toni and Trevisan (1889, p. 1067) with the following diagnosis:

Cocci nudi, nec cystidibus, nec capsulis, nec vaginis obducti, liberi, nunquam moniliformiter concatenati, raro gemini vel in turmas aut zoogloeas consociati. Endosporae microsomae in coccis normalibus obvenientes.

It is included in the family Coccogenae. The following genera are included: Neisseria, Staphylococcus, Micrococcus.

Buchanan (1917, p. 613) recognized the tribe with the following description:

Saprophytes or facultative parasites. Usually grow best under aërobic conditions. Grow well on artificial media, producing abundant surface growths. Planes of fission often at right angles, cells aggregated in groups, packets or zoogloea masses. Generally Gram-negative. Usually pigmented yellow, orange or red.

He included the genera Micrococcus, Rhodococcus and Sarcina.

Winslow et al. (Committee Soc. Am. Bact., 1917, p. 559, 1920, p. 207) have used practically the same description.

It is also accepted by Castellani and Chalmers (1919, p. 925) with the addition of the genus Nigrococcus, and by Bergey et al. (1923, p. 57 ) as the third tribe of the Coccaceae.

Micrococcoglia. A name used by Billroth $(1874$, p. 14) to designate a growth form of his Coccobacteria septica in which the spherical cells were arranged in small zoögloeal masses. The name has apparently not been used to designate a genus.

Micrococcos. An aberrant form of spelling of Micrococcus used by Billroth (1874, p. 6) to designate that growth form or stage in the development of his Coccobacteria septica in which the organism consisted of very small spherical cells.

Micrococcus. This name was first used by Hallier (1866) to indicate a growth form of a mold in accordance with his conception of pleomorphism. He did not use the name in a generic sense, and the genus should therefore not be ascribed to him, as has frequently been done by various authors. Cohn $(1872$, p. 151) adopted the name and defined it as a genus containing very small spherical or oval organisms, 
with colorless or light colored cells, without motility, remaining after cell division united into rosary-like threads, many celled families or slimy masses. The first organism to which the name was given was Micrococcus prodigiosus (Ehr.) Cohn. This organism is now generally removed from this genus, because of its shape. The next organism named was $M$. luteus (Schroet) Cohn. This form may well be considered the type of the genus as it has been adequately described.

The name Micrococcos was used by Billroth $(1874$, p. 6$)$ to designate a growth form of his pleomorphic Coccobacteria septica, in which the cells consisted of very minute spheres. He did not use the name in a generic sense. In 1875 Cohn split his former genus into two, creating the new genus Streptococcus. His revised definition of Micrococcus included those organisms with spherical cells, united into glairy families amorphous, cells without phycochrome, very small. Trevisan (1879 p. 126) gives the following generic description:

Micrococcus Hallier em. Cohn. (Zoogalactina Sette 1824; Serratia Bizio 1827; Microzyma Bechamp 1868; Microsporon Klebs 1872; Microsphaera Cohn 1872). Cellulae globosae vel globoso-ovoideae. Multiplicatio divisione cellularum vegetativa in omnes directiones.

It was included under Eubacterieae. In all, sixteen species were listed, many of them forms now included among the rod-shaped organisms. Among forms listed which may be included among the true cocci are $M$. luteus, $M$. lactis, $M$. septicus. Luerssen $(1879$, p. 171) followed the original description of Cohn, as did also Magnin, (1880, p. 72). The latter divided the genus into three groups of species. Micrococci chromogenes, $M$. zymogenes and $M$. pathogenes Winter (1880, p. 42) gave the following generic diagnosis:

Zellen farblos oder blass gefärbt, kugelig oder eiförmig-elliptisch, unbeweglich, nur in einer Richtung sich theilend. Die Tochterzellen trennen sich entweder bald von einander, oder bleiben zu zwei oder mehr kettenartig verbunden, oder bilden Zoogloea. Sporenbildung nicht sicher bekannt.

Was ich oben über die Unterscheidung der Arten gesagt habe, gilt ganz besonders von Micrococcus. Die angenommen Arten zeigen in Gestalt und Grösse keine oder sehr geringe Unterschiede und es bleibt uns nur die chemiscge Thätigkeit als Mittel zur Auseinanderhaltung der Arten, die daher etwas ausfürlicher behandelt worden ist.

Ogston (1883, p. 27) used the name Micrococcus, but without species designation. He included the chain forms (streptococci) as well as a new type which he termed staphylococci. Van Tieghem (1884), and Grove $(1884$, p. 6) all followed Cohn more or less closely, though 
increasing the number of genera of spherical bacteria. Zopf (1885, p. 51) gives five genera of cocci, Streptococcus, Merismopedia, Micrococcus, Ascococcus and Sarcina. Micrococcus is defined as made up of cocci, not in packets, not producing large quantities of capsular material, and with the cells irregularly arranged in grape like clusters. $\mathrm{He}$ concluded that the generic name Staphylococcus of Rosenbach is a synonym. Cornil and Babes (1886) use Micrococcus as a group name and include under it as subdivisions, Streptococcus, Staphylococcus Ascococcus and Sarcina. Flügge (1886) defined the genus as having cells oval or spherical, non-motile and with the cells separating as soon as division is complete. Schroeter (1886, p. 143) recognizes nine genera of cocci. Micrococcus includes those whose cells are spherical single or arranged irregularly, and in which the cells or colonies are free or embedded in slime without definite gelatinous membranes.

Maggi (1886, p. 81) included this as the first genus of his order Sphaerobactéries.

Hansgirg (1888, p. 267) included this as the only genus of the subfamily Eucoccaceae.

De Toni and Trevisan (1889, p. 1076) include some twenty-two genera among the cocci, one of them Micrococcus with a large number of species.

Various authors before 1895 defined Micrococcus as containing those organisms with irregularly grouped spherical cells. Among them were Billet (1890, p. 24), Hueppe (1892, p. 30), Sternberg (1892, p. 17), Ludwig (1892) and Clements (1894, p. 26). Migula 1892, p. 236 says: "Micrococcus Cohn. Die zellen teilen sich nach 2 Richtungen des Raumes. Bewegungsorgane fehlen. (Z. B. Micrococcus candicans Flügge.)"

Migula (1894) emended the description of Micrococcus, creating new genera for the motile forms. The genus is given the following diagnosis $(1895$, p. 16):

Single cells spherical, often united in twos and fours and then sometimes flattened on surfaces in contact. Division in two directions of space. Non-motile Endospore formation not certainly recognized, probably lacking.

He notes that some four hundred species had been described.

Fischer (1897, p. 32) on the other hand, emphasized that Micrococcus consists of cells which divide irregularly, and not in definite sequence and which are non-motile. Lehmann and Neumann (1896, p. 148) used the following description: 
Die Zellen teilen sich unregelmässig nach verschiedenen Richtungen und lieger heirauf bald einzeln, bald zu 2 oder 4, endlich und zwar vorherrschend in regellosen klumpigen Haufen. Hierher rechnen wir alle Kokken, die nicht unzweifelhatte Streptokokken oder Sarcinen sind.

Many authors have followed the diagnoses of Migula and of Fischer. Among these are Migula (1897, p. 27, 1900, p. 46 and 1904, p. 144), Macé (1897, p. 335), Hewlett (1898), Chester (1897, p. 62), Baumgarten (1900, p. 127), Chester (1901, p. 71), Matzuschita (1902), A. J. Smith (1902, p. 268), Kendall (1902), Klöcker (1903, p. 331), Fischer (1903, p. 59), E. F. Smith (1905, p. 160), Jensen (1909, p. 340), Ellis (1909, p. 4), Frost (1911, p. 57), Meyer (1912, p. 5), Schneider (1912, p. 23) and Löhnis (1913). Migula (1900, p. 46) gives the following list of synonyms: Lampropedia Schröter = Microhaloa Kuzt exp., Cohnia Winter, Hyalococcus Schröter, Leucocystis Schröter, Ascococcus (Billroth) Cohn, Monas Ehrenberg exp., Bacteridium Schröter, Diplococcus Aut. exp., Staphylococcus Aut., Merismopedia., exp., Merista Hueppe exp., Gonococcus Neisser.

The Winslows (1905, p. 669) have again emended the diagnosis of the genus. In its most recent form it is (1908, p. 258),

Facultative parasites or saprophytes. Cells in plates or irregular masses (never in long chains or packets). Generally decolorize by Gram. Growth in agar abundant, with formation of yellow pigment. Dextrose slightly acid, lactose broth generally neutral. Gelatin frequently liquefied. Nitrates may or may not be reduced.

They include as valid species, Micrococcus flavus, $M$. citreus, $M$. luteus and $M$. candicans It will be noted that the species $M$. luteus previously noted as a suitable type species is included.

Vuillemin (1913, p. 520) contends that Micrococcus should be termed a form genus only, and relegated to the bacteriologists who have vulgarized the term.

Buchanan (1917, p. 613) characterized the genus as follows:

Saprophytes or facultative parasites. Cells in plates or in irregular masses (never in long chains or packets). Generally Gram-negative. Growth on agar abundant, with formation usually of yellow pigment. Dextrose broth as a rule slightly acid and lactose broth neutral. Gelatin frequently liquefied.

The type species is Micrococcus luteus (Schroeter) Cohn.

Winslow et al. (Committee Soc. Am. Bact., 1917, p. 561, 1920, p. 208) have used practically the same diagnosis and the same type designation. 
It is probable that Micrococcus Cohn should be recognized as a genus with the type Micrococcus lutous (Schröter) Cohn. This type designation is menaced by the fact that Cohn's first species described was Micrococcus prodigiosus. This form, however, is not a typical Micrococcus in that the cells are not spherical. Under the circumstances, the designation of the second species described, M. luteus is probably justified and valid.

Bergey et al. (1923, p. 58) has followed the Committee, including Micrococcus as the first genus of the tribe Micrococceae.

Microhaloa. A genus of blue green algae created by Kützing (1843, p. 169) with the following description: "Phycoma globosum, grumosum, ex cellulis in glomerulos coadunatis compositum." Two species are included, $M$. botryoides and $M$. rupestris. Its only relationship to bacterial nomenclature is the reference to it of the organism Lamprocystis roseopersicina under the name Microhaloa aeruginosa Kützing.

The name is rejected by Erwin F. Smith (1905).

Micromyces. A generic name first applied to a fungus parasitic upon algae by Dangeard $(1888$, p. 55$)$ with the species $M$. zygogonii Saccardo gives the following generic diagnosis:

Sphaerulae plasmaticae intracellulas Algarum parasiticae, membrana aculeata マ. verrucosa. Cellulae maturitate evacuantur et plasma, membranam tangens, sporangium compositium efficit; sporangium 4- cellulare, cellulae 100 zoosporas uniciliatas gignentes.

The name Micromyces was independently proposed by Grüber as a generic name for a new organism which was isolated from man and showed great resemblances to Actinomyces (1891, p. 648). The species was named Micromyces Hoffmanni. This name as applied to one of the thread bacteria is invalid because of the previous use of Micromyces Dangeard for a distinct group. It is also a synonym of Actinomyces. It is rejected by Merrill and Wade (1919, p. 63).

Microphyta. A name included in the list of those rejected by Erwin F. Smith (1905). No reference to its use as a generic name has been found.

Microsiphonales. An order of fungi named by Vuillemin (1912). Castellani and Chalmers (1919, p. 1040) give the following description.

Definition. Hyphales with the mycelium composed of fine bacilliform hyphae, usually 1 micron or less in diameter. Usually Gram-positive, when young, and without distinct nuclei. Parasitic on man, animals, and plants, or saprophytic.

Remarks. This is a most interesting order, as its members are nearly always mistaken at first sight, by persons unaccustomed to them, for bacilli. Hence the 
descriptions of bacilli as the cause of so many fungal diseases due to these organisms, among which could be classified the diphtheria organisms, the tubercular and leprotic bacilli.

It is included in Vuillemin's Subclass Hyphales. It includes the two families Nocardiaceae and Mycobacteriacecie.

Microsiphones. A group of the higher or filamentous bacteria recognized by Vuillemin (1913, p. 526). In this group the organisms consist of branched filaments which break up into bacilliform elements. The filaments may either be uniform in diameter or inflated at the tips. Sometimes the filamentous forms predominate over the bacilli, sometimes they are rare and the rods divide indefinitely in the manner of the true bacteria. The rods are non-motile, and less fixed in habit than with the true bacteria. The following genera and type species are recognized:

\author{
Nocardia Trevisan 1889 \\ N. Foersteri \\ Pasteuria Metschnikoff 1888 \\ $P$. ramosa \\ Sclerothrix Metschnikoff 1888 \\ S. tuberculosis \\ Corynebacterium Lehmann and Neumann \\ C. diphtheriae
}

Microsphaera. A genus of pyrenomycetous fungi described by Leveille (1851, p. 381). Cohn (1872a, p. 237) named an organism which he observed in the lymph of smallpox vaccine Microsphaera vacciniae. Later $(1872$, p. 150) he corrected the error, using instead the generic name Micrococcus. Microsphaera as a bacterial genus is invalid. Cohn's description of the genus is as follows:

Microsphaera (Kugelbacterie). Familie der Schizomyceten, Gruppe der Bacteriaceae. Zellen farblos, sehr klein, kuglig oder sphäroidisch, in der Regel unbewegt, durch Theilung oder Aschnürung zu 2, 4-8 oder mehrgliedrigen rosenkranzförmigen Ketten vermehrt, durch Verschiebung zu unregelmässigen Gruppirungen, in Folge fortgeschrittener Vermehrung zu zahlreichen Zellhäufchen oder Colonien entwickelt, oder durch schleimige Intercellular substanz zu zoogloea artigen Massen verbunden, vielleicht Dauerzellen bildend.

Microspira. A bacterial genus named by Schröter (1886, p. 168) with the following description.

Vegetative Zellen schwach gekrümmt, meist nur mit $\frac{1}{2}$ Windung (Comma-Form), lebhaft bewegt. Die kurzen Formen können, nachdem sie zur Ruhe gekommen, zu schraubigen Spirochaete-artigen 
Fäden auswachsen und Sporen bilden, welche durch Theilung der Glieder entstehen (Arthrosporen).

The type species was $M$. comma, the organism of Asiatic cholera. Other species were $M$. Finkleri and $M$. buccalis.

Schröter was evidently in ignorance of the previous publication a year earlier of the generic name Pacinia (Trevisan 1885, p. 83) for the same group, which rendered his genus name invalid.

Attention was called to the priority of Pacinia by De Toni and Trevisan (1889, p. 1018). Lehmann and Neumann (1896, p. 107) rejected the name as an invalid synonym of Vibrio.

The name Microspira was also adopted by Migula (1894, p. 237) for a genus of his family Spirillaceae. He used the following description: Zellen staro mit 1, seltener 2-3 polaren, wellig gebogenen Geisseln." The comma bacillus was again the type.

Migula says (1884, p. 237) Microspira Schröter em. Migula Zellen starr, mit 1, seltner 2-3 polaren wellig gebogenen Bewegungs organen (Z. B. Microspira Komma Schröter).

In this characterization of the genus Migula was followed by Chester (1899, p. 63), Migula (1900, p. 31), (1900, p. 960), Chester(1901, p. 332), Kendall (1902), Smith (1902, p. 270), Migula (1904, p. 145) Ellis (1909, p. 6), Frost (1911, p. 59), Meyer (1912, p. 4), Schneider (1912, p. 23) and others.

He was not followed by Fischer (1897) who used the genus name Vibrio, nor by E. F. Smith (1905, p. 161) who likewise used Vibrio, nor by Blanchard (1906, p. 1) and others. Vuillemin (1913, p. 521) believes the generic name Microspira would be preferable to Vibrio in the sense of Cohn providing the relative lengths of the cells would serve to differentiate the genus from Spirillum.

For additional discussion of priority of Pacinia, Microspira and Vibrio see the latter.

Microspironema. Stiles and Pfender proposed (1905, p. 326) this generic name for the organism causing syphilis (to replace Spironema) in the following statement:

The parasite which Schaudinn found in syphilitic patients was first classified by him as a member of the genus Spirochaete Cohn, 1872; this name was simply an emended spelling for Spirochaeta Ehrenberg 1834.

Vuillemin (1905, June 5, pp. 1567-1568) removed Schaudinn's organism from the genus Spirochaeta and proposed for it the genus Spironema, a change in classification which Schaudinn has accepted. The generic name Spironema is preoccupied in Zoölogy, having been used by Meek in 1864 for a genus of Mollusks. It is accordingly not available for the protozoon of syphilis, and under article 
34 of the International Code of Zoological Nomenclature, we herewith propose the generic name Microspironema as substitute, with Microspironema pallidum (Schaudinn, 1905) Stiles and Pfender, 1905, as type species.

This was proposed later, however, than Treponema of Schaudinn (1905, p. 1728) and is hence invalid. It has not been used by subsequent writers. It may be regarded as a synonym of Treponema.

Microspora. A name listed by Erwin F. Smith (1905) in his genera to be rejected. The original reference for this has not been found. Perhaps it is a variant spelling of Microsporon (q.v.).

Enlows (1920, p. 60) ascribes the term to Beijerinck and states "Variant of Microspira Schröter M. tyrosinatica."

Microsporon. A generic name first used by Klebs (1871, p. 33) for the bacterial species $M$. septicum. This is regarded as a very polymorphic organism which was responsible for suppuration in wounds, etc. His descriptions of the organism are misleading for he did not have pure cultures. His theory of pleomorphism was soon discarded and the generic name generally regarded as nomen nudum. It has not been used by subsequent authors in the original sense. $M$. septicum is given as a synonym of Streptococcus pyogenes by De Toni and Trevisan (1889, p. 1062). This genus is generally accepted (sometimes with spelling Microsporum) for a genus of molds parasitic upon man.

Conn (1909, p. 12) describes Microsporon (apparently as a valid genus) as "Bacilli with one flagellum at each end." This is evidently a misstatement.

Microsporon may be regarded as invalid as a bacterial generic name.

Microzoa. Listed by Erwin F. Smith (1905) as a non-valid generic designation for bacteria.

Microzyma. A generic name used by Bechamp (1868, p. 1160) for the parasite of the silk worm, Microzyma bombycis. Schroeter (1889, p. 150) gives an earlier reference to Bechamp (1867, p. 42) but an examination of this fails to show the use of the word Microzyma. Trevisan $(1879$, p. 142) also credits the name Microzyma du lait to Bechamp. This name has never been used as a generic designation by other authors.

The Microzyma bombycis is made a synonym of Streptococcus bombycis by Schroeter (1886, p. 150). The name is rejected by Erwin F. Smith (1905). Enlows (1920, p. 60) lists two species, Microzyma cretae and $M$. bombycis as described by Bechamp (1867, p. 231).

Microzyme. A name used by various earlier authors as equivalent to bacteria (see Burdon-Sanderson 1871, p. 323). A casual name. 
Mikrobakterien. A family name used by Flügge (1886) to include the non-filamentous bacteria. It is an aberrant spelling of Microbacterien (q.v.).

Mikrococcus. A variant spelling of Micrococcus as used by certain German authors, as Unna (1889, p. 393).

Mikrokokkus. A spelling of Micrococcus used by Hueppe (1886, p. 145) to designate an "Untergattung" of his Arthrokokkaceen." Other German writers have also made use of this name. While it is appropriate that Mikrokokkus be used as a casual designation, it should not be used in combination with a species name as a specific designation as it is not a Latin word.

Mikromyces. A variant spelling of Micromyces q.v. used by Gruber (1891).

Mikrospironema. A variant German spelling of Microspironema q.v. (as Gonder 1914, p. 690).

Mikrozymas. A variant German spelling of Microzyma q.v. (as Frenzel 1884, p. 49).

Modderula. A genus of bacteria described by Frenzel (1897, p. 802). The organism was observed first in dishes in which "Modder" was kept in the laboratory. "Modder" is the name given by the North German fisherman to the slime in the bottom of certain of the slow flowing waters of that region. The specific name given to the organism is Modderula hartwigi. The organism is ellipsoid, sometimes longer or almost spherical. It varies considerably in size, but is among the largest organisms ever included with the bacteria. In length it is 25 to $30 \mu$, in diameter 9 to $30 \mu$. The cell shows a double contoured colorless membrane. The interior of the cell shows a relatively compact mass of strongly refractive globules 1 to $2 \mu$ in diameter. They have much the same appearance as the sulfur granules of Beggiatoa, and are interpreted in the same manner. The organism is observed to be slowly motile, but the organ of motion was not determined. Frenzel concluded that the closest affinities of the organism were with the bacteria.

Lauterborn (1898, p. 95) pointed out that the organism described by Frenzel was not a new species, but a form which in 1893 had been shown by Lauterborn to Dr. W. Schewiakoff, who described it (1893) as Achromatium (q.v.). A careful comparison of the descriptions led to the conclusion that the organisms are identical; Modderula therefore lapses into synonomy. According to Bersa $(1920$, p. 231) it is also a synonym of Hillhousia West and Griffiths. 
Monas. A genus of protozoa created by Mueller (1786, p. 1). The description reads "Vermis inconspicuus, pellucidus, punctiformis." As originally described this genus included 31 species of which a number were eventually separated as bacteria. Ehrenberg (1838) separated off certain of Müller's species to form his genus Bacterium. Ehrenterg (1848) in a study of the organism producing red spots in bread, etc., named the causal organism Monas prodigiosa. Since that time this generic name Monas has rarely been used by authors for bacteria. An exception is to be found in the use by Klebs (1875, p. 472) of the name Monas pulmonale for a coccus which he found in human lungs. Mionas is still recognized as a valid protozoan genus. It is invalid as a bacterial designation.

Stiles (1905, p. 30) gives an account of the type of the protozoan genus, which regards as Monas mica Müller.

Monobacillus. A name used by Maggi (1886, p. 174) to designate a growth form of Bacillus.

Monobacteria. A name applied by Billroth (1874, p. 16) to a growth form of his polymorphic Coccobacteria septica in which the organism assumed a rod shape and occurred singly. It apparently has never been used as a valid generic designation. It is rejected by Erwin F. Smith (1905).

Monococcos. A name applied by Billroth $(1874$, p. 5) to a growth form of his Coccobacteria septica which consisted of isolated spherical cells. It has not been used as a valid generic name. It is rejected (with the spelling Monococcus) by Erwin F. Smith (1905).

Monococcus. A variant of Monococcos Billroth listed by Smith (1905). The name was used by Miguel (1891) for those cocci whose cells tend to remain isolated.

Monotricha. The first group of the Gymnobacteria named by Messea according to Kruse. It includes bacteria with a single polar flagellum.

Monovibrio. A casual name used by Maggi (1886, p. 176) to designate a growth form of Vibrio.

Multifermentans. A name given by Heller (1922, p. 16) to the sixth genus of the tribe Clostridioideae. The following is the description.

Clostridioideae that do not liquefy gelatin. Produce gas and acid in meat medium. Clot milk readily, without stormy fermentation. Rather small Grampositive rods with oval central or subterminal spores. Actively saccharolytic. Found occasionally in wounds, not tissue invaders.

Type species $M$. tenalbus (Bacillus multifermentans-tenalbus Stoddard) as described by Stoddard (1915b). This organism, of which Dr. Stoddard was so kind as to send me a culture, does not fit into any other of the genera here defined. 
Stoddard's organism ferments glycerol, maltose, lactose, raffinose, glucose, sucrose, inulin, and salicin. Mannitol and dulcitol are not fermented.

Mycacanthococcus. A generic name proposed by Hansgirg (1890, p. 26) for a species $M$. cellaris Hansgirg.

The description given by Hansgirg is as follows:

Zellen kugelig in vegetativem Zustande mit glatter, in encystirtem Zustande mit kurzen stachel-oder warzenartigen Auswüchsen (ähnlich wie bei der Algengattung T'rochiscia Ktz. (Acanthococcus Lagrh.) versehener Membran.

Veget. Zellen ohne Hülle meist 3 bis 6 , seltener bis 8 , oder nur 1 bis $2 \mu$ mit der Hülle 5 bis $15 \mu$ breit, einzeln oder zu 2 bis 8 in fast kugeligen, meist 25 bis $24 \mu$ breiten Fanilien vereinigt, mit in der Regel völlig homogenem, farblosem, sehr stark lichtbrechendem dichtem, plasmatischem Inhalte, welcher erst zur Zeit der Sporenbildung feinkörnig wird. Zu dieser Zeit tritt das Feinkörnigwerden des Plasmas zuerst blos an der Peripherie des ganzen Zellplasmas gleich auf, erst später ist der ganze plasmatische Inhalt, zuerst gleich fein, später gröber gekörnt.

Vermehrung erfolgt durch veget. Zweitheilung der Zellen innerhalb der Mutterzellkapsel in 2 bis 8 Tochterzellen, welche bald wieder jede je eine Separatkapsel ausscheiden. Charakteristisch für diese Bacteriengattung ist auch die tetraedrische Anordnung der Tochterzellen in vierzellige Familien, welche wieder meist traubenförmig neben einander gruppirt sind.

Während junge Zellen zuerst noch von keiner Specialhülle umgeben sind, besitzen ältere vegetative Zellen ėine deutliche knorpelartige, nicht zerfliessende, meist ziemlich weit (ähnlich wie bei der Algengattung Capsulococcus Bennet) abstehende Specialhülle (Cyste), welche an der Oberfläche glatt, im Dauerzustande aber stumpfwarzig verdickt und weniger durchsichtig ist, als im veget. Zustande.

Die acanthococcusartigen Dauerzellen sind im Querprofil rundlichachteckig, 6 bis $8 \mu$ dick (Zelllumen etwa $5 \mu$ breit), an der Overfläche der etwa $\frac{1}{2}$ dicken, fast farblosen membran mit 8 sehr kurzen, stumpfen, farblosen Emergenzen versehen, ihr Inhalt ist stark lichtbrechend, feingekörnt, farblos. Ausser diesen Dauerzellen, welche zuerst noch von einer öfters zweischichtigen, farblosen Gallerthülle umgeben sind, mit welcher sie bis $10 \mu$ breit werden, habe ich in grösseren (seltener auch in kleineren) vegetativen Zellen noch stark lichtbrechende und scharf contourirte Kugeln mit ganz homogenem Inhalte beobachtet, deren Durchmesser 1 bis $2 \mu$ in sehr grossen Zellen bis $6 \mu$ betrug, deren Bedeutung mir jedoch noch unbekannt geblieben ist.

Diese seltene Kellerbacterien-Gattung kommt meist im Gallertlager anderer unterirdischer Bacterien zerstreut vor; so auf feuchten Mauern in alten Weinkellern auf der Altstadt in Prag, dann in der Pleissenburg und in der Centralhalle in Leipzig.

The genus has apparently not been noted by subsequent authors. It is valid if the organism described is deserving of generic rank.

Mycobacillus. A generic name used by Chantemesse, Matruchot, and Grimberg (1917, p. 652) for a species Mycobacillus synovialis. Enlows (1920, p. 62) has summarized the description as follows: 
Intermediate between the "micromycetes" and true bacilli, hence the name. Young cultures actively motile. Rod-like organism. Spores by "enkystemment partiel." The older filamentous growths lose their motility. Certain portions of the filaments are Gram-positive, others Gram-negative. Isolated from cerebral ventricle in case of acute arthritis.

Mycobacteriaceae. A family name proposed by Chester (1897, p. 37) with the genus Mycobacterium Lehmann and Neumann as a type. It has been used by Chester (1897 and 1899) with the following description:

Cells short or long cylindrical or clavate-cuneate in form without a sheath surrounding the chains of individuals. Without endospores, with possibly the formation of gonidia-like bodies. With true dichotomous branching (this forms an important group standing between the true Bacteriaceae and the true fungi on the one hand and the Chlamydobacteriaceae on the other).

The genera Mycobacterium and Corynebacterium are included.

The definition was somewhat altered by Chester (1901, p. 349) later to include the Actinomyces forms. The diagnosis reads

Cells either short or long, cylindrical-clavate-cuneate in form, which at times may show true branching or as long branched mycelial-like filaments. Filaments not surrounded by a sheath as in Chlamydobacteriaceae. Without endospores, but with the formation of gonidia-like bodies due to a segmentation of the cells. Division at right angles to the axis of a rod or filament.

The family is recognized by A. J. Smith (1902, p. 270) Schneider (1912, p. 25) Benecke (1912) and by Miehe (1908, p. 131). The last named author evidently is unaware of the previous use of this name by Chester, for he proposes it as new. He places it in his scheme of classification following Coccaceae and Bacteriaceae and before Spirillaceae. He included

Einzellige Individuen von sehr unregelmässiger Stäbchenform; auch in normalen Zustand sprossende Verzweigung und zwar regelmässig oder nur gelegentlich; keine Myzelbildung nach Art der Fadenpilze; zuweilen fädige Entwickelung der Individuen, keine Endosporen, keine Bewegung.

Winslow et al. (Committee Soc. Am. Bact., 1917, p. 553) included this family under the Eubacteriales with the description:

Cells usually elongated, frequently filamentous and with a decided tendency to the development of branches, in some genera giving rise to the formation of a definite branched mycelium. Cells frequently show swellings, clubbed or irregular shapes. Endospores not produced, but conidia developed in some genera. Usually Gram-positive. Non-motile. Many species are parasitic in animals or 
plants. Complex proteins usually required. As a rule strongly aerobic (except for some species of Actinomyces and the genera Fusiformis and Leptotrichia), and oxidative. Growth on culture media often slow; some genera show mold-like colonies.

In 1920 the Committee included this family in the order Actinomycetales with the description:

Parasitic forms. Rod shaped, frequently irregular in form but rarely filamentous and with only slight and occasional branching. Often stain unevenly (showing variations in staining reaction within the cell). No conidia.

Castellani and Chalmers (1919, p. 1040) note that this family (credited to Miehe 1909) may be placed as the second family of Microsiphonales Vuillemin with the definition, "Microsiphonales without a mycelium," and including the two genera Mycobacterium and Corynebacterium.

These authors, however, themselves place the family as the fifth in the order Eubacteriales, and credit the name to Chester 1901. They follow Chester also in reducing Corynebacterium to synonymy with Mycobacterium.

Bergey et al. (1923, p. 372) follow the Committee, including the family as the second in the order Actinomycetales.

Mycobacterieae. A tribe named by Buchanan (1918, p. 55) with the following description.

Rod-shaped organisms occasionally showing a tendency to branching, acidfast, Gram-positive, non-motile, without spores.

A single genus is included, Mycobacterium Lehmann and Neumann.

Mycobacterium. A generic name proposed by Lehmann and Neumann (1896, p. 363) with the organism of tuberculosis as a type, Mycobacterium tuberculosis. It is included in their family of the Hyphomycetes. In the translation of the second edition (1901, p. 128) the description reads:

Rods stain with usual staining solutions with difficulty or generally not at all. Stain by the tubercle bacillus method, i.e., it is acid resisting. Clubbed swelling of the ends in cultures rare, in tissues somewhat more often.

In this edition is found the following statement regarding the priority of Sclerothrix:

Since we proposed this name in the first edition, we have seen that Metschnikoff (Virchow's Archiv, 113, p. 70, 1888), who first recognized the peculiar position 
of the tubercle bacillus as opposed to the other then known bacteria, in a work "Regarding the Phagocytic Rôle of the Tubercular Giant Cell," has said: "If one considers that in the perfected stage the tubercle bacteria have grown into (although short) threads, and also differ from other analogous forms (except the lepra bacteria) in the possession of a very dense envelope, then perhaps it will be easier to accept the designation Sclerothrix for the genus, and Sclerothrix Kochii for the species of the tubercle bacterium." We should have immediately accepted these names if we had known of them, but believe that according to the rules of botanical nomenclature our names should now stand, since Metschnikoff only made a conditional proposal, did not accurately define his new genus, and never made any use of the new name himself, while we have ourselves already established a name.

Neither Lehmann and Neumann or Metschinkoff seem to know of the prior use of Schlerothrix (q.v.) as an algal genus by Kützing (1849, p. 37).

Chester (1898) redefined Mycobacterium as follows:

Cells in their ordinary form short cylindrical rods, often bent and irregularly swollen, clavate or cuneate. At times $\mathrm{Y}$ shaped forms or longer filaments with true branchings. May produce short coccoid elements, perhaps gonidia.

The genus with this definition includes the Corynebacterium of Lehmann and Neumann.

The genus is listed as a synonym of Bacterium by Migula, (1900, p. 492).

Chester (1901, p. 349) again used this genus to include the acid fast and the diphtheroid bacteria. The genus is also used by A. J. Smith (1902, p. 270) and by Kendall (1902).

The genus Mycobacterium was also recognized by Miehe (1908, p. 131) who emended the description somewhat. He included in it those forms with rod-shaped cells, usually somewhat bent, with variable width, and length. After division the cells usually bend to one side, and grow side by side, forming a characteristic very firm colony which is not easily broken to pieces, and is easily separated from the medium, usually forming a membrane on liquid media. Budded branching occasional. Usually acid fast, non-motile, slow growth, no liquefaction of gelatin.

Vuillemin (1913, p. 527) rejects the name as a valid genus because of the priority of both Sclerothrix and Coccothrix It has already been noted that the former name is invalid, but it is possible that if the acid fast bacteria are to be recognized as a separate genus the generic designation Coccothrix should be used, which would make Mycobacterium an invalid synonym. 
Winslow et al. (Committee Soc. Am. Bact. 1917, p. 554) have used the definition:

Slender rods which are stained with difficulty, but when once stained are acid-fast. Cells sometimes show swollen, clavate or cuneate forms, and occasionally even branched filaments. Non-motile, Gram-positive. No endospores. Growth on media slow. Aerobic. Several species pathogenic to animals.

The type species is Mycobacterium tuberculosis (Koch) Lehmann and Neumann.

Buchanan (1918, p. 55) gave the following definition and discussion.

Slender rods which stain with difficulty, but when once stained, are acid-fast. Clubbed, swollen, clavate or cuneate cells occur, even filaments with branches. Non-motile. Without spores. Gram-positive.

The type species is Mycobacterium tuberculosis (Koch) Lehmann and Neumann.

Vuillemin (1913, p. 527) contends that Coccothrix resembles too closely Coccotrichum Wallroth. It does not seem that the resemblance is close enough ever to cause confusion, and the genus name Coccothrix is apparently valid. The Committee on Classification of the Society of American Bacteriologists, however, has recommended the use of the generic name Mycobacterium as better known and less likely to result in confusion.

Castellani and Chalmers $(1919$, p. 962$)$ indicate as the type species Mycobacterium leprae (Hausen 1874), and include the diphtheria and glanders types (Corynebacterium) in the genus.

Bergey et al. (1923, p. 372) follow the Committee, and include the genus as the first in the family Mycobacteriaceae.

The validity of Mycobacterium as a valid generic name is menaced apparently only by the older Coccothrix Lutz, q.v. Perhaps inasmuch as the latter name has apparently never been used, it may be passed by in the interest of stability.

Mycococcaceae. A family of bacteria proposed by Hansgirg (1888, p. 266) as the only family of his order Sphaerobacteria. Two subfamilies are included, Cystococcaceae and Eucoccaceae.

Mycoderma. A generic name used by Persoon (1822, p. 96) with the species Mycoderma ollare, $M$. mesentericum, etc., the latter for the film which forms on beer or wine which is exposed to the air. The individual organisms which compose this scum were not studied. We know that this scum may be of yeasts or of bacteria, frequently a mixture of the two. It is not surprising therefore in the subsequent literature to find authors diverging in the use of the term Mycoderma, one group regarding it as a genus of yeasts, the other as a genus of bacteria. 
Desmazieres (1826, p. 59) named the layer which develops on beer, etc. Mycoderma cerevisiae, regarding the organisms, however as animalcula monadina According to Lafar he did not connect the organisms with the chemical changes taking place in the solution.

Kützing (1837, p. 386) discusses the use by Desmazieres of Mycoderma, and later $(1843$, p. 149) substituted for the acetic acid form the generic name Ulvina.

According to Hansen (1894, (1911), p. 465) the designation Mycoderma aceti was used by Thomson (1852). This latter author added yeast and a little bread to a sugar solution. In the course of three months a satisfactory vinegar had developed, and in the bottom of the vessel there was a considerable gelatinous deposit which he identified as the Ulvina aceti of Kützing. He states that this organism is also termed Mycoderma aceti, though Hansen was unable to determine his authority for the statement.

Pasteur (1868, p. 106) used the name Mycoderma aceti for the organism present in acetic fermentation.

This name was also used by Hansen $(1879$, p. 230) as a generic bacterial designation, for the species $M$. Pasteurianum.

The name has come into general use for certain of the yeast like fungi. However, its use for an acetic organism was suggested by Winslow et al. (1917, p. 551) with the following description.

Cells rod-shaped, frequently in chains, non-motile. Cells grow usually on the surface of alcoholic solutions, securing growth energy by the oxidation of alcohol to acetic acid. Also capable of utilizing certain otber carbonaceous compounds, as sugar and acetic acid. Elongated, filamentous, club-shaped, swollen and even branched cells common and quite characteristic.

The type species is Mycoderma aceti (Thompson?) Committee.

Buchanan (1918, p. 45) used the following description.

Cells rod-shaped, frequently in chains, non-motile usually, without spores. Obligate aërobes, growing usually as a film on the surface of alcoholic solutions, transforming the alcohol to acetic acid. Involution forms often developed and quite characteristic.

The type species is Mycoderma aceti Thompson?

There is some doubt as to the appropriateness of Mycoderma as the name of this genus. It is possible that it should be reserved for the yeasts.

Enlows (1920, p. 62) calls attention to the fact that the type species "(first in order of arrangement, and subsequent designation by many authors)" is $M$. ollare. 
The Committee (1920) abandoned Mycoderma as a generic bacterial name, substituting Acetobacter q.v.

The name is rejected by Orla-Jensen (1921, p. 270).

It is probable that Mycoderma is invalid as a designation for a bacterial genus, and should be reserved for certain pellicle forming yeasts.

Mycomonas. A generic name proposed by Orla-Jensen (1909, p. 329) to replace Mycobacterium Lehmann and Neumann to make the designation conform to his principles of nomenclature. It is to be regarded as a synonym of Mycobacterium and Coccothrix, and invalid.

Myconostoc. A genus of bacteria described by Cohn (1875, p. 183) to include a species Myconostoc gregarium. This organism was observed in water as gelatinous masses containing cylindrical colorless cells, frequently curved or spiral. Found in water kept in glass with decaying algae. Water became dark through iron sulphid.

An der Oberfläche sammelten sich farblosen Schleimtröpfchen; diese waren gebildet von isolirten, oder haufenweise am einander hangenden kleinen Gallertkugeln von $10-17 \mu$ Durchmesser und darüber. Diese Kugeln, nach aussen ziemlich scharf abgegrenzt, häufig elliptisch in die Länge gezogen, schlossen in einer durchsichtigen Gallert einen farblosen Leptothrix artigen Faden ein, welche in knäuelartigen aber lockeren Windungen ins Innere eingelagert war. Ob jede Kugel immer nur einen oder auch mehrere solcher Fäden einschliesst, lässt sich nicht leicht ermitteln, obwohl ich das eistere als Regel vermuthe; unmittelbar vermag man nur die kogenartigen Schlingen in der Peripherie, und die durch einander geschlungenen Wundungen im Innern zu unterscheiden. Die farblosen Fäden selbst etwa von der Stärke des Bacillus ulna oder Spirillum volutans, enthalten stark lichtbrechende Körnchen; Gliederung ist nicht erkennbar. Die Vermehrung geschieht, ähnlich wie bei Ascococcus vermittelst Querfurchung der Gallertkugel, die, vermuthlich in Folge bedeutenderer Streckung des eingelagerten Fadens, sich erst elliptisch in die Länge dehut, dann in der Mette sich in zwei Halbkugeln durchfurcht, welche sich nach kurzer zeit von einander trennen. Der Gedanke lag nahe, dass es Spirillen seien welche hier im Gallert eingeschlossen sind.

The genus was included in the tribe Nematogenae.

Strangely enough, there appears to be but one subsequent record of the discovery or observation of this organism. The genus however, was generally recognized during the first two decades following its description.

Trevisan (1879, p. 139) gives the following generic description: "Somatia cylindrica, tenerrima, implicata, convoluta, muco obvoluta, in globulos perparvos congesta." This was included in his subtribe Myconostocaceae. 
The same description was used by Magnin (1880, p. 96). Myconostoc according to Van Tieghem (1884) consisted of spiral cells embedded in gelatin.

Winter (1880, p. 60) gave the following description:

Fäden sehr dünn, farblos, ungegliedert, aber beim Eintrocknen in kurze cylindrische Glieder zerfallend, verschiedenartig gebogen und durch einander geschlungen, von Gallerte umgeben, die rungliche Kugeln von $10-17 \mu$ (und mehr) Durchmesser bildet. Vermehrung durch Einschnürung und Zweitheilung dieser Gallertkugel.

Schroeter (1886, p. 169) gives the following diagnosis:

Zellen in Form dünner, gebogener und gewundener Fäden, welche in eine rundliche Gallertcyste eingeschlossen sind. Die Fäden zerfallen in kürzere Stücke. Die Cysten vermehren sich durch fortgesetzte Zweitheilung.

Hansgirg (1888, p. 265) includes the genus as the sole genus of his family Myconostocaceae, and notes finding the organism among algae in Bohemia, and frequently among his algal cultures.

The genus is accepted by De Toni and Trevisan (1889, p. 1034), Trevisan (1889, p. 26), Billet (1890, p. 24) and Ludwig (1892).

Migula (1900, p. 960) made Myconostoc the second subgenus under his genus Spirosoma.

The genus is rejected by Erwin F. Smith (1905) and by most recent writers. It is proposed by Vuillemin $(1913$, p. 526) as one of his "Formogenera conservanda."

If the organism described by Cohn is worthy of generic recognition, Myconostoc is a valid bacterial genus.

Myconostocaceae. The second family of the order Eubacteria proposed by Hansgirg (1888, p. 265) in the following statement:

Diese noch von Schröter mit der Familie der Bacteriaceen vereinigte Spaltpilz gruppe, welche der Familie der Nostoceen unter den Spaltalgen entspricht ist aus ähnlichen Gründen wie die Crenothrichaceae zu einer den übrigen Familien der Bacterien gleichwerthigen Familie zu erklären.

A single genus, Myconostoc, is recognized.

Myconostoceae. A subtribe created by Trevisan (1879, p. 139) to include the genus Myconostoc. He gave the following characterization: "Somatia substantia intersomatiari in colonias mucosas consociata, eramosa." This is the second subtribe included within his tribe Vibrionieae. 
De Toni and Trevisan (1889, p. 1934) again used the term for a subgenus with the following description: "Baculi spiraliter torti, capsulis inclusi."

Mycophyceae. A name probably of ordinal rank proposed by Hansgirg $(1890$, p. 31$)$ to include those bacteria which are intermediate between the algae (the Schizophyceae) and the Eubacteria. The families Crenotrichaceae, Leptotrichaceae, Myconostocaceae and Mycococcaceae are included.

Mycotetraedron. A generic name proposed by Hansgirg (1890, p. 28) for a species $M$. cellare $\mathrm{n}$. sp. He gives the following description:

Zellen einzeln, rundlich viereckig, die Ecken tetraedrisch gestellt 5 bis $6 \mu$ breit, mit farblosem, homogenem oder stellenweise spärlich feingekörntem, fast wasserhellem Inhalte und dünner farbloser an der Oberfläche glatter Membran, and den Ecken abgerundet und daselbst mit je einem, 1.5 bis $2 \mu$ langen, geraden, farblosen kegelförmigen Stachel versehen.

Die Vermehrung und weitere Entwickelung dieser morphologisch der AlgenGattung Tetraedron Ktz (Polyedrium Näg.) ähnlichen Kellerbacterie ist mir noch unbekannt; ich habe sie bisher blos unter anders Keller-bacterien aus einem alten Weinkeller auf der Prager Altstadt in wenigen Exemplaren beobachtet.

The genus apparently has not been recognized by subsequent writers. If the species described is sufficiently distinct, the generic name would appear to be valid.

Mycothamnion. A name of a genus of algae used by Kützing (1843, p. 120) with the following description: "Trichomata (inarticulata?) achromatica ramosa; rami apice in spermatia intumescentes." One species, $M$. fodinarum Kuetz. is a synonym of the bacterial species Leucocystis cellaris of Schroeter (1886) according to De Toni and Trevisan (1889, p. 1041).

Mycothece. A generic name used by Hansgirg (1888, p. 266) with the following description of the genus and the single species $M$. cellaris Hansgirg:

Genus Mycothece Hansg. Zellen länglich cylindrisch, einzeln oder in zweibis vierzelligen Familien, von einer meist mehrschichtigen deutlich begrenzten farblosen Gallerthülle umgeben, unbeweglich, einzeln oder zu einer dicken, formlosen Masse vereinigt. Vermehrung durch fortgesetzte vegetative Zweitheilung der Zellen blos in einer Richtung des Raumes (der Quere nach), wobei die Tochterzellen sich bald von einander trennen. Sporenbildung unbekannt.

M. cellaris Hansg. Zellen cylindrisch, gerade oder leicht in der Mitte gekrümmt, meist 1 bis 1.5, seltener 2 bis $3 \mu$ dick, drei- bis sechs-, seltener nur zweimal so lang, stark lichtbrechend, farblos, einzeln, selten zu zwei bis vier, von deutlich begrenzten, 4 bis $5 \mu$ dicken, oft geschichteten hyalinen Gallerthüllen umgeben, dicht zu 
gelblichen bis gelbräunlichen Gallertmassen gehäuft oder im schleimigen Lager anderer Kellerbacterien verstreut.

An wenig feuchten Mauern in alten Weinkellern, meist in Gesellschaft des Bacillus subtilis var. cellaris; so auf der Altstadt und in einem Weinkeller auf der Neustadt.

De Toni and Trevisan (1889, p. 1033) make the species Mycothece cellaris Hansgirg a synonym of Klebsiella cellaris Trevisan.

The name has apparently not been used by other authors. It is rejected by Erwin F. Smith (1905). If the organism described is worthy of generic differentiation, it would appear that the genus name is valid.

Mycothrix. A name applied to chains of spherical organisms by Itzigsohn (1867). Cohn (1872, p. 147) makes the following statement: "Itzigsohn und Hallier haben für die Rosenkranzketten der Kugelbacterien den Namen Mycothrix vorgeschlagen; ich bezeichne sie hier als Torulaform."

Apparently the term has never been used in a strict generic sense. The nearest approach seems to have been the ascription by De Toni and Trevisan (1889, p. 1059) to Friedberger of the term "Mycothrix bei Pleuropneumonie des Pferdes" (1873, p. 91). An examination of the latter reference fails to show any such use. It is invalid.

Myxobacillus. A generic name used by Gonnermann (1907, p. 877) (with the spelling Myxobazillus) for a species of bacterium, $M$. betae isolated from sugar beet juice. The organism is a slender rod, 0.3 by $2.3-4.5 \mu$. Easily stained. Often granules. No definite capsule. Grows at $35^{\circ} \mathrm{C}$, but not killed at $60^{\circ}$. Non-motile. It forms spores in twenty-four hours which are oval, of a diameter greater than that of the mother cell. Before spore formation the organism occurs in chains like anthrax bacillus; the filament falls apart into segments each of which produces a spore. It grows well on ordinary media. In sucrose solutions gas and acid are not formed. The solution becomes opalescent and viscous. Apparently this is a synonym of Bacillus.

Myxobacter. A generic name proposed by Thaxter (1892, p. 493) for a species of the Myxobacteriaceae, $M$. aureus. The following generic description was given: "Rods, forming large rounded cysts, one or more free within a gelatinous matrix raised above the substratum." Thaxter later noted that this generic name is invalid because of the prior use of Polyangium q.v. for this form. This name has accordingly been abandoned in later writings on this group. 
Myxobacteriaceae. The name of a family proposed by Thaxter (1892, p. 394) to include the so-called Myxobacteria. The name comes from the genus (now abandoned) Myxobacter Thaxter.

The family diagnosis as given by E. F. Smith is as follows (1905, p. 164):

Motile, rod-like organisms, multiplying by fission secreting a gelatinous base, and forming pseudoplasmodium-like aggregations before passing into a more or less highly developed cyst-producing, resting state in which the rods may become encysted in groups without modification, or may be converted into spore-masses. The vegetative rods, which vary little in size and form in the different genera and species, are typically elongate, sometimes reaching $15 \mu$ in length. Cell division follows an elongation and nearly medium constriction of the rods which, except at the moment of division, are always separate, never united in chains. A slow, sliding locomotion and a Beggiatoa-like, bending motion is characteristic of the active rods. Organs of motion have not been detected. In all species, with one exception, the rods, when seen in masses, are more or less distinctly reddish. A distinct, firm, hyaline gelatinous base is secreted by the colony as it extends itself, over which the individuals may move or in which they become imbedded.

The vegetative period, in artificial cultures, usually lasts about a week, or even two weeks, but in nature the production of cysts must be more rapid. Common in moist situations on dung, decaying wood, fungi, lichens, etc. According to Bauer they grow best at $30^{\circ} \mathrm{C}$.

In forms like Myxococcus in which the rods are somewhat scattered, the first preparation for spore production as seen under the microscope consists in the appearance of groups of rods moving with a circular tendency, in which the more central individuals soon become converted into the spores. The formation of a cystophore, when it occurs, results from the basal constriction of a papillate mass of rods which projects from the surface of the colony. In the encysted condition there are two classes-one in which the individuals thus encysted show little or no modification from the rod-like vegetative state, the other in which they are converted into definite spores. They, however, seem to run into one another.

This family name is also used by Clements (1909, p. 8) and by Benecke (1912).

Buchanan (1918, p. 541) included this as the single family of the order Myxobacteriales, with characters those of the order, q.v. Three genera were included: Chondromyces, Polyangium and Myxococcus. Bergey et al. (1923, p. 412) follow Buchanan.

Myxobacteriales. An ordinal name proposed by Buchanan (1917, p. 163). The description (1918, p. 541) follows.

Motile, rod-like organisms, multiplying by fission, secreting a gelatinous base, and forming a pseudoplasmodium-like aggregation before passing into a more or less highly developed cyst-producing, resting state in which the rods may become encysted in groups without modification, or may be converted into spore masses.

There is one family only, the Myxobacteriaceae. 
It is included as the fifth order of the Schizomycetes.

Winslow et al. (Committee Soc. Am. Bact., 1917, p. 549, 1920, p. 196) recognized the order with the following diagnosis. "Cells united during the vegetative stage into a pseudoplasmodium which passes over into a highly-developed cyst-producing resting stage."

It is also recognized by Castellani and Chalmers $(1919$, p. 924) as the third order of the Schizomycetacea, and by Bergey et al. (1923, p. 412) as the fifth order of the Schizomycetes.

Myxobacterieae. A class name proposed by Heller (1921, p. 549) for the second class of the phylum Bacteria. She states "Bacteria which join to form a complex fruiting body."

Myxobacterium. Under the heading "A New Myxobacterium" an abstract was printed of a paper by Faull (1915, p. 469). Apparently the word is not used binomially. The organism evidently is one of the Myxobacteriales (q.v.).

Myxobactrales. A name proposed by Clements (1909, p. 8) for the second order of the Schizomycetes. His description is: "Cells rod-like, motile, fission in one plane; cells secreting a gelatinous base and forming pseudoplasmodia, then passing into cysts, or spore masses which are often stalked (cystophore)."

One family, Myxobacteriaceae, is included. It may be regarded as variant of the spelling Myxobacteriales, q.v.

Myxobazillus. A variant of Myxobacillus, q.v. used by Gonnermann (1908, p. 877).

Myxobotrys. A generic name of a fungus proposed by Zukal (1896, p. 346) for the species $M$. variabilis. The generic description is as follows:

Die Sporen in dichten Köpfchen auf der blasigen Erwerterung an den Enden eines einfachen oder schwach verzweigten Sporenträgers, oder ohne Träger direct auf eineim dunnen Hypöthallus oder dem Substrate aufsitzend.

It was later shown that this was a redescription of an old genus, one of the Myxobacteriaceae, Chondromyces, (q.v.). The name is therefore invalid.

Myxobotrysaceae. A family created by Zukal (1896, p. 436) to include his mold genus Myxobotrys, with the following description: "Die Sporen entstehen durch Sprossung des Plasmodiums, ohne vorhergehende Sonderung des Plasma in bestimmte Portionen." When it was shown that the genus Myxobotrys was invalid, and the organism did not belong to the fungi, this family name was invalidated. 
Myxococcus. A generic name proposed by Thaxter (1892, p. 403) as a genus of the Myxobacteriaceae. The diagnosis given is: "Rods slender, curved, swarming together after a vegetative period to form definite more or less encysted sessile masses of coccus-like spores." In the possession of the coccus-like spores when encysted it differs from the other genera of the family, Polyangium and Chondromyces.

Eleven species have been described, Myxococcus rubescens Thaxter, $M$. virescens Thaxter, $M$. coralloides Thaxter, $M$. stipitatus Thaxter, $M$. cirrhosus Thaxter, $M$. cruentis Thaxter, M. pyriformis A.L.Smith, M. disciformis Thaxter, M. macrosporus Zukal, M. digitatus Quehl, and M. clavatus Quehl.

The generic name Myxococcus has been accepted and used by Saccardo (1899, p. 460) by Zukal (1897, p. 550) and by Quehl (1906, p. 16).

With the spelling Myxokokkus this name has been also used independently by Gonnermann (1907, p. 877) for a species of bacterium $M$. betae isolated from sugar beet syrup. In this sense the name is invalid.

Buchanan (1918, p. 542) gave the following description.

Rods slender, curved, swarming together after a vegetative period to form definite more or less encysted sessile masses of coccus-like spores.

The type species is Myxococcus rubescens Thaxter.

Bergey et al. (1923, p. 413) included this as the first genus of the family Myxobacteriaceae.

Myxokokkus. A generic name used by Gonnermann (1907, p. 883) for a species Myxokokkus betae Gonnermann isolated from a gummy fermentation of sugar beet sap. The organism is a streptococcus. It grows on all ordinary media except potato, but usually not luxuriantly. It forms on dextrose agar no gum, but only small, at first transparent, discrete colonies with slight gas formation. On ten per cent sucrose agar and gelatin it produces abundant gum and vigorous gas. The organism quickly dies on this medium. It is possible that in nature development is dependent upon growth with a gum producing bacillus. The genus is probably invalid because of the priority of Myxococcus Thaxter, and because of the inadequate characterization. Possibly it is a synonym of Leuconostoc q.v.

Neissereae. A tribe of bacteria named by Winslow et al. (1920, p. 205) as a tribe of the family Coccaceae. One genus only, Neisseria is included. The diagnosis given is: "Strict parasites, failing to grow or growing very poorly on artificial media. Cells normally in pairs. Gram-negative. Growth fairly abundant on serum media." 
Bergey et al. (1923, p. 41) includes this as the first tribe of the family Coccaceae.

It should be noted that the spelling should be Neisserieae.

Neisseria. A generic name proposed by Trevisan (1885, p. 105) with the gonococcus of Neisser as the type The generic description is as follows: "Colonie di 4 cocchi subovoidei, consociati a due in un unico strato ad avoiluppati da densa mucosa, ialina, spianeta a guisa di membranella quadrata, da ultimo libero." The single species listed is Neisseria gonorrhoeae. Trevisan $(1889$, p. 32) includes this as the first genus of his tribe Micrococcee. Fourteen species a re included, the first being $N$. gonorrhoeae. De Toni and Trevisan (1889, p. 1067) give the following diagnosis:

Cocci primitus globosi indivisi, aetate provecta in coccos duos biscoctiformiter geminos latere fratrem versus plus minus complanato, utrinque ad polos isthmis filamentosis tenuissimis insimul nexos, scissi, nunquam in turmas racemiformiter consociati. Endosporae microsomae, in coccis normalibus obvenientes.

Twenty-four species are included in the genus. The name Neisseria has rarely been used, usually being displaced by the term Diplococcus. Neisseria, however, has priority over this name if the gonococcus is the organism which should be taken as the type of the genus, or is to be included within it. It is rejected by Erwin F. Smith (1905). For discussion see Diplococcus. Vuillemin (1913, p. 525) has proposed that Neisseria with the type species $N$. gonorrhoeae be made a Genus conservandum.

Buchanan (1917, p. 612) recognized the genus with the following description:

Parasites, growing poorly in most laboratory media. Cells usually in pairs, flattened, coffee-bean shaped. Gram-negative. As a rule showing considerable fermentative power in carbohydrate media.

The type species is Neisseria gonorrhoeae Trevisan.

It was included as the fourth genus of the tribe Streptococceae.

Winslow et al. (Committee Soc. Am. Bact., 1917, p. 557) used the following diagnosis.

Strict parasites, failing to grow or growing very poorly on artificial media. Cells normally in pairs of flattened cells. Gram-negative. Fermentative powers low. Growth fairly abundant on serum media, usually whitish or yellowish.

The type species is Neisseria gonorrhoeae Trevisan.

The committee (1920, p. 205) made it the sole genus of the tribe Neissereae. 
Castellani and Chalmers (1919, p. 925) include the genus under Streptococceae with the diagnosis:

Streptococceae growing best, and often only, aërobically, without pigment formation, usually present in pairs without a true capsule, and in exudates usually intracellular, and readily decolourized by Gram's method of staining.

Primary cultures grow poorly on usual laboratory media, but best on media containing glucose or blood serum. No lysis with bile. Ferment carbohydrates usually with but slight acid production.

Type species. Neisseria gonorrhoeae (Bumm, 1885).

The genus Neisseria is recognized by Bergey et al. (1923, p. 41) as valid, with the type Neisseria gonorrhoeae Trevisan.

Nematogenes. A tribe of Schizophyta named by Cohn (1875). It included those forms in which the cells are disposed in filaments. Several bacterial genera were included.

Nevskia. A bacterial genus created by Famintzin (1892, p. 484) for the species Nevskia ramosa. According to Migula (1900, p. 1038) the generic description is as follows:

Stäbchenförmige Zellen, welche einseitig Gallerte aussondern und dadurch gestielt erscheinen. Bei der Teilung des Stäbchens teilt sich auch der Sticl, so dass sich allmählich eine in der Form con Chaetophora endiviaefolia erinnernde gelappte Gallertkolonie bildet, die an den Enden der Lappen die Zellen trägt.

The species $N$. ramosa is described as follows:

Zellen etwa $12 \mu$ lang, 2-6 mal so lang als breit, kugelförmige, stark lichtbrechende, sporenartige Gebilde enthaltend, die jedoch in Alkohol löslich sind. Die umschliessende Gallerte lässt sich in 1-proz. Kalilauge nach vorhergegangener Behandlung mit Alkohol leicht lösen. Teilung senkrecht zur Längsachse. Unter bestimmten, nicht näher bekannten Verhältnissen verlassen die Zellen die Gallerte und werden frei; sie stellen dann den Anfang neuer Kolonien dar. Im allgemeinen scheint diese Art Aehnlichkeit mit Bacterium pediculatum Koch und Hosaeus zu haben.

Von Famintzin in Aquarien des botanischen Laboratoriums gefunden.

Erwin F. Smith (1905) places this is his list of doubtful genera. It is apparently valid if the organism described is worthy of generic separation.

Newskia. A spelling of Nevskia used by Migula (1900, p. 1038) and Frwin F. Smith (1905, p. 162).

Nicolaerillus. A name applied by Heller (1922, p. 24) to genus of the tribe Putrificoideae. The description follows: 
Putrificoideae that in meat medium produce gas and various color changes; yellowish, pink, grey or mauve, depending on the medium; the particles of meat are gradually suffused with a black pigment, and bleach at the top. The meat is softened but the particles do not greatly diminish in size. Do not attack sugars. Gram-negative (weak methyl violet) rods that form terminal spherical spores. Colonies in deep agar diverse. Common in soil, found in horse feces, may multiply in wounds, but do not normally invade tissue. Produce a characteristic neuro-toxin.

Type-species $N$. tetani (Bacillus tetani Nicolaier), to be described in a future paper.

The definite designation by Buchanan (1918, p. 38) of Plectridium tetani (Nicolaer) Fischer as the type of this genus would seem to reduce the genus Nicolaerillus to a synonym of Plectridium. However, the author (Heller) insists that this is not the Plectridium of Fischer.

Nigrococcus. A name applied by Castellani and Chalmers (1919, p. 925) to a genus of the tribe Micrococceae. The description (1919, p. 932) follows:

Micrococceae saprophytic, rarely parasitic, producing black or bluish-black pigment.

Type. Nigrococcus nigrescens (Castellani, 1911).

Nitribacillus A generic name suggested by Beijerinck (1914, p. 1163) to replace Nitrobacter Winogradsky. Later (1914, p. 110) he states:

In meiner Mitteilung in der Akademie der Wissenschaften zu Amsterdam, Bd. 23, pag. 1163, 28 März (10 April) 1914, habe ich das Nitratferment, wegen seiner Beweglichkeit Nitribacillus genannt. Doch scheint es mit gegenwärtig, dass der von Winogradsky eingeführte Name Nitrobacter bleiben kann.

Nitrobacter. A name proposed by Winogradsky (1892a, p. 87) (1892b, p. 127) to include those organisms which transform nitrous into nitric acid. No species name was appended, hence from the standpoint of strict nomenclature perhaps the name is invalid as a generic designation. Winogradsky makes the following statement.

S'il fallait donner des nous à tous ces organismes, je proposerais de conserver celui de nitrobacterees à tout le group de microbes, transformed l'ammoniaque en salpetre. . . . Le ferment nitrique porterait le nom de Nitrobacter.

The organism described is a small rod, about $0.5 \mu$ in diameter, about 2 to 3 times as long as broad, non-motile, embedded in delicate gelatinous masses. It stains poorly. It grows only on media containing nitrites and little or no organic matter. It transforms the nitrites to nitrates. 
The organism is termed Bacterium nitrobacter by Migula (1900, p. 514).

The name is rejected by Erwin F. Smith (1905, p. 162).

Beijerinck (1914, p. 109) in a paper on nitrification states that the organisms present include

Nitrobacter oligotrophum-Nitrobacter polytrophum, das Nitratferment selbst. 1) Im nitratierenden, meist unbeweglichen Zustand als $N$. oligothrophum, im saprophytischen oft beweglichen nicht nitratierenden Zustand, als $N$. polytrophum, zu bezeichnen. Die beiden Formen müssen als physiologische Arten bezeichnet werden und verhalten sich zu einander als Modifikationen und nicht als Mutationen. Der Uebergang findet wie der Pfeil andeutet, nur in eine Richtung statt.

Just what nomenclatural recognition should be given these names of Beijerinck is somewhat conjectural. Probably Nitrobacter oligotrophum may be regarded as the first use of the generic name Nitrobacter in a binomial.

Winslow et al. (1907, p. 552) recognized the genus with the following description:

Cells rod-shaped, non-motile, not growing readily on organic media or in the presence of ammonia. Cells capable of securing growth energy by the oxidation of nitrites to nitrates.

Winogradsky named no species, although he described one. It might be termed Nitrobacter Winogradskyi and made the type species.

The genus was placed in the family Nitrobacteriaceae. Substantially the same diagnosis was used by Buchanan (1918, p. 180) the Committee (1920, p. 202), and Bergey et al. (1923, p. 34).

The genus is here considered valid, and the type species Nitrobacter oligotrophum Beijerinck (Nitrobacter Winogradskyi Committee).

Nitrobactereae. A variant spelling of Nitrobacterieae q.v. used by Castellani and Chalmers (1919, p. 932), by Winslow et al. (1920, p. 201) and by Bergey et al. (1923, p. 31).

Nitrobacteriaceae. A family name proposed by Buchanan (1917, p. 349) for the fourth family of the Eubacteriales The diagnosis (1918, p. 180):

Cells spherical or rod-shaped, motile or non-motile, not growing on ordinary laboratory media in the presence of organic matter. Securing growth energy primarily by the oxidation of ammonia to nitrites or of nitrites to nitrates.

Three genera were included, Nitrosomonas, Nitrobacter and Nitrosococcus. 
Winslow et al. (Committee Soc. Am. Bact., 1917, p. 551) used the following description, including this family as the first in the Eubacteriales.

Organisms usually rod-shaped (sometimes spherical in Nitrosomonas and possibly in Azotobacter). Cells motile or non-motile; when motile with polar, never peritrichous, flagella. Endospores never formed. Obligate aërobes, capable of securing growth energy by the direct oxidation of carbon, hydrogen or nitrogen or of simple compounds of these. Non-parasitic (usually water or earth forms).

The Committee (1920, p. 200) divided the family into two tribes, Nitrobactereae and Azotobactereae and revised the diagnosis as follows:

Organisms usually rod-shaped (sometimes nearly spherical in Nitrosomonas, and possibly in Azotobacter). Cells motile or non-motile. Branched involution forms in Rhizobium and Acetobacter. Endospores never formed. Obligate aërobes, capable of securing growth energy by the direct oxidation of carbon, hydrogen or nitrogen or of simple compounds of these. Non-parasitic (except in genus Rhizobium)-usually water or earth forms.

Bergey et al. (1923, p. 30) has included this family as the first in the order Eubacteriales.

Nitrobacterieae. A name used by Castellani and Chalmers (1919, p. 932) to designate the first tribe of the family Bacillaceae with the description: "Growth in ordinary laboratory media entirely or almost entirely absent." Nitrobacterium q.v. is designated as the type genus.

Winslow et al. (Committee Soc. Am. Bact., 1920, p. 201) used this designation (with the spelling Nitrobactercae) for the first tribe of the family Nitrobacteriaceae, with the description: "Organisms deriving their life energy from oxidation of simple compounds of carbon and nitrogen (or of alcohol)."

Bergey et al. (1923, p. 31) have followed the committee.

Nitrobacterium. A generic name proposed by Castellani and Chalmers (1919, p. 933) for the species Nitrobacterium nitrobacter (Winogradsky) Castellani and Chalmers. No description is given. It is the single genus of the tribe Nitrobacterieae q.v.

Nitromicrobium. A name proposed by Stutzer and Hartleb (1899, p. 197) for Nitromicrobium germinans, an organism changing nitrites into nitrates. Cells $0.76-1 \times 1-2.5 \mu$, ellipsoidal one end thicker than the other. Multiplication resembles the budding of yeasts. Growth takes place on nitrate agar, and on agar with soil extract and ammonium phosphate, likewise on nitrate agar. Organic nitrogen unsuited, and carbon compounds also interfere. The authors believe 
Winogradsky's Nitrobacter to have been an impure culture of Nitromicrobium and Hyphomicrobium. Believe that this constitutes a distinct type of organism.

Nitromikrobium. A variant spelling of Nitromicrobium, q.v. used by Behrens (1899, p. 244) in a review.

Nitromonas. A designation for organisms oxidizing ammonia to nitrites used by Winogradsky (1890, p. 258). He later (1892, p. 127) changed the name to Nitrosomonas (q.v.). The name was again proposed by Orla-Jensen (1909, p. 334) as the fourth genus of his family Oxydobacteriaceae to include the bacteria which oxidize nitrites to nitrates, a substitute for Nitrobacter Winogradsky.

Apparently Winogradsky named no species, and this name can be regarded merely as a casual designation The name of Orla-Jensen is a synonym of Nitrobacter.

Nitrosobacterium. A generic name used by Rullmann (1897, p. 288) for a species Nitrosobacterium novae formae This organism grew well in ordinary culture media as a short rod, in inorganic media as simple or branched filaments. The organism possessed the power of oxidizing nitrites. The organism has apparently not been found by subsequent investigators. It is questionable whether this organism belongs with the true nitrite bacteria.

Hartleb and Stutzer (1897, p. 621) believe the organism described by Rullmann to be merely a special growth stage of their "saltpeter fungus."

Nitrosobakterium. A variant spelling of Nitrosobacterium used by Rullmann (1897, p. 228) and other writers.

Nitrosococcus. A name proposed by Winogradsky (1892, p. 127) for the "new world" spherical organisms which oxidize ammonia to nitrites. He says "Les microbes nitreux du nouveau monde feraient le genre Nitrosococcus." Apparently no specific name was given. It was later (1900, p. 194) named Micrococcus nitrosus by Migula. It is rejected by Erwin F. Smith (1905, p. 162).

It was recognized by Buchanan (1918, p. 180) with the following description and type designation.

Cells spherical. Not growing readily on organic laboratory media. Oxidizes ammonia to nitrites.

Winogradsky termed the single species "les microbes nitreux de nouveau monde" but without a species name. It may be termed Nitrosococcus americanus snd regarded as the type. 
Apparently the correct type designation would be Nitrosococcus nitrosus (Migula).

Winslow et al. (Committee Soc. Am. Bact. $(1917,1920)$ ) merged this genus with Nitrosomonas, q.v.

Nitrosomonas. A generic name proposed by Winogradsky (1892, p. 127) to replace the earlier Nitromonas. He says

Les ferments nitreux du vieux monde ferarent partie du genre Nitrosomonas (au lieu de Nitromonas, que j'ai propose avant) avec duex especes: Nitrosomonas europaea, Nitrosomonas javanensis (d'autres encore, peut être) et des varietes locales.

The organisms oxidize ammonia to nitrites. They are rod-shaped forms, being differentiated in this respect from the new world genus Nitrosococcus.

Migula (1900, p. 954) included this genus in his genus Pseudomonas. The name was rejected by Erwin F. Smith (1905, p. 162). OrlaJensen (1909, p. 334) includes this as the fifth genus of his family Oxydobacteriaceae.

Winslow et al. (1917, p. 552) included Nitrosococcus in this genus, and used the following diagnosis.

Cells rod-shaped or spherical, motile or non-motile, if motile with polar flagella. Capable of securing growth energy by the oxidation of ammonia to nitrites. Growth on media containing organic substances scanty or absent.

The type species is Nitrosomonas europoea Winogradsky.

Buchanan (1918, p. 180) gave the following generic description.

Cells rod-shaped. Motile. Not growing readily on organic media. Oxidizing ammonia to nitrates.

The type species is Nitrosomonas europoea Winogradsky.

Bergey et al. (1923, p. 35) followed the Committee, including this as the fourth genus of the tribe Nitrobactereae.

Nocardia. A generic name proposed by Trevisan $(1889$, p. 9) to create a valid name to replace the invalid terms Streptothrix Cohn, Actinomyces Harz and Discomyces Rivolta. It is included as the third genus of the tribe Cladotrichee. The generic description given is "Cladothrix senza vagine." Five species are listed, N.farcinica and $N$. actinomyces being the first two. The generic description given by De Toni and Trevisan (1889, p. 927) is as follows:

Filamenta tenuissima, evaginata, articulata, Cladotricis more pseudoramosa, nunc e nucleo firmo radialiter expansa, nunc varie coalita. Arthrosporae in 
filamentis normalibus obvenientes, transformatione cocci singuli ortae. Est Cladothrix sine vaginis.

Savageau and Radais (1892, p. 242) revived the old name Oospora for the group. Blanchard $(1896$, p. 853) discusses this proposition in the following paragraph:

Sauvageau et Radais rapportent au genre Oospora Wallroth 1833 , toute une série de microphytes de très petite taille, zu'on range communement parmi les Bactéries: tels sont les genres Streptothrix Cohn 1874, Actinomyces Harz 1877, et Micromyces Max Gruber 1891. Ils ont, en effet, une grande ressemblance morphologique avec les Oospora vulgaires, mais ils s'en distinguement par leurs dimensions beaucoup plus restreintes: Trevisan à creé pour eux, avec raison, croyons nous, le genre Nocardia (1889).

This author recognized six species. Wright (1904, p. 396) suggested the separation of the genus Nocardia from Actinomyces because of differences in morphology both within the tissues and on culture media. He says:

I do not accept the prevalent belief, based on the work of Bostroem, Gasperini, and others, that the specific infectious agent of actinomycosis is to be found among certain branching microörganisms, widely disseminated in the outer world, which differ profoundly from Actinomyces bovis in having spore-like reproductive elements. I think that these should be grouped together as a separate genus with the name of Nocardia, and that those cases of undoubted infection by them should be called nocardiosis and not actinomycosis. The term actinomycosis should be used only for those inflammatory processess the lesions of which contain the characteristic granules or "drusen." That a Nocardia ever forms these characteristic structures in lesions produced by it in man or cattle has not been convincingly shown.

\section{He further says (p. 385):}

To members of this group the generic names Streptothrix, Nocardia, Cladothrix, and Oospora already have been given by various writers. Of these, in accordance with well-recognized principles of nomenclature, "Nocardia" is the only one that is tenable for the group, if it be made into a separate genus, because the other names have been previously used for plant genera to which these microörganisms clearly do not belong, and they are therefore untenable.

Against the status of the term "Nocardia" as a generic name for these microorganisms, it may be urged that its original definition was faulty, chiefly in that the branching of the filaments was described as false, but this objection has no weight in view of the fact that Blanchard has published an accurate description of a number of species of this group and adopted "Nocardia" as the generic name.

The name Nocardia is rejected by Erwin F. Smith (1905, p. 162). 
Jordan (1908) accepts Wright's conclusions, and separates Nocardia with the definition "Filaments with true branches, with reproductive elements or spores observed" from Actinomyces in which no such spores are formed.

Pinoy (1913, p. 929) proposed that Nocardia should replace the old name Actinomyces and that a new name, Cohnistreptothrix be created with Cohn's Streptothrix Foersteri as the type.

Vuillemin (1913, p. 526) concluded that the name Nocardia should replace all of these terms, and lists it as a "genus conservandum" in his group Microsiphones.

Winslow et al. (Committee Soc. Am. Bact., 1917, p. 554) gave the following definition.

Branched filaments, resembling a mycelium, readily breaking up into segments, usually saprophytic soil forms. Differs primarily from Actinomyces in the development of aerial hyphae and conidia. Usually aërobic. Many are pigment formers. Colonies as a rule mold-like on culture media.

Merrill and Wade $(1919$, p. 64) reject the name in the following statement.

This name was adopted by De Toni and Trevisan to cover the entire group. Blanchard used it for a time in its original application and Wright (1894) adopted it for nonpathogenic strains only. As many other authors used it in one sense or another, of late it has gained much prestige. Vuillemin, and Chalmers and Christopherson have recently adopted it for the entire genus.

The validity of this name we deny on the grounds indicated in the discussion that follows.

Castellani and Chalmers (1919, p. 1040) recognize the genus as the type of their family Nocardiaceae.

They give the following definition, designation of type, and reasons for adoption of name:

Nocardiaceae growing aërobically, usually easy of culture, and producing arthrospores.

Type Species. Nocardia bovis (Harz, 1877).

Nomenclature. Bollinger's ray fungus (Nocardia bovis) belongs to a genus of which the correct name is Nocardia Toni and Trevisan, 1889, a term derived from Nocard, the celebrated French parasitologist, who was the first investigator to clearly recognize this fungus in France. We state that it is the correct name for the following reasons:

1. It is the oldest name, against which no objections can be raised.

2. It has been formally adopted by the Botanical Section of the First International Congress of Pathology. 
This genus will be regarded as a synonym of Actinomyces, which see for reasons.

Nocardiaceae. A family (first) of the Microsiphonales named by Castellani and Chalmers (1919, p. 1040). It is defined as "Microsiphonales with a mycelium." It contains two genera Nocardia and Cohnistreptothrix.

Nodofolium. A generic name proposed by Ellis (1907, p. 502) for one of the iron bacteria. The species named is Nodofolium ferrugineum. It is defined as a flat band with regular constrictions. Loops and arches developed. Reproduction is by the formation of conidia on the outside of the filament.

Molisch regards this as a synonym of Leptothrix.

Nosema. A generic name proposed by Naegeli (1857, p. 760) for the species Nosema bombycis, which was at first taken for a bacterium. Later it was shown to be a protozoan. It is therefore a protozoan genus.

Novillus. The name of the fifteenth genus of the Clostridioideae given by Heller (1922, p. 22) with the following description.

Clostridioideae that in blood broth produce $\mathrm{H}_{2} \mathrm{~S}$ demonstrable by lead-acetatepaper test; they liquefy gelatin. Produce gas and on continued incubation produce a pink coloration in meat, but this color rapidly fades. Autoagglutinate with extreme readiness. Slowly attack milk and a few carbohydrates, but do not form much acid. Heavy rods of apparently shy growth habit on most media; form a few oval spores that may or may not bulge the sides of the bacilli. Colonies usually large and opaque, may form slender projections or even long fine woolly filaments. Frequently yellowish. Typically toxic tissue invaders which frequently cause formation of a thick gelatinous oedema that does not lose its gelatinous consistency on section. May also produce gas and a black haemorrhagic condition of the muscle if rapid invasion by large numbers of bacilli takes place. One strain causes considerable tissue destruction. Pathogenic for guineapigs, mice, man, hogs, horses, cattle.

Type species $N$. maligni (Bacillus oedematis-maligni II, Novy) as described by Nory.

Octopsis. A genus of bacteria proposed by Trevisan (1885, p. 102) to include Octopsis cholerae-gallinarum of fowl cholera, O. equorum of horse typhoid, $O$. xanthogenicum of yellow fever, and $O$. lyssae of rabies. The name has not been used by subsequent authors and was abandoned by Trevisan himself. However, a strict application of the rules of priority would make this a valid name and reduce to synonymy the later name Pasteurella. It is possible that it might be rejected as invalid upon the basis of an insufficient description, as being "universally regarded as non-valid." 
It is rejected by Erwin F. Smith (1905, p. 162).

Oenobacillus. A generic name used by Forti (1896) for an organism described by him as Oenobacillus Abbae. It was a polymorphic bacillus isolated from red wine. The original description is not available. The name has been used by Kossowicz (1911, p. 113).

In young cultures it appears as a diplococcus, later as rods, rounded at the ends and in pairs. Gelatin is not liquefied. Produces undesirable changes in wine. Non-motile. Grows better in oxygen.

Omelianskillus. A name proposed by Heller (1922, p. 5) as the second genus of the Clostridioideae, with the description:

Clostridioideae that do not grow well in media containing much protein, and may derive all their nitrogen from mineral salts. Split cellulose or hemicellulose. Do not contain starch. Long slender bacilli with spherical spores. Colonies may be produced on potato slants; they are minute, yellowish and transparent. Agents of plant putrefaction, found everywhere.

Type species $O$. hydrogenicus (the ferment of cellulose which produces hydrogen, of Omeliansky) as described by Omeliansky (1895 and 1904 b). In his later work he admits that the cultures studied by him were not pure. Another type, O. methanicus, similar to the above, is said to be the agent of methane formation in cellulose fermentation. This species may be assigned to the same genus.

Oospora. A genus created by Wallroth (1831, p. 182) for a group of eleven species of fungi with the following description: "Sporidia subglobosas oviformia intricata pellucida, primum concatenata, hypham articulatam simplicem teneram decumbentem mentientia, articulisque inter se facile secedentibus fragilia."

The genus has in general been recognized by mycologists. It is of interest in bacteriology because in 1892 Sauvageau and Radias (1892, p. 246) concluded that the Streptothrix of Cohn and the Actinomyces of Harz belonged in this genus.

In this conception they were followed by Lehmann and Neumann (1896, p. 375) and by Chester (1897, p. 37). Berestnew (1899, p. 390) concluded that the genera were distinct, and in this was followed by Lehmann and Neumann in later editions, and by Chester (1901). It is rejected by Musgrave and Clegg (1908, p. 458).

It is probable that the trichomycetes shou d not be given the name Oospora. It is a valid mold genus, but an invalid bacterial genus.

Ophidobacteries. A name used by Maggi (1886, p. 176) for his fifth order of bacteria. He says: "Bacteries a corps filiforme, ondule ou flexueux, a mouvements serpentiformes." The genera included are Vibrio and Tyrothrix. 
Ophidomonas. A genus created by Ehrenberg (1838, p. 43) for one of his cryptomonads. The illustration (1838, fig. 11) (Migula 1897, p. 5) shows an olive green or brownish colored individual. It is probable that the organism was one of the red sulphur bacteria, for Ehrenberg named one of his organisms Ophidomonas sanguinea. Ehrenberg differentiated from Spirillum in that the latter frequently showed incomplete cell divisions, the former always divided completely.

The first species named, Ophidomonas jenensis Ehrenberg (1838, p. 43) is identified by Cohn (1872, p. 183) with his Spirillum volutans. Cohn concludes that Ehrenberg's basis of differentiation of Ophidomonas and Spirillum was inadequate. Cohn later (1875, p. 170) noted an observation of Ophidomonas sanguinea. He says:

Seit dem wir bei dem alten Spirillum volutans Flummergeisseln aufgefunden, besteckt zwischen Spirillum und Ophidomonas uberhaupt kein Unterschied, vorausgesetzt, dass auch bei den kleineren Spirillen Bewegungsorgane noch nachträglich erkannt werden sollten. Wir haben daher nur die Wahl, entweder Ophidomonas als selbständige Gattung zu streichen, und unsere .Art etwa unter dem Namen Spirillum sanguineum gesissemassen als das Mummuth unter die Bacterien enzureihen oder umgekert die mit Flummergeisseln nachweislich ausgerusteten Schraubenfäden (volutans, ienensis und sanguinea), unter Ophidomonas zusammenzufassen, und den Namen Spirillum ausschliesslich für die kleineren Species (tenue, Undula) so lange beizuhalten als an ihnen noch keine Geisseln entdeckt sind. Sollte dies geschehen, so würde umgekehrt der Name Spirillum $\mathrm{zu}$ löschen sein.

The name Ophidomonas was used by Hansgirg (1888, p. 264) for the second section of the genus Spirillum. He says: "Ophidomonas (Ehrb.) Hansg. Zellen rosen-bis blutroth, violett oder röthlichbraun, meist mit Zahlreichen, stark lichtbrechenden Schwefelkörnchen in plasmatischen Inhalte." One species is included, Spirillum sanguineum (Ehrb.) Cohn.

Winogradsky (1888) created the genus Thiospirillum, with Thiospirillum (Ophidomonas) sanguineum as the type.

De Toni and Trevisan (1889, p. 1006) regard Ophidomonas as a synonym of Spirillum.

Migula (1895) followed Hansgirg in making Ophidomonas a subgenus of Spirillum, defining it to include those forms having sulphur granules.

Later, however (1900, p. 1049), he accepted the generic designation Thiospirillum of Winogradsky for the red sulphur bacteria with spiral cells, making Ophidomonas a synonym; with the type Thiospirillum (Ophidomonas) sanguineum. 
This name was placed in a list of rejected genera by Erwin F. Smith (1895, p. 162).

Apparently Winogradsky was in error in creating the genus Thiospirillum when the valid name Ophidomonas was in existence. It would seem that the latter name is a valid generic designation of the red sulphur bacteria with spiral cells. The type species is Ophidomonas jenensis Ehrenberg.

Ophryothrix. A generic name given by Borzi $(1878$, p. 274) to an organism which he named Ophryothrix Thuretiana and regarded as one of the algae. This is made as synonym of Leptothrix Thuretiana by Hansgirg and of Leptotrichia Thuretiana by Trevisan (1889).

It is probably invalid as a bacterial generic name, although its status is not entirely clear.

Oscillospira. A generic name proposed by Chatton and Pérard (1913, p. 1160) for the bacterial species Oscillospira Guillermondi observed in the coecal contents of the cavy. The description is as follows:

Oscillospira Guillermondi se présente sous forme de filaments robustes, assez bien calibrés, d'un diamètre moyen de $5 \mu$ et dont la longueur n'excéde jamais $100 \mu$. Ils sont arrondis aux deux extrèmites. Examinés vivants ils montrent un cloisonnement bien apparent; les cloisons sont très rapprochées, et les compartiments qu'elles limitent, ceux ou se forment les spores excepté, ont de 1 à $2 \mu$ de longueur. Ils sont donc extremement étroits. L'épaisseur des cloisons est d'ailleurs variable. Les plus epaisses sont biconcaves. Le cytoplasme est homogene ou finement granuleux sans pigment ni grains de soufre, ni inclusions d'aucune sorte. Ces filaments se multiplient par simple scission transversale entre deux compartiments, généralement de part et d'autre des grosses cloisons biconcaves qui équivalent aux disjoncteurs des autres Oscillariées. Les filaments sporulés ne sont jamais nombreux. Chacun d'eux forme le plus souvent une, rarement deux, endospores. La spore est contenue dans un des compartiments considérablement allongé, mais très peu élargi, qu'elle ne remplit d'ailleurs pas entièrement. Elle est ellipsoïdale, mesure en moyenne $4 \mu$ de long sur $2.5 \mu$ de large. Elle est orientée suivant l'axe du filament ou très peu inclinée sur cet axe. Aprés coloration, le contenu des compartiments est sans différenciation chromatique centrale. Par contre on y distingue une ou deux vacuoles. Oscillospira est três mobile. Les filaments se deplacent suivant une ligne helicoĩdale à tours trés laches, telle que les filaments les plus longs n'ont jamais plus d'un tour et demi de spire. Nous n'avons pas coloré les cils. La mobilité n'est d'ailleurs pas constante. Chez certains cobayes tous les individus se montrent immobiles. La structure de cet organisme en fait incontestablement une cyanophycee. L'absence de pigment et de corps chromatique central la rapproche des Beggiatoa. Mais dans les conditions ou nous rencontronês Oscillospira elle n'elabore pas de soufre. C'est la d'ailleurs chez les Beggiatoa meme un caractére purement physiologique, subordonné aux conditions de milieu. 
The organism was found quite constantly present in the intestinal contents of cavies at the Pasteur Institute in Paris.

Oxydobacteriaceae. The first family of the order Cephalotrichinae named by Orla-Jensen (1909, p. 329). It includes those obligate aërobic bacteria which oxidize carbon, nitrogen or hydrogen compounds without the production of noteworthy amounts of unoxidized split products. None of the organisms produce thread-like filaments or produce a mycelial growth.

Pacinia. A genus of bacteria named by Trevisan (1885, p. 83) to include the organism which causes Asiatic cholera. The original generic description is:

Tre stadi di sviluppo vegetativo: 1. Bacilli, 2. Filamento, 3. Cocchi. Bacilli (stadio protoplastico tepico) cilindrici, piu o meno ricurvi, inarticolati, incolori, biformi; lunghi (macrobacilli) e corti dio transitorio irregolarmente flessuosoondulato-anglosi risultanti da piu bacilli runasti im conguinzione per incompleta divisione transversale. Cocchi (stadio finale) derivati da michrobacilli, dapparima in brevi monifi, indi liberi. Spore provenienti tauto nei microbacilli quanto nei cocchi.

The first species named is Pacinia cholerae asiaticae. As synonyms he notes Vibrio cholerae Pacini (1854) and Bacillus cholerae asiaticae Trevisan. Other species described are Pacinia Finkleri of cholera mostras, $P$. Lewisii from saliva, and $P$. Cecii from cholera stools. Later $(1889$, p. 23) this genus was included as the tenth of the tribe Bacillee, with the description "Baculi cilindrici, non mai spirali, con protoplasma uniformemente diffuso. Spore macrosome provenienti in una estremita intumescente a guisa di capocchia, di rado in entrambe le estremita, di baculi normali immutati." Sixteen species were listed.

De Toni and Trevisan (1889, p. 1015) give as synonyms Dispora Kern and Microspira Schroeter. The generic diagnosis given is:

Baculi cylindrici, nunquam spiraliter torti, plasmate uniformiter diffuso foeti. Sporae (arthrosporae) macrosomae, ex uno apice (raro utroque) capituli ad instar intumescentes, in baculis normalibus immutatis ortae.

The genus is divided into two sections, Eu-Pacinia with 11 species and Pseudospira with 8 species. Among the species of the first section are $P$. putrifica, $P$. Loefferi (diphtheria bacillus) and $P$. caucasica. The second section includes Pacinia cholerae-asiaticae as its type. It corresponds quite exactly to the Microspira of Schroeter and Migula. 
The genus Pacinia has not been recognized by subsequent authors. It is rejected by Smith (1905, p. 162) although he states that were it not for the availability of the generic designation Vibrio for the genus of which the comma bacillus is the type, Pacinia would have priority over Microspira Schroeter.

The genus is likewise rejected by Vuillemin (1913, p. 521) as not satisfactorily characterized. Pacinia may probably be regarded as a synonym of Vibrio.

Pacinieae. The fifth subtribe of the tribe Bacilleae used by De Toni and Trevisan (1889, p. 1015) with the following diagnosis: "Baculi nudi nunquam spiraliter torti. Arthrosporae." The following genera are included: Pacinia and Bacterium.

Palmella. A genus of algae named by Lyngbye. Various bacteria have been incorrectly placed here. Among them are Palmella mirifica Rabenhorst $=$ Micrococcus mirificus Trevisan, Palmella prodigiosa Montagne $=$ Micrococcus prodigiosus Cohn.

Panhistophyton. According to Zopf (1885, p. 69) the name Panhistophyton ovatum was given by Lebert (1856) to the organism earlier grouped with the bacteria and now known to be a protozoon, Nosema bombycis Nägeli. Trevisan (1882, p. 100) says:

La prima opinione fu emessa dal Lebert, che li ritenne un alga unicellulare, cui diede il nome Panhistophyton ovatum (In Berlin. Entomolog. Zeitschr, 1858), ma il Cohn avendodimostrato che erano Batteri appartenenti al genere Micrococcus, rimaseso nelle tabelle sistematische coll 'apellativo Micrococcus bombycis.

Panhistophyton is not a bacterial genus.

Parachromatium. An alternative to Azotobacter proposed as a generic name by Beijerinck (1903, p. 217). In a footnote he says:

Peut être le nom de Parachromatium qui indique la parenté de notre microbe avec le genre Chromatium de Winogradsky, serait préférable. Des considérations physiologiques m'avatent d'abord conduit à une tout autre opinion mais des études ultéreure me portent a croire que cette parenté generique est indubitable. Zettnow, en examinant mes preparation, avait deja la meme opinion.

The name does not seem to have been used, and may be regarded as invalid as a generic designation.

Paracloster. A generic name used by Fischer (1895, p. 141) to designate those non-motile rod-shaped bacteria in which the cells become spindle shaped when sporulating. The description given is

Unbeweglich, ohne Geisseln, mit Endosporen in spindelförmig aufgeschwollenen Stäbchen; die Spore liegt oft genau in der Mitte, kann aber auch in 
einem der Enden, also ausserhalb der grössten Schwellung liegen. Bis jetzt ist kein Vertreter dieser Gattung bekannt.

Paracloster butyricus, the Granulobacter immobilis of Grassberger and Schattenfroh was later given as the type (1903, p. 60).

This generic name has apparently not been used by other authors. It is rejected by Erwin F. Smith (1905, p. 162). It may be regarded as a synonym of Clostridium.

Paracoccaceae. A subfamily of the Coccaceae proposed by Winslow and Rogers (1905, p. 660) with the diagnosis:

Parasites (thriving only, or best, on, or in the animal body), thrive well under anaërobic conditions. Many forms fail to grow on artificial media, none produce abundant surface growths. Planes of fission generally parallel, producing pairs, or short or long chains.

This diagnosis was emended in 1906, (p.545), by the addition of: "never packets. Generally stain by Gram. Produce acid in dextrose and lactose broth. Pigment, if any, white or orange." In their last contribution (1908, p. 240) the Winslows include the following genera: Diplococcus, Ascococcus, Streptococcus, Albococcus and Aurococcus.

It would seem that the subfamily name Paracoccaceae is invalid for two reasons; it has the ending prescribed by the botanical code for families and not subfamilies, furthermore, it is not formed as prescribed in the code by the addition of an appropriate ending to the name of one of the genera included. Inasmuch as no tribes are included in the Winslow's classification, the tribal name Streptococceae used by Trevisan might well be used in place of this subfamily.

Parameningococcus. A casual name used by Dopter (1909, p. 74) for a type of meningococcus. It is differentiated primarily by its agglutination relationships.

Paraplectrum. A generic name used by Fischer (1895, p. 141) for non-motile rod-shaped bacteria which produce spores in the cell tips, with consequent enlargement and formation of "drumsticks." The description given is "Unbeweglich, ohne Geisseln, mit Endosporen in einem kopfig aufgeschwollenen Ende." The type given is Paraplectrum Peroniella, the Bacillus Peroniella of Klein (1889, p. 65). The species mentioned later $(1903$, p. 61) is Paraplectrum foetidum Weigmann.

This genus has not been used by other authors. It is rejected by Erwin F. Smith (1905, p. 162). It may be regarded as a synonym of Plectridium. 
Paraschizae. A subdivision of the group Schizomycetes named by Jennings (1899, p. 315) to include the genera Astrobacter and Pasteuria characterized by longitudinal rather than transverse fission of the cell in multiplication. The coördinate subdivision is named Diaschizae.

Paraspirillum. A genus used by Dobell (1911, p. 97) to include the species Paraspirillum vejdovskii found in a culture of Oscillatoria.

The living organisms are, for the most part, in the form of spiral or S-shaped rods, very like ordinary spirilla. Short individuals are about $8 \mu$ in length, the largest individuals attaining a length of about $25 \mu$. The average length is about $15 \mu$.

The organisms are variable in thickness, with a well marked thickening toward the middle of the body. They taper decidedly toward the ends. The cell is described as a "much elongated and spirally twisted spindle." "In the middle region, the organisms measure from $1.5 \mu$ to $2 \mu$ across - the thickness varying in different individuals."

In each living cell at thickest point is an oval or rounded structure regarded as a nucleus. Immediately surrounding the nucleus is an area of hyaline cytoplasm. Toward the ends of the cells are granular inclusions (volutin or metachromatic granules).

"Movement from place to place is effected by means of flagella, similar to those of common spirilla. In the living organisms, I have never succeeded in seeing any flagella." The flagella were demonstrated, however, in stained mounts, a single one, or one at each end.

The genus was recognized as the third of the family Spirillaceae by Buchanan (1918, p. 179) with the description:

Cells spiral or S-shaped, like spirilla, variable in thickness, with a well marked thickening toward middle of the body, and tapering toward the ends, a much elongated and spirally twisted spindle. Motile by means of flagella.

The type species is Paraspirillum vejdovskii Dobell.

Pasteurella. A genus created by Trevisan (1887, p. 94) primarily to include the bacillus of fowl cholera. His description follows:

Pasteurella, Trevis. (nuovo genere). Tre stadi di sviluppo vegetativo: 1. Baculi, 2. Filamenti, 3. Cocchi. Baculi (stadio primigeno tipico) brevemente cilindrici o ellissoidi, inarticolati incolori; protoplasma polare-diblastico. Filamenti (stadio anormale transitorio) visulanti da baculi rimasti in conguinzione per incompleta temnogenesi. Cocchi segregati (monococchi e cocchi ottoformi) o seriati in catenelle. Spore provenienti nei baculi.

The species first named is Pasteurella cholerae-gallinarum. Other species named were $P$. Davainei and $P$. suilla. Later (1889, p. 21) 
twelve species were included. The genus as discussed in Saccardo's Sylloge contains, eighteen species. The genus is characterized as follows: "Baculi plasmate polari-diblastice foeti. Sporae (arthrosporae-) isosomae, microsomae." In the analytical key the following additional characters are found, "Baculi recti vel incurvi, nunquam spiraliter totti." "Baculi in coenobium reticulatum non connexi." "Baculorum divisio semper in unam eandemque directionem longitudinalem repetita."

The name is rejected by Erwin F. Smith (1905, p. 162).

The genus Pasteurella has been recognized by various authors particularly Lignieres (1900, p. 212) who worked with the hemorrhagic septicemia group of organisms, as the cause of the so-called "Pasteurelloses," but has not found its way into formal classification. Lignieres (1900, p. 331) gives the following diagnosis of Pasteurella:

Parmi les maladies qui forment le groupe des septicémies hémorragiques, on en trouve un certain nombre dont les microbes spécifiques répondent aux caractéres invariables suivants: Cocco-bacilles, sans mouvements de translation, ne prenant pas le Gram, trés polymorphes, donnant des formes d'involution, ne liquéfiant pas la gélatine, ne coagulant pas le lait dont la reaction reste normale. ne donnant pas de culture visible sur pomme de terre naturelle acide, ni d'indol dans le bouillon pancreatique, ne rougissant pas le gelose de Würtz, surtout aërobies, mais aussi anaérobies, présentant une odeur sui generis dans les cultures. Pas de spores, pas de cils. Virulence trés variable, en général grande. Par injection intra-veineuse, affinité spéciale pour les synoviales tendineuses et articulaires. Les caractéres que je viens de mentionner sont fixes, absolus; l'absence de l'un ou de l'autre exclut le microbe du groupe des Pasteurella. Comme indication générale, on peut ajouter que ces microbes se colorent facilement aux deux extrémités en laissant le centre clair; qu'ils ne se colorent pas aussi aisément que d'autres microbes, le coli, par exemple; qu'ils poussent parfois discrétement sur les milieux de culture habituels; que dans certains cas enfin, ils sont tres difficiles à mettre en evidence au sein de l'organisme.

Vuillemin (1913, p. 521) accepts the view of Fischer that the bipolar staining characteristic of this group is an artefact, but believes that the organisms related to fowl cholera constitute a homogeneous group of pathogenic bacteria. However, he advocated abandoning the term Pasteurella to the bacteriologists who have vulgarized it into a purely nominal genus.

Kitt in Kolle and Wassermann (6:37) improperly credits the name to Lignieres, and suggests its abandonment in the following statement:

Von Lignieres ist für die Septicaemia avicum und überhaupt die Septic. haemorrhagica der Name Pasteurellose und für die Bakterien der Name Pasteurella 
einzuführen. Einige französische Autoren haben daraufhin diese Nominiering gewählt, während Montfallet \& Boschetti mit begründeter Darlegung Stellung dagegen nahmen. Auch Referentem scheint die Neubenennung unnötig und willkürlich, und der Name, welcher den Charakter der Krankheit ausdrückt, passender.

Winslow et al. (Committee Soc. Am. Bact., 1917, p. 561) accepted the designation with the description:

Short rods, single or rarely in chains, usually showing distinct polar staining. Non-motile. Gram-negative. Without spores. Aërobic and facultative. Powers of carbohydrate fermentation slight; no gas produced. Gelatin not liquefied. Parasitic, frequently pathogenic, producing plague in man and hemorrhagic septicemia in the lower animals.

The type species is Pasteurella cholerae-gallinarum (Flügge) Trevisan.

Buchanan (1918, p. 52) used the following description:

Short rods, single or rarely in chains, usually showing distinct polar staining, non-motile. Gram-negative, without spores, aërobic and facultative, usually not producing gas, powers of fermentation slight, often pathogenic, not acid-fast, not liquefying gelatin.

The type species is Pasteurella cholerae-gallinarum (Fluegge) Trevisan.

The genus is made the type of the tribe Pasteurelleae by Castellani and Chalmers (1919, p. 943). Bergey (1923, p. 264) also includes the genus in the tribe Pasteurelleae.

The name of the type species is somewhat puzzling. Apparently the first species name for the fowl cholera organism was Micrococcus gallicidus Burrill (1883, p. 320). His description is inadequate, but he claimed he was describing the cause of fowl cholera. Zopf (1885, p. 87) called the organism Micrococcus cholerae-gallinarum and Trevisan Pasteurella cholerae-gallinarum. It would appear the correct designation would either be Pasteurella cholerae-gallinarum (Zopf) Trevisan or Pasteurella gallicida (Burrill) comb. nov.

Pasteurelleae. A name proposed by Castellani and Chalmers (1919, p. 932) for the eighth tribe of the family Bacillaceae. The description $(1919$, p. 943$)$ is:

Bacillaceae with good growth on ordinary media, without endospores, aërobic, without fluorescence or pigment formation, unable to liquef gelatine, and Gramnegative, but with polar staining.

Type genus. Pasteurella De Toni and Trevisan, 1889.

Winslow et al. (Committee Soc. Am. Bact., 1920, p. 211) independently proposed the same name with the following diagnosis: "Gram- 
negative rods, showing bipolar staining. Parasitic forms of slight fermentative power."

The only genus included is Pasteurella.

Pasteuria. A generic name proposed by Metschnikoff (1888, p. 166) for Pasteuria ramosa, an organism described from the bodies of the water fleas Daphnia pulex and D. magna. The generic diagnosis given by De Toni and Trevisan (1889, p. 941) follows:

Baculi primitus in cumulos rotundatos, axi centrali ramoso instructos, arctissime acervati, confluentes, dein ob pluries repetitam divisionem longitudinalem segregati, demum soluti, ellipsodei, stipitulati. Sporae (Endosporae) globosae, microsome, ad apicem baculorum liberorum obvenientes.

Obs. A caeteris Baculogenis ob forman valde peculiarem cumulorum primigeniorum et baculorum divisionem semper longitudinalem praedistincta.

The organism apparently has not been observed by other investigators. Lehmann and Neumann (1896, p. 20) say that the organism can scarcely be regarded as belonging to the bacteria in a strict sense.

Migula (1904, p. 128) doubts the bacterial nature of this organism and excludes it from his classification. The name is included by Erwin F. Smith (1905, p. 162) among the rejected genera.

Vuillemin (1913, p. 527) states that this organism may be differentiated from Nocardia (!) by its claviform ramifications, by its dichotomy and by the formation of spores inside the cells. He proposes it as a genus conservandum of the Microsiphonees with the type species $P$. ramosa Metchnikoff.

The nomenclatural status and position of this genus is uncertain. The type species is Pasteuria ramosa Metchnikoff.

Pasteuriaceae. A family name proposed by Metschnikoff (1888, p. 165) to include his genus Pasteuria and the bacteria of the root nodules of leguminous plants.

Pasteurieae. A subtribe of the tribe Bacilleae named by De Toni and Trevisan (1889, p. 941) with the following diagnosis: "Baculorum divisio semper in unam eandemque directionem longitudinalem repetita. Endosporae." The single genus Pasteuria is included.

Pectinobacter. A generic name proposed by Makrinov (1916, p. 440) for the species (type) Pectinobacter amylophilum. Enlows (1920, p. 69) summarized the description of the species as follows:

Rods 4 to $6 \mu$ long by 0.5 to $1 \mu$ wide. Motile. Spores are formed, prior to which a fusiform aspect is assumed. Gram positive. Grows better on starch media than on any other. Active fermentative agent. Isolated from soil. 
Pectobacillus. The second genus of the family Butyribacteriaceae proposed by Orla-Jensen $(1909$, p. 342). It is defined to include those forms of his family Butyribacteriaceae which attack pectins. They stain blue with iodine and ferment many carbohydrates. An organic source of nitrogen is required, the species are anaërobic. The Granulobacter pectinovorum of Beijerinck is the type.

This name may be regarded as a synonym of Clostridium and Granulobacter unless the phenomenon of pectose fermentation should prove of generic significance.

Pediococcus. According to Lindner (1888, p. 97) a species of bacterium was named Pediococcus cerevisiae by Balcke (1884, p. 183). This was an organism previously noted as occurring in diplococcus and tetrad forms in beer by Pasteur. Hansen (1882) termed the organism a Sarcina. According to Lindner the Pediococcus cerevisiae produces colorless colonies on gelatin, which later become yellowish or yellowish brown. The gelatin is not liquefied. On meat infusion gelatin it grows in stroke culture as a gray white, moist iridescent streak with relatively smooth edges.

Lindner (1888) described two additional species of Pediococcus, $P$. acidi lactici and $P$. albus. Trevisan (1889, p. 28) included this as the third genus of Sarcinee. It is ascribed to Lindner (1887). The generic description is "Cocchi aggregati a 4 a 4 in famiglie unistrate nella ganga gelatinosa equalbilmente spianata a guisa di membranella parallelogrammica. Temnogenesi in due direzioni." Ten species were included.

This generic name was accepted by De Toni and Trevisan (1889, p. 1050) with the following description:

Cocci globosi, v. ovoidei, quaternati, in exiguas familias regulares, unistrates muco amorpho tenuisculo, vix conspicuo, ceto dilabente obvolutas, laxe consociati. Coccorum divisio in duas directiones.

Three additional species are here listed. These authors credit the generic name Pediococcus to Lindner and not to Balcke. Eisenberg (1891) lists the three species recognized by Lindner under "Pediokokkus." Lehmann and Neumann (1896, p. 102) include this genus as a synonym of Micrococcus.

The genus is recognized by Fischer (1897) with the following description: "Two planes of fission, alternate and at right angles." "Micrococcus tetragenus" is given as an example, also the gonococcus. This genus is again listed in the second edition (1903, p. 60). 
Sollied (1903, p. 491) described another species P. hennebergi from beer.

Klöcker (1903, p. 331) ascribes the genus to Francke and states "The cells are arranged in flat colonies, they divide along two planes."

Erwin F. Smith (1905, p. 162) placed this name among the rejected genera. Vuillemin (1913, p. 520) dismisses Pediococcus as an invalid synonym of Merista Van Tieghem (1883).

If the cocci which are arranged in tetrads are to receive generic recognition, the name Pediococcus would appear to be valid. If not, this becomes a synonym, perhaps of Micrococcus. The type species is Pediococcus cerevisiae Balcke.

Pediokokkus. A variant of Pediococcus (q.v.) used by Eisenberg (1891) and other German writers.

Pedioplana. A generic name proposed by Wolff (1907, p. 9) for the species $P$. haeckeli. The genus corresponds to Pediococcus except that the cells are motile by means of flagella. The name has apparently not been used by other investigators. It may be regarded as a synonym of Pediococcus.

Pelochromatium. A generic name proposed by Lauterborn (1913, p. 99) for an organism morphologically resembling Chlorochromatium but containing bacteriopurpurin. Included in his family Rhodobakteriaceae. The only (type) species is Pelochromatium roseum Lauterborn.

Pelodictyon. A generic name proposed by Lauterborn (1913, p. 98) for a genus of his family Chlorobakteriaceae containing organisms with elongate cells 2 to $3 \mu$ long, yellowish-green in color, and united into a net in a fashion similar to Thiodictyon Winogradsky. The single species (type) named was Pelodictyon clathratiforme (Aphanothece clathratiformis) (Szafer) Lauterborn. The inclusion of this genus among the bacteria rather than the blue-green algae is questionable.

Pelogloea. A generic name proposed by Lauterborn (1913, p. 99) for a genus of his family Chlorobakteriaceae with the following description.

Pelogloea chlorina nov. gen. nov. spec. Zellen 0,003 bis 0,004 mm. lang, kettenartig zu (fast Nostocartigen) locker gewundenen Fäden zusammenschliessend und in eine gemeinsame Gallertmasse eingebettet. Kolonien bis $1 \mathrm{~mm}$ im Durchmesser.

The inclusion of this form among the bacteria is questionable. 
Peloploca. A name proposed by Lauterborn (1913, p. 99) for a genus of bacteria belonging to the colorless forms. The description is:

Peloploca nov. gen. Fadenförmige Zellreihen, in wechselnder Zahl parallel zu starren Bündeln oder Bändern vereint. Zellen mit Pseudovakuolen. Bewegungslos.

$P$. undulata nov. spec. Zellfäden alle sehr locker spiralig gedreht, zu einem scheinbar wellenförmig gebogenen, parallel gestreiften Fadenbündel dicht zusammenschliessend.

$P$. taeniata nov. spec. Zellfäden zu ziemlich breiten, öfter gedrehten Bändern vereint, die durch die Pseudovakuolen der Einzelzellen wie gegittert erscheinen. Zellen 0,003-0,004 mm. lang, Bänder bis über $0.7 \mathrm{~mm}$. lang.

Peloploca ist im faulenden Schlamm von Characeen-Teichen nicht selten, scheint aber wegen einer gewissen Ähnlichkeit mit mazerierten pflanzlichen Gefässbündeln bisher übersehen worden zu sein.

Pelosigma. A generic name proposed by Lauterborn (1913, p. 100) to include Pelosigma colniii. This organism as Spiromonas cohnii the author states was erroneously placed in the flagellate genus Spiromonas by Wärming.

Pelosphaera. A generic name given by Lauterborn (1906, p. 197) in the following description.

Pelosphaera rotans nov. gen. nov. spec. Zellen keilförmig, vorn verbreitert und abgerundet, mit ziemlich derber Membran und meist körnigem Inhalt, in grösserer Zahl radiär zu maulbeerförmigen kugeligen bis elliptischen Kolonien vereinigt, die sehr au gewisse Flagellaten-Kolonien erinnern. Frei beweglich mit Hilfe von Geisseln.

Jüngere Kolonien farblos durchsichtig, kugelig bis elliptisch, Zellen sehr dicht zusammenschliessend, im Centrum der Kugel öfter einen Hohlraum freilassend, sehr lebhaft beweglich. Aeltere Kolonien meist schwach gelbbräunlich gefärbt, oft unregelmässig im Umriss; Zellverband lockerer, die freien Zellenden mehr oder weniger halbkugelig über die Oberfläche vorspringend. Einzelne Zellen bisweilen vergrössert, im Innern mit ansehnlichem, stark lichtbrechendem, kugeligem Gebilde (Spore?). Durchmesser der Kolonie: 0,015-0,040 mm.

Vermehrung: Bisher nur Teilung der Kolonie beobachtet: die Kolonie streckt sich und schnürt sich einseitig durch.

Peptonococcus. A generic name for peptonizing lactic acid cocci proposed by Orla-Jensen (1909, p. 340) in the following statement:

Da die peptonisierenden Milchsäurekokken reichliche Mengen Pepton, aber sehr wenig weitere Eiweiszzersetzungsprodukte bilden, während die von den Proteus-Bakterien abgeleiteten Kokken durch Indolproduktion charakterisiert sein missen, so liesze sich vielleicht zwischen den Gattungen Peptonococcus und Indolococcus unterscheiden. 
Orla-Jensen himself does not include this genus in his formal classification. It is probably invalid as no species is designated.

Peritricha. The fourth group of the Gymnobacteria named by Messea (1891, p. 232) to contain bacteria with flagella on all sides.

Peritrichinales. Orla-Jensen (1921, p. 270) suggests splitting Eubacteriales (Buchanan) into Pseudomonadales and Peritrichinales. This latter is the equivalent of his previously used Peritrichinae (q.v.). He includes the following genera: 1. Thermobacterium, 2. Streptobacterium, 3. Streptococcus, 4. Betabacterium, 5. Betacoccus, 6. Propionibacterium, 7. Microbacterium, 8. Tetracoccus, 9. Coccus, 10. Bacterium, 11. Bacillus, 12. Clostridium.

Peritrichinae. An order named by Orla-Jensen (1909, p. 328) to include those bacteria with spherical or rod-shaped, never spiral, cells which, when motile, have peritrichous flagella. The group as a whole is not typically made up of water bacteria. The organisms of this group do not secure their growth energy solely by oxidative processes. The other of the two orders into which the Schizomycetes is divided is Cephalotrichinae (q.v.).

The order Peritrichinae includes the following families: Acidobacteriaceae. Alkalibacteriaceae, Butyribacteriaceae and Putribacteriaceae.

Perroncitoa. This genus of cocci was named by Trevisan (1889, p. 29 ), with the description "Cocchi compressi seriati lateralmente a due a due (diplococchi transversali) in filamenti semplici rivestiti di vagine cilindriche membranaceo-gelatinose. Spore macrosome provenienti nei filamenti. La forma compressa dei cocchi, appaiata a guisa delle Neisserie, é affato speciale. Quando si liberano dalla vagina divengono perfettemente globulosi." The single species listed is Perroncitoa scarlatinosa (Micrococcus scarlatinosus, Trevisan). The diagnosis is given as follows by De Toni and Trevisan (1889, p. 1053).

Cocci compressi, lateraliter duo per duos seriati (diplococci transversales) in filamenta simplicia, vaginis cylindricis membranaceo gelatinosis obducta concatenati. Arthrosporae macrosomae in filamentis obvenientes. Cocci e vagina liberati exacte globulosi fiunt.

One species is included, Perroncitoa scarlatinosa Trevisan, the Streptococcus rubiginosus Edington (1887, p. 1262).

This genus is undoubtedly founded upon a misconception of morphology. It has never been used by other authors. It is rejected by Erwin F. Smith (1905, p. 162). It may be regarded as invalid, or at least based upon an unidentified organism. 
Petalobacillus. A name used by Maggi (1886, p. 174) to designate a growth form of a Bacillus.

Petalobacteria. A name applied by Billroth $(1874$, p. 16) to a growth form of his pleomorphic Coccobacteria septica in which the organism assumed a rod shape and formed a flat gelatinous layer of cells. The term has apparently never been used as a generic name.

Petalobacterium. A name used by Maggi (1886, p. 84) to designate a growth form of Bacterium aceti Zopf.

Petalococcos. A name applied by Billroth $(1874$, p. 6) to a growth form of his pleomorphic Coccobacteria septica in which the cells are spherical and occur arranged in a flat gelatinous mass or plate.

This name has not been used as a generic designation, although Smith (1905, p. 162) includes "Petalococcus" in his list of invalid bacterial names.

Petalococcus. A name included by Erwin F. Smith (1905, p. 162) in his list of rejected genera. See Petalococcos. Maggi (1886, p. 81) gives Petalococcus aceti var Duclauxi as a variety of his Micrococcus aceti.

Petalo-Gliabacteria. A growth form of Coccobacteria septica as described by Billroth (1874, p. 17). A casual name.

Pfeifferella. A generic name ${ }^{1}$ proposed by Buchanan (1916) and $(1918$, p. 54) as the seventh genus of the subtribe Bacteriinae, with the description:

Non-motile rods, slender, Gram-negative, without spores, staining poorly, sometimes forming threads and showing a tendency toward branching. Gelatin may be slowly liquefied. Do not ferment carbohydrates. Growth on potato characteristically honey-like.

The type species is the glanders bacillus, Pfeifferella mallei.

Winslow et al. (Committee Society of American Bacteriologists, 1920 , p. 200) used the same description and designate the type species as Pfeifferella mallei (Loeffler) Buchanan.

Bergey et al. (1923, p. 389) follow Winslow. It is possible that Malleomyces q.v. has priority.

${ }_{1}^{1}$ This generic name for the glanders group came into being through a clerical error. The author had intended to propose the name Pfeifferella for the influenza group of bacteria, and Loefferella for the glanders group. It was suggested by the Committee of the Society of American Bacteriologists that Hemophilus would be an appropriate name for the influenza group, it was intended therefore in manuscript in preparation to eliminate Pfeifferella. Through some inexplicable clerical mistake Loefferella was dropped and Pfeifferella substituted in mimeo- 
Photobacillus. A generic designation used by Miquel and Cambier (1902, p. 881) for certain photogenic bactera described by Kat (1891, p. 159). No species name was used. The name cannot be considered as adequately published without specific names. It may be considered a casual designation. The name is rejected by Erwin F. Smith (1905, p. 162).

Photobacter. A name proposed by Beijerinck (1900) for the photogenic bacteria. He named Photobacter luminosum and Photobacter indicum with two varieties, $P h$. splendidum and $P h$. splendor, likewise $P h$. phosphorescens and $P h$. Fischeri. These were studied primarily with reference to their ability to split urea.

Later $(1900$, p. 197) he states that this is to be regarded as a physiologic genus including three unrelated form groups, and giving the inference that the name should have no nomenclatural status.

Enlows (1920, p. 71) suggests that apparently Beijerinick uses Photobacter interchangeably with Photobacterium (q.v.). It is probably to be regarded as a synonym of the later.

Photobacterium. A generic name proposed by Beijerinck (1889, p. 401) to include certain photogenic marine bacteria. He says

Comme il n'a pas été possible d'etablir, entre les cinq (ou six) especes que j'ai etudiées, de distinctions assez importantes pour autoriser quelque separation generique, et comme, d'un autre cote, le besoin se fait sentir de penvoir facilement, designer par une nom ces organismes si interessant, je me hasarde a les rapporter toutes an genre Photobacterium.

The species listed are $P h$. luminosum, $P h$. phosphorescens, $P h$. indicum and $P h$. Fischeri. The reasons for grouping these species, among them cocci, bacilli and spirilla, in a single genus are given as follows:

1. All the species grow best in media containing $3 \frac{1}{2}$ per cent $\mathrm{NaCl}$.

2. All lose the power of photogenesis by the addition of 2 per cent or more of glucose.

3. Peptone is the principal nutrient.

4. A trace of acid stops photogenesis.

5. All are motile and do not form spores.

6. None produce any diastatic or inverting enzyme.

7. All give a similar spectrum.

graphed outlines distributed at the meeting of the Society of American Bacteriologists. This constituted valid publication, and to prevent further confusion no effort has been made to correct the error. While Pfeifferella is not so appropriate in this connection, it is not invalid in consequence. 
Bernhard Fischer (1894, p. 19, et al.) 'notes the occurrence in the Atlantic Ocean of the West Indian Light Bacillus (Photobacterium indicum). He also described as new species Ph. delgadense, Ph. digenerans, Pg.tuberosum, Ph. papillare, Ph. glutinosum, Ph. annulare, $P h$. coronatum, Ph. caraibicum. All are comma bacilli, showing considerable variation in form.

Migula (1897, p. 336) insists that this genus is to be regarded strictly as physiologic, and invalid in nomenclature. All with the exception of Beijerinck's Ph. phosphorencens he placed in Microspira. He states that to bring all these forms together into a single genus is from a systematic point of view quite incorrect, for they belong not only in different genera, but in different families. He states further that Beijerinck's $P h$. phosphorescens is a true Micrococcus, the Ph. delgadense of Fischer a Pseudomonas and Ph. coronatum a Microspira. Apparently he is mistaken with reference to $P h$. phosphorescens, for although Beijerinck gives as a synonym Micrococcus phosphorescens Cohn, the pictures show the organism to be a rod. Possibly Migula's suggestion that all these forms should be included in Microspira is appropriate. The name is rejected as invalid.

The type species is designated by Enlows (1920, p. 71) as Photobacterium phosphorescens (Cohn) Beijerinck.

If the phosphorescent bacteria of this group are regarded as deserving of generic recognition, Photobacterium may be regarded as a valid designation, otherwise it may be regarded as a synonym (probably of Vibrio.)

Photobakterium. A spelling of Photobacterium used by Flügge (1896, p. 333) and other German writers.

Photomonas. A name suggested by Orla-Jensen (1921, p. 271) in the following statement: "As the phosphorescent bacteria form, biologically, a connected whole, I deem it correct to unite them so as to form one genus, for which a better name than Photomonas can hardly be found."

No species is named. Probably may be regarded as a synonym of Photobacterium, and as invalid.

Photospirillum. A generic name proposed by Miquel and Cambier (1902, p. 888) for the species Photospirillum dunbari, described by Dunbar (1893, p. 799) Enlows (1920, p. 71) states: "Photogenic. Finest light is produced at $22^{\circ}$ on gelatin prepared from peptonized beef bouillon. Pathogenic for guinea-pigs." The type species is therefore Photospirillum dunbari Miquel and Cambier. The genus may probably be regarded as a synonym of Photobacterium. 
Phragmidiothrix. Engler (1882, p. 19) named an organism found on the body of a crustaccan (Gammarus locusta) Beggiatoa multiseptata. Later (1883, p. 187), his diagnosis was as follows:

Phragmidiothrix, Engl. Filis rectis vel. leviter flexuosis, gelatinosis, cellulis brevibus egranulosis. Ph. multiseptata Engl. Cellulis brevissimis, saepe diametro diversis, multis semel vel pluries septatis.

Zopf (1S83, p. 104) (1S85, p. 103) gave the name Phragminliothrix multiseptata ascribing the name to Engler. His description is "Faden scheidenlos, successiv Theilungen sehr weit gehend. Zellen schwefelfrei. Wasserbewohner." Flügge (1886, p. 398) defined the genus as one showing variable growth forms.

Trevisan (1889, p. 10) included this genus with its single species as the third of his tribe Leptotrichee.

De Toni and Trevisan place this organism next to the genus $\mathrm{Beg}$ giatoa among the filamentous water bacteria with the following description:

Filamenta evaginata, articulata, articuli diametro longitudinali brevissimo, simplicia, ubique aequilata, basi affixa. Multiplicatio cellularum articulorum divisione in duas directiones (septis transversis et longitudinalibus in coccos (an sporiferos?) abeuntium. Baculogonidia nulla.

The species is described as follows:

Filamentis $3-6 \mu$ in diameter, articulis diametro longitudinali quadruplo-sextuplo breviori quam transversali. Hab. in aqua marina, ad Gammarum Locustam affixa, in sinu Kulensi Germaniae (Engler). Cocci quamquam adhne filamentis matricalibus incluse, hue illuc germinant novaque filamenta procreant, guvam ob rem filamenta primigenia lateraliter ramosa, videntur.

Hueppe (1891, p. 31) says "Die Faden sind in niedrige Cylinderscheiben gegliedert, welche in Halbscheiben, Quadranten und schliesslich in Kugeln zerfallen."

Hansgirg (1891, p. 313) concluded Phragmidiothrix should be included in the genus Crenothrix, for the filaments of Phragmidiothrix multiseptata are not as Engler stated, sheathless, but are enclosed in a thin sheath which in all respects corresponds with that of Crenothrix. He states that a species Crenothrix marina previously named by him (1890, p. 20) is probably Crenothrix multiseptata or even C. foetida (Fiorini-Mazzanti), or C. mucor (Ocrstedt). Hansgirg concludes that the genus Crenothrix Cohn may be divided into two sections, Phragmidiothrix including the marine forms with $C$. foetida as the type and Eucrenothrix with fresh water forms and $C$. Kuhniana as the type. 
Migula 1894, p. 238:

Phragmidiothrix Engler, Zellen zu anfangs unverzweigten Fäden verbunden, sich nach 3 Richtungen des Raunes teilend und so einen Zellenstrang derstellend. Später körmen einzelne Zellen durch die sehr feine eng anliegende Scheide hindurchwachsen und zu Verzweigung Veranlassung werden.

Migula (1895, p. 38) believed also that Phragmidiothrix might be united with Crenothrix, but set aside the genus, "So lange aber nicht erwiesen ist, dass die von Engler einmal beobachteten seitlichen Ausstrahlungen keine Verzweigungen, sondern Epiphyten sind, ist sie als Gattung beizubehalten." His description of the genus is as follows:

Fadenbacterium mit sehr zarter, eng anliegender nur alten Fäden sichbarer Scheide, bis $100 \mu$ lange und $3-12 \mu$ breite Fäden bildend. Die Fäden bestehen anfangs aus flachen Scheibenzellen, welche sich jedoch später nach 3 Richtungen des Raumes teilen und so Sarcina-artige Packete bilden. Die einzelnen Zellen runden sich $a b$ und werden aus der wie es scheint gleichzeitung zerflieszenden Scheide frei.

The genus was again recognized by Engler in 1897 (p. 47) and 1900 (p. 1034), Chester (1901, p. 371) gives the same description. Kendall (1902, p. 484) says "Cell division in three planes, very delicate sheath." Others who have used the genus are Smith (1902, p. 272), Migula (1904, p. 145), E. F. Smith (1905, p. 162), Ellis (1909, p. 9), Frost (1911, p. 59).

The type species is Phragmidiothrix multiseptata Engler. The genus probably should be merged with Crenothrix.

Phycobacteriaceae. A family name used by Engler (1912) for the filamentous bacteria surrounded by a more or less definite sheath, and which divide but rarely in three planes. It is a synonym of Chlamydobacteriaceae.

Phytobacter. A generic name proposed by Groenewege (1912, p. 217) for the species Phytobacter lycopersicum. Enlows gives the description of the species as follows:

Rods of varying length, 1.5 to $2.5 \mu$ by 0.5 to $0.7 \mu$. No spores. Very slightly resistant to heat. Young cultures motile. Zoogloea in old cultures, which appear as a complex of rods bound together by a viscous slime. Found in decaying tomato fruits.

Phytomonas. A name proposed by Bergey et al. (1923, p. 174) for a genus of bacterial plant pathogens. The genus is included as the second in the tribe "Erwiniae." The description is as follows: 
"Rods, yellow or white, motile or non-motile, the motile species possessing either mono- or lophotrichous flagella. May or may not form yellow pigment."

The type species is Phytomonas campestre (Pammel) Bergey.

Phytomyxa. A generic name used by Schröter (1886, p. 135) for the organisms causing nodules upon the roots of leguminous plants. This organism had previously been named Schinzia leguminosarum by Frank (1879, p. 376). Since the generic name Schinzia (q.v.) was preoccupied Schröter (1886) gave the name Phytomyxa leguminosarum, including this organism among the Myxomycetes in the order Phytomyxini. He also named a similar species from the lupine, Phytomyxa Lupini. He based his inclusion of this genus with Plasmodiophora among the slime molds on the work of Prillieux (1879, p. 98). The plasma-like filaments in the nodules he interpreted as the vegetative growth, and the bacteriods as spores. Beijerinck (1888, p. 758) named this organism Bacillus radicicola. It was again included among the slime-molds a year later by Schröter (1889, p. 7). Frank (1889, p. 338) concluded that the assignment of the organism to the slime molds was incorrect, and that a new generic name should be chosen. He used Rhizobium leguminosarum. More recently this organism has been known by several names, as Pseudomonas radicicola, Bactridium radicicola (Fischer 1903, Lotsy 1907), Bacterium leguminosarum (Smith 1905). Maire and Tison (1909, p. 241) have emphasized the fact that even though the genus Phytomyxa was erroneously included by Schröter among the Myxomycetes this did not invalidate the genus name.

Phytomyxa is probably technically a valid generic name for organisms of the type which cause nodule formation on the roots of legumes if this type is worthy of generic recognition, with the type Phytomyxa leguminosarum (Frank) Schröter.

However, Winslow et al. (Committee Society of American Bacteriologists 1917) recommended that Rhizobium be recognized as a genus conservandum for this group. In this they have been followed by Buchanan (1918), Bergey (1923) and others.

Planococcus. A genus of cocci proposed by Migula (1894, p. 236) who says: Planococcus nov. gen. Die Zellen teilen sich nach 2 Richtungen des Raumes wie bei Micrococcus besitzen aber geisselförmige 
Bewegungsorgane (Z. B. Planococcus citreus (Menge) Mig.") The generic diagnosis given later is

Zellen einzeln oder zu 2 oder 4 genähert, oft in gröszerer Zahl unregelmäszige Haufen bildend. Die einzeInen freien Zellen Kugelrund; Teilung abwechselnd nach 2 Richtungen des Raumes. Die Zellen sind frei beweglich. Die Bewegung wird vermittelt durch $1-4$, meist 1 Geiszel, die in der Regel vielmals langer ist als die Zelle.

This generic name has been used quite generally by writers on systematic bacteriology, among others by Migula (1897, p. 46; 1900, p. 269; 1904 , p. 144), Fischer (1897, p. 32, 1903, p. 59), Chester (1897, p. 63; 1901, p. 114), Kendall (1902), A. J. Smith (1902, p. 270), E. F. Smith (1905, p. 160), Ellis (1909, p. 4), Frost (1911, p. 57).

Meyer (1912, p. 5) uses Planococcus as the designation of a section of Micrococcus with the description "Die begiesselten Formen."

Vuillemin (1913, p. 525) proposes that this be made a "genus conservandum" with the type species Planococcus europaeus (Nitrosomonas europaea Winogradsky).

The genus Planococcus is valid if this character of motility is sufficient to differentiate from Micrococcus, otherwise is a synonym of the latter name. The type species is Planococcus citreus (Menge) Migula.

Planomerista. A "genus conservandum" proposed by Vuillemin (1913, p. 525) to include those cocci which divide regularly in two planes and which remain united in tetrads and are motile. It is a motile Merista (q.v.). The type species cited is Planomerista ventriculi (Micrococcus tetragenus mobilis ventriculi Mendoza 1889).

The genus name is valid if the organisms of this type are worthy of generic recognition, otherwise it is to be regarded as a synonym of Micrococcus, or Pediococcus.

Flanosarcina. A genus of cocci, created by Migula (1894, p. 236) who says: "Planosarcina nov. gen. Die Zellen teilen sich wie bei Sarcina nach 3 Richtungen des Raumes, besitzen aber geisselförmige Bewegungsorgane (Z. B. Planosarcina agilis (Cohen) Migula, Pl. mobilis (Mauria) Mig.)" The cells when isolated are quite spherical usually arranged in pairs and fours, and flattened somewhat on the contiguous sides. Division occurs in three directions of space, the cells may remain united into packets or break apart. The packets are usually developed only in sugar media. Cells are actively motile by means of flagella. The two species $(1895$, p. 19) first mentioned are Planosarcina mobilis and $\mathrm{Pl}$. agilis. 
This genus has been frequently recognized in the literature of systematic bacteriology. The following authors among others have used it: Migula (1897, p. 46; 1900, p. 275; 1904, p. 144), Chester (1897, p. $63 ; 1901$, p. 115), Fischer (1897, p. 32), Kendall (1902), A. J. Smith (1902, p. 270), Fischer (1903, p. 60), E. F. Smith (1905, p. 160), Ellis (1909, p. 4), Frost (1911, p. 57).

Vuillemin (1913, p. 525) has proposed that Planosarcina be recognized as a "genus conservandum."

Meyer (1912, p. 5) uses Planosarcina as a designation for a section of the genus Sarcina with the description "Die begeisselte Spezies."

If the character of motility is sufficient to differentiate this group, the name is valid, but it is probably to be regarded as a synonym of Sarcina. The type species is Planosarcina agilis (Cohen) Migula.

Planostreptococcus. A name used by Meyer $(1912$, p. 4) to designate a section of the genus Streptococcus. The description reads, "Begeisselte Spezies." No species are named.

Plectridieae. A subfamily of bacteria created by Fischer (1897, p. 33) to include those rod shaped organisms which become drumstick shaped during sporulation. The only genus included is Plectridium.

Plectridium. A genus of rod-shaped bacteria named by Fischer (1895, p. 147) with the following definition: "Beweglich mit diffusen Geisseln und Endosporen in einem kopfig geschwollenen Ende der Stäbchen (Köpfchenbakterien, Klöppel-, Trommelschlägen- oder Kaulquappenform), das andere Ende nicht geschwollen." Three species Plectridium paludosum, $P$. tetani and $P$. des Rauschbrandes. It is recognized that the organisms are anaërobic.

Hueppe (1895, p. 38) notes the genus. It is again described by Fischer in (1897, p. 32) and (1903, p. 61). In the latter he notes as species the butyric acid bacilli, the tetanus bacillus, and a decay form, Plectridium putrificum.

Buchanan (1918, p. 38) emended the genus as follows:

Cells rod-shaped, straight or at least never spiral, motile by diffuse flagella or non-motile. Endospores produced under favorable conditions, causing an enlargement of one tip of the cell, giving rise to a drumstick appearance. Usually Grampositive. Anaërobic or microaërophilic.

The type species is Plectridium tetani (Nicolaier) Fischer.

The same type species was later (1922) used by Heller for the genus Nicolaierillus, which becomes a synonym. 
It is possible that Plectridium is not sufficiently distinct to require recognition separate generically from Clostridium. It is made a synonym of Clostridium by Winslow et al. (Committee Soc. Am. Bact., 1917, and 1920) and by Bergey et al. (1923).

Plectrillum. A generic name proposed by Fischer (1895, p. 144) for rods motile by means of a tuft of polar flagella, and with spores terminal and causing enlargement of the rod (Drumstick shapes). No species were named.

Plectrinium. A genus of rod shaped bacteria named by Fischer (1895, p. 142) with the following definition:

Plectrinium nov. gen. Beweglich mit polarer Einzelgeissel, Endosporen in einem aufgeschwollenen Ende. Auch fur diese Gattung fehlt es vorläufig noch an einem sicheren Beispiel. Zopf bildet $\mathrm{zwar}$ eine Kopfchenbakterie mit einer Geissel am nicht geschwollenen Ende ab, giebt aber weder den Fundort noch sonst etwas an.

No species was named. The genus is apparently invalid.

Plennobacterium. A spelling of Plennobakterium (q.v.) used by Kossowicz and others.

Plennobakterium. Gonnermann (1907, p. 887) named an organism belonging to the hay bacillus group Plennobakterium. It is nonmotile and gram positive, forms spores and liquefies gelatin. The rods are 0.4 to 0.6 wide, 2.5 to $5.0 \mu$ long. Sometimes in filaments. Characteristic spiral bands were observed within the cell. It was isolated from sugar beet sap.

No species is named. It may be regarded as a casual designation and not entitled to generic standing.

The name is spelled Plennobacterium by certain authors as Kossowicz.

Pleurococcus. A genus of algae named by Meneghini (1842) to which certain bacteria have been assigned as Pleurococcus Beigelii Rabenhorst 1867 which became Hyalococcus beigelii Schröter and Micrococcus beigelii Migula, and Pleurococcus roseo-persicinus Rabenhorst which became Lamprocystis roseo-persicinus Migula.

Pleurospora. A subgenus of the bacterial genus Cornilia used by De Toni and Trevisan (1889, p. 1002) with the description: "Sporae macrosomae e latere protuberantes" to contain two species, Cornilia tremula and C. sphinx. The name has apparently not been used by other authors. 
Plocamobacterium. Löwi (1920, p. 730) proposed the name Plocamobacterium crassum for Bacillus crassus Lipschütz. The organism is a gram positive facultative anaërobe, with characteristic growth on Drigalski agar, maltose nutrose agar and dextrose agar. The cells in young cultures are small rods, while in older cultures they are filamentous. Non-motile. No spores. A common inhabitant of the normal vagina, but occasionally pathogenic causing acute ulcer of the vulva.

Pneumobacillus. This name has been used commonly as a quasiscientific name for the organism described by Friedlander as the causal organism of pneumonia. Arloing (1889, p. 428) proposed the name Pneumobacillus liquefaciens bovis for the organism which he isolated as the cause of contagious peripneumonia of cattle. The use of the name in a trinominal would appear to invalidate it as a generic designation. It has never come into common use. This organism was later termed Bacterium bovis (Arloing) Migula (1900, p. 442).

The name is placed by Erwin F. Smith (1905, p. 162) among the rejected genera.

Pneumococcus. A name usually used as a casual designation of the organism of pneumonia. It was apparently first used in a generic sense by Arloing (1889, p. 430) who named three species, Pneumococcus gutta-cerei, $P$. lichenoides and $P$. flavescens, all present together with Pneuomobacillus liquefaciens bovis in bovine pleuropneumonia. The species are inadequately described.

It has occasionally apparently been used in a generic sense by other writers as witness Schmidlechner (1905, p. 291) who uses the designation Pneumococcus lanceolatus Fraenkel in a list of species.

The name Pneumococcus mucosus is used also by Dochez and Avery (1915, p. 114) and by Lyall (1915, p. 146). It is placed by Erwin F. Smith (1905, p. 162) in his list of rejected genera.

Pneumococcus is probably best regarded as a synonym of Diploccocus.

Pollendera. According to De Toni and Trevisan (1889, p. 943) this generic name was used by Trevisan (1884) for the anthrax bacillus which he named Pollendera anthracis.

The original reference to this use by Trevisan has not been discovered by the writer. The name has not been used by other authors, and is rejected later by Trevisan as a synonym of Bacillus.

It would seem that this name would become valid if non-motile rod-shaped bacteria are to be grouped in a genus. It certainly would have priority over Bacterium in the sense of Migula and over Aplanobacter E. F. Smith. 
It may be noted that Smith (1905, p. 174) rejects the name Pollendera (which he spells Pollendra) at the same time he proposes A planobacter.

Pollendra. A spelling of Pollendera (q.v.) used by Erwin F. Smith (1905, p. 174).

Polyangium. This genus was first created by Link (1795, p. 40) according to Zukal $(1897$, p. 550) for the species P. vitellinum. He regarded it as a species of fungus, and as such it appeared in several floras and works on fungi. What is evidently the same species was described later by Thaxter (1892, p. 394) as Myxobacter aureus. He first recognized the true affinities of the organism as a genus of the Myxobacteria, and that it is not a true fungus, nor, as had been urged by Bonordon, an insect egg. That the genus Myxobacter of Thaxter is a synonym of Polyangium Link was pointed out by Zukal (l.c.). Myxobacter aurcus Thaxter therefore became Polyangium vitellinum Link. This explanation was accepted by Saccardo $(1899$, p. 844) who states:

Polyangium Link Syll. VII. p. 47. (inter dubia) Huc ducendum est genus Myxobacter Thaxt. Syll. XI. p. 461 cuius species $M$. aureus Thaxt. collidit cum Polyangio vitellino Link jam ab anno 1795 descripto, sed huiusque inter dubia, relato.

This was accepted later by Thaxter (1904, p. 37).

Cystobacter Schröter (q.v.) is given by Thaxter as a synonym, in part. Seven species are recognized, as follows: Polyangium vitellinum Link, P. simplex Thaxter, P. fuscum (Schroeter) Thaxter, P. septatum Thaxter, $P$. compositum Thaxter, $P$. sorediatum Thaxter, and $P$. primigenium Quehl.

The genus is apparently valid. It is so recognized by Smith (1905, p. 165) and by Quehl (1906, p. 16).

The diagnosis of the genus given by Thaxter is: "Rods forming large, rounded cysts, one or more free within a gelatinous matrix raised above the substratum." Together with the genera Myxococcus and Chrondromyces, it constitutes the family Myxobacteriaceae.

Buchanan (1918, p. 542) included this as the second genus of the family Myxobacteriaceae with the following description.

Rods forming large rounded cysts, one or more, free within a gelatinous matrix raised above the substratum.

The type species is Polyangium vitellinum Link.

Bergey et al. (1923, p. 416) followed Buchanan. 
Polybacteria. A genus (?) of bacteria named by Van Tieghem (1880, p. 149) to include bacteria growing in naked masses made up of cylindrical cells. Polybacteria catenata was found in a decoction of horse manure. A Polybacteria sulphurca was described from rotting beans.

The descriptions are so inadequate that probably the organisms cannot be identified. The generic name does not seem to have been used by other authors.

Polycephalum. A fungus genus named by Kalchbrenner and Cooke (1880, p. 22) with the species Polycephalum aurantiacum. Thaxter (1892, p. 399) states that this is a possible synonym of Chondromyces (q.v.).

Propionibacterium. A genus of bacteria proposed by Orla-Jensen (1909, p. 337). The genus is included in the family Acidobacteriaceae, order Peritrichinae. It includes those rod-shaped bacteria which ferment lactose and lactates with formation of considerable amounts of propionic acid.

Orla-Jensen's statement is as follows:

Da die Propionsäurebakterien wie die Coli-Bakterien sich dadurch auszeichnen, dasz sie die gebildeten Spaltungsprodukte sowohl oxydieren als auch reduzieren können, ist es natürlich, auch sie von den letzteren abzuleiten. In kultureller Beziehung nehmen sie eine $Z$ wischenstellung zwischen den AërogenesBakterien und den Milchsäurebakterien ein, indem sie in der Stichkultur sich auf der Oberfläche uın so weniger ausbreiten, je gröszer ihre Fähigkeit zur Bildung von Propionsäure ist. Sie bilden unbewegliche Stäbchen oder Diplokokken, die völlig an Streptcoccus lacticus erinnern. Sie vergären sowohl Laktose als auch Laktate. Sie greifen das Kasein nicht an, sondern spalten die von den peptonisierenden Bakterien gebildeten Produkte weiter. Wegen ihrer reduzierenden Eigenschaften entwickeln sie Schwefelwasserstoff, wenn sie Pepton zur Verfügung haben. Wir wollen die Gattung Propionibacterium nennen.

Later (1921, p. 272) he again emphasizes the genus.

The status of the genus is doubtful, as no species is described or referred to.

Propionicoccus. A generic name suggested by Orla-Jensen (1921, p. 272) in the following statement:

Whereas the shape of cells was formerly used as a family character, I have adopted it only as a generic one, and if we do not want to further confine its signification and only consider it as a specific character, we shall doubtless have to set up the genus Propionicoccus hesides the genus Propionibacterium. 
Proteae. The seventh tribe of the family Bacillaceae named by Castellani and Chalmers (1919, p. 932) with the description: "Bacillaceae growing well on ordinary laboratory media, not forming endospores, aërobic, without fluorescence or pigment formation, but liquefying gelatine."

Two genera are included, Proteus and Cloaca.

Proteobacter. A name used by Beijerinck (1900, p. 195). In a discussion of hydrogen sulphide production he says,

Wenn die Quantität der organischer Körper im Schlamme sehr gross ist, wie, z. B. in den Stadtgräben zu Delft, wo Gerberien und Brennerieien ihre Abwässer seit langer Zeit darin geleert haben, so sind die Lebensbedingungen für die gewöhnlichen Anaëroben der Eiweissfäulnis gegeben, während Spirillum desulfuricans infolge der Anhäufung organischer Körper, zurücktritt. Von den bei der Eiweissfäulnis in Betracht kommenden. Arten habe ich die drei wichstigsten (Proteobacter septicum, P. skatol, P. pseudopulcher) bei einer anderen Gelegenheit besprochen. Es hat sich gegeben, dass diese Mikroben nicht nur Schwefelwasserstoff erzeugen, sondern auch die entsetzlichem Sulfiden der Mercaptangruppe.

Proteus. A generic name used by Hauser (1885, p. 1) to designate three species of putrefactive bacteria, Proteus vulgaris, $P$. mirabilis and $P$. Zenkeri. No discussion or definition of the generic name is given apart from the species description. All the species agree in showing great variability in morphology; short and long rods, filaments, and spirals, and many involution forms may be observed. All are motile by means of peritrichous flagella, none produce spores. All the species produce "islands" on the surface of moist solid media, these seem to be endowed with some motility. All the species are closely associated with decay and putrefaction.

This name is regarded as a synonym of Bacillus by De Toni and Trevisan (1889) and of Spirulina by Hueppe (1891). The genus is recognized by Cornil and Babes (1890, p. 151) subsequent writers have practically all until recently regarded the term as synonomous with Bacillus, and have not considered its pleomorphism as distinctive.

Lehmann and Neumann $(1896$, p. 103) make it a synonym of Bacterium.

Macé (1897, p. 487) says that Proteus cannot be separated from Bacillus. Erwin F. Smith (1905, p. 174) includes Proteus in his list of genera to be rejected. Orla-Jensen (1909, p. 338) makes Proteus a synonym of Liquidobacterium. 
Buchanan (1918, p. 54) emended the generic description as follows:

Short rods, showing great variation in morphology, filamentous and bent rods as involution forms frequent. Motile by means of peritrichous flagella. The species commonly produce motile "islands" on the surface of moist solid media. No spores. Gram-negative. Usually producing acid and gas from certain carbohydrates. In general the species are closely associated with decay and putrefaction, sometimes pathogenic.

The type species is Proteus vulgaris Hauser.

Winslow et al. (Committee Soc. Am. Bact., 1920, p. 210) have described the genus as follows:

Highly pleomorphic rods, filaments and curved cells being common as involution forms. Gram negative. Actively motile. Characteristic amoeboid colonies on moist media. Liquefy gelatin rapidly and produce vigorous decomposition of proteins. Ferment glucose and sucrose (but usually not lactose), with formation of acid and gas (the latter being $\mathrm{CO}_{2}$ only).

Type species, $P$. vulgaris Hauser.

The genus is also recognized by Castellani and Chalmers (1919, p. 943).

Bergey et al. (1923, p. 209) include Proteus as the third genus of the tribe Bactereae with the following description.

Highly pleomorphic rods. Filamentous and curved rods are common as involution forms. Gram-negative. Actively motile, possessing peritrichous flagella. Produce characteristic amoeboid colonies on moist media and decompose proteins. Ferment dextrose and sucrose but not lactose. Do not produce acetyl-methyl carbinol.

Protobacteriés. A name used by Maggi $(1886$, p. 81$)$ as the designation of his first order of bacteria, with one genus Aphaneroglia, but without description.

Protococcus. A genus of green algae proposed by Agardh. One species Protococcus roseo-persicinus Kützing (1849) was later described by Schröter as Lamprocystis roseo-persicina and included among the bacteria. Protococcus is a valid algal generic name and should not be used for the bacteria.

Miller (1892, p. 123) makes the following statement:

Klencke (1850) beschreibt auch einen, von ihm entdeckten Parasiten, eine Protococcus art, Protococcus dentalis, welcher Schmelz und Zahnbeim in ählicher Weise verflüssigt, wie der Hausschwamm, Merulius lacrymans, das Holz der Häuser oder Möbel erweicht. 
Protomycetum. Lewis (1879, p. 394) makes the following statement concerning Spirillum obermeieri.

Since the period of its discovery in the blood by Obermeier it has been referred to under various names: Spirathrix, Protomycetum recurrentis, in Lebert's article on recurrent fever and in Ziemss' 'Handbuch' of Medicine; spirillum by Erichsen, Litten, Birch-Hirschfeld etc.; Spirillum tenue by Naunyn; and Spirochoete Obermeieri by Cohn (fig. 15).

Pseudobacterium. Trevisan (1888, p. 781) included this name in the following sentence:

Senze dipartirci da Klebsiella, basterebbe ricordare come, tra le specie che attualmente se ne conoscono, altre s'ebbero le denominazioni generiche Micrococcus, Diplococcus, Pseudodiplococcus, edaltre quelle di Bacterium, Pseudobacterium, Proteus, Bacillus, Ascobacillus, etc.

What organism is referred to is not evident.

Pseudodiplococcus. A generic name used by Bonome (1888, p. 321) to designate Pseudodiplococcus pneumonicus, an organism which he isolated from a fibrinous exudate. The organism is stated to resemble closely morphologically and biologically the "Diplococcus pneumoniae."

The organism is termed Klebsiella Leydeni by Trevisan (1889, p. 1030). The genus has not been recognized by other authors. It may be regarded as a synonym of Diplococcus.

Pseudomeningococcus. A casual name proposed by Elser and Huntoon (1909, p. 384) for "a group of organisms which cannot be differentiated from the meningococcus excepting by serum reactions."

Pseudomonadaceae. The third family of the Eubacteriales named by Winslow et al. (Committee Soc. Am. Bact., 1917, p. 555) with the following description.

Short rods, usually motile. Flagella single, polar. Gram-negative. Not obligate aërobes. Many species active ammonifiers. Many species produce water-soluble pigments or green fluorescence; yellow pigment common. Some species are photogenic. Soil and water bacteria, with many plant parasites.

The single genus Pseudomonas is included.

Pseudomonadales. A name proposed by Orla-Jensen (1921, p. 270 ) as one of the two orders into which he would divide Eubacteriales Buchanan. He would include in this group some eleven genera as follows: 1. Methanomonas, 2. Carboxydomonas, 3. Hydrogenomonas, 4. Nitrosomonas, 5. Nitromonas, 6. Azotomonas, 7. Rhizomonas, 8. Acetimonas, 9. Fluormonas, 10. Photomonas, 11. Spiromonas. 
Pseudomonas. A genus name proposed by Migula (1894, p. 237) with the following description: "Pseudomonas nov. gen. Zellen mit polaren Bewegungsorganen, Endosporenbildung kommt bei einigen Arten vor, ist aber seltener (A. B. Pseudomonas violacea.)"

It will be noted that no clue to what previously described violacea he is referring is given. This cannot therefore be accepted as the type, and the genus was technically not adequately published until the next year (1895, p. 29) when the following description is given.

Kürzer oder längercylindrische Zellen, welche zuweilen kleine Fäden bilden, lebhaft beweglich mit polarer Begeiszelung. Die Zahl der an einem Pol stehenden Geiszeln schwankt bei den verschiedenen Arten zwischen 1-10 und ist am häufigsten 1 oder 3-6. Endosporenbildung kommt vor, aber nur bei wenigen Arten.

Eine Trennung der hierhergehörigen Arten in zwei Gattungen, je nach dem am Pol nur 1 Geiszel oder ein Büschel von Geiszeln steht, wie dies von Fischer vorgeschlagen wurde, ist unthunlich, da alle Übergänge zwischen streng eingeiszeligen und vielgeiszeligen Arten vorhanden sind.

The first species named and described is Pseudomonas pyocyanea which in its corrected form, Pseudomonas aeruginosa (Schröter) may be regarded as the type.

Migula (1900, p. 876) notes the close relationship of this genus to Microspira in the following statement.

Die Grenze gegenuber Microspira ist vielleicht eine kunstliche; es ist nicht immer moglich, zu beurteilen, ob es sich bei eingeiszeligen Formen um eine Microspira oder eine Pseudomonas handelt. Leichte Krummungen, namentlich in gefarbten Praparaten, beobachtet man bei vielen Pseudomonasarten. Gewohnlich laszt sich die Entscheidung, zu welcher Gattung eine Art gehort, durch Beobachtung von mehreren zusammenhangenden Zellen ermoglichen. Bei Pseudomonas kommen dann niemals regelmaszige Schraubenwindungen vor.

The genus has been accepted by many subsequent writers, among them Migula (1897, p. 47, 1900, p. 29, 1904, p. 145), Chester (1901, p. 306), Schmidt and Weis (1902, p. 91), A. J. Smith (1902, p. 270), Ellis (1909, p. 6), Frost (1911, p. 57), Schneider (1912, p. 23) and Meyer (1912, p. 3).

Conn (1909, p. 12) defines the genus as made up of rod-shaped bacteria with a single flagellum.

Erwin F. Smith (1905, p. 160) and Vuillemin (1913, p. 522) independently reached the conclusion that the generic name Bacterium (q.v.) has priority for this group of organisms. 
Winslow et al. (Committee Soc. Am. Bact., 1917, p. 556) used the following generic description.

Rod-shaped, short, usually motile by means of polar flagella or rarely nonmotile. Aërobic and facultative. Frequently gelatin liquefiers and active ammonifiers. No endospores. Gram stain variable, though usually negative. Fermentation of carbohydrates as a rule not active. Frequently producing a water-soluble pigment which diffuses through the medium as green, blue, purple, brown, etc. In some cases a non-diffusible yellow pigment is formed. Many yellow species are plant parasites.

Buchanan (1918, p. 48) discussed at length the nomenclatural status of the genus, and gave the following description.

Rod-shaped bacteria, never spiral, usually motile by means of polar flagella or rarely non-motile. Aërobic and facultative. Frequently liquefying gelatin. Without spores. Gram stain variable. Usually producing a water-soluble pigment which diffuses through the medium as a green, blue, purple, or brown or in some cases a yellow pigment. Fermentation of carbohydrates usually not active.

The type species is Pseudomonas aeruginosa (Schröter) Frost?

Later Winslow et al. (1902, p. 204) designated the type species as Ps. aeruginosa (Schröter) Frost? Enlows (1920, p. 74) states, "Type species (monotype)-Pseudomonas violacea (Schröter 1886) Migula." This designation can be made only by reference to Migula's publications after the first in which Pseudomonas was proposed. There had been previously described:

Pediococcus violaceus Trevisan 1889
Lampropedia violacea Trevisan 1889
Thiocystis violacea Winogradsky 1889
Spirillum violaceum Warming
Bacteridium (Bacillus) violaceum Schröter
Chromobacterium violaceum Bergonzini
Chromococcus violaceus Bergonzini
Micrococcus violaceus Cohn
Streptococcus violaceus (Cohn) Trevisan

Migula (1895) particularly emphasizes the fluorescent pigment production as characteristic. The first species described is one which is typical and should be designated as the type as was done by Winslow et al.

Bergey et al. (1923, p. 122) include Pseudomonas as the fourth genus of the tribe Chromobactereae with the following description: "Principally water and soil bacteria producing a water-soluble pigment which 
diffuses through the medium as green, blue or yellowish-green. Motile or non-motile. Gram-negative."

Pseudorhizobium. A generic name used by Hartleb (1900, p. 887) for an organism isolated from the nodule of a legume. He named the form Pseudorhizobium ramosum. The organism resembled the normal legume bacteria but appeared to be non-infectious. The name has apparently not been used by other writers.

Pseudosarcina. According to Löhnis (1913, p. 449) the genus Pseudosarcina was named by Macé (1903, p. 887). An examination of the statement of the latter author fails to show such generic name. The term used is pseudosarcine, employed apparently simply in a casual sense. He says:

Ce microbe se présente insolé, et alors il est sphérique, ou sous forme d'agregats plus ou moins volumineaux, d'un aspect mûriforme: rappelant une grosse sarcine, en raison de cette analogie je le désignerai provisoiremen par le terme de pseudosarcine cal il ne semble pas que ses bipartitions se fassent suivant deux plans perpendiculaires.

\section{Pseudo-sarcine. See Pseudosarcina.}

Pseudospira. A subgenus of the genus Pacinia used by Trevisan (1889, p. 1018) with the following diagnosis:

Baculi curvi, non raro semicirculares, saepissime in filamenta undulatoflexuosa vel irregulariter pseudospirilia, nunquam vere spiraliter ut in Spirilleis torta, consociati Arthrosporae notabiliter quam in Eu-Paciniis minores, nunquam duplo diametri transversalis baculorum latiore.

Eight species are included in the subgenus. The type species may be designated as Pacinia cholerae asiaticae. The organisms of this group are those ordinarily assigned to Vibrio or to Microspira.

Punctula. A generic name used by Van Tieghem (1880, p. 150). The following summary is from Journal Roy. Mic. Soc. (1880, p. 1001).

Punctula. The spherical cells are ordinarily extremely minute; they appear like innumerable dots united by a gelatinous cement. A close examination is required to distinguish the colonies composed of them from simple naked cells consisting of a finely granular protoplasm.

In Punctula rosea the colonies are of a bright rose colour; they are spherical, and with a sharply defined outline; the dots, which are so many elementary cells, are arranged in them with perfect regularity in radial rows and concentric circles. After each division, the two halves of the colony become rounded off, and separate completely. When one of these spheres is crushed, it is resolved into its elementary cells, and the formation can then be followed of so many new colonies by the repeated increase and division of each of the cells. 
Two other species, P. cubica and P. glomerata are named.

The species are so inadequately described as probably to represent practically nomina nuda.

Punctum. A generic name apparently proposed by Mühlhäuser (1884, p. 97). Enlows gives the following summary.

Very small $(0.0005 \mathrm{~mm}$.) of varied form, but usual oval; at first not motile, later very lively, moving around in a circular fashion. It can traverse $0.1 \mathrm{~mm}$. in one second. In young cultures (stagnant water) the longer forms are found. No chains or filaments.

Type species. Punctum saltans. Syn. (Trevisan, Saccardo's Sylloge Fungorum, v. 8, 1889, p. 1008) Spirillium obermeieri Cohn, 1875 (Beit. z. Biol. der Pflanzen, v. 1, p. 196).

Putribacillus. A generic name proposed by Orla-Jensen (1909, p. 342 ) as one of the genera of his family Putribacteriaceae. It includes the anaërobic putrefactive bacteria which do not produce an exotoxin. Jensen makes the following statement:

Einen anderen Zweig bilden die anaëroben Fäulnisbakterien, die Gattung Putribacillus. Diese sind dadureh gekennzeichnet, dasz sie die Eiweiszstoffe unter Verbreitung eines furchtbaren Gestankes zersetzen. Die Entwickelung geht hier wie bei den aëroben Füulnisbakterien von säurebildenden zu säureempfindlichen Arten. So entsprechen z. B. Bacillus bifermentans sporogenes und Bacillus oedematis maligni (welche Traubenzucker, aber nicht Milchzucker vergären), sowie Bacillus perfringens und Paraplectrum foetidum (die sowohl Traubenzucker als auch Milchzucker vergären, ja des letztere zerlogt sogar ebensowie Butyribacillus Chauvoei Milchsäure) den Proteusbakterien, während Bacillus putrificus, den wir Putribacillus vulgaris nennen wollen, den aëroben Bacillen entspricht. Letztere Bakterie ist gar nicht zuckerspaltend, was sonst für fast alle fakultativ oder obligat anaëroben Bakterien charakteristisch ist, und sie musz sich daher die ganze nötige Energiemenge lediglich durch Zersetzung der Proteinstoffe verschaffen können. Innerhalb der anaëroben Bakterien hat sie deshalb die höchste Entwickelung als Eiweiszvergärer, ebenso wie Cellulobacillus methanigenes als Kohlenhydratvergärer, erreicht.

This genus perhaps may be regarded as a synonym of Clostridium or possibly of Plectridium.

It is difficult to determine what is regarded as the type species. The only one of the species mentioned which he specifically places in this genus is his Putribacillus vulgaris or properly Putribacillus putrificus. This may therefore be termed the type. With this understanding, this generic name has priority over Putrificus Heller (q.v.).

Putribacteriaceae. A family of bacteria proposed by Orla-Jensen $(1909$, p. 343) to include obligate anaërobic or microaërophilic bacteria 
which act largely on proteins and bring about putrefactive changes. The family is included in the order Peritrichinae. It contains the following genera: Putribacillus and Botulobacillus.

Putriclostridium. Orla-Jensen (1921, p. 273) states:

The use of the term Clostridium as a generic name presents the inconvenience that under the same we must group together not only the clostridia but also the plectridia. The division into true butyric acid bacteria (Butyriclostridium), the requirements of which in regard to nitrogenous nutriment are very moderate (they are able to assimilate even the nitrogen of the air) and anaërobic, putrefying bacteria (Putriclostridiunt) seems natural to me.

Putrificoideae. A name given by Heller (1921, p. 550) to the second subfamily of the Clostridiaceae with the following description:

Clostridiaceae which on meat medium produce after twenty days' incubation at $37^{\circ}$ under vaseline a reaction of $\mathrm{pH} 7.1$ or a more alkaline reaction, the reaction being read after the culture had been boiled.

Eleven genera are included: Seguinillus, Regillus, Robertsonillus, Nicollaierillus, Martelillus, Recordillus, Tissierillus, Putrificus, Ermengenillus, Metchnikovillus and Weinbergillus.

Putrificus. A generic name proposed by Heller (1922, p. 27) with the following description.

Putrificoideae that do not attack sugars. Slender Gram-negative or Grampositive rods with oval terminal spores. Colonies in deep agar have radiate periphery and opaque center. Putrefactive organisms found in soil and wounds.

Type species P. Bienstocki (Bacillus putrificus Bienstock) as defined by Bienstock (1906). References; Bienstock (1884, 1901, 1906), Klein, Rodella (1905).

Pyobacillus. A name used by Koppanyi (1907, p. 429) to designate his Pyobacillus capsulatus cuniculi or Bacillus pyemiae cuniculi. The organism was isolated from rabbits. It is a non-motile capsulated rod, grows on weakly alkaline nutrient media only if at same time exudate is carried over on to the nutrient medium, or serum, or serum agar. Protein-rich substances necessary for growth. No growth on gelatin, room temperature not suitable. It probably is to be regarded as non-valid, as binomial nomenclature is not used.

Pyobacterium. A generic name used by Küttner (1895, p. 760), for the species Pyobacterium Fischeri. The organism was found in an epigastric abscess. It is closely related to Bacterium coli commune, but is more slender, forms colonies pure white in color and is actively motile. Milk is slowly coagulated with flocculent curd. It ferments 
sugars less vigorously and does not make meat infusion alkaline. Produces indol and nitrites. Pathogenic for mouse, guinea-pig, rabbits and pigeons. Animal infected intravenously quickly succumb to septicemia. In subcutaneous inoculation there is pus production (abscess formation).

Pyococcus. A term used by Ludwig (1892, p. 27) as a synonym of Staphylococcus. It evidently has not been used as a generic designation.

Radiobacter. A name occasionally used in a pseudo-generic sense in reference to Bacillus radiobacter, as by Stoklasa (1908, p. 484).

Radiococcus. A name used by Maggi $(1886$, p. 81$)$ to designate a growth form of his Micrococcus aceti.

Rasmussenia. A genus of bacteria created by De Toni and Trevisan $(1889$, p. 930$)$ to include the slender filamentous bacteria of the mouth usually known as Leptothrix. The generic diagnosis is as follows:

Filamenta cylindrica, vagina tenui gelatinosa facile evanescente obducta, simplicia, basi subiculo zoogloeico affixa, articulata, articulis aetate provecta in baculos et coccos solutis. Multiplicatio baculis primitus vivacites mobilibus, cito immotis. Arthrosporae transformatione encci singuli ortae.

Five species are described: $R$. gigantea, $R$. buccalis, $R$. maxima, $R$. anceps and $R$. variabilis. The type first described may probably be regarded as Rasmussenia gigantea (Miller) Trevisan, from the mouth.

Clements $(1894$, p. 28$)$ is apparently the only other author who has used this generic designation. His generic description is: "Cells elongate-cylindrical, flexuose, simple, with a thin, gelatinous sheath, often separating into bacilli or cocci, from which the arthrospores arise."

One species is described, Rasmussenia buccalis (Rob. and Leb.) Trev.

Unless the type, $R$. gigantea (Miller) Trevisan is so different from $R$. buccalis (Rob. and Leb.) Trev. as to warrant genera for the two species, the genus Rasmussenia is a synonym of Leptotrichia q.v. of which $L$. buccalis is the type.

Recordillus. A name proposed by Heller (1922, p. 26) for a genus of the tribe Putrificoideae with the following description.

Putrificoideae that, though they sporulate, are exceedingly delicate and soon die in meat medium and other media. Their growth in meat medium resembles that of the organisms of genus Martellillus, they do not produce much gas, they color the meat particles a greyish color and form a blackish pigment. Gramnegative rods with central or subterminal cocoon-shaped spores. Parasitic forms which infect cattle in California and Nevada. I venture to place such organisms in a separate genus on account of their parasitic habit and on account 
of their delicacy. It may be that they are descended from organisms of the genus Martellillus.

Type species $R$. fragilis nov. sp. Characters of genus.

Reducibacteriaceae. A family of bacteria proposed by Orla-Jensen (1909, p. 333) to include those genera of his order Cephalotrichinae which are spiral or bent in shape, which are active reducers, which do not contain sulphur or bacteriopurpurin, which are in filaments and which do not show a tendency to branching. The characteristic reaction may be regarded as the reduction of nitrates to nitrites. The genera included are: Solidovibrio and Spirillum.

Reglillus. A generic name proposed by Heller (1922, p. 23) for a genus of the Putrificoideae with the following description.

Putrificoideae that show to the eye little proteolytic action on meat. They may or may not blacken it slightly, but the meat particles do not diminish in size. Sugars are attacked. Milk is digested. Gram-positive rods which readily form oval subterminal or median spores. Colonies minute, opaque, complex, yellow. Typically toxic tissue invaders which produce in the guinea-pig a clear white oedema that does not rapidly lose its oedematous nature on section.

Type species $R$. progrediens nov. sp. To be described in a future paper. Two species, one found in a case of human gas gangrene (see Barney and Heller), the other in a sheep.

Rhabdochromatium. A genus of sulfur bacteria proposed by Winogradsky (1888, p. 100) as differentiated from Chromatium by the elongated rod and spindle shape and through its variable growth forms. He regarded it as possibly of subgeneric rank under Chromatium. The type species, Rhabdochromatium roseum Win. he regards as probably identical with Rhabdomonas rosea Cohn. Two other species, $R h$. minus and $R$. fusiforme were also described.

De Toni and Trevisan (1889, p. 942) include it as a subgenus of Mantegazzaea with the diagnosis: "Species chromogenae, baculis granula sulphuris foventibus." Three species are included.

Rhabdochromatium was recognized by Migula (1900, p. 1048) with the description: "Zellen frei, stab- und spindelförmig, zeitlebens schwarmfähig, mit Geisseln an den Polen." This description has also been used by Smith (1905, p. 164).

Orla-Jensen (1909, p. 334) makes this a synonym of Rhabdomonas. This is probably the correct assignment of the genus. 
Rhabdomonas. A generic name proposed by Cohn (1875, p. 167) for the species Rhabdomonas rosea, with the following description:

Ausser der Monas Okenii enthielt das rothe Wasser aus Kahla noch vereinzelte spindelförmige, blass rosenrothe Körperchen, welche nach beiden Enden verjüngt, in ausgewachsenem Zustande etwa $8 \mathrm{mal}$ länger als breit sind: ich bestimmte die Breite zu 3.S-5 $(0.0038-0.005 \mathrm{~mm}$.) die Länge je nach dem Zustande der Theilung: 20-30 . Die Vermehung durch Quertheilung ist häufig zu beobachten die Theilhälften erreichen fast ihre normale Grösse, ehe sie sich trennen. Charakteristich sind auch für diese Körperchen die dunkelen, stark Licht brechenden, in die rosafarbene Substanz eingelagerten Körnchen, die sich bald in grösserer, bald in geringerer Zahl vorfinden; auch wasserhelle vacuolen in der Mitte und an den Enden wurden beobachtet. Die Bewegung ist langsam zitternd; abwechselnd vor und rückwarts unter beständiger Drehung un die Längsächse; ein wirbel am hintem Ende deutet auf eine nachschleppende Flimmergeissel, wie bei Monas Okenii, die ich jedoch nur einmal wirklich unterscheiden Konnte. So viel ich weiss, ist diese rothe Spindelmonade noch nicht beschrieben: sie gehört unter die Ehrenbergsche Section Rhabdomonas als eine neue Art, die ich als Rhabdomonas rosea bezeichnen will.

Trevisan $(1879$, p. 137) introduced the generic name Mantegazzaea (q.v.) to replace Rhabdomonas on the plea that the latter was "nomen ineptum." Winogradsky (1888, p. 100) proposed still a third generic name Rhabdochromatium (q.v.) with two additional species.

Rhabdomonas is included by most subsequent writers as a synonym of Rhabdochromatium. It is so included by Migula (1900, p. 1048). It is rejected as invalid by E. F. Smith (1905). Orla-Jensen (1909, p. 334) suggests that it should be used to replace Rhabdochromatium.

Buchanan (1918, p. 471) included this genus as the first of the tribe Chromatieae with the following description.

Differentiated from Chromatium by the elongated rod-shaped or spindleshaped cells. Cells red, with sulphur granules, polar flagella.

The type species is Rhabdomonas rosea Cohn.

Bergey (1923, p. 402) followed Buchanan.

Rhizobacterium. A generic name used by Kirchner (1895, p. 213) for the species of root nodule organism found in the nodules of Lupinus, Ornithopus and Soja, under the name Rh. japonicum. He proposed the name because he regarded Rhizobium as invalid on account of the previous use in entomology of the generic name Rhizobius for a genus of aphids. This reason is not valid, for both botanical and zoological codes recognize the validity of identical names in the two fields of science, though they are not recommended. Apparently other writers 
have not used this name. It may be regarded as a synonym of Rhizobium.

Rhizobium. A generic name proposed by Frank (1889, p. 338) to include the organisms causing the formation of nodules on the roots of leguminous plants. He expresses the belief that the organism probably belongs to the fission fungi or bacteria and states:

Um in der vielleicht noch sich aufwerfenden Discussion, ober zu den Myxomyceten oder zu den Spaltpilzen, sei, in der Namengebung nichts zu präjudiciren, ist vielliecht die Beziechnung Rhizobium leguminosarum für ihn empfehlenswerth.

This generic name has been used by several authors, among them Ludwig (1892, p. 99) Schneider (1892, p. 203) and Hiltner and Störmer (1903, p. 151).

The name is rejected by Erwin F. Smith (1905, p. 174). OrlaJensen $(1909$, p. 334) proposed the substitution of the name Rhizomonas.

Winslow et al. (Committee Soc. Am. Bact., 1917, p. 553) make the following statement.

Phytomyxa Schröteı has priority over Rhizobium, but because of the confusion which would arise from the substitution of the older correct name for the better known term Rhizobium, the committee recommends the adoption of the latter.

Minute rods, motile when young by means of polar flagella. Involution forms abundant and characteristic when grown under suitable conditions. Obligate aerobes, capable of fixing atmospheric nitrogen when grown in the presence of carbohydrates in the absence of compounds of nitrogen. Produce nodules upon the roots of leguminous plants.

The type species is Rhizobium leguminosarum Frank.

\section{Buchanan (1918, p. 46) gave the following description.}

Rod-shaped cells, motile when young by means of polar flagella, obligate aërobes, fixing atmospheric nitrogen when grown in a nitrogen-free medium containing suitable carbohydrates, involution forms abundant and characteristic, usually growing in the nodules of the roots of leguminous plants.

The type species is Rhizobium leguminosarum Frank.

The name of this genus has been a source of confusion. The organism of leguminous nodules was placed in the mold genus Schinzia by Frank as Schinzia leguminosarum. Schroeter $(1886$, p. 134) concluded the organism to be one of the slime molds and created the genus Phytomyxa, including it in the order Phytomyxini among the Myxomycetes. He based his conclusions as to the position of this organism among the slime molds upon the work of Prilleaux (1879, p. 98). Beijerinck (1888, p. 758), named the organism Bacillus radicicola. Frank (1889, p. 338) renamed the organism Rhizobium leguininosarum. The fact that Schröter included this genus incorrectly among the slime molds does not invalidate the 
name. The Committee on Classification of Bacteria, of the Society of American Bacteriologists, however, has recommended the use of the generic name Rhizobium as better known and probably resulting in less confusion than the use of Phytomyxa.

The genus is included by Bergey et al. (1923, p. 40) as the second in the tribe Azotobactereae with the following description.

Minute rods, motile when young, branching forms abundant and characteristic when grown under suitable conditions. Obligate aërobes, capable of fixing atmospheric nitrogen when grown in the presence of carbohydrates and in the absence of organic nitrogen compounds. Produce nodules upon the roots of leguminous plants.

Rhizobiinae. The name of a subtribe proposed by Buchanan (1918, p. 43) for the third subtribe of the tribe Bacterieae with the description: "Rod-shaped organisms, securing their growth energy by the oxidation of carbonaceous compounds, as carbohydrates, alcohol, etc. Do not require serum, etc. Not parasitic in animals."

Three genera are included, Mycoderma, Rhizobium and Azotobacter.

Rhizomonas. A generic name proposed by Orla-Jensen (1909, p. 334) as a substitute for Rhizobium (q.v.) to designate the organisms which are responsible for the development of nodules on the roots of leguminous plants. It may be regarded as a synonym of Rhizobium and Phytomyxa (q.v.).

Rhodobacillus. A genus of bacteria named by Molisch (1907; p. 14) to include bacteria containing bacterio-purpurin and bacteriochlorin but no free sulfur granules. The organisms are short rods, rounded at the ends, usually solitary and motile. One species is described, Rhodobacillus palustris Molisch.

Meyer (1912, p. 2) used Rhodobacillus as a designation for the second section of the genus Bacillus with the description: "Sie sol die durch Bakteriopurpurin gefärbten Spezies der Gattung Bacillus enthalten, sowohl die schwefelfreien wie die schwefelhaltigen Spezies."

Buchanan $(1918$, p. 473) included this as the fifth genus of the tribe Rhodobacterioideae, as "Rod shaped cells, solitary, usually motile" with the type species designated as Rhodobacillus palustris Molisch.

Bergey et al. (1923, p. 406) followed Buchanan.

Rhodobacteria. An order of bacteria named by Molisch (1907, p. 27) with the following description: "Bakterien, deren Zellinhalt durch Bakteriopurpurin und (sowert untersucht) durch Bakteriochlorin rosa, rot, violett oder karminrot gefärbt sind." Two families are included, Thiorhodaceae and Athiorhodaceae. 
Rhodobacteriaceae. A family of bacteria created by Migula (1900, p. 1042) to include all bacteria containing bacteriopurpurin, and in consequence colored rose, red or violet. They also contain sulfur granules. This family is recognized by Smith (1905, p. 163), OrlaJensen (1909, p. 313), Benecke (1912), Frost (1911, p. 60) and others. An ordinal name Rhodobacteria (q.v.) is used by Molisch (1907, p. 27).

Buchanan (1918, p. 464) included this as the third family of the order Thiobacteriales with two subfamilies Chromatioideae and Rhodobacterioideae. His description is: "Cells of various types, not filamentous, containing bacterio-purpurin with or without sulphur granules also."

Bergey et al. (1923, p. 394) included this as the first family of the order Thiobacteriales.

Rhodobacterioideae. A name given by Buchanan (1918, p. 471) to the second subfamily of the Rhodobacteriaceae. The name may be considered a synonym of Athiorhodaceae Molisch. The diagnosis is: "Cells not filamentous, containing bacteriopurpurin but not granules of sulphur." The following genera were included: Rhodocystis, Rhodonostoc, Rhodosphaera, Rhodobacterium, Rhodobacillus, Rhodovibrio and Rhodospirillum.

Rhodobacteroideae. A variant spelling of Rhodobacterioideae q.v. used by Bergey et al. (1923, p. 404).

Rhodobacterium. A genus of bacteria first described by Molisch (1907, p. 16) to include those bacteria containing bacteriopurpurin, devoid of sulphur granules, rod shaped, and non-motile. A single species, (type) Rhodobacterium capsulatum Molisch is included.

Buchanan (1918, p. 472) included this as the fourth genus of the tribe Rhodobacterioideae. Bergey et al. (1923, p. 406) followed Buchanan.

Rhodocapsa. A genus of sulfur bacteria described by Molisch (1906, p. 223). The cells contain granules of free sulfur; and are free that is, not united into families, not capable of swarming. In mass the organisms are rose or cherry red, due to their content of bacteriopurpurin. One species was described, Rhodocapsa suspensa (the type).

This name was also used by Orla-Jensen $(1909$, p. 334) as the tenth genus of his family Rhodobacteriaceae. It appears that he proposes to use this name to replace an older designation Thiocapsa. In this sense the name would be invalid.

Buchanan (1918, p. 471) includes this as the fourth genus of the tribe Chromatieae with the description: "Cells spherical, free (not united 
into families), not capable of swarming (non-motile). In mass the organisms are cherry red. Contain sulphur granules."

Bergey et al. (1923, p. 404) follow Buchanan.

Rhodococcus. This generic name has been introduced three times into bacteriological nomenclature. It was first used by Zopf (1891, p. 28) to apply to two species of red bacteria whose physiological characters had previously been studied at length by Overbeck (1891, p. 399). These organisms had been known as Micrococcus erythromyxa and $M$. rhodochrous. He characterized the genus (or subgenus as he terms it) as follows:

Colonien auf gewöhnlicher Nährgelatine gebirgsrückenartig; roth gefärbte Zellen weder ausgesprochen fädige noch flächenförmige oder körperliche Verbände bildend, sondern unregelmässig zusammengelagert, ohne Gallerthülle, einen rothen Fettfarbstoff enthaltend, der nach der Ausscheidung in rothen, auffälligen Aggregaten krystallisirt, und durch ein einziges breites Absorptionsband bei $F$. ausgezeichnet ist.

The species Rhodococcus erythromyxa was isolated by Zopf from tap water. Overbeck describes it as producing round sharply circumscribed red colonies in plate cultures. In stab cultures in agar and gelatin growth occurs only in the upper portion of the stab. Grows well on potato, egg, etc., forming an abundant red pigment, cultures generally being slimy. Cells are about $1.1 \mu$ in diameter, spherical. In general they are grouped irregularly, but packets are sometimes formed in suitable media. Gelatin is not liquefied. The pigment was determined to be a lipochrome.

These species are disposed of in various ways of subsequent authors. Migula (1900, p. 487) uses the designation Bacterium erythromyxa (Zopf) Mig. Matzuschita (1902, p. 389) changes it to Bacillus erythromyxa, because of its shape. He (p. 441) however uses the name Micrococcus rhodochrous. He describes it as

Grosse Zellen. Kleine, mattglänzende, kreisrunde gewölbte, dunkelkarminrosa gefärbte Kolonien. Auf Agar erst karminrosa, dann tief zinnoberrote Auflagerung. In Bouillon bild er sich eine dicke rosa Haut, glatt, feucht und ein roter flockig-bröckeliger Bodensatz.

This shows that at least one of the species is a true coccus. It would seem evident therefore if the red pigmented cocci are worthy of generic designation, that Rhodococcus Zopf is valid.

Winslow and Rogers (1906, p. 546) evidently without knowledge of the previous use of the name by Zopf, proposed Rhodococcus as a generic 
designation for the red cocci. In their later publication (1908, p. 261) they give the following diagnosis:

Saprophytes. Cells in groups or regular packets. Generally decolorize by Gram. Growth on agar abundant, with formation of a red pigment. Dextrose broth slightly acid, lactose broth neutral. Gelatin rarely liquefied. Nitrates generally reduced to nitrites, but not to ammonia.

They recognize two species only, Rhodococcus roseus (Flügge) Winslow and Rh. fulvus (Cohn) Winslow. It is apparent that this description may well be regarded simply as an emendation of that of Zopf.

Rhodococcus was independently introduced as a bacterial genus by Molisch (1907, p. 20). The only species described is named Rhodococcus capulatus Molisch. This organism is described as belonging with the Athiorhodaceae, that group of the sulphur bacteria which contain bacterio-purpurin, but not free sulphur granules. This generic name is a homonym of Rhodococcus Zopf. This genus is recognized by Orla-Jensen $(1909$, p. 334) as the seventh in the family Rhodobacteriaceae as a synonym of Thiopcdia. In this sense the name is invalid.

Meyer (1912, p. 4) included Rhodococcus as a section of the genus Streptococcus with the description "Alle durch Bacteriopurpurin gefärbten Streptococcusarten." He also includes a section by the same name under Micrococcus with the description "Mit Schwefelkörnchen."

Buchanan (1915, p. 12) discussed the synonymy and relationships of the genus.

Buchanan (1917, p. 614) included this genus as the second of the tribe Micrococceae with the description:

Saprophytes. Cells in groups or regular packets. Usually Gram-negative. Abundant growth with red pigment on surface of culture media. Slight acid from dextrose, none from lactose. Gelatin rarely liquefied. Nitrate usually reduced to nitrites, but not to ammonia.

The type species is probably Rhodococcus roseus (Flügge) Winslow.

This genus was also recognized by Winslow et al. (Committee Soc. Am. Bact., 1917, p. 560 and 1920, p. 208) with the designation of the type species as Rhodococcus rhodochrous Zopf. Castellani and Chalmers (1919, p. 931) state Rhodococcus roseus (Flügge) emendavit Dyar (1895) to be the type. Bergey et al. (1923, p. 75) follow the Committee.

It would appear that Rhodococcus Zopf, is a valid name to apply to the red cocci as a generic designation if they are to be grouped separately, and that the type is Rhodococcus rhodochrous Zopf. 
Rhodocystis. A name used by Molisch (1907, p. 22) to designate a genus of bacteria characterized by the presence of bacteriopurpurin, the absence of sulfur granules, the union of cells into families, the division of cells in only one direction of space, the cells rod-shaped, embedded in a common slimy capsule. One species Rhodocystis gelatinosa is described.

Orla-Jensen (1909, p. 334) proposed this name to replace Thiocystis. In this sense it is probably invalid.

Meyer (1912, p. 2) included this genus in his section Rhodobacillus of the genus Bacillus.

The genus was recognized by Buchanan (1918, p. 472) and the type species designated as Rhodocystis gelatinosa Molisch. The description reads: "Cells rod-shaped, dividing in only one plane embedded in a common slimy capsule."

Rhododictyon. A generic name proposed by Orla-Jensen (1909, p. 334) to replace the older name Thiodictyon Winogradsky, as the third genus of the family Rhodobacteriaceae. It is probably to be regarded as a synonym.

Rhodomonas. A generic name proposed by Orla-Jensen (1909, p. 33) to replace the older name Chromatium. It is included as the first genus of the family Rhodobacteriaceae. It is probably an invalid synonym.

Rhodonostoc. A genus described by Molisch (1907, p. 23) to include bacteria containing bacteriopurpurin without sulfur granules, with cells united into families, cells spherical or short rods, in chains like a rosary and embedded in a common gelatinous capsule. One species, Rhodonostoc capsulatum is included.

It is recognized by Buchanan (1918, p. 472) with the designation of Rhodonostoc capsulatum Molisch as type, and the description: "Cells spherical or short rods, in rosary like chains, and embedded in a common gelatinous capsule."

Bergey et al. (1923, p. 405) followed Buchanan.

Rhodopolycoccus. A generic name proposed by Orla-Jensen (1909, p. 334) to replace the older name Thiopolycoccus. It is included as the sixth genus of his family Rhodobacteriaceae. It may be regarded as a synonym of Thiopolycoccus.

Rhodosarcina. A generic name used by Orla-Jensen (1909, p. 334) to replace the older name Thiosarcina. It may be regarded as an invalid synonym of this latter term. 
Meyer (1912, p. 5) also used Rhodosarcina as a designation for a section of the genus Sarcina to include those species containing bacteriopurpurin. He includes here the genera Thiocystis, Lamprocystis and Thiocapsa.

Rhodosphaera. A name proposed by Buchanan (1918, p. 472) to replace the homonym Rhodococcus Molisch (q.v.). The genus is included as the third in the tribe Rhodobacterioideae, with the description:

Cells spherical, non-motile, free not united into families.

The type species is Rhodosphaera capsulatus (Molisch) Buchanan.

Bergey et al. (1923, p. 405) followed Buchanan.

The name is invalid as a generic designation for the bacteria, as the name Rhodosphaera was given by Engler in 1881 to a genus in the family Anacardiaceae among the flowering plants.

Rhodospira. A name proposed by Meyer (1912, p. 4) for the first section of the genus Microspira with the description "Bakteriopurpurin enthaltende Spezies."

Rhodospirillum. A generic name used by Molisch (1907, p. 24) to include bacteria containing bacteriopurpurin, without sulfur granules, with cells free, bent in a spiral, actively motile by means of a polar flagellum or cluster of flagella. Two species are described as new Rhodospirillum giganteum Molisch and Rh. photometricum Molisch, and Esmarch's species Spirillum rubrum is included as Rh. rubrum (Esmarch) Molisch.

This name was also used by Orla-Jensen $(1909, \mathrm{p} .334)$ to replace the older name Thiospirillum as the twelfth genus of his family Rhodobacteriaceae. This use of the name is invalid.

Meyer (1912, p. 3) makes Rhodospirillum the second section of the genus Spirillum with the diagnosis "Spirillen welche Bakteriopurpurin in dem Protoplasten enthalten." He believes Molisch's genus Rhodospirillum should be thus disposed of.

Buchanan (1918, p. 473) included the genus as the seventh in the subfamily Rhodobacterioideae with the description "Cells spiral, actively motile by means of polar flagella." The type species is designated as Rhodospirillum rubrum (Esmarch) Molisch.

Bergey et al. (1923, p. 407) followed Buchanan.

Rhodothece. A genus of bacteria named by Molisch (1906, p. 223) to include organisms containing bacteriopurpurin and sulfur granules, cells not united into families, not capable of swarming, each cell surrounded by a spherical or ellipsoidal capsule, cell usually spherical 
and occurring in pairs. One species, Rhodothece pendens Molisch is described.

This name was also introduced by Orla-Jensen (1909, p. 334) to replace the older name Thiothece, as the fifth genus of the family Rhodobacteriaceae. In this sense the name is probably invalid.

Buchanan (1918, p. 471) included this as the fifth genus of the tribe Chromatieae with the description:

Cells usually spherical and in pairs, each surrounded by a spherical or an ellipsoidal capsule. Non-motile. Cells not united into families. Cells contain bacteriopurpurin and sulphur granules.

The type species is Rhodothece pendens Molisch.

Bergey et al. (1923, p. 404) followed Buchanan.

Rhodovibrio. A generic name used by Molisch (1907, p. 21) to include those bacteria containing bacterio-purpurin, without sulfur granules, with cells short, comma shaped, actively motile by means of a single terminal flagellum. One species Rhodovibrio parvus Molisch is described.

Buchanan (1907, p. 21) included this as the sixth genus of the subfamily Rhodobacterioideae with the description:

Cells short, comma shaped, free, actively motile by means of a single terminal flagellum.

The type species is Rhodovibrio parvus Molisch.

Bergey et al. (1923, p. 407) followed Buchanan.

Rickettsia. A generic name proposed by Da Rocha Lima (1916, p. 567) for the organism causing typhus fever. The description was elaborated by Arkwright, Bacot and Duncan (1919, p. 76). Enlows (1920, p. 79) gives the following summary:

Very small, 0.3 to $0.5 \mu$ by 1.5 to $2 \mu$. Morphologically like a coccus, diplococcus or a short bacillus. Gram-negative. Not acid fast. Stains well by Giemss, appearing as small dots, paired cocci or bipolar staining bacilli with an unstained central part. Not motile. Occurs sparsely in blood films. Not successfully grown on artificial media.

Prowazek regards this organism as a protozoon largely because it is insect borne, and Da Rocha Lima seems rather inclined to this view on account of its peculiar staining reactions. Arkwright, Bacot, and Duncan, however, regarded its Giemsa staining reactions as quite like those of other bacteria. They conclude: "Nevertheless this class of microörganism and its associated diseases appear to have sufficiently distinct characteristics to justify the retention of the name Rickettsia for the present." They state that Da Rocha Lima found these bodies in the midgut of lice (Pediculus humanus) fed on trench fever patients, 
and that he considered the species causing typhus and trench fevers distinct. In typhus he claimed that the organism (Rickettsia prowazeli) invaded the epithelial cells of the gut wall, while only rarely is this the case with the trench fever organism (R. quintana), and with $R$. pediculi which is found in normal lice. He also claims that morphological differences are easily discernible if serial sections are cut. He infected a few guinea pigs, but was not able to pass the disease on from pig to pig, nor to infect mice.

\section{The type species is Rickettsia prowazeki Lima.}

Rivoltillus. A name proposed by Heller (1922, p. 20) for the twelfth genus of Clostridioideae with the following description:

Clostridioideae possessing moderately strong saccharolytic powers. Liquefy gelatin but do not produce $\mathrm{H}_{2} \mathrm{~S}$ demonstrable by a lead-acetate-paper test in blood broth. Produce in meat medium gas and a pink coloration which does not rapidly fade. Clot milk. Do not liquefy serum or egg or disintegrate meat particles. Gram-positive rods, usually short, with median, sub-terminal, or terminal spores, which usually bulge the sides of the bacillus. Sporangia not often much larger than vegetative rods. In tissue the sporangia may be uneven in their staining reactions, "granulose" being present; orgonts are long, frequently with parallel sides. Usually form chains on the liver of animals. Colonies in deep agar, though they may start as lenticular structures, consist later of a dense center and a wide loose woolly periphery. They vary in size, etc., according to species. Typically highly pathogenic tissue invaders that produce haemolysis ih the animal body. Pathogenic for a wide range of species.

Type species $R$. vibrion (the vibrion septique of Pasteur), as defined in a future paper. Robertson (1920) has divided the group into four sub-groups on the basis of the agglutination reaction.

Robertsonillus. A name proposed by Heller (1922, p. 24) for a genus of the Putrificoideae with the following description:

Putrificoideae that produce on meat medium a little gas and a terra cotta coloration, multiplying slowly for a long period. A black pigment is absent. Sugars not fermented. Weakly Gram-positive rods with oval spores, usually subterminal, that somewhat distend the bacillus. Two spores are produced. One species, found twice in moulds. Non-pathogenic for guinea-pigs in pure culture.

Type species $R$. primus (Bacillus I, Hempl) as described by Hempl. Descriptions of bacilli similar to this have not been noted. Proteolytic organisms producing a terra cotta coloration in meat medium are not uncommon, however.

Saccharobacillus. A species of organism named Saccharobacillus pastorianus by Van Laer (1889) was found by this author to be the cause of the disease of beer called "turning," in which the beer loses its brilliancy, becomes disagreeable in smell and taste and forms a sediment. According to Henneberg (1909, p. 480) the colonies on wort 
agar are smooth, gray-white, with flocculent sediment in the center. In the stab the growth is better than on the surface. Mash becomes clouded in two to three days with gas formation, and becomes clear after five to fourteen days. In wort flocculent masses form on the walls, when shaken it is clouded. In liquids the organism consists of slender, long rods which usually are united in 2,3 or more straight, bent or wavy lines. Maximum growth temperature is about $37^{\circ}$, optimum 29 to $33^{\circ}$ and minimum $11^{\circ} \mathrm{C}$. Lactic acid to amount of 1.5 per cent is produced.

The following sugars are acidified: arabinose, trehalose, dextrose, levulose, galactose, maltose, methyl glucosid, raffinose, mannite, dextrin, cane sugar. Starch and lactose are slightly fermented. Xylose, rhamnose, inulin, erythrit, quercit and dulcit are not fermented.

This generic name is rejected by Erwin F. Smith (1905, p. 174).

The genus Saccharobacillus has not come into general use, and is probably to be regarded as a synonym of Lactobacillus.

Saccharobacter. A generic name used by Beijerinck (1900, p. 200) for organisms closely related to his genus Aerobacter (q.v.). The types mentioned are those generally termed Bacillus megatherium and $B$. hortulensis. The name is listed as invalid by E. F. Smith (1905, p. 174).

Salmonella. A generic name used by Lignieres (1900, p. 389) and others for the organisms of the hog cholera bacillus or intermediate group of the intestinal bacteria. Lignieres states:

Le microbe de la Schweineseptikemie rentre dans le groupe des Pasteurella; celui du Hog-cholera ou schweinepest est tres different, if pourait servir de prototype pour la creation d'un autre groupe, celui des Salmonella.

Again (1901, p. 734) he states: "J'ai, de plus, jeté les bases déen autre groupe, celui des samonelloses, ayant pour type le microbe du hog-choléra de Salmon."

Buchanan (1918, p. 53) used this name as a designation of his second subgenus of the genus Bacterium with the definition: "Fermenting glucose but not lactose with formation of acid and gas. The type species is Bacterium (Salmonella) cholerae suis?"

Castellani and Chalmers (1919, p. 934) recognize this as the sixth genus of the tribe Ebertheae. The definition is:

Ebertheae which completely ferment glucose, but do not ferment lactose, and partially or completely ferment mannitol, in addition to other carbohydrates. Milk not clotted.

Type species. Salmonella paratyphi (Schottmüller, 1902). 
Apparently Castellani and Chalmers are in error in fixing the type species. Lignières included only the organism associated with hog cholera in the group or genus. It remains to determine just what specific name should be applied.

Bergey et al. (1923, p. 212) state:

Motile forms occurring in the intestinal canal of animals, in various types of acute, inflammatory conditions. Attack numerous carbohydrates with the formation of both acid and gas. In general do not form acetyl-methylcarbinol.

The type species is Salmonella schotmülleri.

Saprospira. A genus of free living spirochetes named by Gross (1911, p. 190) with the following diagnosis: "Spironemacea mit spiralig gebogenem Körper. Vermehrung durch Zerfallstheilung, Freilebend.

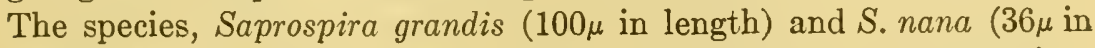
length) were described. Later (1912, p. 84) he says: "Die Saprospiren (Fig. 2) gleichen den Cristispiren in hohem Masze, nur fehlt ihnen die Crista. Es erscheint daher geboten, für sie ein eigenes Genus zu schaffen."

Winslow et al. (Committee Soc. of American Bacteriologists, 1917, p. 563) state:

Non-parasitic forms similar to Cristispira, but without the flattened ridge or "crista" which is, if present, here replaced by a straight columella or thickening of the periplast.

The type species is Saprospira grandis Gross.

Buchanan (1918, p. 544) included this as the second genus of the family Spirochaetaceae.

Slender spiral cells living free in salt water, actively motile, flexuous. Cross section circular.

The type species is Saprospira grandis Gross.

The genus is also recognized by Castellani and Chalmers (1919, p. 439) and by Bergey et al. (1923, p. 422).

Sarcina. A genus created by Goodsir (1842, p. 432) to include the species Sarcina ventriculi which he discovered in microscopical examination of vomit. His publication created a good deal of interest and many papers were published in the next quarter century upon this "Sarcinosis." The organism was apparently found repeatedly under similar conditions. This form is of interest because it is one of the first organisms which we now include among the bacteria to be 
described definitely as a plant. Enlows (1920, p. 80) has summarized the characteristics of the species as follows:

Frustules 16; color light brown; transparent matrix very perceptible between the frustules, less so around the edges; size " 0.800 to 0.1000 of an inch." "The individual organisms were transparent and slightly yellow or brown. When carefully examined under favorable circumstances the cell walls appeared rigid, and could be perceived passing from one flat surface to the other as dissepiments. These dissepiments, as well as the transparent spaces, were from compression of contiguity rectilinear, and all the angles right angles; but the bounding cells bulged somewhat irregularly on the edges of the organism by reason of the freedom of pressure. These circumstances gave the whole organism the appearance of a wool pack, or of a soft bundle bound with cord, crossing it four times at right angles, and at cqual distances." Found in the human stomach.

Robin (1847, p. 47) characterized the genus as follows:

Plante coriace, trausparente, consistant en masses cubiques ou allongées, composces de 16 à 64 cellules cubiques, partagćes en 4 frustules, arrangées l'une à coté de l'autre. Espéce S. ventriculi (Goodsir). Frustules 16, de couleur brune clairc. Masse transparente, laissant voir son intérieur entre les frustules. Les bords de celles sont emousses. Diametre 1/120 a 1/100 de ligne. Habite l'estomac humain.

The first definite inclusion of the genus in a scheme of classification was the assignment of this form to a position in the tribe Glaeogenae by Cohn (1875). The genus was also discussed by Luerssen (1879, p. 21) who mentions the species $S$. ventriculi Goodsir. He states that the spherical cells divide in three directions of space and form cubical families. Magnin (1880, p. 96) states that "Sarcina is very nearly allied to Merismopedia, from which it only differs by the absence of chlorophyll; its siliceous skeleton allies it with the diatoms." $\mathrm{He}$ mentions no species.

Trevisan (1879, p. 145) accepted the genus among the bacteria under the subtribe Sarcineae, with the following definition:

Cellulae globosae, divisionis tempore ovoideae, quaternatim in colonias tabulatas consociatae, tegumentis propris gelatinosis crassiusculis confluentibus obvolutae. Coloniae tegumento communi destitutae.

Two species are listed, the Sarcina ventriculi Goodsir and Sarcina urinae Welcher.

Before 1885 the genus is discussed by at least three other writers, Van Tieghem (1884, p. 1114), Grove (1884, p. 20) and Winter (1880, p. 48). Grove gives the definition of Winter, stating: 
Cells roundish, dividing in two or three dimensions of space. Daughter cells connccted for some time, forming small solid families or plates which are often again in their turn united to form larger colonies. Families usually consisting of four or a multiple of four cells.

He is thus enabled to bring into the genus some four other organisms which had previously been termed Merismopedia. Zopf (1885, p. 51) limited the genus to those forms in which cell division occurs regularly in three planes with formation of packets. Falkenheim (1885, p. 229) made use of the newly developed gelatin plate methods to secure cultures of Sarcina ventriculi Goodsir. He found that this species would grow readily upon artificial media, forming light yellow, round colonies in from thirty-six to forty-eight hours. Packets characteristic of Sarcina were missing in all media tried, except hay infusion. In this medium the packets were well developed. A study of this paper shows how extensive a literature had grown up concerning Sarcina. He notes that twenty years earlier (1865) fifty titles were already known. It would seem that the organism described by Falkenheim might well be taken as the type of the genus.

The genus as defined by Zopf was recognized by many writers up to 1895 , among them Schröter (1886, p. 153, S. ventriculi and 3 new species), Flügge (1886), De Toni and Trevisan (1889, p. 1044, 15 species), Cornil and Babes (1890, p. 148), Billet (1890, p. 24), Hueppe (1885, 1891, p. 30), Ludwig (1892) and Sternberg (1892, p. 17).

Migua (1894, p. 236) says

Sarcina Goodsir. Die Zellen teilen sich nach 3 Richtungen des Raumes, wodurch, wenn sie nach der Teilung verbunden bleiben, warenballenartig eingeschnürte Packets enstehen können. Bewegungsorgane fehlen. (Z. B. Sarcina ventriculi Goods., S. rosea Schröter.)

Migula (1895, p. 18) defined the genus somewhat more accurately, insisting that the outstanding generic character is division in three planes and not necessarily the formation of the packets. He also separated the motile forms into the new genus Planosarcina. He notes that about 45 species are known. Gruber (1895, p. 239) monographed the genus. He gives the following generic description:

Zellen rund, einzeln oder zu waarenball artig eingeschnürten packetförmiger Verbänden vereinigt, oder zu 2 (Diplococcenform) oder 4 einander genähert. Teilung nach drei Richtungen des Raumes. Bleiben die Tochterzellen nach der Teilung vereinigt, so sind sie an den Berührungsflïchen mehr oder weinger abgeplattet; trennen sie sich nach der Teilung so sind sie völlig kugelrund. 
He recognizes in all 39 species. With Migula's diagnosis the genus has been used by Lehmann and Neumann (1896, p. 135), Chester (1897, p. 62), Migula (1897, p. 27, 1900, p. 18 and 1904, p. 144), Macé (1897, p. 335), Fischer (1897, p. 32), Hewlett (1898), Baumgarten (1900, p. 127), Chester (1901, p. 109), Lehmann and Neumann (1901), Schmidt and Weis (1902, p. 288), Kendall (1902), Matzuschita (1902), A. J. Smith (1902, p. 270), Fischer (1903, p. 59), Klöcker (1903, p. 331), E. F. Smith (1905, p. 160), Fluegge (1908), Ellis (1909, p. 4), Orla-Jensen (1909, p. 340), Heim (1911, p. 249), Frost (1911, p. 57), Schneider (1912, p. 22), Löhnis (1913, p. 45), and Vuillemin (1913, p. 519).

The Winslows (1905, p. 669) have proposed a somewhat radical emenclation of the genus. In its latest form (1908, p. 260) it reads:

Facultative parasites or saprophytes. Division occurs under favorable conditions in three planes, producing regular packets. Generally decolorize by Gram. Growth on agar abundant, with formation of yellow pigment. Dextrose broth slightly acid, lactose broth generally neutral. Gelatin frequently liquefied. Nitrates may or may not be reduced.

They recognize three species. Sarcina lutea, S. citrea and S. flava. To these Kligler (1913, p. 432) has added Sarcina aurantiaca, an orange organism, emending therefore the generic description by the insertion of "and orange" after "yellow." The Winslows (1. c., p. 236) in discussion of Sarcina ventriculi state:

Another interesting Sarcina, possibly related to S. lutea, is the form originally isolated by Goodsir in 1842 and named by him S. ventriculi. It was described as a non-liquefying sarcina, isolated from the stomach in cases of hyperacidity of the gastric juice. More recent investigations suggest that there is nothing specific in the relation of this organism to the pathological condition in question (Flügge, 1896). S. ventriculi was distinguished from the type of $S$. lutea by the production of an orange, instead of a yellow, pigment. It corresponds therefore to the non-liquefying S. aurantiaca. Whether Goodsir's form was a packet-forming Aurococcus or an orange Sarcina can only be decided from a study of similar form which the future may bring to notice.

The writer has been unable to find the authority for terming $S$. ventriculi orange, Falkensheim (1885), Flügge (1886), Eisenberg (1891) and Gruber (1897, p. 259) all state that this organism is yellow on culture media, except that the latter states that on potato "Später orangegelb werdende Colonien." It would appear therefore that this name, Sarcina ventriculi should have been given to one of their species, 
and constitute the type of the genus. Beijerinck (1906, p. 200) identified Sarcina ventriculi. Vuillemin $(1913$, p. 525) proposes that this genus should be a "Genus conservandum."

Buchanan (1915, p. 10) discussed in detail the validity of the generic name and concluded the type should be Sarcina ventriculi Goodsir. Later $(1917$, p. 614) he included it as the third genus of the tribe Micrococceae with the following description:

Saprophytes or facultative parasites. Division occurs under favorable conditions in three planes, producing regular packets. Usually Gram-negative. Growth on agar abundant with formation of yellow pigment. Dextrose broth slightly acid, lactose broth generally neutral. Gelatin frequэntly liquefied. Nitrates may or may not be reduced.

The same disposition and practically the same diagnoses have been used by Winslow et al. (Committee Soc. Am. Bact., 1917, p. 559, 1920, p. 208), Castellani and Chalmers (1919, p. 925) and Bergey, et al. (1923, p. 70).

Sarcinacoccos. According to Enlows $(1920$, p. 81) this casual name was used by Billroth $(1874$, p. 8 ) for one of the growth forms of his Coccobacteria septica.

Sarcinaglobulus. A generic name used by Poulsen, (1879, p. 232). Enlows $(1920$, p. 81$)$ gives the following as the description used:

Schizophytarum corpora perpava hyalina e cellulis incoloribus minimis composita formans. Cellulae plantae vivae vix conspicuae reagentibus chemicis additis apparent. Divisionis modus ut in Sarcina, quacum maximam similitudinem habet. $\mathrm{Ab}$ hoc genere eo differt, quod non fasiculos hexaedricos sed globulos vel flebas subisodiametricas vel irregulares rotundatas format. Nucleum cellularum non observati. Species adhus una cognita, scil.

Type species (monotypy). S. punctum. Char. gen.: Magn. 2 to $200 \mu$. In. limo putido litoris freti cresund prope Haunias legi.

The position and status of this genus is uncertain.

Sarcinastrum. A generic name proposed by Lagerheim (1900, p. 280) for an organism Sarcinastrum Urosporae found producing galls upon the seaweed Urospora mirabilis. The following description of the organism is given.

Die zu Stäbchen ausgewachsenen Coccen erzeugen wahrscheinlich durch längsspaltung Kolonien, bestehend aus parallelen Stäben, die zu einer runden, gebogenen Scheibe angeordnet sind. Diese Scheibe wird später durch fortgesetzte Längsteilung der Stäbe balbkugelig, zuletzt fast hohlkugelig. Nachdem die Kolonie eine gewisse Grosse erreicht hat, tritt Quertheilung der Stäbe zu Coccen ein; die Kolonie besteht schliesslich aus einer sehr grossen Anzahl 
sehr kleiner, reihenweise angeortneter, kugeliger Zellen. Die gallertartige Substanz, die die Zellen zusämmenhält und die ganze Kolonie umgiebt, löst sich darauf allmählich auf, so dass die winzigen Coccen von einander frei werden und durch Wasserströmungen etc. fortgetrieben werden können. Eine Eigenbewegung der Coccen wurde nicht beobachtet. Durch die Schleimschicht können dieselben der Urospora-Membran angeklebst werden und sich weiter entwicklen.

Der Parasit ist von dem in mehreren Hinsichten ähnlichen Sarinoglobulus punctum Pouls. stofflich verschieden. Jodjodkalium und Anilinfarben bewirken bei jenem eine schwächere Färbung, als bei diesem.

The genus is probably valid, although the location of this organism among the bacteria might be questioned.

The type species is Sarcinastrum urosporae Lagerheim.

Sarcineae. A subtribal name under Bacterieae used by Trevisan (1879, p. 136) with the following description: "Cellulae substantia intercellulari in colonias mucosas determinatas consociatae." The genera included were: Sarcina, Chlamydatomus and Ascococcus. De Toni and Trevisan (1889, p. 1044) also used the name as a tribal designation with the following description: "Cocci in familias pluristratas vel unistratas, muco matricali plus minus conspicuo involutas, consociati. Cystides nullae. Endosporae microsomae in coccis normalibus obvenientes.

The following genera are included: Thiopolycoccus, Sarcina, Lampropedia, Thiocapsa, Pediococcus.

Sarcinee. A tribal designation used by Trevisan (1889, p. 27) for the second tribe of the suborder Coccogene. Four genera are included. Thiopolycoccus, Sarcina, Pediococcus and Thiocapsa. The description is "Cocchi più o meno densemente aggregati senz'ordine, o ad 8 ad 8 , o a 4 a 4 , in famiglie pluristrate od unistrate, più o meno anvolte in ganga gelatinosa, non mai racchiuse in cisti speciali." It is a variant of Sarcineae.

Sarcinoglobulus. See Sarcinaglobulus. The original spelling has not been determined, as the article is not available. Enlows (1920, p. 81) gives Sarcinaglobulus while Lagerheim (1900, p. 280) and others (see Journ. Roy. Mic. Soc., 1880, p. 1001) write Sarcinoglobulus.

Schinzia. According to Schröter (1886, p. 134) this generic name was first used by Dennstätt. He says: "Eine Gattung Schinzia ist schon früher 1818 im Dennstätt aufgestellt worden." The same name in another sense was used by Naegeli (1842, p. 279) as the generic designation of a fungus found in the rhizome of the Iris. Frank (1879, p. 376) concluded the organism responsible for the root nodules of leguminous plants belonged to the genus defined by Naegeli. To it 
he gave the name Schinzia leguminosarum. When later it was found that these organisms are bacteria, and not fungi, they were removed from this genus. Schinzia is not tenable as a genus name among bacteria.

Schizomycetacea. The class name of the bacteria as written by Castellani and Chalmers (1919, p. 924) with the description:

Thallophyta without chlorophyll and as a rule without chromatophores, with the vegetative body consisting of a single cell, in which the nucleus is not present in the form typical for other thallophytes. Reproduction by fission or spore formation.

Three orders are recognized, Eubacteriales, Thiobacteriales and Myxobacteriales.

Schizomycetaceae. De Toni and Trevisan (1889, p. 923) were apparently the first to use this name as a family designation for the entire group of bacteria. They give the following description:

Fungi mycelio proprio carentes, typice unicellulares, minutissimi, simplicissimi (globosi, elliptici, lineares, filiformes, recti v. incurvi v. spirales), vegetatione apicali genuina destituti, rarissime pseudoramosi. Multiplicatio vegetativa fit cellularum divisione in unam $\mathrm{v}$. duas vel tres directiones repetita; individua in statu vegetativo immobilia vel vivide oscillantia, saepe etiam in colonias vel alio modo congregata. Sporarum formatio duplex: tum plasmatis homogenei pars a liqua vel cellulae plasma totum contrahitur, condensatur et membrana peculiari induta in sporam transmutatur (ENDOSPORAE), tum cellula tota, sine plasmatis contractione, in sporam transformatur (ARTHROSPORAE).

OBS. Fungilli minimi sed in oeconomia universali maximi penderis, sunt enim pathogeni, zymogeni vel saprogeni.

These authors subdivide the family into the following tribes, Trichogenae, Baculogenae and Coccogenae.

Schizomycetes. A name first used by Naegeli (1857, p. 760) as a general designation of the forms we now recognize as bacteria. $\mathrm{He}$ included the organism causing silk worm disease, Nosema bombycis, also Umbina aceti (mother of vinegar), Bacterium, Vibrio, Spirillum, Hygrococis and Sarcina.

This designation for the group of the bacteria has been quite generally accepted by bacteriologists.

Cohn (1872a, p. 236) used term "Klasse der Schizomyceten."

Cohn (1872a, p. 237) uses term "Familie der Schizomyceten."

Thiselton-Dyer (1875, p. 325) used Schizomycetes, as did Lankester (1876, p. 37), Grove, (1884, p. 1), Balbiani (1886, p. 543). 
The name has frequently been used in the form Schizomyceten, Schizomycetacea (q.v.) and Schizomycetaceae.

Hansgirg (1888, p. 229) gives this as a synonym of Bacteria.

Clements $(1909$, p. 8) recognizes this as a class name with the two orders Bacteriales and Myxobactrales, and the description:

Typically one-celled fungi, dividing by fission in 1, 2 or 3 planes, sometimes forming true filaments, but then motile or sheathed, and without true branches; resting cells often developed; sexual reproduction lacking.

Vuillemin (1913, p. 512) gave an excellent characterization of the group. He states that they are simple organisms, formed of a single element without septa and unbranched. The element is circumscribed by a rigid vegetable like membrane, elastic, but not contractile, sometimes also with a capsule. It may undergo plasmolysis of plasmoptysis. The protoplasm is less differentiated than that of most cells; the chromatin particles do not form an individual nucleus of a permanent type. Division is amitotic. Some forms are motile with flagella which traverse the membrane at points characteristic of the species (polar or diffuse). They are not broader than $5 \mu$ when not in bunches or unimpregnated with metal or colloidal coloring material. The resting stage may be either an arthrospore resulting from a simple modification of the membrane or an endospore. In some cases the spore bearing element retains its form or is modified passively by the enlargement of the spore, in other cases it is a specialized element for spore production. Only the latter type of sporulation is satisfactory for generic characters. The amitotic division usually occurs by a pinching transversely with rapid separation of two individuals. These may remain united into families, in chains, layers or packets as determined by the successive planes of division. $\mathrm{He}$ emphasizes that all forms showing contractility should be placed in the protozoa, that the myxobacteria constitute a distinct group, and that forms like the tubercle bacillus which show branching should be placed in the mold group Microsiphones.

Buchanan (1917, p. 155) used the following characterization:

Typically unicellular plants, cells usually small and relatively primitive in organization. The cells are of many shapes, spherical, cylindrical, spiral or filamentous; cells often united into groups, families or filaments; cccasionally in the latter showing some differentiation among the cells, simulating the organization seen in some of the blue-green, filamentous algae. No sexual reproduction known. Multiplication typically by cell fission. Endospores are formed by some species of the Eubacteriales (see below), gonidia (conidia, arthrospores) by some of the filamentous forms. Chlorophyll is produced by none of the bacteria (with 
the possible exception of a single genus). Many forms produce pigments of other types. The cells may be motile by means of flagella; some of the forms intergrading with the protozoa are flexous, a few filamentous forms (as Beggiatoa) show an ocillating movement similar to that of certain of the blue green algae (as Oscillatoria).

He recognized six orders, the Eubacteriales, Chlamydobacteriales, Thiobacteriales, Actinomycetales, Myxobacteriales, and Spirochaetales.

Winslow et al. (Committee Soc. Am. Bact., 1917, p. 549) used the following description:

Minute, one-celled, chlorophyll-free, colorless, rarely violet-red or greencolored plants, which typically multiply by dividing in one, two or three directions of space, the cells thus formed sometimes remaining united into filamentous, flat, or cubical aggregates. Capsule or sheath composed in the main of protein matter. The cell plasma generally homogeneous without a nucleus. Sexual reproduction absent. In many species resting bodies are produced, either endospores or gonidia. Cells may be motile by means of flagella.

The same definition is used by Bergey et al. (1923, p. 29).

Schmidlea. A generic name proposed by Lauterborn (1913, p. 98) for one of the family Chlorobakteriaceae. His diagnosis is:

Schmidlea nov. gen. mit Sch. luteola (Aphanothece luteola Schmidle). Zellen elliptisch, 0,0015-0,002 $\mathrm{mm}$. lang, zu wolkenartigen, rundlichen bis ovalen, oft gelappten gallertigen Kolonien vereint, die bisweilen vakuolenartige Rüume umschliessen. Die Kolonien umfassen oft Tausende von Zellen und erreichen nicht selten mehr als 0,2 bis $0,3 \mathrm{~mm}$. Durchmesser.

The organism is found in decomposing plant remains in lake bottoms, particularly in decomposing Chara.

The position of this genus among the bacteria is questionable.

Schuetzia. A genus proposed by Trevisan (1889, p. 29) as the second genus of his tribe Streptococcee. The description is "Cocchi globulosi o per incipiente temnogenesi brevemente ellissoidi (monococchi), seriati in filamenti moniliformi, semplici, racchiusi in tenui capsule membranaceo-gelatinose. Spore macrosome provenienti nei filamenti." Three species are included, Sch. Poelsii, the organism of equine distemper, Sch. Laughlini and Sch. Dissei. The diagnosis given by De Toni and Trevisan (1889: p. 1052) follows:

Cocci globosi vel divisinis tempore ovoidei, in filamenta moniliformiter concatenati, capsulis membranaceo-gelatinosis, arctic, tenuiusculus, homogeneis, non lamellosis obducta. Arthrosporae macrosomae, in filamentis obvenientes. 
Five species are included, one Schuetzia equi (Sand et Jensen) Trevisan, is the organism commonly known as Streptococcus equi, the cause of equine "strangles."

The first species listed by De Toni and Trevisan (1889, p. 1052) is Schuetzia Lagerheimii (Ludwig) Trevisan. Probably Sch. equi may be considered the type. Its exact nomenclatural status is uncertain.

Sclerothrix. This name was apparently first used by Kuetzing (A.g. Aq. dulc Dec. 11) for one of the blue green algae under the designation Sclerothrix Callitrichae. Later Kuetzing (1849, p. 319) gave the following generic description: "Trichomata vaginata subramosa radiatim congesta, aequilonga, in cespitem globosum coalita. (Parasiticae palustres.)" This author had previously described this alga (1843, p. 229) as Hypheothrix Callitrichae.

Metschnikoff (1888, p. 70) proposed this as a generic name for organisms resembling the tubercle bacillus. He states that this organism in its perfect state may grow into short threads, and also differs from other forms except the leprosy bacillus, in the possession of a dense envelop. The name Sclerothrix Kochii was proposed for the organism causing tuberculosis.

This genus was regarded as a synonym of Bacillus by De Toni and Trevisan (1889). The name is rejected by Lehmann and Neumann in the following statement:

Since we proposed this name (Mycobacterium) in the first edition, we have seen that Metschnikoff (Virchow's Archiv., 113, p. 70, 1888), who first recognized the peculiar position of the tubercle bacillus as opposed to the other then known bacteria, in a work "Regarding the Phagocytic Rôle of the Tubercular Giant Cell," has said: "If one considers that in the perfected stage the tubercle bacteria have grown into (although short) threads, and also differ from other analogous forms (except the lepra bacteria) in the possession of a very dense envelope, then perhaps it will be easier to accept the designation Sclerothrix for the genus, and Sclerothrix Kochii for the species of the tubercle bacterium." We should have immediately accepted these names if we had known of them, but believe that according to the rules of botanical nomenclature our names should now stand, since Metschnikoff only made a conditional proposal, did not accurately define his new genus, and never made any use of the new name himself, while we have ourselves already established a name.

This is also rejected by Erwin F. Smith (1905, p. 174).

Schlerothrix has been proposed by Vuillemin $(1913$, p. 527) as a "Genus conservandum of the Microsiphones with Sclerothrix tuberculosis Metschnikoff as the type." 
If the organisms of the type of the tubercle bacillus are to be given generic recognition, Sclerothrix can be used as a generic name only if it can be shown that the previous use by Kuetzing does not invalidate it, and that Coccothrix (Lütz (q.v.)) is invalid, for the latter term has priority.

Seguinillus. A name proposed by Heller (1922, p. 23) for a genus of Putrificoideae with the following description:

Putrificoideae that do not exert a marked action on protein. Soften and may blacken meat. Milk clotted, may later be digested. Attack a few sugars. Very reluctant to form spores. Minute Gram-positive or Gram-negative rods, uniform in thickness but not in length. Spores oval, sub-terminal. Deep colonies lenticular or modified lenticular. Occasional tissue invaders which produce a proteolytic gangrene or phlegmon.

Type species S. aerofoetidus (Bacillus aerofoetidus Weinberg and Séguin) as described by Weinberg and Séguin (p. 161). The organism forms oval subterminal spores.

Semiclostridium. A genus of bacteria proposed by Maassen (1905, p. 5) with Semiclostridium commune as the type. This organism is aërobic bacillus which form spores, the sporangia being of a type which would place it in Fischer's Clostridiaceae. It has an unusual growth temperature range, from $18^{\circ}$ to $55^{\circ}$. Its optimum is about $45^{\circ}$, it is a facultative thermophile. The organism is motile, with peritrichic flagella. It peptonizes milk. In sugar solutions it forms larger gelatinous zoogloeal masses. Other species described are $S$. citreum, S. flavum and S. rubrum.

This is probably to be regarded as a synonym of Bacillus.

Serratia. The original article in which the name was proposed by Bizio (1823, p. 288) for fungus genus is apparently not available in America. However, the original report is reviewed by Bizio in a communication to the Paris Academy of Sciences (1844, p. 951). He states that in July 1819 in the province of Padua there was observed a phenomenon of reddening of the surface of "polenta," a porridge made from corn (maize) meal. In the course of eight to ten hours this was covered by a substance having the color of blood. It also appeared on bread and on rice kept under the same conditions. The phenomenon excited so much surprise and astonishment among the natives that it came to the attention of the public authorities and a commission of professors from the University of Padua was appointed to investigate. Bizio thought the phenomenon might be due to some fungus. $\mathrm{He}$ placed some polenta in a saturated atmosphere at $21^{\circ}$ Reamur. In 
eight hours purplish spots were observable, and within twenty-four hours the entire surface was covered. The results of this experiment were published in Gazetta privilegiata, Venice, Aug. 24, 1819. He observed further that a bit of the reddened polenta placed in contact with freshly prepared polenta caused the latter to redden more quickly. He concluded it to be due to the "seeds" of some microscopic fungus present in the air.

\section{He says}

J'examinai aussi les taches purpurines de la polenta de mais avec le microscope, et, j'apercus un agrégat de très-petites vésicules hémisphériques, couvertes d'une pellicule mince, un peu luisante, et parsemée de petits points d'une couleur pourpre si foncée, qu'elle paraissait presque noire. J'ai jugé que des points étaient les sporules ou étaient placées les semences qui reproduisent l'espèce. Aprês avoir fait l'examen de ce cryptogame, il me sembla ne pouvoir le classer avec justesse dans aucun des genres alors connus; c'est pourquoi j'en établis un nouveau et je l'appelai Serratia, du nom d'un illustre Italien, en y joignant les phrases génériques et spécifiques qui suivent: Funguli acaules, hemispherici, capsulis contortis. S. marescens. Vesicula tenuissima, latice primo roseo, dehinc rubro repleta.

(Breed in a personal communication states that "contortis" is a misprint for "confertis," and "marescens" for "marcescens.").

Bizio found the color of dried reddened polenta was insoluble in water, and very soluble in alcohol. By use of mordants, it will dye silk and linen, but the color fades prompty in direct sunlight. A summary of his work was published in 1827 in the first volume of his Opuscoli chemici-fisici.

In 1844 Bizio called attention to the report of a French commission to the Minister of War relating to discoloration of war bread.

What is commonly regarded as the same organism was named Zaogalactina imetropha Sette 1824, Monas prodigiosa Ehrenberg 1848, Palmella prodigiosa Montagne, Bacteridium prodigiosum Schröter 1872, Micrococcus prodigiosus Cohn 1872, Bacillus imetrophus Trevisan 1887, and Bacillus marcescens De Toni and Trevisan 1889.

Pfeiffer (1887) ascribes the genus to Bergamaschi (1822).

Vuillemin (1913, p. 521) concludes that the genus name Serratia should be revived for the rod shaped organisms that have diffuse flagella. He states that the characters as described by Bizio have no generic value. However, inasmuch as the genus Bacillus had been "vulgarized" by bacteriologists he proposed that Serratia be made a genus conservandum with the type species Serratia subtilis. 
Buchanan (1918, p. 51) has used this as a designation for the red rod-shaped bacteria in the following description.

Cells rod-shaped, without spores. Motile by means of peritrichous flagella or non-motile. Gram stain variable. Aërobic, producing a red or pink pigment, a lipochrome. Possibly closely related yellow and orange lipochrome-forming bacteria should be included here as woll.

The type species is Serratia marcescens Bizio, the organism usually termed Bacillus prodigiosus.

Erythrobacillus Fortineau (q.v.) was proposed by Winslow et al. (1917, 1920, p. 209) as a substitute.

Bergey et al. (1923, p. 85) include Serratia as the first genus of the tribe Chromobactereae with the description:

Small, aërobic rods, producing a red or pink pigment, usually a lipochrome. Gram-negative. Motile or non-motile.

The type species is Serratia marcescens Bizio.

Shigella. A generic name proposed by Castellani and Chalmers (1918, p. 934) for the third genus of the tribe Ebertheae, with the following description:

Ebertheae non-motile, partially fermenting glucose with the production of acid, but no gas; lactose not fermented. Milk not clotted.

Types. Shigella dysenteriae (Kruse, 1899).

It is also used by the same authors $(1919$, p. 937$)$ as the name of a subgenus of the genus Shigella to include those types which do not ferment mannitol.

Siderocapsa. A generic name proposed by Molisch (1909, p. 29) for an organism from the surfaces of immersed leaves of aquatic plants showing iron stains. The organisms are epiphytic on parts of plants in fresh water, such as the older stems and leaves of Elodea, the under side of leaves of Nymphaea, etc., which show a brownish crust. Under a magnification of 300 to 500 diameters the surface is seen to be made up of irregularly circular areas, with a lighter center. The bacteria are invisible in direct light, and can be differentiated by staining only with difficulty. He found colorless "Schiff" solution best. When the areas are immersed for a time in this reagent the iron oxid area colors up red-violet and the bacteria of the central area are recognizable. In the species Siderocapsa treubii there occur one, two or occasionally as many as six cells. The diameter of the "rusted" area was 5 to $18 \mu$, of the clear central area 1.8 to $3.6 \mu$, and of the coccus 0.4 to $0.6 \mu$. 
In Siderocapsa major the cells are coccus-like short rods united into colonies of 2 to 100 cells 5 to $28 \mu$ in diameter. The cells are 0.7 to $1.8 \mu$ long.

The organism does not appear to have been grown in culture media.

Siderocapsa is probably a valid generic designation, with Siderocapsa treubii Molisch as the type.

Siderocapseae. A name given by Buchanan (1917, p. 615) to the third tribe of the Coccaceae with the description:

Cells spherical or ovoid, non-motile, epiphytic upon the leaves and other parts of water plants. Have not been cultivated. Thick capsules enclosing the cells become encrusted with iron oxid.

One genus only has been described, Siderocapsa.

Siphonomyxa. A generic name used by Billroth (1874, p. 27) for his Siphonomyxa Nosocomii Viennensis an organism, apparently one of the iron bacteria found in a tap water. He regarded it as a pleomorphic organism resembling his Coccobacteria septica, but distinct from it. The name would appear to be invalid, as it is used in a trinomial, and the description does not make it possible to recognize the original.

Solidococcus. A generic name proposed by Orla-Jensen (1909, p. 332) to include cocci which do not as a rule require organic nitrogen, and which belong to the family Luminibacteriaceae of the order Cephalotrichinae, and do not liquefy gelatin.

The generic name is probably a synonym of Micrococcus.

Solidovibrio. A generic name proposed by Orla-Jensen (1909, p. 333 ) to include short spiral organisms which do not as a rule require organic nitrogen, which often reduce sulfates to hydrogen sulfid, and which do not liquefy gelatin. The description is as follows:

Als Schraubenformen, die sich aus der Gattung Denitromonas entwickelt haben, rechne ich die erwähnten sulfatreduzierende Vibrionen; denn das Reduktionsvermögen von Nitrat und von Sulfat müssen ja verwandte Eigenschaften sein. Die weitere Entwickelung dieser bereits spirillenähnlichen Vibrionen, Solidovibrio, führt zu den echten (schwefelfreien) Spirillen. Ein wesentlicher Unterschied zwischen den monotrichen Vibrionen und den lophotrichen Spirillen existiert nicht; denn es ist selbstverständlich, dasz, während dem die kürzeren Bakterien mit unvollständigen Schraubengang sich mit einer einzigen Geissel als Propell begnügen können, so müssen die längeren, stärker gewundenen Formen einen ganzen Büschel haben. Die Gattungen Solidovibrio and Spirillum wollen wir zur Familie Reducibacteriaceae sammeln.

The generic name is probably to be regarded as a synonym of $V i b$ rio (q.v.). 
Sphaerobacteria. A group name used by Cohn (1872, p. 146) to include all the spherical bacteria. It is equivalent to the modern name Coccaceae.

This name was also used by Hansgirg (1888, p. 266) for the third order of Bacteria, including one family only, Mycococcaceae.

Sphaerobacteries. A name used by Maggi (1886, p. 81) for his second order of bacteria, to include the genera Micrococcus and Leuconostoc, but without description.

Sphaerococcus. Agardh (1821, p. 227) used this as a generic algal name with the following description: "Char. essent. Functus uniformis: capsulae glomerulum seminum minutissorium sphaericum includentes." On the following pages over 100 species are listed. J. S. Agardh (1842, p. 154) says "Sphaerococcus Ag. Grev. Alg. Butt., p. 137."

This genus of algae was recognized by Kuetzing (1843, p. 408) with the type species Sphaerococcus confervoides. In (1849, p. 772) he included this in his family Sphaerococceae. This name was used by Marpmann (1885, p. 121) as the generic designation of a coccus capable of souring milk. The name Sphaerococcus lactis acidi was given to this organism. This genus name has apparently not been used by other writers. It was rejected by Erwin F. Smith (1905, p. 174). It is invalid for bacteria.

Sphaerokokkus. An aberrant spelling of Sphaerococcus, Marpmann used by Eisenberg (1891, p. 50).

Sphaerotilus. This genus was described by Kützing (1833, p. 385), with the species Sph. natans. Later the same author included this genus in his Phycologia generalis (1843, p. 150) naming three species Sph. natans, Sph. thermalis and Sph. lacteus. The generic description is "Stratum floccosum ex globulis minutissimis aggregatis compositum." The description of Sphaerotilus natans is S. natans, fuscescens; floccis fugacissimis."

Bildet sich an Frühlings-und Sommertagen auf stillen Gewässern fast überall. Diese Alge stellt anfangs ein feines bräunliches Häutchen dar, welches durch den kleinen Wellenschlag des Wassers zusammengeschoben und an einzelnen Stellen wieder in Gestalt einzelner Flocken denselben und gängen sich häufig an hervorragende Gegenstände, ohne hängen sich häufig an hervorragende Gegenstände, ohne ihren Zusammenhang zu verlieren. Sie bilden sich besonders bei ruhigem, warmen Wetter und oft so schnell, dass sie in wenigen Tagen einen ganzen Teich bedecken. Diese Decke besitzt eine schmutzige Farne, und wird auch wolhaufig fur blossen Schmutz gehalten, aber man erkennt unter dem Mikroskope sehr feine organischekügelchen, die einen geringen Zusammenhang untereinander haben. 
Indessen kommt es allerdings auch vor, dass fremdartige kleine Korper, besonders Diatomeen sich ansetzen und von den Flocken eingeschlossen werden. So waren unter den Exemplaren, die ich in der Linnaea abgebildet habe, eine Menge kleiner Kalktheilchen, daher die mikroskopische Zeichnung nicht genau und hiernach zu berichtigen ist.

In 1849 (p. 147) two other species, Sph. ochraceus and Sph. glaucus were named.

Apparently the same organism was described under the name Cladothrix dichotoma by Cohn (1875, p. 185). Eidam (1876, p. 133) used the generic name Sphaerotilus. Winter (1880, p.62) gives the following diagnosis:

Zellen rundlich-eckig oder länglich, an den Ecken abgerundet, in grosser Zahl reiheniveise in einer farblosen Schleimscheide vereinigt zu langen Fäden, die dicht zopfartig verflochten und verwirt schwimmende. Flocken bilden. Vermehrung durch sich isolirende, vegetative Zellen, die durch fortgestzte Theilung neue Faden erzeugen. Fortpflanzung durch Sporen, die endogen in den vegetativen Zellen sich bilden.

Grove $(1884$, p. 53) uses the same description. It was regarded by Flügge (1886) as a doubtful genus. The generic description was revised by Schröter (1886, p. 173) and included as a valid genus in "Die Pilze Schlesiens."

De Toni and Trevisan (1889, p. 926) recognize both Cladothrix and Sphaerotilus. The description given of the latter follows:

Filamenta primitus affixa, basi ab apice superiori distincta, mitio simplicia, dein Cladotricis more pseudoramosa a basi ad apicem subaequiliata articulata, vagina gelatinosa obducta, in fasciculos crassos floccosus varie divisos consociata. Multiplicatio fragmentis filamentorum secedentibus, quae filamenta et fasciculos, novos efficiunt. Arthrosporae numerosissimae, articulorum divisiones in tres directiones ortae.

The genus was also recognized by 'Ludwig (1892). Migula (1909, p. 1035) redescribed the genus. This description as given by Smith (1905, p. 162) is as follows:

Cells cylindric, enveloped in sheaths, forming dichtomously branched threads with no differentiation into base and apex. Multiplication by means of conidia which swarm out of the sheath, attach themselves anywhere, and immediately grow out into new threads. The conidia possess a tuft of flagella inserted sidewise under one pole.

It should be noted that this same author (Smith 1905) includes Sphaerotilus in a list of generic names to be abandoned. Orla-Jensen 
(1909, p. 331) regards Sphaerotilus as a synonym of Cladothrix. Molisch (1910, p. 18) retains Cladothrix as the correct generic designation. He says:

Migula stellt Cladothrix zu Sphaerotilus. Ich habe vorläufig davon Abstand genommen, weil Bau und Entwickelung der letzteren Gattung noch mangelhaft bekannt sind und weil sich nach Gewinnung von Reinkulturen der Sphaerotilus natans und nach einen genaueren Studium dieser vielleicht doch herausstellen dürfte, dass die Aufstellung der Gattung Cladothrix neben Sphaerotilus berechtigt ist. Migula sagt, die Gattung Sphaerotilus erzeuge dichotom verzweigte Fäden ohne Gegensatz von Spitze und Basis. Aber die Fäden der Cladothrix dichotoma die er zu Sphaerotilus stellt, lassen doch deutlich Spitze und Basis unterscheiden.

The generic name Cladothrix (q.v.), has been more generally used by authors than has Sphaerotilus, although the latter term would seem to have priority.

Buchanan (1918, p. 305) gave the following description.

Attached colorless threads showing false branching, making a pseudodichotomy. Filaments consist of rod or oval cells, surrounded by a thin, firm sheath. Multiplication occurs both by non-motile and motile gonidia, the latter with a clump of flagella near one end.

Sphaerotilus natans Kuetzing is the type.

Bergey et al. (1923, p. 392) have used the same description and arrangement.

Spherobacteria. A variant spelling of Sphaerobacteria (q.v.) used by Magnin (1880, p. 71).

Spirella. A name of a genus proposed by Dubosco and Lebailly (1912, p. 835) to include the new species (type) Spirella canis. The description of the species follows.

Spirella canis resemble à une petite spiruline qui serait pourvue d'un cil à chaque pôle. Certains individus, issus sans doute d'une division transversale recente, paraissent manquer de cil à l'une des extremitiés ou n'avoir là tout au plus qu'un court prolongement. Le corps est constitué par un filament épais contourné en hélice, à pas serrés et à tours plus ou moins nombreux.

Les formes les plus communes (formes courtes) ont de 3 a 7 tours de spire. Ce sont les seules qui aient été vues par Bizzozero. Elles ont l'aspect de petites vis effilées seulement aux extrémitiés et toujours rectilignes dans leur ensemble. Il existe, en outre, dans l'estomac du chien, des formes longues ayant jusqu'à 20 tours de spire, et Regaud en figure de plus longues chez le spirille du chat. Ces longues Spirella, qui sont souvent intracellulaires (dans les canaux intracellulaires de Golgi des cellules bordantes), sont courbées en crochet, en U, en S ou de facon plus compliquée. Leur longueur, comme celle des formes précédentes, peut s'exprimer en $\mu$ par le nombre de leurs tours. Il faut compter, en plus, les cils terminaux qui mesurent de $3 \mu$ à $4 \mu$, quelle que soit la longueur du corps. 
Etant très réfringentes, les Spirella sont trìs visibits à l'éclairage orçinaire, qui permet même de voir leurs cils terminaux. Par le Giemsa, le corps se colore en bleu et montre de nombreux grains rouges distribuées en série assez régulière, souvent par couples. Le bleu de toluidine donne une coloration analogue, le corps étant bleu avec des grains rouges. Mais ceux-ci sont beaucoup moins nombreux, toujours périphériques et faisant même saillie en déformant la spire. Nul doute que ce ne soient des grains métachromatiques (volutine) tandis que certains grains rouges du Giemsa représentent peut-être la vraie chromatine.

A chaque pôle, à la base du cil, est un corpuscule chromatique très bien mis en evidence par l'argent, se colorant en rouge par le Giemsa et le Mann. C'est le granule basal découvert par Swellengrebel (1907) chez Spirillum giganteum, et comparé par Fuhrmann (1910) à un blépharoplaste.

Dans certaines Spirella, les grains rouges sont remplacés par des corpuscules nlus gros, de couleur pourpre, qui paraissent être mis en liberté par dissociation du filament. Des corpuscules pareils de Spirillum volutans sont interprétés comme spores par Amato (1909).

Edkins (1923, p. 288) has discussed a similar organism from the cat, which he terms Spirella regaudi.

Spirilina. The first genus of Bory de St. Vincent's (1826, p. 533) family Vibrionides. The organisms are without appendages, linear or worm like, opaque, coiled in a discoid spiral.

Spirillaceae. A family name probably first used by Migula (1894, p. 237). He says: "Spirillaceae Mig. Zellen schraubig gewunden oder Teile eines Schraubenumgangs darstellund. Teilung nur nach einer Richtung des Raumes nach voraufgegangener Längsstreckung." $\mathrm{He}$ included the genera Spirillum, Spirosoma, Microspira and Spirochaeta. The name was also used by Fischer $(1897$, p. 32) to include the genera Vibrio, Spirillum and Spirochaetc. This family has been quite commonly recognized with the Migula conception by bacteriologists, among them Chester (1899, p. 63), Lehmann and Neumann (1896, p. 107, 1901, p. 125), A. J. Smith (1902, p. 270), Schmidt and Weis (1902, p. 91), Kendall (1902), Fischer (1903, p. 61), Erwin F. Smith (1905, p. 161), Swellengrebel (1907, p. 581), Flügge (1908), Ellis (1909, p. 3), Frost (1911, p. 57), Benecke (1912, p. 188), Schneider (1912, p. 23).

Blanchard (1906, p. 1) makes Spirillaceae a synonym of the older name Spirobacteria, used by Cohn (1875).

Winslow et al. (Committee Soc. Am. Bact., 1917, p. 556) use the following description, including this as the fourth family of the Eubacteriales.

Cells elongate, more or less spirally curved. Cell division always transverse, never longitudinal. Cells non-flexuous. Usually without endospores. As a 
rule motile by means of polar flagella, sometimes non-motile. Typically water forms, though some species are intestinal parasites.

Buchanan (1918, p. 175) and Bergey et al. (1923, p. 97) used this designation for the third family of the Eubacteriales, including the genera Vibrio, Spirillum and Paraspirillum. Castellani and Chalmers (1919, p. 924) include this as the third family of the Eubacteriales with the genera Spirosoma, Vibrio and Spirillum.

Spirilleae. The name given by De Toni and Trevisan (1889, p. 1006) to a subtribe of bacteria belonging to the tribe Bacilleae. The diagnosis given is "Baculi spiraliter torti. Endosporae." The following genera are included: Spirillum and Spiromonas.

Spirillina. A group created by Perty $(1852$, p. 179) to include the genera Spirillum and Spirochaete. The name has never come into common use.

Spirillineae. A subfamily name used by Rabenhorst (1865, p. 70) to include the following genera: Vibrio, Spirillum and Spirochaeta. The diagnosis given is:

Spirillineae (Cohn in ed). Trichomata abbreviata vel elongata flexuosa vel spiraliter torta flexibilia et mobilis, plis minus distincte articulata, nuda vel moc liquido hyalino achromatico involuta; articuli saepe leviter constricti.

Spirillobacteriaceae. A family name proposed by Orla-Jensen (1921, p. 264) in the following statement:

As to the family names of the bacteria, it will be convenient to let all of them end in -Bacteriaceae, by which it will be seen directly what is in question. If there are to be formed families of the cocci and spirilla, they must consequently be termed Coccobacteriaceae and Spirillobacteriaceae (or by the older name of Zopf, Spirobacteriaceae).

Spirilloflagellata. According to Dobell (1911, p. 536), this name was given to the group of spirochetes by Krzysztalowicz and Siedlicki (1908). They include this group among the protozoan group Mastigophora.

Spirillum. A generic name first used by Ehrenberg (1830, p. 38) to inclucle the spiral bacteria. The species named is Spirillum volutans, the Vibrio spirillum of Müller (1786).

Dujardin (1841, p. 223) gave the generic description: "Corps filiforme contourne en helice, non extensible quoique contractile." $\mathrm{He}$ described three species, S. undula, S. volutans and S. plicatile. Perty (1852, p. 179) included species descriptions of Spirillum volutans. 
Sp. undula and Sp.rufum. Davaine (1859) interpreted the genus as containing any spiral rod. Rabenhorst $(1865$, p. 72$)$ gives the following diagnosis: "Trichomata filiformia, divisione spontanea imperfecta articulata, spiraliter torta, cochleam rigidam vel cylindriformam simulantia." Cohn (1872, p. 181) also used this generic name. The organisms described all were found in stagnant water and in infusions. Cohn later (1875) included the genus in his tribe Nematogenes, and defined it to include short spiral, rigid filaments without phycochrome, free and unbranched. The generic designation was used in this sense by Luerssen $(1879$, p. 25), and Magnin (1880, p. 94). Trevisan (1879, p. 148) gives the generic description: "Somatia cylindrica, articulata, valida, abbreviata, rigida, spiraliter, torta, anfractibus paucis latis." Three species are listed, Spirillum tenue, S. undula and S. volutans. Winter (1880, p. 62) included Vibrio Mueller (Cohn) and Ophidomonas Ehrenberg as synonyms. His diagnosis reads:

Zellen cylindrisch oder schwach zusammen gedrückt, einfach bogenförmig gekrümmt order spiralig gewunden, starr, an jedem Ende mit einer Geissel (ob bei allen Arten?): Vermehrung durch Querteilung; die Tochterzellen trennen sich meist bald von einander. Mitunter kommt auch Zoogloeabilding vor. Sporenbildung änhlich wie bei Bacillus.

The same description was used by Grove (1884, p. 46).

Zopf $(1885$, p. 61) in accordance with his ideas of pleomorphism redefined the genus to include organisms which are spiral, and which consist of rods only or of rods and cocci. De Bary (1884) included in the genus the endospore-producing spiral rods. This conception was also held by Hueppe (1885). Zopf (1885) on the other hand stated that spores were lacking or unknown. Fluegge (1886) used Spirillum in a general or broad sense to include Spirochaeta, and in a more limited sense. He differentiated in the latter from the genus Vibrio because of the more pronounced and extended spirals. Schröter (1886, p. 167) followed De Bary in regarding the presence of endogenous spores as characteristic. Hueppe (1886, p. 143) agrees with Schröter.

Hansgirg (1888, p. 264) recognized this as the sole genus of his subfamily Spirobacteria. He subdivided the genus into two sections, Vibrio and Ophidomonas. De Toni and Trevisan (1889, p. 1006) give the following diagnosis: "Baculi cylindrici, spiraliter torti, plasmate uniformiter diffuso instructi. 'Sporae (endosporae) microsomae in baculis normalibus immutatis ortae." They include as synonyms Ophidomonas, Spirochaeta and Thiospirillum and list 36 species. 
Billet (1890, p. 25) included all spiral forms. Ludwig (1892) used the term to designate all stiff or rigid spiral rods. Sternberg (1892) included all curved rods and spiral filaments, whether rigid or flexible.

Migula (1894, p. 237) divided the old genus Spirillum into Spirosoma, Spirillum and Microspira. He says: "Spirillum Ehren. Zellen starr mit polaren Büscheln von 5-20 halbkreisförmig gebogenen Geisseln." The definition of Migula has been quite commonly used by bacteriologists, among others by Fischer (1897, p. 32), Mace (1897, p. 484), Chester (1899, p. 63), Migula (1897, p. 6, 1900, p. 1017), Lehmann and Neumann (1896, p. 344), 1901, p. 126), Chester (1901, p. 342), Matzuschita (1902), Kendall (1902), A. J. Smith (1902, p. 270), Fischer (1903, p. 61), Migula (1904, p. 145), E. F. Smith (1905, p. 161), Fluegge (1908), Ellis (1909, p. 6), Frost (1911, p. 59), Schneider (1912, p. 23), Löhnis (1913).

A few others have adhered to the definition that the genus Spirillum includes all spiral organisms. Among such are Hewlett (1898) and Baumgarten (1900).

Blanchard (1906, p. 1) defines the genus as follows:

Corps spiralé, à section cylindrique, non effile aux extrémités. Pas de membrane ondulante. Un ou plusieurs flagelles infléchis en combe réguliére, soit aux deux entrémités, soit seulement à l'une d'elles. Formation de spores endogënes constatée chez nombre d'espèces. Organismes de taille relativement considérable, se cultivant assez aisément sur divers milleux usités en bacteriologie.

He lists seventeen species that had been described to 1906.

Orla-Jensen (1909, p. 333) includes this genus of elongated spiral forms as the second in his family Reducibacteriaceae, order Cephalotrichinae. He states that as a rule combined organic nitrogen is not necessary, that in general free oxygen is not required and that the organisms are active reducers.

Vuillemin (1913, p. 519) has proposed that Spirillum Ehrenberg be made a genus conservandum with the type species Spirillum undula (Müller) Ehrenberg. The genus is defined as made up of bacteria with spiral body, polar flagella and an undulating motion.

Winslow et al. (Committee Soc. Am. Bact., 1917, p. 557) give the following generic description.

Cells rigid rods of various thicknesses, length, and pitch of the spiral, forming either long screws or portions of a turn. Cells motile by means of a tuft of polar flagella (5 to 20 ) which are mostly half circular, rarely wavy-bent. These flagella occur on one or both poles; their number varies greatly and is difficult to determine, since in stained preparations several are often united into a common strand. 
Endospore formation has been reported in some species. Habitat; water or putrid infusions.

Buchanan (1918, p. 179) includes the genus as the second in the family Spirillaceae with the description:

Cells definitely spiral, not enlarged at center, motile by means of 5 to 20 polar flagella, or non-motile. Not readily cultivated in ordinary culture media.

The type species is Spirillum undula (Müller) Ehrenberg.

This designation of type was also accepted by Winslow et al. (Com. Soc. Am. Bact., 1920, p. 204) and Bergey et al. (1923, p. 82).

It should be noted that from the standpoint of zoölogical nomenclature, Spirillum was invalid as a generic designation for a protozoan. Stiles (1905, p. 34) says:

Judged from the zoölogical point of view, Vibrio spirillum is the type species by absolute tautonymy, but the zoölogical name Spirillum, 1830 was a stillborn homonyn, having been used by Oken, 1815, for a genus of polychaete worms. It is not the function of the zoollogical code to determine the names in bacteriology, but it is undoubtedly not the most wise or farseeing policy for either zoölogists or botanists (including bacteriologists) to accept unnecessarily a generic name for organisms so near the border line when that name is a homonym in either zoölogy or botany; should further investigations again bring bacteriology into zoölogy, the generic names would come under the zoological code, and in this case Spiril lum, 1830 , would be rejected. If Spirillum is retained in bacteriology, consistency calls for the rejection of the name Spirillum volutans Ehrenberg in favor of Spirillum spirillum (Müller).

Stiles is in error in holding that the type species should be called Spirillum spirillum for Article 55 of the Brussel's Code reads "Specific names must also be rejected . . . when they merely repeat the generic name." The opposite is true in zoölogy.

The question whether the fact that Spirillum was a homonym when first given by Ehrenberg should invalidate its use for Ehrenberg's types in bacteriology in one which is not adequately answered by the botanical code. Its general acceptance by bacteriologists would argue against its being discarded.

The generic name Spirillum may probably be regarded as valid.

Probably the designation of Spirillum volutans Ehr. as the type by Stiles (1905) is valid, and has priority over the designation of Spirillum undula Ehr. by Buchanan, Vuillemin and the Committee.

Spirobacillus. A generic name proposed by Metschnikoff (1889, p. 61) for an organism Spirobacillus cienkowskii. This organism was found in Daphnia producing a disease which colored this entomostracan 
red. In the younger stages the organism appeared as a long oval, like certain yeasts, but not more than 3 to $5 \mu$. Later the cells become longer, narrower, rod-shaped, and finally spiral, similar to Spirillum volutans. These spirals break up again into short bent segments, somewhat more slender. Small ovoid bodies often develop. On the death of the infected animal very numerous, small, strongly bent, motile rods, which become Spiromonas-like, escape. At the ends of these cells there develop strongly refractive swellings which were regarded as spores.

De Toni and Trevisan (1889, p. 1019) have included this organism in their genus Pacinia. Their description of the organism reads:

Baculis prima aetate magnis ellipsoideis, mox rectis, dein incurvis cylindricis, apice rotundatis, demum in filamenta pseudospiralia consociatis; filamentis postremo in baculos commae vel litterae $\mathrm{S}$ administar incurvis, minutissimos, post Daphniae mortem uno apice arthrosporiferos solutis. In ullo medio nutritivo huiusque adhibito non crescit.

Certes (1889) described a giant spirillum as Spirobacillus gigas (according to Zettnow, 1903, p. 383) and later studied it in greater detail $(1900$, p. 714). Zettnow also gives a description of this species.

Blanchard (1906, p. 1) emended the diagnosis somewhat. He states:

Bactériacées de forme spiralée atteignant de grandes dimensions. Spores endogénes. Pas de flagelles polaires, mais flagelles disposés, en petit nombre, sur les cotés de chaque segment, comme ches les Bacillus. Deux espèces acutellement connues. Sp. cienkovskyi Metschnikoff 1889. Sp. gigas Certes 1889.

The genus is rejected as invalid by Erwin F. Smith (1905, p. 174) and by Vuillemin (1913, p. 521), but is recognized by Meyer (1912, p. 3).

It is probably that this is a valid generic designation, but its exact position and nomenclatural status is uncertain.

Spirobacteria. The fourth tribe of bacteria recognized by Cohn $(1872$, p. 180) as including the spiral or bent forms. Hansgirg (1888, p. 264) used this for his first subfamily of his family Bacteriaceae. Two genera were included, Spirochaete and Spirillum. The same designation was also used by Blanchard $(1906$, p. 1) to include the four genera Spirosoma, Vibrio, Spirobacillus and Spirillum. The diagnosis given is:

Bactéries plus ou moins incurvees en vis, l'incurvation ne formant dans d'autres cas des tours de spire plus ou moins nombreux. Organisms peu ou pas flexibles se multipliant par division transversale. Formation de spores endogènes constatee dans nombre d'espèces. 
Spirobacteriaceae. A name for a "Gattung" used by Hueppe (1886, p. 143) with the spelling Spirobakteriaceen to include spiral organisms which produce endogenous spores. Two "subgenera" are included, Vibrio, and Spirillum. Later (1891, p. 30) he included those forms which produce short spirals, which may develop also into longer spirals.

Orla-Jensen (1921, p. 264) states: "If there are to be formed families of the cocci and spirilla, they must consequently be termed Coccobacteriaceae and Spirillobacteriaceae (or by the older name of Zopf, Spirobacteriaceae)."

Spirobacterium. Klein (1885, p. 37) uses this term apparently as a synonym of Spirillum but without description. Probably invalid.

Spirobakteriaceen. A name used by Hueppe to designate the spiral bacteria which produce endogenous spores. Two "subgenera" are included. Vibrio and Spirillum. A variant of Spirobacteriaceae (q.v.).

Spirobazillus. A variant of Spirobacillus, q.v. used by Meyer (1912, p. 3). The generic description follows:

Gattung Spirobazillus. (Siehe Zettnow, Festschrift zum 50. Geburtstage von Robert Koch, 1903, S. 383). Peritriche Begeisselung der Oidien. Zellen sich nur quer zur Richtung des Längswachstums teilend. Oidien fast kreisförmig gekrümmt. Zellfäden lange steile, dicht gewundene Spiralen bildend. Sporen anscheinend wie bei Bacillus.

Spirochaeta. A genus of microörganisms first described by Ehrenberg $(1833$, p. 313), and later by the same author (1838, p. 83), as containing very slender, spiral, forms, actively motile, the cells very much elongated and the spirals consisting of numerous turns. The following diagnosis was used:

Schlangenthierchen. Familie der Zetterthierchen, Vibrionia, Character generis: Polygastricum? Anenterum, Gymnicum, nec loricatum. Corpus filiforme, contractione non incrassatum, sed flexuosum, sponte in multas partes transverse dividuum? in spiram angustam, filiformen, plicatilem, contortum."

The species Spirochaeta plicatilis from stagnant water was described as "S. corpore spirali plicatilique, tenuissimo spirae anfractibus, ipso corpore vix duplo latoribus, augustissimus numerosissimus."

Dujardin (1841, p. 225) united Spirochaeta to Spirillum, but used the spelling Spirochoeta.

The name Spirochaeta was applied to a genus of Compositae by Turczaninow (1851, p. 166). This is usually regarded as a synonym 
of Elephantopus. Baker (1902, p. 53) insists that the single species described is worthy of generic recognition, and uses Spirochaeta. These uses in botany are of course invalidated by the earlier use of Spirochaeta by Ehrenberg, if this organism is to be included among plants. The species Spirochaeta plicatilis was recognized by Perty (1852, p. 179).

Rabenhorst (1865, p. 73) states: "Genus a Spirillo vix discerndum." The single species is described as: "Sp. longissima, distincte articulata anfractibus numerosissimis."

Cohn (1872, p. 180) changed the spelling to Spirochaete, (q.v.) a form commonly used at present among bacteriologists. He says: "Spirochaete mit flexiler und langer enggewundener Schraube." $\mathrm{He}$ discusses his observations of $S p$. plicatilis. Later (1875, p. 196) he named the slender spiral organism found in the blood in cases of relapsing fever, Spirochaete obermeieri. He included the genus in the tribe Nematogenes, and described it as having long filaments, spiral, flexible, without phycochrome, unbranched and free. Trevisan $(1879$, p. 148) gives the following description: "Somatia cylindrica, distincte articulata, valida, elongata flexilia, spiraliter torta, anfractibus numerosis densis." This genus is included in the subtribe Euvibrionieae. Three species are included, Spirochaete plicatilis, S. obermeieri of relapsing fever, and $S$. cohnii from the tartar of teeth. Luerssen $(1879$, p. 25$)$, Winter $(1880$, p. 60$)$, Grove $(1884$, p. 43$)$, Van Tieghem (1884) and Schröter (1886, p. 168) followed closely the diagnosis of Cohn. Cohn (1883, p. 198) described a new species from gelatinous growths from wine cellars Spirochaete Schroeterii.

Hueppe (1885) differentiated Spirochaeta from Spirillum in that the former had no endospores. Fluegge (1886) combined the genus with Spirillum. Hansgirg (1888, p. 264) included the genus in his subfamily Spirobacteria, with the species Spirochaete ferruginea (Ehrb.) Hansgirg.

De Toni and Trevisan (1889, p. 1006) regard Spirochaete as a section of the genus Spirillum. They say "Spirilli regulariter spirales flexiles, valde elongati, spiris primoriis et secondariis instructi." Eleven species are included in this section.

Billet (1890, p. 24) followed Cohn in his definition, as did Sternberg (1892, p. 18), Ludwig (1892) and Fischer (1897, p. 32). Migula (1894, p. 237) says "Spirochaete Ehrenb: Zellen schlangenartig biegsam. Bewegungsorgane unbekannt, vielleicht eine undulierende Membran 
(Z. B. Spirochaete plicatilis Ehrenb.)." Migula (1897, p. 87) and later (1900, p. 1029) revised the diagnosis as follows:

Zellen schraubig gewunden, dünn, aber meist verhaltnissmassig lang, beweglich und flexil, schlangenartig sich windend, aber auch schraubig sich fortbewegend. Bewegungsorgane bisher unbekannt. Endosporenbildung nicht beobachtet. Der Algengattung Spirulina nahe verwandt, aber farblos und nicht in einzelne Zellen geghedert.

This description has been adopted by many writers, among them Chester (1897, p. 63), Chester (1901, p. 347), Lehmann and Neumann (1896, p. 348, 1901, p. 126), Kendall (1902), Matzuschita (1902), A. J. Smith (1902, p. 270), Fischer (1903, p. 61), Migula and (1904, p. 145).

Stiles (1905, p. 94) called attention to the fact that this generic name is usually misspelled, and that the original and correct spelling is Spirochaeta. This same point was later brought out by Blanchard (1906, p. 2) who showed the spelling Spirochaete to be incorrect. $\mathrm{He}$ recognizes sixteen species.

Among the later writers who have followed Migula in his treatment of this genus may be mentioned E. F. Smith (1905, p. 161), Ellis (1909, p. 7), Orla-Jensen (1909. p. 334), Frost (1911, p. 59), Bosanquet (1911, p. 69) and Löhnis (1913).

Much interest was centered in the group of flexuous spiral organisms after the discovery of the form causing syphilis by Schraudinn. Difference of opinion was at once expressed as to the propriety of including them with the bacteria. Vuillemin (1905) proposed the generic name Spironema (q.v.) which was found to be invalid. Later in the same year Schaudinn (1905) proposed Treponema (q.v.) and Stiles and Pfender (1905) Microspironema. •

Blanchard (1906, p. 2) places the genus Spirochaeta with the protozoa. He gives the following description:

Corps excessivement grèle, spiralé, aplati, l'ectoplasme s'étaltant en une étroite membrane ondulante qui entoure en spirale tout le corps. Pas de flagelles; pas de spores endogénes. Un noyau trés allonge, filiforme, occupant l'axe du corps, avec gravis de chromatine distribués à sa surface. La multiplication se fait, selon toute apperence, par division longitudinale. La culture de ces organismes ne reussit sur aucun des milieux usités en bacteriologie.

He regards this genus as related to the other flagellates through the genera Treponema and Trypanosoma. He lists sixteen species as belonging to this genus. 
Thesing (1906, p. 351) takes exception to placing the spirochetes among the protozoa, holding them to be typical bacteria, and Spirochaeta to include all.

Swellengrebel (1907, p. 582) gave the following diagnosis:

Cellules san cils, avec appendice periplastique bien developpe et souvent de structure alveolaire. Quelquefois, il y a une bande de myonemes dans l'appendice. Type Spirochaeta plicatilis Ehrenberg.

It will be noted that he excludes from the genus the forms parasitic in higher animals. The genus Spirochaeta together with Treponema and Borrelia are included together under the subfamily Spirochaetaceae of the family Spirillaceae. He regarded the organisms as belonging definitely with the bacteria.

Dobell (1910, p. 536) restricts the generic designation Spirochaeta to include only the groups closely resembling the original Spirochaeta plicatilis Ehrenberg. The genus therefore includes only the free living water or marine forms, all parasitic types being excluded.

Zuelzer (1911, p. 51) after a careful study of Spirochaeta plicatilis came to the same conclusion as Dobell-Spirochaeta includes the fresh water and free living spirochetes; Cristispira, the mussel spirochetes; and Treponema, the group of pathogenic forms. She defines the genus Spirochaeta to include the strict anaërobic mesosaprophilic organisms, living usually in the presence of $\mathrm{H}_{2} \mathrm{~S}$ and growing well in the presence of Beggiatoa. The organism is actively flexible, the protoplasm being spirally wound around a straight elastic axis filament. In the plasma spiral there regularly occur volutin granules. The plasma is naked, that is, there is no differentiation of membrane or pariplast. The cell is circular in cross section. The organism multiplies by transverse fission. Three new species of Spirochaeta were described by this author.

Bosanquet (1911, p. 69) includes all spirochaetes in the genus Spirochaeta. This author is inclined to include these under the heading of bacteria. Heim (1911, p. 252) lists the pathogenic forms under the generic name Spirochaete with the species S. obermeierii.

Doflein (1911, third edition, p. 351) used the generic name Spirochaeta in two senses; in a limited sense, to include all slender spiral organisms, and in a somewhat narrower sense, as a term to include fresh water spirals and their near relatives, differentiating the genera Cristispira and Treponema.

Gross (1911, p. 109) has accepted the definition of Spirochaeta used by Zuelzer and insisted upon the necessity for another generic name 
for the organism specific for syphilis. The same conclusion was reached by Gleitmann (1913, p. 31), but he stated that there is as yet no uniformity in the nomenclature of these forms.

Gonder (1914, p. 674) gives the following diagnosis, agreeing in essential points with Zuelzer:

Charakterisiert ist demnach die Gattung Spirochaeta wir folgt: (stark aktiv flexibel; ein in echten Spiralen stark gewundener, nackter, einlichen Achsenstab mit Volutinkörnern in den Plasmaspiralen; Fortpflanzung durch echte Querteilung.)

It would seem that there is sufficient evidence to show the advisability of including only those forms closely related to Spirochaeta plicatilis in the genus Spirochaeta.

Winslow et al. (Com. Soc. Am. Bact., 1917, p. 563) give the generic diagnosis:

Non-parasitic, with flexible undulating body and with or without flagelliform tapering ends. Cornmon in sewage and foul waters.

The type species is Spirochaeta plicatilis Ehrenberg.

Buchanan (1918, p. 543) states:

Slender, spiral cells, living free, usually in water containing hydrogen sulphide, actively motile, flexuous. Flagella unknown. Anaërobic. Protoplasm is spirally wound around a flexible or elastic axis filament. Volutin granules regularly present in the plasma. No differentiation of exterior. Cell circular in cross section.

The type species is Spirochaeta plicatilis Ehrenberg.

The genus is also recognized in this limited sense by Castellani and Chalmers (1919, p. 436) and by Bergey et al. (1923, p. 419).

Spirochaetacea. An order of flagellates named by Fantham (1908) according to Castellani and Chalmers $(1919$, p. 435) who give the following description:

Plasmodromata, generally parasitic, in form narrow, wavy, and thread-like, with or without an undulating membrane. The cytoplasm is divided into endoplasm and ectoplasm, and is bounded by a flexible, chitinous periplast. The nucleus consists of a spiral achromatic filament, on which are arranged transverse bars or rodlets of deeply staining chromatin.

Two families are included, Spirochaetidae and Treponemidae.

Spirochaetaceae. A subfamily name used by Swellengrebel (1907, p. 581) under the family Spirillaceae. This author includes in the 
subfamily those spiral bacteria in which the cells are flexible. Three genera are recognized: Spirochaeta, Treponema, and Borrelia. As a family name this is used by Schneider (1912, p. 23), coördinate with six other families of bacteria. It is defined to include long, unicellular, flexible, spirally twisted threads without flagella. One genus only, Spirochaeta, is recognized.

Winslow et al. (Com. Soc. Am. Bact., 1917, p. 562) regard this as a group intermediate between the bacteria and the protozoa with the following description:

Free living or parasitic spirilliform organisms with or without flagella, with undulating or rigid spiral twists. Reproduction by transverse division and by "coccoid bodies," the equivalent of spores.

Spirochaetales. The name proposed by Buchanan (1918, p. 542) for the sixth order of the Schizomycetes with the description:

Protozoan-like in many characters. Cells usually relatively slender flexuous spirals: multiplication of cells apparently by longitudinal division in some types, by transverse division in others, or both.

One family is recognized, Spirochaetaceae.

Spirochaete. A rariant of the spelling of Spirochaeta Ehrenberg first used by Cohn $(1872$, p. 180). It was later used by Luerssen (1879, p. 25), Trevisan (1879, p. 148), Van Tieghem (1884), Schroeter (1886, p. 168), De Toni and Trevisan (1889, p. 1006), Billet (1890, p. 24), Sternberg (1892, p. 18), Ludwig (1892), Fischer (1897, p. 32), Migula (1897, p. 47), Lehmann and Neumann (1901, p. 126), Kendall (1902, p. 484), Matzuschita (1902), Fischer (1903, p. 61), Migula (1904, p. 145), Thesing (1906, p. 351), Ellis (1909, p. 7), Heim (1911, p. 252), and by many writers in the modern literature of medical bacteriology. Attention has been drawn to the fact that this form is incorrect by Stiles (1905, p. 94) and by Blanchard (1906).

Spirochaetidae. A family (zoölogical) name ascribed to Ehrenberg 1833 by Castellani and Chalmers (1919, p. 436). They state "Spirochaetacea with an undulating membrane. Body may be ribbon shaped on transverse section." The genera included are Spirochaeta, Cristispira, Saprospira, Pseudospira, and Spiroschaudinnia.

Spirochaetoidea. A name used for a group of spiral organisms by Dobell (1911, p. 536). Three genera are recognized: Spirochaeta, Treponema and Cristispira. He says:

The organisms commonly called Spirochaetes may be conveniently collected into a single group, for which I propose the name Spirochaetoidea. This group 
comprises three different sets of forms, which may be correspondingly classified in three different genera: Spirochaeta, Treponema, Cristispira. These three groups of organisms, whilst showing certain resemblances to one another, possess no definite relations with Protozoa, Bacteria, or Cyanophyceae. The Spirochaetoidea should therefore be regarded-for the present-as a group of Protista which stands apart.

Spirochetaceae. A variant spelling of Spirochaetaceae (q.v.) used by Schneider.

Spirochoeta. A spelling of Spirochaeta used by Dujardin (1841) according to Stiles (1905) and occasionally used by medical writers.

Spirodiscus. A generic name used by Ehrenberg (1828, p. 34) as the fifth genus of the Vibrionen. One species, $S$. fulvus, was described from a mountain stream, growing among Conferva. The organism is described as forming a flat spiral. Its relationship to the bacteria is very doubtful. It apparently has not been observed since the first description. Ehrenberg states, "Animale e familia Vibrioniorum, divisione spontania imperfecta (et obliqua?) in catenam filiformen S. cochleam rigidam disciformen accrescens."

Diujardin (1841, p. 226) regarded this as a doubtful genus.

Perty (1852, p. 179) questioned the location or identification of this genus in the following statement:

Hier würde sich noch die Sippe Spirodiscus E. anschliessen, da die einzige bekannte Species ( $S p$. fulvus E. p. 86, t. 5, f. 1) nicht etwa eine Pilzspore ist, bei welchen öfters Bewegung wahrgenommen wird.

Migula (1897, I, p. 6) states that perhaps this form belongs with the sulphur spirilla, but that it is in a high degree doubtful whether it should be regarded as belonging to the bacteria. The genus may be regarded as of questionable value.

Spiromonas. A genus described by Perty (1852, p. 171). The organism was described as related to the spirilla, but with the cells flat and band shaped. It multiplies through transverse fission. One species is included, Spiromonas volubilis.

The genus was recognized by Trevisan (1879, p. 138) with the description "Somatia compressa ligammiformia, valida, abbreviata, spiralita torta." It was included in his subtribe Euvibrionieae. Winter $(1884$, p. 62) gave the following generic description: "Zellen "blattartig" (flach) zusammengrdrückt, um eine ideale Achse der länge nach gewunden. Vermehrung durch Quertheilung." 
The description given by Winter of S. volubilis, is as follows:

Farblos, durchsichtig, glatt, ohne irgend auffallende Differenzirung, Bewegung ziemlich schnell unter rascher Drehung um die Achse, um welche der blattförmige Körper gewunden ist. Körper manchmal sehr wenig gewunden, nie mehr als einen Umgang bildend.

The second species S. cohnii was described by Warming (1876, p. 370). Both species are recognized by De Toni and Trevisan (1889, p. 1015).

Migula (1897, p. 62) states that the morphology of this organism is so poorly understood that it is possible that it should not be included among the bacteria, but rather among the flagellates. Erwin F. Simith (1905, p. 162) includes Spiromonas in his list of doubtful genera.

Orla-Jensen (1921, p. 269) independently proposed this as generic designation in the following statement.

Certainly the lophotrichic spirilla, both in regard to their morphological and to their biological properties, form a natural group. This thoroughly justifies the setting up of a genus, Spirillum, or better Spiromonas, a new designation, which would also make it possible to incorporate nearly related monotrichic species in this group

In this sense the genus is invalid.

The nomenclatural status of the genus is uncertain. The type is Spiromonas volubilis Perty.

Spironema. This name was proposed by Vuillemin (1905) for the generic designation of the organism causing syphilis, which had been named Spirochaeta pallida by Schaudinn (1905). This organism was regarded by Schaudinn as a protozoan. Schaudinn (October 26, 1905) noted that Spironema was preoccupied in zoölogical nomenclature (by Spironema Meek (1864) a genus of molluses and by Spironema Klebs (1893) a genus of protozoa). He accordingly proposed the generic name Treponema. Blanchard (1906, p. 4) agrees that Spironema is invalid, as does Dobell (1911, p. 535) also.

Stiles and Pfender (December 2, 1905, p. 936), evidently unaware of the previous publication by Schaudinn of the name Treponema proposed Microspironema.

Gross (1912, p. 89) gives the following diagnosis: "Spironema Vuillemin. Spironemacea mit wellenförmig gebogenem Körper und Endfaden. Theilung mit Ausziehung einer Plasmabrücke."

Gross (1911, p. 109) contends that the organism causing syphilis belongs with the bacteria and not the protozoa, and that as Spironema 
has not been previously used in botany, Vuillemin's designation is tenable. In this he is apparently in error, for Spironema was used by Hochstetter (1842, p. 226) for a genus of Verbenaceae. This is given as a synonym of Clerodendron L. Lindley (1840) used Spironema as the name of a genus of the family Commelinaceae. Rafinesque (1836) used this name for a genus of the family Lauraceae, the name being now listed as a synonym of Cassytha $\mathrm{L}$.

It is apparent therefore from the preceding statements that Spironema is valid as a generic name for the syphilis organism neither in botany or zoölogy.

Gross (1912, p. 84) again emphasized his belief in the validity of Spironema as a bacterial genus. Gleitsmann (1913, p. 31) regarded as invalid. The name is also used by Gonder (1914, p. 683).

Bergey et al. (1923, p. 424) have recognized Spironema Vuillemin as a valid generic name with the description: "A spiral, flexible body with terminal filaments but no membrane."

Spironemacea. A group (family?) name used by Gross (1910, p. 88) to include the genera Spirochaeta, Saprospira, Cristispira and Spironema. His description is "Spironemacea nov. fam. Langgestreckte, spiralig oder wellenförmig gebogene Bacterien mit flexibilem, aus einer Wabenreihe bestehendem drehrunder Körper. Vermehrung durch Quertheilung."

A later (1911, p. 202) description reads: "Vielzellige, lang gestreckte spiralig oder wellenformig gebogene Bacterien mit flexibilem, aus einer einzigen Zellen reihe bestehendem Körper Vermehrung durch Quertheilung."

Spirophyllum. A genus of bacteria described by Ellis (1907. p. 516) with one species, S. ferrugineum. The following description (1907, p. 516) is given:

Body of the cell elongated, flattened and spirally twisted. The number of spiral turns may vary from a quarter to fifteen turns and more. The width varies from 1 to $6 \mu$. There is no definite membrane, but the edge is thickened so as to form a kind of rampart all around the cell. The ends are usually irregular, angular and unsymmetrical. The spirals may be very close or very wide apart, but the majority of the individuals have spiral lengths three or four times greater than the width. The youngest stages are coated with a thick deposit of ferric hydroxide.

The name is accepted by Orla-Jensen $(1909$, p. 331) as one of the genera of his family Trichobacteriaceae. 
Molisch (1910) states that Spirophyllum is a synonym of Gallionella and that $S$. ferrugineum is a peculiar growth form of Gallionella ferruginea.

It is probable that Spirophyllum is to be regarded as a synonym of Didymohelix.

It may be noted that this name was used by Schindler (1905, p. 82) as the name of a subsection of the section Pentapteris of the subgenus Eumyriophyllum of the genus Myriophyllum of the family Halorrhagidaceae.

Spiroschaudinnia. Sambon (August, 1907, p. 833) used this generic name for the organism which is commonly known as Spirochaeta recurrentis. He says:

Spirchaeta Ehrenberg 1843, pro parte: Spirochaete Cohn 1875 pro parte. The name Spiroschaudinnia is here proposed to designate an important group of blood parasites hitherto referred to the genus Spirochaeta.

It apparently is an invalid synonym, as Borrelia g.v. has priority.

Gleitsmann (1913, p. 31) called attention to the priority of Borrelia for this type.

The genus is recognized by Castellani and Chalmers (1919, p. 439) with the following description.

Spirochactidae parasitic in the blood and tissues of vertebrates and in some blood-sucking invertebrates.

Remarks. This genus, as we believed would happen, is now recognized by many authorities, and therefore we adopt it, though we had hesitated to do so in the previous edition.

Type species. Spiroschaudinnia recurrentis Lebert, 1874.

Morphology. This has been most carefully studied by Fantham in S. recurrentis, S. duttoni, and S. marchouxi, and he finds that they have long, narrow bodies, bent into many spirals coils, enclosed in a firm periplast, with a very tenuous membrane, which is often invisible. The nucleus consists of granules of chromatin distributed along the body.

Spirosoma. A generic name proposed by Migula (1894, p. 237). He says: "Spirosoma nov. gen. Zellen ohne Bewegungsorgane, starr. (Z. B. Spirosoma lingualis (Weibel) Mig." He included non-motile spiral bacteria. Later (1905) five poorly described species are included, among them the Myconostoc gregarium of Cohn. Two subgenera were included, Euspirosoma and Myconostoc. Chester (1899, p. 63), Migula (1900, II, p. 955), A. J. Smith (1902, p. 270), Kendall (1902), Migula (1904, p. 145), E. F. Smith (1905, p. 161), Blanchard (1906, p. 1), Ellis (1909, p. 6), Frost (1911, p. 59), Meyer $(1912$, p. 3) and others have used this name. 
It is rejected by Lehmann and Neumann (1896, p. 107). Vuillemin (1913, p. 523) proposes that Spirosoma shall be retained as a form genus.

The genus is probably to be regarded as a synonym in part of $M y$ conostoc and in part of Spirillum.

Spirothrix. Guttmann $(1880$, p. 1) in an article on recurrent fever states:

Der erste und eigentlich der einizige Autor, welcher diese Körperchen in charakteristischer Weise beschreibt, ist Bliesener, ohne aber der Neuheit dieses Befundes Erwähnung zu thun. Bliesener theilt in seiner Inauguraldisserlation (Berlin), die im Juli 1873 (also wenige Monate nach der Veröffenthlichung von Obermeyer über die Spirillen im Blute im Recurrensanfall) erschien, 3 Fälle von Febris recurrens mit, von denen 2 bei wiederholter Untersuchung des Blutes diese Körperchezeigten, nehmlich "feine, stark lichtbrechende Körnchen, einzeln oder gepaart; letztere durch einen feinen kurzen Faden verbunden, so dass sie in hantelähnlicher Form erscheinen; die Körnchen zeigen eine zitternde Bewegung mit langsam fortschreitender Locomotion." Sie fanden sich im Anfall und in der Remission. Ob zwischen ihnen und der "Spirothrix" ein engeres Verhältniss bestehe, lässt Bliesener unentschieden.

Lewis $(1879$, p. 394) says:

Since the period of its discovery in the blood by Obermeier it has been referred to under various names: Spirothrix, Protomycetum recurrentis, in Lebert's article on recurrent fever and in Ziemss' "Handbuch" of Medicine; Spirillum by Erichsen, Litten, Birch-Hirschfeld, etc.; Spirillum tenue by Naunyn; and Spirochoete Obermeieri by Cohn (fig. 15).

The nomenclatural status is uncertain. Probably a casual name.

Spirulina. A genus of blue green algae named by Turpin (1827), according to West (1904) and Tilden (1910, p. 86). Rabenhorst (1865, p. 90) gives the authority as Link (1834).

Cohn (1853, p. 125) discusses the organism named by Ehrenberg Spirochaeta plicatilis under the name Spirulina plicatilis. Rabenhorst (1865, p. 90) gives the following description: "Trichomata articulata spira spiralia, motu proprio spirali praedita, in muco matricali achromatico plus minus liquido indulantia. Propagatio adhuc ignota."

Kirchner $(1878$, p. 250) used the name Spirulina ferruginea for the iron bacterium generally known as Gallionella or Chlamydothrix ferruginea.

Hueppe (1886, p. 146) used the name in an entirely new sense to designate an "Untergattung" of his "Arthrobakteriaceen," and as a synonym of Proteus Hauser. He gave the following diagnosis: "Die 
Faden können gerade, wellig gebogen, und schraubiggewunden sein." The genus is regarded in part as a synonym of Spirillum by De Toni and Trevisan (1889, p. 1006). Sternberg (1892, p. 18) ascribed the genus to Hueppe, and defined it as follows: "The vegetative cells are sometimes rod-shaped and sometimes spiral; in suitable media they may grow out into long, straight, wavy or spiral filaments. These filaments may break up into cocci-like reproductive elements- 'arthrospores'." This bacterial genus is also accepted by Baumgarten (1900, p. 128).

The genus Spirulina is at present generally recognized by algologists as a valid genus of the blue green algae. Its use for a genus of bacteria is therefore invalid.

Sporonema. A genus of bacteria named by Perty (1852, p. 181). He gave as a diagnosis of the genus, "Ein äussert kleiner cylindrischer ungegliedeter, hohler Faden schliesst an einem Ende (selten an beiden) cin, manchmal auch zwei elliptische Körperchen (wohl Sporen) ein." The specics was named Sp. gracile. The organism was so incompletely described that it has not since been recognized with certainty. The genus has not been used by subsequent authors, as Migula (1892, 1, p. 7 ).

This name had previously been used by Desmazieres (1851, p. 319) to designate a genus of Discomyceies, now included usually underPeziza, and is invalid as a bacterial designation.

Sporosarcina. A genus of bacteria proposed by Orla-Jensen (1909, p. 477) to include spore bearing packet cocci. No species are named. He says: "Mit demselben Recht, wie man die Gattung Bacillus aufstellt, kann man auch die Gattungen Sporospirillum und Sporosarcina aufstellen, und eigentlich ist es inkonsequent, es nicht zu tun."

Sporospirillum. A name proposed by Orla-Jensen (1909, p. 340) to include the spiral bacteria which produce spores. As a rule these - forms are stated not to require organic sources of nitrogen. No species are named. He says: "Mit demselben Recht, wie man die Gattung Bacillus aufstellt, kann man auch die Gattungen Sporospirillum und Sporosarcina aufstellen, und eigentlich ist es inkonsequent, es nicht zu tun."

Staphylococcus. Ogston (1883, p. 27) first used this name to designate cocci, observed microscopically in pus, in which the cells were irregularly arranged in grape-like clusters. No species name was given by Ogston, the genus should not therefore be credited to him. Rosenbach (1884, p. 19) cultivated two organisms from pus, which he 
described and named Staphylococcus pyogenes aureus and Staph. pyogenes albus respectively, or, as they are later designated in his paper Staphylococcus aureus and Staph. albus. Fluegge (1886) defined the genus as made up of spherical or oval non-motile cells in irregular masses. Hueppe (1886) also used this name. Trevisan (1889, p. 32) included this genus as the second in the tribe Micrococcee, with the description "Spore microsome." Nine species are enumerated. De Toni and Trevisan $(1889$, p. 1072) ascribe the genus to Ogston and give the following description:

Cocci primitus globosi indivisi, aetate provecta in coccos duos biscoctiformiter geminos, latere fratrem versus plus minus complanato, utrinque ad polos isthmis filamentis tenuissimis insimul nexos, scissi, in turmas racemiformiter consociati. Endosporae microsomae in coccis normalibus obvenientes.

The genus is also recognized by Cornil and Babes (1890, p. 145). Lehmann and Neumann (1901, p. 123) state:

The genus Staphylococcus Ogston has no botanical rights, for the property of forming "grape like" clusters is possessed at times by all varieties described today as micrococci. The name Staphylococcus does not primarily designate any "new" genus. Ogston found (microscopically) two forms of micrococci in pus (without cultivating them), grape cocci and chain cocci, and designated them by the well-chosen names of Staphylococcus and Streptococcus (Billroth). Rosenbach later cultivated the varieties which Ogston had seen, and gave the name Staphylococcus to the bunched cocci, which we may today employ as the ordinary name for species of micrococci causing suppuration, and which we will use, but it must be dropped from the botanical classification.

The argument of these authors is not particularly convincing. As previously noted Rosenbach definitely and adequately described two species of the new genus. The whole question is whether these organisms are worthy of generic separation from the older genus Micrococcus.

Migula (1897) regarded Staphylococcus as a synonym of Micrococcus and not worthy of separate generic differentiation. Most authors in recent years have accepted Migula's views and have used Staphylococcus as a casual name to designate a method of cell grouping or a form genus.

The Winslows (1905) have proposed to split the old genus Staphylococcus into two genera, Aurococcus and Albococcus. If these organisms are worthy of generic rank one should be Staphylococcus and the other Albococcus.

Buchanan (1917, p. 612) emended the generic description as follows (including it as the fifth genus in the tribe Streptococceae): 
Usually parasitic, cells as a rule in irregular groups or short chains, rarely in true packets, usually Gram-positive. Growth fair to good on the surface of artificial media. Sugars as a rule fermented with acid. Gelatin commonly liquefied. Nitrates may or may not be reduced. Pigment orange or white.

It is probable that the genus should be divided upon the basis of pigment production into two genera, Staphylococcus and Albococcus, or perhaps these should rank as subgenera.

The type species is Staphylococcus aureus Rosenbach.

Winslow et al. (Committee Soc. Am. Bact., 1917, p. 558, 1920, p. 207), used practically the same description, as did Bergey et al. (1923, p. 24).

It is probable that Staphylococcus is a valid generic designation, with Staphylococcus aureus Rosenbach the type.

Staphylokokken. A variant spelling of Staphylococcus (Heim, 1911, p. 249).

Staphylokokkus. A variant spelling of Staphylococcus used by various German writers.

Stigmatella. A generic name proposed by Berkeley and Curtis (1857, p. 313) and described by Berkeley (1874) for an organism grouped with the Hyphomycetes. Saccardo (1886, IV, p. 679) gives the following description:

Sporodochia superficialia, globosa, compacta. Hyphae seu sporophora arcte fasciculata, filiformia continua, simplicia vel furcata (flexuosa). Conidia magna, globoso-ellipsoideae, continua, hyalina per caudam subpersistentem cuspidatam sporophoris haerentia. Genus distinctum, sed quo ad locum systematicum dubium, hinc Aegerliae hinc Naemateliae subaffine. De identitate Sphaerocreatis cum Stigmatella nullum mihi est dubium.

The genus is included under the Tuberculariae mucedineae, Amerosporae.

Thaxter (1892, p. 339) concluded that this name is a synonym of Chondromyces B. and C. and included this genus in his family Myxobacteriaceae. The type species is Stigmatella aurantiaca B. and C.

Stoddardillus. A name proposed by Heller (1922, p. 19) for the eleventh genus of the Clostridioideae with the following description:

Clostridioideae of energetic growth habit that liquefy gelatin, but do not produce $\mathrm{H}_{2} \mathrm{~S}$ demonstrable by a lead-acetate-paper test in blood broth. Produce abundant gas but little acid in meat medium. Grow very shyly or not at all in milk. Attack a few sugars, but do not produce much acid. Short chunky Grampositive rods which do not form spores. Colonies in deep agar large, lenticular and opaque. Not easily distinguished from Welchillus. May invade tissue, causing considerable destruction of muscle but no foul odor. One strain, reported from a case of human gas gangrene. 
Type species S. egens (Bacillus egens Stoddard) as described by (Stoddard (1919a)). Splits glucose, laevulose, mannose, maltose, dextrin, glycogen, inosite and glycerol. Does not sporulate on six days' incubation in inspissated serum.

Streblothrichia. A generic name used by Guignard (1890, p. 142) for a species of marine microörganism Streblothrichia Bornetii, which he placed with the bacteria. The organism was found in rock fissures by the ocean. It shows certain relationship to Nostoc in habitat and to Rivularia in manner of growth. No heterocysts or sporocysts, however, are formed. Migula (1900, p. 1039) gives the following description:

Diese neue Bakteriengattung bildet kleine farblose bis stecknadel grosse Zoogloen von charakteristischem Bau, . . . In der gemeinsamen Gallerte verlaufen, von dem gemeinsamen Anheftungspunkte ausstrecklend, zarte $1 \mu$ dicke Bakterienfaden, die anfanglich dicht gedrangt und gerade, später gewinden sind und namentlich in der Peripherie der Zoogloea dicht und regellos durcheinander gewirrt erscheinen. Diese Faden sind aus annahrend isodiametrischen Gliedern mit fein granuliertem Inhalte zusammengesetzt und haben eine ziemlich dicke Membran, die in der gelatinosen Grundmasse mitunter schwer $\mathrm{zu}$ erkennen ist.

The name is rejected by Erwin F. Smith (1905, p. 174). This is a doubtful bacterial genus.

Streblotrichia. A variant spelling of Streblothrichia used by Enlows (1920, p. 88). Probably a typographic error.

Streptobacillus. This name has occasionally been used as the designation of a form genus. Maggi (1886, p. 173) designated thus a growth form of Bacillus. Migula (1900, II, p. 374) credits the name Streptobacillus pseudotuberculosis rodentium to Preisz (1894, p. 231). An examination of this paper fails to show however any use of Streptobacillus as a generic name. The nearest approach is the following statement:

Nous proposons de denominer cette maladie la pseudotuberculose des rongeurs (pseudotuberculosis rodentium) et d'appeler avec M. Dor Streptobacille son agent producteur, car ce terme rappelle un des caractères importants de ce bacille.

Streptobazillus ulceris mollis was described by Unna (1892, p. 485) from soft chancres.

Ucke (1898, p. 996) named an anaerobe from the soil Streptobacillus terrae.

The organism which is responsible for acid production in the Egyptian sour milk beverage is termed Streptobacillus lebenis by Rist and 
Thoury (1902, p. 65) also by Guerbet (1906, p. 495). Olson-Sopp (1912, p. 9) described a Streptobacillus taette from Norwegian slimy milk.

The name is rejected by Erwin F. Smith (1905, p. 174).

The nomenclatural status of Streptobacillus as a generic name is questionable. The various organisms described are for the most part quite unrelated. Technically perhaps Streptobacillus terrae may be considered the type, as the first organism described for which a binomial nomenclature was used.

Streptobacter. A subgeneric name used by Schroeter (1886, p. $157 \mathrm{ff}$.) for seven species of the genus Bacillus, among them Bacillus erythrospora, $B$. subtilis and $B$. anthracis. All the species so designated are characterized by formation of chains of rods. This name has apparently not been used by other authors.

Streptobacteria. A name used by Billroth (1874, p. 18) to designate a growth form of his pleomorphic Coccobacteria septica, in which the organism occurred as rods in chains. He also used it in the combination Streptobacteria gigas-pericardii $(1874$, p. 60) for an organism found in pericardial exudate. De Toni and Trevisan (1889, p. 945) give the following description of the species. "Baculis cylindricis, rectis, rigidis, apicibus rotundatis, $3.25-4 \times 1.25$, subinde in filamenta brevia dispositis; sporis microsomis." These authors term the species Bacillus gigas. The name is rejected by Erwin F. Smith (1905, p. 174). Vuillemin (1913, p. 519) stated that the genus should not be retained because the parallelism of planes of division is characteristic of all rod-shaped organisms.

Streptobacterium. A variant of Streptobacteria used by Maggi (1886, p. 84) to designate a growth form of Bacterium aceti Zopf. It was also used by Billet $(1890$, p. 23$)$ as a form genus to designate rod shaped organisms which occurred in chains. Later it was used by Jacqué and Masay (1912, p. 180) in a generic sense in the combination Streptobacterium foetidum. The organism described is a short rod, with rounded ends, a "coccobacillus." It is actively motile, and does not form spores. In bouillon cultures there is a marked tendency to the production of long chains. It stains readily, is Gram negative, and with dilute stains shows polar staining. The organism is facultative, grows readily in culture media, produces gas from dextrose and maltose, milk is not coagulated, liquefies gelatine and serum, and produces a foetid odor in culture media. The organism described is apparently close to Proteus. 
The nomenclatural status of this name is uncertain. The type species apparently is Streptobacterium foetidum.

Streptococceae. The third tribe of the family Coccogenae used by De Toni and Trevisan (1889, p. 1051) with the following diagnosis: "Cocci in filamenta moniliformiter concatenati. Arthrosporae macrosomae in filamentis vel in eorum apicibus obvenientes." The following genera are included: Leuconostoc, Schuetzia, Perroncitoa, Babesia, and Streptococcus.

Buchanan (1917, p. 609) included this as the first tribe of the family Coccaceae with the description:

Cells spherical when isolated. Usually parasitic, growing well in the absence of oxygen, particularly in the presence of carbohydrates, from which acid is developed. Gas rarely produced. Many forms require special media. Abundant surface growths are rarely developed. Planes of fission are commonly parallel, resulting in the formation of pairs, or of longer or shorter chains of cells; regular packets of cells never formed. With the exception of a few strict parasites, the cells are Gram-positive. Pigment white, orange or none.

The genera Streptococcus, Leuconostoc, Diplococcus, Neisseria and Staphylococcus are included.

Winslow et al. (Committee Soc. Am. Bact., 1917, p. 557 and 1920, p. 205) give the following diagnosis:

Parasites (thriving only or best on or in the animal body) except genus Leuconostoc. Grow well under anaerobic conditions. Many forms grow with difficulty on serum-free media, none very abundantly. Planes of fission usually parallel, producing pairs or short or long chains, never packets. Generally stain by Gram. Produce acid but no gas in glucose and generally in lactose broth. Pigment, if any, white or orange.

Practically the same description is used by Castellani and Chalmers (1919, p. 924). These authors include as genera Ascococcus, Diplococcus, Streptococcus, Aurococcus and Albococcus.

The name is also used by Bergey et al. (1923, p. 44).

Streptococcee. A variant of Streptococceae used by Trevisan (1889, p. 28) for the third tribe of the suborder Coccogene. The description is "Cocchi seriati in filamenti." The genera included are Leuconostoc, Schuetzia, Perroncitoa, Babesia and Streptococcus.

Streptococcos. An aberrant spelling of Streptococcus used by Billroth (1874, p. 10).

Streptococcus. This name in the form Streptococcos was first used by Billroth $(1874$, p. 10) as a designation of a growth form of his pleomorphic species, Coccobacteria septica. His use of the term was in 
no sense generic, and he should not be cited as the authority, as is often the case. (Migula, Winslow, Vuillemin, etc.)

Cohn at first did not use the name Streptococcus (1875, p. 144) in the designation of a genus. He states: "Was Billroth Streptococcus nennt, hatte ich selbst als Torula form von Micrococcus bezeichnet." Later, however, he included the genus in the tribe Nematogenae. He described it as containing those organisms whose cells are disposed in filaments, filaments unbranched, free, without phycochrome and made up of spherical cells. However, there seems to be no record of any species being assigned to it. This is essential to the validity of a genus, hence Cohn cannot be quoted as authority for the genus.

In 1883 (p. 27), Ogston again used the term streptococcus as a form group. He states:

Micrococcus is met with in two distinct forms, chains and groups. They are often found together, yet the two are different, and the chain form does not pass into the grouped form, nor the grouped into the chain form. Throughout this paper the term Micrococcus is used as embracing both forms; the chain coccus is often called streptococcus (Billroth), and I shall call the grouped form staphylococcus.

Here again the name is not used in a strict generic sense.

Fehleisen (1883) studied the streptococci of erysipelas, and by Zopf is given credit for the name Streptococcus erysipelatis. A careful examination of the paper however shows that not once is any binomial used. The organisms are designated as "kettenbildenden Mikrokokken," "Mikrokokkus des Erysipels" and "Erysipelkokken." He did not use the designation Streptococcus.

Apparently the first valid use of the generic name Streptococcus was that of Rosenbach (1884, p. 22). He states:

Wollen wir einen Coccus, welcher sich aus mehreren Einzelcoccen zu charakteristischen Reihen, Ketten, Ringeln oder rosenkränzähnlichen Figuren gruppirt mit Ogston, welcher Billroth's Nomenklatur acceptirt hat, Streptococcus nennen, so bezeichnet auch hier dieses Wort nur eine Gattung: denn es gibt mehrere Arten, welche sich mikroskopisch in gleicher Weise zur Ketten anordnen.

The first species named, that of wound infections, is Streptococcus pyogenes, the second, a species previously described by Fehleisen, Strept. erysipelatos. The genus should therefore be ascribed to Rosenbach.

In the third edition of Die Spaltpilze, Zopf (1885, p. 51) credits the genus to Billroth. He characterizes the genus as containing cocci 
occurring in chains, division only in one direction of space. The two species of Rosenbach are recognized.

Fluegge $(1886$, p. 121) regarded the name as one for a growth form, used it in a generic sense in naming some nine species. Schroeter (1886, p. 149) added to the description that spores were unknown. He recognized seven species. Forty-seven species of Streptococcus are listed by Trevisan (1889, p. 29). De Toni and Trevisan (1889, p. 1054) differentiated several closely related genera from Streptococcus, listing fifty-six species in this genus. They stated that arthrospores may be found in the chains.

Since 1890 this genus has been more generally accepted by bacteriologists than any other with the possible exception of Micrococcus. Among those who accept the genus in its original sense may be listed Cornil and Babes (1890, p. 142), Baumgarten (1890, p. 127), Billet (1890, p. 24), Hueppe (1891, p. 30), Sternberg (1892, p. 17), Ludwig (1892), Fischer (1895, 1897, p. 32, and 1903, p. 60), Migula (1894, p. 97, 236 who says: "Streptococcus (Billroth) Zopf. Die Zellen teilen sich nur nach einer Richtung des Raumes, wodurch, wenn sie nach den Teilung verbunden bleiben, perlschnurartige Ketten enstehen können. Bewegungsorgane fehlens (Z. B. Streptococcus erysipelats Fehleisen, Str. mesenterioides (Cienk.))" Migula (1895, 1897, p. 46, and 1900, p. 15), Hewlett (1898), Chester (1897, p. 62, 1901, p. 55), Lehmann and Neumann (1896, p. 117, 1901, p. 123), Matzuschita (1902), Kendall (1902), A. J. Smith (1902, p. 268), Migula (1904), E. F. Smith (1905, p. 160), Fluegge (1908), Ellis (1909, p. 4), Jensen (1909, p. 340), Heim (1911, p. 248), Frost (1911, p. 56), Schneider (1912, p. 22), Vuillemin (1913, p. 525) and Löhnis (1913). In 1905 the Winslows (p. 669) emended the characterization of the genus to read as follows:

Parasites, cells normally in short or long chains (under favorable conditions sometimes in pairs and small groups-never in large groups or packets). On agar streak effused translucent growth with isolated colonies. In stab culture, little surface growth. Sugars fermented with formation of acid.

Buchanan (1915, p. 7) reviewed the nomenclatural status of this genus and later (1917, p. 611) included it as the first genus of the tribe Streptococceae with the following description:

Usually parasitic, though able to maintain a saprophytic existence. Cells usually in chains of greater or less length, the elements of the chains sometimes arranged as diplococci, never in packets. As a rule Gram-positive. Growth on surface of usual laboratory media not luxuriant. Growth better in liquid media 
containing sugars, which are as a rule fermented with acid production, but rarely gas. Usually do not liquefy gelatin or reduce nitrates. No formation of zoogloeal masses in sugar solutions.

The type species is probably Streptococcus pyogenes Rosenbach.

Winslow et al. (Committce Soc. Am. Bact., 1917, p. 558 and 1920, 206) also include it in Streptococceae with the following description:

Chiefly parasites. Cells normally in short or long chains (under unfavorable conditions, sometimes in pairs and small groups, never in large packets). Generally stain by Gram. Capsules rarely present, no zoogloeal masses. On agar streak, effused translucent growth, often with isolated colonies. In stab culture, little surface growth. Many sugars fermented with formation of large amount of acid, but inulin is rarely attacked. Generally fail to liquefy gelatin or reduce nitrates.

Type species is Streptococcus pyogenes Rosenbach.

Castellani and Chalmers (1919, p. 927) give the following description:

Streptococceae parasitic in short or long chains or pairs, forming a large quantity of acid in fermented sugars. Haemolysis present or absent. Without characteristic group serum reactions.

Type species. Streptococcus erysipelatos Fehleisen, 1883.

Bergey et al. (1923, p. 46) follow the Committee.

The generic designation Streptococcus Rosenbach (not Billroth) would appear to be valid, with Streptococcus pyogenes Rosenbach as the type. The genus is proposed as a genus conservandum by Vuille$\min (1913$, p. 525).

Streptokokken. A variant of Streptococcus used by certain German writers, as Baumgarten (1890, p. 127).

Streptokokkus. A variant spelling of Streptococcus used by various German writers as Hueppe (1891, p. 30).

Streptomicrococcos. A name applied by Billroth (1874, p. 11) to a growth form of his pleomorphic Coccobacteria septica in which the cells appeared as small spheres, in chains. It is not a generic name.

Streptospirillum. The name given by Billet $(1890$, p. 24$)$ to a form genus for those spiral rod shaped bacteria which occur in chains. It is not a valid generic designation.

Streptothrix. A generic name introduced by Corda (1839, p. 27) for one of the Hyphomycetes. The single species described, Streptothrix fusca, was also figured. This species has been repeatedly figured and described in floras. The description given by Saccardo (1886, 
p. 282) is as follows: "Hyphae fertiles erectae virgato ramosae, ramis ramulisque spiraliter tortis. Conidia globosa v. ovoidea, in ramulis solitaria acrogena, subinde pleurogena, sessilia v. stipitellata, fusca." Several species of this genus are listed in Saccardo's Sylloge Fungorum.

Cohn $(1875$, p. 186) used the generic name Streptothrix for a totally distinct organism, one of the thread bacteria producing concretions in the lachrymal duct, with the name Streptothrix Foersteri. This species is described by De Toni and Trevisan (1889, p. 928) as follows: "Filamentis tenuissimis, hyalinis, parallele insimul stratiformi-coalitis rectis vel incurvis, sparse irregulariterque ramosis, in fragmenta inaequalia secedentibus."

Cohn (1875) confused somewhat this genus with Cladothrix by his statement that the filaments are cylindrical, colorless, and with false branching. He included it in his tribe Nematogenes.

Trevisan (1879, p. 139) gave the generic description: "Somatia cylindrica, leptotrichoidea, indistincte articulata, tenerrima, stricta vel auguste spiralie parce ramosa." $\mathrm{He}$ included this genus in his subtribe Cladothriceae.

Magnin (1880, p. 97) states the filaments to be in the form "of Leptothrix, very slender, colorless, not articulated, straight or slightly spiral, a little branched."

Much confusion has arisen in the literature of recent years due to the confusion of Streptothrix Corda, Streptothrix Cohn, Oospora Wallroth, Actinomyces Harz, Nocardia Trevisan, Cladothrix Cohn.

It is probable that all uses of the name Streptothrix not in accord with the organism named by Corda are invalid. Many authors have used Streptothrix in place of Actinomyces (q.v.).

De Toni and Trevisan (1889) used the generic name Nocardia.

Gasperini (1889, p. 449) identified the Streptothrix Foersteri of Cohn as a common air form.

Sauvageau and Radais (1892, p. 246) called attention to the use of Streptothrix by Corda, and urged that the Streptothrix of Cohn was a synonym of the older name Oospora Wallroth.

Migula (1894, p. 237) says: "Streptothrix Cohn. Zellen zu einfachen unverzweigten Fäden vereinigt. Teilung nur nach einer Richtung des Raumes. Endosporenbildung oder eine sonstage besondere Fortpflanzungsform fehlt."

Migula (1897, p. 47) gives the following diagnosis of Streptothrix: "Zellen zu einfachen, unverzweigten Fäden vereinigt. Teilung nur nach einer Richtung des Raumes. Fortpflanzung durch bewegungslose 
Conidien." He has been followed by Chester (1899, p. 64). Hewlett (1898) groups all thread bacteria under Streptothrix. Berestnew (1899, p. 390) rejected the name as invalid. Chester (1901, p. 360) uses the following definition:

Cells in their ordinary form as long branched filaments. Cultures on solid media raised. Growth coherent, dry, rough or crumpled, often with a moldy appearance due to the formation of aerial hyphae. Without endospores, but by a multiple segmentation of a filament, the production of short, gonidia like bodies.

Lehmann and Neumann (1901, p. 128) definitely discard Streptothrix in favor of Actinomyces.

A. J. Smith (1902, p. 270) and Kendall (1902) agree with Chester. Petruschky (1903, 2, 832) includes Actinomyces, Streptothrix, Cladothrix and Leptothrix as "species" of the Trichomycetes. Streptothrix is used as the generic designation of the organisms causing mycelomata.

E. F. Smith (1905) rejects the name as invalid for a genus of bacteria. Foulerton (1906, p. 302) according to Musgrave and Clegg (1908, p. 459) uses the name Streptothrix for the following reasons:

1. He does not consider that Corda's indefinite use of the term in 1883 should make Streptothrix Cohn (1875) untenable.

2. This being acceptable, Streptothrix becomes the correct botanical name by priority of description.

3. Streptothrix was adopted by the committee of the Pathological Society.

4. It is by far the most generally used name.

Musgrave and Clegg (1908, p. 471) while agreeing that probably Streptothrix Cohn is not tenable, nevertheless adopt it tentatively for lack of a better designation. Jordan (1908) holds Streptothrix to be invalid. Heim (1911) includes Actinomyces under Streptothrix. Petruschky (1913, p. 270) believes that no confusion can arise through the use of Streptothrix to designate two such unlike organisms as the hyphomycete of Corda and the thread bacterium of Cohn. Streptothrix is to be differentiated through its abundant true branching, its ability to fragment into segments, its wavy filaments and its chains of conidia.

The name Streptothrix is probably invalid as a generic designation among the bacteria.

Streptovibrio. A name given by Maggi (1886, p. 176) to a growth form of Vibrio in which the cells occur in chains.

Sulfomonas. A genus of sulphur bacteria proposed by Orla-Jensen (1909, p. 313) to include those forms which are not spiral, autotrophic. 
The genus is included as the first in his family Thiobacteriaceae. OrlaJensen's statement follows:

Ausser den erwähnten Schwefelbakterien, die also zur vollständigen Ausnützung des Schwefelwasserstoffes ausgerüstet sind, gibt es nach Natanssohn und Beijerinck auch Bakterien, die Schwefelwasserstoff nur zu Schwefel oxydieren, und somit in demselben Verhältnis zu den ersteren stehen wie der Nitrosomonas zum Bacillus nitrator. Ein solches von Beijerinck näher beschriebenes Kurzstäbchen, Thiobacillus thioparus, benutzt die Kohlensäure der Luft als Fohlenstoffquelle und musz deshalb als eine der allerältesten Schwefelbakterien betrachtet werden. Wir wollen ihm den Gattungsnamen Sulfomonas geben. Von diesem mikroskopisch nicht zu unterscheiden soll Sulfomonas (Thiobacillus) denitrificans sein, der auch autotroph lebt, und welcher Schwefel zu Schwefelsäure oxydiert. Dies geschieht jedoch nicht mittels des Luftsauerstoffes, sondern mit Salpeter als Oxydationsmittel:

$5 \mathrm{~S}+6 \mathrm{KNO}_{3}+2 \mathrm{H}_{2} \mathrm{O}=\mathrm{K}_{2} \mathrm{SO}+4 \mathrm{KHSO}_{4}+3 \mathrm{~N}_{2}+626 \mathrm{Kal}$.

$$
6 \times 1112 \times 69 \quad 338 \quad 4 \times 273 \text { Per Gramm } 0,78 \text { Kal. }
$$

Dieser Organismus bildet also das natürliche Verbindungsglied zwischen den Schwefelbakterien und den denitrifizierenden Bakterien, welche wir jetzt besprechen werden. Hiermit gehen wir zu den bakteriellen Oxydationen über, die mittels gebundenen Sauerstoffes zustande kommen.

Termobacterium. This generic name has been used with species not closely related. Zeidler (1896, p. 739) described an acetic acid organism from beerwort as Termobacterium aceti. He later states that this organism is probably identical with Bact. oxydans Henneberg. Other species as T. lutescens, T. fuscescens, T. iridescens, T. album and T. erythrinum have been named by Lindner (1909, p. 508). Henneberg $(1909$, p. 123) states that organisms called Termobacterium are small actively motile wort bacteria. Spores are not produced. It is a group designation for such forms found in wort as do not belong either to the lactic or acetic bacteria. They are suppressed by the growth of yeasts. They are organisms closely related to Bacillus vulgaris, the old Bacterium termo. Zeidler's organism is not a typical Termobacterium.

Delbrück $(1910$, p. 66) states that this is a generic designation of organisms of the type of Bact. termo, that the term was first used by Lindner. The name has been written Thermobacterium (q.v.) by some writers. The nomenclatural status of the genus is uncertain.

Termobakterien. A variant spelling of Termobacterium used by Henneberg (1909, p. 124) to designate the wort bacteria.

Tetrabacterium. A casual name used by Maggi (1886, p. 85) to designate a growth form of Bacterium. 
Tetracoccus. A form genus used by Billet (1890, p. 24) to designate cocci which occur in fours. The name is rejected by E. F. Smith (1905). Miquel (1891) also used this generic designation.

Apparently the first use in a binomial was by Klecki (1894, p. 354) who described a species Tetracoccus butyri from rancid butter.

An independent introduction of a genus name Tetracoccus is that of Orla-Jensen (1919, p. 154). He says:

In this genus (Table XXVII) I include all sugar-fermenting micrococci and sarcinae. From the sugar they form, besides lactic acid, smaller or greater quantities of acetic acid. The quantity of lactic acid was in many cases so small that we were not able to determine with certainty of what sort it was. As they thus stand at the limit of what we will term lactic acid bacteria, we have not sought for them systematically, as for the cocci already described, and thus make no claim to have found, even approximately, representatives of all species belonging thereto, but merely of some of those most frequently met with in the dairy.

The first species named is Tetracoccus liquefaciens (Micrococcus casei liquefaciens Orla-Jensen). Others named are Tc. casei, Tc. mastitidis, Tc. pyogenes aureus, Tc. pyogenes albus and Tc. mycodermatus.

Later (1921, p. 268) he states:

The acid forming micrococci and sarcinae I have brought together in the genus $T$ etracoccus, as I believed it to be quite as wrong to draw a limit between the micrococci and the sarcinae as between the short- and long-chained streptococci.

Tetradiplococcus. Bartoszewicz and Schwarzwasser (190S, p. 614) proposed the name Tetradiplococcus filiformans lodzensis. The organism was isolated from the Lodz tap water by means of plate culture. In hanging drop the organism appears always in the form of tetrads so constructed that each element of the tetrad is a diplococcus. Each cell has the form of the gonococcus. The tetrads are actively motile in young cultures, but flagella could not be demonstrated. The tetrads are 4 to $6 \mu$ in diameter. The organism grows well at room temperature, but much better at 30 to $37^{\circ}$. Gelatin is not liquefied. The most conspicuous growth character is the formation of slender filaments in broth which rise from the bottom of the tube toward the mouth. The filaments do not develop well at room temperature. The broth remains clear, but there is a gelatinous deposit. In stab cultures in agar a fir tree growth develops. Plate colonies are small, white granular known on the surface. Gelatin kept at $30^{\circ}$ shows the filament formation well. Practically an obligate aërobe. The cells are Gram-positive. 
Apparently this name has not been used in a binomial, and is therefore invalid.

Tetragenus. A name apparently first used as a pseudogeneric designation by Kruse (1896, p. 94). As a binomial apparently it was first used by Vincenzi $(1897$, p. 758) for an organism isolated from a lymph node and named Tetragenus citreus. A second species Tetragenus tardissimus was named by Altana (1909, p. 44).

If the first species (type) Tetragenus citreus Vincenzi is worthy of of generic designation, the genus is valid. It probably is a synonym.

Tetrakokkus. A variant spelling of Tetracoccus used by IKlebs (1887, p. 337) for the species Tetrakolkus variolae, the cause of variola.

Thermoactinomyces. A genus described by Tsiklinsky (1899, p. $500)$ to include two species of thermophilic thread bacteria, Thermoactinomyces vulgaris and Th. lanuginosus. These organisms grow at temperatures between $48^{\circ}$ and $68^{\circ} \mathrm{C}$.

Morphologically these species do not differ from the soil species of Actinomyces (q.v.), of which this name may be regarded as a synonym.

The name is rejected by Erwin F. Smith (1905, p. 174).

According to Enlows (1920, p. 92) the type species is Thermoactinomyces vulgaris Tsiklinsky.

Thermobacillus. A generic name proposed by Orla-Jensen (1909, p. 33) to include thermophilic rod shaped bacteria, requiring as a rule organic sources of nitrogen. The genus is included in the family Alkalibacteriaceae and the order Perithricinae. The description given by Jensen is as follows:

Eigentümlich, für die aëroben Bacillen ist das grosz Temperaturintervall, innerhalb dessen sie gedeihen können. Die Heubacillen z. B. wachsen zwischen $6-50^{\circ}$. Eine weitere Anpassung an die höheren Temperaturen und damit Abgewöhnung von den niedrigen führt zu den thermophilen Bakterien. Diese bilden Sporen, welche hinsichtlich ihrer Widerstandsfähigkeit sogar diejenigen der Kartoffelbacillen übertreffen. So erklärt sich das Phänomen, dasz hochsterilisierte Milch, welche Wochen lang bei $35^{\circ}$ unverändert blieb, bisweilen nach wenigen Tagen bei $70^{\circ}$ gerinnt. Es wäre vielleicht angezeigt, Thermobacillus als selbständige Gattung aufzustellen.

Erwin F. Smith (1905, p. 174) includes Thermobacillus in a list of rejected genera. A use of the name earlier than that of Jensen has not been found.

It is probable that this generic name is synonymous with Bacillus.

Thermobacterium. Probably a misprint for Termobacterium. Fuhrmann (1906, p. 8) refers to Thermobacterium aceti of Zeidler. The name is listed as invalid by E. F. Smith (1905, p. 174). 
Benecke (p. 442) makes Thermobacterium Zeidleri a synonym of Bact. acetigenum.

As a generic name Thermobacterium was proposed by Orla-Jensen (1919) for the thermophilic lactic acid organisms. The first species mentioned is Thermobacterium bulgaricum. In addition he names Thermobacterium cereale, and Tbm. lactis. It would seem that this is a synonym of Lactobacillus. Probably the type species may be designated as Thermobacterium bulgaricum Orla-Jensen.

Thiobacillus, A generic name used by Beijerinck (1904, p. 593) for organisms oxidizing sulphur, but not containing sulphur granules or bacteriopurpurin. The first species named, Thiobacillus thioparus oxidizes $\mathrm{H}_{2} \mathrm{~S}, \mathrm{Na}_{2} \mathrm{~S}_{4} \mathrm{O}_{6}$ and other sulphur compounds for energy, and is oligocarbophilous, utilizing carbonates. The organism is motile and sporeless. The second species Thiobacillus denitrificans when grown in the presence of free sulphur, carbonates and nitrates, reduces the last with evolution of free nitrogen, oxidizes the sulphur and utilizes the inorganic carbon.

Other species of Thiobacillus have been described by other workers as Waksman and Joffe (1922, p. 239) who named Thiobacillus thiooxidans.

Apparently the genus is valid, and the type species Thiobacillus thioparus Beijerinck.

Bergey et al. (1923, p. 37) include the genus as the seventh in the tribe Nitrobactereae with the following description:

Small rod-shaped organisms deriving their energy from the oxidation of sulfides, thiosulfates or elementary sulfur, forming sulfur, persulfates, and sulfates under acid or alkaline conditions and deriving their carbon from carbon dioxide or from bicarbonates and carbonates in solution.

The type species apparently is Thiobacillus thioparus Beijerinck.

Thiobacteria. An ordinal name introduced by Migula (1900, p. 1039) to include the sulphur bacteria. The diagnosis given is: "Zellen ohne Centralkörper, aber Schwefeleinschlusse enthaltend, farblos oder durch Bacteriopurpurin rosa rot oder violett gefarbt, niemals grün." This order is recognized by E. F. Smith (1905, p. 162), Frost (1911, p. 60) and others.

Vuillemin (1913, p. 522) excludes the entire group from the bacteria with the statement that it belongs with the Schizophyceae.

Thiobacteriaceae. A family of the order Cephalotrichinae created by Orla-Jensen $(1909$, p. 303) for organisms which contain sulphur but 
no bacteriopurpurin, and with cells not in thread-like filaments. The following genera are included: Sulfomonas, Thiomonas, Thiococcus and Thiospirillum. There is no genus Thiobacter or Thiobacterium hence the family name is incorrectly constituted.

Thiobacteriales. An order of bacteria named by Buchanan (1917) to include the sulphur bacteria. The following is his description (1918, p. 461).

Cells various, typically containing either granules of free sulphur, or bacteriopurpurin, or both, usually growing best in the presence of hydrogen sulphide. The cells are plant-like, not protozoan-like, not producing a pseudoplasmodium or a highly developed encysted resting stage. Spores are rarely or never formed.

Classification within this group is in a very unsatisfactory and very superficial state. Few investigators have studied these forms, and most of the work is old, and in need of careful revision. Undoubtedly many of the genera are to be regarded as growth forms, merely.

Three families were recognized; Achromatiaceae, Beggiatoaceae and Rhodobacteriaceae. The order was recognized by Winslow et al. (Committee Soc. Am. Bact., 1917, p. 549, and 1920, p. 196) by Castellani and Chalmers (1919, p. 924), Heller (1921, p. 449) and Bergey et al. (1923, p. 393).

Thiocapsa. A genus of sulphur bacteria described by Winogradsky (1888, p. 84) with the species Thiocapsa roseo-persicina. The genus resembles in the grouping and multiplication of the cells the algal genus Aphanocapsa. Cell division occurs in all directions of space, the cells are spherical, with thick confluent membranes, which unite to form a structureless gelatinous layer. The cells are a bright rose red color and contain numerous sulphur granules.

Trevisan (1889, p. 28) includes Thiocapsa as the fourth genus of the tribe Sarcinee. The description reads "Cocchi lassamente aggregati in famiglie irregolari nella ganga mucosa disugualmente spianata senza forma definita. Temnogenesi in tre direzioni."

De Toni and Trevisan (1889, p. 1049) recognize this genus, as do Migula (1900, p. 1043) (1904, p. 146), E. F. Smith (1905, p. 163) and Frost (1911, p. 61). Smith gives the following description:

Non-swarming, globose cells spread out upon the substratum in flat families, which are loosely enveloped in a common gelatin. The membrane is split by the growth of the family, and the cells are separated as if by the swelling of an intermediate substance.

Orla-Jensen (1909, p. 334) incorrectly made this a synonym of Rhodocapsa. 
Buchanan (1918, p. 467) gave the following generic diagnosis (including it as the fourth genus of the tribe Thiocapseae).

Cell families resembling in grouping and multiplication the cells of the algal genus A phanocapsa. Cell division occurs in all directions of space, the cells are spherical, with thick confluent membranes, which unite to form a structureless, gelatinous layer. The cells are of a bright rose red color and contain numerous sulphur granules. The cells do not swarm.

The type species is Thiocapsa roseo-persicina Winogradsky.

Bergey et al. (1923, p. 396) followed Buchanan.

Thiocapsaceae. A subfamily described by Migula (1900, p. 1042). It includes those sulphur bacteria in which the cells are united into families, and division of the cells takes place in three directions of space. The following genera are included, Thiocystis, Thiocapsa and Thiosarcina. The subfamily is recognized by Migula (1904, p. 146). (1905, p. 163) by Frost (1911, p. 61) and by Molisch (1910).

Thiocapseae. A tribal designation proposed by Buchanan (1918, p. 467) for the first tribe of the subfamily Chromatioideae with the following description: "Bacteria containing both sulphur granules and bacteriopurpurin. Cells divide in three directions of space, united into families."

The genera included were Thiocystis, Thiosphaera, Thisophaerion, Thiocapsa and Thiosarcina.

Bergey et al. (1923, p. 395) used the same description.

Thiococcus. The third genus of spherical sulphur bacteria of the family Thiobacteriaceae used by Orla-Jensen (1909, p. 330). $\mathrm{He}$ mentions as a type a colorless sulphur coccus described by Warming (1876).

Thiocystis. A genus of sulphur bacteria described by Winogradsky (1888, p. 60). The spherical cells are massed in small compact families, enveloped singly or several together in a gelatinous cyst, and capable of swarming. Usually 4 to 20 or 30 cells are united into a single family. The cells are light colored, single cells almost colorless. In masses the cells show a beautiful violet or red-violet color. The cells are frequently filled with sulphur granules. Thiocystis violacea and Th. rufa were described.

The genus was included by Trevisan $(1883$, p. 27) as the sixth of the tribe Ascococcee.

De Toni and Trevisan (1889, p. 1040) give the following description:

Cocci globosi vel divisionis tempore globosovoidei, modice numerosi, in muco matricali nidulantes, in familia forma indefinitas, irregulares, parvulas, intus 
solidas, singulas vel plures simul cystidibus universalibus amplis, crassis homogenis, non lamellosis, gelatinoso-subcartilagineis, involutas, arcte consociatis. Cystides speciales nullae. Coccorum divisio alternatim in tres directiones.

The genus is discussed by Migula (1900, p. 1042) (1904, p. 140) E. F. Smith (1905, p. 163) and Frost (1911, p. 61). Smith gives the following description:

Families small, compact, enveloped singly or several together in a gelatinous cyst, capable of swarming. When the families have reached a definite size they escape from the gelatinous cyst, the latter either swelling and softening uniformly or at some particular spot. The escaped cells either pass into the swarm stage or unite into a larger fused complex of families, the individual cells of which separate and swim away only after a long time, and by means of much vigorous struggling.

Orla-Jensen (1909, p. 334) incorrectly made this generic name a synonym of Rhodocystis.

Buchanan (1918, p. 466) include this as the first genus of the tribe Thiocapseae with the following description.

Usually 4 to 20 or 30 cells massed into small, compact families, enveloped singly or several together in a gelatinous cyst, capable of swarming. When the families have reached a definite size they escape from the gelatinous cyst, the latter either swelling and softening uniformly or at some particular spot. The escaped cells either pass into the swarm stage or unit into a larger fused complex of families. Cells are light colored, single cells almost colorless. In masses the cells show a beautiful violet or red violet color. The cells are frequently quite filled with sulphur granules.

The type species is Thiocystis violacea Winogradsky.

Bergey et al. (1923, p. 395) used the same description.

Thioderma. A name proposed by Miyoshi (1897, p. 158) to include certain sulphur bacteria. Two species were described, Thioderma rubrum and $T h$ roseum. The later is described as follows: Thioderma roseum nov. gen. e spec. Cells spheroidal, $2.5 \mu$ long and $1.5 \mu$ wide of a light rose color, containing small, inconspicuous sulphur granules. United into thin, removable, smooth purple red skin. On grass culms, leaves, etc., on soil. Migula (1900, p. 1044) concluded the generic name to be a synonym of Lamprocystis.

Buchanan (1918, p. 468) included this as the second genus of the tribe Thiopedieae with the following description:

Cells spheroidal, light rose in color, containing small, inconspicuous, sulphur granules. United into thin purplish membrane.

The type species is Thioderma roseum Miyoshi. 
Bergey et al. (1923, p. 398) used the same description.

Thiodictyon. A genus of sulphur bacteria described by Winogradsky $(1888$, p. 80$)$. The organisms are rod-shaped, with ends united to form a net work. The species Thiodictyon elegans was described by this author. Winogradsky gives the following description of this organism:

Die Stäbchen sind schlank spindelförmig, mit scharf zugespitzten Enden, $5 \mu$ lang, 1,7 $\mu$ dick, vor der Theilung fast doppelt so lang; nach der Theilung ist das eine Ende in der Einschnürung abgerundet, bei weiterem Wachstum spitzt es sich wieder zu. Auch in gut wachsendem Zustande zeigen die Zellen in ihrem Inhalte die characteristische "Vacuole," deren Umrisse denen des Stäbchens parallel sind. Das Plasma bildet nur eine sehr schmale wandständige Schicht, in der allein (nie in der "Vacuole") winzige, punktförmige Schwefelkörnchen eingelagert sind. Die Schwefelaufspeicherung ist immer, auch unter den dafür günstigsten Bedingungen relativ unbedeutend. Die Färbung ist so schwach, dass die Stäbchen bei gewöhnlicher Beleuchtung manchmal farblos erscheinen; wenn man aber diesselben bei starker Beleuchtung mit dem Abbe 'schen Condensor ohne Diaphragma betrachtet, merkt man immer einen schwachen, aber deutlichen violetten Ton (p. 82).

De Toni and Trevisan (1889, p. 941) gave the following generic description:

Baculi fusiformes vel ellipsoideo-cylindracei, recti, apicibus conformibus, in coenobium reticulatum, Hydrodictyi utriculati coenobia simulans, connexi. Multiplicatio cingulis ( ) 5-15-cellularibus qui a colonia matricali movimento peculiari secedunt.

\section{The genus is described by Migula (1900, p. 1046) as follows:}

Familien aus stabchenförmigen, mit ihren Enden zur einem Netz verbundenen Zellen bestehend. Aus einer anfänglich kompakten Stäbchenmasse gehen durch allmähliche Umlagerung hydrodictyonartige Zellverbände hervor, die sich unter ungünstigen Verhältnissen wieder in solche kompakte Stäbchenmassen zusammenziehen können. Die Vermehrung der Familien erfolgt durch Teilung oder durch Ablösung langsam beweglichen kleiner Zellverbände.

The genus was noted by Migula (1904, p. 146), E. F. Smith (1905: p. 164) and Frost (1911, p. 61).

Smith gives the generic description as follows:

Families consisting of rod-shaped cells having their ends united into a net. Out of an originally compact mass of rods there gradually results from re-arrangement a Hydrodictyon-like cell-union, which under unfavorable conditions, may again draw together into a compact mass of rods. The multiplication of the families results from division or by loosening of slowly motile small cell-colonies. 
Orla-Jensen (1909, p. 334) incorrectly termed this genus a synonym of Rhodidictyon. Buchanan (1918, p. 469) included this as the second genus of the tribe Amoebobacterieae with the following description.

Cells rod-shaped or spindle-shaped, with sharply pointed ends, united into a net. The compact mass of rods finally assumes an appearance like that of Hydrodictyon. Slight violet color.

The type species is Thiodictyon elegans Winogradsky.

Bergey et al. (1923, p. 399) used the same description.

Thiomonas. A genus of sulphur bacteria belonging to the Thiobacteriaceae named by Orla-Jensen (1909, p. 330). The organisms are not autotrophic, cells rod shaped, not spiral. The organisms described by Hinze (1903, p. 309) and Jegunow (1896, p. 11) are assigned to this genus.

Thiopedia. A genus name used by Winogradsky (1888, p. 85) to include Merismopedia-like organisms with bacterio-purpurin and sulphur granules. The species described is Th. rosea. De Toni and Trevisan (1889, p. 1048) regard this as a synonym of Lampropedia Schroeter. The genus is discussed by Migula (1900, p. 1045) (1904, p. 146), E. F. Smith (1905, p. 163) and Frost (1911, p. 61). Smith gives the following description of the genus: "Families tabular, formed of cells arranged in fours, and capable of swarming."

Orla-Jensen (1909, p. 334) incorrectly makes this the genus Rhodococcus.

It seems that Lampropedia has priority over Thiopedia.

Thiopediaceae. A subfamily name used by Migula (1900, p. 1044) to include those sulphur bacteria in which the cells are united into families and cell division is in two directions of space. The only genus is Thiopedia Winogradsky. The subfamily is recognized by Smith (1905, p. 163) and Frost (1911, p. 61).

Thiopedieae. The third tribe of the subfamily Chromatioideae as named by Buchanan (1918, p. 468) with the description: "Sulphur bacteria in which the cells are united into families, and cell division is in two directions of space, resulting in the development of plates of cells."

The genera included are Lampropedia and Thioderma.

Bergey et al. (1923, p. 397) use the same description.

This designation probably should be changed to Lampropedieae, as the tribe does not contain a valid genus Thiopedia.

Thiophysa. A generic name given by Hinze (1903, p. 310) to a sulphur bacterium from the Bay of Naples. 
In der typischen Form kugelige, mit schwefeltröpfchen beladene Zellen, welche von einer die Reaktionen der Pektinstoffe gebenden Membran umgrenzt sind. Der protoplasmatische Wandbeleg umschliesst eine grosse centrale Vakuole; eine Zellkern ist nicht nachweisbar. Geisseln fehlen. Vor der Teilung streckt sich die Zelle in die Lange, schnürt sich biscuitförmig ein und zerfällt in zwei sich später gebundende kalottenförmige Zellen.

One species, Thiophysa volutans was named. The cells vary from 7 to $18 \mu$ in diameter. Cells possess power of very slow motion. The central portion or "vacuole" contains sulphur.

This genus is recognized by Buchanan (1918, p. 463) as the second of the family Achromatiaceae with the description:

Spherical cells laden with sulphur. The protoplasmic layer surrounds a large central vacuole. Cell nucleus not recognized. Flagella lacking. Cells elongate before division, divide to biscuit-shaped cells. Cells 7 to $18 \mu$ in diameter.

The type species Thiophysa volutans Hinze was secured from the Bay of Naples.

Bergey et al. (1923, p. 411) gives the following generic description.

Spherical cells the cell membrane of which is laden with sulphur granules. The protoplasmic layer surrounds a large central vacuole. The oxalate is contained in the vacuole. Cell nucleus not recognized. Flagella lacking. Cells elongate before division, divide into biscuit-shaped cells. Cells 7 to 18 microns in diameter.

In the presence of an excess of oxygen the sulphur drops disappear and only the oxalate remains. With a lack of oxygen, in the presence of $\mathrm{H}_{2} \mathrm{~S}$, the oxalate disappears and sulphur drops fill the cell.

Thioploca. A generic name given by Lauterborn (1907, p. 238) to one of the sulphur bacteria. The genus is placed in the family Beggiatoaceae. The generic description is:

Faden von Beggiatoaartigem Habitus, mit reichlichem Schwefelkörnern, beweglich, in oft betrachtlicher Zahl parallel nebeneinander verlaufend, zu seilartigen Bündeln vereinigt und verflochten. Nach aussen umschlossen von weit abstehenden farblosen Gallertröhren, meist mit Schlammpartikeln inkrustiert und bisweilen mit ringförmigen Einschnürungen versehen.

The species is described as follows:

Zellen der Fäden 5-9 $\mu$ dick, 1-1 $\frac{1}{2} \mathrm{mal}$ so long als breit, Gallertschläuche 50$160 \mu$ dick, bis mehrere Centimeter lang. Vorkommen: Untersee des Bodensees in der Gegend von Ermatingen, in 15-20 m. Tiefe des Innere des kalkreichen Grundschlicks durchziehend.

Buchanan (1918, p. 464) gives the following description. The genus is included as the third in the family Beggiatoaceae. 
Filaments Beggiatoa-like, with numerous sulphur granules, motile, lying parallel in considerable numbers, or united in bundles enclosed in a colorless layer of gelatin.

The type species, Thioploca schmidlei Lauterborn has filaments 5 to $9 \mu$ thick, and gelatinous sheath 50 to $160 \mu$ thick. From the ocean bed.

Bergey et al. (1923, p. 410) uses the same description and position of the genus.

Thiopolycoccus. A genus of sulphur bacteria named by Winogradsky (1888, p. 79) with one species Thiopolycoccus ruber. The description given follows:

Die gestaltlosen dichten Aggregate von kleinen, runden, lebhaft gefärbten Zellen, welche man zusammen mit Amoebobacter, Lamprocystis u. s. w. findet, gehören manchmal zu dem in der Ueberschrift genannten Organismus. Nur die Beobachtung der weiteren Entwicklung dieser soliden Häufchen kann entscheiden, ob sie nicht vielleicht zu anderen rothen Zoogloea-Formen, deren Entwickelung oben geschildert ist gehören. Die Thiopolycoccus-familien sind, im Gegensatze zu Amoebobacter, vollkommen unbeweglich und bilden bei ihrem weiteren Wachsthum keine hohlkugeligen Zoogloeen wie Lamprocystis, sondern stellen immer grössere oder kleinere solide und ganz uregelmässige Coccen-Aggregate dar.

De Toni and Trevisan (1889, p. 1044) recognized the genus and gave the following description:

Cocci globosi vel divisionis tempore ovoidei, numerosissimi, in familias solidas, immobiles, cumuliformes, sine forma definita, tegumento gelatinoso tenuissimo vix conspicuo praeditas, densissime aggregati. Coccorum divisio in unam directionem. Sporae ignotae.

The genus was also described by Migula (1900 II, p. 1046):

Familien solid, unbereglich, aus kleinen, dicht zusammen gepressten Zellen bestehend. Vermehrung der Kolonien erfolgt dadurch, dass die Kolonien sich an der Oberfläche auflocker und zahlreiche kurze Fitzen und Lappen entstehen und diese in immer kleiner Häufchen zerfallen.

E. F. Smith (1905 p. 164) uses the following description:

Families solid, non-motile, consisting of small cells closely pressed together. Multiplication of the colonies by the breaking up of the surface into numerous short shreds and lobes which continue to split up into smaller heaps.

Orla-Jensen (1909, p. 334) incorrectly makes this a synonym of Rhodopolycoccus.

Buchanan (1918, p. 470) made this the fourth genus of the tribe Amoebobacterieae with the description: 
Families solid, non-motile, consisting of small cells closely appressed. Multiplication of the colonies by the breaking up of the surface into numerous short shreds and lobes which continue to split up into smaller heaps. Cells red.

The type species is Thiopolycoccus ruber Winogradsky.

Bergey et al. (1923, p. 400) followed Buchanan.

Thiosarcina. A generic name proposed by Winogradsky (1888, p. 104) for the species Thiosarcina rosea, named Sarcina rosea by Schroeter (1886, p. 154). The genus is regarded as a synonym of Sarcina by De Toni and Trevisan $(1889$, p. 1044). The genus has been described by Migula (1900, p. 1043) (1904, p. 146), E. F. Smith (1905, p. 163), and Frost $(1911$, p. 61). Smith's description follows: "Nonswarming cells arranged in packet shaped families, corresponding to the genus Sarcina in the Eubacteriaceae."

Orla-Jensen $(1909$, p. 334) incorrectly makes this genus a synonym of Rhodosarcina.

Buchanan (1918, p. 467) describes this as the fifth genus of the tribe Thiocapseae as follows:

Non-swarming cells arranged in packet shaped families, corresponding to the genus Sarcina. Cells red, with sulphur granules.

The type species is Thiosarcina rosea (Schroeter) Winogradsky.

Bergey et al. (1923, p. 396) followed Buchanan.

Thiosphaerella. A generic name given by Nadson (1914, p. 52). Enlows (1920, p. 94) gives the following description:

Type species (monotypy). T. amylifera. A sulfur bacterium. Cells are round or slightly elliptical, measuring 4.8 by $6 \mu$. A very thick cell membrane enveloped in a colorless gelatinous layer. Protoplasm sometimes has a graygreen color, and in it are found sulfur granules, and a substance resembling starch. Motile. Multiplication by transverse division. Found frequently associated with Thiophysa Hinze and Achromatium Schewiakoff.

Thiosphaera. A genus of sulphur bacteria named by Miyoshi (1897, p. 170) with the species Thiosphaera gelatinosa. The description given by Migula (1900, II, p. 1044) is: "Zellen sphaeroellipsoidisch, $7 \mu$ and $8 \mu$ gross, leicht violett gefarbt, mit einer farblosen Gallertsubstanz zu einer Familie locker verbunden. Schwefeleinschlusse ziemlich Zahlreich. Schwarmfähig."

Migula changed the name (p. 1044) to Lamprocystis gelatinosa (Miyoshi) Migula.

The genus is rejected by E. F. Smith (1905, p. 174). 
Buchanan (1918, p. 466) included this as the second genus of the tribe Thiocapseae with the description:

Cells spherical-ellipsoidal, relatively large $(7$ to $8 \mu)$ light violet in color, bound into loose families by a colorless gelatin. Capable of swarming. Sulphur inclusions relatively abundant.

The type species is Thiosphaera gelatinosa Miyoshi.

Bergey et al. (1923, p. 396) followed Buchanan.

Thiosphaerion. A genus of sulphur bacteria named by Miyoshi (1897, p. 170) for the species Thiosphaerion violaceum. The description given by Migula is: "Zellen sphäro-ellipsoidisch, ca. 2.5 und 1.8 grosz, violett gefarbt, mit winzigen Schwefeleinschlussen, durch eine gallertartige Substanz zu soliden rundlichen Familien verbunden. Schwarmfähig."

Migula calls it Lamprocystis violacea (Miyoshi) Mig. and says:

Ich halte diese wie die 3 folgenden Arten nicht fur so verschieden von Lamprocystis roseo-persicina.

An Faden von Thiothrix nivea.

The genus is not accepted by E. F. Snith (1905, p. 174).

Buchanan includes this as the third genus of Thiocapseae with the following description:

Cells spherical-ellipsoidal, small (1.8 to $2.5 \mu$ ) violet in color, with delicate sulphur inclusions. United by means of gelatin into solid spherical families. Capable of swarming.

The type species is Thiosphaerion violaceum Miyoshi.

Bergey et al. (1923, p. 396) followed Buchanan.

Thiospira. A generic name proposed by Wislouch (1914, p. 50). Enlows summarizes the description as follows:

Motile, colorless, slightly curved sulfur spirilla with pointed ends. Sulfur granules present. A few polar flagella. T. winogradskii (Omélianski). A giant sulfur spirillum $3.5 \mu$ by $50 \mu$. T. bipunctata (Molisch). Small, very delicately curved sulfur spirilla 1.7 to $2.4 \mu$ by 6.6 to $14 \mu$ long.

Bergey (1923, p. 411) includes this genus as the third in the family Achromatiaceae with the description: "Colorless, motile, slightly bent, somewhat pointed at the ends, with drops of sulphur within the cells and a small number of flagella at the ends."

The type species may be designated as Thiospira Winogradskyi Wislouch. 
Thiospirillum. A genus of red sulphur bacteria named by Winogradsky (1888) to include the spiral sulphur bacteria. The genus is apparently a synonym of Ophidomonas Ehrenberg (q.v.). Two species, Thiospirillum sanguineum and Th. jenensis are included.

The genus is reduced to subgeneric rank under Spirillum by De Toni and Trevisan (1889, p. 1012). It is recognized as valid by Migula (1900, II, p. 1049), "Zellen frei, zeitlebens schwarmfähig, spiralig gewunden" (1904, p. 146), E. F. Smith (1905, p. 164) and Frost (1911, p. 62).

Orla-Jensen $(1909$, p. 330) used this generic name to include colorless sulphur bacteria of the type described by Omelianski (1905, p. 769) changing the name of the corresponding red forms (incorrectly) to Rhodospirillum.

Enlows (1920, p. 94) designates the type species as Thiospirillum sanguineum (Ehrenberg) Winogradsky.

Buchanan (1918, p. 471) gives the following description:

Spiral motile bacteria containing sulphur granules and bacterio-purpurin .

The type species is Thiospirillum sanguineum (Ehrenberg) Winogradsky.

Bergey et al. (1923, p. 402) followed Buchanan.

Thiothece. A genus of sulphur bacteria named by Winogradsky (1888, p. 82) with the species Thiothece gelatinosa. Winogradsky gives the following description:

Dieser Organismus zeigt in seinem Wachsthumsmodus eine vollkommene Uebereinstimmung mit der Chroococcaceen-Gattung Aphanothece Nägeli. Indessen wäre eine Vereinigung dieser neuen Gattung mit Aphanothece unstatthaft oder wenigstens verfrüht. Von dieser unterscheidet sie sich durch ihr Pigment und den Schwefelkörnergehalt, hauptsächlich aber durch die Fähigkeit der Zellen, in den Schwärmzustand überzugehen, was bis jetzt unter allen Chroococcaceen, soviel ich weiss, nicht bei Merismopedia beobachtet worden ist.

De Toni and Trevisan (1889, p. 1040) recognize the genus with the following diagnosis:

Cocci globosi vel divisionis tempore globosovoidei, pauci, in muco matricali sparsi, remoti, cystidibus universalibus amplissimis, crassissimis, persistentibus, homogeneis, non lamellosis, gelatinososubcartilagineis, persistentibus, involuti. Cystides speciales nullae. Coccorum divisio in unam directionem.

Migula (1900, II, p. 1046) (1904, p. 146), E. F. Smith (1905, p. 164) and Frost (1911, p. 61) discuss the genus. The description given by Smith follows: 
Families enclosed in a thick gelatinous cyst. Cells capable of swarming and very loosely embedded in a common gelatin. When the swarm stage supervenes, the cells lie more loosely, the gelatin is swollen, and the cells swarm out singly and rather irregularly.

Orla-Jensen (1909, p. 334) renamed this genus Rhodothece.

Buchanan (1918, p. 469) included this as the third genus of the tribe Amoebobacterieae with the description:

Cells spherical, in families enclosed in a thick, gelatinous cyst. Cells capable of swarming and very loosely embedded in a common gelatin. When the swarm stage supervenes, the cells lie more loosely, the gelatin is swollen, and the cells swarm out singly and rather irregularly.

The type species is Thiothece gelatinosa Winogradsky.

Bergey et al. (1923, p. 399) followed Buchanan.

Thiothrix. A genus of sulphur bacteria proposed by Winogradsky (1888, p. 39) with the following diagnosis:

Fäden unbeweglich, gegliedert, mit einer zarten Scheide, einen deutlichen Gegensatz von Basis und Spitze zeigend, durch ein Gallertpolster an feste Gegenstände befestigt, unter normalen Wachsthumsbedingungen dicht mit Schwefelkörnern gefüllt; Reproduction durch Stäbchengonidien, welche auf festen Gegenständen kriechend sich langsam bewegen, nach kurzer Bewegungsdauer sich auf verschiedene Gegenstände festsetzen und zu Fäden auswachsen.

The genus is recognized by many subsequent authors, among them Migula (1897, p. 40), Fischer (1897, p. 32), Migula (1894, p. 238) says: "Thiothrix Winogradsky. Unverzweigte in feine Scheiden eingeschlossene, unbewegliche Fäden mit Teilung der Zellen nach einer Richtung des Raumes. Die Zellen enthalten Schwefelkörnchen)," Chester (1899, p. 64), Migula (1900, p. 1039), Chester (1901, p. 378), Fischer (1903, p. 61), E. F. Smith (1905, p. 162), Orla-Jensen (1909), Heim (1911, p. 254), Frost (1911, p. 60). The generic description by Smith is as follows:

Threads attached, not uniformly thick, enveloped in a delicate sheath which is not easily demonstrable, non-motile, contents containing sulphur granules. The threads produce rod-shaped conidia at their end. These conidia, which are selfmotile by means of a slow, creeping motion, attach themselves by one end to any sort of substratum, extrude a slime cushion at the base, bend over ordinarily in their middle to a nearly right angle and grow into a new thread. Habitat, hot sulphur springs.

Buchanan (1918, p. 463) included this genus as the first in the family Beggiatoaceae with the following description: 
Filament non-motile, segmented, a definite differentiation into base and tip, attached, usually filled with sulphur granules. The threads produce rod shaped conidia at their ends. These conidia are self motile by means of a slow creeping motion, attach themselves and develop into new threads. The habitat is hot sulphur springs.

The type species is Thiothrix nivea (Rabenhorst) Winogradsky.

Bergey et al. (1923, p. 408) followed Buchanan.

Thiotrix. A variant spelling of Thiothrix used by Schmidt and Weis (1902, p. 92). It is spelled thus in a key. Probably a misprint, as Thiothrix is used later in the text.

Tilletia. A generic name given by Tulasne (1847) to a group of the smut fungi. According to Trevisan $(1879$, p. 60) several bacteria were incorrectly placed in the genus by Hallier (1869) under the names of Tilletia scarlatinosa and Tilletia diphtherica.

Tissierillus. A name proposed by Heller (1922, p. 27) for a genus of Putrificoideae with the description:

Putrificoideae that attack sugars and clot milk. Slender Gram-negative or Gram-positive rods with oval terminal spores. Colonies in deep agar have radiate periphery and opaque center. Frequently intestinal saprophytes.

Type species T. paraputrificus (Baciillus paraputrificus defined by Bienstock) as described by McIntosh under the name Bacillis putrificus. Ferments glucose, maltose, lactose, sucrose and starch.

Treponema. A generic name proposed by Schaudinn (1905, p. 1728) for the species Treponema pallida, the causal organism of syphilis. This organism was first named Spirochaete pallidum by Schaudinn and Hoffmann (1905), later the generic name Spironema (q.v.) was proposed by Vuillemin (1905). Schaudinn noted that Spironema was preoccupied, and proposed Treponema. A short time later Microspironema was proposed by Stiles and Pfender (1905). Blanchard (1906, p. 4) gives the following generic diagnosis:

Corps spirale, non aplati, à section cylindrique, effilé aux extrémites. Un flagelle a chaque extremité; pas de membrane ondulante. Multiplication par division longitudinale, le stade initial pouvant être marque par la duplicite du flagelle à l'une des extremities. Une seule éspéce certaine: $\operatorname{Tr}$. pallidum (Schau$\operatorname{dinn}(1905)$.

This generic name was also used by Swellengrebel (1907, p. 582). Dobell (1910, p. 536) extended the definition to include all the spirochetes parasitic in animals. Doflein (1911), treats Treponema as a subgenus under Spirochaeta. Gonder (1914, p. 687) gives the following description: 
Der einzellige Organismus ist stark flexibel, wodurch neben der schrauben oder korkzieherartigen Bewegung auch eine schlängelnde, peitschende. Bewegung hervorgerufen werden kann. Die eng gewundene Spirale bleibt dabei fast unverändert, ist präformiert. Besonders bei den pathogenen Formen ist die Zahl der steilen Windungen auffallend grosz. Eine feine plasmatische Hülle (periplast), die an den Enden in feinste geiszelartige Fortsätze auslaufen kann, ist jedenfalls vorhanden. Die Fortpflanzung geschieht, soweit bis heute festgestellt werden konnte, durch Längs- oder Querteilung.

Winslow et al. (Committee Soc. Am. Bact., 1917, p. 563) include this as genus four of the family Spirochaetaceae with the description:

Treponema Schaudinn. Parasitic and frequently pathogenic forms with undulating or rigid spirilliform body. Without crista or columella. With or without flagelliform tapering ends.

The type species is Treponema pallidum Schaudinn.

Buchanan (191S, p. 544) proposed the following description:

Cells slender, spiral, not flattened, attenuated at tips, without crest. Multiplication by longitudinal or by cross division. Parasites in warm-blooded animals. Motile.

The type species is Treponema pallida Schaudinn.

Castellani and Chalmers (1919, p. 454) include this as the single genus of the family Treponemidae q.v.

Bergey et al. (1923, p. 426) include this genus as the fifth in the family Spirochaetaceae with the diagnosis: "Parasitic and frequently pathogenic forms with undulating or rigid spirilliform body. Without crista or columella. With or without flagelliform tapering end."

Treponemidae. A family name proposed by Schaudinn (1905) according to Castellani and Chalmers (1919, p. 454). The latter authors give the following description:

Spirochaetacea with a minute threadlike body twisted into numerous fine coils, with pointed tapering extremities. The body is cylindrical on section, and not flattened, and the spirals appear preformed. There is no undulating membrane. Transverse and longitudinal division have been observed, the latter type being the only one found in cultures.

One genus only, Treponema, is included.

Trichobacteria. A group name proposed by Messea (1891) and used by many authors for the filamentous bacteria.

Trichobacteriaceae. A family of bacteria named by Fischer (1895, p. 13S) to include the filamentous bacteria. Fischer's statement follows: 
Sämtliche Bakterien möchte ich zunächst in zwei Orduungen eintheilen, die Haplobakterien, Einzelbakterien, und die Trichobakterien, Fadenbakterien. Das unterscheidende Merkmal liegt in dem Bau des Vegetationskörpers, der bei den Trichobakterien immer ein unverzweigter oder verzweigter aus einzelnen aufgebauter Faden ist, während die Haplobakterien einen einzelligen Vegetationskörper besitzen, der kugelig, stabartig oder schraubig ist. Wenn bei den Trichobakterien die Fäden in ihre einzelnen Glieder zerfallen und diese zuschwarmen, so haben wir hier eine Fortpflanzungs erscheinung vor aus, die einzelnen Glieder werden zu Schwärmern, zu Gonidien. Der vollendet erwachsene Trichobakterien "im Faden."

The genera included are Crenothrix, Thiothrix, Cladothrix and Beggiatoa.

The same family name was used by Orla-Jensen (1909, p. 303) to designate the typically filamentous water bacteria showing no tendency to the formation of a mycelium. The family is included in the Cephalotrichinae, and includes the following genera, Cladothrix, Leptothrix, Crenothrix, Spirochaeta, Spirophyllum, Beggiatoa and Thiothrix.

Trichobacterinae. An ordinal name used by Fischer (1897, p. 32) for bacteria whose "vegetative phase consists of an unbranched or branched filament or chain of cells, the individual members of which break off as swarm spores (gonidia)." The order contains the single family Trichobacteriaceae.

This name is also used by Schmidt and Weis (1902, p. 373) and by Frost (1911, p. 59) as a name for a suborder.

Trichobakterien. A variant (German) spelling of Trichobacteriaceae used by Fischer (1595, p. 138) and others.

Trichogenae. A sub-family of Schizomycetaceae named by Trevisan (1888). De Toni and Trevisan (1889, p. 924) give the following diagnosis:

Adsunt tres status evolutionis, h.e. filamenta (individua), baculi, cocci. Filamenta (status primarius, initialis seu archetypus) tum vaginata tum evaginata, ut plurimum basi ab apice superiori distincta praedita, affixa vel e puncto centrali radiantia, rarius utrinque (apicibus conformibus) libera. Baculi et cocci in filamentis inclusi.

This subfamily together with Baculogenae and Coccogenae constitute the family Schizomycetaceae. Trichogenae is divided into the following tribes, Crenotriceae, Cladotriceae, Kurthieae and Leptotrichieae.

Trichomycetes. A group name used by various writers to include various genera of the thread bacteria, probably first by Petruschky (1903). Jordan (1910, p. 411) gives the following discussion: 
The organisms included under this head are filamentous forms and possess many characters relating them to the group of true molds (Hyphomycetes) rather than to the bacteria proper (Schizomycetes). They may be said perhaps to stand in an intermediate position between the bacteria and the higher fungi. All have a more complicated cycle of development than has been observed in any of the true bacteria. On the other hand, they are distinguished from the higher fungi by the slenderness of their filaments and their more simple life-history. Among the so-called Trichomycetes themselves great confusion has prevailed both in classification and in nomenclature, and there is still far from being any universal agreement concerning the subdivision of the group and their designations.

The genera Leptothrix, Cladothrix, Nocardia, and Actinomyces are included.

Petruschky (in Kolle and Wasserman, Vol. 5, p. 267) includes Actinomyces and Streptothrix under the heading of Trichomycetes but places Cladothrix and Leptothrix with the Trichobacieria.

Heim (1911, p. 253) has modified the conception somewhat. $\mathrm{He}$ says:

Der Name ist von J. Petruschky für eine Gruppe von Microörganismen vorgeschwungen worden, die man bisher entweder under die Hyphomyzeten eingereiht oder denen man eine besondere Stelle zwischen diesen und den Schizomyceten zuerkannt hat. Es sind fadenförmige Gebilde mit echten Verzweigungen, die entweder spitz oder mit einer kolbigen Anschwellung endigen und in ihren Breitendurchmesser die Bakterien nicht beträchtlich übertreffen.

Diese Eigentümlichkeiten kommen vielen Bakterien unter gewissen Ernährungsbedingungen $\mathrm{zu}$, darum ist man geneigt, solche, und zwar insbesondere die Tuberkel-, Rotz-, Diphtheriebazillen und ihre Verwandten hierher zu rechnen.

Castellani and Chalmers (1919, p. 1040) make this a synonym of Nocardiaceae.

Trichomyzeten. A variant of Trichomycetes used by Heim (1911, p. 253).

Tricogene. A variant of Trichogenae used by Trevisan (1889, p. 9) for the first suborder of bacteria. He states: "Tre stati di sviluppo vegetativo: 1. Filamenti; 2. Baculi; 3. Cocchi. Filamenti; (state primario, iniziale, archetipo) ora rivestitidi vagina propria ambiente, ora non vaginati, per lo piu forniti di base distinta dalla estremità superiore, affisi o irradianti da un punto centrales, di rado liberi colle due estremità perfettamente eguali. Baculi e cocchi provenienti dai filamenti." 
Tyrothrix. A name proposed by Duclaux $(1882$, p. 79) as a generic name for bacteria found in cheese. The first species named is Tyrothrix tenuis. The description is summarized by Migula (1900, p. 587 under Bacillus tenuis) as follows:

Diese Bakterienart bildet kleine, cylindrische, lebhaft bowegliche, im Innern scheinbar fein granulierte, $0.6 \mu$ dicke und $3.0 \mu$ lange Stäbchen, die oft zu langen Fäden auswachsen. Dieselbe ist sporenbildend, ihre Sporen können in alkalischen Nährmedien ein Temperatur von $115^{\circ} \mathrm{C}$ ertragen. Von besonderem Interesse ist ihr Verhalten in Milch. Vor allem wird das Casein gefällt, das Coagulum ist jedoch weicher als das durch Lab verursachte. Späterhin beginnt in den oberen Schichten die Lösung desselben; ist dieselbe beendet, so zeigt das Ganze eine opalescierende Flüssigkeit. Duclaux schliesst aus dieser Erscheinung, dass Tyrothrix tenuis eine labähnliche, Caseinfällende Substanz (présure) und einen Caseinlösenden Stoff (Casease) abscheidet. Diese Substanz wird ron dieser Species in bestimmten Zeitpunkten in sehr grosser Menge produziert und kann durch Alkohol isoliert werden. Weigmann stellte die Casease in Substanz dar und fand, dass dieselbe, frischer Käsemasse zugesetzt, die Reifung des Käses ausserordentlich beschleunigt.

Nach Duclaux' Ansicht dient die Casease dazu, um das Casein in eine für die Bakterien assimilierbare Verbindung (Caseone) zu verwandeln. Dieselbe tritt in den Lebenskreislauf der Zelle ein, um in neue Verbindungen (Extraktivstoffe?) verwandelt zu werden. Das Endprodukt der Zersetzung dieser "Caseone" besteht aus einem Gemenge von Ammoniaksalzen, Leucin und Tyrosin. Tyrothrix tenuis erzeugt in Milchkulturen speciell valeriansaures Ammoniak. Glycerin wird von demselben vollkommen verbrannt und der milchsaure Kalk in Calciumkarbonate verwandelt. Die nachfolgenden Tyrothrixarten liefern auch Casease, jedoch nicht in solcher Menge wie Tyrothrix tenuis.

In addition to this species, six other aerobic forms were described, Tyrothrix filiformis, T. distortus, T. geniculatus, T. turgidus, T. scabei and $T$. virgula, also three anaerobes $T$. urocephalum, $T$. claviformie and $T$. catenula. The various species described have little in common other than origin.

Maggi (1886, p. 17) listed Duclaux's species with brief descriptions, including the genus as valid in his classification.

De Toni and Trevisan $(1889$, p. 963) renamed Tyrothrix tenuis as Bacillus tenuis (Duclaux) Trevisan. The other species are distributed in Bacillus and Cornilia.

Macé states (1897, p. 486):

Duclaux (2) a groupé sous la designation de Tyrothrix, sans toutefois vouloir lui attribuer une valeur generique, toute une serie d'interessantes especes qu'il a rencontrees dans les fermentations des albuminoides, en particulier de la caseine du lait. Ces Tyrothrix appartiennent tous au genre Bacillus, tel que nous le comprenons ici. 
Migula (1900, II, pp. 322-588) has apportioned some ten species between the genera Bacillus and Bacterium. The genus name is rejected by E. F. Smith (1905, p. 174).

Lehmann and Neumann (1907, p. 396) make the following statement:

Das Genus Tyrothrix Duclaux fällt mit Bacillus zusammen, es bezeichnet ursprünglich aus Milch und Käse stammende, sporentragende, längere Fäden bildende Arten. Zwei spezies sind untenbeschreiben. Die Tyrothrix arten sind neuerdings von Niede (C. B. L. XII. 344) mit einem von ihm genau beschriebenen Bacillus parvus für synonym erachtet worden.

The lack of adequacy in the original description make determination of the nomenclatural status of this genus difficult. It is probably a synonym of Bacillus Cohn. The type species may be designated as Tyrothrix tenuis.

Ulvina. A generic name applied as Ulvina aceti to mother of vinegar by Kuetzing in the 11th decade of his Algae aquae dulcis (1837). In the same year (1837, p. 26) the organism is mentioned by name and later (p. 30) illustrated.

Later (1843, p. 149) the following generic description is given: "Stratum compactum lubricum ex granulis minutissimis compositum." Four species are listed, $U$. myxophila from sour quince slime, $U$. rubi-idaei from fermenting raspberry juice, $U$. aceti from mother of vinegar, and $U$. sambuci from the aqua sambuci flor, of the apothecary.

Naegeli (1849, p. 5) mentions Ulvina as a genus to be included among the fungi and excluded from the unicellular algae.

In his Species Algarum (1849, p. 147) the generic description is "Globuli gonimici minutissimi in stratum compactum cohaerens fluitans coaliti." The same four species previously described are listed. Ulvina aceti is again mentioned in 1852, (p. 269).

Rabenhorst $(1864$, p. 8 ) in a footnote under Subfamilia II, Leptothricheae says:

Fungorum genera Leptothricheis et Oscillarieis quasi affinia:

a. Cryptococcus: Cellulae sphaericae, in stratum mucosum aggregatae.

b. Ulvina: Cellulae minutissimae, in stratum membranaceum coalitae.

According to De Toni and Trevisan $(1889$, p. 1021) (g.v.) the Ulvina aceti was termed Mycoderma aceti by Pasteur (1868, p. 106), Bacterium aceti by Lanzi (1876, p. 257), Torula aceti by Saccardo (1878, p. 315), Bacillus aceti by Schroeter (1886, p. 161). 
Migula (1900, p. 399) gives an incorrect reference to the name Ulvina (Kuetzing 1837, p. 385).

The name has not been used by recent writers. It is rejected by E. F. Smith (1905, p. 174).

It is probable that Ulvina has priority as a separate generic name for the acetic acid bacteria. However, the author of the name undoubtedly was dealing with mixed cultures of such a nature that a reasonably certain identification of his species (type) Ulvina aceti is probably not practicable. To eliminate this difficulty, Winslow et al. (Committee Soc. Am. Bact., 1917) have accepted the later name Acetobacter.

Umbina. According to Migula (1897, p. 10) this name was used by Naegeli (1848) (should read 1849) in the combination Umbina aceti for the organism forming mother of vinegar.

An examination of Naegeli's work shows no use of this name, but instead (p. 5) a statement that Ulvina belongs with the unicellular fungi and not the algae.

In 1857 (p. 760) he includes Umbina aceti with Nosema, Bacterium, Vibrio, Spirillum Hygrocrocis and Sarcina in his new group, Schizomycetes. He says: "Umbina aceti die Essigmutter, ist mit Nosema sehr verwandt, jedoch fallen die Zellen nicht auseinander, sondern bleiben vereinigt."

Umbina is a synonym of the older Mycoderma and Ulvina.

Urobacillus. A physiological genus proposed by Miquel (1889, p. 517) for certain rod shaped bacteria found in decomposing urine. The species described by Miquel were for the most part spore-bearing motile rods. The first species described is Urobacillus Pasteurii and may be designated (Enlows, 1920, p. 96) as the type.

The name has not apparently been recognized by many authors as a true generic designation. It is used by Beijerinck (1901, p. 40) also $(1902$, p. 30). It is rejected by E. F. Smith (1905) as invalid. It is proposed as the third genus of the family Alkalibacteriaceae by Orla-Jensen (1909, p. 339). He says,

Einen besonderen $Z$ weig der aëroben Bacillen bildet die Gattung Urobacillus. Diese ist jedoch ohne Zweifel desselben Ursprungs wie die Gattung Bacillus; denn die meisten Proteus Bakterien (auch Lb. prodigiosum) hydrolysieren den Harnstoff. Diese Fähigkeit wird auch bei einzelnen Coli-Arten, vielen Kokken und den meisten anaëroben Fäulnisbakterien angetroffen und kann deshalb nicht für sich allein als ein Gattungsmerkmal dienen. Eine Urobakterie ist erst dann typisch, wenn sie sich derart an die durch die Hydrolyse des Harnstoffes hervorgerufene hohe Alkalität gewöhnt hat, dasz sie für die gewöhnlichen Nährsubstrate 
zu säureempfindlich geworden ist. Die ausgesprochensten Urobakterien verflüssigen die Gelatine nicht, denn sie Bedürfen keiner anderen Stickstoffquellen als des normalerweise reichlich vorhandenen Harnstoffes, und proteolytische Enzyme würden wegen der gebildeten groszen Ammoniakmenge überhaupt nicht wirken können. Die Entwickelung zu den, was sonst der Fall ist-von gelatineverflüssigenden Formen. Nach Miquel sollen die wichtigsten stäbchenförmigen Urobakterien die folgenden sein:

Nichtsporenbildend $\left\{\begin{array}{l}\text { Urobacillus Miquelii } \\ \text { Urobacillus Schützenbergii I } \\ \text { Urobacillus Schützenbergii II } \\ \text { Urobacillus Freudenreichii }\end{array}\right\}$ Gelatineverflüssigend

Sporenbildend $\quad\left\{\begin{array}{l}\text { Urobacillus Leubei } \\ \text { Urobacillus Maddoxii } \\ \text { Urobacillus Pasteurii } \\ \text { Urobacillus Duclauxii }\end{array}\right\} \begin{gathered}\text { Nichtgelatineverflüssig- } \\ \text { end }\end{gathered}$

Da die drei ersten Arten keine Sporen bilden, sind sie laut unserer Definitioneinfach den Proteus-Bakterien zuzuzählen; Liquidobacterium Miquelii bildet auch in der Gelatine die für diese Gattung charakteristischen bildende Art, Urobacillus Freurlenreichii, und sie nähert sich dadurch wie auch durch die Gelatineverflüssigung den ältesten Arten der Gattung Bacillus.

Urobacillus is probably best regarded as a synonym of Bacillus, or possibly as a subgenus.

Urobacter. According to Cohn (1875, p. 188), Trecul used the name Urobacter as the name of a bacterial genus. The original paper has not been found. Cohn says "Ebenso hatte Trecul in den geschwänzten Bacterien eine selbständige Gattung erblickt, die er Urobacter nannte."

The name is rejected by E. F. Smith (1905, p. 174).

Urocephalum. A name used by Trecul (1865, p. 432) to designate certain granules of uncertain affinities found in decaying plant cells. The name has apparently never been used in a strict generic sense, although Trecul undoubtedly saw bacteria. He says:

Malgré la variété des formes de ces petits végétaux, ou plutôt à cause de cette variété même, puisque l'on passe d'une forme à l'autre par toutes les gradations; en raison aussi de l'amidon qu'ils contiennent, et pour rappeler la ressemblance des formes cylindroides avec les Bactéries, je crois utile de les réunir sous lenom d'Amylobacter. Si on voulait les diviser d'après les formes les plus disparates,

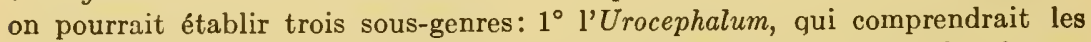
formes en têtard; $2^{\circ} 1^{\prime}$ Amylobacter vrai, auquel seraient attribuées les formes cylindracées; $3^{\circ}$ le Clostridium, qui renfermerait les formes en fuseau.

What Trecul observed were probably butyric acid bacteria. Migula (1897, p. 324) gives this as a synonym of Clostridium butyricum Prazmowshi. 
The name is rejected by Erwin F. Smith (1905, p. 174).

Urococcus. Urococcus was proposed as a generic name by Kuetzing (1849, p. 206), for a group of algae. This author ascribed the name to Hassall (1845, p. 322) but this latter author used the name Ourococcus as a subgeneric designation under the genus Haematococcus.

Miquel (1888, p. 518) used this as a generic designation for cocci bringing about ammoniacal fermentation of urea.

Beijerinck (1902, p. 37) says:

Pour reconnaître et distinguer les urobactéries, M. Miquel les a classees en coques qu'il designe par le nom d'Urococcus, et en bacilles qu'il appelle Urobacillus. Dan le genre physiologique Urococcus il classe 9, dans le genre Urobacillus 8 espèces.

The description and designation of species by Miquel have not been found. However, Macé states (1912, p. 590) that the Micrococcus ureae Van Tieghem is probably the Urococcus Van Tieghemi Miquel.

Beijerinck (1901, p. 54) renamed the Micrococcus ureae Cohn as Urococcus ureae.

The nomenclatural status of the genus and the designation of type species are uncertain.

Urosarcina. A generic name used by Miquel (1888, p. 517) for a motile sarcina form in urine. It is listed as a synonym of Sarcina by De Toni and Trevisan (1889, p. 1044) but no species is listed in which the name was used. Beijerinck (1901, p. 43) states that this organism is a bacillus. It is rejected as a generic name by E. F. Smith (1905, p. 174).

Vallorillus. A generic name proposed by Heller (1922, p. 16) as the seventh in the Clostridioideae. The description given is:

Clostridioideae that do not liquefy gelatin. They produce gas and acid in meat medium but no digestion. They clot milk slowly and attack various sugars. Rather slender Gram-positive rods with little or no tendency to form spores. Form lenticular colonies, "coeurs jaunes," in deep agar. Many invade tissue, producing oedema and gas. Pathogenicity transitory.

Type species V.fallax (Bacillus fallax Weinberg and Séguin) as described by the Committee (p.27), the type which ferments glucose, laevulose and maltose.

Vibrio. A generic name proposed by Miüller (1773, p. 39) in the group Infusoria crassiuscula with the generic description "Vermis inconspicuus simplicissimus, teres elongatus." Other descriptions of the genus as taken from the keys are "Tentaculis destitute, vagantes, 
organis externis nullis, teretes, corpus elongatum," "Infusoria" "Aquatici," "Hyalini," "Gelatinosi, Vibrionis species." "Tentaculis nullis, inconspicui, teretes" "Vacillantes pellucidi." The species first described is Vibrio lineola, which would thereby become the type. Other species named are Vibrio bacillus and Vibrio undula.

Mueller (1786, p. 43) described Vibrio lineola as follows:

Linearis minutissimus. Animalculum omnium minutissimum; monadem termonem exiguitate, fere superans, Vibrioneque Bacillo tricies minus et prorsus diversum. Motus tremulus myriadum punctulorum oblongorum obscuriorumque in unica guttula, seu undulatio oculo, lenticula maxime amplificante, exhibetur. In infusione vegetabili substantiam aquae post plures dies fere adimplet; in alia foetente ultra trimestre servata, et in non foetente post menesem Lemna cooperta cum Cyclidio glaucomate.

Other species named are Vibrio rugula, V. bacillus, $V$. undula, $V$. serpens and $V$. Spirillum which quite certainly were forms now included among the bacteria. Altogether some 31 species were described. The fact that the first named organism probably belonged to the bacteria, though many of the others were protozoa, makes its status in bacteriology a matter of concern.

Two lines of study are necessary in determination of the present nomenclatural status of this genus. First, it is of interest to note the gradual change in the concept of this genus, and second, to trace the fate of Müller's type species.

Bory de St. Vincent (1826, p. 533) included Vibrio as the third genus of his family Vibrionides. The organisms are described as linear or worm-like, body diaphanous, attenuate at both tips.

Ehrenberg (1828, p. 24) gave the following generic diagnosis: "Animal Polygastricum, Anenterum, elongatum, monomorphum (contractione non incrassatum), transverse in multas partes sponte dividuum, ore terminali, corpore filiformi cylindrico undatim flexili." He included two species of Mueller, V. lineola and $V$. rugula.

Ehrenberg (1838) split this genus into three, Vibrio, Spirillum and Spirochaeta. Vibrio included the organisms which are straight rods, but are flexuous when in motion. Spirillum included the spiral nonflexuous forms, and Spirochaeta the spiral flexuous types. He described six species in the genus Vibrio, V. lineola, tremulans, subtilis, rugula, prolifer and bacillus. In 1840 he named two organisms which can be recognized even today, Vibrio syncyaneus from blue milk and $V$. synxanthus from yellow milk. 
Fuchs (1841, p. 190) also described Vibrio cyanogenus and $V$. xanthogenus.

Dujardin (1841, p. 216) characterized the genus as follows: "Corps filiforme, plus ou moins distinctement articulé par suite, d'une division spontanée imparfaite, susceptible d'un mouvement ondulatoire comme un serpent." The family of Vibrionia he characterized as "Animaux sans organes locomoteurs visibles, se mouvent par l'effect de leur contractibilite generale." Four species of Vibrio are recognized, V. Lineola, rugula, bacillus and serpens.

Leidy $(1849$, p. 228$)$ was apparently the first to suggest the placing of this genus among plants rather than animals. He discussed two species which he believes belong to the genus Vibrio, from the coecum of Julus. He says:

Even those moving filamentary bodies belonging to the genus Vibrio, I am inclined to think, are of the character of algous vegetation. Their movement is no objection to this opinion, for much higher confervae, as the Oscillatorias, are endowed with inherent power of movement, not very unlike that of the Vitrio, and indeed the movement of the latter appears to belong only to one stage of its existence. Thus, in the toad (Bufo americanus), in the stomach and small intestine, there exist simple, delicate, filamentary bodies, which are of three different kinds. One is exceedingly minute, forms a single spiral, is endowed with a power of rapid movement, and appears to be the Spirillum undula of Ehrenberg; the second is an exceedingly minute, straight and short filament, with a movement actively molecular in character, and is probably the Vibrio lineola of the same author; the third consists of straight, motionless filaments, measuring $1 / 1125$ th inch long, by $1 / 15,000$ th broad; some were, however, twice, or even thrice this length, but then I could always detect one or two articulations, and these, in all their characters, excepting want of movement, resemble the Vibrio. In the rectum of the same animal, the same filamentary bodjes are found, with myriads of Bodo intestinalis; but the third species, or longest of the filamentary bodies, have increased immensely in numbers, and now possess the movement peculiar to the Vibrio lineola which, however, does not appear to be voluntary, but reactionary; they bend and pursue a straight course, until they meet with some obstacle, when they instantly move in the opposite direction, either extremity forward."

Perty (1852) divides the family Vibrionida into two groups, Spiritlina, containing organisms in chains or filaments spirally wound and Bacterina in which the filaments are flexuous or straight. In the group Bacterina three genera were included, Vibrio, Bacterium and Metallacter. He retained only two species in Vibrio, V. rugula and $V$. lineola but recognized $V$. syncyaneus and $V$. synxanthus. Davaine (1859) used practically the same definition of the genus. 
According to Trevisan (1885, p. 83), Pacini (1854, p. 40) used the designation Vibrio cholerae for the organism causing Asiatic cholera, but a search of the original paper fails to show it. The nearest approach is the following statement:

Finalmente notero che nel fluido intestinale trovai ancora una grandessima quantita di vibrioni; i quali, attesa la loro estrema tenuita, possono facilmente passare inosservati, quando siano dispersi in una certa quantità di fluido. Questi vibrioni avevano una lunghezza di 0.0020 a $40 \mathrm{~mm}$, ed un diametro di 0.0005 a $7^{\mathrm{mm}} \cdot$ : mentre avevano qualche simiglianza al Bacterium termo di Dujardin.

Cohn (1854) concluded the Bacterium termo of Dujardin was the Vibrio lineola of Ehrenberg, and a result of his study of the organism, placed it in the plant kingdom.

Rabenhorst (1865, p. 71) gives the following generic diagnosis: "Trichomata abbreviata filiformia, plus minus distincte articulata, motu proprio, plerumque flexuoso praedita; cytioplasma pallidum, interdum dilute seruginosum, coeruleum vel caesium." He lists seven species, three described by Ehrenberg and four by Mueller.

Cohn $(1872$, p. 178) emended the definition of the genus. The organisms are characterized by the wavy motion of the filaments, which by their rotation give the appearance of sinuous motion, and constitute a transition to the spiral bacteria. The two species named are $V i b r i o$ rugula and $V$. serpens.

Cohn (1875) included the genus in his tribe Nematogenes. Luerssen (1879, p. 25) used the same definition and species. Trevisan (1879, p. 148) gave the following definition "Somatia cylindrica, articulata, valida, abbreviata, undulato-flexuosa." The two species listed are $V$. serpens and $V$. rugula. This genus is included in the subtribe Euvibrionieae. Magnin (1880, p. 92) lists the same species. Lehmann and Neumann (1901) credit Vibrio cholerae to Buchner (1884). Van Tieghem (1884) defined the genus as made up of spiral cells, promptly dissociating. Zopf (1885, p. 61) states "Faden schraubig, in den langeren oder kurzeren Gliedern Sporenbildung." Trevisan (1885, p. 83) replaced this with Pacinia with Koch's comma bacillus as the type. Hueppe (1886) included forms with spiral cells, which produce endospores and change the cell form when spores are produced. Flügge (1886) states that this genus differs from Spirillum in that the spirals are not as pronounced. Maggi (1886, p. 176) included Vibrio as the first genus of his order Ophidobacteries. Schroeter (1886, p. 166) introduced Microspira with Koch's comma bacillus as the type. Hansgirg (1888, p. 264) makes this the first subgenus of the genus Spirillum. 
with the definition "Zellen farblos, meist ohne grössere Schwefelkörnchen in plasmatischen Inhalte." De Toni and Trevisan (1889, p. 1005) give the following diagnosis:

Baculi cylindrici, leviter curvuli v. undulatoflexuosi (nunquam 'spirales), plasmate uniformiter diffuso instructi. Sporae (endosporae) macrosomae, ovoideae in baculorum specialium apice claviformi-intumescenti ortae. Baculi speciales, qui ad sporas ferendas praeparantur, fiunt breviores, crassiores, plasmate tenuissime granuloso.

They list as species Vibrio rugula, V. urinae, V. amphibolus and $V$. typhosus.

Billet (1890, p. 24) defined the genus as made up of curved organisms with a single curve.

Sternberg (1892, p. 18) makes the following statement:

Filaments flexible, straight or sinuous; movements sinuous. A considerable number of bacteria which are usually seen as short, curved rods, but which may grow out into long, spiral filaments, are described by some authors under the generic name Vibrio, e.g., the so-called "comma bacillus" of Koch-"Spirillum cholerae Asiaticae;" the spirillum of Finkler and Prior-"Vibrio proteus;" the spirillum described by Gameleia_"Vibrio Metschnikovi," etc. These microörganisms have not the characters which distinguished the genus Vibrio as established by Ehrenberg, and we prefer to follow Flügge in describing them under the generic name Spirillum.

Among those referred to by Sternberg who used Vibrio for the short spirals are Firtsch $(1888$, p. 369) who discussed Vibrio proteus (the Spirillum of Finkler and Prior), Gameleia (1888, p. 482). According to De Toni and Trevisan (1889, p. 1018) the name Vibrio cholerae was used by Pacini (1854). Pouchet (1849) five years before had observed vibrios in cholera stools. It is by no means certain, however, that these observers actually saw the true comma bacillus, but it is not improbable.

Lehmann and Neumann (1896, p. 316) give the following description:

Zellen kurz, schwach bögig, starr, kommaartig gekrümmt, zuweilen in schrau • benartigen Verbänden an einander hängend, stets nur mit einer, ausnahmsweise 2 endständigen Geisseln. Endosporen fehlen, nach Hüppe Bildung von Arthrosporen.

Macé (1897, p. 485) makes the following statement concerning the use of Vibrio:

Le genre Vibrio d'Ehrenberg etait trop peu homogene pour être conserve. Le plus grand nombre de ses espèces sont de vrais Bacillus, le restant des Spirillum. 
Il en reste la denomination francaise de Vibrion, que l'on ne doit pas considerer comme un terme de classification, mais comme une simple expression de valeur generale. Elle a été tres employee par l'école de Pasteur, qui l'a appliquee a bien des Bactéries mobiles, Micrococcus ou Bacillus. Le Vibrion pyogene est un Micrococcus; le Vibrion lactique, le Vibrion butyrique, le Vibrion septique, sont des Bacillus.

Fischer $(1897$, p. 32) ascribes an emendation of Vibrio to Loeffler. He includes in the genus the very slightly curved rods which are "comma" shaped; motile, monotrichous, with the type species Vibrio cholerae-asiaticae. Lehmann and Neumann (1901, p. 126) use this same definition. These authors credit the name Vibrio cholerae to Buchner (1884). Migula (1897 and 1900) follows Schroeter (1886) in the use of Microspira.

Matzuschita (1902) defines a Vibrio as a short spiral.

E. F. Smith (1905, p. 173) agrees that the original description of Vibrio by Müller does not define the organism, and accepts Loeffler's emendation of Vibrio with Koch's comma bacillus as the type.

Blanchard (1906, p. 1) credits Vibrio to Ehrenberg (1838) with $V$. comma as the type.

Flügge (1908) includes in Vibrio all comma shaped organisms with polar flagella, all gram negative.

Vuillemin (1913, p. 518) concludes that Vibrio as a generic name should be suppressed because of its varied uses and believes that if the short spirals are worthy of generic recognition, the name Microspira should be used.

Löhnis (1913) accepts the definition of Vibrio as a comma shaped rod.

Winslow et al. (Committee Soc. Am. Bact., 1917, p. 556) used the following definition, including Vibrio as the first genus of Spirillaceae.

Cells short bent rods, rigid, single or united into spirals. Motile by means of a single (rarely two or three) polar flagellum, which is usually relatively short. Many species liquefy gelatin and are active ammonifiers. Aerobic and facultative. No endospores. Usually Gram-negative. Water forms, a few parasites.

The type species is Vibrio cholerae (Koch) Buchner.

Buchanan (1918, p. 178) followed the committee, using the following diagnosis:

Short, bent rods, sometimes almost straight. Motile by means of a single (rarely 2 or 3) polar flagellum. Aërobic, and facultative. Grow well on ordinary 
media. Frequently liquefy gelatin. Not enlarged near center. No spores. Usually Gram-negative.

The type species is Vibrio cholerae.

Castellani and Chalmers (1919, p. 962) state:

Spirillaceae motile, with short comma-like cells, possessing one, rarely more, flagellum at one, rarely at both ends.

Type. It is difficult to decide which is the type of this genus so defined.

Remarks. The important species is the Vibrio comma Koch, 1854, which is the cause of Asiatic cholera, but there are many others which cause paracholera.

Bergey et al. (1923, p. 77) followed Castellani and Chalmers.

It is apparent that the modern use of the term Vibrio is not consistent with the conception of Vibrio lineola as the type. Apparently either the genus should be dropped as having a type species that cannot be identified, or there should be an agreement that Vibrio cholerae, a somewhat arbitrary choice, shall be selected as the type. The latter alternative is the one here adopted.

Vibrion. A casual name for bacteria apparently first used by Pasteur (1876) in the phrase "vibrion septique." Not a generic name.

Vibrionia. A family of protozoa used by Ehrenberg (1838) to include the genera Bacterium, Spirillum, Vibrio, Spirochaeta and Spirodiscus.

Perty (1952, p. 179) used this as the single family of his Sectio Lamprozoidia. It contained two subfamilies Spirillina and Bacterina.

It has also been used in a sense equivalent to "bacteria" (Quart. Journ. Mic. Sci., 1855, p. 205).

Vibrionides. The sixth family of the first order Gymnodes of Bory de St. Vincent's (1826, p. 533) group Microscopique.

The order Gymnodes is described as without tests, perfectly smooth, without cilia or other vibratile organs. The family is characterized as without appendages, linear or wormlike. Five genera are included, Spirilina, Melanella, Vibrio, Lacrimatoria and Pupella.

Vibrionieae. A tribe of bacteria created by Trevisan (1879, p. 137) with the following description:

Bacteriaceae pluricellulares. Individua e cellulis pluribus in somatia saepe filiformia dispositis conflata. Sporae intra somatium matricale uniseriales. Multiplicatio divisione somatiorum vegetativa semper ad eandem directionem longitudinalem.

It was divided into the subtribes Euvibrionieae, Myconostoceae and Cladothriceae. 
Vibrioniens. The single family of the first order of the Infusoria named by Dujardin (1841, p. 209). The diagnosis given is: "Animaux filiformes extrêmement minces, sans organisation appreciable, sans organes locomoteurs visibles." Three genera are included: Bacterium, Vibrio and Spirillum.

Vibriothrix. A generic name proposed by Castellani (1917). Castellani and Chalmers (1919, p. 1068) give the following description:

The mycelial articles are motile, of very different shape: bacillary, vibriolike, spirillum-like, at times club-ended. Globular or pear-shaped bodies of very variable size may be present. Gram-negative, not acid-fast. Cultivable on ordinary media.

Type species. Vibriothrix zeylanica Castellani, 1910.

Synonyms. Spirillum zeylanicum Castellani, 1910; Vibrio zeylanicus Castellani, 1913; Bacillus zeylanicus Castellani, 1913; Vibriothrix zeylanica Castellani, 1917 ; Spirobacillus zeylanicus Castellani, Spagnolo, and Russo, 1918.

Remarks. Very polymorphic organism vibrio-like, bacillus-like, and undulating forms being often found in the same preparation. Very small, medium size, and occasionally large roundish bodies are at times observed, and club-like forms may also be present.

The organism is motile, Gram-negative, not acid-fast. Easily grown on ordinary media. On potato the growth is often of a reddish colour. In broth there is often a pellicle; preparations from the fluid medium generally show a predominance of vibrio-like or bacillary forms, while in the pellicle long undulating forms are often found. On MacConkey's medium the colonies are white, and somewhat resemble those of the typhoid-dysentery group. The organism does not ferment any of the usual laboratory carbohydrates or alcohols: glucose,levulose, galactose, maltose, lactose, saccharose, mannitol, dulcite, raffinose. There is, in fact, frequently a production of alkalinity. Milk is not clotted and is rendered alkaline, and certain strains after several weeks may induce a certain degree of peptonization. The great majority of strains are non-pathogenic to rabbits and guinea-pigs.

\section{Weinbergillus. A generic name proposed by Heller (1922, p. 31)} with the following description:

Highly proteolytic Putrificoideae that in meat medium cause the formation of balls of amino-acid crystals. They digest the meat particles till their bulk is greatly reduced and form large amounts of ammonia, amino-nitrogen and fatty acids. They digest the casein in milk rapidly. Attack few or no sugars. Produce little or no gas in agar media. Gram-positive or Gram-negative rods with sub-terminal oval spores. Colonies in deep agar small, delicate woolly structures. May invade living tissue in company with other organisms, or at times alone, producing a rapid and complete digestion of muscular and connective tissue structures.

Type species W. histolyticus (Bacillus histolyticus Weinberg and Séguin) as described by Henry (p. 370). Weinberg and Séguin and the Committee allow con- 
siderable variation in characters for the strains termed by them Bacillus histolyticus.

Welchillus. A generic name proposed by Heller (1922, p. 18) with the following description:

Clostridioideae that liquefy gelatin but do not produce hydrogen sulfid demonstrable by lead-acetate-paper test in blood-broth. They produce much acid and gas on meat medium, but they do not digest it, nor do they digest casein, coagulated serum, or egg-white. They produce stormy fermentation of milk and attack many sugars vigorously. Their multiplication is extraordinarily rapid; they are killed by their own growth products in acid media, in which they fail to sporulate. Deeply Gram-positive non-flagellate rods with square ends. They produce oval subterminal or median spores in alkaline media, or in media free of fermentable carbohydrates; these spores do not bulge the sides of the bacilli. When growing rapidly the rods are very short, and resemble closely no other type bere listed except Stoddardillus. When growing slowly the rods are less abundant and longer, and may be mistaken for Martellillus and similar organisms. Typically intestinal saprophytes; ubiquitous. Many strains produce toxin and invade tissue, forming gas, and causing the formation of oedema, and in many cases causing the disintegration of muscle and of connective tissue without the production of a foul odor. This disintegration occurs only in vivo, and is probably due to the enzymes of the host tissue. Welchillus are the most frequent anaerobic invaders noted on the hospital autopsy table. The organisms are present in human intestines. Causative agents of a probably greatly overestimated percentage of gas gangrene cases following war wounds. Comparatively rare as animal invaders.

Type species W. aerogenes (Bacillus aerogenes-capsulatus Welch and Nuttall) type I as defined by Simmonds (type IV of Esty). Ferments besides other carbohydrates, inulin and glycerol. Usually pathogenic for guinea pigs.

Wesenbergus. A generic name proposed by Castellani and Chalmers $(1919$, p. 934) for the eighth genus of the tribe Ebertheae with the following description:

Ebertheae which ferment glucose completely and lactose partially producing acid, but no gas. Milk not clotted.

Type species. Wesenbergus wesenbergi Castellani, 1913.

Winogradskya. A generic name proposed by Trevisan (1889, p. 12). De Toni and Trevisan $(1889$, p. 1028) give the following description: "Baculi cylindracei et filamenta aggregata in familias zooglaeicas repetite ramosas, capsula tenui gelatinosa inclusa. Sporae ignotae."

One species is included. Winogradskya ramigera (Itzig). Trev. This is the Zoogloea ramigera Itzigsohn.

The genus is probably not tenable. 
Zaogalactina. A variant of the generic name Zoagalactina used by Sette $(1824$, p. 51) for an organism which in 1819 caused red spots to appear in various food stuffs such as bread, macaroni, rice, etc. Trevisan (1887, p. 278) says:

Vincenzo Sette delegato d'officio ad investigare le cause del fenomeno che il fanatesmo del popoli attribuiva ad un potere sopranaturele, mise in chiara pel primo che la cagione unica n'era un frungo nuovo di genere e di specie, cui impose il binomio Zaogalactina imetropha. Che se ventiquattio annipiu tardi Ehrenberg erroneamente riferendo la Zaogalactina de Sette alle Monadi tragli Infusorj, l'appello Mcnas prodigiosa, non per questo, per la volgare legge id priorito potrebbe essere posposto il piu antico nome specific; und eche come vel 1879 in quest 'aula medesima proposi che aversse a chiamarsi Micrococcus imetrophus d'ora umanza dovrebbe dirsi Bacillus imetrophus.

The priority of Zaogalactina, or rather its definition was questioned by Schroeter (1872, p. 109). He says:

Sette beschrieb die rothen Schleimklumpschen schon 1824 als Zoogalactina imetropha, sah aber die einzelnen, sie constituirenden Organismen nicht, desshalb kann dieser Name keine Priorität für die Beziechung der Körperchen beanspruchen.

He further states that he has found in potatoes red slimy drops which were not bacteria, but yeasts. He contends that Sette's type is therefore not recognizable and should be abandoned.

The name Serratia (q.v.) evidently has priority.

Zoagalactina. Enlows (1920, p. 98) states that this is the original spelling for Zaogalactina $(q . v$.$) .$

Zoogalactina. A variant spelling of Zaogalactina used by Schroeter (1872, p. 109) and others.

Zoogloea. A generic name proposed by Cohn (1854, p. 123). He gave the following description:

Cellulae minimae bacilliformes hyaline, gelatina hyalina in massas globosas, uvaeformes, mox membranaceae consociatae, dein singulae elapae, per aquam vacillantes. The species named was Zoogloea termo.

Itzigsohn (1867) named an organism Zoogloea ramigera. Bollinger (1870, p. 583) used the name Zoogloea pulmonis equi. Billroth (1874, p. 6) proposed that the terms Coccoglia or Gliacoccos should be substituted for Zoogloea. Eberth (1873) named an organism Zoogloea Beigeliana. Cohn definitely abandoned Zoogloea (1872b, p. 141) as a generic designation believing that this was simply a growth form. 
Since that time the name has not been used except as a casual name. Vuillemin (1913, p. 526) designates this as a form genus to be preserved.

The generic name is probably invalid because not based upon pure culture.

Zopfeae. A name proposed by Winslow et al. (Committee Soc. Am. Bact., 1920, p. 209) for the third tribe of the family Bacteriaceae with the following description: "Gram-positive rods, growing freely on artificial media. Not attacking carbohydrates."

The single genus is Zopfius.

The tribe is included by Bergey et al. (1923, p. 193) as the fifth in the family Bacteriaceae.

The correct spelling of this name probably is Zopfieae.

Zopfiella. A genus proposed by Trevisan (1885, p. 4) with the species Zopfiella tumescens, (Bacillus tumescens). The description given is as follows:

Tre stadi di sviluppo vegetativo: 1. Filamenti. 2. Bacilli. 3. Cocchi. Filamenti (stadio protoplastico tipico) cilindrici, articolati, micolori, diritti. Bacilli (stadio transitorio) cilindrici, inarticolati, filiformi: macrobacilli e microbacilli. Cocchi (stadio finale) derivati da microbacilli, d apprima in brevi monili, indo liberi. Spore provenienti.

The name was later abandoned (De Toni and Trevisan, 1889, p. 972) becoming a synonym of Bacillus.

Zopfius. A generic name proposed by Wenner and Rettger (1919, p. 334). The generic description is summarized by Enlows as follows:

Cells rod-shaped, usually about 0.8 by $3.5 \mu$ in size, have somewhat rounded ends, and in young cultures occur in long evenly curved chains. Gram-positive. Motile by means of peritrichiate flagella. No spores. No capsules. Facultative anaerobes. No visible change in litmus milk. Gelatin not liquefied and none of the carbohydrates are attacked. A more or less characteristic spider-web growth on agar and gelatin plates, but inoculations in the condensation water of agar slants do not result in a spreading over the surface such as occurs in the genus Proteus. The authors include here Bacterium zopfi Kurth, and Proteus zenkeri Hauser, which they regard as identical, after a study of a number of strains of each type finding few differentiating properties. See Proteus (Hauser) em. Wenner and Rettger. The name Zopfius having been chosen as the name for new genus, the type species (by virtual tautonomy) would be Zopfius zopfii (Kurth) Wenner and Retter.

Winslow et al. (Committee Soc. Am. Bact., 1920, p. 210) include this as the single genus of the tribe Zopfece, with the following characterization: 
Long rods occurring in evenly curved chains. Gram positive. Motile. Proteus-like growth on media. Facultative anaerobes. Carbohydrates and gelatin not attacked, hydrogen sulphide not formed.

Type species, Z. zopfii (Kurth) Wenner and Rettger.

Bergey et al. (1923, p. 193) include this genus in the tribe Zopfeae. Apparently this name is an exact synonym of Kurthia which has priority. Both are based on the same type species.

1. Zygobacterium. According to De Toni and Trevisan (1889, p. 1023) this generic name was used by Maggi (1887, p. 318) for the species Zygobacterium nitrosum which is regarded by the former as a synonym of Bacterium lineola (Mueller) Cohn.

Zymosotis. A generic name proposed by Salisbury (1868). Enlows (1920, p. 99) gives the following summary:

$Z$. regularis. Spores very minute well defined in outline, and uniform in size and shape. Multiply by duplicate segmentation, and develop into filaments with great rapidity. Filaments are well defined, uniform in diameter, and have cross markings or interruptions in the inside tubular membrane at regular intervals, hence its name. Found in human blood.

Z. escularis. The filaments in their early stages of development are mostly moniliform. The more mature filaments have the outside tube continuous and uniform in diameter, while the inside nembrane has not only interruptions at irregular intervals, but the interruptions are of variable length. Where the inside membrane occurs it affords a double wall to the tube and communicates greater opacity than have the intervening spaces. Found in the freshly drawn blood of horses affected by a fatal disease characterized by a remittent fever. 


\section{BIBLIOGRAPHY}

Afanassjew, M. J. 1887 Die Aetiologie und klinische Bakteriologie des Keuch-

hustens. St. Petersb. Med. Wochenschrift. 4: 323; 331; 339; 347.

Agardh, C. A. 1821 Species Algarum. Vol. 1.

1828 Icones Alg. Eur. Nos. 21-23.

Agaroh, J. G. 1824 Syst. Alg.

1842 Algae Maris Mediterranei et Adriatici. p. 154.

Alessand, P. E., e Maggr, L. 1887 Acque potabili.

Altana, Giuseppe. 1909 Ueber einen vom Meerschweinchen isolierten Tetragenus. Centralbl. f. Bakteriol., Jena. Abt. 1. 48: 44 .

Ambrož, Adolf. 1913 Denitrobactericum thermophilum spec. nova, ein Beitrag zur Biologie der thermophilen Bakterien. Centralbl. f. Bakteriol., Jena. Abt. 2. 37: 3-16.

Amiradžıbi, S. S. 1907 Melococcus ostrjanini Chariłkov. Med. žurn. 4: 309-312.

Arkwright, J. A., Bacot, A., And Duncan, F. M. 1919 The association of Rickettsia with French fever. Jour. Hyg., Cambridge. 18: 76-94.

Arloing, S. 1889 Sur l'étude bactériologique des lésions de la péripneumonic contagiense du boeuf. Compt. rend. Acad. d. sc. Par. 109: 428.

ARndt, Rudolf. 1880 Beobachtungen an Spirochaete denticola, des Spirochaete des Zahnschleimes. Arch. Path. Anat. u. Physiol. (Virchow). 79: 76-86.

Axenfeld, Theodor. 1897 Ueber die chronisehe Diplobacillen conjunctivitis. Centralbl. f. Bakteriol., Jena. 21: 1.

Babes, V. 1883 Le rein et le foie dans la fièvre jaune. Compt. rend. Acad. d. sc. Par. 97: 682-685.

1888 Sur l'hemoglobinurie bacterienne du boeuf. Compt. rend. Acad. d. sc. Par. 107: 692 .

1889 Die Aetiologie des seuchenhaften Haemoglobinurie des Rindes. Arch. Path. Anat. u. Physiol. (Virchow). 115: 81.

1890 in Cornil, A. V., and Babes, V. Les Bacteries.

Baker, C. F. 1902 Revision of the Elephantopeae. Trans. Acad. Sci. St. Louis. 12: 53 .

Balbiani. 1886 Evolution des Micro-organismes animaux et végétaux. Jour. Microg. 10: 535-544.

Barendrecht, H. P. 1901 Die Agglutination von Hefe. Centralbl. f. Bakteriol., Jena. Abt. 2. 7:623-627.

Bartoszewicz, St., and Schwarzwasser, Josef. 1908 Eine neue Form von Diplococcus Tetradiplococcus filiformans lodzensis. (Vorl. Mitt.) Centralbl. f. Bakteriol., Jena. Abt. 2. 21: 614-616.

Baumgarten, PaUl v. 1890 Lehrbuch der pathologischen Mykologie. Leipzig. de Beaurepaire Aragas, H., and Vienna, G. 1913 Pesquizas sobre o granuloma venereo. Mem. do Inst. Oswaldo Cruz. 5: 211-238. 
BÉchamp, A. 1867 Sur le corpuscle vibrant de la pébrine, consideré comme organisme producteur d' alcool. Compt. rend. Acad. d. sc. Par. 64: 231-232.

1868 Sur la maladie à mycrozymas de vers a soie. Compt. rend. Acad. d. sc. Par. 56: 1160.

Behrens. 1899 Review. Koch's Jahresbericht, 10: 244-246.

Beijerinck, M. W. 1888 Die Bakterien der Papilionaceenknöllchen. Bot. Ztschr. 46: 758 .

1889 Le Photobacterium luminosum (Bactérie lumineuse de la mer du Nord). Arch. néerl. d. sc. exactes. 23: 428-444.

1893 Ueber die Butylalkoholgärung und das Butylferment. Verhandel. K. Akad. Wetensch. Amsterdam. Sect. II. Deel I. No. 10. p. 51. 1894 Ueber die Butylalkoholgärung und das Butylferment. Abs. Centralbl.

f. Bakteriol. Abt. 1. 15: 171.

1896 Sur la Fermentation et le Ferment butyliques. Arch. néerl. d. sc. exactes. Series I. 29: 1 .

1898 Sur les diverses espèces de bacteries acétifiantes. Arch. néerl. d. sc. exactes. Ser. II. 2: 180-189.

1898 Ueber die Arten der Essigbakterien. Centralbl. f. Bakteriol. Abt. 2. 4: 209-216.

1900 Schwefelwasserstoffbildung in den Stadtgräben und Aufstellung der Gattung Aërobacter. Centralbl. f. Bakteriol., Jena. Abt. 2. 6:193-206. 1901 Over oligonitrophile bacterien. (On oligonitrophilous bacteria). Amsterdam Vers1. Wis. Nat. Afd. K. Akad. Wet., 9: 633-642. (Dutch); Amsterdam, Proc. Sci. K. Akad. Wet. 3: 586-595. (English.)

1901 Sur la formation de l'hydrogen sulfuré dans les canaux et le genre nouveau Aërobacter. Arch. Néerl. Sci. Soc. Holl. Ser. 2. 4:1-18.

1901 Sur les ferments lactiques de l'industrie. Arch. néerl. d. sc. exactes. Ser. 2. 6: 212-243.

1901 Sur les ferments lactiques de l'industrie. Haarlem. Arch. néerl. Sci. Soc. Holl. Ser. 2. 6: 212-243.

1901 Uber oligonitrophile Mikroben. Centralbl. f. Bakteriol. Abt. 2. 7: 561-582.

und VAN Delden, A. 1902 Ueber die Assimilation des freien Stickstoffs durch Bakterien. Centralbl. f. Bakteriol., Jena. Abt. 2. 9: 3-43.

1903 Sur des microbes oligonitrophiles. Arch. néerl. d. sc. exactes. Sec. 2. 8: 217 .

und van Delden, A. 1903 Sur l'assimilation de l'azote libre par les bactéries. Haarlem, Arch. Néerl. Sci. Soc. Hol. Ser. 2. 8: 319-373.

ANd VAN Delden, A. 1904 Sur les bacteries actives dans le rouissage du lin. Haarlem, Arch. Néerl. Sci. Soc. Holl. Ser. 2. 9: 418-441.

1904 Ueber die Bakterien, welche sich im Dunkeln mit Kohlensäure als Kohlenstoffe ernähren können. Centralbl. f. Bakteriol., Jena. Abt. 2. 11: 598 .

1906 Une sarcine de fermentation anaérobie obligaloire. Haarlem, Arch. Néerl. Sci. Soc. Holl. Ser. 2. 11: 199-205.

1908 Fermentation lactique dans le lait. Arch. néerl. d. sc. exactes. Ser. 2. 13: 359 . 
1908 Die Erscheinung der Flockenbildung der Agglutination bei Alkoholhefen. Centralbl. f. Bakteriol., Jena. Abt. 2. 20:641.

1911 Ueber Pigmentbildung bei Essigbakterien. Centralbl. f. Bakteriol., Jena. Abt. 2. 29: 169-176.

1914 Ueber Schröter und Cohn's Lackmusmicrococcus. Folia microbiol., Delft. 2: 185-200.

1914 Ueber das Nitratferment und ueber Physiologische Artbildung. Folia microbiol., Delft. 3: 91-113.

Benecke, Wilhelm. 1912 Bau und Leben der Bakterien.

Berestnew, N. 1899 Zur Frage du Kilassifikation und Systematischen Stellung der Strahlenpilze. Centralbl. f. Bakteriol., Jena. Abt. 1. 26: 390.

Bergamaschi, Guiseppe. 1822 Osservazioni micologiche ed enumerazione storica di tutli i funghi di Pavese. Milano.

Bergey, David H. et al. 1923 Manual of Determinative Bacteriology. Baltimore.

Bergonzini, Curzio. 1881 Sopra un nuovo Bacterio Colorato. Annuario della Societa dei naturalisti in Modena. Ser. II. 14: 149-158.

Berkeley, M. J. 1857 Introduction to Cryptogamic Botany.

1874 Notes on North American Fungi. Grevillea. 3: 64.

Bettencourt, Annibal, and Kopke, Ayres, Renzende, Gomes De, And Mendes, Correia. 1904 Ueber die Aetiologie der Schlafkrankheit. Centralbl. f. Bakteriol., Jena. Abt. I. 35: 55.

Biedert, Ph. 1885 Beitrag zur Frage nach der Constanz der Spaltpilze. (Kokkobacillus zymogenus and Bacterium termo). Virchow's Arch. f. path. Anat., Berl. 100: 439.

Billet, A. 1888 Sur le cycle évolutif et les variations morphologiques d'une nouvelle Bacteriacee marine. Compt. rend. Acad. d. sc. Par. 106: 293.

1888 Sur le cycle évolutif d'une nouvelle Bactériacée chromogène et marine, Bacterium Balbiani. Compt. rend. Acad. d. sc. Par. 107: 423.

1890 Contribution a l'étude de la Morphologie et du Developpement des Bacteriacees. Extrait du Bulletin scientifique de la France et de la Belgiquè. Paris.

Billroth (Christian Albert) Theodore. 1874 Untersuchungen über die Vegetationsformen von Coccobacteria septica-Berlin.

Bızıo, B. 1819 Gazetta privilegiata. Venice. Aug. 24.

1823 Polenta porporp. Biblioteca italiana o sia Giornale di lettera, scienza ed arti. (Anno VIII.) 30: 275.

1827 Opuscoli chimico-fisici.

1844 Sur un altération du pain causée par le développement d'un cryptogame: observation faite, il y a tres longtemps d'un phénomène qui rentre dans la class de ceux sur lesquels Möser a appelé 1'. Compt. rend. Acad. d. sc. Par. I. Sem. 18: 951 .

Black, G. V. 1892 Micro-organisms of the oral cavity. Transactions of the Illinois Dental Society, 1886, cited by Miller. Mikroorganismus der Mundhöhle. p. 78.

Blanchard, Raphal. 1896 Parasites végetaux a l'exclusion des Bactéries. Bouchards' Traité de Pathologie Generale. 2: 811-926. 
1906 Spirilles, spirochêtes et autres microorganismes à corps spiralé. La. Semaine Medicale. 26: 1 .

Bollinger, Oтto. 1870 Mycosis der Lunge beim Pferde. Virchow's Arch. f. path. Anat., Berl. 49: 583.

1888 Ueber Botryomykose beim Pferd. Kleinere Mitheilungen XIII. Deut. Ztschr. Thiermed. 13: 177 .

BoNgERT. 1901 Corynethrix pseudotuberculosis murium ein neuer pathogener Bacillus für Mäuse. Ztschr. f. Hyg. u. Infektionskrankh., Leipz. 37: 449-475.

Воnомe, A. 1888 Pleuro-pericarditis und cerebro-spinal Meningitis Serofibrinosa durcheinen dem Diplococcus pneumonicus sehr ähnlichen Mikroorganismus erzeugt. Centralbl. f. Bakteriol., Jena. 2: 321.

Borrel, Dujardin-Beaumetz, Jeantet and Jouan. 1910 Le Microbe de la Peripneumonie. Ann. de l'Inst. Pasteur, Par. 24: 179.

Bory de St. Vincent, J. B. 1824 Encyclopédie méthodique.

1826 Microscopiques. Dictionnaire classique d'histoire naturelle. 10: 533-546.

Borzi, Antonino. 1878 Note allei morfologia e biologia delle Alghe Ficocromaceae. Nuovo Gior. Bot. Ital. 10: 236-288.

Bosanquet, Wh. C. 1911 Spirochaetes.

Breed, R. S., Conn, H. J., ANd BaKer, J. C. 1918 Comments on the evolution and classification of bacteria. Jour. Bact., Balt. 3: 445-459.

And Conn, H. J. 1919 The nomenclature of the Actinomycetaceae. Jour. Bact., Balt. 4: 585-602.

1920 The nomenclature of the Actinomycetaceae (Addenda). Jour. Bact., Balt. 5: $489-490$.

Brompt, E. 1910 Precis de Parasitologie. Paris.

Brdssoff, A. 1916 Ferribacterium duplex, eine stäbchenförmige Eisenbakterie. Centralbl. f. Bakteriol., Jena. Abt. 2. 45: 546-554.

Buchanan, R. E. 1915 Nomenclature of the Coccaceae. J. Infe t. Dis., Chicago. 17: 528-541.

1916 Studies in the nomenclature and classification of the bactoria. I. The problem of bacterial nomenclature. Jour. Bact. 1: 591-596.

1917 Studies in the nomenclature and classification of the vacteria. II. The primary subdivisions of the Schizomycetes. Jour. Bact. 2: 155-162.

1917 Studies in the nomenclature and clasification of the bacteria. III. The families of the Eubacteriales. Jour. Bact. 2: 347-350.

1917 Studies in the nomenclature and classification of the bacteria. IV. Subgroups and genera of the Coccaceae. Jour. Bact. 2: 603-617.

1918 Studies in the nomenclature and classification of the bacteria. V. Subgroups and genera of the Bacteriaceat. Jour. Bact. 3:27-61.

1918 Studies in the nomenclature and classification of the bacteria. VI. Subdivisions and genera of the Spirillaceae and Nitrobacteriaceae. Jour. Bact. 3: 175-181.

1918 Studies in the classification and nomenclature of the bacteria. VII. The subgroups and genera of the Chlamydobacteriales. Jour. Bact. 3: 301-306. 
1918 Studies in the classification and nomenclature of the bacteria. VIII. The subgroups and genera of the Actinomycetales. Jour. Bact. 3: 403-406.

1918 Studies in the classification and nomenclature of the bacteria. IX. The subgroups and genera of the Thiobacteriales. Jour. Bact. 3: $461-474$.

1918 Studies in the classification and nomenclature of the bacteria. X. Subgroups and genera of the Myxobacteriales and Spirochaetales. Jour. Bact. 3: $541-545$.

Buder, Johannes. 1913 Chloronium mirabile. Ber. d. deutsch. Bot. Gesellsch., Berl. 31: $\$ 0-97$.

Bum, E. 1855 Der Mikroorganismus der Gonorrhoischen Schleimhaut Erkrankungen, "Gonococcus-Neisser." Wiesbaden.

Burdon-Sanderson, John S. 1871 Origin and Distribution of the Microzymes in Water and in the Tissues and Liquids of the Organism. Quart. Jour. Micr. Sc., Lond. 11: 323-352.

Burrill, T. J. 1883 New species of Micrococcus (Bacteria). Amer. Nat. 17: 319-320.

Caspary, Robt. 1874 Merismopedium Reitenbachii, n. sp. Schr. Physikal. Ökonom. Gesell. Königsb. 15: 104.

Castellani, Aldo, and Chalmers, Albert J. 1919 Manual of Tropical Medicine, 3rd ed.

1920 Sur la classification de certain groupes de bacilles aerobies de l'intestin humain. Ann. de l'Inst. Pasteur, Par. 34: 600-621.

Chalmers, Albert J., And Christopherson, J. B. 1916 A Sudanese Actinomycosis. Ann. Trop. Med. and Parasitol., Liverp. 10: 223-283.

Chatton, Edodard, and Pérard, Charles. 1913 Schizophytes du caecum du cobaye. I. Oscillospira guillermondi, n.g., n.sp., II. Metabacterium polyspora n.g., n.sp. Compt. rend. Soc. de biol., Par. 74: 1159 and 1223.

Chadtemasse, A., Matruchot, L., And Grunberg, A. 1917 Une maladie nouvelle, simulant le rheumatisme articulaire aigu, avec ses complications viscérales et causée par un microbe nouveau (Mycobacillus synovialis). Bull. Acad. de méd., Par. 3rd Ser. 77: 708-712.

1917 Un microbe nouveau Mycobacillus synovialis, causant chez l'homme un maladie évoluant comme le rhumatisme articulaire. Compt. rend. Acad. d. sc., Par. 164: 562-565.

Chester, F. D. 1897 A preliminary arrangement of the species of the genus Bacterium. 9th Ann. Rept. Del. Coll. Agr. Exp. Sta. p. 53-146.

1897 Classification of the Schizomycetes. 9th Ann. Rept. Del. Coll. Agr. Exp. Sta. p. 62-63.

1898 A preliminary arrangement of the species of the genus Bacillus. 10th Ann. Rept. Del. Coll. Agr. Exp. Sta. p. 100-137.

1899 Description of certain species of bacteria isolated from cultivated soil. Ann. Rept. Del. Coll. Agr. Exp. Sta. p. 52-75.

1899 Studies in systematic bacteriology. Ann. Rept. Del. Coll. Agr. Exp. Sta. 11: 36 . 
1901 Manual of Determinative Bacteriology.

1903 Observations on an important group of soil bacteria. 15th Ann. Rept. Del. Coll. Agr. Exp. Sta. p. 42-96.

Chudrakov, N. 1897 Zur Lehre von der Anaërobiose. Theil I. (Russian). Iioch's Jahresbericht. 8: 44-46.

Cienkowski. 1878 Untersuchung uber die Gallertbildungen des Zuckerrubensaftes (Resumé allemend du memoire russe. Charkow). Arbeit. d. Naturforsch. Gesellsch. a. d. Univ. a. Charkoff. p. 12.

Clements, Frederick E. 1894 Family-Bacteriaceae in Part I. Flora of Nebraska. p. 25-28.

1902 Greek and Latin in biological nomenclature. University Studies. Pub. by U. of Nebraska. 3: 1-84.

1909 The Genera of Fungi. Minneapolis.

Coats, G., And Forbes, J. G. 1910-1911 On the relation of the Meningococcus intracellularis to Pseudoglioma. Proc. Roy. Soc. Med., Lond. 4. Pathol. Section. p. 242-250.

Cohn, Ferdinand. 1854 Untersuchungen über die Entwickelungsgeschichte der mikroskopischen Algen und Pilze. Der Akademie übergeben den 1 Mai, 1853. Nov. Act. Acad. Caes. Leop.-Carol. Nat. Cur. 24: 103-256.

1872 Untersuch. über Bakterien. Beitr. Biol. Pflanz. 1: 127-224.

1872 (a) Organismen in der Pockenlymphe. Virchow's Arch. f. path. Anat., Berl. 55: 229-238.

1870 Ueber den Brunnenfaden (Crenothrix polyspora) mit Bemerkungen über die mikroskopische Analyse des Brunnenswassers. Beitr. Biol. Pflanz. (Heft. 1.) 1: 108-131.

1875 Untersuchungen über Bakterien. II. (Heft. 3.) Beitr. Biol. Pflanz. 1: 141-208.

1876 Untersuchungen über Bacterien. IV. Beiträge zur Biologie der Bacillen. (Heft. 2.) 2: 249-277.

Collin, Bernard. 1913 Sur un ensemble de Protistes parasites des Batraciens. Arch. zool. exper. 51: 59-76.

Conn, H. W. 1909 Agricultural Bacteriology. Ed. 2.

Conda, A. C. J. 1839 Prachtflora europäischer Schimmelbildungen. Leipzig u. Dresden. p. 27.

Cornil and Babes. 1890 Les Bacteries.

Cunningham, Allan. 1839 Flora Insularum Novae Zelandiae Precursor. Ann. Nit. Hist. 2: 47.

Dallinger, W. H. 1878 On the measurement of the diameter of the flagella of Bacterium termo: a contribution to the question of the "Ultimate Limit of Vision" with our present lenses. Jour. Roy. Micr. Soc., Long. 1: $159-175$.

Dangeard, A. 1909 Memoire sur les Chytridinées. Le Botaniste. 1: 55. 1891 Contribution a l'étude des Bacteriacees vertes (Eubacillus nov. gen.). Le Botaniste. 2: 151.

Da Rocha, Lima. 1916 Zur Aetiologie des Fleckfiebers. Berl. klin. Wchnschr. p. $567-569$. 
Davaine, C. 1863 Recherches sur les infusoires du sang dans la maladie connue sous le nom de sang de rate. Compt. rend. Acad. d. sc., Par. 57:220-223.

1863 Nouvelle recherches sur la maladie du sang de rate considérée au point de vuc de sa nature. Memoires lus a la Société de Biologie. Ser. 3. 5: 193-202.

1864 Nouvelles recherches sur la nature de la maladie charbonneuse connue sous le nom de sang de rate. Compt. rend. Acad. d. sc., Par. 59:393-396.

1865 Sur la présence constante des Bactéridies dans les animaux affectes de la maladie charbonneuse. Compt. Rend. Acad. d. sc., Par. 61: 334-335.

1868 Dictionnaire Encyclopedique des Sciences Medicales. Ser. I. 8: 21.

De Bary, A. 1884 Vergl. Morph. u. Biol. d. Pilze, Mycetozoa und Bacterien. Leipzig.

1886 Vorlesungen über Bakterien.

D'Herelle, F. 1914 Le Coccobacille des Sauterelles. Ann. de l'Inst. Pasteur, Par. 280: 28-387.

DE KRUYFF, E. 1906-8 Les Bacteries hydrolysant et oxydant les graisses. Bull. 1-15. Dept van Landbouw. Dutch East Indies.

De Lanessau, J. T. 1880 Revue Internationale des Sciences Biologiques. 5: 245.

Desmazik̀res, J. B. 1826 Recherches microscopiques et physiologiques sur le genre Mycoderma. Ann. Sci. Nat. Bot. Ser. 1. 10: 42-67.

1851 Sur les plantes cryptogames recement decouvertes en France. Ann. Sci. Nat. Bot. Ser. 3. 16: 319.

De Toni, J. B., and Trevisan, V. 1889 Schizomycetaceae Naeg., in Saccardo, P. A. Sylloge Fungorum. 8: 923-1087.

Dobeld, C. Clifford. 1911 Paraspirillum vejdovskii n.g. n.sp., a new bacterial form. Arch. f. Protistenk., Jena. 24: 97.

1911 On Cristispira veneris n.sp. and the affinities and classification of spirochaets. Quart. Jour. Micr. Sc., Lond. 56: 507-540.

Dochez, A. R., ANd Avery, O. T. 1915 Varieties of Pneumococcus and their relation to lobar pneumonia. Jour. Exper. Med., Balt. 21: 114 .

Doflein, F. 1911 Lehrbuch der Protozoenkunde., Jena.

Dopter, CH. 1909 Etude de quelques germes isolés du Rhino-pharynx, voisin du Méningo-coque (para-méninogocoques). Compt. Rend. Soc. de biol., Par. 67: 74-76.

Dubosco, O., And Lebailly, Сh. 1912 Spirella canis n.g., n.sp., spirelle de l'estomac du chien. Compt. rend. Acad. d. Sc., Par. 154: 835-837.

Duclaux, E. 1882 Memoire sur le lait. Ann. Inst. Nat. Agron. 4: 23-138 (for years 1879-80). Chapter IV. Ferments du lait pp. 74-117.

1895 Sur la Nutrition intra-cellulaire. Ann. de l'Inst. Pasteur, Par. 9: 811-839.

Dujardin, Felix. 1841 Hist. nat. des Zoophytes infusoires. Paris. Mem. sur une classification des Infusoires en rapport avec leur organisation. Compt. rend. Acad. d. sc. 11: 281-286. 1840. Microsc. Journ. 1: 53-56. 1841. 
1841. Histoire naturelle des Zoophytes. Infusoires. Paris.

DUnbar, W. 1893 Untersuchungen über choleraähnliche Wasserbacterien. Deutsche med. Wchnschr., Berl. and Leipz. 19:799.

Duncker, H. C. J. 1887 Ueber Actinomyces musculorum suis. Arch. f. wissensch. u. prakt. Tierh., Berl. 13: 224.

Dyer, W. T. Thiselton. 1875 Sexual reproduction of Thallophytes. Quart. Jour. Micr. Sc., Lond. N. S. 15: 295-326.

Edington, Alexander. 1887 A method of prophylaxis and an investigation into the nature of the contagium of scarlet fever. Brit. Med. Jour. 1: 1265.

Edkins, J. S. 1923 Spirella regaudi in the cat. Parasitology. 15: 296-307.

Ehrenberg, C. G. 1828 Symbolae Physicae seu Icones et Descriptiones animalium evertebratorum sepositis insectis quae ex itinere per Africam Borealem et Asiam occidentalem. IV. Evertebrata. Berlin.

1830 Berträge zur Kenntniss der Organisation der Infusorien und ihrer geographischen Verbreitung. Abhandlungen d. Berl. Akad. p. 1-80.

1832 Die geographische Verbreitung der Infusionsthierchen in NordAfrika und West Asien, etc. Abhandl. d. K. Akad. d. Wissensch. zu Berlin. Physik. Klasse.

1833 Dritter Bertrag zur Erkenntniss grosser Organisation in der Richtung des kleinsten. Abhandl. Berl. Akad. p. 145-336.

1836 Vorlaüfige Mittheilungen über das wirkliche Vorkommen fossiler Infusionen und ihre grosse Verbreitung. Ann. Phys. Ser. 2. 8: 217.

1838 Die Infusionsthierchen als vollkommende Organismen. Leipzig.

1840 Characteristik vom 274 neuen Arten von Infusorien. Berichte über die Verhandlungen der Königl. Preuss. Akademie der Wissenschaften zu Berlin. 5: 197-219.

1848 Fortsetzung der Beobachtung des sogenannten Blutes im Brode als Monas prodigiosa. Bericht über die zur Bekanntmachung geeigneten Verhandlungen der Königl. Preuss. Akademie der Wissenschaften zu. Berlin. 354-362.

Eidam, E. 1876 Ueber die Entwickelung des Sphaerotilus natans. Jahresber. Schles. Gesell. Vaterländ. Cult. 54: 133.

Eisenberg, James. 1886 Bakteriologische Diagnostik. Hamburg and Liepzig. (Voss).

1891 Bakteriologische Diagnostik. Ed. 3.

Ellis, D. 1897 On the discovery of a new genus of thread-bacteria (Spirophyllum ferrugineum). Proc. Roy. Soc., Edinb. 27: part I. (No.6.) p. 21.

1907 A contribution to our knowledge of the thread bacteria. Centralbl. f. Bakteriol., Jena. Abt. 2. 19: 516 .

1909 Outlines of Bacteriology.

1910 A contribution to our knowledge of the thread-bacteria (II). Centralbl. f. Bakteriol., Jena. Abt. 2. 26.

Elser, W. J., and Huntoon, F. M. 1909 Studies on meningococcus. Jour. Med. Research, Bost. 20: 371-541. 
Engelmann, T. W. 1883 Bacterium photometricum. Ein Beitrag zur vergleichenden Physiologie des Lichts und Farbensinne. Pflügers Arch. f. Physiol. 30: 95-124.

ENGLer, A. 1882 Uber die im Kieler Hafen in dem sogenannten "toten Grund" vorkommenden Pilzformen. Verhandl. Bot. Ver. Brandenb. 24: 17-20.

1882 Ueber die Pilz-Vegetation des weissen oder todten Grundes in der Kieler Bucht. Vierter Bericht der Commission zur wissenschaftlichen Untersuchung der deutschen Meere in Kiel für 1877 bis 1881. Abt. 1. 187-193.

Evgler, G. 1912 Syllabus der Pflanzenfamilien. Ed. 7.

Enlows, Ella M. A. 1920 The generic names of bacteria. Hygienic Laboratory-Bull. No. 121. Treasury Dept. U. S. P. H. Service.

Escherich, Th. 1885 Die Darmbacterien des Neugeborenen und Saüglings. Fortschr. d. Med. No. 15. 3: 520 .

1886 Die Darmbakterien des Säuglings.

1886 Beiträge zur Kenntniss der Darmbakterien. München. med. Wehnschr. 33: 759-763.

Evans, Alice C. The nomenclature of the melitensis-abortus group of bacterial organisms. Pub. Health Rep. U. S. Mar. Hosp. Serv., Wash. 38: 1943-1948.

Falkenheim, H. 1885 Ueber Sarcine. Arch. f. exper. Path. u. Pharmakol., Leipz. 19: 339 .

Fanintzin, A. 1892 Arbeiten aur dem botanischen Laboratorium der Kaiserlichen Akademie der Wissenschaften zu St. Petersburg. No. 2. Eine neue Bacterienform. Nevskia ramosa. Bul. Acad. Imp. Sci. St.Pétersb. 34: (N. S. 2) : 481-486.

FaUll, J. H. 1915 A new myxobacterium. (Proc. Roy. Soc. Canada) Sci. N. S. 43: 469 .

Fehleisen. 1883 Die Aetiologie des Erysipels. Berlin.

Fick, Adolf E. 1887 Ueber Mikroorganismen in Conjunctivalsack. Wiesbaden.

Fischer, Alfred. 1895 Untersuchungen uber Bakterium. Jahrb. f. wissensch. Bot., Berl. 27: 1-163.

1897 Lectures on Bacteria. Eng. translation of Vorlesungen über Bakterien.

1903 Vorlesungen über Bakterien. 2nd ed.

Fischer, Bernhard. 1894 Die Bakterien des Meeres. Ergebisse der Plankton-Expedition der Humboldt-Stiftung. p. 1-82.

FItz, AlK. 1878 Ueber Schizomyceten-Gährungen III. Ber. Deut. Chem. Gesell. 11: 42-55.

FLÜGGE, C. 1886 Die Mikroorganismen, Leipzig.

1908 Grundriss der Hygiene. Ed. 6.

Foג ANd Bordono-UfFreduzzr. 1888 Ztschr. f. Hyg. u. Infektionskrankh., Leipz. $4: 67$.

Forti, C. 1896 Notizie complementari su alcuni studi di zimotechnia enologica eseguiti a tutto il 1896. Ann. della soc. chim. di Milano. Vol. 3, fascil.

Fortinead, L. 1905 L'Erythrobacillus pyosepticus. Compt. rend. Acad. d. sc. Par. et de la Soc. de Biologie. Paris. 58: 104. 
Frank, B. 1889 Ueber die Pilzsymbiose der Leguminosen. Ber. d. deutsch. Bot. Gesellsch., Berl. 7: 338.

Frenzel, Johannes. 1884 Ueber die Mikrozymas in der Leber und im Pankreas. Biol. Centralbl., Leipz. 3: 49-52.

1897 Neue oder wenig bekannte Süsswasserprotisten. Biol. Centralbl. 17: 801-808.

Freudenreich, Eduard. 1894 Les Microbes et leur rôle dans la Laiterie.

Frost, W. D. 1911 in Marshall's Microbiology.

Fuchs, C. H. 1841 Beiträge zur nähern Kenntniss der gesunden und fehlerhaften Milch der Hausthiere. Magazin für die gesammte Thierheilkunde. 7: 133-198.

Fuhrmann, F. 1905 Morphologisch-biologische Untersuchungen über ein neues Essigsäuresbildendes Bakterium. Beiheft zum bot. Centralbl. 19:1-31.

Gameléra, N. 1888 Vibrio Metschnikovi (n.sp.) et ses rapports avec le microbe du cholera asiatique. Ann, de l'Inst. Pasteur, Par. 2: 482.

1888 Zur Aetiologie der Hühnercholera. Centralbl. f. Bakteriol., Jena. 4: 167.

Gasperini, G. 1889. Recherches morphologiques et biologiques sur un Microorganisme de l'Atmosphere, le Streptothrix Foersteri. Cohn. Ann. Microg. 10: 449 .

1895 Discussione. Atti dell' XI congresso med. internaz. Roma. 6: (igiene) $80-82$.

Gedoelst, L. 1902 Les Champignones Parasites de l'Homme et des Animaux Domestiques. Paris.

Glaser, R. W., and Chapman, J. W. 1912 Studies on the wilt disease or "flacherie" of the gypsy moth. Science, N. Y. and Lancaster, n.s. 36: 219-224.

Gleitsmann. 1913 Beitrag zur Entwickelungsgeschichte der Spirochäten (Borrelien). Centralbl. f. Bakteriol., Jena. Abt. I. 68: 31.

Gonder, Richard. 1914 Spironemacea (Spirocheten). Prowazek's Handbuch der pathogenen Protozoen. Lief. 6. p. 671.

Gonnermans, M. 1907 Uber gallertbildende Bakterien. Zeitschrït für Zuckerindustrie und Landwirtschaft. 36: 877-888.

Goodsir, John. 1842 History of a case in which a fluid periodically ejected from the stomach contained vegetable organisms of an undescribed form. Edinburgh Med. and Surg. Jour. 57: 432.

Griffith, J. W. 1853 On Gallionella ferruginea (Ehrenb.). Ann. and Mag. Nat. Hist. Ser. 2. 12: 438.

Groenewege, J. 1912 De rotting der tomatenvruchten, veroorzakt door Phytobacter lycopersıcum, n.sp. meded. van de Rijks Hoog. Land.Tuin-en Boschbouwschool. Deel. v. 5: Afl. 5. 217-239.

Gross, J. 1910 Cristispira nov. gen. Ein Beitrag zur Spirochätenfrage. Mittheil. zool. Stat. Neapel. 20: 41-93.

1911 Ueber freilebende Spironemaceen. Mittheil. Zool. Stat. Neapel. 188-204.

1912 Ueber Systematik, Struktur und Fortpflanzung der Spironemacea. Centralbl. f. Bakteriol., Jena. Abt. 1. 65: 83 . 
Grove, W. B. 1884 A Synopsis of the Bacteria and Yeast Fungi.

Gruber, M. 1891 Micromyces Hoffmanni. Centralbl. f. Bakteriol. 10:648.

Grober, Theodor. 1895 Die Arten der Gattung Sarcina. Arbeiten Bacteriologisches Institut der Technischen Hochschule zu Karlsruhe. 1:239-290. Guerbet, M. 1906 Notes sur la fermentation du yoghurt. Compt. rend. Soc. de biol., Par. 60: 495.

Goignard, Leon. 1890 Sur une nouvelle Bacteriacee marin, le Streblothrichia Bornetii. Compt. rend. Soc. de biol., Par. 42: 124.

Guillebeat, A. 1890 Studien über Milchfehler und Euterentzündungen bei Rindern und Ziegen. Landwirtsch. Jahrb. d. Schweiz, Berne. 4: $27-44$.

1891 Beiträge zur Lehre von den Ursachen der fadenziehenden Milch Landwirtsch. Jahrb. d. Schweiz, Berne.

1892 Studien ü Milchfehlen und Euterentzündungen bei Rindern und Zieglen I. Ueber Ursachen der Euterentzündungen. Landwirtsch. Jahrb. d. Schweiz, Berne. 4:27-44.

Guttmann, Padl. 1880 Zur Histologie des Blutes bei Febris recurrens. Arch. f. path. Anat. u. Phys. Virchow. 80: 1-9.

HaAss, Everhard. 1906 Bertrage zur Kenntniss der Aktinomyceten. Centralbl. f. Bakteriol., Jena. Abt. I. 40: 180-186.

HAASE, W. 1887 Gesammelte Beobachtungen über die Influenza der Pferde. Archiv für Thierheilkunde. 13: 347 .

HAJEK, M. 1888 Die Bakterien bei der akuten und chronischen Coryza, sowie bei du Ozaena, und deren Beziehungen zu den genannten krankheiten. Berliner klin. Wochenschr. 25: 659 .

Hallier, Ernst. 1866 Bericht über mykologische Untersuchungen. Bot. Zeitung. 24: 383 .

1866 Die Pflanzlichen Parasiten des menschlichen Körpers für Aerzte, Botaniker und Studirende zugleich als Einleitung in das Studium der iniederen Organismen. Leipzig.

1868 Ueber einen bei der Rotzkrankheit der Pferde auftretenden Parasiten, vergleichen mit dem der Syphilis. Bayerschen ärztlichen Intelligenzblatte. p. 327.

Hansen, E. 1879 De af mig i $\emptyset l$ og ølurt jagttagne Organismer. Meddel. Carlsberg Lab. Labor. 2: 222.

1894 Gesammelte Theoretische Abhandlungen über Gärungsorganismen. p. 465.

Hansgirg, Axton. 1888 Neue Beiträge zur kenntniss der halophilen der thermophilen und der Berg Algen-Flora, sowie der chemophilen Spaltpilz flora Böhmen. 38: 41, 87, 114, 149.

1888 Beiträge zur Kenntniss der Kellerbacterien nebst Bemerkungen zur Systematik der Spaltpilze (Bacteria). Österr. Bot. Ztschr. 38: $227-230,263-267$.

1890 Ueber neue Süsswasser- und Meeres-Algen und Bacterien. II. Aerophytische und im Meere lebende Bacterien. Sitzungs Berichte der K. böhm. Gesellsch. der Wissensch. Math.-Naturwiss. Classe. 1: 1-34. 
1890 Ueber neue Süsswasser Bakterien mit Bemerkungen zur Systematik dieser Phycophyten und über den Einfluss des Lichtes auf die Ortsbewegungen des Bacillus Pfefferi. Sitz.-ber. K. böhm. Gesellsch. d. Wissenschaften. p. 20-31.

1891 Ueber die Bacteriaceen Gattung Phragmidiothrix Engler und einige Leptothrix arten. Bot. Ztg. 49: 313.

Hartleb, R. 1900 Die Morphologie und systematische Stellung der sogenannten Knöllchenbakterien. Chem. Ztg. 24: 887.

Hartleb, R. ANd Stutzer, A. 1901 Bemerkungen zu der Mittheilung von Dr. W. Rullmann. Centralbl. f. Bakteriol., Jena. Abt. 2. 3:621.

Harz, C. O. 1877-78 Actinomyces bovis, ein neuer Schimmel in dem Gewebe des Rindes. Jahresber. d. Muenchener Central-Thierarzneischule. p. 125-140.

Hauser, G. 1885 Ueber die Entwickelungsgeschichte und pathogenen Eigenschaften einer fäulniserregenden Bakterienart. Sitz.-ber. d. phys.mediz. Sozietät zu Erlangen. 156-171. After C. Fischer. Biol. Centralbl., Leipz. 5: 36-38.

Hazen, Tracy E. 1896-99 Life history of Sphaerella lacustris. Mem. Torrey Bot. Club. 6: 211-246.

Heim, Ludwig. 1911 Lehrbuch der Bakteriologie.

Heller, Hilda Hempl. 1921 Suggestions concerning a rational basis for the classification of the anaerobic bacteria. Jour. Bact., Balt. 6: 521-553.

1922 Certain genera of the Clostridiaceae. Jour. Bact., Balt. 7: 1-36.

Henfrey, Arthor. 1856 Notes on some fresh water confervoid algae new to Britain. Transactions of the Microscopical Society of London. New Series. 4: 49-54.

Henneberg, W. 1909 Gärungsbakteriologisches Praktikum, Betriebsuntersuchungen und Pilzkunde. p. 480.

Hertwig. 1886 Ueber den Actinomyces musculorum der Schweine. Arch. f. wissensch. u. prakt. Tierh., Berl. 12: 365-372.

Hewlett, R. I. 1898 A Manual of Bacteriology. p. 18.

Hinze, G. 1903 Thiophysa volutans, ein neues Schwefelbakterium. Ber. d. deutsch. Bot. Gesellsch., Berl. 21: 309.

Hochstetter, CH. F. 1842 Nova genera plantorum Africae australis tum tropicae borealis proponit et describit. Flora. 25: 226.

Hoeliing, A. 1910 Die Kernverhältnisse von Fusiformis termitidis. Arch. f. Protistenk., Jena. 19: 240.

Hонц, J. 1902 Ein neuer, aus Strohisolierter, "das Fadenziehen" der Milch verursachender Coccus (Carphococcus pituitoparus). Centralbl. f. Bakteriol., Jena. Abt. 2. 9: 338-344. Also Molchztg. 12: 446-448.

Hoyer, Dirk Pieter. 1898 Bijdrage tot de kennis van de Azijnbacteriën. Proefschrift ter Verkrijging van den Graad van Doctor in de Scheikunde van de Rijks-Univeriteit te Leiden. 115 pp. Delft. (Waltma jr.) Abs. Cent. 2nd Abt. 4. 867-875.

Hueppe, F. 1886 Die Formen der Bakterien und ihre Bezichungen zu den Gattungen und Arten. Wiesbaden.

Hoss, HARALD. 1908 Eine fettspaltende Bakterie (Bactridium lipolyticum n.sp.) Centralbl. f. Bakteriol., Jena. Abt. 2. 20: 474-484. 
Itzigsohn, Hermann. 1858 Zur Naturgeschichte der Sarcina ventriculi Goodsir. Arch. f. path. Anat. u. Phys. (Virchow). 13: 541-549.

Jacque, Léon, And Masay, Fernand. 1912 Le Streptobacterium foetidum, agent pathogéne nouveau de l'homme. Centralbl. f. Bakteriol., Jena. Abt. 1. Orig. 62: 180-181.

Jegunow, M. 1896 Bakterien-Gesellschaften. Centralbl. f. Bakteriol., Jena. Abt. 2. 2: 11-21.

Jennings, A. Vaughn. 1899 On a new genus of bacteria (Astrobacter). Proc. Roy. Irish Acad. Ser. 3. 5: 315.

Johne, Albert. 1881 Die Actinomykose oder Strahlenpilzerkrankung, eine neue Infektionskrankheit. Deut. Ztschr. Thiermed. 7: 141-192.

JoRdan, E. O. 1908 General Bacteriology.

Kalchbrenner, Rev. Carl and Cooke, M. C. 1880 Australian Fungi. Grevillea. 9: 17-34.

KARWACKI, LEON. 1909 Casuistique bacteriologique. Coccobacillus fusiformis n.sp. Agent pathogene de la septicemie. Gaz. lek., Warszawa. 29: $679-681$.

Kendall, Arthur I. 1902 A proposed classification and method of graphical tabulation of the characters of bacteria. Proc. Amer. Pub. Health Ann. 28: 484 .

Kern, Eduard. 1882 Dispora caucasica. nov. g. et nov. sp., eine neue Bakterienform. Biol. Zent. 2: 135.

1882 Ueber ein neues Milchferment aus dem Kaukasus. Bul. Soc. Imp. Nat. Moscou. 66: (part 2) 141-173.

KIrchner, O. 1878 Algen. Kryptogamen-flora von Schlesien.

1895 Die Wurzelknöllchen der Sojabohne. Beitr. Biol. Pflanz. 7: 213.

Кітт, Тн. 1888 Der Micrococcus ascoformans und das Myofibrom des Pferdes. Centralbl. f. Bakteriol., Jena. 3: 247.

Krı.EBS, Edwin. 1871 Die Ursachen der infectiösen Wundkrankheiten. Cor.-Bl. f. schweiz. Aerzte.

1875 Beiträge zur Kentniss der pathogenen Schistomyceten. Arch. f. exper. Path. u. Pharmakol., Leipz. 1873, I: 31, 443; 1875, III: 305; IV: $107,207,409 ; 1876, \mathrm{~V}: 350$.

1879 Das Contagium der Syphilis. Arch. f. exper. Path. u. Pharmakol., Leipz. 10: 161-218.

KLECKI, V. vos. 1894 Ueber einige aus ranziger Butter kultivierte Mikroorganismen. Centralbl. f. Bakteriol., Jena. Abt. I. 15: 354-362.

KLeIN, E. 1885 Microorganisms and Disease.

KLIGLER, I. J. 1913 A systematic study of the Coccaceae in the collection of the Muspum of Natural History. Jour. Infect. Dis., Chicago. 12: 432.

1915 A Biochemical Study and Differentiation of Oral Bacteria, with Special Reference to Dental Caries. Diss. Ph.D. Columbia University.

KuINGer, R. 1912 Ueber einen neuen pathogenen Anaëroben aus menschlichem Eiter (Coccobacterium mucosum anaërobicum n.sp.) Centralbl.

f. Bakteriol., Jena. Abt. I. Originale. 62: 186-191. 
Klöcker. AlB. 1903 Fermentation Organisms. English Translation by Allan and Miller, p. 332.

Косн, Alfred ANd Oelsner, Alice. 1923 Ueber nucleoproteidespaltende Bakterien und ihre Bedeutung für die Ersschliessung des Phosporkapitels im Ackerboden. Biochem. Ztschr. 134: 76-96.

Kolle, W., ANd Hetsch, H. 1911 Die experimentelle Bakteriologie und die Infektionskrankheiten, 3rd ed.

Koppanyi, Emerich. 1907 Ueber eine mit fibrinösen Pleuritis einhergehende Pyämie der Kaninchen. Ztschr. f. Tiermed., Jena. 11: 429-454.

Kossowicz, ALEx. 1911 Einführung in die Mykologie der Nahrungsmittelgewerbe.

1912 Einführung in die Agrikulturmykologie.

Krokiewiez, A. 1904 Zur Pathogenese des Diplopneumococcus Fränkel-Weichselbaum; ein Fall von Pneumococcosepsis metastaticae. Wien, klin. Wchnschr. 17: 563-565.

Krzysztalowicz AND Siedickr. 1908 Etude experimentale de la Syphilis; morphologie de Spirochaeta pallida. Bul. Acad. Sci. Cracovie. p. 173-234.

KÜTTNER, H. 1895 Ueber einen neuen, beim Menschen gefundenen Eitererreger. Ztschr. f. Hyg. u. Infektionskrankh., Leipz. 19:263-290.

KützrNG, F. T. 1833 Sphaerotilus natans, eine neue Süsswasseralge. Linnaea. 8: 385 .

1837 Mikroskopische Untersuchungen über die Hefe und Essigmutter. Jour. Prakt. Chem. 11: 386.

1843 Phycologia generalis.

1849 Species Algarum.

1904 Mikroskopische Untersuchungen über die Hefe und Essigmutter, nebst mehreren anderen dazu gehörigen vegetabilischen Gebilden. Auszage vorgetragen in der Versammlung des naturhistorischen Vereins der Harzes in Alexisbad am 26 Juli 1837. Reprinted in Delbrück, M. and Schrohe, A. Hefe, Gärung und Fäulnis. p. 25-38.

KUNTh, Kart Sigismund. 1850 Enumeratio plantarum, etc. 5: 35.

Kurth, H. 1883 Ueber Bacterium Zopfi, eine neue Bakterienart. Ber. d. deutsch. Bot. Gesellsch., Berl. 1: 97-100.

1883 Ueber Bacterium Zopfi, eine neue Bakterienart. Bot. Ztg. 41: 369-386, 393-405, 409-420, 425-435.

LACHNER-SANdoval, V. 1898 Ueber Strahlenpilze. Inaugural Diss. Strassburg. LAGerheim, G. 1901 Mykologische Studien III. Beiträge zur Kenntniss der parasitischen Bakterien und der bakterioiden Pilze. Bihang till K. svenska Vetenskaps-Akademien Handlingar. Band. 26. No. 4. 1900. Bot. Centralbl., Cassel. 85: 280-283.

LANKESTER, E. RAY. 1873 On a peach-coloured bacterium-Bacterium rubescens. Quart. Jour. Micr. Sc., Lond. 13: 408-410.

1876 Further observations on a peach-or red-coloured bacterium-Bacterium rubescens. Quart. Jour. Micr. Sc., Lond. N. S. 16: 27-40.

LANZI, M. 1874 Sulla orgine e natura dei batteri. Arch. di Med. chir. ed. ig. Roma. 12: 65, 129.

1876 I Batteri Parassitidi funghi. Nuovo Gior. Bot. Ital. 8: 256-261. 
Lauterborn, Robert. 1898 Ueber Modderula hartwigi Frenzel. Biol. Centralbl., Cassel. 18: 95 .

1906 Zur Kenntniss der sapropelishen Flora. Allg. bot. Ztschr. Karlsruhe. 12: 196-197.

1907 Eine neue Gattung der Schwefelbakterien (Thioploca Schmidlei nov. gen. nov. spec.) Ber. d. deutsch. Bot. Gesellsch., Berl. 25: 238-242.

1913 Zur kenntniss einiger sapropelischer Schizomyceten. Allgemeine Bot. Zeitschrift. 19: 99-100.

Lebert, Herirann. 1856-57 Ueber die Krankheit des Insekts der Seide. Verein z. Beförd d. Seiden baues d. Prov. Brandenb.

Lehmann, K. B., and Nedmann, R. 1896 Atlas und Grundriss der Bakteriologie München.

1901 Bacteriology. English Translation of 2nd German edition by G. H. Weaver. 2: 127.

Leidy, Joseph. 1849 Entophyta. Proc. Acad. Nat. Sc., Phila. 4: 225.

1849 Entophyta. Proc. Acad. Nat. Sc., Phila, 4: 249.

1851 Descriptions of new entophyta growing within animals. Proc. Acad. Nat. Sc., Phila. 5: 35 .

1852 A flora and fauna within living animals. Smithsonian Contributions to knowledge. 5: 1-67.

LeтвE, W. 1885 Ueber die ammoniakalische Harngährung. Archiv. f. path. Anat. (Virchow). 50: 540-570.

LEVEILlÉ, J. H. 1851 Organisation et Disposition methodique des especes qui composent le genre Erysiphé. Annales science naturelles. Botanique. Series 3. 16: 109-179 and 381 .

Levy, E. 1899 Ueber die Actinomyces gruppe (Aktinomyceten). Centralbl. f. Bakteriol., Jena. Abt. I. 26: 1.

Lewis, Tiмотну Richards. 1879 The Microphytes which have been found in the blood and their relation to disease. Quart. J. Micr. Sc., Lond. N. S. 19: $356-404$.

Lieske, Rudolf. 1921 Morphologie und Biologie der Strahlenpilze.

Lignières, M. 1900 Contribution a l'étude et à la classification des Septicemies hemorrhagiques. Rec. de méd. vét., Par. Ser. 8. 7: 331-332.

1901 Contribution à l'étude et la classification des septicemies hemorrhagiques, les "Pasteurelloses." Ann. de l'Inst. Pasteur, Par. 15: $734-736$.

Lignik̀res, Jose AxD Spitz, Jorge. 1902 Actinobacilosis. Boletin de Agricultura y Ganaderia. Buenos Ayres. 11: 169-230.

1904 Contribution à l'étude, à la classification et à la nomenclature des affections connues sous le nom d'actinomycose. Centralbl. f. Bakteriol., Jena. Abt. I. Originale. 35: 452-461.

Lindad, Gustav. 1898 Bibliography. Schizomyceten. 1894-1898. Sammelwerke, Lehrbucher, Monographieen etc. Gonococcus Neisseri. p. 100-103. Just's Bot. Jahresber. Abt. 1. 26: 1-139.

Lindner, P. 1887 Die Sarcina-Organismen der Gährungsgewerbe. Diss. Berlin. 1888. Centralbl. f. Bakteriol., Jena. 2: 340 .

1909 Mikroskopische Betriebskontrolle in den Gärungsgewerben. Ed. 5. 
Lingelsheim, W. v. 1912 Streptokokken. Kolle and Wasserman's Handbuch der pathogenen Mikroorganismen. Ed. 2. p. 494.

Link, H. 1795 Dissertationes botanicae, Sverini. F. 65.

Lister, Joseph. 1873 A further contribution to the natural history of bacteria and the germ theory of fermentation changes. Quart. Jour. Micr. Sc., Long, xiii: 380-408.

Loeffler. 1886 Die Aetiologie der Rotzkrankheit. Arb. a. d. k. Gsndhtsamte, Berl. 1: 143 .

LöHNIs, F. Handbuch der landwirtschaftliche Bakteriologie.

1913 Vorlesungen über landwirtschaftliche Bakteriologie.

Löhnis, F., And Hanzawa, J. 1914 Die Stellung von Azotobacter im System. Centralbl. f. Bakteriol., Jena. 2 Abt. 42: 1-8.

Lotsy, J. P. 1907 Vorträge über botanische Stammesgeschichte. Vol. I. Algen und Pilze.

Löwi, Emı. 1920 Ueber den Bacillus crassus Lipschutz. Wien. klin. Wchnschr. 33: 730-733.

Lodwig, Friedrich. 1892 Lehrbuch der niederen kryptogamen.

1898 Abstract of paper by Hoyer (1898). Centralbl. f. Bakteriol., Jena. 2 Abt. 4: $867-875$.

1899 Beobachtungen über Schleimflüsse der Bäume im Jahr 1898. Ztschr. f. Pflanzenkr., Stuttg. 9: 10-14.

LÜDERs, JoH. 1866 Ueber Abstammung und Entwickelung des Bacterium Termo Duj., Vibrio lineola Ehr. Bot. Ztg. 24: 33-39, 41-46.

Luenssen, Artur, And Kühn, M. 1908 Yoghurt die bulgarische Sauermilch. Centralbl. f. Bakteriol., Jena. Abt. 2. 20: 241.

Luerssen, Chr. 1879 Botanik. 1:22.

LUtz, Adolph. 1886 Zur Morphologie des Mikroorganismus der Lepra. Separat Abdruck aus Dermatologische Studien. Herausg. von Dr. P. G. Unna. Heft. 1. p. 22.

Lyall, H. W. 1915 The types of pneumococei in tuberculous sputum. Jour. Exper. M. Balt. 21: 146.

Lyngbye, H. Christian. 1820 Hydrophyt. Danica. Account of a new arrangement of the Algae. Edinb. Phil. Jour. 2: 282-287.

MaAssen, Albert. 1905 Uber Gallertbildungen in den Säften der Zuckerfabriken. Ein Beitrag zur kenntniss der gallertbildenden Bodenbakterien. Arb. a. d. k. Gsndhtsamte, Berl. Biol. Abt. 5: 1.

MACÉ, E. 1897 Traité pratique de Bactériologie. 3rd ed.

1913 Traité pratique de Bactériologie. 6th ed.

MacNab, W. R. 1877 On the classification of the vegetable kingdom. Jour. Bot. London. 6: 340 .

MAGgi, Leopoldo. 1886 Essai d'une classification protistologique des ferments vivants. Jour. Microg. 10: 80-85, 173-178, 327-333.

1887 Acque potabili.

Magnin, A. 1878 Les bactéries. Paris.

Maire, René and Tison, Adrièn. 1909 La Cytologie des Plasmodiophoracées et la classe des Phytomyxinae. Ann. Mycolog., Berl. 7: 241. 
Makrinov, I. A. 1916 Sur un nouveau microorganisme provoquant la fermentation de l'amidon, et des matiòres pectiques. Arch. d. Sci. Biol. de Petrograd. 18: 440-452.

Malerba, P., and Sanna-Salaris, G. 1888 Ricerche sul Gliscrobatterio. Rendiconto della R. Accademia della Science fis. e mat. di Napoli. Fasc. 6. 1888 according to Buchner. Centralbl. f. Bakteriol., Jena. 4: 486.

Marpuann, G. 1889 Ueber die Erreger der Milchsäure-Gährung. Ergänzungshefte zum Centralblatt für allgemeine Gesundheitspllege. 2: $118-132$.

Matzuschita, T. 1902 Bakteriologisches Diagnostik.

MAzE, N. 1903 Sur la fermentation formenique et le ferment qui la produit. Compt. rend. Acad. d. sc. Par. 137: 887.

McNAB, A. 1904 Ueber den "Diplobacillus liquefaciens (Petit)" und ueber sein VerhäItnis zudem Morax-Axenfeldschen Diplobazillus der Blepharokonjunctivitis. Klinsche Monatsblätter für Augenheilkunde. 42: 54-70.

Mendel, Josepr. 1919 Cladothrix et infection d'origine dentaire (Cladothrix matrouchoti). Compt. rend. Soc. de biol., Par. 82: 583-686.

Merrill, E. D., And Wade, H. W. 1919 The validity of the name Discomyces for the genus of fungi variously called Actinomyces, Streptothrix and Nocardia. Philippine Jour. Sc., Manila. 14: 55-69.

Messei, Al. 1891 Contribuzione allo studio delle ciglia dei batterii e preposta di una classificazione. Rivista d'Igiene e Sanità Pubblica. Anno I. No. 14. Arch. Sci. Med. (Turin)., Torino e Palernio. 15: 233-236.

Metchnikoff, Elie. 1888 Pasteuria ramosa, un representant des bacteries a divisione longitudinale. Ann. de l'Inst. Pasteur, Par. 2: 166.

1888 Ueber die phagocytäre Rolle der Tuberkelriesenzellen. Virchow's Archiv. 113: 63-94.

1889 Contributions à l'étude du pleomorphisme des bacteriens. Ann. de l'Inst. Pasteur, Par. 3:61.

Mettenhener, C. 1858 Ueber Leptothrix ochracea Kütz, und ihre Beziehung zur Gallionella ferruginea Ehr. Abhandl. herausgeben von der Senckenbirgischen naturforsch. Ges. Frankfurt a M. 2: 139.

Meyen, J. 1827 Actinomyce (Strahlenpilz), eine neue Pilzgattung. Linnaea. 2: 433 .

1839 Jahresberichte über die Resultate der Arbeiten im Felde der physiologischen Botanik de Jahre. 1838. Weigmann's Arch. Naturgesch. 2: 1-152.

Meyer, Arthur. 1897 Studien über die Morphologie und Entwickelungsgeschichte der Bakterien, ausgeführt an Astasia asterospora A. M. and Bacillus tumescens Zopf. Flora. 81: 185.

1898 Neues über die Morphologie der Bacterienzelle und die Entwickelungsgeschichte der Bacteriensporen. Sitzungsberichte der Gesellschaft zur Befördung der gesammten Naturwissenschafter zu Marburg. No. 5. p. 49.

1912 Die Zelle der Bakterien, Jena.

MEYer, K. F., ANd Shaw, E. B. 1920 A comparison of the morphologic cultural and biochemical characteristics of $B$. abortus and B. Melitensis. Studies on the genus Brucella nov. gen. I. Jour. Infect. Dis., Chicago. 27: 173184. 
Miene, Hugo. 1908 Beiträge zur Biologie, Morphologie und Systematik des Tuberkelbazillus. Ztschr. f. Hyg. u. Infektionskrankh., Leipz. 62: 131.

Migdla, W. 1890 Bakterienkunde für Landwirte. Berlin.

1894 Ueber ein neues System der Bakterien. Arb. Bact. Inst. Karlsruhe. 1: 235-238.

1895 Schizomycetes. Engler and Prantl. Natürlichen Pflanzenfamilien. p. 20.

1897 Ueber Gallionella ferruginea Ehrenberg. Ber. d. deutsch. Bot. Gesellsch.. Berl. 15: 321.

1897-1900 System der Bakterien. Vol. 1. 1897, Vol. 2. 1900.

1904 Allgemeine Morphologie, Entwickelungsgeschichte, Anatomie und Systematik der Schizomyceten in Lafar. Handbuch der technischen Mykologie. 2nd ed. p. 1-149.

1904 Botanisches Vademecum. Wiesbaden.

Miller, W. D. 1886 Einige gasbildende Spaltpilze des Verdauungstractus, ihr Schicksal im Magen und ihre Reaction auf verschiedene Speisen. Deutsche med. Wchnschr., Berl. and Leipz. 12: 117-119.

1888 Beiträge zur Kenntniss der Mundpilze. Deutsche med. Wchnschr., 14: 612 .

1892 Mikroorganismen der Mundhohle. Ed. 2.

Miquel, M. P. 1879 Etudes sur la fermentation ammoniacale et les ferments de l'urée. Ann. Microg. 1: 414, 417, 506, 552.

1880 Etudes sur la fermentation ammoniacale et les ferments de l'urée. Ann. Microg. 2: 13, 53, 122, 145, 367, 488.

1881 Etudes sur la fermentation ammoniacale et les ferments de l'urée. Ann. Microg. 3: 275, 305.

Miquel, P., and Cambier, R. 1902 Traité de Bact. Paris. p. 881.

Miyoshi, Manabu. 1897 Studien über die Schwefelrasenbildung und die Schwefelbacterien der Thermen von Yumoto bei Nikko. Jour. Col. Sci. Imp. Univ. Tokyo. 10: 143-170.

Molisch, Hans. 1906 Zwei neue Purpurbakterien mit Schwefelkörperchen. Bot. Ztg. Abth. I. Orig. 64: 223-232.

1907 Die Purpurbakterien. Jena.

1909 Festschrift für Treub. Extrait des Ann. Jard. Bot. Buitenzorg. Series 2. Supp. 3. p. 29-33.

1910 Die Eisenbakterien. Jena.

Morax, V. 1896 Note sur un diplobacille pathogene pour la conjonctivite humaine. Ann. de l'Inst. Pasteur, Par. 10: 337.

Moreno, J. MADrid. 1901 Eine neue Art von Ascobacillus, entdeckt im Wasser des Lozayakanals bei Madrid. Centralbl. f. Bakteriol. Jena. 30: 111-114.

Mori, N. 1913 Di un nuovo batterio patogene e di molti altri batteri nei quali quo provocarsi lïndividuazione di un nucleo tipico. Ann. d. Staz. Sper. p. 1. malattie inffettive del bestiame. 1: 1 .

Morren, Charles F. A. 1831 Mémoire sur les vibrions lamellinaires. Messager des sciences de Gand. $9^{\mathrm{e}}$ et $10^{\mathrm{e}}$ liv. $6^{\mathrm{e}}$ vol. 1830 . Abstract. Bull. des sciences naturelles et de Geologie. 27: 203-205. 
Mdeller, O. F. 1773 Vermium Terrestrium et fluviatilum. seu Animalium infusoriorum, helminthicorum et Testaceorum, non marinorum. Vol. 1.

Mueller, O. F. 1786 Animalcula infusoria et marina, Hauniae.

MÜhlhäUSer, F. A. 1884 Ueber Spirillen. Arch. f. path. Anat. u. Phys. (Virchow). 47: 84-106.

Muggrave, W. E., Clegg, M. T., And Polk, MARY 1908 Streptothricosīs with special reference to the etiology and classification of mycetoma. Phillip. Journ. Sci., Ser. B., Med. Sci. 3: $447-544$.

Nadson, G. A. 1906 Zur morphologie der niederer Algae. I. Utber Veraenderungen bei Stichococcus bacillaris Näg. in Abhangigheit om den Bedigungen der Ernährung. II. Über Endosporenbildung bei Stichococcus bacillaris Näg. und Chlorö̈dium Krugeri. III. Chlorobium limicola ein grüner chlorophyll-führender Mikrobe. Bull. du Jard in Imp. Bot. de St. Petersb. 6: 184-192.

Naegeli, Carl Wilhelir von. 1842 Botanische Beiträge. Linnaea. 16: 279. Jahrb. Wiss. Bot. (Pringsheim).

1857 Bericht über die Verhandlungen der bot. Section der 33 Versammlung deutscher Naturforscher. und Arzter. Bot. Ztg. p. 760.

Nicolle, M., Aid Cesari, E. 1914 Études sur les staphylocoques dorés. Ann. de l'Inst. Pasteur, Par. 28: 219.

Nijdan, H. W. M. 1907 Aërobacter tartarivorum (Dutch). Delft. (vanMarken).

Niklewski, Bronislaw. 1910 Ueber die Wasserstoffoxydation durch Mikroorganismen.

Nissex, Franz. 1889 Zur Fenntniss der bacterienvernichtenden Eigenschaft des Blutes. Ztschr. f. Hyg. u. Infektionskrankh., Leipz. 6: 487-520.

Noguchi, Hidero. 1917 Spirochaeta icterohaemorrhagiae in American wild rats and its relation to the Japanese and European strains. Jour. Exper. Med., Balt. 25: 755-763.

Nogdchi, Hidexo, and Akatsu, Seinai. 1917 Immunological studies on pure cultures of various spirochetes. Jour. Exper. Med., Balt. 25: 765-788.

Noguchi, Hideyo. 1918 Morphological characteristics and nomenclature of Leptospira (Spirochaeta) Icterohaemorrhagiae (Inada and Ido). Jour. Exper. Med., Balt. 27:575-592.

1918 Further study on the Cultural conditions of Leptospira (Spirochaeta) Icterohaemorrhagiae. Jour. Exper. Med., Balt. 27: 593-608; 609-625; $667-678$.

Oersted, A. S. 1840-1841 Beretnung om en Excursion til Trindelen en Alluvial dannelsei Odensefjord. Naturhistorisk Tidsskrift. 2: 552-569.

1844 De regionibus marinis. p. 44.

Ogston, Alex. 1883 Micrococcus Poisoning. Jour. Anat. et Physiol. (Paris). 17: 27.

Olsen-Sopp, O. J. 1912 Taette, die urnordische Dauermilch und verwandte Milchsorten, sowie ihre Bedeutung für die Volksernährung. Centralbl. f. Bakteriol., Jena. Abt. 2. 33: 1-54.

Orla-Jensex; S. 1909 Die Hauptlinien des natürlichen Bakterien systems. Centralbl. f. Bakteriol., Jena. Abt. 2. 22:305-346. 
1909 Vorschlag zu einer neuen bakteriologischen Nomenklatur. Centralbl. f. Bakteriol., Jena. Abt. 2. 24: 477.

1919 The lactic acid bacteria. Mém. de l'Acad. Roy. d. Sci. et dl Lettres de Danemark, Copenhagen, 1919. Sec. d. Sci. 8me, sér. 5: (no. 2.) 81-196.

1921 The main lines of the natural bacterial system. Jour. Bact., Balt. 6: 263-273.

Overbeck, A. 1891 Zur Kenntniss der Fettfarbstoff Production bei Spaltpilzen. Nova Acta d. k. Leop. Carol. deutsch. Akad. d. Naturf. 55: 399.

Pastedr, Louis. 1868 Etudes sur la vinaigre.

Perfiliev, B. V. 1914 Sur une "bacterie verte" à chlorophylle, le Pelodictyon clathratiforme Lauterb. Jour. Microbiol. 1: 179-194.

Perroncito, Eduard. 1879 Ueber das epizootic Typhoid der Hühner. Arch. f. wissensch. u. prakt. Tierh., Berl. 5: 22-51.

1879 Ueber den Actinomyces bovis und die Sarkome der Rinder. Deut. Ztschr. Thiermed. 5: 31-40.

Perrone. 1905 Contribution a l'étude de là bacteriologie de l'appendicite. Ann. de l'Inst. Pasteur., Par. 19: 371.

Persoon. 1822 Mycologia europaea. Sectioprima.

Perty, Maxmilian. 1852 Zur Tienntniss kleinster Lebensformsn.

PeтRuschку. 1913 Die pathogenen Trichomyceten und Trichobakterien. Streptuthrix, Cladothrix, Leptothrix. Kolle and Wassermann. Handbuch der pathogene Mikroörganismen. 2nd ed. 5: 267-300.

Petschenko, Boris De. 1908 Sur la structure et le cycle évolutif de Bacillopsis styloygae n.g. et n.sp. Bull. Acad. Sci. Cracovie. pp. 359-371.

1911 Drepanospira Mülleri n.g. n.sp. parasite des paraméciums: contribution a l'étude de la structure des bacteries. Arch. f. Protistenk., Jena. 22: $248-298$.

Pfeiffer. 1887 Synonymia botanicae.

Pinor, E., And Morax. 1911 Sur les concrétions des voies lacrymales. Etud mycologique. Bull. Soc. Ophtalmologie de Paris. No. 3.

1913 Actinomycoses et Mycetomes. Bul. Inst. Pasteur. 11:929.

Poulsen, V. A. 1880 Ueber einige mikroskopische Pflanzenorganismen. Bot. Ztg. 38: 509 .

Prazmowski, Adam. 1879 Zur Entwickelungsgeschichte und Fermentwirkung einiger Bacterien-Arten. Verläufige Mitt. Bot. Ztg. 37: 409 424.

1880 Untersuchungen über die Entwickelungsgeschichte und Fermentwirkung einiger Bakterien. p. 23.

Preisz, Hugo. 1894 Recherches comparetives sur les pseudotuberouloses bacillaires. Ann. de l'Inst. Pasteur, Par. 8:231.

Prillieux. 1879 Sur la nature et la cause de la formation des tubercules quinaissent sur les racines des Legumineuses. Bul. Soc. Bot. France. 26: 98 .

Rabenionst, L. 1864-1865 Flora Europaea Algarum.

Ralfs, John. 1843 On the British Diatomaceae. Ann. and Mag. Nat. Hist. Ser. 1. 12: 351 .

Reichenbach, H. L. 1852 Gartenorchiden. Bot. Ztg. 10:928. 
REitz, A. 1906 Weitcre bacteriologische Untersuchungen mit der Stuttgarter Markt-und Handelsbutter. Centralbl. f. Bakteriol. Jena. 2nd Abt. 16: 719 .

Rist, E., And Kinoury, J. 1902 Etudes sur un lait fermente comestible, le Leben d'Egypte. Ann. de l'Inst. Pasteur. Par. 16: 65-84.

Rivolta, S. 1878 Sul cosi detto mal del rospo del Truta e Sull "Actinomyces bovis" di Harz. Clin. vet., Milano. 1: 169 and 201.

1882 Ueber die Priorität der Beschriebung der Formen der Actinomykose und ihrer eigenthümlichen Elemente bei den Rindern. (Virchow) Archiv. f. path. Anat. u. Phys. u. f. klinische Medecin. 88: 389-390.

1888 Pleurite infettiva nel gatto e nel cane. Giornale di Anatomia Fisiologia e Patologia degli Animali. 20: 1-8.

Robin, Charles. 1847 Des végétaux qui croissent sur les animaux vivants. Paris.

1853 Histoire naturelle des Végétaux Parasites qui croissant sur l'homme et sur les animaux vivants. Paris.

Rosenbach, A. J. F. 1854 Mikroörganismen bei den Wund Infektionskranheiten.

1909 Experimentelle, morphologische und klinische. Studie über die krankheitserregenden Mikroörganismen des Schweinesrothlaufs, des Erysipeloides und der Mäusesepsis. Ztschr. f. Hyg. u. Infektionskrankh., Leipz. 63: 3.13-371.

Rothiaxi, E. A. 1901. Glischrobacterium als Ursache der schleimigen Gärung des Menschurins. Centralbl. f. Bakteriol., Jena. Abt. 1. Originale. 37: 491 .

Rougentzoff, D. 1914 La Flore intestinale des lapins nourris de carottes et des lapins soumisa l'inanition. Ann. de l'Inst. Pasteur, Par. 28: 639-661.

Roze, E. 1898 Sur un nouveau type générique des schizomycètes, le Chatinella. Compt. rend. Acad. d. sc., Par. 127: 825. Bull, de la soc. mycol. de France. p. 69.

Ruata, Vikton. 1909 Ueber einen Kokkobacillus der menschlichen Bindehaut. Ein Beitrag zur Kenntniss der gram-negativen Diplokokken. Centralbl. f. Bakteriol., Jena. Abt. I. Originale. 51: 630 .

Rulluann, W. 1901 Ueber ein Nitrosobacterium mit neuen Wuchsformen. Centralbl. f. Bakteriol., Jena. Abt. 2. 3: 228.

Salisbury, J. H. 1868 Microscopic examination of the blood, and vegetations found in variola, vaccinia and typhoid fever.

Sambon, L. 1907 In Manson's, Tropical Diseases.

Sampietro, G. 1908 Sulla vitalita e virulenza die batteri intestinali conservati nel terreno. Ann. d'Igiene Roma. 18: 119-135.

1908 Sopra due casi di actinomicosi nell'uomo. Ibid. 391-461.

Sadvagead, C., ANd Radais, M. 1892 Sur les genres Cladothrix, Streptothrix, Actinomyces et description de deux Streptothrix nouveaux. Ann. d. l'Inst. Pasteur, Par. 6: 242-273.

Schamberg, F. 1902 On the Microbacillus seborrhoeae (Sabourand) Zurn. dermatol. sifilidol. Russ. trans. St. Petersburg. 2: 293. 
Schattenfroh, A., And Grassberger, R. 1899 Ueber Buttersäuregahrung. Centralbl. f. Bakteriol., Jena. 2nd Abt. 5: 697-702.

Schaudinn, F. 1905 "Korrespondenzen." Deutsche med. Wchnschr., Berl. and Leipz. 31: 1728.

SchaUdinn UNd HofFinans. 1905 Vorläufiger Bericht über das Vorkommen von Spirochäten in syphilitischen Krankheitsproduktion und bei Papillomen. Arb. K. Gsndhtsamt. 22: 527.

SchewiakofF, W. 1893 Ueber einen neuen bacterienähnlichen Organismus des Süsswassers. Heidelberg.

Schindler, Anton K. 1905 Halorrhagidaceae. Das Pflanzenreich. Heft. 23: 82 .

Schlegel, M. 1913 Morphologie des Aktinomycespilzes. Kolle u. Wasserman, Handbuch der pathogenen Mikroorganismen. 2nd ed. 5: 303.

Schmidechner, Kard. 1905 Ein durch Vincentsche Bakterien verursachte Puerperalerkrankung. Zeitschr. für Geburtshülfe und Gynäkologie. 56: 291.

Schuidt And Weis. 1902 Die Bakterien.

Schneider, A. 1912 Pharmaceutical Bacteriology.

Schorler, B. 1904 Beiträge zur Kenntniss der Eisenbakterien. Centralbl. f. Bakteriol., Jena. Abt. 2. 12: 691.

Schroeter, J. 1872 Ueber einige durch Bacterien gebildete Pigmente. Cohn's Beiträge z. Biologie d. Pflanzen. Heft 2. 1: 109-126.

1886 Schizomycetes. Cohn's Kryptogeme-Flora von Schlesien. 3: 136-174.

Schoetz. 1887 Di Ursache der Brustseuche der Pferde. Arch. f. wissensch. u. prakt. Tierh., Berl. 13:27.

Schwers, Henri. 1908 Le fer dans les eaux souterraines. Rev. d'hyg., Par. 30: 11-43, 100-126, 185-221, 287-306.

Seligmann, E. 1911 Bakteriologische Befunde bei Säuglingsgrippe. Beiheft. Centralbl. f. Bakteriol., Jena. Abt. 1. Referate. 50: 81*-82*.

Sette, Vincenzo. 1824 Sull'arrossimento straordinario di alcune sostanze alimentose osservato nella provincia di Padova l'anno 1819. Venezia 1824.

Smith, Allan J. 1902 Laboratory Exercises in Bacteriology.

Smith, Erwin F. 1905 Bacteria in Relation to Plant Diseases. Vol. 1. Carnegie Institute. Washington, D. C.

Smith, R. Grieg. 1902 The gummosis of the sugarcane (Boc. vascularum Cobb). Sydney, N. S. W., Proc. Linn. Soc. N. S. Whales. 27: 31-47.

1902 An Ascobacterium from the sugar cane. Ibid. pp. 137-145. Int. Cat. Sci. Lit. 2: 157-158.

1902 Die Gummigärung von Zuckerrohrsaft. Das Verderben der Krystalle von rohem und raffiniertem Zucker. Die Säuregärung des Rohrzuckers. Centralbl. f. Bakteriol., Jena. Abt. 2. 8: 597-600.

Sollied, Peter Rav. 1903 Studien über den Einfluss von Alkohol auf die an verschiedenen Brauerei- und Brennereimaterialen sich vorfin den Organismen, sowie Beschreibung einer gegen Alkohol sehr widerstandsfähigen neuen Pediokokkus art. (Pediococcus hennebergi, n.sp.) Ztschr. Spiritusindus. 26: 481-482, 491-493. 
Sternberg, G. M. 1892 Manual of Bacteriology.

STILEs, C. W. 1905 The international code of zoological nomenclature as applied to medicine. Bull. Hygienic Laboratory, Washington, D. C. 24.

1905 The correct spelling of Spirochaeta. Am. Med. 10:94.

Stiles, C. W., And Pfender, C. A. 1905 The generic name of the parasite of syphilis. Am. Med. 10: 936.

Stockhausen, FERd. 1907 Ökologie, "Anhäufungen" nach Beijerinck Beiträge zur natürlichen Reinzucht der Mikroörganismen. Berlin.

Stoklasa, Jolius. 1908 Beitrag zur kenntniss der chemischen Vorgähge bei der Assimilation des elementaren Stickstoffs durch Azotobacter und Radiobacter. Centralbl. f. Bakteriol., Jena. Abt. 2. 21: 282-509.

Streinz, W. M. 1862 Nomenclator fungorum.

Stutzer, A., ANd Hartleb, R. 1899 Untersuchungen über die beider Bildung von Salpeter beobachteten Mikroorganismen. Mitt. Landw. Inst. Breslau. 1: 75., 2: 197.

Swellengrebel, M. 1907 Sur la cytologie comparée des Spirochètes. Ann. d. l'Inst. Pasteur, Par. 21: 448 and 562.

Terni, C. 1894 Actinomyces Gruberii. Atti dell'xi congresso med. internaz. Roma. 6: (Igiene): 79.

Thaxter, Roland. 1892 On the Myxobacteriaceae, a new order of Schizomycetes. Bot. Gaz., Chicago. 17: 394.

Thesing, Cort. 1906 Spirochaete, Spironema oder Spirillum. Centralbl. f. Bakteriol., Jena. Abt. I. 40: 351 .

Thiercelin, E. 1899 Du diplocoque ou entérocoque son rôle dans la pathogénie de certaines affections digestives. Bull. Soc. de Péd. de Paris. 1: 208-223.

1899 Zur un diplocoque saprophyte de l'intestin susceptible de devenir pathogénique. Compt. rend. Soc. de biol., Par. 51: 269-271.

1902 Procédès faciles pour isoler l'entérocoque des selles normale; filtration des selles; culture préalable en anaërobie. Compt. rend. Soc. de biol. 54: 1082.

Thin, George. 1880 On Bacterium foetidum; an organism associated with profuse sweating from the soles of the feet. Proc. Roy. Soc., Edinb. 30: $473-478$.

1881 Bacterium decalvans; an organism associated with the destruction of the hair in alopecia areata. Proc. Roy. Soc., Edinb. 33: 247-253.

Thomson, Robert D. 1852 Ueber die Natur und die chemischen Wirkungen der Essigmutter. Annalen der Chemie und Pharmazie. 83:89.

Tieghem, Ph. van. Observations sur des bactériacées vertes, sur des phycochromacees, blanches, et sur les affinités de ces deux familles. Bul. Soc. Bot. France. 27: 174-179.

Tilden, Josephine. 1910 Minnesota Algae. 1: 86.

Tissier, Henry. 1900 Recherches sur la Flore Intestinale des Nourrissons (Etat normal et pathologique). Thèse pour le Doctorat en Médécine. Paris.

1905 Répartition des microbes dans l'intestin du nourrisson. Ann. d. l'Inst. Pasteur, Par. 19: 109-123. 
Trécol, A. 1865 Matière amylacée et cryptogames amyliferes dans les vaisseaux du latex de plusieurs Apocyneés. Compt. rend. Acad. d. sc. Par. 61: $156-160$.

1865 Production de plantules amylifères dans les cellules végétales pendant la putréfaction. Chlorophylle cristallisée. Compt. rend. Acad. d. sc. Par. 61: 432-436.

Trelease, W. 1885 Observations on several zooloeae and related forms. Studies Biol. Lab. Johns Hopkins Univ. 3: 194-216.

Trevisan, V. 1842 Prospetto della Flora Euganea.

1879 Prime linee d'introduzione allo studio bei Batterj italiani. Rendiconti Reale Instituto Lombardo di Scienze e Lettere. Ser. II. 12:13-21.

1879 Prime linee d'introduzione allo studio dei Batterj italiani. 2nd communication. Rendiconti. Reale Instituto Lombardo di Scienze e Lettere. IV. Ser. II. 12: 13-21, 133-151.

1879 Sulla causa dell'asfissia e dell'agglutianzione dei globuli del sangue nelle difterite. Rendiconti. Reale Instituto Lombardo di Scienze e Lettere. Ser. II. 12: 54-62.

1882 Emilio Cornalia. Atti della Accademia Fisio-Medico-Statistica di Milano. p. 100.

1882 Processi Verbali Delle Adunanze. Atti della Accademia Fisio-MedicoStatistica di Milano. p. 151.

1883 Il Batterio del tifo abdominale (Metallacter Ileotyphi) e il Batterio della pellagra, (Bacterium Maydis). Atti della Accademia Fisio-Medicostatistica in Milano. Ser. 4. 1: 149-157.

1884 A proposits del bacillo del cholern; Koch o Pacini? intoruo al modo di agire del bacillo nel corpo umeno. Gazz. med. lomb., Milano. 8 s. 6: $373 ; 547$.

1884 Il batterio del cholera è un vibrione, non un bacillo; è agente esogeno e cansor occasionale delea malattia, non agente endogeno e causa assoluta. Gazz. med. lomb., Milano. 8s. 6:417-427.

1885 Il fungo del choléra asiatico. Questioni risolte. Atti della Accademia Fisio-Medico-Statistica in Milano. Ser. 4. 3: 78-91.

1885 Caratteri di alcuni nuovi generi di Batteriacee. Atti della Accademia Fisio-Medico-Statistica in Milano. Ser. 4. 3: 92-107.

1885 Quadrosinottico delle malattie dell'uomo e degli animali caratterizzate dalla presenza di batteri patogeni. Atti della Accademia Fisio-MedicoStatistica in Milano. Ser. 4. 3: 107-119.

1887 Sul Micrococco della rabbia e sulla possibilita di riconoscere durante il periodo d'incubazione, dall'esame del sangue della persona morsicata, se ha contratta l'infezione rabbica. Rendiconti. Reale Instituto Lombardo di Scienze e Lettere. Ser. II. 20: 88-105.

1887 Se sia vero che il Bacillo imetrofo (Micrococcus prodigiosus di antichi autori) preceda sempre come agente specifico predisponente il calcino del baco da seta. Rendiconti. Reale Instituto Lombardo di Scienze e Lettere. Ser. II. 20: 797-804.

1887 Caratteri di Alcuni Nuovo Generi di Batteriacee. Reale Instituto Lombardo di Scienze e Lettere. Rendiconti. Piso. p. 94.

1889 Klebsiella. Reale Instituto Lombardo di Scienze e Lettere. Rendiconti. Ser. II. 30: 777-790.

1889 I genera e le specie delle Batteriacee. Milan. 
Troili-Petersson, G. 1903 Studien über die Mikroorganismen des schwedischen Günterkäses. Centralbl. f. Bakteriol., Jena. Abt. 2. 11: 120-143.

Tsilinsky, P. 1889 Sur les Mucédinées Thermophiles. Ann. de l'Inst. Pasteur, Par. 13: 500.

Turczaninow, Nicolaus. 1851 Synanthereae quaedam hucus que indescriptae. Bull. Soc. natur. Moscow. 24: 156 .

Ueke, A. 1898 Ein Beitrag zur kenntniss der Anaëroben. Centralbl. f. Bakteriol., Jena. Abt. I. 23: 996.

Unna, P. G. 1892 Der Streptobacillus des weichen Schankers. Monats. f. Prakt. Derm. 14: 485-490.

Unna, P. G., and Tommasoli, P. Flora dermatologica (Fortsetzung). Bacillen, kokken und Hefeformen. Monatshefte für praktische Dermatologie. 9: 60 .

Valentse, G. G. 1836 Repert. für. Anat. und Phys. 1: 110.

1837 Hygrocrocis intestinalis, eine auf der lebendigen und ungestört functionirenden Schleimhaut des Darmcanales vegetirende Conferve. Repert. f. Anat, u. Phys. 1: 110-114.

VAN LAER, H. 1889 Contributions à l'histoire des ferments des hydrates de carbone. Bacille des bières tourneés. Mem. de l'Acad. royale de Belgiquè. 43:

Van Tieghem, Ph. 1878 Sur la Gomme de Sucrerie (Leuconostoc mesenteroides). Ann. Sci. Nat. Bot. Ser. 6. 7: 198.

1879 Sur le ferment butyrique (Bacillus amylobacter) à l'époque de la houille. Compt. rend. Acad. d. Sc., Par. 89: 1102-1104.

1880 Sur quelques bacteries agregées. Bul. Soc. Bot. France. 27: 148-153.

1884 Traité de Botanique. Paris. p. 114.

Veley, V. H., AND Veley, Lilian J. 1898 The microorganism of faulty rum. London. Frowde. Abs. Kochs J. 9: 154.

Vincenzi, L. 1897 Di un nuovo tetrageno patogene (tetragenocitreo). Riforma Med. 13: 758-760.

VoN BAER, K. E. 1827 Die Verwandtschafts-verhältnisse unter den Niedern Thierformen. Nova Acta Phys.-Med. Acad. Caes. Leop. Nat. Cur. 13: 748.

Vuillemin, Paul. 1888 Les tubercules radicaux des légumineuses. Ann. de la Sci. Agron. France. et Etrangère. 4: 121-212.

1905 Sur la dénomination de l'agent de la syphilis. Compt. rend. Acad. d. sc., Par. 140: 1567.

1913 Genera Schizomycetum. Ann. Mycologic., Berl. 11: 546.

Waksman, Selman, A. 1919 Cultural studies of species of Actinomyces. Soil Sc., New Brunswick, N. J. 8: 71-207.

Waksman, Selman A., and Joffe, J. S. 1922 Microorganisms concerned in the oxidation of sulfur in the soil. II. Thiobacillus thiooxidans, a new sulfuroxidizing organism isolated from the soil. Jour. Bact., Balt., 7: 239-256. 
Wallroth, Fred Guil. 1837 Flora Cryptogamica German. 2: 182.

Warming, Eugenius. 1875 Om nogle ved Danmarks Kysterlevende Bakterien. Videnskab. Meddelelser fra den naturhist. Forening i Kjöbenhavn. 7: $307-420$.

1876 Observations sur quelques Bactéries qui se rencontrent sur les côtes du Danmark. Resumé d'un mémoire publié dans les "Videnskabelige Meddelelser" de la Société d'histoire naturelle de Copenhague, Avec 4 Planches. Den Naturhistoriske Forening Kjöbenhaven. Videnskabelige Meddelelser. Appendix. 28: 1-36.

Weichselbaum, A. 1886 Untersuchungen ïber Pneumonie. Bakt. Theil. Medizinische Jahrbücher. 82. Neue Folge. 1: 506.

1887 Zur Aetiologie der acuten Endocarditis. Centralbl. f. Bakteriol., Jena. 2: 209-217.

Wenner, J. J., And Rettger, Leo F. 1919 A systematic study of the proteus group of bacteria. Jour. Bact., Balt. 4: 331-353.

West, G. S. 1904 The British Freshwater Algae.

West, G. S., ANd Griffiths, B. M. 1909 Hillhousia mirabilis, a giant sulfur Bacterium. Proc. Roy. Soc. Long. Biol. Sci. 81: 398-399.

Wille, N. 1903 Algologische Notizem x. Nyt. Magazin f. Naturvidenskab. 41: 89-185.

Winogradsky, Sergius. 1888 Beiträge zu Morphologie und Physiologie der Bakterien. Heft. 1. Zur Morphologie und Physiologie der Schwefelbacterien. Leipzig.

1892 Contributions à la morphologie des organismes de la nutrification. Arch. Sci. Biol. (St. Petersb.) p. 87.

Winslow, C. E. A., Broadhurst, Jean, Buchanan, R. E., Krumwiede, Charles Jr., Rogers, L. A., And Smith, G. H. (Committee of the Society of American Bacteriologists on Characterization and Classification of Bacterial types.) 1917. Preliminary report. The families and genera of bacteria. Jour. Bact., Balt. 2: 552 .

1920 The families and genera of bacteria. Final report of the Committee of the Society of American Bacteriologists on Characterization and Classification of Bacterial Types. Jour. Bact., Balt. 5: 191-229.

Winslow, C. E. A., And Rogers, Anne F. 1905 A revision of the Coccaceae. Science, N. S. 21: 669-672.

1906 A statistical study of generic characters in the Coccaceae. Jour. Infect. Dis., Chicago. 3: 485-546.

Winslow, C. E. A., Rothberg, W., and Parsons, E. I. 1920 Notes on the classification of the white and orange Staphylococci. Jour. Bact., Balt. 5: 145-167.

Winslow, C. E. A., And Winslow, Anne Rogers. 1908 The Systematic Relationships of the Coccaceae.

Winter, Georg. 1880 Die Pilze. Rabenhorst's Kryptogamen flora. 2nd ed. Vol. 1.

WisLodch, S. M. 1914 Spirillum Kolkwitzii, nov. sp., und einige neue Schwefelbakterien Prof. Molisch's. Jour. de Microbiologie (Russian). 1:50.

Wolff, Max. 1907 Pedioplana haeckelin.g., n.sp., und Planosarcina schaudinni n.sp. Centralbl. f. Bakteriol., Jena. Abt. 2. 18: 9-26. 
Wollmax, Eugene. 1912 Recherches sur les Microbes Amylolytiques de l'intestin. Ann. de l'Inst. Pasteur, Par. 26: 610-634.

Wright, JAMES Homer. 1904-1905 The biology of the microörganisms of Actinomycosis. Jour. Med. Research. New Series. 8: 349-350.

Zeidler, A. 1896 Ueber eine Essigsäure bildende Termobacterie. Centralbl.

f. Bakteriol., Jena. Abt. II. 2: 739 .

Zetrinow, 1903 Beiträge zur Kenntnis von Spirobacillus gigas. Fertschrift z. 60 Gebrutst. v. Robert Koch, Jena. p. 383-388.

Zopf, W. 1883 Die Spaltpilze. Encyklop. der Naturwiss. Abth. 1. Lief. 32. 1884 (3) Die Spaltpilze. Auflage II.

1885 Die Spaltpilze. 3rd ed.

1891 Ueber Ausscheidung von Fettfarbstoffen (Lipochromen) seitens gewisser Spaltpilze. Ber. d. deutsch. Bot. Gesellsch., Berl. 9: 28.

Zuelzer, Margarete. 1911 Ueber Spirochaeta plicatilis. Ehrbg. und deren Verwandtschftsbezichungen. Arch. f. Protistenk., Jena. 24: 51.

Z бкаL, Hugo. 1885 Neue Pilze aus Nieder-Oesterreich. Verhandl. K. K. Zool. Bot. Gesell. Wien. p. 333-342.

1896 Myxobotrys variabilis Zuk. als Repräsentunt einer neuen Myxomyceten Ordnung. Ber. d. deutsch. Bot. Gesellsch., Berl. 14:346.

1897 Ueber die Myxobacterien. Ber. d. deutsch. Bot. Gesellsch. 15: 550. 



\section{SUBJECT INDEX}

Acanthococcus, 383.

Acetimonas, 69, 152, 154, 434.

aceti, 152.

schuetzenbachii, 152, 153.

Acetobacter, 96, 98, 103, 153, 389, 400, 519.

aceti, $153,154$.

melanoginum, 153.

pastorianus, 153.

plicatum, 153.

Acetobacterium, 153, 154.

xylinum, 153, 154.

xylinum var. Lagerheimii, 154.

Achromatiaceae, 84, 154, 156, 330, 502, $507,510$.

Achromatium, 84, 154, 155, 156, 330, $381,504$.

Mülleri, 155.

oxaliferum, 155, 156.

Achromobacter, 105, 156.

liquefaciens, 156.

Achromobactereae, 104, 105, 156.

Acidobacteriaceae, 69, 71, 156, 157, 225, $247,287,419,431$.

Acid fast group, 67.

Actinobacille, 157.

Actinobacillosis, 158.

Actinobacillus, 72, 83, 96, 97, 106, 157, 158, 159, 161.

lignieresi, 158.

paulotrophus, 159.

Actinobacilo, 157, 158, 159.

Actinobacilosis, 158 .

Actinobacter, 26, 159, 160, 161, 289.

polymorphum, 26, 160.

Actinobacterium, 63, 159, 161.

israeli var. Spitzi, 161.

lactis viscosum, 161.

Actinocladothrix, 161.

Actinococcus, 161, 162. cyaneus, 161.

Actinomyce, 162, 165, 166. horkelii, 162.
Actinomyces, 24, 34, 45, 58, 67, 68, 69, $74,83,87,89,96,106,157,159,161$, $162,163,164,165,166,167,168$, $169,171,241,246,261,264,294$, $295,377,384,385,402,403,404$, 405, 406, 496, 497, 500, 516 .

bovis, 24, 161, 162, 163, 165, 166, 167, 294, 295, 403.

klinik I \& II, 161.

musculorum, 163.

paulotrophus, 159.

Actinomycetaceae, 74, 83, 96, 106, 159, 167, 168, 169, 304, 353.

Actinomycetales, 79, 96, 102, 106, 167, $385,461$.

Actinomycetes, 58, 69, 168, 169, 248, $280,333$.

Actinomycosis, 158.

Aerobacter, 56, 82, 105, 169, 226, 312, $339,452$.

aerogenes, 169, 170 .

coli, 169.

liquefaciens, 169.

tartarivorum, 169.

viscosum, 169.

Aerogenesbacterium, 99, 170, 277.

Aerogenesbacterium aerogenes, 170.

Aethyl-Bacillus, 170.

Agonium, 170.

centrale, 171.

Aktinomyces, 171.

Albococcus, 61, 65, 87, 90, 92, 96, 171, 172, 173, 193, 411, 488, 489, 492.

albus, 172, 173.

canescens, 171, 172.

candicans, 171, 172.

candidus, 171.

epidermidis, 171, 173.

pyogenes, 171, 172, 173.

rhenanus, 171, 172.

tetragenus, 171.

ureae, 171.

Alcaligenes, 93, 95, 105, 173, 298. 
Alcaligenes faecalis, 173. vivax, 173.

Alkalibacteriaceae, 69, 71, 173, 202, $358,419,500,519$.

Alkaligenes, 173, 243.

faecalis, 243.

Allococcaccae, 51, 60, 174.

Amarantaceae, 260.

American Code, 145.

Amoebobacter, 36, 42, 55, 70, 85, 174,

$175,176,186,508$.

bacillosus, 174, 175.

granula, 174, 176.

roseus, 174, 175.

Amoebobactereae, 176.

Amoebobacteriaceae, 55, 63, 175, 176.

Amoebobacteriae, 42.

Amoebobacterieae, 84, 85, 174, 176, 186, $256,506,508,512$.

Amocbobacterinae, 176.

Amoebobacterioideae, 176.

Amoebomonas, 70, 176.

Amphitricha, 177.

Amylobacter, 19, 177, 268, 269, 287, 520.

butylicus, 177.

ethylicus, 177.

Amylobakter, 178, 268.

Anabaena, 23.

Anacardiaceae, 449.

Anacystis, 37.

Anthrax group, 66.

Aphaneroglia, 178, 433.

aquae potabilis, 178.

A phanocapsa, 22, 37, 502, 503.

A phanothece, 22, 37, 511.

clathratiformis, 417.

luteola, 461.

A planobacter, 61, 178, 179, 211, 225, $429,430$.

Arloingillus, 102, 179, 267, 370.

Chauvoei, 102, 179.

Arthrobacillus, 179.

Arthrobacter, 48, 179.

Arthrobacteriaceen, 179, 181.

Arthrobacterium, 29, 180, 181, 199. aceti, 180.

Arthrobactridium, 49, 180.

Arthrobactrillum, 49, 180, 232.

Arthrobaclrinium, 49, 180, 233.
Arthrobakteriaceen, 181.

Arthrobakterium, 179, 181.

Arthrokokkaceen, 181.

Arthromitus, 18, 181, 182, 183.

batrachorum, 183.

cristatus, 181, 182, 332.

nitidus, 181, 182.

Arthrospirobactcrium, 183.

Arthro-Spirobacterium, 184.

Arthrospirobakteriaceen, 184.

Arthrostreptococcus, 184.

Arthro-Streptokokkus, 181, 184.

Ascobacillus, 184, 185, 186, 434.

aquatilis, 185, 186.

citreus, 184, 185.

sacchari, 185.

Ascobacteria, 30, 185.

ulvina, 185, 186.

Ascobacterium, 43, 185, 186.

aquatile, 186.

luteum, 185, 186.

Ascococccae, 35, 41, 176, 186, 250, 274, 306,315 .

Ascococcee, 274, 503.

Ascococcos, 186, 187, 272.

parvus, 187, 188.

Ascococcus, 22, 23, 25, 27, 29, 31, 32, 33, $35,37,38,41,43,45,65,91,186$, 187, 188, 189, 287, 306, 356, 375, $376,389,411,458,492$.

Billrothii, 23, 187, 188, 189, 190, 191.

Billrothii var. thermophilus, 189.

buccalis, 189.

cantabridgensis, 190.

cellaris, 189.

equi, 190.

mesenteroides, 24, 188, 190, 355, 356.

vibrans, 188.

Ascokokkus, 191.

Askokokkus, 181, 191.

Astasia, 53, 81, 191, 203.

asterospora, 53, 191.

Asterococcus, 72, 81, 191, 329.

mycoides, 192.

Astrobacter, 54, 192, 412.

Athiorhodaceae, 63, 192, 444, 445, 446.

Aurococcus, 61, 65, 92, 172, 193, 411,

456, 488, 492.

aurantiacus, 193. 
Aurococcus aureus, 193.

mollis, 193.

Authority, 111.

Azotobacter, 58, 69, 74, 81, 87, 89, 96, $98,103,193,194,195,340,400,410$, 444.

chroococcum, 194.

Azotobactereae, 96, 103, 195, 400, 444.

Azotobacterieae, 195.

Azotomonas, 194, 195, 434.

Babesia, 42, 195, 492.

erysipeloides, 195.

xanthopyretica, 195.

Bacillaceae, 51, 59, 60, 66, 73, 87, 88, $91,92,95,99,103,106,195,196$, $197,209,211,230,232,243,266$, $269,297,298,299,309,322,325$, $326,367,400,414,432$.

Bacillaceĩ, 195, 197.

Bacilleae, 40, 51, 60, 80, 92, 94, 95, 196, 197, 223, 233, 410, 415, 471.

Bacillee, 197, 200, 234, 267, 278, 360, 409.

Bacillë, 4S, 196, 197.

Bacillococcus, 197.

Bacillopsis, 198.

stylopygae, 198.

Bacillus, 21, 22, 26, 27, 28, 29, 30, 31, $32,33,35,37,38,40,43,44,45,46$, $47,48,50,51,53,54,57,58,59$, $60,66,67,71,73,74,75,77,78,80$, $81,90,94,99,106,153,159,163$, $173,178,191,194,196,197,198$, $199,200,201,202,203,204,205$, $206,207,218,219,221,222,223$, $225,231,234,235,257,267,275$, 288, 289, 290, 297, 300, 303, 306, $308,311,312,314,322,327,339$, $347,369,370,371,382,392,420$, $429,432,434,444,447,462,463$, $464,472,475,487,490,491,500$, $517,518,519,520,525,526,531$. aceti, 152, 518 .

acidophilus, 373 . aerofoetidus, 463. aerogenes capsulatus, 101, 529. alvei, 278 . amylobacter, 177, 267, 268, 269, 323. anthracis, 21, 178, 198, 199, 201, 211, 491.

azotobacter, 194.

asterosporus, 191.

bifermentans, 361 .

bifermentans sporogenes, 361, 438.

botulinus, 66, 302.

bulgaricus, 296.

bütschlii, 366.

camptospora, 183.

carotarum, 201.

caucasicus, 296.

chauvoei, 244.

cholerae-asiaticae, 409.

cholerae-gallinarum, 337.

chroococcus, 194.

citreus, 185.

cochlearius, 101, 314 .

coli communis, 170.

crassus, 429.

denitrificans, 288.

denitrificans II, 287.

denitrificans agilis, 287.

egens, 101, 490.

enteritidis sporogenes, 179, 370 .

erythromyxa, 446.

erythrospora, 491 .

fallax, 101, 521.

felis, 274.

flexilis, 366.

fusiformis, 314.

gigas, 491.

hastilis, 360 .

histolyticus, 528, 529.

hortulensis, 452.

imetrophus, 464, 530 .

lactis aerogenes, 169.

lacunatus, 291.

lebenis, 296.

liodermos, 324.

liquefaciens, 170.

marcescens, 464.

maximum buccalis, 366 .

megatherium, 452.

multifermentans tenalbus, 101.

mycoides, 202.

nitrator, 498. 
Bacillus oedematis maligni, 405, 438. oligocarbophilus, 159.

pantotrophus, 331 . paraputrificus, 513. parasporogenes, 370 . parvus, 518.

perfringens, 361, 438. perlibratus, 290.

peroniella, 411.

prodigiosus, 15, 358, 465. putrificus, 438, 439, 513. pyemiae cuniculi, 439. pyocyaneus, 229, 233. radicicola, 425, 443.

radiobacter, 440 .

ramosus, 191.

rhusiopathiae suis, 304. saccharo-butyricus, 268. sanguineus, 257. schuetzenbachii, 152, 153. solmsii, 290. sphenoides, 100, 297.

spirogyra, 366.

sporogenes, 370 .

| subtilis, 21, 53, 178, 191, 198, 201, 202, 203, 204, 267, 296, 306, 307, $369,370,491$.

subtilis var. cellaris, 392.

synxanthus, 229.

tenuis, 517.

lertius, 101, 329.

tetani, 398.

tetanomorphus, 100, 359 .

tumescens, 531.

typhosus, 369.

ulna, 21, 198, 389.

violaceus, 284, 358 .

vulgaris, 498.

welchii, $370,371$.

zeylanica, 528.

Bactereae, 96, 104, 105, 173, 205, 212, $306,433$.

Bacteria, 99, 100, 205, 309, 310, 394.

Bacteriaceae, 24, 29, 34, 35, 37, 43, 46, $47,48,49,52,54,56,57,58,72$, $74,79,80,87,89,90,96,99,102$, $103,104,156,178,197,205,206$, $207,208,209,212,230,234,242$,
$243,247,260,279,299,302,303$, $307,308,309,328,329,338,378$, $384,475,531$.

Bacteriaceen, 206, 208.

Bactériacées, 207, 208.

Bacteriace ̈, 33, 207, 208.

Bacteriales, 209, 460.

Bacteridia, 209.

Bactéridiè, 209.

Bacteridieae, 92, 93, 209, 211, 310.

Bacteridium, 20, 81, 93, 178, 179, 199, $200,202,203,209,210,211,217$, $232,369,376$.

anthracis, 211.

prodigiosum, 210, 211, 464.

violaceum, 221, 436.

Bacterieae, 24, 80, 81, 205, 211, 298, 444,458 .

Bacterien, 212.

Bactéries, 212.

Bacteriinae, 81, 82, 212, 420.

Bacterina, 18, 212, 216, 523, 527.

Bacterine $\ddot{\imath}, 196$.

Bacteriopsis, 31, 35, 200, 212, 213.

aceti, 212.

ianthina, 213.

merismopedioides, 212.

ovata, 213.

pasteuriana, 212.

rasmusseni, 212, 213.

synxantha, 213.

ureae, 213.

Bactcrium, 17, 18, 19, 20, 21, 22, 25, $26,27,28,30,31,32,33,35,37$, $38,41,43,44,45,46,47,49,54$, $57,58,59,61,66,68,71,72,74$, $75,77,82,87,89,99,153,156,157$, $159,160,169,170,178,180,181$, 196, 198, 201, 206, 207, 212, 213, $214,215,216,217,218,219,220$, $221,222,223,224,225,226,227$, $228,229,230,234,242,277,298$, $306,308,310,360,369,372,382$, $386,410,419,429,434,435,452$, $459,498,518,519,523,527,528$. abortus, 226, 244.

aceti, 153, 180, 220, 223, 224, 420, $491,518$. 
Bacterium acetigenum, 501 . acidi-lactici, 221, 222.

actinocladothrix, 161.

acrogenes, 67, 169, 219, 226.

aeruginosum, 218, 219, 220, 222, 227, 229.

alcaligenes, 226.

allantoides, 223.

anthracis, 221, 223, 227.

articulatum, 214, 360 .

aurantiacum, 222.

balbianii, 223.

bovis, 429 .

brunneum, 220, 229.

candidum, 222.

casei, 237.

catenula, 215, 220, 369.

caucasicum, 237.

chauvoei, 179.

chlorinum, 222.

chalerae-gallinarum, 223.

chalerae suis, 452.

coli, 169, 225, 226, 227.

coli commune, 222, 439.

decalvans, 221.

diphtheriae, 67.

duplex, 291.

dysenteriae, 67 .

enchelys, 215.

erythromyxa, 446.

fluarescens non-liquefaciens, 288.

foetidum, 221.

fusiforme, 219, 360 .

griseum, 219.

ianthinum, 213, 221.

incarnatum, 222.

influenzae, 67.

lactis, 219, 242.

lactis acidi, 242, 340.

lactis aerogenes, 160, 170, 222.

laminariae, $240,337$.

leguminosarum, 425.

lineola, 220, 288, 360, 532.

litoreum, 219.

lucens, 220.

luteum, 222.

mallei, 67 .

merismopoedioides, 180, 212. morbilli, 222.

nitrobacter, 399.

oxydans, 498.

paratyphi, 66.

pasteurianum, 153, 212, 223.

pastorianum, 180.

pediculatum, 397.

pestis, 67.

photometricum, 222.

pneumoniae, 160.

pneumoniac crouposae, 335, 336.

punctum, 215, 220.

pyocyaneum, 225, 227, 229.

rhusiopathiae, 67.

roseum, 360.

rubescens, 219.

septichaemiae, 223.

subtile, 221.

syncyaneum, 218, 219, 220, 222, 229.

synxanthum, 218, 220, 222.

termo, 213, 214, 215, 216, 217, 218, $219,220,222,223,224,225,227$, $228,229,498,524$.

tortuosum, 222.

tremulans, 215, 220.

triloculare, 17, 213, 214, 215, 217, $226,230,360$.

tuberculosis, 67, 221.

typhi, 66, 298.

typhosum, 221.

ureae, 179, 272.

violaceum, 222, 257, 284.

viride, 221.

xanthinum, 220, 229.

xeroseos, 67.

xylinum, 154.

zopfii, 180, 222, 328, 337, 338, 531.

Bacterius, 59, 230.

Bacteroideae, 92, 94, 95, 104, 105, 230.

Bacteroides, 94, 105, 230, 231, 315.

fragilis, 230, 231.

fusiformis, 230.

Bactrella, 231, 369 .

bacillus, 231.

filum, 231.

undula, 231.

Bactridieï, 49, 196, 231.

Bactridium, 49, 51, 60, 197, 210, 211, 231. 
Bactridium butyricum, 232.

coli, 232.

lipolyticum, 232.

megatherium, 232.

radicicola, 425 .

subtilis, 232.

typhi, 232.

vulgaris, 232.

Bactrillë, 49, 196, 232.

Bactrillius, 58, 232.

Bactrillum, 49, 51, 60, 197, 232.

cyanogenum, 232.

fluorescens, 232.

pseudo-termo, 232.

syncyaneum, 232.

Bactrinicï, 48, 232, 233.

Bactrinium, 48, 51, 60, 197, 233. pyocyaneum, 51, 233.

Bactrinius, 59, 233.

Baculogenae, 34, 39, 40, 197, 223, 233, $234,515$.

Baculogene, 234, 337, 459.

Bakteriaceen, 234.

Bakterium, 179, 181, 234.

Balkanella, 93, 96, 234, 298. coagulans, 234.

Bangia tenuis, 345 .

Batteriacee, 206, 234, 274, 360.

Beggiatoa, 18, 20, 22, 25, 26, 27, 28, $29,31,32,34,35,36,37,40,43$, $44,45,46,48,50,52,53,55,59$, $61,64,70,74,84,234,235,236$, $237,258,310,312,345,351,352$, 353, 357, 381, 408, 461, 479, 515. alba, 234, 236, 310 . arachnoideae var. uncinata, 310 . multiseptata, 423. punctata, 18, 234. leptomitiformis, 234. roseo-persicina, 258.

Beggiatoaceae, 47, 48, 52, 53, 55, 56, $59,74,84,209,236,502,507,512$.

Beggiatoeae, 37, 235, 237, 344.

Betabacterium, 237, 238, 419. breve, 237.

caucasicum, 237.

longum, 237, 238.

Betacoccus, 238, 239, 419. arabinosaceus, 239.

bovis, 239.

mesenteroides, 239.

Bibliography, 532.

Billetia, 240, 353.

Blatta orientalis, 198, 332 .

Bollingera, 41, 186, 240, 241, 295, 306. equi, $240,295$.

vacchetae, 240, 295.

Borrelia, 64, 240, 241, 479, 481, 485. gallinarum, 240.

Botanical code, International, 112.

Botanical Society of America Code, 145.

Botryococcus, 240, 241.

Botryocoques, 241.

Botryomyces, 38, 240, 241. ascoformans, 241.

Botulobacillus, 71, 241, 439. botulinus, 242.

Brachybacterium, 242. apiculatum, 242.

Brachybacterien, 61, 242.

Brucella, 242, 243, 244. abortus, 244. bronchisepticus, 244. melitensis, 243.

Brussel's Code, 112.

Bufo calamita, 183.

Bursaria, 14, 15.

Butyl-Bacillus, 244.

Butyribacillus, 71, 244, 245, 247, 268. 438.

pasteurianus, 245.

Butyribacteriaceae, 69, 71, 244, 245, 247, 416, 419.

Butyriclostridium, 245, 268, 439.

Byolysis, 245.

Calothrix, 23. lutescens, 345.

Calymmatobacterium, 245, 335. granulomatis, 245.

Carboxydomonas, 69, 87, 89, 98, 103, 245, 246, 434. oligocarbophila, 246.

Carphococcus, 246. pituitoparus, 246. 
Carteria, 246.

Carterii, 246.

Caryobacterium, 246, 247.

equi, 246.

Caseobacterium, 71, 156, 157, 247. casei, 247.

Cassytha, 484.

Casual names, 111.

Cellulobacillus, 71, 245, 247. methanigenes, 247.

Cellulomonadeae, 104, 105, 247.

Cellulamonas, 105, 247.

biazoteus, 248.

Cenomesia, 41, 186, 248, 306.

albida, 248.

lilacina, 248.

Cephalotrichinae, 68, 69, 152, 157, 169, $247,248,287,342,358,359,371$, 409, 419, 441, 466, 473, 501, 515.

Chaetophora endiviaefolia, 297.

Chaetophorae, 161.

Chamaesiphon, 23, 37.

Chara, 461.

Chatinella, 249. scissipara, 249.

Chionyphe, 249. carteri, 249.

Chlamydatomus, 25, 41, 186, 249, 250, $316,331,458$.

beigelii, 249, 250.

cellaris, 250.

Chlamydobacteriaceae, $47,48,52,53$, $54,56,57,59,74,83,91,106,209$, $250,263,266,283,289,290,308$, $309,351,384,424$.

Chlamydobacteriales, $79,87,88,100$, $102,106,251,461$.

Chlamydobacterinae, 251.

Chlamydothrix, 55, 60, 74, 251, 252, 319, 350. epiphytica, 252.

ferruginea, 252, 318, 321, 486.

fluitans, 252.

hyalina, 252.

ochracea, 72, 251, 252.

sideropous, 71, 252.

Chlorobacterium, 252.

lactis, 252, 253.
Chlorobacteriaceae, 253.

Chlorobakteriaceae, 253, 254, 461.

Chlorobium, 253.

limicala, 253.

Chlorochromatium, 253, 254, 286, 417. aggregatum, 253, 254, 286.

Chloronium, 254.

mirabi?e, 254.

Chlorophyllophyceae, 24.

Chondromyces, 19, 62, 74, 86, 107, 254, $255,287,393,394,395,430,431,489$.

Chondromyces crocatus, 254, 255.

Chorynebacterium, 255.

Chromatiaceac, 55, 63, 255, 256.

Chromatieae, 84, 85, 256, 442, 445, 450.

Chromatioideae, 84, 176, 256, 257, 445, 503, 506.

Chromatium, 33, 36, 56, 70, 75, 85, $200,207,220,255,256,257,308$, $311,410,441,442,448$.

Chromatium minus, 256.

minutissimum, 256.

okenii, 256, 257.

vinosum, 256, 257.

violascens, 256.

weissii, 256.

Chromatoideae, 257.

Chromobacillus, 38, 200, 257, 371.

Chromobactereae, 96, 104, 257, 258, 313, $436,465$.

Chromobacterieae, 257.

Chromobacterium, 82, 96, 99, 104, 212, 257, 284.

violaceum, 221, 258, 436.

Chromobeggiatoa, 37, 235, 258.

Chromococcus, 258, 285.

vialaceus, 258, 436.

Chroococcaceae, 24.

Chroococcus, $22,37$.

Chthonoblastus, 23.

Ciliata, 18.

Cladochytrium, 258. tuberculorum, $25 \mathrm{~s}$.

Cladophytum, 18, 181, 182, 258, 259. comatum, 182, 259. ramossissimum, 259.

Cladothricaceae, 37.

Cladothriceae, 26, 259, 260. 
Cladothrichaceae, 259, 260, 288.

Cladothrichace i, 259. 260.

Cladothricheae, 260.

Cladothricheen, 259, 260, 261.

Cladothrix, 23, 26, 27, 29, 30, 31, 32, $34,35,37,39,43,44,45,46,48$, $50,52,53,58,59,60,67,68,70$, $79,250,252,259,260,261,262,263$, 264, 265, 266, 335, 353, 402，469, $496,497,515,516$.

dichotoma, 23, 65, 72, 260, 262, 263, $264,468$.

dichotoma var. leptochaetoformis, 261. placoides, 263.

Cladotriceae, 39, 264, 515.

Cladotricee, 264, 402.

Cladotricheae, 264.

Cladotricheen, 264.

Clathrococcus, 264.

roseo-persicinus, 264.

Clathrocystis, 22, 32, 37, 264, 265, 276, $277,342$.

aeruginosa, 264, 277.

roseo-persicina, 19, 219, 264.

Clerodendron, 484.

Clitridium, 265.

Cloaca, 93, 265, 432.

cloacae, 265.

Clonothrix, 61, 74, 83, 106, 251, 265, 266. fusca, 65, 72, 265, 266. gracillima, 266.

Clostridiaceae, 100, 266, 302, 439, 463. Clostridieae, 51, 60, 196, 266.

Clostridioideae, 100, 179, 256, 267, 268, $297,313,329,359,371,382,405$, $406,451,489,521,529$.

Clostridium, 19, 27, 28, 31, 33, 35, 40, $44,46,49,51,53,59,60,76,80,87$, $90,99,100,106,177,178,179,197$, $199,202,206,207,234,242,245$, $266,267,306,308,324,411,415$, $419,428,438,439,520$.

amylobacter, 268, 269.

butyricum, 100, 267, 268, 269, 520.

feseri, 267.

pasteurianum, 244.

polymyxa, 267.

Clostrillum, 49, 232, 269.
Clostrinium, 49, 233, 269.

Clostrydium, 269.

Coccaceae, 46, 47, 49, 51, 52, 54, 56, $58,59,60,65,66,72,73,74,78$, $79,87,88,90,91,96,97,103,174$, 209, 269, 270, 171, 274, 292, 308, $309,326,331,337,368,373,384,395$, $396,411,466,467,492$.

Coccaceen, 269.

Coccacei, 32, 271, 273.

Coccobacillus, 38, 200, 271, 272, 337.

acridiorum, 272.

avicidus, 38, 272.

conjunctivae, 272.

fusiformis, 272.

perfoetans, 272.

zymogenes, 271, 272.

Cocco-Bacillus, 272.

Cocco-Bacillus anaerobius perfoetans, 272.

Coccobacteria, 21, 32, 270, 272, 273, 337, 361.

septica, 21, 187, 272, 274, 275, 276, $291,320,328,347,361,366,372,373$, $374,382,420,457,466,491,492,495$.

Coccobacteriaceae, 273, 471, 476.

Coccobacterium, 273, 337. felis, 274.

mucosum anaerobium, 274.

prodigiosum, 274.

Cocco Bacterium, 274.

Coccochloris, 22.

Coccogenae, 35, 39, 41, 186, 248, 250, $274,373$.

Coccogene, 274, 458, 459, 492, 515.

Coccoglia, 274, 530 .

Coccomonas, 274, 275, 276.

Coccos, 275, 276.

Coccothrichaceen, 31, 275.

Coccothrix, 31, 200, 275, 337, 386, 387, $389,463$.

leprae, 275.

tuberculosis, 275.

Coccotrichum, 275, 387.

Coccus, 275, 276, 337, 419, 493. albus non-liquefaciens, 276. aquatilis, 276.

candicans, 276. 
Coccus cumulus minor, 276.

Coccus salivarius septicus, 276.

Code, Lehmann and Neumann, 109.

Codes of nomenclature, 108.

Code of Nomenclature, Zoological, 136.

Coelosphaerium, 22, 248.

Cohnia, 27, 37, 265, 276, 277, 341, 376. rosco-persicina, 276.

Cohniella, 276.

Cohnistreptothrix, 73, 95, 164, 167, 276, $404,405$.

foersteri, 164.

israeli, 164, 277.

Coleothrix, 277.

methystes, 277.

Colibacterium, 99, 170, 277.

Colon bacillus group, 66 .

Cominelinaceae, 454.

Committee on Classification, 119.

Conferva moniliformis, 316.

nummuloides, 316.

ochracea, 317.

Conidiosporales, 94.

Conidiothrix, 278.

Coniothecium, 278. syphiliticum, 278.

Coniomycetes, 163.

Cornilia, 40, 197, 278, 306, 310, 428. alvei, 278, 279, 310 . pasteuri, 278.

Cornilia sphinx, 428. tremula, 428.

Coryncbacterium, 50, 52, 53, 57, 82, 87, 89, 94, 98, 106, 161, 168, 212, 255, $279,280,333,378,384,385,386,387$. diphtheriae, 279,378 .

Corynemonas, 69, 169, 280. diphtheriae, 280.

Corynethrix, 58, 280.

Corynocladus, 18, 280. radiatus, 280.

Crenothrichaceae, 290, 288, 390, 391.

Crenothrix, 20, 23, 25, 27, 29, 30, 31, $32,34,35,37,39,43,44,45,46$, $48,50,52,53,55,58,59,60,70,74$, $83,106,250,251,265,281,282,283$, $310,312,340,345,351,352,234,424$, 515 . foetida, 282, 423.

kuhniana, 282, 283, 310, 423.

marina, 2S2, 423.

mucor, 423.

multiseptata, 423.

polyspora, $20,65,72,281,282,283,363$.

Crenotrichaccae, 283.

Crenotriceae, 39, 283, 515.

Cristispira, 72, 78, 86, 88, 107, 283, 453,

$479,481,482,484$.

balbianii, 78, 254 .

interragationis, 283.

veneris, 283, 284.

Cromobacterium, 2S, 257, 284.

violaceum, 2S, 284.

Cromococcus, 258, 285.

violaceus, 285.

Crypta, 245, 285.

syphilitica, 285.

Cryptococcus, 20, 286, 518.

xanthogenicus, 286.

Cryptodesma, 18, 286.

tenuis, 286

Cyanophyceae, 24.

Cyclidium, 15.

Cylindrogloea, 254, 286.

bactifera, 286.

Cystobacter, 34, 45, 207, 255, 286, 287, 308,430 .

erectus, 255, 286.

fuscus, 286.

Cystococcaceae, 189, 287, 331, 356.

Cytobacter, 287.

Daphnia pulex, 415.

Deazotonitraazobacterium, 287.

thermophilum, 287.

Deazatonitránitriazobacterium, 287.

Deazotonitriazobacterium, 287.

Denitrobacillus, 287.

Denitrobacterium, 71, 156, 157, 287. agile, 287.

thermophilum, 287.

Denitromonas, 70, 288, 314, 358, 359, 466.

fluorescens, 288.

Desmobacteria, 21, 35, 37, 260, 280, 288, 344. 
Desmobacteriaceac, 74, 288, 289.

Desmobacteries, 200, 289.

Desmobacterinae, 74, 288, 289, 326.

Desmobacterium, 289.

Detoniella, 39, 289, 332, 338, 348. ochracea, 289.

Dialister, 106, 289. pneumosintes, 289.

Diaschizae, 289, 411.

Dicoccia, 41, 289, 290, 310, 337. glossophila, 290.

Didymohelix, 19, 83, 106, 251, 290, 317, $319,485$.

ferruginea, 290, 321 .

ochracea, 319.

Diffusionsbacillus, 290.

Diphtheria group, 67.

Diplectridium, 49, 290.

Diplobacillus, 290, 291.

brevis endocarditidis, 290.

liquefaciens, 291.

Morax, 291.

Morax-Axcnfeld, 291.

Diplobacteria, 291.

Diplobacterium, 291.

Diplococcos, 291.

Diplococcus, 31, 44, 45, 65, 66, 80, 92, 96, 104, 291, 293, 336, 376, 396, 411, 429, 434, 492.

albicans tardissimus, 292.

coryzae, 292.

lanceolatus capsulatus, 66.

luteus, 292.

pneumoniae, 31,292, 293, 336, 434.

roseus, 292.

subflavus, 292.

Diplokokken, 293.

Diplokokkus, 43, 293.

Diplopneumococcus, 293.

Diplostreptococcus, 293, 294.

intestinalis, 294.

pleuropneumoniae,_293, 294.

Diplovibrio, 294.

Disconnices, 294.

Discomyces, 24, 158, 163, 164, 165, 166,

240, 294, 402.

bovis, 24, 295.

equi, 163, 240, 241, 294, 295. pleuriticus, 163, 294.

pleuriticus canis familiaris, 240, 294. somaliensis, 333.

Discomycetaceae, 295.

Discomycetes, 164, 295.

Dispora, 28, 289, 296, 297, 409. caucasica, 28, 296.

Douglasillus, 100, 266, 297. sphenoides, 100, 297.

Drepanospira, 297. mülleri, 297.

Drepanospora, 297.

Dysenteroides, 93, 96, 297, 298. metadysentericus, 297.

Ebertheae, 92, 95, 173, 234, 297, 298, 301, $306,343,452,465,529$.

Eberthella, 82, 105, 226, 298.

typhi, 298.

Eberthus, 93, 96, 298.

typhosus, 298.

Eccrina, 18, 298.

longa, 298, 299.

moniliforma, 298.

Eiterbacterium, 299.

Eitercoccus, 299.

Elephantopus, 477.

Encapsulateae, 92, 95, 104, 105, 299, 200.

Encapsulatus, 92, 95, 105, 299, 331, 336. pneumoniae, 299.

Enchelis, 14, 15.

Endobacterium, 300.

Endostreptococcus, 300.

Endostreptokokkus, 300.

Enterobrus, 300.

attenuatus, 300 .

elegans, 300 .

spiralis, 300 .

Enterobryus, 18, 298, 301.

elegans, 182.

Enterococcus, 301. saccharomyces, 301.

Enterocoque, 301.

Enteroides, 93, 298, 301. entericus, 301.

Entophyta, 301.

Erebonema, 301, 354. divaricatum, 301. 
Erebonema hercynicum, 301, 302, 355.

Ermengillus, 302, 439.

botulinus, 302 .

Erwineae, 96, 104, 302, 303.

Erwinia, S7, 90, 99, 105, 303. amylovora, 303.

Erwiniae, 105, 302, 303, 424.

Erwinieae, 302, 303.

Erysipelcoccus, 303.

Erysipelothrix, 71, 82, 96, 97, 106, 212, 303, 304.

erysipeloides, 303.

murisepticus, 303.

porci, 303, 304.

rhusiopathiae, 304.

Erythrobacillus, 62, 96, 99, 257, 304, 465. prodigiosus, 304.

pyosepticus, 304 .

Erythroconis, 305, 343.

littoralis, 305.

Escherichia, 93, 105, 298, 306. coli, 306.

Euascococceae, 41, 1S6, 248, 306.

Eubacilleae, 40, 197, 306.

Eubacillus, 38, 44, 75, 200, 306, 307. multisporus, 307.

Eu-Bacïllus, 81, 203, 307.

Eubacteria, 37, 56, 61, 74, 75, 206, 297, 307, 30S, 371, 390, 391.

Eubacteriaceae, 308.

Eubacteriales, 78, 79, 87, 88, 89, 91, 100, $102,103,196,208,251,266,308,309$, $354,385,399,400,319,434$, 459, 460 , $461,470,471$.

Eubacterieae, 24, 100, 212, 309, 310, 374.

Eu-Bacterium, 82, 226.

Eubeggiatoa, 37, 235, 310.

Eucoccaceae, 310, 375, 387.

Eucoccus, 310.

Eu-Cornilia, 310.

Eucornilia, 278, 310.

Eucrenothrix, 282, 310, 423.

Euglenaceae, 24.

Euklebsielleae, 41, 289, 310, 337 .

Eumantegazzaea, 310, 360.

Eumicrospira, 75, 310.

Eümonas, 311.

Eumyriophyllum, 485.

Eu-Pacinia, 311, 409.
Eupacinia, 311, 409.

Euplanococcus, 311.

Euplanosarcina, 311.

Eupseudomonas, 311.

Eusarcina, 311.

Euspirillum, 75, 312.

Eu-Spirillum, 312.

Euspirosoma, 54, 312, 385.

Euvibrionieae, 25, 235, 281, 312, 477, 482.

Fenobacter, 312.

Ferribacterium, 312.

duplex, 312.

Fixococcus, 76, 313.

Fixosarcina, 76, 313.

Fixostreptococcus, 76, 313.

Flavobacterium, 104, 185, 313. aquatilis, 313.

Flemingillus, 101, 266, 313.

cochlearius, 101, 314.

Flexner group, 93.

Flexnerella, 93, 314.

Fluorescent group, 66.

Fluormonas, 99, 314, 35s, 434.

Fungi-Imperfecti, 94.

Fusiforminae, 81, 212, 314.

Fusiformis, 72, 81, 87, 89, 97, 106, 168, $231,314,315,360,385$.

dentium, 314 .

muris, 314.

termitidis, 314, 315.

Gaffkya, 31, 35, 41, 186, 315, 316.

tetragena, 315, 365 .

Gaffkyeae, 41, 186, 250, 315.

Gaillonella, 17, 316, 317, 318, 319, 320. ferruginea, 17, 251, 316, 317.

lineata, 316.

Galactobacterium, 319.

Galactococcus, 320.

albus, 320.

fulvus, 320 .

versicolor, 320 .

Galeria melanella, 363.

Gallionella, 17, 74, 252, 316, 317, 318, $320,350,485,486$.

ferruginea, 19, 64, 72, 283, 290, 317,

$318,321,332,349,363,485$.

ferruginea var lata, 319, 348 . 
Gammarus locusta, 423.

Genera conservanda, 118, 119.

Glaeogenes, 320.

Glanders group, 67.

Glaucothrix, 37.

Gleobacter, 320 .

Gliabacteria, 320.

Gliacoccos, 272, 274, 320.

Gliacoccus, 320, 530. aceti, 320 .

Glia-kokkus, 320 .

Glischrobacterium, 320, 321.

Gliscrobacterium, 320.

Gloeocapsa, 22, 37.

Gloegenae, 265, 454.

Gloeogenes, 22, 188, 355.

Gloeosphera, 318, 321.

Gloeosphaera ferruginea, 318, 321 .

Gloeothece, 22, 37.

Gloeotila, 290, 317, 321.

Gloeotila ferruginea, 217, 321. ochracea, 321 .

Glucobacter, 321.

Glycobacter, 321, 322. peptolyticus, 322 . proteolyticus, 321.

Gomphosphaeria, 22.

Gonium, 15, 322.

Gonium hyalinum, 322.

Gonococcus, 292, 322, 376.

gonorrhoeae, 322 . neisseri, 322.

Graciloideae, 92, 93, 95, 322, 323.

Graciloides, 93, 322, 323. albofaciens, 323.

Granulobacillus, 323.

saccharobutyricus immobilis liquefaciens, 323.

saccharobutyricus mobilis non-liquefaciens, 268.

Granulobacter, 50, 59, 177, 178, 323, 324, 415.

butylicum, 323.

Granulobacter immobilis, 411.

lactobutyricum, 323.

pectinovorum, 416.

polymyxa, 323.

saccharobutyricum, 323.

Granulobakter, 324. butylicum, 324.

pectinovorum, 324.

saccharo-butyricum, 268.

urocephalum, 324.

Grippestreptokokkus, 324.

Gummibacillus, 324.

Gymnobacteria, 324, 382, 419.

Gymnodes, 16, 527.

Gyrococcus, 324.

flaccidifex, 324.

Haematococcus, 325, 521. nivalis, 325.

Hämatokokkus, 325.

Haemophileae, 92, 325.

Haemophilus, 325, 329.

influenzae, 325.

Halibactcrium, 47, 325.

aurantiacum, 325 .

liquefaciens, 325.

pellucidum, 325, 326.

polymorphum, 325.

purpurcum, 325 .

roseum, 325.

rubrofuscum, 325.

Halorrhagidaceae, 485.

Haplobacteriacei, 326, 327.

Haplobactcrinae, 51, 59, 73, 326.

Haplobakterien, 327.

Hay bacillus group, 66 .

IIelicobacterium, 327, 328.

acrogenes, 327.

klebsii, 327.

Helicomonaden, 327, 328.

Itelicomonas, 327. syphiliticum, 327.

Helikobakterium, 328. zopfii, 328.

Helikomonas, 328.

Helminthica, 14.

Helobacteria, 328.

Hemisporales, 94.

Hemophrlaeae, 328.

Hemophileae, 95, 96, 104, 106, 289, 328, 329.

Hemophilinae, 81, 192, 212, 323.

Hemophilus, 81, 87, 89, 99, 106, 325, 328, 329.

influenzae, 329. 
Henrillus, 101, 266, 329.

tertius, 101.

Hiblerillus, 101, 267, 329.

megalosporus, 330 .

rectus, 330 .

septimus, 330.

sextus, 101, 330.

Hillhousia, 71, 84, 154, 330, 331. mirabilis, 330.

Homococcaceae, 51, 60, 331.

Homonyms, 124, 127, 148.

Hormosiphon, 23.

Hyalococcus, 33, 34, 37, 38, 45, 287, 331, $336,376$.

beigelii, 250, 331, 428 .

cellaris, 250.

pneumoniae, 331, 336.

Hydrogenomonas, 69, 87, 89, 98, 103, 331, $332,434$.

Rava, 331, 332.

pantotropha, 331, 332.

vitrea, 331, 332.

Hydrotremellinae, 162.

Hygrocrocis, 20, 259, 332, 343, 369, 459. intestinalis, 183, 332.

ochracea, 316, 345 .

olivacea, 345 .

Hyphales, 94, 377, 378.

Hypheothrix, 23, 37, 332, 345. callitrichae, 462.

Hyphomycetes, 50, 94, 163, 166, 333, 385.

Hyphomicrobıum, 333, 401. vulgare, 333.

Hyphomycetes, 489, 495, 516.

Hypnococcus, 61, 333.

Hyponym, 148.

\section{Indiella, 333.} somaliensis, 333 .

Indiellopsis, 333. somaliensis, 333.

Indolococcus, 333, 334, 418.

Influenza group, 67.

Infusori:, 14, 16.

Iodococcus, 334.

Iron bacteria, 64 .

Jodococcus, 334. magnus, 334, 335.

parvus, 334.

vaginatus, 334 .

Julus, 181, 258, 332.

marginatus, 182, 259, 300.

Kalymmabacterium, 335.

Karphococcus, 335.

Karpholoklive, 335.

Keratophyton, 335 .

Kladothrix, 335.

Klebsiella, 31, 35, 41, 77, 289, 300, 310, $320,335,337,434$.

aerobia, 335 .

cellaris, 392.

crouposa, 335, 336 .

edingtoni, 184.

enteritidis, 336.

friedlanderi, 336 .

leydeni, 434.

pneumoniae, 335, 336.

rhinoscleromatis, 335, 336.

salivaris, $335,336$.

Klebsielleae, 35, 41, 233, 289, 299, 310, 336, 337.

Klebsiellee, 234, 337.

Kokkacceen, 337.

Kokken, 337.

Kokkobacillus, 337. avicidus, 337.

zymogenus, 337.

Kokkobacteria, 337.

Kokkobacterium, 337. lyssae, 337.

Kohkothrix, 337.

Kolikus, 43, 276, 337.

Kolpoda, 15.

Kurthia , 31, 34, 39, 240, 337, 338, 353, 532.

zopfi, 337, 338.

Kurthieae, 39, 289, 338, 515.

Lacrimatoria, 16, 527 .

Lactobacillaceae, 87, 89, 96, 338, 339.

Lactobacillae, 338, 340, 501.

Lactobacilleae, 96, 104, 105, 338.

Lactobacillus, 82, 87, 90, 99, 105, 153, $212,242,247,338,339,340,452$. 
Lactobacillus caucasicus, 339. delbrückii, 339.

fermentatum, 237. fermentum, 339. longus, 339.

Lactobacter, 340 .

Lactobacteriaceae, 340 .

Lactococcus, 339, 340, 341. agglutinans, 341, 356.

hollandiae, 341.

lactis, 340, 341.

Lactosarcina, 341.

Lampozoidea, 18, 341.

Lamprocystaceae, 55, 63, 341.

Lamprocysteae, 84, 85, 256, 341, 342 .

Lamprocystis, 27, 33, 34, 36, 37, 41, 55, $70,74,85,186,248,264,265,277$, 306, 311, 341, 449, 504, 508.

gelatinosa, 509 .

roseo-persicina, 342, 377, 42S, 433, 510. violacea, 510.

Lampropedia, 33, 34, 37, 42, 85, 305, $342,376,458,506$.

hyalina, 322, 343.

reitenbachii, 364 .

violacea, 436.

Lampropedieae, 506.

Lankoides, 93, 96, 298, 343.

pyogenes, 343 .

Lauraceae, 484.

Leptomitus, 259, 343.

divergens, 344.

Leptonema, 344, 352. nivea, 344.

Leptospira, 107, 344.

icterohaemorrhagiae, 344.

icteroides, 344.

Leptothricaceae, 37, 237, 288

Leptothrichaceae, 344.

Leptothriceae, 37.

Leptothricheae, 20, 344, 348, 518.

Leptothricheen, 345.

Leptothrix, 18, 20, 22, 26, 27, 28, 29, 30, $31,32,34,35,37,43,45,46,50$, $53,57,67,68,70,83,106,206,221$, $251,252,260,261,278,289,317$, $319,345,346,347,348,349,350$, $351,352,389,405,440,496,497,515$, 516. aeruginea, 345 .

buccalis, 18, 346, 347, 348, 350, 352.

cellaris, 348 .

fontana, 345 .

insectorum, 346.

kuhniana, 283.

lutescens, 345.

maxima, 351.

ochracea, 18, 64, 251, 278, 283, 318,

345, 346, 348, 349, 350, 351, 362.

parasitica, 347, 348 .

thuretiana, 348, 408.

Leptotrichaceae, 344, 351, 391.

Leptotrichacei, 34, 351.

Leptotricheae, 39, 345, 351, 515.

Leptotricheen, 351.

Leptotrichia, 25, 34, 39, 83, 87, 89, 97, $106,168,213,312,347,348,351,352$,

$353,357,385,440$.

amphibola, 353 .

buccalis, 347, 353, 353, 440.

mucor, 357.

nivea, 344 .

ochracea, 348 .

thuretiana, 408.

rigidula, 344 .

Leptotrichieae, 34, 353.

Leptotrichiee, 240, 337, 352, 353.

Leptotrichiella, 353.

Leucocystis, 33, 34, 37, 38, 41, 186, 287,

$302,306,353,354,355,376$.

cellaris, 353, 391.

cellaris var. cavernarum, 355 .

pneumoniae, 354.

Leuconostoc, 24, 28, 29, 31, 33, 35, 37, $38,42,44,45,51,74,80,96,97$, $104,181,188,190,206,240,269$, $287,341,355,356,357,395,467,494$, 492.

agglutinans, 356.

lagerheimii, 154, 356.

lagerheimii var. subterraneum, 356 .

mesenteroides, 24, 355, 357.

Leucothrix, 353, 357.

Liliaceae, 276.

Limnochlide, 23.

Lineola, 16, 357.

Lipobacter, 63, 357.

Liquidobacterium, 71, 173, 357, 358, 432. 
Liquidobacterium miquelii, 520. prodigiosum, 358, 519. vulgare, 358.

Liquidococcus, 70, 358, 359.

Liquidomonas, 70, 288, 314, 358, 359. fluorescens, 358.

Liquidovibrio, 70, 359. comma, 359.

Loefflerella, 420.

Lophotricha, 359.

Luminibacteriaceae, 68, 70, 157, 248, 2SS, 358, 359, 466.

Lyngbya, 37. ochracea, 317, 345, 349.

Lyngbyeae, 234.

Lyngbyoideae, 234.

Macintoshillus, 100, 266, 359. tetanomorphus, 100, 359.

Macrococcus, 359.

Makrokokkus, 359.

Malleomyces, 360. equestris, 360.

Mantegazzaea, 25, 40, 78, 197, 306, 310, $312,315,360,441,442$.

articulata, 360 .

cienkowskii, 360 .

hastilis, 360 .

Martellillus, 361, 370, 439, 440, 441, 529.

bifermentans, 361 .

Mastichomonas, 361.

Mastigophora, 471.

Megabacteria, 361.

Megabacterien, 361 .

Megabacterium, 361.

Megacoccos, 361.

Megacoccus, 359, 362.

Megalothrix, 362. discophora, 362.

Melanella, 16, 363, 527. atoma, 363.

erythraea, 363.

flexuosa, 363, monadina, 363. spirillum, 363.

Melococcus, 363. ostrjanini, 363.
Meloscira, 316, 363. ochracea, 290, 363.

Melosira, 317, 318, 319, 363. ochracea, 317, 363 .

Meningococcus, 292, 363, 364. intracellularis, 364.

Meningokokkus, 364. intracellularis, 364.

Merismopedia, 22, 30, 43, 44, 45, 269, $305,343,364,365,375,376,454,455$, 511.

gonorrhoeae, 364 .

littoralis, 364 .

Merismopedium, 37, 365. reitenbachii, 364, 365.

Merista, 30, 43, 77, 181, 343, 364, 365, $376,417,426$.

laevigata, 365 .

tetragena, 365 .

ureae, 365 .

Merizomyria, 23, 365.

aponina var. fasciculata, 366.

Merulius lacrymans, 433.

Mesobacteria, 366.

Mesobacterien, 366 .

Mesobacterium, 366.

Mesococcos, 366.

Mesococcus, 366.

Metabacterium, 77, 81, 197, 366, 367, 368. polyspora, 366, 367 .

Metacoccaceae, 61, 65, 270, 368.

Metacoccus, 368.

Metallacter, 18, 25, 200, 212, 216, 231, $312,368,369,370,523$.

amylobacter, 369.

anthracis, 369.

bacillus, 368, 369.

ileotyphi, 369.

tremulus, 369.

ulna, 369 .

Metchnikovillus, 370. sporogenes, $370,439$.

Methanomonas, 69, 87, 89, 99, 103, 370, $371,434$.

methanica, 371 .

Metonym, 148.

Meyerillus, 102, 267, 371.

sadowa, 102, 371. 
Micraloa teres, 216.

Microbacillus, 371.

seborrhoeae, 371 .

Microbacteria, 21, 35, 38, 200, 207, 217, $223,371$.

Microbacterien, 371, 372, 381 .

Microbacteries, 372.

Microbacterium, 99, 372, 419.

flavum, 372.

lacticum, 372, 373.

mesentericum, 372.

Micrococca, 211.

Micrococceae, 42, 79, 80, 87, 91, 92, 103, 104, 271, 274, 368, 373, 377, 398, $447,457$.

Micrococcee, 274, 396, 488.

Micrococcoglia, 373.

Micrococcos, 373, 374 .

Micrococcus, 21, 22, 24, 26, 27, 28, 29, 30,$32 ; 33,35,37,42,43,44,45$, $46,47,49,51,53,54,56,58,59,60$, $65,66,67,71,72,74,76,77,80$, $87,90,92,104,156,157,171,172$, $174,188,189,190,191,211,246$, $269,270,276,310,313,339,355,358$, $364,365,368,373,374,375,376,377$, $381,416,417,422,425,426,434$, 447, 466, 467, 488, 493, 494, 526.

aceti, 320, 420, 440 .

ascoformans, 240, 241.

aureus, 172.

beigelii, 428 .

billrothii, 190.

bombycis, 410 .

botryogenes, 240, 241.

butyricus, 362 .

candicans, 375, 376.

casei liquefaciens, 499.

catarrhalis, 66.

cellaris, 355 .

cholerae-gallinarum, 414.

citreus, 376.

erythromyxa, 446.

fickii, 276.

flavus, 376.

gallicidus, 414.

gonorrhoeae, 66, 322 .

imetrophus, 530. intracellularis meningitidis, 66.

lactis, 374.

luteus, 373, 374, 376, 377 .

melitensis, 243.

mirificus, 410.

nitrosus, 401.

ovalis, 301.

phosphorescens, 422 .

prodigiosus, 373, 377, 410, 464.

pyogenes, 171, 172.

rhodochrous, 446.

scarlatinosus, 419.

septicus, 374 .

tetragenus, 66, 315, 365, 416.

tetragenus mobilis ventriculi, 426.

ureae, 213, 272, 365, 521 .

violaceus, 436.

Microhaloa, 376, 377.

aeruginosa, 377 .

botryoides, 377 .

rupestris, 377 .

Micromyces, 44, 163, 377, 403.

hoffmanni, 377.

zygogonii, 377.

Microphyta, 377.

Microsiphonales, 94, 377, 278, 385, 405.

Microsiphonés, 279, 378, 404, 415, 460, 462.

Microsphaera, 21, 374, 378. vacciniae, $21,378$.

Microspira, 33, 34, 48, 54, 57, 59, 61, $74,75,207,297,308,310,359,378$, $379,409,410,422,435,437,449,470$, $473,524,526$.

buccalis, 379 .

comma, 379 .

finkleri, 379.

Microspironema, $62,379,380,478,483$, 513.

pallidum, 380 .

Microspora, 380 .

tyrosinatica, 380 .

Microsporon, 20, 68, 374, 380 .

septicum, 20, 380 .

Microsporum, 380.

Microzoa, 380.

Microzyma, 374, 380, 381.

bombycis, 380 . 
Microzyma cretae, 380.

Microzyme, 380.

Mikrobakterien, 381.

Mikrocaccus, 44, 381.

Mikrokokkus, 43, 181, 381.

Miliromyces, 381.

Mikrospironema, 381.

Mikrozymas, 381 .

Modderula, 155, 381.

hartwigi, 155, 381 .

Monadina, 17.

Monas, 14, 15, 17, 32, 311, 361, 376, 382. crepusculum, 17, 311.

lens, $15,361$.

mica, 382 .

mülleri, 155.

o.. enii, $219,256,361,442$.

prodigiosa, 3S2, 464, 530.

pulmonale, 382 .

punctum, 15, 361 .

terma, 15, 213, 214, 215, 218, 361.

Monabacillus, 382.

Monobacteria, 382.

Monococeos, 382.

Monacoccus, 382.

Monatricha, 382.

Monovibrio, 382.

Morax-Axenfeld bacillus, 291.

Mortierclla, 249.

Mucar, 249.

Multifermentans, 101, 267, 382.

tenalbus, 101, 332.

Mycacanthacoccus, 42, 383 .

cellaris, $3 \mathrm{S3}$.

Mycabacillus, 383, 394. synorialis, 383.

Mycobacteriaceae, 52, 53, 56, 57, 73, 87, $88,89,91,94,96,106,167,168,279$, $309,326,378,384,385,387$.

Mycabacterieae, $80,83,385$.

IIycobacterium, 50, 52, 53, 57, 58, 83, $87,89,94,97,106,159,161,168$, $275,333,384,385,356,387,389,462$.

leprae, 387.

rhusiopathiae, 304.

tubcrculosis, 3S5, 387.

Mycococcaceae, 38, 270, 287, 310, 387, 391, 467.
Mycaderma, 16, 81, 87, 89, 96, 153, 154, $259,387,388,389,444,519$.

aceti, $212,388,518$.

cerevisiae, 388.

mesentericum, 16, 387.

ollare, $387,388$.

pasteurianum, 388.

Mycomanas, 69, 169, 389.

Myconostoc, 23, 26, 27, 30, 32, 33, 34, $37,38,41,45,54,207,308,312$,

$337,389,390,485,486$.

gregarium, 23, 3S9, 485 .

Myconostocaceae, 38, 308, 389, 390, 391.

Myconostaceae, 26, 34, 41, 337, 390, 527.

Mycophyceae, 283, 391.

Mycatetraedron, 42, 391.

cellare, 391.

Mycathamnion, 391.

fodinarum, 391.

Mycathece, 37, 38, 287, 391.

cellaris, 391, 392.

Mycothrix, 392.

Myriaphyllum, 485.

Myrisine urrillei, 365.

Myxabacillus, 64, 392.

betae, 392.

Myxobacter, 46, 392, 393, 430. aureus, 392, 430 .

Myxobacteria, 61, 393, 431.

Myxabacteriaceae, 15, 75, 86, 107, 255, $326,392,393,394,395,430,489$.

Myxobacteriales, 79, 87, 88, 91, 102, 107, 309, 393, 394, 459, 461.

Myxoáacterieae, 100, 310, 394.

Myxobacterium, 394.

Myxobactrales, 394, 460.

Myrobazillus, 392, 394.

Myxabatrys, 394.

variabilis, 255, 394.

Myxabatrysaceae, 394.

Myxococcus, 46, 72, 74, 86, 107, 255, $393,395,430$.

cirrhasus, 395.

clavatus, 395.

coralloides, 395.

cruentis, 395.

disciformis, 395.

digitatus, 395. 
Myxococcus macrosporus, 395.

pyriformis, 395.

rubescens, 395.

stipitatus, 395.

virescens, 395.

Myxokokkus, 64, 395.

betae, 395.

Myxomycetales, 102.

Myxomycetes, 425, 443.

Neissereae, 103, 395, 396.

Neisseria, 42, 77, 80, 87, 90, 91, 96, 97, $103,292,293,322,364,373,395,396$, $397,492$.

gonorrhoeae, 396, 397.

Neisserieae, 396.

Nematogenae, 19, 22, 188, 234, 260, 346, $355,389,397,493$.

Nematogenes, 198, 347, 397, 472, 477, 496, 524.

Nevskia, 46, 397. ramosa, 397.

Newskia, 397.

Nicolaerillus, 397, 398, 427, 439. tetani, 398.

Nigrococcus, 92, 373, 398.

nigrescens, 398.

Nitribacıllus, 398.

Nitrobacter, 46, 83, 87, 89, 98, 103, 398, 399, 401.

oligotrophum, 399.

polytrophum, 399.

winogradskyi, 399.

Nitrobactereae, 92, 95, 96, 103, 154, 246, $332,399,400,402,501$.

Nitrobacteriaceae, $79,83,87,88,89,96$, $98,103,195,308,399,400$.

Nitrobacterieae, 399, 400.

Nitrobacterium, 400 . nitrobacter, 400.

Nitromicrobium, 400, 401. germinans, 400.

Nitromikrobium, 401.

Nitromonas, 69, 401, 402, 434.

Nitrosobacterium, 401. novae formae, 401.

Nitrosobakterium, 401.

Nitrosococcus, 46, 83, 399, 401, 402. americanus, 401.

nitrosus, 401.

Nitrosomonas, 46, 69, 83, 87, 89, 98, 103, 399, 400, 401, 402, 434, 498. europoea, 402, 426. javanensis, 402.

Nocardia, $39,67,83,87,89,94,96,163$,

- $165,166,167,246,264,277,294,295$, $333,378,402,403,404,405,415$, 496,516 .

actinomyces, 161, 163, 402.

bovis, 404.

farcinica, 402.

foersteri, 378 .

somaliensis, 333 .

Nocardiaceae, 94, 277, 378, 404, 405, 516.

Nodofolium, 72, 405.

ferrugineum, 319, 405.

Nomenclature, 108.

Nomina hybrida, 124.

Nosema, 19, 405, 519.

bombycis, 405, 410, 459 .

Nostoc, 23, 37, 356, 490.

Nostocaceae, 24, 29, 355.

Novillus, 102, 267, 405.

maligni, 102, 405.

Octopsis, 405.

cholerae-gallinarum, 405.

equorum, 405.

lyssae, 405.

xanthogenicum, 405.

Oenobacillus, 50, 405.

abbae, 50, 406.

Omelianskillus, 100, 266, 406.

hydrogenicus, 100, 406.

methanicus, 406.

Oospora, 50, 53, 57, 58, 163, 164, 166, 167, 333, 403, 406, 496.

Ophidobacteries, 406, 524 .

Ophidomonas, 38, 407, 408, 472, 511. jenensis, 407, 408. sanguinea, 407.

Ophryothrix, 352, 353, 408.

thuretiana, 408.

Orchidaceae, 276.

Oscillaria, 23, 37, 234, 235, 236.

Oscillariaceae, 19. 
Oscillarieae, 20, 355.

Oscillatoria, 18, 234, 461. ochracea, 318 .

Oscillatoriaceae, 24.

Oscillospira, 77, 332, 367, 408. guillermondii, 408.

Ourococcus, 521.

Oxydobacteriaceae, 68, 69, 152, 194, 245, 248, 331, 370, 401, 402, 409.

Pacinia, 31, 35, 40, 197, 296, 306, 311, 379, 409, 410, 437, 475, 524.

caucasica, 296, 409.

cecii, 409.

cholerae-asiaticae, 311, 409, 437.

finkleri, 409.

lewisii, 409.

loeffleri, 409.

putrifica, 409.

Pacinieae, 410.

Palmella, 302, 410, 464.

infusionum, 216.

mirifica, 410.

prodigiosa, 410.

Palmellaceae, 24.

Panhistophyton, 410. ovatum, 213, 410.

Parachromatium, 410.

Paracloster, 48, 60, 266, 267, 410.

butyricus, 411.

Paracoccaceae, 61, 65, 171, 270, 411.

Parameningococcus, 411.

Paramoecium, 15.

Paraplectrum, 48, 60, 411. foetidum, 411, 438. peroniella, 411.

Paraschizae, 289, 412.

Paraspirillum, 73, 83, 412, 471. vejdovskii, 412.

Passalus cornutus, 286, 300.

Pasteurella, 35, 40, 82, 87, 89, 93, 99, 105, $197,212,272,290,291,306,405$, $412,413,414,415$.

cholerae-gallinarum, 412, 414.

davainei, 412.

gallicida, 414.

suilla, 412.

weichselbaumii, 291.
Pasteurclleae, 92, 93, 95, 96, 104, 105, 414.

Pasteuria, 35, 40, 197, 378, 412, 415.

ramosa, 35, 378, 415.

Pasteuriaceae, 416.

Pasteurieae, 40, 197, 415.

Pectinobacter, 415.

amylophilum, 415.

Pectobacillus, 71, 245, 416.

Pediococcus, 29, 42, 51, 59, 60, 331, 416, $417,426,458$.

acidi-lactici, 416.

albus, 416.

cerevisiae, 29, 416, 417.

hennebergi, 417.

violaceus, 436.

Pediokokkus, 416, 417.

Pedioplana, 64, 417.

haeckeli, 417.

Pelochromatium, 253, 417.

roseum, 417.

Pelodictyon, 253, 417. clathratiforme, 417.

Pelogloea, 253, 417. chlorina, 417.

Peloploca, 418. undulata, 418. taeniata, 417.

Pelosigma, 418. cohnii, 418.

Pelosphaera, 418. rotans, 418.

Pentapteris, 485.

Peptonococcus, 157, 334, 418.

Peritricha, 419.

Peritrichinales, 419.

Peritrichinae, 69, 71, 156, 173, 287, 358, 419, 431, 439, 500.

Perroncitoa, 42, 419, 492. scarlatinosa, 419.

Petalobacillus, 420.

Petalobacteria, 272, 420.

Petalobacterium, 420.

Petalococcos, 21, 273, 420.

Petalococcus, 420.

aceti var. Duclaux, 420.

Petalo-Gliabacteria, 420.

Peziza, 487. 
Pezizales, 164.

Pfeifferella, 82, 96, 98, 106, 212, 360, 420, 421. mallei, 420.

Photobacillus, 421.

Photobacter, 169, 339, 421.

Photobacter fischeri, 421. indicum, 421. luminosum, 421. phosphorescens, 421. splendidum, 421. splendor, 421.

Photobacterium, 38, 421. annulare, 422. caraibicum, 422. coronatum, 422 . degenerans, 422 . delgadense, 422. fischeri, 421. glutinosum, 422. indicum, 421, 422. luminosum, 421. papillare, 422. phosphorescens, 421, 422. tuberosum, 422.

Photobakterium, 422.

Photomonas, 99, 422, 434.

Photospirillum, 422. dunbari, 422 .

Phragmidiothrix, 29, 31, 34, 40, 43, 46, $48,53,55,58,59,74,250,282,310$, $345,351,353,423,424$. multiseptata, 423, 424.

Phycobacteriaceae, 74, 424.

Phycochromaceae, 24.

Phytobacter, 424. lycopersicum, 424.

Phytomonas, 105, 424, 425. campestris, 425 .

Phytomyxa, 425, 443, 444. leguminosarum, 425. lupini, 425.

Phytomyxini, 425, 443.

Phytozoidia, 18.

Plague group, 67.

Planococcus, 47, 51, 54, 56, 58, 60, $74,76,77,174,270,311,313,425$, 426. citreus, 426.

europaeus, 426.

Planomerista, 77, 426. ventriculi, 426.

Planosarcina, 47, 51, 54, 56, 58, 60, 76, $270,311,331,426,427,455$. agilis, 426, 427. mobilis, 426.

Planostreptococcus, 76, 427.

Plasmodiophora, 425.

Plectonema, 37.

Plectrideae, 51.

Plectridieae, 60, 196, 427.

Plectridium, 49, 51, 60, S0, 197, 242, 268, 398, 411, 427, 428, 438.

paludosum, 427.

putrificum, 427.

tetani, 398, 427.

Plectrillum, 49, 232, 428.

Plectrinium, 49, 233, 428.

Plennobacterium, 64, 428.

Plennobakterium, 428.

Pleurimices, 163.

Pleurococcus, 428. beigelii, 250, 428 . roseo-persicinus, 265,42 .

Pleurospora, 278, 310, 428.

Plocamobacterium, 429. crassum, 429.

Pneumobacillus, 331, 429. liquefaciens, bovis, 429.

Pneumococcus, 292, 336, 429. flavescens, 429. gutta-cerei, 429. lanceolatus, 429. lichenoides, 429. mucosus, 429.

Point of departure, 117, 148.

Pollendera, 178, 179, 200, 429, 430. anthracis, 429.

Pollendra, 430.

Polyangium, 15, 62, 74, 86, 107, 392, $393,395,430$. compositum, 430 .

fuscum, 430 . primigenium, 430 . septatum, 430. simplex, 430. sorediatum, 430 . 
Polyangium vitellinum, 15, 255, 430.

Polybacteria, 30, 185, 431.

catenata, 431.

sulphurea, 431.

Polycephalum, 255, 431. aurantiacum, 431.

Polycoccus, 22, 37.

Polycystis, 22, 37.

Polydesmus granulatus, 298: virginiensis, 182, 298, 299.

Polyedrium, 391.

Polygastrica, 17.

Polynomial nomenclature, 110.

Priority, 116, 141.

Propionibacterium, 71, 156, 157, 419, 431.

Propionococcus, 99, 431.

Proteae, 92, 93, 95, 265, 432.

Proteobacter, 432.

pseudopulcher, 432.

septicum, 432.

skatol, 432.

Proteus, 15, 31, 43, 82, 93, 96, 98, 105, $179,181,200,202,212,232,357,358$, $359,432,433,434,486,491,519$, 531.

mirabilis, 432.

vulgaris, 432, 433.

zenkeri, 432, 531.

Protobacteries, 178, 433.

Protococcus, 265, 433.

dentalis, 433.

roseo-persicinus, 433.

Protomycetum, 434, 486. recurrentis, 434, 486.

Protophyta, 24.

Pseudobacterium, 434.

Pseudadiplococcus, 434. pneumonicus, 434.

Pseudodysentery group, 93.

Pseudomeningococcus, 434.

Pseudomonadaceae, 87, 88, 89, 99, 434.

Pseudomonadales, 419, 434.

Pseudomonas, 47, 54, 57, 61, 68, 74, 75, $82,87,89,99,104,196,207,212,225$, $229,232,288,311,339,358,359,402$, $422,434,435,436,437$.

aeruginosa, 229, 434, 436. pyocyanea, 229, 434.

radicicola, 425 .

violacea, 435, 436 .

Pseudorhizobium, 56, 437.

ramosum, 437.

Pseudosarcina, 43\%.

Pseudosarcine, 437.

Pseudospira, 311, 409, 437, 481.

Pseudospirillum, 312.

Punctula, 29, 437.

cubica, 438.

glomerata, 438.

rosea, 437.

Punctum, 438.

saltans, 438.

Pupella, 16, 527.

Putribacillus, 71, 438, 439.

putrificus, 438.

vulgaris, 438 .

Putribacteriaceae, 69, 71, 241, 419, 438, 439.

Putriclostridium, 99, 245, 268, 439.

Putrificoideae, 100, 266, 302, 361, 370, $397,398,439,440,441,451,463$, $513,528$.

Putrificus, 438, 439.

bienstacki, 439.

Pyobacillus, 439.

capsulatus cuniculi, 439.

Pyobacterium, 439, 440.

fischeri, 299, 439.

Pyococcus, 440.

Radiobacter, $\mathbf{4 4 0}$

Radiococcus, 440.

Rapanea, 365 .

Rasmussenia, 39, 213, 338, 348, 353, 440. anceps, 213, 440.

buccalis, 440.

gigantea, 440 .

maxima, 440.

variabilis, 440.

Recordillus, 439, 440.

fragilis, 441.

Reducibacteriaceae, 68, 70, 248, 441, 466, 473.

Regillus, 439, 441.

progrediens, 441. 
Rhabdochromatium, 56, 70, 255, 360, 441, 442.

fusiforme, 441.

minus, 441.

roseum, 441.

Rhabdomonas, 32, 36, 70, 85, 220, 256, $360,441,442$.

rosea, 441, 442 .

Rhizobacterium, 442.

japonicum, 442.

Rhizobiinae, 81, 212, 444.

Rhizobium, 38, 81, 87, 89, 96, 98, 103, 195, 258, 400,442, 443, 444.

leguminosarum, 425, 443.

Rhizobius, 442.

Rhizomonas, 69, 169, 434, 443, 444.

Rhodobacillus, 64, 75, 86, 192, 444, 448. palustris, 444.

Rhodobacteria, 63, 192, 444, 445.

Rhodobacteriaceae, $55,68,70,73,74$, $84,176,248,256,326,342,445,447$, $448,449,450,502$.

Rhodobacterioideae, 84, 85, 444, 445, 449, 450.

Rhodobacteroideae, $\mathbf{4 4 5}$.

Rhodobacterium, 64, 86, 192, 445. capsulatum, 445.

Rhodobakteriaceae, 417.

Rhodocapsa, 63, 70, 85, 192, 256, 445, 502.

suspensa, 445.

Rhodocapsaceae, 63.

Rhodococcus, 44, 61, 63, 65, 70, 76, 80,

$87,90,92,97,104,192,313,368$,

$373,446,447,449,506$.

capsulatus, 447.

erythromyxa, 446.

fulvus, 447.

rhodochrous, 446.

roseus, 447.

Rhodocystis, 63, 70, 85, 192, 445, 448, 504.

gelatinosa, 448.

Rhododictyon, 70, 448, 506.

Rhodomonas, 70, 257, 448.

Rhodonostoc, 63, 87, 192, 445, 448. capsulatum, 448.

Rhodopolycoccus, 70, 448, 508.
Rhodosarcina, 70, 76, 448, 449, 509.

Rhodosphaera, 86, 445, 449.

capsulata, 449.

Rhodospira, 75, 310, 449.

Rhodospirillum, 64, 70, 75, 86, 192, 445,

449, 511.

giganteum, 449 .

photometricum, 449.

rubrum, 449.

Rhodothece, 63, 70, 85, 192, 256, 449, $450,512$.

pendens, 350 .

Rhodovibrio, 64, 86, 192, 445, 450.

parvus, 450.

Rickettsia, 450, 451.

pediculi, 451.

prowazeli, 451.

quintana, 451.

Rivoltillus, 101, 266, 267, 451.

vibrion, 101, 451.

Rivularia, 23, 490.

Rivulariaceae, 24.

Robertsonillus, 439, 451.

primus, 451.

Rules of botanical nomenclature, 112 .

Saccharobacillus, 59, 451, 452.

pastorianus, 451.

Saccharobacter, 452.

Saccharomycetaceae, 24.

Saccharomycetes, 24.

Salmonella, 82, 93, 96, 105, 226, 298, $452,453$.

paralyphi, 452.

schottmülleri, 453.

Saprospira, 72, 86, 88, 107, 453, 481, 484.

grandis, 453 .

nana, 453.

Sarcina, 18, 19, 22, 25, 26, 27, 28, 30, $32,33,35,37,42,43,44,45,46,47$, $49,51,53,54,56,58,59,60,65,66$, $67,71,73,74,76,77,80,87,90,92$, $97,104,156,157,181,269,270,276$, $311,313,331,341,365,368,373,375$, $416,427,449,453,454,455,456$, $457,458,459,509,519,521$.

aurantiaca, 456. 
Sarcina citrea, 456.

flava, 456.

littoralis, 305.

lutea, 456.

rosea, 455, 509.

urinae, 454.

ventriculi, $18,322,364,453,454,455$, 456, 457.

Sarcinacoccos, 457.

Sarcinaglobulus, 457, 458.

punctum, 457.

Sarcinastrum, 56, 457.

urosporae, 457, 458.

Sarcineae, 25, 42, 212, 249, 274, 454, 458.

Sarcinee, 274, 416, 458, 502.

Sarcinoglobulus, 458.

Schinzia, 425, 443, 458, 459.

leguminosarum, 425, 443, 459.

Schizofiti, 206.

Schizomycetacea, 91, 394, 459, 460.

Schizomycetaceae, 39, 233, 459, 460, 515.

Schizomyceten, 460.

Schizomycetes, 19, 24, 47, 49, 54, 74, 78, $87,88,102,205,206,251,289,308$, $309,394,412,419,459,460,461$, $481,516,517$.

Schizophyceae, 251, 391, 501.

Schizophyta, 22, 24, 397.

Schizosiphon, 23.

Schmidlea, 253, 461.

luteola, 461.

Schuetzia, 42, 461, 492.

dissei, 461.

equi, 462.

lagerheimii, 462.

laughlini, 461.

poelsii, 461.

Sclerothrix, 38, 200, 275, 378, 385, 386, $462,463$.

callitrichae, 462.

kochii, 386, 463.

tuberculosis, 378, 462.

beigelianum, 250 .

Scytonema, 260.

Scyionemaceae, 24.

Seguinilluз, 439, 463.

aerofoetidus, 463.

Semiclostridium, 62, 463. citreum, 463.

commune, 463.

flavum, 463.

rubrum, 463.

Septicemia group, 67.

Serratia, 15, 77, 82, 104, 203, 212, 274, $304,369,374,463,464,465,530$.

marcescens, 15, 464, 465.

marescens, 464.

subtilis, 203, 464.

Shigella, 93, 96, 298, 314, 465.

dysenteriae, 465.

flexneri, 314.

Siderocapsa, 71, 80, 465.

major, 72, 466.

treubii, 72, 465, 466.

Siderocapseae, 80, 466.

Siphonomyxa, 466.

nosocomii viennensis, 466.

Solidococcus, 70, 359, 466.

Solidovibrio, 70, 441, 466.

Spermosira, 23.

Sphaerella, 325.

Sphaerobacteria, 21, 35, 38, 273, 387, 467, 469.

Sphaerobactéries, 375, 467.

Sphaerococcaceae, 467.

Sphaerococcus, 467.

confervoides, 467.

lactis acidi, 467.

Sphaerokokkus, 467.

Sphaerotilus, 17, 20, 27, 32, 34, 39, 44, $45,52,55,74,83,106,251,261,262$, 264, 467, 46s, 469.

glaucus, 468.

lacteus, 467.

natans, 17, 467.

ochraceus, 468.

thermalis, 366, 467.

Spherobacteria, 469.

Spirella, 469, 470.

canis, 469.

regaudi, 470 .

Spirilina, 16, 470, 527.

Spirillaceae, 47, 50, 51, 52, 57, 59, 60, $64,67,73,74,79,83,87,88,89,91$, $94,97,103,104,209,297,308,309$, $326,379,384,412,470,474,479$, $480,526,527$. 
Spirilleae, 34, 40, 197, 471.

Spirillina, 18, 216, 471, 523, 527.

Spirillineae, 19, 471.

Spirillobacteriaceae, 273, 471, 476.

Spirilloflagellata, 471.

Spirillum, 17, 18, 19, 20, 21, 23, 25, 26, $27,28,29,30,31,32,33,34,35,37$, $40,43,44,45,46,48,50,52,53,54$, $57,59,60,62,64,67,68,70,73,74$, $75,77,83,87,90,94,97,104,197$, $199,206,207,215,217,306,308,312$, $318,379,407,434,441,449,459,466$, $470,471,472,473,474,475,476$, $483,486,487,511,519,522,524,525$, 527, 528.

desulfuricans, 432.

giganteum, 470.

obermeieri, 434, 438.

plicatile, 471.

proeclarum, 183.

rubrum, 52, 449.

rufum, 20, 472.

sanguineum, 407.

serpens, 312.

spirillum, 474.

tenue, 17, 20, 312, 434, 472.

undula, 17, 20, 52, 312, 471, 472, 473, $474,523$.

violaceum, 436.

volutans, $20,389,407,471,472,474$, 475.

zeylanicum, 528.

Spirobacillus, 38, 62, 474, 475, 476.

cienkowskii, 474.

gigas, 475.

zeylanicus, 528.

Spirobacteria, 21, 35, 37, 43, 62, 207, $470,472,475$.

Spirobacteriaceae, 273, 471, 476.

Spirobacterium, 476.

Spirobakteriaceen, 476.

Spirobazillus, 75, 476.

Spirochaeta, 17, 18, 20, 27, 28, 32, 35, $48,57,59,62,64,70,72,73,78,86$, $88,107,184,215,241,312,379,470$, $472,475,476,477,478,479,480$, $481,482,484,485,513,515,522,527$. balbianii, 64 . biflexa, 343. buccalis, 64 .

gallinarum, 64, 240.

pallida, 483 .

plicatilis, 17, 20, 64, 78, 476, 477, 479, 480, 486.

recurrentis, 485 .

Spirochaetacea, 480, 481.

Spirochaetaceae, 64, 86, 107, 240, 284, $344,453,479,480,481,482,514$.

Spirochaetales, 102, 107, 461, 481.

Spirochaete, 21, 23, 25, 26, 30, 33, 34, $37,43,44,45,56,50,52,54,59,60$, $73,74,77,207,308,379,470,471$, $477,478,481,485$.

cohnii, 477.

ferruginea, 318, 477.

obermeieri, 52, 477, 479.

pallidum, 513.

plicatilis, 477, 478.

schroeterii, 477.

Spirochaetidae, 480, 481, 485.

Spirochaetoidea, 72, 481.

Spirochetaceae, 482.

Spirochoete, 476, 482. obermeieri, 434.

Spirodiscus, 17, 215, 482, 527 . fulvus, 17, 482.

Spiromonas, 25, 27, 32, 40, 197, 306, 312, $418,434,482,483$.

cohnii, 418, 471, 483.

volubilis, 482, 483.

Spironema, 62, 78, 107, 379, 478, 483, 484, 513.

recurrentis, 78 .

Spironemacea, 283, 453, 484.

Spirophyllum, 53, 64, 70, 318, 350, 484, $485,515$.

ferrugineum, 319, 484, 485.

Spiroschaudinnia, 240, 241, 481, 485.

duttoni, 485.

marchouxi, 485.

recurrentis, 485.

Spirosoma , 47, 54, 57, 59, 62, 74, 75 , $78,94,297,312,390,470,471,473$, $475,485,486$.

Spirothrix, 434, 486.

Spirulina, 23, 37, 43, 179, 181, 318, 319, $432,486,487$.

ferruginea, 318,486 . 
Spirulina plicatilis, 486.

Sporonema, 18, 216, 487. gracile, 368, 487.

Sporosarcina, 157, 487.

Sporospirillum, 487.

Staphylococcus, 30, 35, 42, 43, 44, 65, 66, $73,76,80,87,90,96,97,104,171$, $172,173,193,241,320,358,373,375$, 376, 440, 487, 488, 489, 492. albus, 172,488 . aureus, 171, 172, 193, 488, 489. epidermidis, 173.

epidermidis albus, 173.

pyogenes albus, 171, 193, 488. pyogenes aureus, 66, 171, 193, 488.

Staphylokokken, 489.

Staphylokokkus, 489.

Stigmatella, 19, 254, 489. aurantiaca, 489.

Stoddardillus, 101, 267, 489, 490, 529. egens, 101, 490.

Streblothrichia, 44, 490. bornetii, 44, 490.

Streblotrichia, 490.

Streptobacillus, 490, 491. anaerobicus-rectus, 330 .

lebenis, 490.

pseudotuberculosis rodentium, 490 . taette, 491.

terrae, 490, 491.

Streptobacter, 200, 491.

Streptobacteria, 200, 273, 369, 491. gigas-pericardii, 491.

Streptobacterium, 419, 491.

foetidum, 491, 492.

Streptobazillus ulceris mollis, 490.

Streptococceae, 42, 65, 79, 80, 87, 91, $103,104,271,274,293,357,396,397$, $411,488,492,494,495$.

Streptococcee, 195, 274, 461, 492.

Streptococcos, 273, 492.

Streptococcus, 23, 30, 33, 35, 37, 42, 43, $44,45,46,47,49,51,53,54,56$, $58,59,60,66,67,71,74,76,77,80$, $87,90,92,97,104,156,157,180,184$, $195,242,269,270,313,331,341,356$, $357,363,365,374,375,411,419,427$, 447, 488, 492, 493, 494, 495. bombycis, 380 .

equi, 462.

erysipelatis, 303, 493, 494.

erysipelatos, 493, 495.

lacticus, 431.

lactis, 219.

mesenteroides, 66, 239, 494 .

pyogenes, 380, 493, 494.

rubiginosus, 419.

violaceus, 258, 436.

xanthopyreticus, 195.

Streptokokken, 495.

Streptokokkus, 43, 495.

Streptomesobacterio, 353.

Streptomicrococcos, 495.

Streptospirillum, 495.

Streptothrichaceae, 73.

Streptothrix, 23, 26, 32, 37, 43, 48, 53, $57,59,68,164,165,166,167,246$, $250,251,252,259,261,262,402,403$, 406, 495, 496, 497, 516 .

foersteri, 23, 73, 163, 164, 404, 496. fusca, 495. paulotrophus, 159.

Streptovibrio, 497.

Stylopyga orientalis, 198.

Sulfomonas, 69, 497, 498, 502. denitrificans, 498.

Sulphur bacteria, 36, 63, 176.

Synechococcus, 22, 37.

Swine erysipelas group, 67.

Synonyms, 124, 127, 148.

Termobacterium, 59, 498, 500 .

aceti, 498.

album, 498.

erythrinum, 498.

fuscescens, 498 .

iridescens, 498.

lutescens, 498.

Termobakterien, 498.

Testacea, 14.

Tetrabacterium, 498.

Tetracoccus, 419, 499, 500.

butyri, 499.

casei, 499.

liquefaciens, 499.

mastitidis, 499. 
Tetracoccus mycodermatus, 499. pyogenes albus, 499. pyogenes aureus, 499.

Tetradiplococcus, 499. filiformans lodzensis, 499.

Tetraedron, 391.

Tetragenus, 500. citreus, 500. tardissimus, 500.

Tetrakokkus, 500. variolae, 500.

Thallophyta, 24.

Thallosporales, 94.

Thermoactinomyces, 500 . lanuginosus, 500. vulgaris, 500.

Thermobacillus, $\mathbf{5 0 0 .}$

Thermobacterium, 419, 498, 500, 501 . aceti, 500. bulgaricum, 501. cereale, 501. lactis, 501. zeidleri, 501.

Thiobacillus, 61, 103, 501. denitrificans, 501 .

thio-oxydans, 501 . thioparus, 498, 501.

Thiobacter, 501.

Thiobacteria, 54, 55, 61, 74, 501.

Thiobacteriaceae, 68, 69, 248, 498, 501, 503, 506.

Thiobacteriales, 79, 84, 87, 88, 91, 100, 102, 107, 154, 445, 459, 461, 502.

Thiobacterium, 501.

Thiocapsa, 36, 42, 55, 70, 85, 445, 449, 458, 502, 503.

roseo-persicina, 502, 503.

Thiocapsaceae, 55, 63, 503.

Thiocapseae, 84, 85, 256, 503, 504, 509, 510.

Thiococcus, 70, 502, 503.

Thiocystis, 36, 41, 55, 70, 85, 186, 306, 311, $342447,449,503,504$. rufa, 503 . violacea, 436, 503, 504 .

Thioderma, 53, 85, 504, 506.

Thioderma roseum, 504. rubrum, 504.
Thiodictyeae, 40, 197.

Thiodictyon, 36, 40, 55, 70, 85, 175, 176, 197, 417, 448, 505. elegans, 505, 506.

Thiomonas, 69, 257, 502, 506.

Thiopedia, 36, 55, 70, 311, 343, 447, 506. rosea, 305, 506.

Thiopcdiaceae, 55, 63, 506.

Thiopcdieae, 84, 85, 256, 343, 504, 506.

Thiophysa, 61, 84, 154, 506, 507, 509. volutans, 507.

Thioploca, 64, 84, 237, 607. schmidlei, 508.

Thiopolycoccus, $36,42,55,70,85,175$, 176, 189, 310, 448, 458, 508. ruber, 508, 509.

Thiorhodaceae, 63, 256, 444.

Thiosarcina, 36, 55, 70, 75, 85, 311, 448, 503, 509. rosea, 509.

Thiosphaera, 53, 85, 503, 509, 510. gelatinosa, 509, 510 .

Thiosphaerella, 509. amylifera, 509.

Thiosphaerion, 53, 85, 503, 510. violaceum, 510.

Thiospira, 510. bipunctata, 510 . winogradskii, 510 .

Thiospirillum, 36, 56, 70, 75, 85, 255, $256,312,407,408,449,472,502,511$, 512.

jenensis, 511. sanguineum, 407, 511.

Thiothece, 36, 41, 55, 70, 85, 175, 176, 186, 306, 355, 450, 511, 512 . gelatinosa, 511, 512 .

Thiothrix, 36, 48, 50, 52, 53, 55, 58, $61,70,74,84,236,237,250,352$, $353,612,513,515$. nivea, 510, 513.

Thiotrix, 513.

Tilletia, 513. diphtherica, 513. scarlatinosa, 513 .

Tissierillus, 439, 513. paraputrificus, 513.

Torula, 221. 
Torula aceti, 518.

Treponema, 62, 63, 64, 72, 78, 86, 88, $107,241,380,478,479,481,482$, 483, 513.

pallida, 64, 78, 513, 514.

Treponemidae, 480, 514.

Trichobacte;ia, 177, 324, 514, 516.

Trichobacteriaceae, 52, 60, 69, 70, 248, 289, 349, 484, 514, 515.

Trichobacteriace $2,326$.

Trichobacterinae, 52, 60, 515.

Trichobakterien, 515 .

Trichogenae, 34, 39, 283, 459, 515, 516.

Trichomycetes, 67, 497, 515, 516.

Trichomyzeten, 516.

Tricogene, 264, 353, 516.

Trichosporum, 250.

beigelii, 250.

Trochiscia, 383.

Trypanoplasma, 63.

Trypanosoma, 63, 478.

Trypanosomidae, 62 .

Type, 142.

Type basis code, 145 .

Typonym, 148.

Tyrothrix, 26, 202, 406, 517, 518. catenula, 517.

claviforme, 517.

distortus, 517.

filiformis, 517.

geniculatus, 517.

scabei, 517.

tenuis, 517, 518.

turgidus, 517.

urocephalum, 517.

iirgula, 517.

Ulva, 185.

Ulvina, 20, 153, 154, 388, 518, 519.

aceti, 388, 518, 519 .

myxophila, 518 .

rubi-idaei, 518 .

sambuci, 518.

Umbina, 19, 153, 154, 519.

aceti, 459, 519 .

Urobacillus, 24, 71, 173, 519, 521.

duclauxii, 520 .

freundenreichii, 520 . leubii, 520 .

maddoxii, 520.

miquelii, 520 .

pasteurii, 519, 520.

schützenbergii, 520 .

Urobacter, 520.

Urocephalum, 19, 177, 520.

Urococcus, 24, 58, 521.

ureae, 521.

van tieghemi, 521.

Urosarcina, 24, 521.

Urospora mirabilis, 457.

Vallorillus, 101, 266, 521.

fallax, 101, 521 .

Verbenaceae, 484.

Vermes, 14.

Vibrio, 14, 15, 16, 17, 18, 19, 20, 21, 23, $25,26,28,30,31,32,34,35,37,40$, $43,44,46,50,51,59,60,61,62,64$, $67,73,77,83,87,89,94,97,104$, $197,199,206,212,215,216,217,218$, $231,288,294,306,312,359,363,379$, $382,406,410,422,437,459,466,470$, $471,472,475,476,497,519,521$, 522 , 523, 524, 525, 526, 527, 528.

amphibolus, 525 .

bacillus, 15, 16, 17, 20, 231, 368, 369, $522,523$.

cholerae, 409, 524, 525, 526, 527.

cholerae-asiaticae, 51, 67, 526 .

comma, 526.

cyanogenus, 218, 229, 523.

lineola $15,16,17,20,216,363,522$, $523,524,527$.

prolifer, 17, 20, 522 .

proteus, 525 .

rugula, $15,16,17,20,363,522,523$. $524,525$.

serpens, 15, 20, 522, 523, 524 .

spirillum, 15, 16, 471, 474, 522.

subtilis, 17, 20, 369, 522 .

syncyaneus, 17, 218, 219, 229, 522, 523 .

synxanthus, 17, 213, 218, 522, 523.

tremulans, 17, 20, 522.

typhosus, 525.

undula, 15, 231, 522 .

urinae, 525. 
Vibrio xanthogenus, 218, 523. zeylanicus, 527.

Vibrion, 526, 527. septique, 101, 279, 527.

Vibriones, 217.

Vibrionia, 17, 215, 523, 527.

Vibrionida, 18, 216, 523.

Vibrionidss, 16, 363, 470, 522, 527.

Vibrionieae, 259, 260, 312, 390, 627.

Vibrioniens, 528.

Vibriothrix, 528. zeylanica, 528.

Vienna code, 112.

Volvox, 14, 15.

Weinbergillus, 439, 528. histolyticus, 528.

Welchillus, 101, 267, 489, 529. aerogenes, 101, 529 .

Wesenbergus, 93, 96, 298, 529. wesenbergi, 529.

Winogradskya, 41, 197, 310, 337, 529. ramigera, 529 .
Zaogalactina, 15, 304, 530.

imetropha, 15, 464, 530.

Zoagalactina, 530 .

Zoogalactina, 374, 530.

Zoogloea, 19, 216, 218, 220, 274, 320, 530.

beigeliana, 250.

pulmonis equi, 240, 241, 530.

ramigera, 217, 529, 530.

termo, 216, 217, 530 .

Zoological Code of Nomenclature, 136.

Zopfeae, 96, 104, 105, 531, 532.

Zopfieae, 531.

Zopfiella, 31, 34, 531.

tumescens, 531.

Zopfielleae, 34.

Zopfius, 96, 98, 105, 338, 531. zopfi, 531, 532.

Zygobacterium, 35, 532.

Zymosotis, 532.

escularis, 532.

regularis, 532. 


\section{AUTHOR INDEX}

Abel, 300 .

Adamson, 371.

Affanasieff, 161 .

Agardh, 316, 325, 332, 343, 363, 433, 467.

Altana, 500 .

Amato, 470.

Ambroz, 287.

Amiradzibi, 363.

Arkwright, 450.

Arloing, 429.

Avery, 429.

Axenfeld, 291.

Babes, 43, 186, 189, 195, 200, 203, 208, $271,272,296,325,375,432,455$, $488,494$.

Bacot, 450.

Baker, 226, 227, 230, 477.

Balbiani, 168, 459.

Balcke, 29, 416.

Barendrecht, 341, 356 .

Bartoszewicz, 499.

Baumgarten, 42, 43, 201, 204, 223, 227, $260,276,293,337,353,376,456,473$, $494,495$.

Beaurefaire-Arago, 245, 335.

Bechamp, 380.

Behrens, 401.

Beijerinck, 38, 50, 56, 58, 61, 153, 159, $161,169,177,193,194,290,312$, $323,324,338,339,340,341,356,357$, $380,398,399,421,425,432,443,452$, 457, 498, 501, 519, 521.

Benecke, 73, 196, 270, 278, 288, 289, 326, $384,393,445,470,501$.

Berestnew, 163, 406, 497.

Bergamaschi, 464.

Bergey, 102, 154, 155, 156, 158, 165, 167, $168,170,173,176,194,195,196,203$, $209,212,226,227,230,236,237,246$, $247,251,255,256,257,258,266,269$, $272,279,283,284,289,293,298,299$,
$300,302,303,304,306,313,315,328$, $329,330,332,338,340,342,344,351$, $353,357,371,373,377,385,387,393$, $394,395,396,397,399,400,402,414$, $420,424,425,428,430,433,436,442$, $444,445,446,447,448,449,450,453$, $457,461,465,469,471,474,480,484$, $492,495,501,502,503,504,505,506$, $507,508,509,510,511,512,513,514$, 527, 531, 532 .

Bergonzini, 28, 221, 257, 25s, 284, 285, 286.

Berkeley, 19, 254, 489.

Bettencourt, 61, 294, 333.

Biedert, 337.

Bienstock, 439, 513.

Billet, 186, 189, 200, 223, 240, 265, 276 , $291,294,337,348,364,365,375,390$, $455,473,477,481,491,494,495,499$, 525.

Billroth, 21, 185, 186, 187, 217, 272, 273, $275,276,291,320,328,347,361,366$, $371,372,373,374,382,420,457,466$, $491,492,493,495$.

Bizio, 15, 463, 464.

Bizzozero, 469.

Blanchard, 62, 164, 295, 379, 403, 404, $470,473,475,478,481,483,485,513$, 526.

Bollinger, 23, 38, 162, 241, 295, 530.

Bongert, 5S, 280.

Bonome, 434.

Bonordon, 430.

Bordono-Uffreduzzi, 363.

Borrel, 72, 191.

Borsa, 330, 381.

Bory de St. Vincent, 16, 316, 363, 470, $522,527$.

Borzi, 408.

Bosanquet, 73, 478, 479.

Bostroem, 167.

Bredemann, 244. 
Breed, 96, 102, 165, 226, 227, 230, 464.

Broadhurst, 86.

Brown, C. H., 13.

Brown, Margaret, 13.

Brumpt, 72, 157, 158, 161, 295, 333.

Brussoff, 312.

Buchanan, R. E., 78, 86, 102, 107, 153, $154,156,158,165,167,169,172,175$, $176,191,192,193,194,197,203,208$, $211,212,225,227,236,237,242,251$, $255,256,257,258,263,266,268,271$, $279,283,284,290,293,298,303,307$, $308,314,315,328,329,330,339,341$, $342,343,351,353,367,368,373,376$, $385,387,388,393,395,396,397,399$, $401,402,412,414,420,425,427,430$, $433,436,442,443,444,445,446,447$, $448,449,450,452,453,457,460,465$, $466,469,471,474,480,481,488,492$, 494, 502, 503, 504, 506, 507, 508, 509, 510, 511, 512, 513, 526 .

Buchner, 524, 526.

Buder, 254.

Bumm, 291.

Burdon-Sanderson, 380.

Burrill, 414.

Busk, 322.

Cambier, 421, 422.

Carter, 249.

Caruel, 206.

Caspary, 364, 365.

Castellani, 91, 95, 102, 165, 173, 196, $197,209,211,226,227,230,234,243$, $249,251,264,265,277,293,297,298$, $299,301,306,308,314,315,322,323$, $325,329,333,343,351,373,378,385$, $387,394,397,398,399,400,404,405$, $414,432,433,447,452,453,457,459$, $465,471,480,485,492,495,502,514$, $516,527,528,529$.

Cattani, 330.

Certes, 475.

Cesari, 241.

Chalmers, 91, 95, 102, 162, 165, 173, $196,197,209,211,226,227,230,234$, $243,249,251,264,265.277,293,295$, 297, 298, 299, 301, 306, 308, 314, 315,
$322,323,325,329,333,343,351,373$, $377,385,387,394,397,398,399,400$, $404,405,414,432,433,447,452,453$, $457,459,465,471,480,481,485,492$, $495,502,514,516,527,528,529$.

Chantemasse, 383 .

Chapman, 324.

Chatton, 77, 183, 332, 366, 408.

Chester, 52, 53, 56, 202, 203, 204, 208, $224,227,236,237,250,262,270,279$, $282,348,376,379,384,385,386,406$, $424,426,427,435,456,470,473,478$, $485,494,497,512$.

Choukevitch, 330, 370.

Christopherson, 102, 295, 333, 404.

Chudiakov, 232.

Cienkowski, 188, 190, 261, 355, 356.

Clairmone, 300.

Clark, Clarissa, 13.

Clark, W. M., 170, 278.

Clegg, 162, 246, 406, 497.

Clements, 12, 123, 201, 207, 209, 224, $236,237,250,375,393,394,440,460$.

Coats, 363.

Cohn, Ferdinand, 19, 20, 21, 22, 110, $163,171,188,198,199,203,204,205$, $210,212,216,217,218,219,220,222$, $227,228,229,235,252,260,263,264$, $265,277,281,288,301,302,320,328$, $347,355,365,368,369,370,371,372$, $373,374,378,379,389,390,392,397$, $406,407,442,454,459,467,468,470$, $472,475,477,481,486,493,496,520$, 524,530 .

Collin, 183.

Confare, Ruth, 13.

Conn, 67, 165, 202, 204, 225, 226, 227, $230,368,380,435$.

Cooke, 431.

Coppen-Jones, 192, 195, 326.

Corda, 110, 163, 164, 495, 496, 497.

Cornil, 43, 189, 200, 203, 208, 271, 27\%, 296, 375, 432, 455, 488, 494.

Corsini, 237.

Cunningham, 365.

Curtiss, 254, 489 .

Dallinger, 220, 227. 
Dangeard, 44, 306, 377 .

Davaine, $20,178,209,210,212,217,227$, $472,523$.

Davis, $170,278$.

DeBary, 29, 179, 180, 199, 203, 204, 355, 472.

DeCandolle, 264.

deKruyff, 63, 357.

DeLanessan, 27, 28.

Delbrück, 498.

D'Herelle, 272.

Dennstätt, 458.

Desmazieres, 388, 487.

DeToni, 38, 39, 161, 170, 171, 174, 177, $180,184,189,195,197,200,203,213$, $223,227,233,236,240,241,248,249$, $257,258,261,264,267,271,272,274$, $275,276,278,282,283,287,289,291$, $294,296,302,305,306,310,311,312$, $315,318,327,331,332,336,337,338$, $342,343,344,346,348,353,355,356$, $357,360,364,366,369,373,375,379$, $380,390,391,392,396,402,404,407$, $409,415,417,419,423,428,429,440$, $441,455,458,459,461,462,468,471$, $472,475,477,481,483,487,488,491$, $492,494,496,502,503,505,506,508$, $509,511,515,517,518,521,525,529$, 531,532 .

Diesing, 216, 361 .

Dobell, 72, 73, 283, 314, 367, 412, 471, $479,483,513$.

Dochez, 429.

Doflein, 62, 72, 283, 325, 479, 513.

Donaldson, 370 .

Dopter, 411.

Drysdale, 227.

Dubosco, 469.

Duclaux, 26, 115, 159, 160, 177, 287, 517.

Dujardin, 17, 191, 215, 216, 217, 218, $223,227,471,476,482,523,524,528$.

Dunbar, 422.

Duncan, 450.

Duncker, 163.

Eberth, 530.

Edington, 184, 419.

Edkins, 470.

Ehrenberg, 16, 17, 191, 213, 214, 215,
$218,226,229,290,316,317,319,320$, $322,363,368,382,407,471,474,476$, $477,481,482,486,522,524,526,527$.

Eidam, 468.

Eisenberg, 276, 325, 337, 416, 417, 467. Ellis, 53, 64, 72, 202, 204, 208, 225, 227, $251,252,262,265,270,278,282,318$, $319,349,363,376,379,405,424,426$, $427,435,456,470,473,478,481,484$, 485, 494.

Elser, 434.

Engelmann, 222.

Engler, 74, 118, 423, 424, 449.

Enlows, 95, 153, 158, 169, 175, 180, 183, $184,185,241,245,247,252,253,254$, $269,285,286,287,288,290,297,303$, $304,320,323,327,328,333,335,343$, $361,362,363,366,367,371,380,388$, $415,421,422,424,436,438,450,454$, $457,458,490,500,509,510,511,519$, $530,531,532$.

Erichsen, 434.

Escherich, 222, 227, 301, 328.

Esmarch, 449.

Evans, 173, 242, 243.

Falkenheim, 455.

Famintzin, 46, 397.

Fantham, 480 .

Faull, 394.

Fehleisen, 493.

Fick, 276.

Firtsch, 525 .

Fischer, Alfred, 48, 50, 59, 174, 179, $180,195,197,201,204,224,227,231$, $232,236,251,261,262,266,267,269$, $270,282,290,320,325,326,327,331$, $375,376,379,410,411,413,416,425$, $426,427,428,456,470,473,477,478$, $481,494,512,514,515,526$.

Fischer, Bernhard, 47, 422 .

Fitz, 170, 244, 362.

Fitzgerald, 300 .

Fleischner, 243.

Flügge, 31, 32, 65, 66, 189, 196, 200, $203,222,225,227,235,265,270,282$, $290,291,347,375,381,422,423,455$, $456,468,470,472,473,477,488,494$, $524,526$. 
Foa, 363.

Forbes, 364.

Forti, 50, 406.

Fortineau, 62, 304, 465.

Foulerton, 165.

Francke, 417.

Frank, 38, 425, 443, 458.

Frankland, 197.

Frenzel, 155, 381.

Freudenreich, 46, 203, 223, 227.

Fricke, 300.

Friedberger, 392.

Friedlander, 354, 429.

Friere, 286.

Frost, 72, 175, 176, 202, 204, 208, 225, $236,237,251,252,255,257,270,282$, $308,341,342,376,379,424,426,427$, $435,456,470,473,478,485,494,501$, $502,503,504,505,506,509,511,512$, 515.

Fuchs, 28, 229, 523.

-Fuhrmann, 470, 500.

Gamaleia, 38, 272, 525.

Gasperini, 163, 496.

Gedoelst, 164.

Glaser, 324.

Gleitsmann, 241, 479, 484, 485.

Gonder, 78, 283, 381, 479, 484, 513.

Gonnermann, 64, 392, 394, 395, 428.

Goodsir, 18, 453.

Grassberger, 178, 244, 323, 324, 411.

Griffith, 19, 290, 317.

Griffiths, 71, 330 .

Grimberg, 383.

Groenewege, 424.

Gross, 72, 283, 453, 479, 483, 484.

Grove, 29, 188, 199, 203, 222, 227, 235, 257, 261, 277, 281, 347, 355, 374, $454,459,468,472,477$.

Grüber, 44, 323, 377, 381, 455.

Guerbet, 491.

Guignard, 44, 490.

Guillebeau, 319, 320.

Guttmann, 486 .

Haase, 291.

Haass, 63, 161.

Hallier, 20, 217, 278, 360, 373, 392, 513.
Hammer, 102.

Hankin, 190.

Hansen, 388, 416.

Hansgirg, 36, 37, 42, 189, 200, 205, 207, $223,235,237,257,258,260,261,270$, $282,283,287,306,307,308,310,318$, $319,331,344,345,348,351,355,356$, $371,375,383,387,390,391,407,408$, 423, 460, 467, 472, 475, 477, 524 .

Hanzawa, 194.

Harrison, 102.

Hartleb, 56, 333, 400, 401, 437.

Harz, 23, 166, 167, 295, 406.

Hassall, 521.

Hauser, 31, 432.

Hazen, 325.

Heim, 72, 73, 203, 225, 227, 236, 262, $282,350,456,479,481,489,494,497$, $512,516$.

Heller, Hilda Hempl, 99, 100, 179, 205, $266,268,297,302,309,310,313,329$, $359,361,370,371,382,394,397,405$, $406,427,439,440,441,451,463,489$, $502,513,521,528,529$.

Hempl, 451.

Henfrey, 19, 264.

Henneberg, 451, 498.

Henry, 370, 528.

Hertwig, 163.

Hetsch, 73.

Hewlett, 53，202，204，262，376，456, $473,494,497$.

v. Hibler, 330, 370.

Hiltner, 443.

Hinze, 61, 506.

Hochstetter, 484.

Hoelling, 72, 314.

Hoffman, 513.

Hohl, 246.

Höllig, 301.

Hoyer, 153, 154.

Huebner, 364.

Huntoon, 102, 434.

Hüppe, 111, 179, 180, 181, 184, 191, 200 , $203,204,207,222,227,228,234,236$, $260,261,267,270,282,300,337,345$, $348,352,355,365,375,381,423,427$, $455,472,476,477,486,487,488,494$. 495,524 . 
Huss, 232.

Israel, 161, 167.

Itzigsohn, 217, 392, 530.

Jacqué, 491.

Jeantet, 191.

Jegunow, 506.

Jennings, 54, 192, 289.

Joffe, 501.

Johne, 171.

Jordan, 67, 164, 262, 349, 404, 497, 515.

Jouan, 191.

Kalchbrenner, 431.

Kallwacks, 300.

Karwacki, 272.

Kat, 421.

Kendall, 58, 202, 204, 208, 224, 227, 230, $232,233,236,237,250,262,270,282$, $376,379,386,424,426,427,456,470$, $473,478,481,485,494,497$.

Kern, 2S, 296.

Khoury, 491.

Kirchner, 318, 442, 486.

Kitt, 241, 413.

Klebahn, 118.

Klebs, 20, 184, 320, 327, 337, 369, 380, 382,500 .

Klecki, 499.

Klein, 259, 370, 372, 411, 476.

Kligler, 171, 263, 350, 456.

Kline, 307.

Klinger, 274.

Klöcker, 59, 208, 224, 270, 376, 417, 456.

Kolle, 73.

Kopke, 61, 333.

Koppanyi, 439.

Kossowicz, 341, 406, 428.

Krokiewicz, 293.

Krumwiede, 86.

Kruse, 177, 324, 382, 500.

Krzysztalawicz, 471.

Kuetzing, 18, 153, 154, 161, 234, 241, $252,265,290,332,365,377,518,521$.

Kühn, 294.

Kunth, 276.

Kunze, 231.
Kurth, 222, 337.

Küttner, 299, 439.

Kützing, 17, 38, 286, 301, 302, 317, 318, $321,343,344,345,347,351,364,386$, $388,391,462,467$.

Lachner-Sandoval, 163, 164, 168.

Lafar, 388.

Lagerheim, 56, 457, 458.

Lankester, 219, 227, 459.

Lanzi, 206, 220, 222, 234, 518.

Lauterborn, 64, 155, 253, 286, 381, 417, 418, 461, 507.

Lebailly, 469 .

Lebert, 410, 434.

Lehmann, 49, 58, 109, 164, 168, 190, 202, $203,207,224,227,270,279,291,300$, $307,333,356,364,365,375,379,385$, $386,406,415,416,432,456,470,473$, $478,481,486,488,494,497,518,524$, 525,526 .

Leichmann, 242, 340.

Leidy, 18, 181, 258, 259, 280, 286, 298, $300,301,332,523$.

Leube, 271, 272.

Leveille, 378.

Levine, Max, 13.

Levy, 163.

Lewis, 434, 486.

Lieske, 165, 351.

Lignières, 157, 158, 159, 161, 413, 452, 453.

Lima, 450.

Lindau, 163, 322.

Lindley, 484.

Lindner, 29, 324, 416, 498.

Lingelsheim, 293, 294.

Link, 15, 430, 486.

Linnaeus, 110.

Lister, 219, 227, 242.

Loeffler, 278, 526.

Löhnis, 76, 160, 194, 203, 225, 227, 242, $318,376,437,456,473,478,494,526$.

Lotsy, 63, 204, 425 .

Lüders, 217, 227.

Ludwig, 44, 153, 154, 163, 201, 203, 223, $227,236,261,282,287,331,348,355$, $375,390,440,443,455,468,473,477$, $481,494$. 
Luerssen, 26, 199, 203, 220, 222, 227, $235,294,347,374,454,472,477,481$, 524.

Lutz, 31, 275.

Lyall, 429.

Lyngbye, 410.

McIntosh, 314, 359, 513.

McNab, 24, 206, 291.

Maassen, 62, 463.

Macé, 185, 186, 189, 190, 202, 204, 207, $210,224,263,270,348,356,376,432$, $437,517,521,525$.

Maggi, 35, 160, 178, 180, 200, 222, 289, $290,294,296,320,353,355,362,372$, $375,382,406,420,433,440,467,490$, 491, 497, 498, 517, 524, 532.

Magnin, 24, 188, 199, 203, 220, 227, 235, $260,347,374,390,454,469,472,496$, 524.

Magnus, 118.

Maire, 425.

Makrinov, 415.

Malerba, 320.

Mantegazza, 360 .

Martelly, 361.

Marpmann, 467.

Masay, 491.

Matruchot, 383.

Matzuschita, 59, 202, 204, 224, 227, 376, 446, 456, 473, 478, 481, 494, 526.

Meek, 379 .

Mendes, 61.

Meneghini, 428.

Merrill, 158, 162, 165, 246, 295, 377, 404. Messea, 177, 324, 359, 382, 419, 514.

Metschnikoff, 35, 38, 370, 385, 386, 415, $462,474$.

Mettenheimer, 317.

Meyen, 162, 364.

Meyer, 53, 75, 191, 242, 243, 307, 308, $310,312,313,370,376,379,426,427$, $435,444,447,448,449,475,476,485$.

Micellone, 294.

Miehe, 384, 385, 386.

Migula, 44, 47, 53, 54, 61, 155, 156, 172, $175,176,178,185,189,191,201,202$,
$204,207,208,223,224,225,227,228$, $236,237,250,251,255,256,257,261$, $262,264,269,270,282,283,294,305$, $307,308,311,312,318,319,322,324$, $334,341,342,343,355,356,369,375$, $376,379,386,390,397,399,401,402$, $407,415,422,424,425,426,427,435$, $436,441,442,445,446,455,468,470$, $473,477,478,481,482,483,485,488$, $490,493,494,496,501,502,503,504$, $505,506,508,509,510,511,512,517$, $518,519,520,526$.

Miller, 189, 327, 334, 359, 433.

Miquel, 24, 382, 421, 422, 499, 519, 520, 521.

Miller, 189, 327, 334, 359, 433.

Miyoshi, 53, 504, 509, 510.

Molisch, 63, 64, 71, 192, 262, 265, 282, $317,318,350,405,444,445,446,448$, $449,450,465,469,485,503$.

Moore, 164.

Morax, 73, 291.

Moreno, 185.

Mori, 246.

Morren, 231, 369.

Mueller, O. F., 14, 15, 16, 213, 214, 215, $322,368,382,471,521,522,524,526$.

Mühlhäuscr, 439.

Muir, 291.

Musgrave, 162, 246, 406, 497.

Nadson, 253, 509.

Naegeli, $19,153,154,405,458,459,518$, 519.

Neisser, 322.

Neumann, 49, 58, 109, 164, 168, 190 , $202,203,207,224,227,270,279,291$, $300,307,333,356,364,365,375,379$, $385,386,406,415,416,432,456,470$, $473,478,481,486,488,494,497,518$. $524,525,526$.

Nicolle, 241.

Nijdam, 169.

Niklewski, 331, 332.

Nissen, 276.

Noguchi, 344.

Novy, 405.

Nowakowski, 258. 
Obermeier, 434.

Oersted, 170, 305, 357.

Ogston, 193, 374, 487, 488, 493.

Olson-Sopp, 491.

Omeliansky, 406, 511.

Orla-Jensen, 68, 71, 99, 134, 152, 154, $156,157,164,169,170,173,176,194$, $195,202,203,225,227,236,237,238$, $241,244,245,247,248,252,257,262$, $268,273,276,277,280,282,287,288$, $314,318,331,333,340,342,349,357$, $358,359,370,372,376,389,401,402$, $409,416,418,419,422,431,432,434$, $438,439,441,442,443,444,445,447$, $448,449,450,456,466,468,471,473$, $476,478,483,484,487,494,497,498$, $499,500,501,502,503,504,506,508$, $509,511,512,515,519$.

Overbeck, 446.

Pacini, 524, 525.

Parsons, 173, 193.

Pasteur, 278, 388, 416, 518, 527.

Perard, 77, 183, 332, 366, 408.

Perfiliev, 286.

Perkins, 300.

Perroncito, 162, 163, 272.

Perrone, 294.

Persoon, 16, 153, 154, 387.

Perty, 18, 191, 212, 216, 227, 256, 332, $341,368,369,370,471,477,482,487$, $523,527$.

Petit, 291.

Petruschky, 164, 349, 497, 515, 516.

Petschenko, 198, 297.

Pfeiffer, 161, 164.

Pfender, 62, 379, 478, 483, 513.

Pinoy, 73, 164, 165, 167, 277, 404.

Polk, 162, 246.

Potron, 166.

Pouchet, 525.

Poulsen, 457.

Prazmowski, 27, 177, 267, 269, 365.

Preisz, 490.

Prilleaux, 443.

Pringsheim, 244.

Prowazek, 450.

Quehl, 395, 430.
Rabenhorst, 19, 21, 216, 234, 241, 265, $283,305,318,321,343,344,346,364$, $365,368,471,472,477,486,518,524$.

Radais, 163, 261, 403, 406, 496.

Rafinesque, 484.

Ralfs, 290, 317, 363.

Reichenbach, 276.

Reitz, 161.

Renzende, 61, 333.

Rettger, 338, 531.

Rist, 490.

Ritchie, 291.

Rivolta, 24, 163, 164, 273, 274, 294, 295, 337.

Robertson, 451.

Robin, 18, 182, 259, 322, 345, 346, 364, 454.

Rogers, Ann, 61, 78, 171, 190, 193, 292, $356,411$.

Rogers, 170, 191, 278, 368, 446.

Römer, 301.

Rosenbach, 30, 71, 171, 172, 193, 299, $303,335,375,487,493,494$.

Rothberg, 173, 193.

Rothmann, 321.

Rougentzoff, 301.

Roze, 249.

Ruata, 272.

Rullmann, 401.

Sabouraud, 371.

Saccardo, 255, 395, 430, 489, 495, 518.

Salisbury, 245, 285, 532.

Sambon, 241, 485 .

Sampietro, 161.

Sanna-Salaris, 320.

Sauvageau, 163, 261, 402, 406, 496.

Schambert, 371 .

Schattenfroh, 178, 244, 323, 324, 411.

Schaudinn, 62, 367, 379, 380, 478, 483, $513,514$.

Schewiakoff, 155, 156, 381 .

Schindler, 485.

Schlegel, 161, 164.

Schmidlechner, 429.

Schmidt, 196, 202, 224, 236, 237, 250, $251,264,270,274,282,435,456,470$, 513,515 . 
Schneider, 202, 204, 208, 225, 227, 270, $376,379,384,435,456,470,473,481$, $482,494$.

Schorler, 61, 265.

Schneider, 73, 237, 443.

Schroeter, 27, 32, 163, 189, 200, 203, 206, $208,210,218,221,222,227,229,236$, $255,256,259,260,261,264,265,267$, $270,273,282,286,288,302,307,322$, $331,341,342,346,348,351,353,355$, $356,375,378,379,380,390,425,433$, $443,455,458,468,472,477,481,491$, 494, 509, 518, 524, 526, 530.

Schütz, 293.

Schwarzwasser, 499.

Schwers, 319, 349, 362.

Seguin, 330, 361, 463, 528.

Seligmann, 324 .

Sette, 15, 530 .

Shaw, 242, 243.

Siedlicki, 471.

Silberschmidt, 161.

Simmonds, 529.

Smith, Allan, J., 59, 202, 204, 208, 224, $227,250,262,270,282,305,348,376$, $379,384,386,424,426,427,435,456$, 470, 473, 478, 485, 494, 497.

Smith, Erwin F., 61, 160, 169, 170, 175, $176,177,178,179,180,181,192,194$, $195,202,204,208,210,213,224,225$, $227,228,229,232,233,236,237,240$, $241,248,250,251,255,256,257,268$, $270,272,275,276,277,279,282,290$, $291,295,297,302,304,305,308,312$, $315,320,321,324,326,328,331,334$, $336,338,340,341,342,343,349,355$, $356,359,361,362,363,364,366,369$, $372,376,377,379,380,382,390,392$, $393,396,397,399,401,402,403,406$, $408,410,411,413,415,417,419,420$, $421,424,425,426,427,429,430,432$, $435,442,443,445,452,456,462,467$, $468,470,473,475,478,483,485,490$, $491,494,497,499,500,501,502,504$, $505,506,508,509,510,511,512,518$, $519,520,521,526$.

Smith, 86.

Sollied, 417.
Spitz, 157, 158, 159, 161.

Sternberg, 45, 189, 201, 204, 220, 223, $227,264,267,292,351,356,364,375$, 455, 473, 477, 481, 487, 494, 525 .

Stiles, 62, 113, 114, 121, 131, 379, 382, 474, 478, 481, 482, 483, 513.

Stockhausen, 194, 323, 324, 341.

Stoddard, 382, 390.

Stoklasa, 440.

Störmer, 443.

Streinz, 162.

Strickland, 113.

Stutzer, 333, 400, 401.

Swellengrebel, 64, 240, 470, 479, 480, 513.

Tavel, 294.

Terni, 163.

Thaxter, R., 15, 19, 46, 255, 287, 392, $393,395,430,431,489$.

Thesing, 479, 481.

Thienmann, 249.

Thin, 221.

Thiercelin, 301.

Thiselton-Dyer, 459.

Thomson, 388.

Tilden, 486.

Tison, 425.

Tissier, 272, 301, 361.

Tizzoni, 330.

Tommasoli, 184, 185.

Trecul, 19, 27, 177, 269, 520.

Trelease, 222.

Trevisan, 18, 24, 31, 34, 38, 39, 161, 163, $171,174,176,177,180,184,186,188$, $189,195,197,199,200,203,206,211$, $212,213,220,223,227,231,233,234$, $235,236,240,241,248,249,257,258$, $260,261,264,267,271,272,273,274$, $275,276,278,281,282,283,287,289$, $291,294,296,302,305,306,309,310$, $311,312,315,318,322,327,331,332$, $335,336,337,338,342,343,344,346$, $347,348,351,352,353,355,356,357$, $360,363,364,366,368,369,370,373$, $374,375,379,380,389,390,391,392$, $396,402,404,405,407,408,409,412$, $414,415,416,417,419,423,428,429$, 
$434,437,440,441,442,454,455,458$, $459,461,462,468,471,472,475,477$, $481,482,483,487,488,491,492,494$, $496,502,503,505,506,509,511,513$, $515,517,518,521,524,525,527,529$ 530, 531, 532.

Troili-Petersson, 61, 242.

Tsilinsky, 500 .

Tulasne, 513.

Turczaninow, 476.

Turpin, 486

Ucke, 490.

Unna, 184, 185, 337, 381, 490.

Valentin, 183, 332.

Van Laer, 451.

Van Tieghem, 24, 29, 185, 186, 188, 190 , $199,203,220,221,222,227,235,269$, $282,355,356,364,365,374,390,431$, $437,454,477,481,524$.

Veillon, 230.

Veley, 277.

Vianna, 245, 335.

Vincenzi, 500 .

Von Baer, 16, 357.

von Hibler, 179.

Vuillemin, 62, 77, 118, 119, 180, 203, $211,225,227,228,229,250,251,258$, $268,279,295,297,315,331,336,343$, $357,360,363,365,367,369,376,377$, $378,379,386,387,390,396,404,410$, $413,415,417,426,427,435,456,457$, $460,463,473,474,475,478,483,484$, $486,491,493,494,495,501,513,526$, 531 .

Wade, 158, 162, 164, 165, 246, 295, 377, 404.

Waksman, 165, 501 .

Wallroth, 163, 231, 406.

Ward, H. Marshall, 11.

Warming, 155, 219, 418, 483, 503.

Weichselbaum, 31, 290, 292.

Weinberg, 329, 330, 361, 463, 528.
Weis, 196, 202, 224, 236, 237, 250, 251, $264,270,274,252,435,456,470,513$, 515.

Weiss, 256.

Weldin, J. C., 13.

Wenner, 338, 531.

Werkman, Mrs. C. H., 13.

West, 71, 241, 266, 325, 330, 349, 4 S6.

Wille, 325 .

Winogradsky, 19, 36, 46, 64, 174, 175, $176,189,235,236,256,265,268,269$, $342,343,398,401,402,407,408,441$, $442,502,503,505,506,508,509,511$, 512 .

Winslow, C.-E. A., 10, 61, 65, 78, 86, 96, $102,153,154,158,171,172,173,190$, $191,193,194,195,196,203,205,208$, $225,226,240,246,251,257,258,268$, $269,270,279,284,292,293,302,303$, $304,308,309,315,328,329,332$, 338, $339,353,356,357,368,371,373,376$, $384,387,388,394,395,396,399,400$, $402,404,411,414,420,425,428,433$, $434,436,443,446,447,453,456,457$, $461,470,473,474,480,481,488,489$, $492,493,494,502,514,519,526,531$.

Winter, 26, 27, 29, 188, 198, 203, 221, 227 . $235,261,265,276,281,305,346,347$, $355,374,390,454,468,472,477,483$.

Wislouch, 510 .

Wolf, 167.

Wolff, 64, 161, 417.

Wollmann, 321.

Wright, 161, 164, 167, 403, 404.

Zeidler, 498, 500.

Zettnow, 410, 475, 476.

Zopf, 28, 30, 44, 53, 189, 199, 203, 204, 206, 208, 221, 222, 227, 228, 235, 259, $260,264,267,282,283,345,347,351$, $355,364,375,410,414,423,446,455$, $472,493,524$.

Zuber, 230.

Zuelzer, 479, 480.

Zukal, 222, 255, 394, 430. 



\section{Sans Tache}

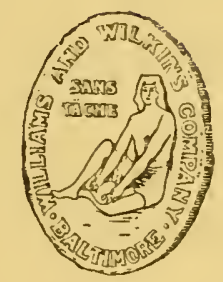




\section{Sans Tache}

T THE "elder days of art" each artist or craftsman enjoyed the privilege of independent creation. $\mathrm{He}$ carried through a process of manufacture from beginning to end. The scribe of the days before the printing press was such a craftsman. So was the printer in the days before the machine process. $\mathrm{He}$ stood or fell, as a craftsman, by the merit or demerit of his finished product.

Modern machine production has added much to the worker's productivity and to his material welfare; but it has deprived him of the old creative distinctiveness. His work is merged in the work of the team, and lost sight of as something representing him and his personality.

Many hands and minds contribute to the manufacture of a book, in this day of specialization. There are seven distinct major processes in the making of a book: The type must first be set; by the monotype method, there are two processes, the "keyboarding" of the MS and the casting of the type from the perforated paper rolls thus produced. Formulas and other intricate work must be hand-set; then the whole brought together ("composed") in its true order, made into pages and forms. The results must be checked by proof reading at each stage. Then comes the "make-ready" and press-run and finally the binding into volumes. 
All of these processes, except that of binding into cloth or leather covers, are carried on under our roof.

The motto of the Williams \& Wilkins Company is Sans Tache. Our ideal is to publish books "without blemish"-worthy books, worthily printed, with worthy typography-books to which we shall be proud to attach our imprint, made by craftsmen who are willing to accept open responsibility for their work, and who are entitled to credit for creditable performance.

The printing craftsman of today is quite as much a craftsman as his predecessor. There is quite as much discrimination between poor work and good. We are of the opinion that the individuality of the worker should not be wholly lost. The members of our staff who have contributed their skill of hand and brain to this volume are:

Composing: Zeddie Breithaupt, Howard Fogle, Harry Harmeyer, Kurt Woernle, William Kidner, Ray Kauffman, Benjamin Hatcher, Thomas Loving, Herbert Leitch, William Fite, Harry LaMotte, Edward Rice, Roland Stultz, John Dotterweich, William Koch, George Behr, Ernest Salgado, William Sanders, George Moss, Andrew Rassa, Frank Zeller, Walter Phillips, Richard King, Henry Shea.

Press: August Hildebrand, Raymond Gallagher, Robert Gallagher, Clarence Ridgeway, Henry Eckert, Henry Augsburg.

Keyboard: Minnie Foard, Harry Susemihl, Vera Taylor, Anna Kelly, Kathryn Wilson, Anna Thomas, Eleanor Luecke, Catherine Kocent, Hannah Scott.

Casler: Kenneth Brown, Ernest Wann, Charles Aher, Mahlon Robinson, George Smith, Theodore Nilson, Oscar Helbrig, Frank Malanosky.

Folder: Lawrence Krug.

Proof Room: Sarah Katzin, Mary Reed, Alice Reuter, Ruth Trieschman, Ethel Strasinger, Lucille Bull, Angeline Eifert, Audrey Tanner, Edna Clark, Lewis Forney, Dorothy Strasinger, Lillian Gilland, Arthur Baker. 


\section{Some Recent Books}

\section{Ability to Sell}

What sales-manager wouldn't like to spot it? What enterprising individual who hasn't asked himself whether or not he has it? In these days of competition, when salesmanship means so much to business, the ability to sell is an important qualification. Dr. Merrill Jay Ream's little book under this title tells a big story-worthy of careful study. Based on certain experimental tests in actual selling.

\section{Cloth, $\$ 1.25$ postpaid Published 1924}

\section{Job Analysis and the Curriculum}

Are you training young men for executive and supervisory positions? Are you aiming at development into such a position? More and more, the industrial world senses the crucial importance of job analysis. This book by Edward K. Strong and Richard S. Uhrbrock has special reference to the training of printing executives. A bibliography of job analysis is subjoined.

\section{Cloth, $\$ 2.00$ Paper, $\$ 1.00$ postpaid Published 1923}

\section{Popular Research Narratives}

A group of fifty-five minute stories of research invention or discovery, directly from the "men who did it," pithily told in language for laymen, young and old. They were collected by the Engineering Foundation, of New York City. Give the busy man a better idea of what's doing in the scientific world than hours spent in diligent digging. Admirable adventure stories for the youth in school or industry. A special arrangement with Engineering Foundation makes possible a

Price of 50c. 160 pages, cloth bound

\section{Common Sense of the Theory of Relativity}

Yes, it has common sense to it. Dr. Paul Heyl's little book brings it out, and by apt and vivid illustration enables any mind of intelligence to get the fundamental idea Einstein presents. A little book which you can read in half an hour; but one which you will want to read many times.

Cloth, $\$ 1.00$ postpaid 


